\title{
Development of Inherent and Dynamic Resilience in Traffic Networks: Microscopic Simulation, Dynamic Stochastic Assignment and Bayesian Decision Models
}

by

Omar Hosam Elsafdi

A thesis submitted to the Faculty of Graduate and Postdoctoral Affairs in partial fulfillment of the requirements for the degree of

Doctor of Philosophy

in

\section{Civil Engineering}

\section{Carleton University}

Ottawa, Ontario

(C) 2020

Omar Hosam Elsafdi 


\begin{abstract}
This research addresses knowledge gaps in resilience of a traffic network for resisting loss of ability to serve its function during severe disruptive events. It is aimed at the identification of measures and the development of methods for the investigation of how to enhance inherent (static) and dynamic resilience. The need for inherent and dynamic resilience arises in order to cope with highly disruptive events with potential for major impacts on key arterials and corridors. Specifically, the objectives of this thesis are (1) to define and test link/corridor-level means to enhance the inherent resilience in terms of sustained ability to serve traffic while resisting deterioration of quality of flow, (2) to develop and assess dynamic resilience measures that address dynamic and stochastic characteristics of traffic affected by a major disruptive event, and (3) to define decision-making guides for managing traffic under disruptive conditions.
\end{abstract}

This original research covers the traffic service resilience, but it does not include the physical resilience of transportation infrastructure owed to structural design to withstand earthquakes and road condition deterioration. As for the spatial scope, the studies of inherent resilience are meaningful at the link and corridor level. On the other hand, to define and assess dynamic resilience measures, corridor and network level studies are essential.

Based on microscopic level simulations, predictive models of link performance are developed and applied for the quantification of resilience improvement. Dynamic traffic assignment methods are developed at the macroscopic level due to the necessity to study dynamic resilience measures at the network level. Due to the uncertainties in 
traffic flow during highly disruptive events, Bayesian decision analysis method for assessing dynamic resilience actions is researched. The dynamic resilience actions encompass combinations of user-equilibrium and stochastic assignment methods. These methodological developments lead to defining linkages of dynamic resilience measures with traffic control.

Finally, products of new and original research reported can potentially serve as means to reduce impacts of major stochastic events. Both inherent (i.e. static) resilience and the dynamic resilience are needed to counter the impacts of highly disruptive events. 


\section{ACKNOWLEDGEMENTS}

It is a humbling experience to acknowledge the support, patience, and great love of my family, my mother: Ehsan; my father: Hosam; my wife: Hayfaa; my kids; my brothers and my sisters. I am indebted to so many for encouragement and support.

My sincerest thanks to my supervisor Prof. Ata M. Khan for the continuous support, for his patience, motivation, and immense knowledge. Without his guidance and encouragement during the past years, the goal of this thesis would not have been realized.

My sincere thanks also go to Prof. Baher Abdulhai, Prof. John Gaydos, Prof. Steven Prus, and Prof. Thomas Walker, for their insightful comments and encouragement. Their time and support are deeply appreciated.

My appreciation for the City of Ottawa officials for their assistance and providing the relevant data.

Thank you, to my many friends and family, you should know that your support and encouragement was worth more than I can express on paper. 


\section{TABLE OF CONTENTS}

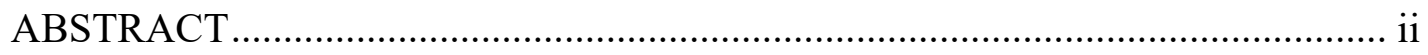

ACKNOWLEDGEMENTS .............................................................................

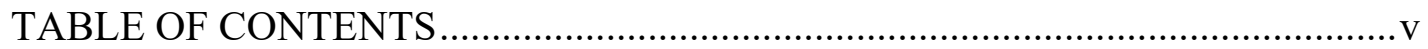

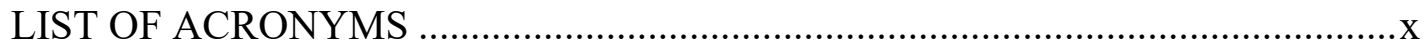

LIST OF TABLES .......................................................................................

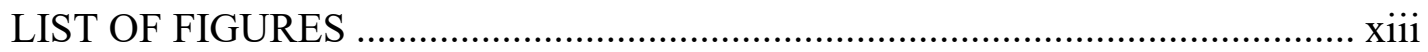

LIST OF APPENDICES ................................................................................

1 INTRODUCTION AND PROBLEM DEFINITION .............................................. 1

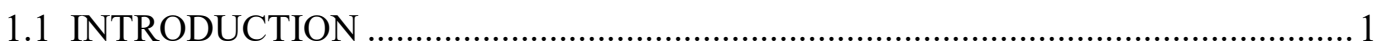

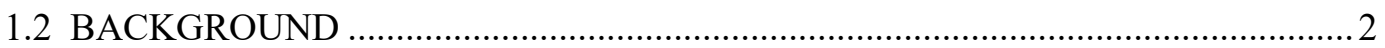

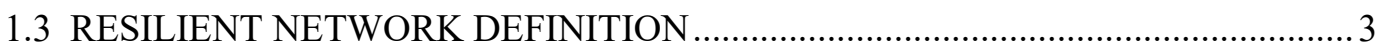

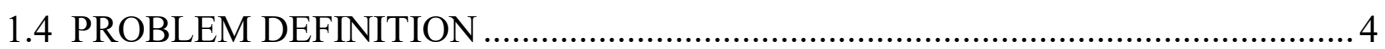

2 RESEARCH OBJECTIVES AND SCOPE ....................................................... 10

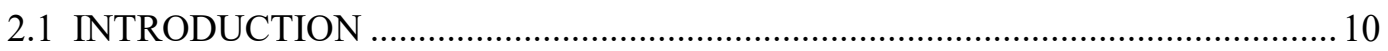

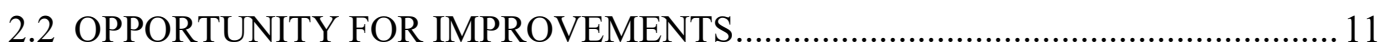

2.2.1 Flow-Speed Estimation ............................................................................ 11

2.2.2 Inherent Resilience .............................................................................. 11

2.2.3 Dynamic Resilience …………………………………………………..... 12

2.2.4 Vulnerability analysis........................................................................... 13

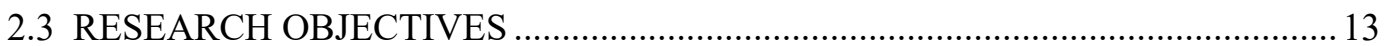

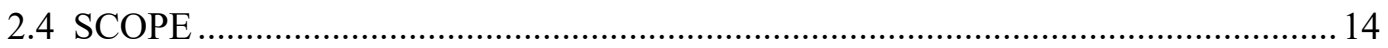

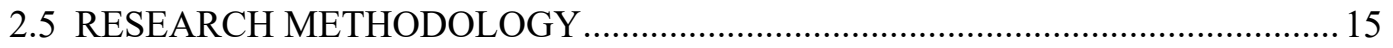

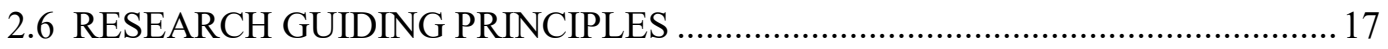

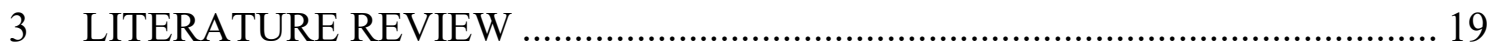

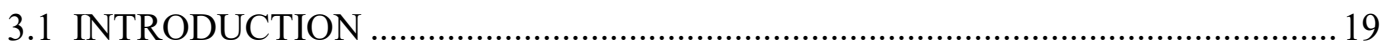

3.2 TRANSPORTATION NETWORK RESILIENCE …………………………........21

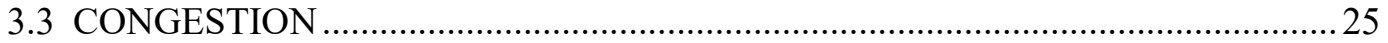

3.4 VULNERABILITY OF TRANSPORTATION LINKS ..........................................2

3.5 TRAVEL-TIME AND SPEED ESTIMATION (INHERENT RESILIENCE

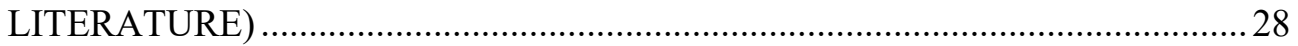

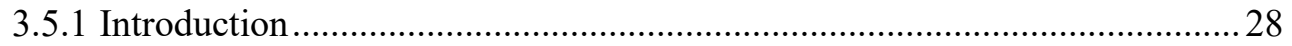

3.5.2 Volume Delay Function ...........................................................................2 29

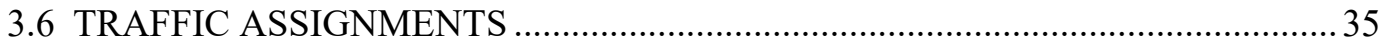

3.6.1 Static Traffic Assignment and Introduction to Dynamic Assignment ...........35

3.6.2 Dynamic Traffic Assignment....................................................................... 38

3.7 THE FUTURE OF TRANSPORTATION MANAGEMENT ......................................39

4 INHERENT RESILIENCE............................................................................. 43

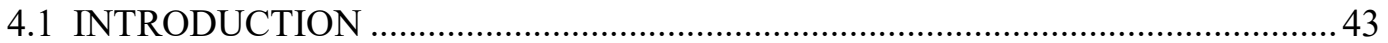

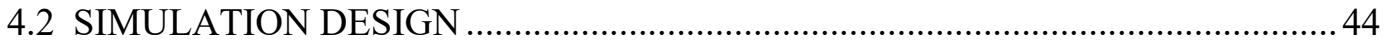

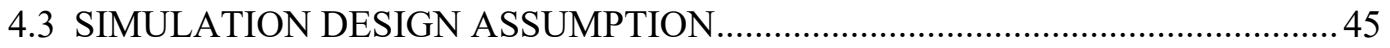


4.4 MODELS OUTPUT

4.5 GRAPHICAL REPRESENTATION OF DESIGNED INTERSECTION ...............47

4.6 DECISION MAKING ON VALUES OF VARIABLES ............................................ 48

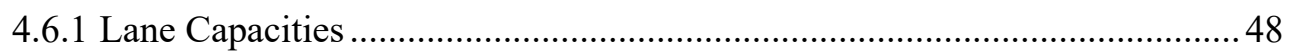

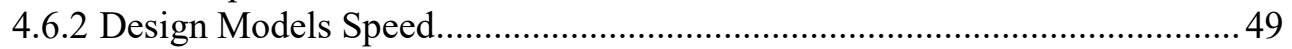

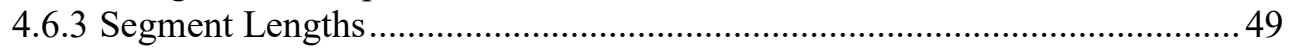

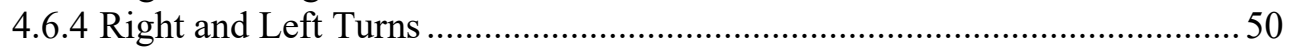

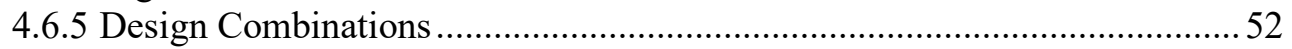

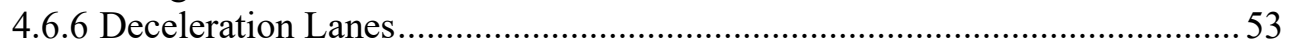

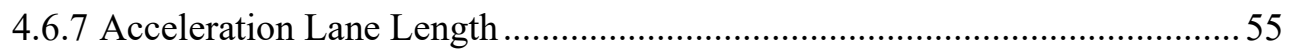

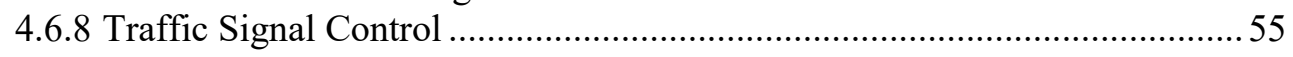

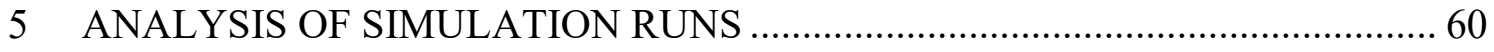

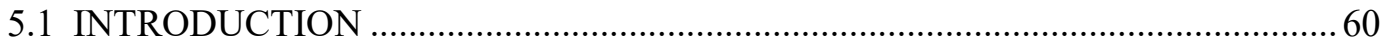

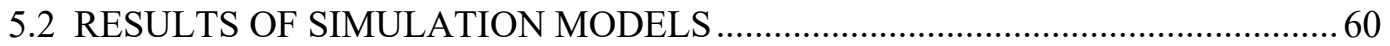

5.3 EFFECTIVENESS OF RESILIENCE MEASURES ON TRAVEL TIME /TRAVEL

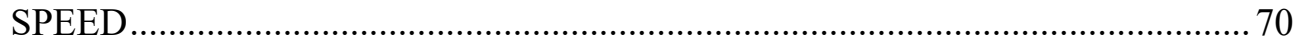

5.4 EFFECTIVENESS OF INHERENT RESILIENCE MEASURES ON

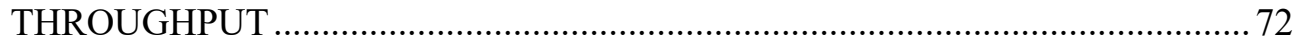

6 TESTING INHERENT RESILIENCE IN AN IMPACTED NETWORK............. 75

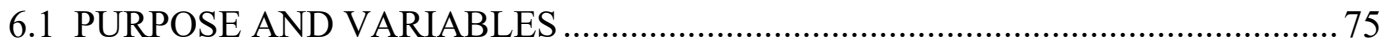

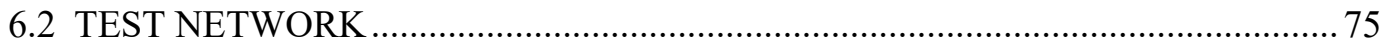

6.3 METHODOLOGICAL FRAMEWORK FOR ASSESSING NETWORK RESILIENCE UNDER DISRUPTION ................................................................ 76

6.4 METHODOLOGY FOR ASSESSING BEFORE \& AFTER INHERENT RESILIENCE APPLICATION ...................................................................... 78

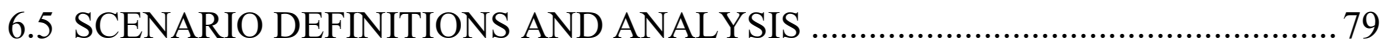

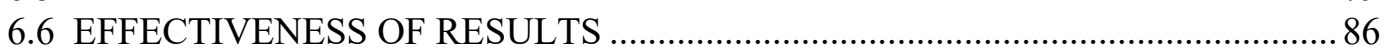

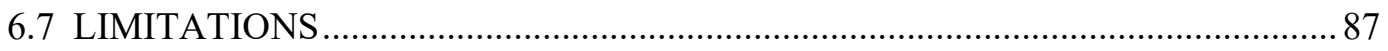

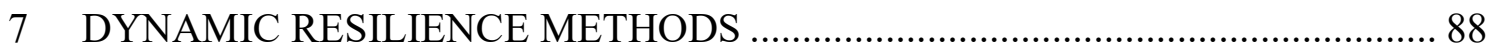

7.1 METHODS FOR DEVELOPING AND ASSESSING DYNAMIC RESILIENCE

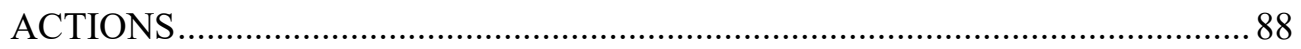

7.2 DYNAMIC NETWORK ANALYSIS ……….................................................. 89

7.3 MODELING OF USER EQUILIBRIUM TRAFFIC ASSIGNMENT VS DYNAMIC STOCHASTIC TRAFFIC ASSIGNMENT ……….......................................... 92

7.4 DYNAMIC STOCHASTIC ASSIGNMENT MODEL PROCEDURE ..................... 93

7.4.1 Similarity of Routes and Commonality Factor ..........................................98

7.5 PROCESS OF CREATING DYNAMIC RESILIENT TRANSPORTATION

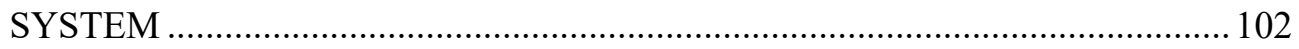

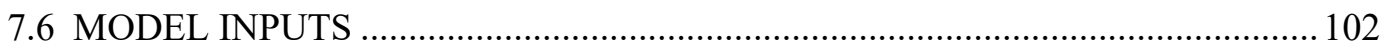

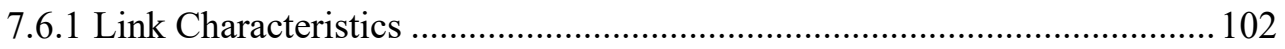

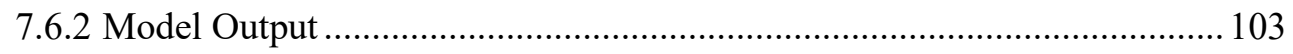

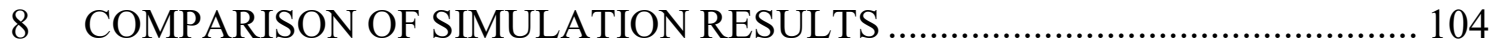

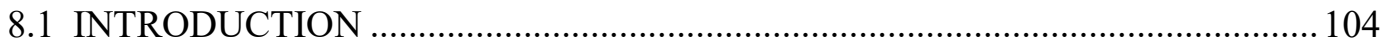

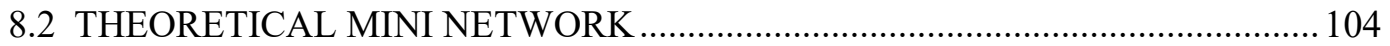




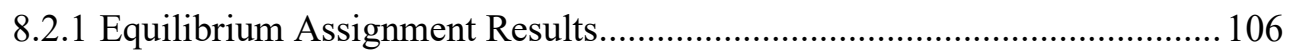

8.2.2 Dynamic Stochastic Assignment.......................................................... 107

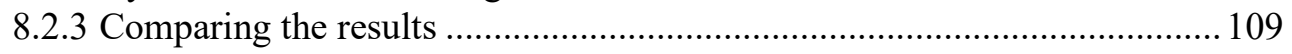

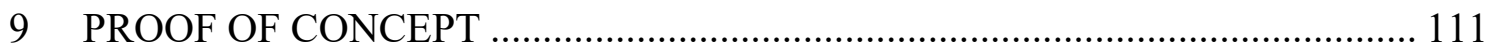

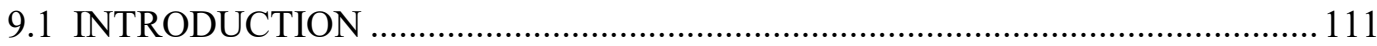

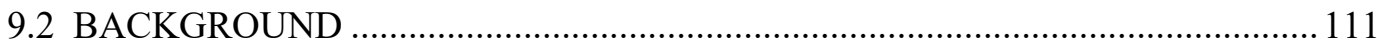

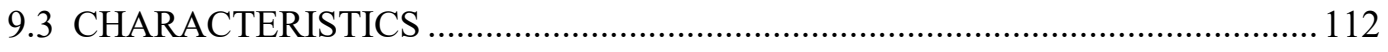

9.3.1 User Equilibrium (UE) Assignment ...................................................... 112

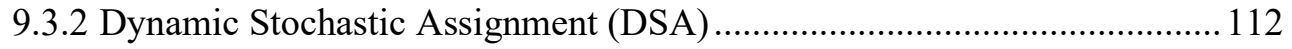

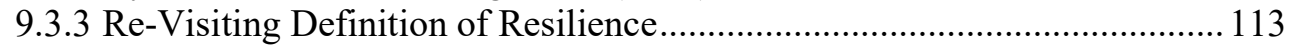

9.4 APPLICATION OF METHODOLOGY ……..................................................... 114

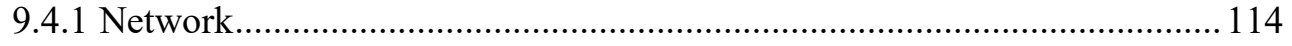

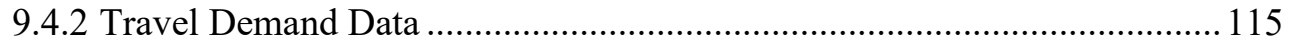

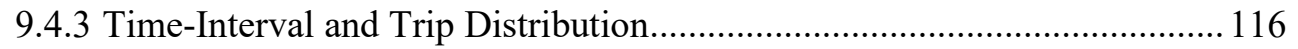

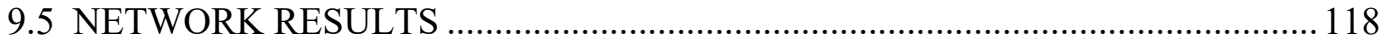

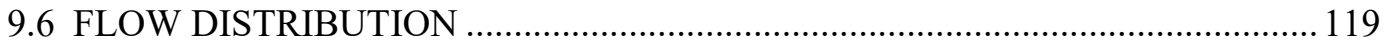

9.7 TRAFFIC CROSSING SCREEN LINES DURING PEAK HOUR …..................... 121

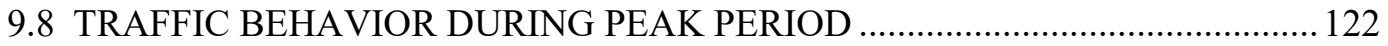

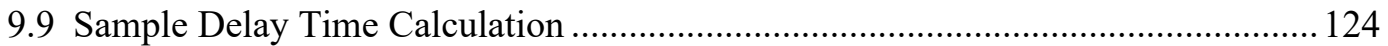

9.10 RESULTS FOR OTTAWA-HULL REGIONAL UE AND DSA SIMULATION125

9.10.1 Model 1 - UE Traffic Assignment for PM Peak Hour........................... 125

9.10.2 Model 2 - DSA Traffic Assignment for PM Peak Hour ......................... 126

9.10.3 Model 3 - DSA Traffic Assignment for PM Peak Hour ......................... 128

9.10.4 Model 4 - UE Traffic Assignment for PM Peak Period........................... 129

9.10.5 Model 5 - DSA Traffic Assignment for PM Peak Period ....................... 130

9.10.6 Model 6 - DSA Traffic Assignment for PM Peak Period ........................ 131

9.10.7 Model 7 - UE Traffic Assignment for PM Peak Hour ............................ 132

9.10.8 Model 8 - DSA Traffic Assignment for PM Peak Hour ......................... 133

9.10.9 Model 9 - UE Traffic Assignment for PM Peak Period.......................... 134

9.10.10 Model 10 - DSA Traffic Assignment for PM Peak Period ..................... 135

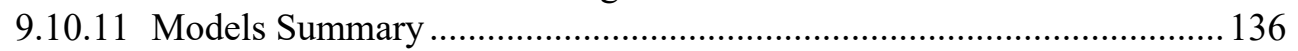

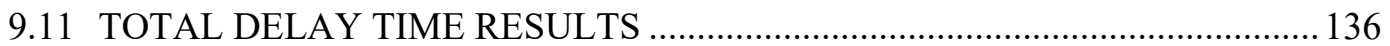

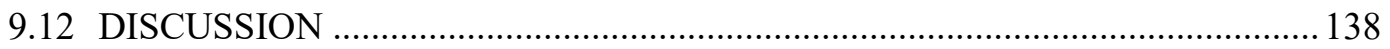

10 APPLICATION OF METHODOLOGY TO ALL FOUR BRIDGES ................. 139

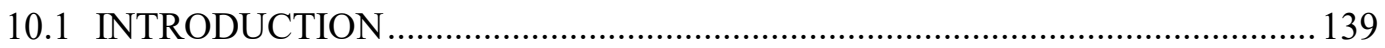

10.2 INDIVIDUAL COMPARISON OF FACTORS ................................................ 140

10.2.1 Volume/Capacity Ratio................................................................ 140

10.2.2 Comparison of Average Volumes Travelling Across Alternative Bridges 141

10.2.3 Comparison of Average Travel Speed per TI Across Alternative Bridges 142

10.2.4 Comparison of Average Delay Time per TI on Alternative Corridors .. 143

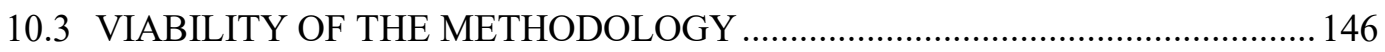

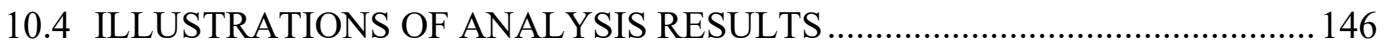


10.4.1 Event 1 - Macdonald-Cartier Bridge under Stress - 2018 Demand Data 147

10.4.2 Event 1 - Macdonald-Cartier Bridge under Stress - 2031 Demand Data 150

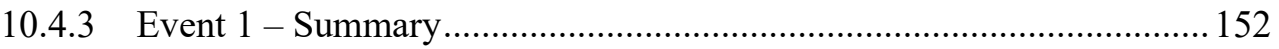

10.4.4 Event 2 - Alexandra Bridge under Stress - 2018 Demand Data ........... 153

10.4.5 Event 2 - Alexandra Bridge under Stress - 2031 Demand Data ........... 156

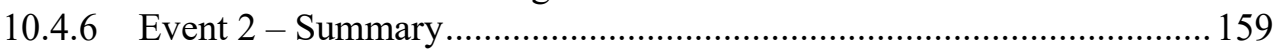

10.4.7 Event 3 - Portage Bridge under Stress - 2018 Demand Data................ 160

10.4.8 Event 3 - Portage Bridge under Stress - 2031 Demand Data................ 163

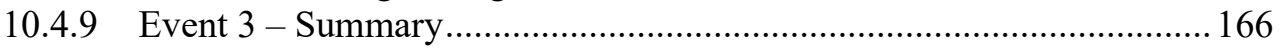

10.4.10 Event 4 - Chaudière Bridge under Stress - 2018 Demand Data ........... 167

10.4.11 Event 4 - Chaudière Bridge under Stress - 2031 Demand Data ............ 170

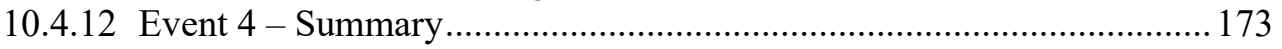

10.4.13 Event 5 - Analysis of main Corridors connecting Ottawa - Hull Area 2018 Demand Data 174

10.4.14 Event 5 - Analysis of main Corridors connecting Ottawa - Hull Area 2031 Demand Data 177

10.4.15 Analysis of main Corridors connecting Ottawa - Hull Area - Demand Data Summary: 180

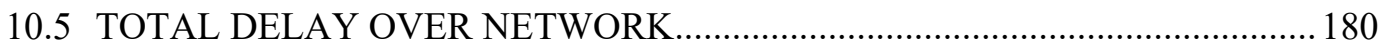

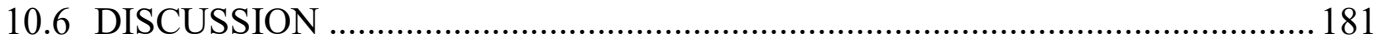

10.7 EFFECTIVENESS OF DYNAMIC STOCHASTIC ASSIGNMENT VERSUS USER EQUILIBRIUM ASSIGNMENT UNDER DISRUPTION CONDITION:

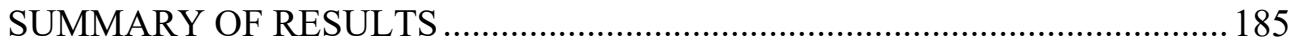

11 UNCERTAIN TOTAL DELAY AND CHOICE OF DYNAMIC RESILIENCE

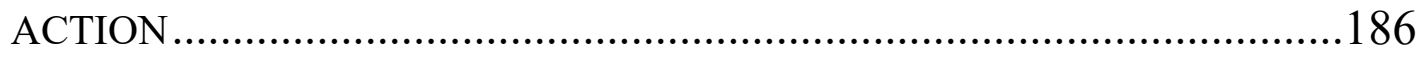

11.1 EFFECT OF TRAFFIC LEVEL AND NETWORK LEVEL DELAY UNDER

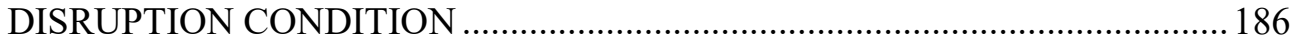

11.2 INACCURACY IN TRAVEL FORECASTS …............................................... 187

11.3 COPING WITH UNCERTAINTIES IN NETWORK LEVEL DELAYS ............. 188

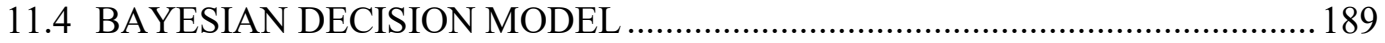

11.4.1 Structuring the Decision Problem ......................................................... 189

11.4.2 Bayesian Statistical Decision Model - Variables and Basic Formulation 192

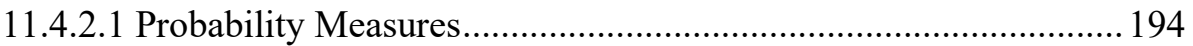

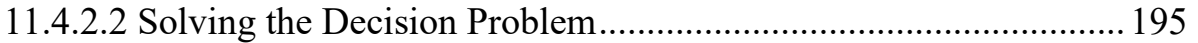

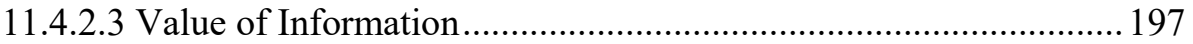

11.4.3 Application to Portage Bridge Corridor Disruptive Event ..................... 199

11.4.3.1 Alternatives: UE-based and DSA-based ......................................200

11.4.3.3 Alternatives: Hybrid of 6 minutes of UE-based and then DSA-based

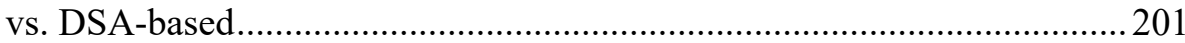

11.4.3.5 Alternatives: Hybrid of 18 minutes of UE-based and then DSA-

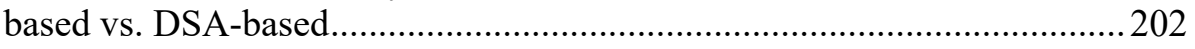

11.4.3.7 Alternatives: Hybrid of 30 minutes of UE-based and then DSA-

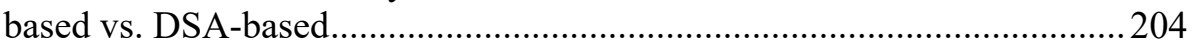

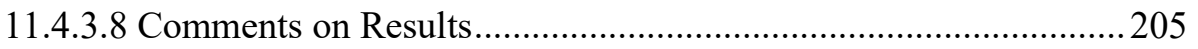


11.4.4 Application to Network 4 Disruption Event ........................................206

11.4.4.1 Network 4 Case Alternatives: UE-based and DSA-based..............206

11.4.4.3 Network 4 Case Alternatives: UE-based and DSA-based.............207

11.4.4.5 Network 4 Case Alternatives: UE-based and DSA-based.............209

11.4.4.7 Network 4 Case Alternatives: UE-based and DSA-based............. 210

11.4.4.9 Network 4 Case Alternatives: UE-based and DSA-based............. 212

11.4.4.11 Network 4 Case Alternatives: UE-based and DSA-based...........213

11.4.4.13 Network 4 Case Alternatives: UE-based and DSA-based...........214

11.4.4.15 Comments on Results................................................................ 216

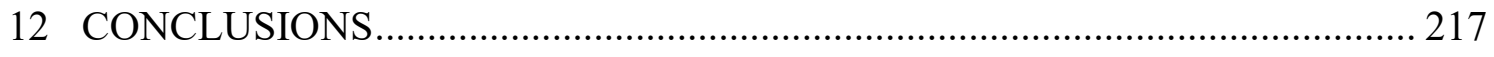

12.1 KEY FINDINGS AND MAJOR CONCLUSIONS ……....................................2.

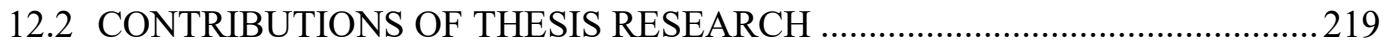

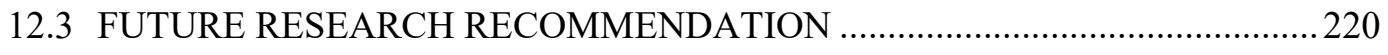

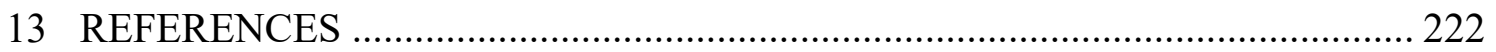




\section{LIST OF ACRONYMS}

AADT: Annual average daily traffic

BPR: The Bureau of Public Roads

CBD: central business district

DSA: dynamic stochastic assignment

FDOT: Florida Department of Transportation

FFS: Free Flow Speed

$\mathrm{g} / \mathrm{C}$ : green time/Cycle length

HCM: Highway Capacity Manual

HCS: Highway Capacity Software

HOT: high occupancy toll

HOV: high occupancy vehicle

ITE: Institute of Transportation Engineers

ITS: Intelligent Transportation Systems

LTB: left turn bay

NASA: National Aeronautics and Space Administration

NCR: National Capital Region

$\mathrm{O}-\mathrm{D}$ : origin-destination

PCU: passenger car units

RTOR: right turning movement on red

RTB: right turn bay

SPSS: Statistical Package for Social Sciences

STO: Société de transport de l'Outaouais

SO: system optimum

TAC: traffic adaptive control

TDM: Transportation Demand Management

TI: time interval

TMA: Traffic Management Agency

UAS: unmanned aerial system

UAV: unmanned aerial vehicle

UE: user equilibrium

UTM: unmanned traffic management

v/c: volume / capacity

VDF: volume-delay-function 


\section{LIST OF TABLES}

Table 3-1: Field Estimated Free-Flow Speeds and Capacities (Mtoi and Moses, 2014)............................. 34

Table 3-2: Parameter Estimates for Fitted Models (Mtoi and Moses, 2014) ............................................. 34

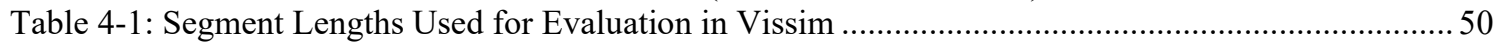

Table 4-2: Turning Volume Movement Based on City of Ottawa 2011 Data............................................51

Table 4-3: Right and Left Turn Combination Used for Evaluation in Vissim .........................................52

Table 4-4: Link Design Combination for Evaluation in Vissim...........................................................53

Table 4-5: AASHTO 2004 Deceleration Length for Various Speed Limits (AASHTO, 2004)..................53

Table 4-6:Deceleration Lane Lengths (Pline and Institute of Transportation Engineers, 1999) .................. 54

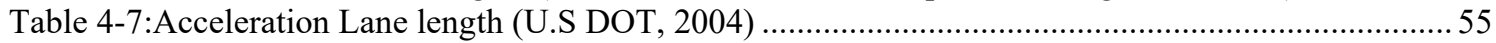

Table 4-8: Typical Minimum Green Interval Duration Needed to Satisfy Driver Expectancy.(National

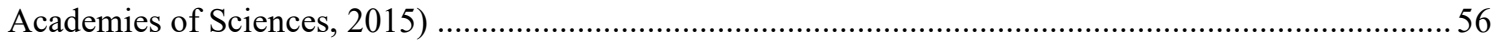

Table 4-9: Red Clearance Interval (Signal Timing Manual - Second Edition, 2015) (National Academies

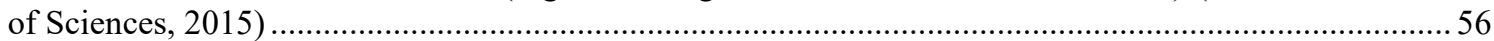

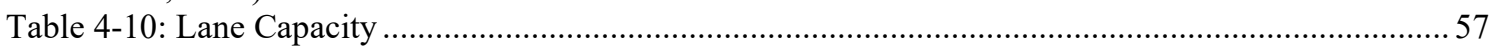

Table 4-11:HCS signalized Intersection Results in HCS 2010 .............................................................5

Table 5-1: Link 1 with Segment Length $500 \mathrm{~m}$ and g/C 0.4 Simulation Results ......................................... 62

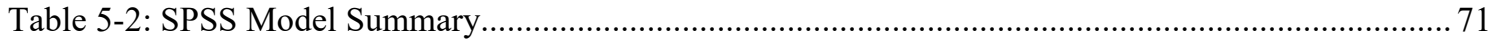

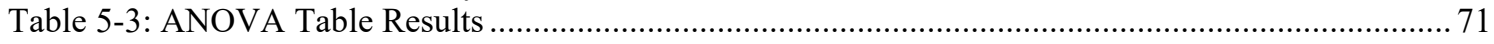

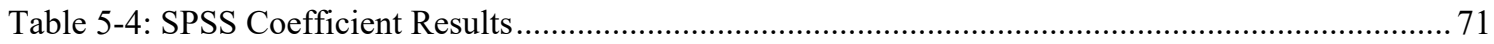

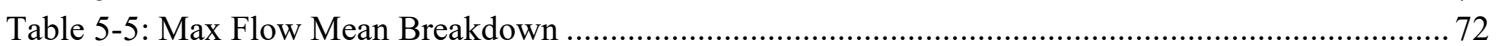

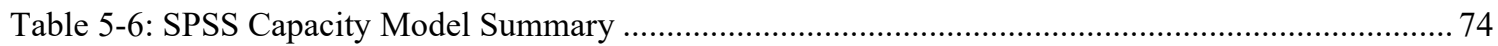

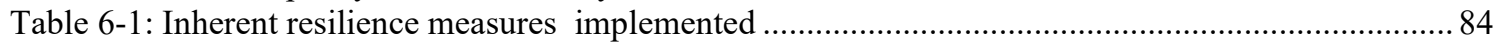

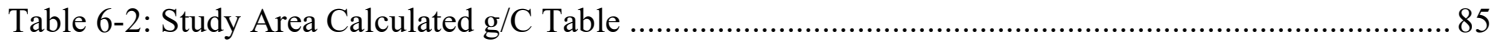

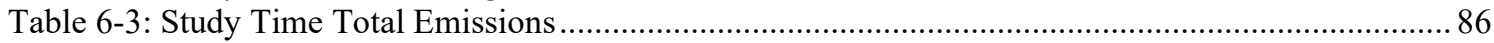

Table 6-4: Total volumes, Total Average Queue Lengths, and Total Average Delay for the Study Period

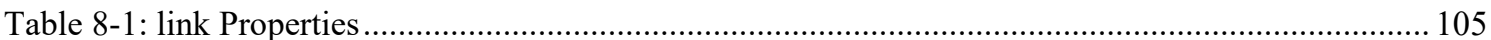

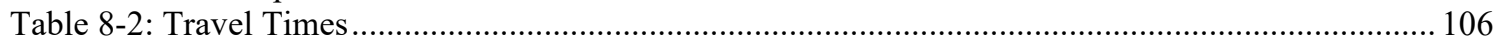

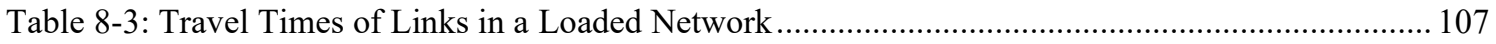

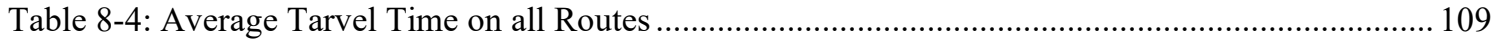

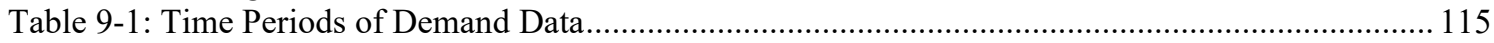

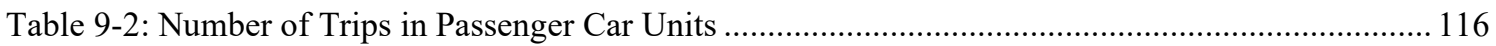

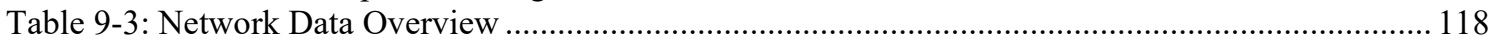

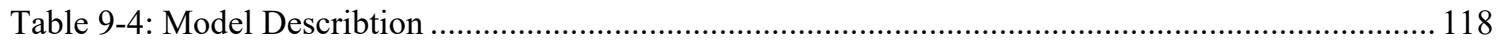

Table 9-5: Volumes Crossing Screen Lines - 2018 Peak Hour Traffic Flow (Model 4 \& 6).................... 121

Table 9-6: Flow and Travel Times Across Major Bridges for 2018 Traffic Data (UE Traffic Assignment)

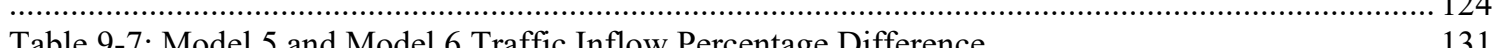

Table 9-8: Models Differences Summary

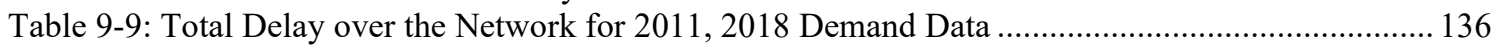

Table 10-1: Average v/c Ratio Percentage per TI Comparison of DSA and UE .................................... 141

Table 10-2: Average Volumes Percentage Traveling per TI Comparison of DSA and UE (\%) ................ 142

Table 10-3: Average Travel Speed Percentage per TI Comparison of DSA and UE (\%) ........................ 142

Table 10-4: Average Delay Percentage per TI Comparison of DSA and UE (\%) .................................. 143

Table 10-5: Event 1 - Comparison of Total Delay Across Alternatives for Vehicles Traveling from Ottawa

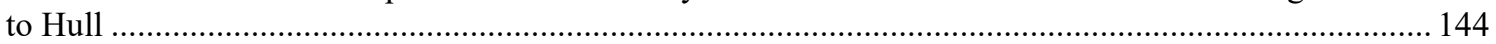

Table 10-6: Event 2 - Comparison of Total Delay Across Alternatives for Vehicles Traveling from Ottawa

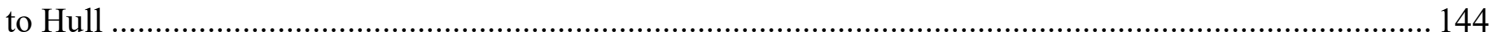

Table 10-7: Event 3 - Comparison of Total Delay Across Alternatives for Vehicles Traveling from Ottawa

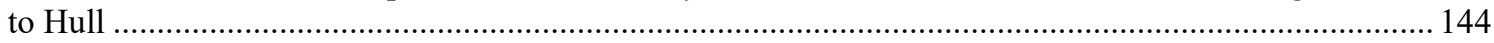

Table 10-8: Event 4 - Comparison of Total Delay Across Alternatives for Vehicles Traveling from Ottawa

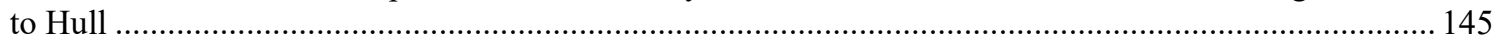


Table 10-9: Event 5 - Comparison of Total Delay Across Alternatives for Vehicles Traveling from Ottawa

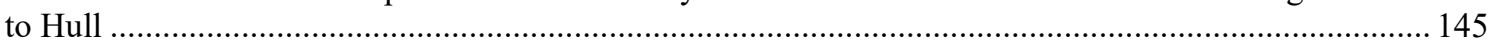

Table 10-10: Comparison of Total Network Delay During Events - 2018 Demand ................................. 145

Table 10-11:Comparison of Total Network Delay During Events - 2031 Demand ................................. 146

Table 10-12: Comparison of Volumes of Vehicles Traveling from Ottawa to Hull Across Alternatives -

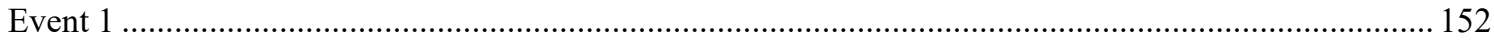

Table 10-13: Comparison of Total Delay Across Alternatives for Vehicles Traveling from Ottawa to Hull

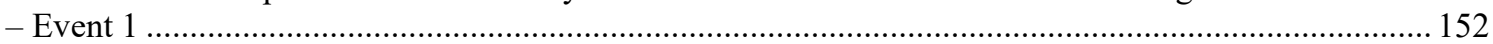

Table 10-14: 2018 Demand Volumes Across Alternatives - Event 2 .................................................... 159

Table 10-15: Event 2 - Comparison of Total Delay Across Alternatives for Vehicles Traveling from

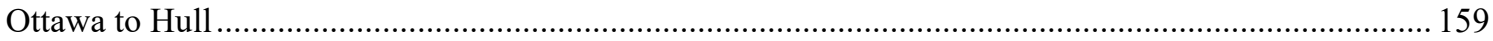

Table 10-16: 2018 Demand Volumes Across Alternatives - Event 3 …............................................ 166

Table 10-17: Event 3 - Comparison of Total Delay Across Alternatives for Vehicles Traveling from

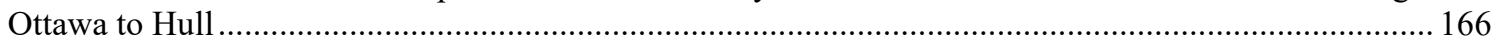

Table 10-18: 2018 Demand Volumes Across Alternatives - Event 4 ………..................................... 173

Table 10-19: Event 4 - Comparison of Total Delay Across Alternatives for Vehicles Traveling from

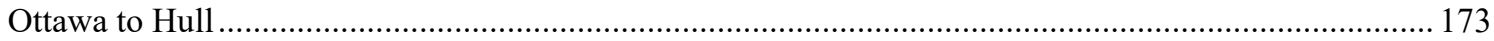

Table 10-20: 2018 Demand Volumes Across Alternatives - Event 5 ................................................... 180

Table 10-21: Event 5 - Comparison of Total Delay Across Alternatives for Vehicles Traveling from

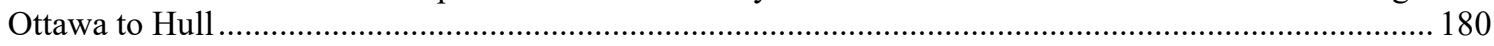

Table 10-22: Comparison of Total Network Delay During Events - 2018 Demand ................................ 180

Table 10-23: Comparison of Total Network Delay During Events - 2031 Demand .................................. 181

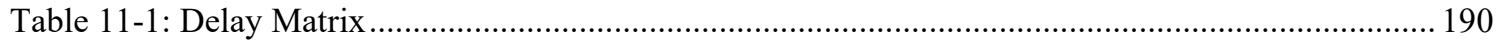

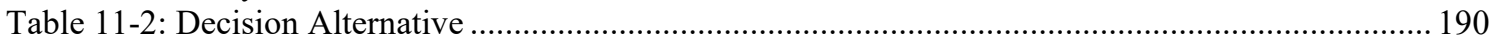

Table 11-3: Comparison of Total Network Delay During Network 4 Event: Traffic Demand at 2018 \&

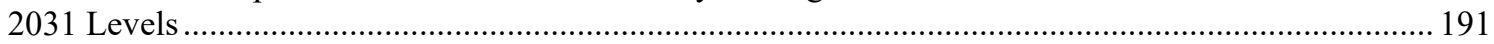

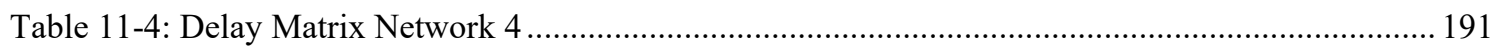

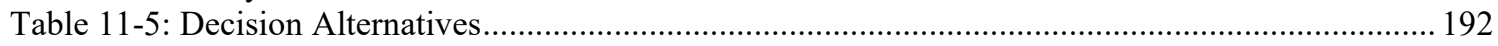




\section{LIST OF FIGURES}

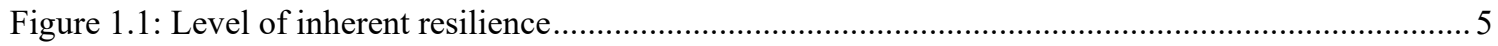

Figure 1.2: Gridlock on the Queensway in Ottawa. (Source: CTV News (Schnurr, 2017)) ......................6

Figure 1.3: High Water Level Passes Under Chaudiere bridge. (THE CANADIAN PRESS, 2017) ........... 7

Figure 1.4: Rideau Street Sinkhole Swallows Three Lanes. (Source: CBC.ca (Burke, 2017)) .................... 8

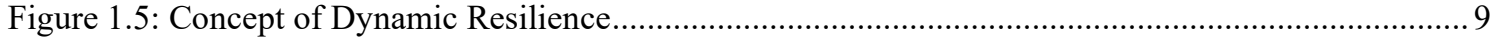

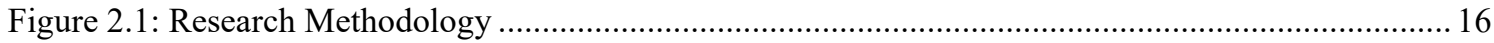

Figure 2.2: Research Methodology ........................................................................................ 16

Figure 3.1: Typical performance response curve of an infrastructure system following a disruptive event.

(Ouyang et al., 2012)............................................................................................................ 20

Figure 3.2: Relationship Between Running Speed and Segment Length (Zi-lei et al., 2010) ..................31

Figure 3.3: Relationship Between Number of Lanes and Average Running Speed (Zi-lei et al., 2010)..... 31

Figure 3.4: Comparison of Freeway Speed-Estimation Techniques (Skabardonis and Dowling, 1997)..... 32

Figure 3.5: Comparison of arterial speed-prediction techniques, Ventura Boulevard, Los Angeles

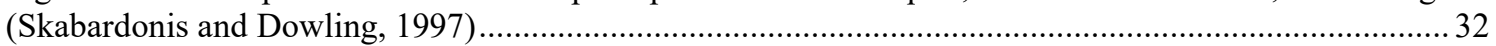

Figure 3.6: Sensitivity of HCM94 Estimated Arterial Speeds to AT (Skabardonis and Dowling, 1997) ... 33

Figure 3.7: Comparison of Freeway Speed-Prediction Techniques: I-880 Freeway, Hayward, California

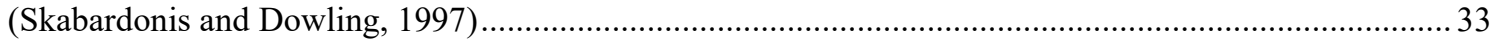

Figure 3.8: Assigning a Time-Dependent Demand Using a Static Assignment with Demand Slices and a

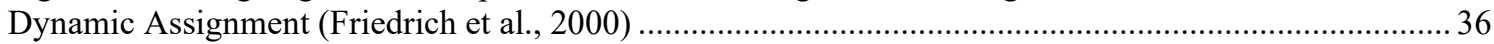

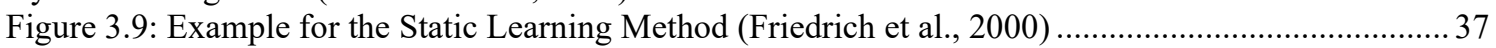

Figure 3.10:Example for a Dynamic Assignment with the Learning Method ((Friedrich et al., 2000) ...... 39

Figure 4.1: Intersection Design Used for Evaluation of Inherent Resilience Options in Vissim ..............47

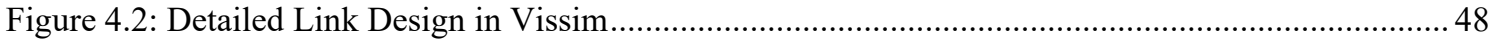

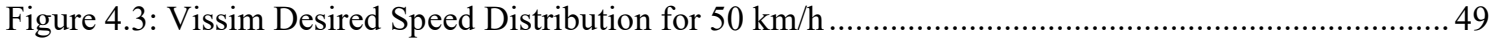

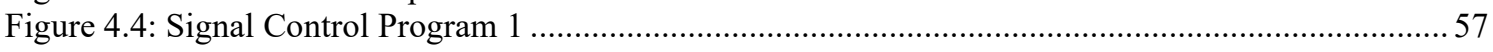

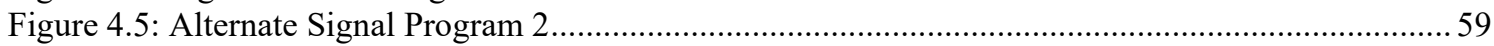

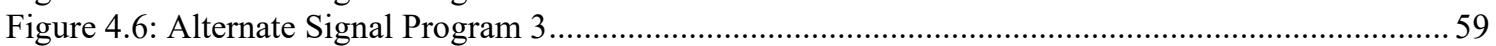

Figure 5.1: Link 1 with Segment Length $500 \mathrm{~m}$ and g/C 0.4 Graph (Note: See Table 4.4 for Link

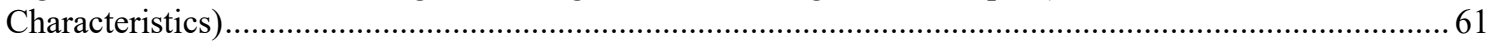

Figure 5.2: Effect of Left Turn Bay and Right Turn Bay on Travel Speed (Note: See Table 4.4 for Link

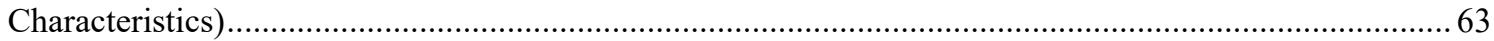

Figure 5.3: Link 1 All Segments Lengths and g/C 0.3 Simulation Results (Note: See Table 4.4 for Link

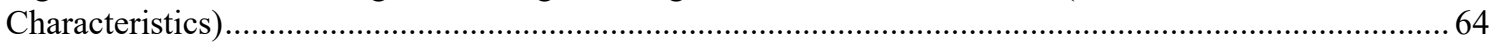

Figure 5.4: Link 1 All Segments Lengths and g/C 0.4 Simulation Results (Note: See Table 4.4 for Link

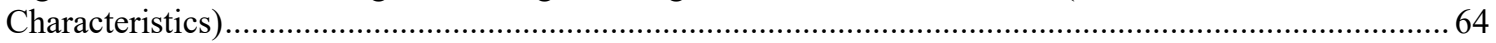

Figure 5.5: Link 1 All Segments Lengths and g/C 0.5 Simulation Results (Note: See Table 4.4 for Link

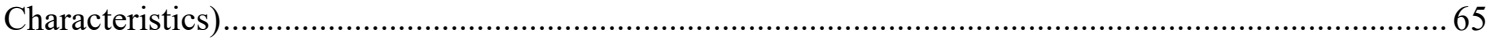

Figure 5.6: Link 2 All Segments Lengths and g/C 0.3 Simulation Results (Note: See Table 4.4 for Link

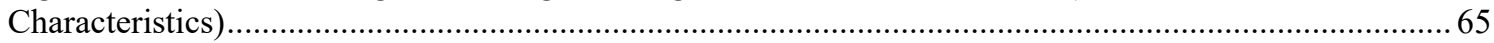
Figure 5.7: Link 2 All Segments Lengths and g/C 0.4 Simulation Results (Note: See Table 4.4 for Link

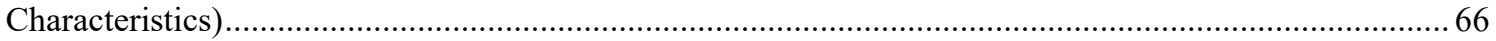
Figure 5.8: Link 2 All Segments Lengths and g/C 0.5 Simulation Results (Note: See Table 4.4 for Link

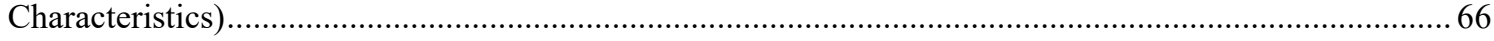
Figure 5.9: Link 3 All Segments Lengths and g/C 0.3 Simulation Results (Note: See Table 4.4 for Link

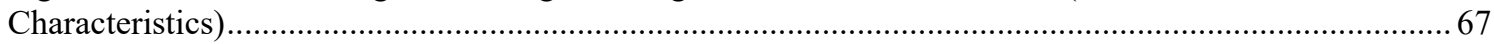
Figure 5.10: Link 3 All Segments Lengths and g/C 0.4 Simulation Results (Note: See Table 4.4 for Link

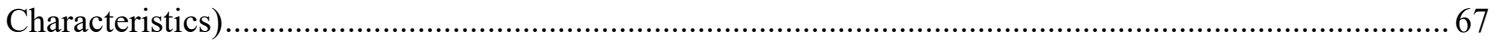
Figure 5.11: Link 3 All Segments Lengths and g/C 0.5 Simulation Results (Note: See Table 4.4 for Link Characteristics).....

Figure 5.12: Link 4 All Segments Lengths and g/C 0.3 Simulation Results (Note: See Table 4.4 for Link

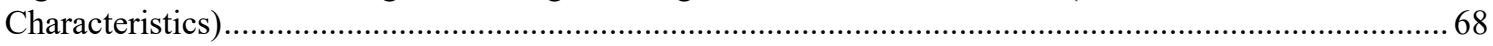
Figure 5.13: Link 4 All Segments Lengths and g/C 0.4 Simulation Results (Note: See Table 4.4 for Link Characteristics).. 
Figure 5.14: Link 4 All Segments Lengths and g/C 0.5 Simulation Results (Note: See Table 4.4 for Link

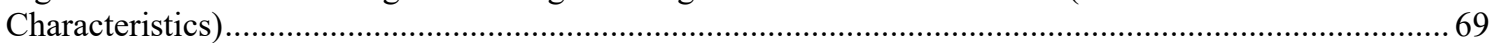
Figure 5.15: Graphical Representation of Maximum Flow of Different Links Structure and g/C (Note: See

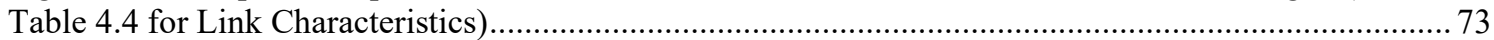

Figure 5.16: Capacity vs g/C for All Links (Note: See Table 4.4 for Link Characteristics) ....................... 74

Figure 6.1: Ottawa-Gatineau Case Study Area ………........................................................................ 76

Figure 6.2: Methodological Framework for Assessing Network Resilience ............................................... 77

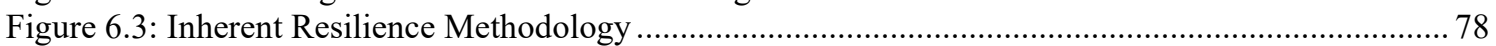

Figure 6.4: Highly Impacted Intersection Due to Disruption ................................................................ 81

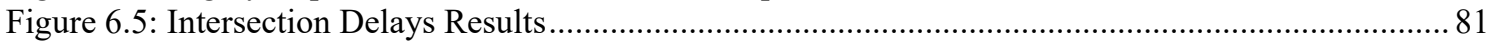

Figure 6.6: Booth St./ Wellington St. Intersection During Disruption - Case 2 ....................................... 82

Figure 6.7: Wellington St./Portage Br. Intersection During Disruption - Case 2 ....................................... 82

Figure 6.8: Wellington St. / Bay St. and Lyon St. Intersections During Disruption - Case 2 .................... 83

Figure 6.9: Bronson Ave./ Slater St. Intersection During Disruption - Case 2........................................ 83

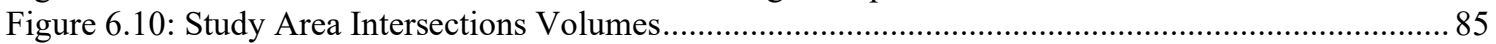

Figure 6.11: Average Intersection Queue Length Base on Vissim Simulation ........................................ 87

Figure 7.1: Difference in Travel Time Between Chosen Route and Shortest Time Route (Zhu and

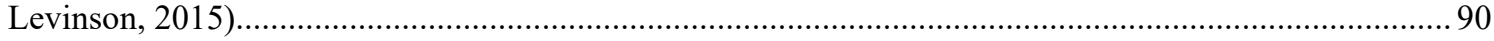

Figure 7.2: The Procedure of Dynamic Stochastic Assignment (PTV AG, 2019) ................................... 101

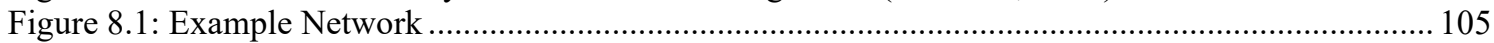

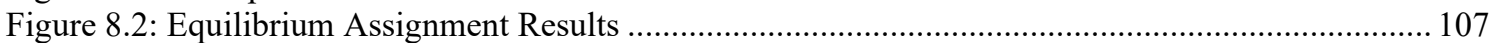

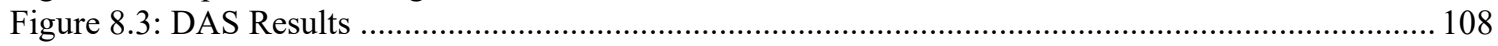

Figure 8.4: Dynamic Stochastic Assignment Vehicle Inflow Every 5 Minutes ....................................... 108

Figure 8.5: Travel Time on Each Link for the Simulation Period ............................................................ 109

Figure 9.1: Infrastructure Response Curve During Disruptive Event ..................................................... 114

Figure 9.2: Computer Screen of Ottawa-Hull Study Area in Visum................................................... 115

Figure 9.3: Trip Start Time Distribution and Peak Period Trips (IBI Group, 2016) ................................. 116

Figure 9.4: Computer Shot of DSA Analysis Time-Intervals ............................................................ 117

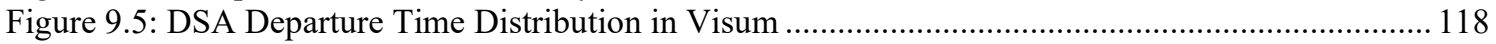

Figure 9.6: DSA Traffic Flow in and out of the Network - 2018 Traffic Data (model 6)........................ 119

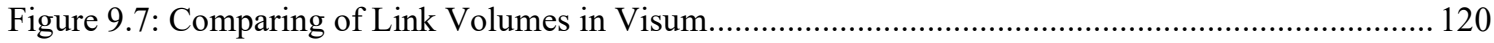

Figure 9.8: Zoom in of Comparison of Link Volumes $<500$ Vehicles in Visum ................................... 120

Figure 9.9: Zoom in of Comparison of Link Volumes $<250$ Vehicles in Visum .................................... 121

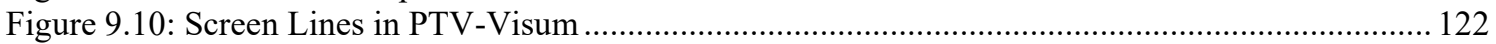

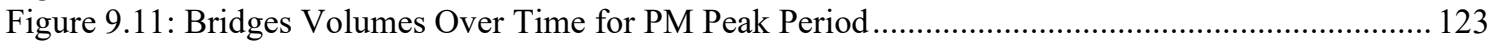

Figure 9.12: Bridges Travel Time over PM Peak Period ...................................................................... 123

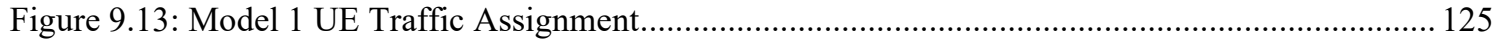

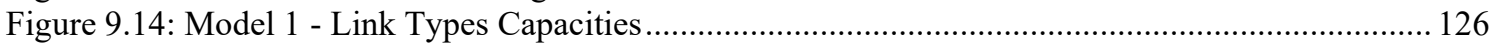

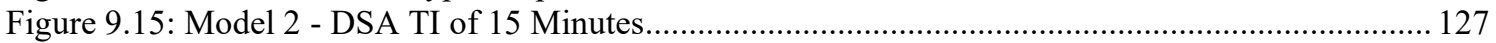

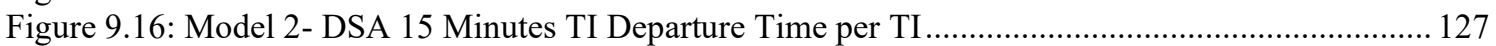

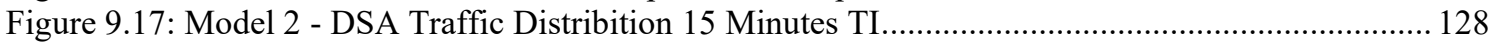

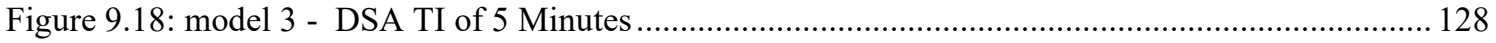

Figure 9.19:Model 3 - DSA Peak Hour 5 Minutes TI Departure Time per TI ......................................... 129

Figure 9.20: Model 4 - UE 2.5 Peak Period Link Types and Capacities .................................................... 129

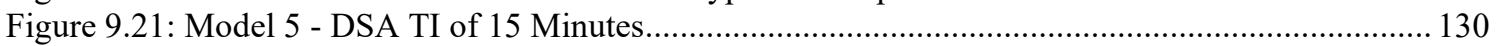

Figure 9.22: Model 5 - DSA Peak Period 15 Minutes TI Departure Time per TI....................................... 130

Figure 9.23: Model 6 - DSA Departure Time per TI to Reflect Realistic Scenario ................................... 131

Figure 9.24: Model 7 - Peak Hour UE Traffic Flow with Portage Bridge Closed .................................... 132

Figure 9.25: Model 8 - Peak Hour DSA Traffic Flow with Portage Bridge Closed, TI = 15 minutes ...... 133

Figure 9.26:Model 9 - Peak Period UE Traffic Flow with Portage Bridge Closed .................................. 134

Figure 9.27: Model 10 - Peak Period DSA Traffic Flow with Portage Bridge Closed, TI = 15 minutes .. 135

Figure 9.28: Total Delay Times over the Network for All Models ....................................................... 137

Figure 10.1: DSA of 2018 Data for Event 1 - 15:45 to 16:00 TI Simulation ......................................... 147

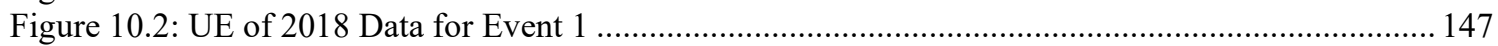

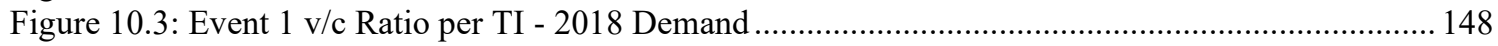

Figure 10.4: Event 1 Volumes Across Alternatives - 2018 Demand ........................................................ 148 
Figure 10.5: Event 1 Travel Speed Across Alternatives - 2018 Data..................................................... 149

Figure 10.6: Event 1 Delay per TI Across Alternatives - 2018 Data....................................................... 149

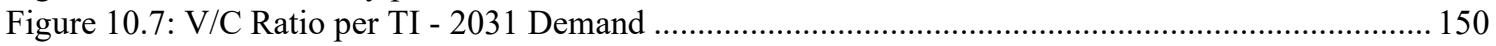

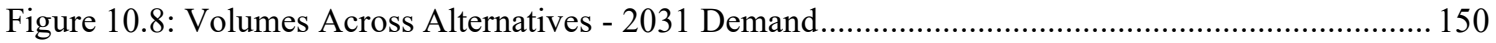

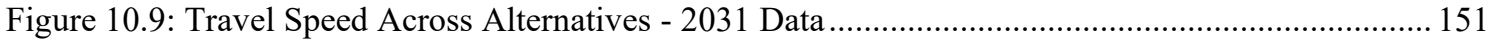

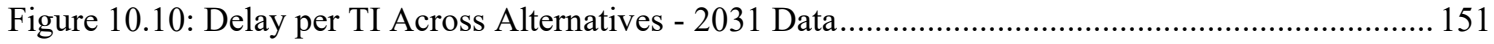

Figure 10.11: DSA of 2018 Data for Event 2 - 15:45 to 16:00 TI Simulation ......................................... 153

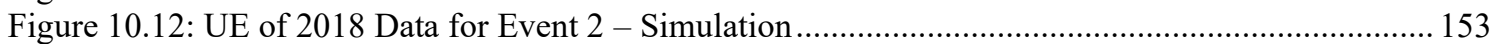

Figure 10.13: Event 2 v/c Ratio per TI - 2018 Demand .................................................................... 154

Figure 10.14: Event 2 Volumes Across Alternatives - 2018 Demand..................................................... 154

Figure 10.15: Event 2 Travel Speed Across Alternatives - 2018 Data................................................... 155

Figure 10.16: Event 2 Delay per TI Across Alternatives - 2018 Data....................................................... 155

Figure 10.17: DSA of 2031 Data for Event 2 - 15:45 to 16:00 TI Simulation ......................................... 156

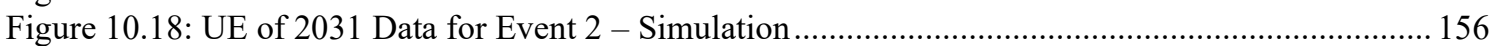

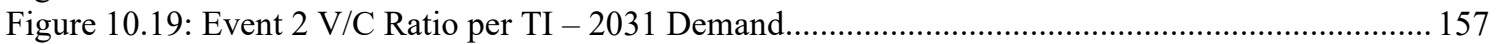

Figure 10.20: Event 2 Volumes Across Alternatives - 2031 Demand................................................... 157

Figure 10.21: Event 2 Travel Speed Across Alternatives - 2031 Data .................................................... 158

Figure 10.22: Event 2 Delay per TI Across Alternatives - 2031 Data ..................................................... 158

Figure 10.23: DSA of 2018 Data for Event 3 - 15:45 to 16:00 TI Simulation ......................................... 160

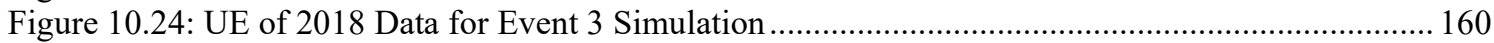

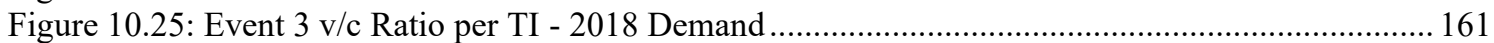

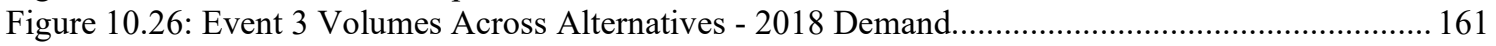

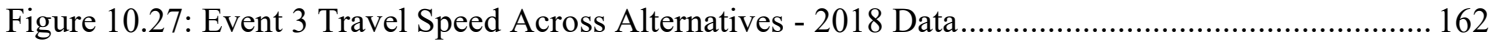

Figure 10.28: Event 3 Delay per TI Across Alternatives - 2018 Data....................................................... 162

Figure 10.29: DSA of 2031 Data for Event 3 - 15:45 to 16:00 TI Simulation .......................................... 163

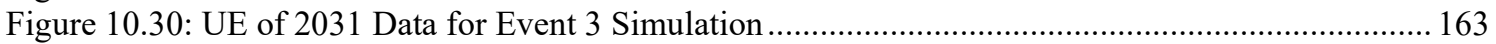

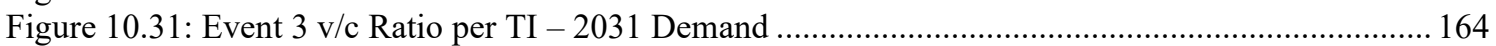

Figure 10.32: Event 3 Volumes Across Alternatives - 2031 Demand..................................................... 164

Figure 10.33: Event 3 Travel Speed Across Alternatives - 2031 Data .................................................... 165

Figure 10.34: Event 2 Delay per TI Across Alternatives - 2031 Data.................................................... 165

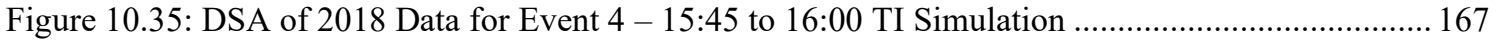

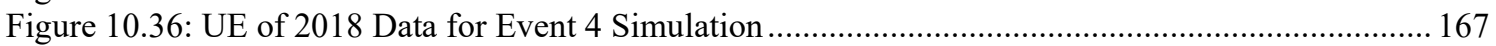

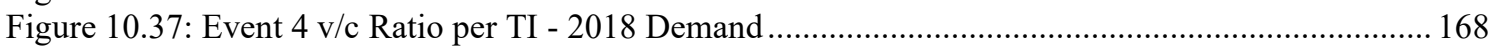

Figure 10.38: Event 4 Volumes Across Alternatives - 2018 Demand.................................................... 168

Figure 10.39: Event 4 Travel Speed Across Alternatives - 2018 Data.................................................. 169

Figure 10.40: Event 4 Delay per TI Across Alternatives - 2018 Data....................................................... 169

Figure 10.41: DSA of 2031 Data for Event 4 - 15:45 to 16:00 TI Simulation ........................................ 170

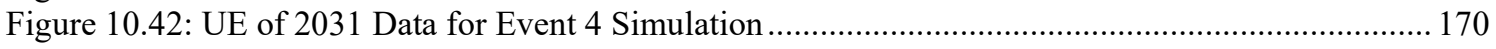

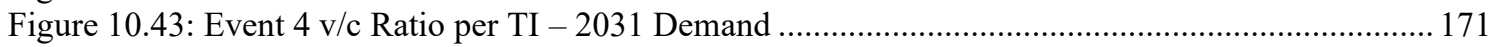

Figure 10.44: Event 4 Volumes Across Alternatives - 2031 Demand....................................................... 171

Figure 10.45: Event 4 Travel Speed Across Alternatives - 2031 Data .................................................... 172

Figure 10.46: Event 4 Delay per TI Across Alternatives - 2031 Data ....................................................... 172

Figure 10.47: DSA of 2018 Data for Event 5 - 15:45 to 16:00 TI Simulation ........................................ 174

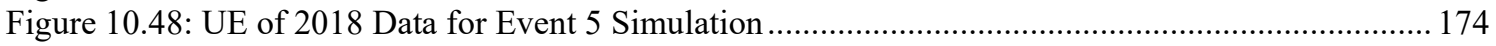

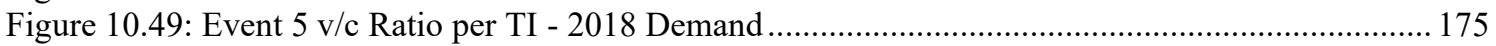

Figure 10.50: Event 5 Volumes Across Alternatives - 2018 Demand........................................................ 175

Figure 10.51: Event 5 Travel Speed Across Alternatives - 2018 Data.................................................... 176

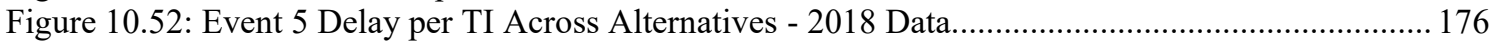

Figure 10.53: DSA of 2031 Data for Event 5 - 15:45 to 16:00 TI Simulation .......................................... 177

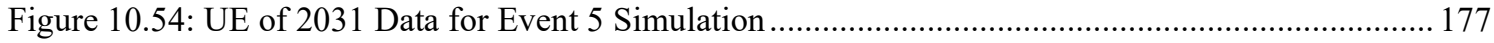

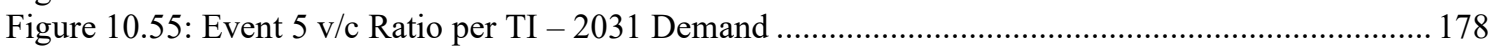

Figure 10.56: Event 5 Volumes Across Alternatives - 2031 Demand.................................................... 178

Figure 10.57: Event 5 Travel Speed Across Alternatives - 2031 Data ................................................. 179

Figure 10.58: Event 5 Delay per TI Across Alternatives - 2031 Data .................................................... 179

Figure 11.1: Stated Causes of Inaccuracies in Traffic Forecasts (Flyvbjerg et al., 2007) .......................... 187

Figure 11.2: Total Delay Time with Traffic Demand Uncertainty ............................................................ 188 


\section{LIST OF APPENDICES}

APPENDIX-A




\section{INTRODUCTION AND PROBLEM DEFINITION}

\subsection{INTRODUCTION}

Numerous ways have been adopted by transportation engineers to mitigate the problem of congestion. A substantial amount of funding accompanies many ways of alleviating traffic congestion and available methods and technology are employed for this purpose. However, the latest thinking in the field is to go beyond current knowledge and practices by developing methods and technologies that enhance resilience of a transportation system.

Traffic congestion in the business-as-usual context occurs in two forms. Recurring traffic congestion is the first form, which is owed to the increasing demand over time while the capacity supply does not improve at the same rate. The second form of congestion is the non-recurring type, which is owed to surges in traffic due to frequent type incidents (e.g. traffic accidents) or roadwork zones. There is a third type of congestion that is caused by less frequent, but very disruptive, types of events, such as severe traffic incidents, nature-induced disruptions (e.g. flooding of major arterials, bridge collapse), or human-related disruption (e.g. terrorist attack).

Severe shocks to traffic operations caused by stochastic events such as those noted above require new knowledge, and there is not much experience that can guide transportation departments of a city to manage traffic effectively. "It is intended to contribute new knowledge on how advanced methods in association with intelligent systems can further improve resiliency attributes for enhancing adaptive capacity of urban road traffic networks so that efficiency, equity of access, energy, and environmental issues of urban transportation can be addressed in a more effective 
manner than can be done today with existing knowledge." (Khan et al., 2016). The emergence of Intelligent Transportation Systems (ITS) has focused on "transportation planning to enhance adaptive capacity to handle recurring imbalance of demand vs. capacity as well as non-recurring incidents or operational inefficiencies or wide variation in conditions" (Khan et al., 2016). Technology advancements have introduced the analytical capability to manage existing infrastructure and to shift away from new construction, which might not be an option in fully developed areas. In addition to attaining efficiency gains obtainable from ITS and currently available methods, this research aims to enhance the sustainability of transportation by using resiliency measures in traffic system development and operation.

To achieve a better understanding of the resiliency measures of transportation, two key elements of resilience were introduced and advanced as this research progressed: inherent (also called static) resilience and dynamic resilience. This research will define inherent resilience options and how these options can be built-in to improve the inherent resilience of road networks. As well, the research will identify how dynamic resilience can be initiated, using the Bayesian method, when there is a major traffic incident. The framework is developed so that traffic planners can cope with major incidents that may otherwise create major issues in the urban traffic system.

\subsection{BACKGROUND}

Resilience is defined as the ability to resist the loss of traffic-serving capability owing to geometric and control system design (i.e., the inherent resilience) and by dynamically activating capacity-enhancing measures (i.e. the dynamic resilience) (Khan et al., 2016). Resilience (also called reliability and risk management) also "refers to the 
system's ability to accommodate variable and unexpected conditions without catastrophic failure" (Victoria Transport Policy Institute, 2017), or "the capacity to absorb shocks gracefully" (Wise et al., 1993). A resilient transportation network should have the ability to accommodate unusual traffic conditions, whether they occur due to infrastructure construction or maintenance, emergency, or natural disaster. The problem of resilience should be thought of before the occurrence of an event to increase the safety and sustainability of our community and infrastructure. "It is like having lifeboats even when they are not being used" (TRB and ECONorthwest, 2002).

The subject of inherent (or static) and dynamic resilience of adaptive capacity in urban traffic networks is new and developing. Although the benefits of traffic adaptive control became clear over a decade ago, research in systems of higher capability and wider scope has been fragmented, and published sources are scarce. There is a general recognition in the research community that advances should be made in know-how for coping with predictive recurring major changes in traffic demand as well as stochastic non-recurring surges of traffic (Khan et al., 2016). In relative terms, the severe nonrecurring surges in traffic offer much challenge to researchers.

\subsection{RESILIENT NETWORK DEFINITION}

A "resilient network" is a network that can mitigate the loss of traffic serving capability. To better reduce the drawbacks of congestion and understand the level of transportation network resilience, three significant steps had been planned in this thesis:

1. Inherent resilience: is the ability to resist the loss of traffic serving capabilities owing to segment geometric and control systems such as traffic signal timing, road segment length, number of lanes, etc. The serving capability of a segment might be underestimated using conservative design parameters. Better estimation 
of the traffic serving capabilities and the effect of different characteristics segment length, and traffic signal timing - will aid in the better understanding of infrastructure capability to serve traffic.

2. Dynamic resilience: is the ability to plan, foresee, and follow effective capacityenhancing measures. Dynamic traffic assignment methods will aid traffic managers to see the distribution of traffic over the network. Examples of dynamic resilience include, but are not limited to, changing the direction of traffic on a road during peak traffic, informing road users to use a different path, and if technology progresses, route guidance techniques can guide each road user to their destination based on the best interest for all road users at the time.

3. Vulnerable segments: a vulnerable road or road segment has two cases:

a. Case 1: a link segment cannot serve more traffic if more traffic is to travel through that segment.

b. Case 2: if a link segment is targeted, the network cannot absorb the traffic travelling on the link segment.

The research will discuss the need to explore a new approach to better estimate inherent resilience of a transportation network and possible dynamic resilience capacityenhancing measures. Although vulnerable links within the network will not be searched, the network analyses do take into account such limitations within a network.

\subsection{PROBLEM DEFINITION}

Resilience reflects the ability of the network to serve road users when an unforeseen event or combination of conditions occurs. These unpredictable conditions work to paralyze the mobility of the network and cause traffic overload. Components and variables of a transportation network that contribute to network resilience are: links or connections, link capacity, number of intersections per segment, green lights duration (that is optimized for delay minimization), segment length, traffic volumes, number of lanes, etc. 
Stochastic events affecting a link or a corridor cause capacity-reduction. If traffic demand is not altered, delays occur. Depending upon imbalance of demand and capacity, the delay could increase rapidly. This means that a small addition of vehicles over capacity leads to a significant addition to travel time, which translates into more congestion. Acceptable travel time is dependent on how much traffic the network can serve (inherent resilience). The availability of alternative routes or dynamic solution to overthrow congestion is called dynamic resilience.

Depending upon the inherent resilience of a link or a corridor, the rate of decline of service flow can vary from one link to another. From a planning and design perspective, it is highly desirable to enhance the inherent resilience of a facility to reduce the rapid decline of its traffic serving ability. Figure 1.1 shows profiles of inherent resilience impacted by disruptive events. How to reduce rapid drop in the ability of a facility to serve traffic is the same question as how to improve the inherent resilience.

\section{LEVEL OF INHERENT RESILIENCE}

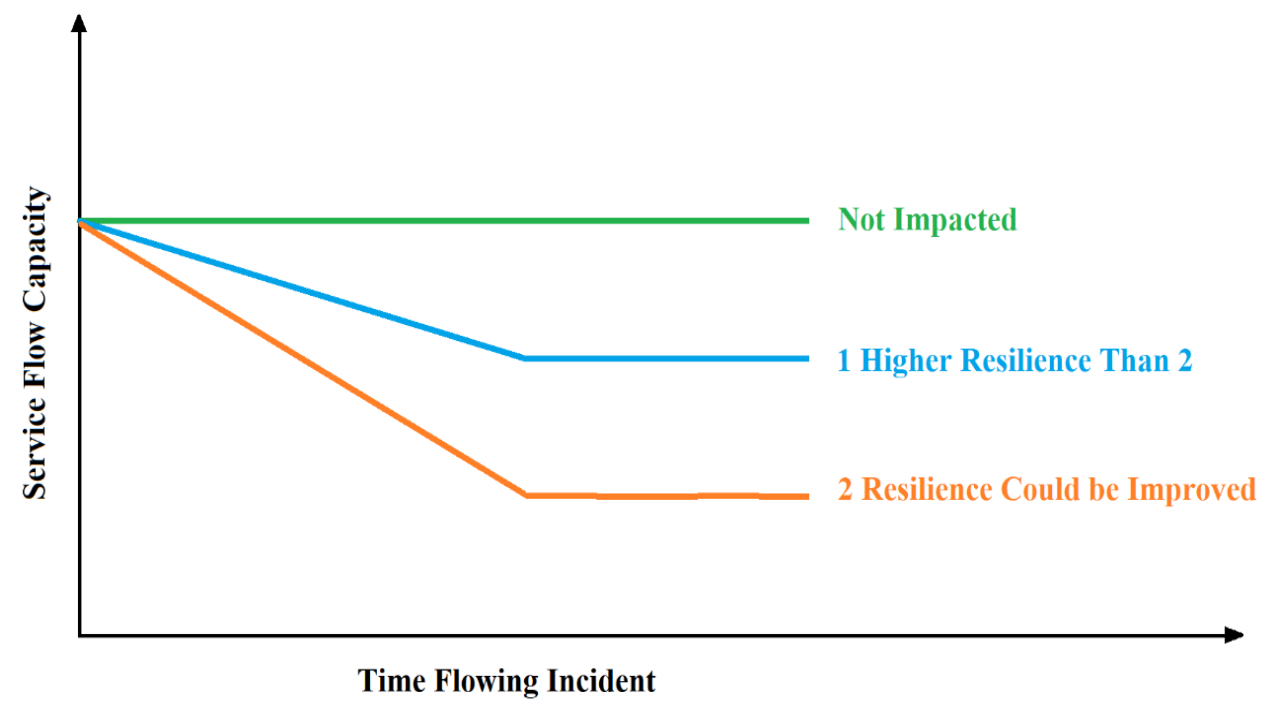

Figure 1.1: Level of inherent resilience 
It is of course understood that urban areas experience congestion on a routine basis, while traffic and other incidents cause extra congestion. Some examples are noted here. On February 20, 2017, CTV News published an article titled "Ottawa 4th most congested city in Canada according to study". Drivers in Ottawa spend 31.5 hours a year stuck in gridlock behind the wheel. Ottawa comes fourth after Montreal's 52 hours per year, Toronto's 45.6 hours per year, and St. Johns' 31.8 hours per year for every driver stuck behind the wheel in gridlock. These statistics are characteristics of normal congestion conditions, without considering the effect of unexpected events, which occurred or might occur in the transportation network. Figure 1.2, shows a gridlock on the Queensway in Ottawa. If inherent resilience of links and corridors can be improved, it will ease the effect of all types of congestion.

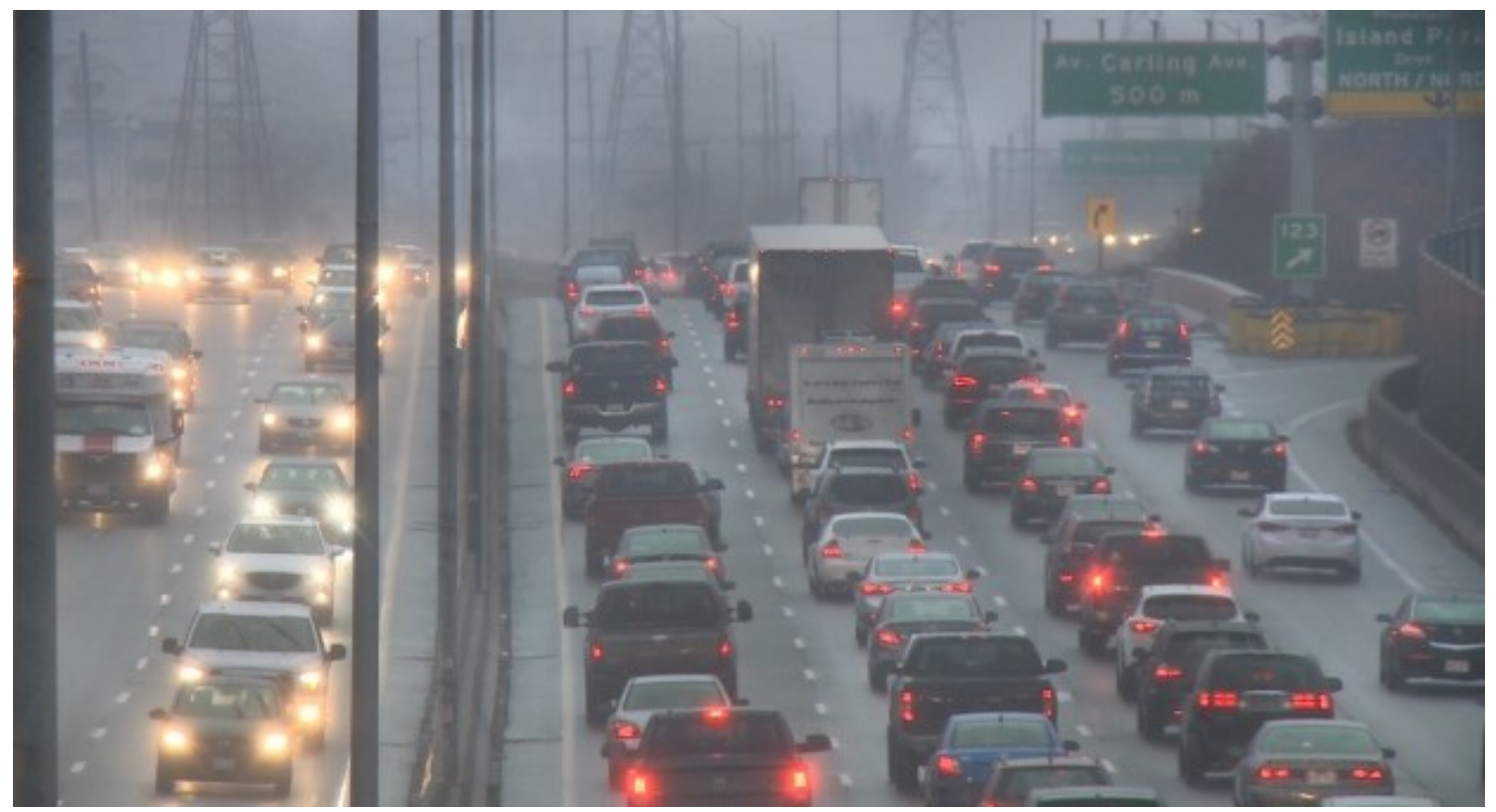

Figure 1.2: Gridlock on the Queensway in Ottawa. (Source: CTV News (Schnurr, 2017))

Moving to examples of unusual events, on May 6, 2017, the Chaudière Bridge closed as Ottawa River level rose.(See Figure 1.3). According to the city of Ottawa, the Chaudière Bridge serves over 27,500 vehicles a day. To reduce congestion, many local 
agencies and organizations had to change plans. What follows are some changes (source: CBC News (Burke, 2017)):

- Federal and provincial government buildings in Gatineau, from government offices to the Canadian Museum of History, were closed.

- The City of Gatineau closed municipal buildings, including libraries and sports centres.

- Gatineau and Hull hospitals cancelled non-urgent procedures and surgeries.

- People who travel by Société de transport de l'Outaouais (STO) were able to ride the bus for free from Monday to Friday, as the City of Gatineau attempted to reduce ongestion.

- The Western Quebec School Board closed elementary and secondary schools in Gatineau, Chelsea, and Onslow, as well as its adult vocational training centres.

- The Commission scolaire des Draveurs closed its schools and its administrative offices, as did the Commission des scolaire Portages-de-l'Outaouais.

- Ottawa-Carleton District School Board schools were expected to be open, although the board advised that buses could be delayed due to road conditions.

- Monday morning classes were cancelled at the Outaouais campus of the University of Québec.

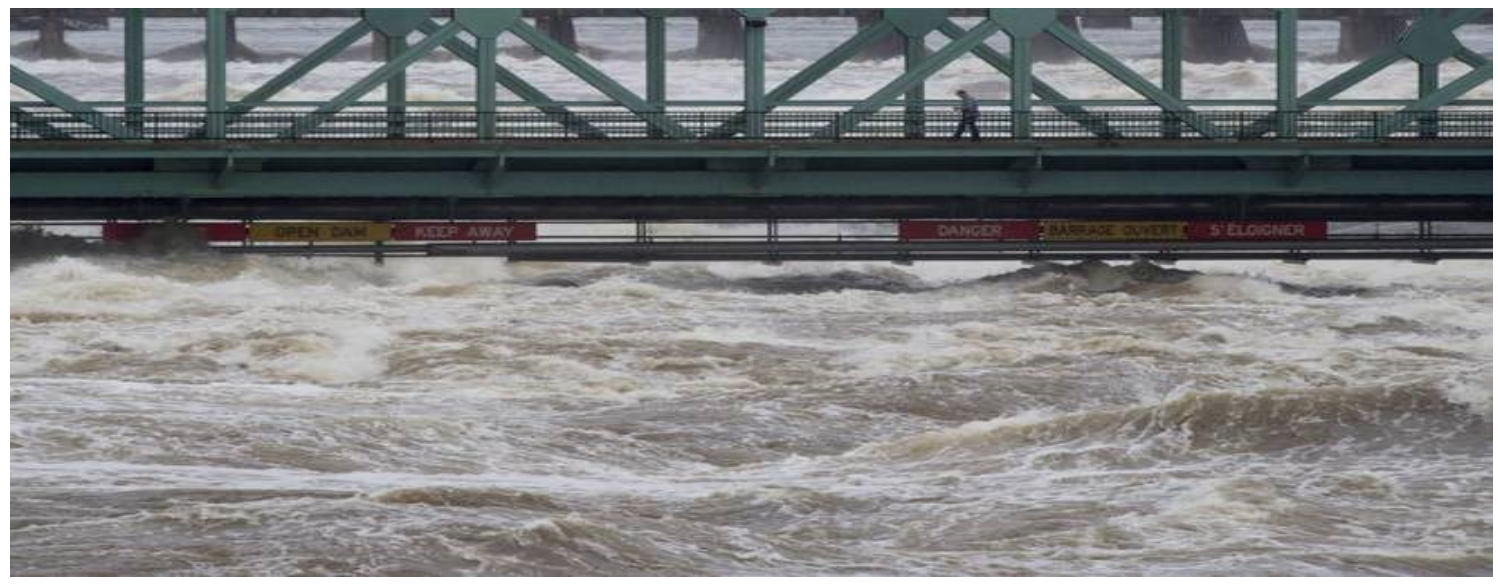

Figure 1.3: High Water Level Passes Under Chaudiere bridge. (THE CANADIAN PRESS, 2017)

Another example of unexpected congestion was the sudden sinkhole that formed on Rideau Street, near the Rideau Centre, on June 8, 2016. It caused the Rideau street 
and access to Colonel by Drive to close for traffic. The outcome was more traffic piling on adjacent routes for more than four weeks. Three lanes of Rideau Street were closed during the four weeks repair period. Figure 1.4 shows the massive sinkhole that opened on Rideau Street.

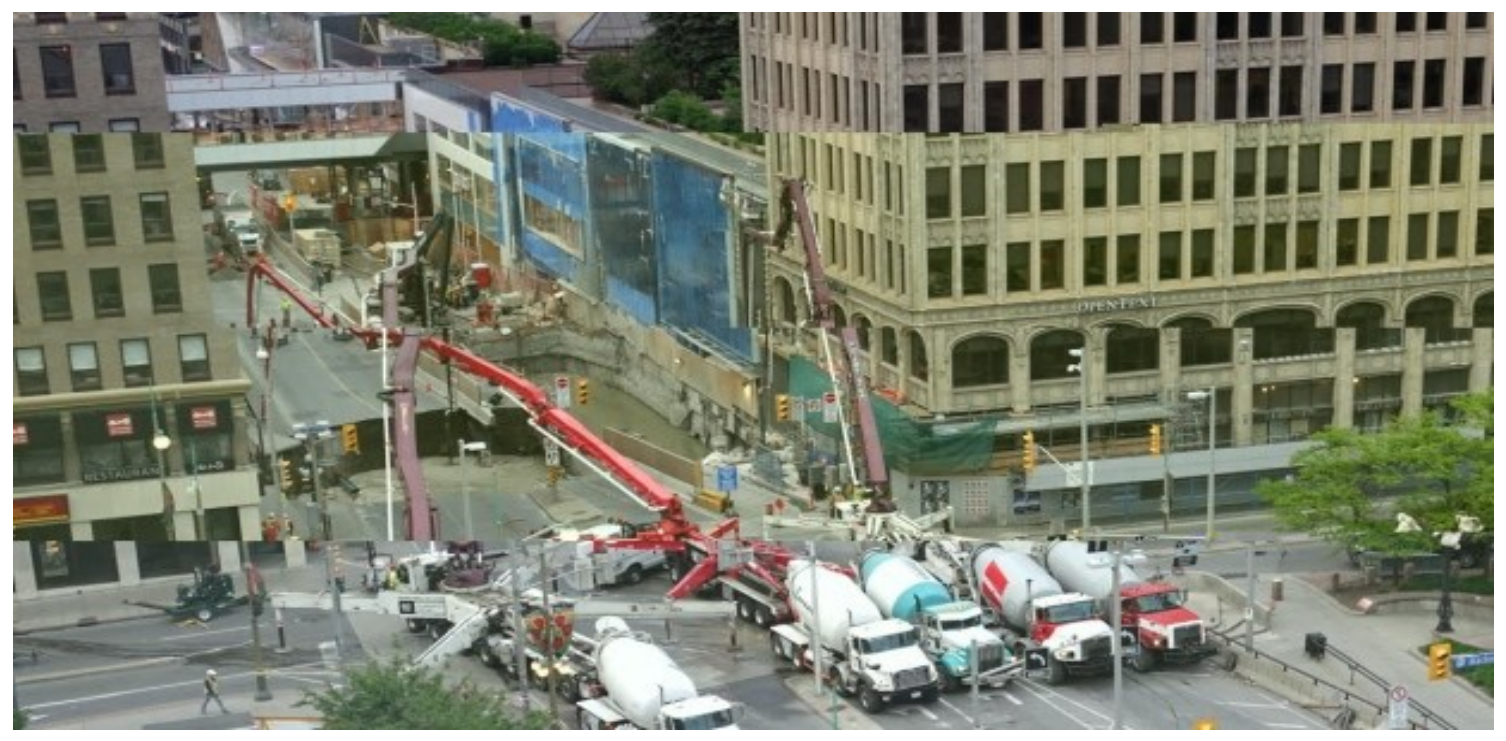

Figure 1.4: Rideau Street Sinkhole Swallows Three Lanes. (Source: CBC.ca (Burke, 2017))

In Atlanta, Georgia, a fire under a section of the I-85 highway led the overpass to collapse causing months of congestion in the area and nearby roads (Lopez, 2017). The incident forced traffic onto local streets and the outer loop. The section closed served between 250,000 and 400,000 vehicles a day. The cost of congestion and delays were suffered for months.

Above were some examples of many unexpected events, which directly add to the cost of congestion that takes place every year. Although random, the traffic engineering departments can develop good traffic management practice in order to reduce their impact. The cost of time, fuel, economic cost, and impact on environment can be reduced significantly with the approach of creating a more resilient transportation network. 
In events such as noted earlier, transportation networks experience delays and congestion which may continue for days or even months. The Rideau Street (Ottawa) Sinkhole or the collapse of the bridge in Atlanta are relevant examples. In the case of bridge closure due to rising water level, the impact can be experienced for one or more days. The aim of improving network resilience is to enhance network performance by taking into account future risks and plan for the possible loss of capability to serve traffic.

When an event occurs, the question becomes whether the transportation network can be resilient to serve the excess traffic or not? The inherent resilience is the first defence against impacts of major disruptions. However, dynamic resilience plays a role in easing effects of traffic shocks in the network caused by major disruptive events.

Figure 1.5 illustrates the role of dynamic resilience in stabilizing service in the network. Transportation network resilience is critical to prepare for an unexpected event. Creating a framework to mitigate some effect and pointing out vulnerabilities in the network will create a more resilient network. This thesis is aimed to study the resilience of a transportation network and implement the framework in real-life scenarios.

\section{Concept of Dynamic Resilience}

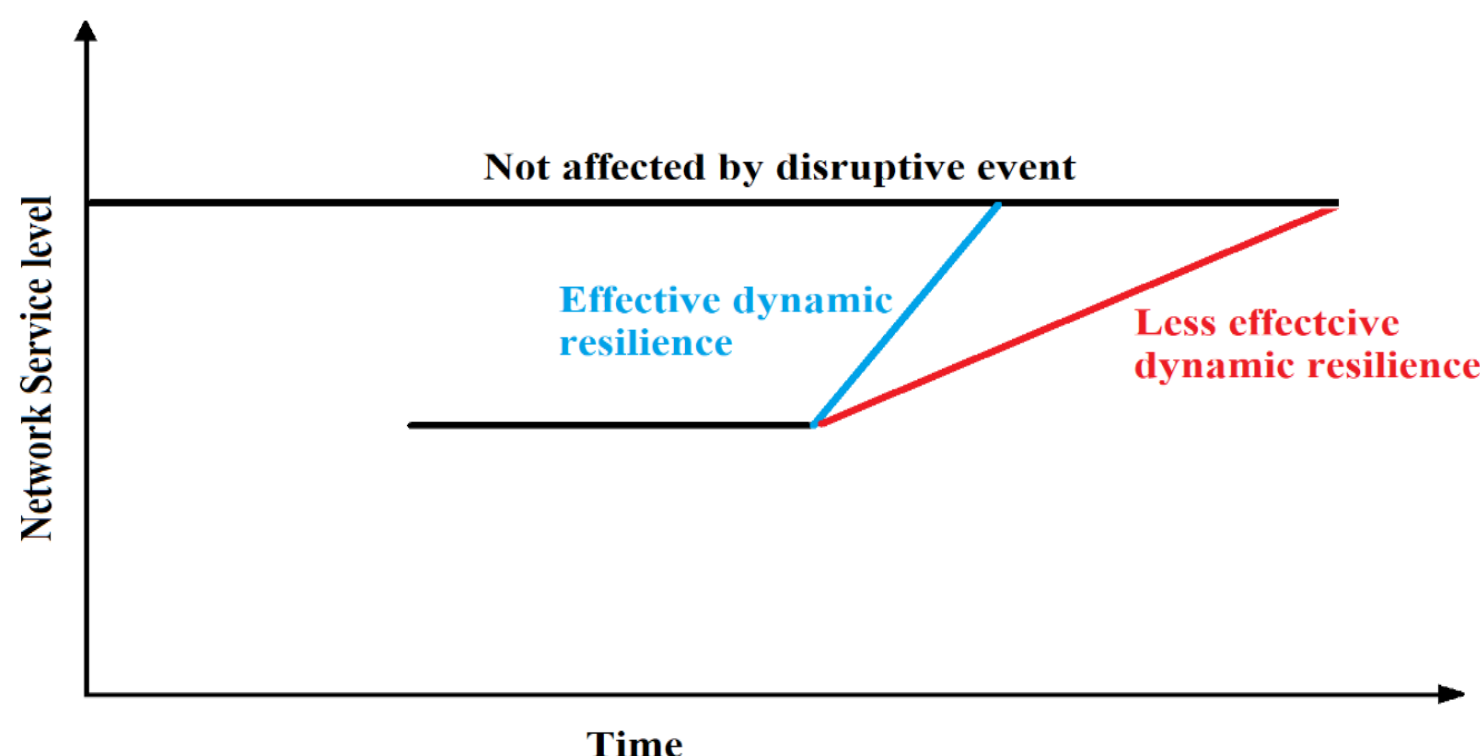

Figure 1.5: Concept of Dynamic Resilience 


\section{RESEARCH OBJECTIVES AND SCOPE}

\subsection{INTRODUCTION}

A traffic network is expected to serve traffic at low, normal, as well as high traffic periods at an acceptable level of service. However, under severe traffic shocks, the business-as-usual case does not apply and under such conditions, resilience plays a role. Resilience focuses on analyzing the risks, which might face the transportation system, and the means to enhance ability to serve traffic. The number of users, user's decision, available infrastructures (including factors that affect capacity and level of service such as geometric features, traffic control, and design), human factors, and safety, all are variables that contribute towards system performance. Resilience philosophy considers the effect of incidents, which might happen in the future and prepare traffic managers to react to a probable event.

- If a major link or bridge goes out of service, a number of questions will require answers: Where will traffic go? Or which route will a traveler select given the available information? Is there an alternative route for the excess traffic? (Note: when a bridge or a link cannot serve its traffic function, then this traffic becomes excess to the alternative routes.)

- $\quad$ Can the alternative routes (or the network) serve the excess traffic?

- Does traffic planner have means, information, and a plan to help dissolve the excess traffic into alternative routes effectively?

- $\quad$ Are we ready to react to any disaster avoiding long waiting hours and multiple Uturns? 
In broad terms, the objective is to enhance inherent resilience ahead of time and to establish dynamic resilience measures that can be implemented when needed. Research can lead to means for improving inherent resilience which can be built into the road network. Likewise, research-based dynamic resilience measures can be developed and implemented in response to a stochastic disruptive event.

\subsection{OPPORTUNITY FOR IMPROVEMENTS}

\subsubsection{Flow-Speed Estimation}

Assessment of transportation network resilience needs reliable estimates of vehicle flow-speed and travel times under varying densities that can approach highly congested conditions. This capability is the first step so that effects of resilience measures can be tested. Improvement to network simulators are frequently describe in the literature. These commonly focus on fine-tuning volume-speed or volume-travel time or volume-delay functions.

\subsubsection{Inherent Resilience}

Since measures that can potentially enhance inherent resilience were not known in the past, the above noted functions were not defined to a level of detail that is necessary for testing the effectiveness of these measures. That is, tools are to be formulated to incorporate detailed road and traffic control characteristics so that better estimate of flow, flow-speed, and travel time prediction can be obtained. Following this capability, the analyst will have the opportunity to define and simulate the effect of inherent resilience at a link or corridor or even network level.

Research is needed in calibration of volume-travel time and volume-delay function (VDF) parameters for each applicable link type with different properties (i.e. 
speed limit, segment length, number of lanes, geometric design features for turning movements, etc.). It is hypothesized that among the above noted variables, segment length and geometric design features can potentially enhance resilience in terms of adapting to shocks in traffic flow. Advanced simulators with required capabilities can be used for quantifying the effectiveness of inherent resilience measures in terms of throughput and quality of flow.

Past studies of resilience such as (Murray-Tuite and Mahmassani, 2004; Wang et al., 2013; and Faturechi and Miller-Hooks, 2014) were conducted in an idealized network or to evaluate system performance given a predefined condition. However, as noted above, inherent resilience estimation approach requires microsimulation of traffic for the study of link or corridor or network properties (incorporating inherent resilience measures) in terms of traffic flow. Should actual traffic volumes flow on links that are simulated, a comparison of data with simulated traffic would be useful.

\subsubsection{Dynamic Resilience}

Dynamic resilience implies strategies and tactics intended to cope with disruption and consequent traffic congestion caused by a severe event. These dynamic resilience actions are based on dynamic traffic control methods. The approaches to implement these actions include directing road users to follow specific routing instruction under severe event conditions. Existing technology can be used to connect to road users and new technologies have the potential to serve dynamic traffic management functions. The idea is to minimize the knowledge gap between traffic management personnel/planner and road users. For example, road users could be reached by:

1. radio stations, 
2. a wide range of navigation systems and software which can be optimized to change the route of traffic giving the number of users that are following a specific path and updating the inputs more frequently, and

3. dynamic traffic signs above the raod or on the side of the road to warn travelers about the road condition ahead.

Knowledge of dynamic resilience enables the identification of potential solutions for navigating traffic to alternate routes.

\subsubsection{Vulnerability analysis}

A vulnerable link can be defined as a link which will not serve the required traffic flow to connect two points, i.e., if only one link x connects origin A to destination $\mathrm{B}$, and there is no alternative to link $\mathrm{x}$, then link $\mathrm{x}$ is a vulnerable link. In addition, a vulnerable link can be defined as high traffic serving capable link which hugely affects mobility in the network in case of a disruptive event.

Vulnerability analysis adds more to the planning of a resilient transportation system. There have been several attempts by researchers to define vulnerable links in a transportation network. Although vulnerability of links will not be addressed directly in this thesis research, the dynamic traffic assignment method has the ability to explicitly work with traffic service characteristics of all links in the network.

\subsection{RESEARCH OBJECTIVES}

The objectives of this research are:

1- To investigate link and corridor-level means to enhance the inherent resilience in terms of sustained ability to serve traffic while resisting deterioration of quality of flow. Specifically, identify static (inherent) resilience measures for increasing 
traffic serving ability of urban roads/corridors and to develop a predictive model for testing such measures. The predictive model is intended to estimate improvements in service flow and operating speed as a result of changes in geometric design under given traffic control factors (i.e. segment length, turning bays, posted speed limit).

2- To develop dynamic resilience measure that incorporates dynamic and stochastic characteristics of traffic affected by a disruptive event.

3- To develop decision-making guides for managing traffic under disruptive conditions while formally taking into account uncertainties in the estimates of network level delays.

\subsection{SCOPE}

This research is aimed at the identification of resilience measures and the development of methods for the investigation of how to enhance resilience of the traffic network. It is intended to use the existing knowledge and methods for network analysis under incidents as the starting point. New and original research proposed here will result in contributions intended to serve as means to reduce impacts of major stochastic events. Both static (i.e. inherent) resilience and the dynamic resilience are of interest. However, the physical resilience of transportation infrastructure is not included in this thesis research.

As for the spatial scope, the studies of inherent resilience are meaningful at the link and corridor level. On the other hand, to define and assess dynamic resilience measures, corridor and network level studies are essential. 


\subsection{RESEARCH METHODOLOGY}

The research methodology presented in Figure 2.1 encompasses:

1. Problem definition

2. Research objectives and scope

3. Literature review

4. Development and application of methodology for testing inherent resilience measures

5. Development and application of methodology for testing dynamic resilience measures

6. Linkages of dynamic resilience measures with traffic control

7. Conclusions and contributions to knowledge

The problem definition starts with noting highly disruptive events with potential for major impacts on key arterials and corridors. In some cities such as Ottawa-Hull (Gatineau), bridges used for serving commuter and other traffic can be impacted by major floods. As a part of problem definition, the need for inherent and dynamic resilience is highlighted.

The problem definition step leads to setting research objective and establishing scope for this doctoral thesis research. These have been noted in previous sections. The objectives logically call for development and testing of resilience measures. In order to achieve these objectives, methods are to be developed so that resilience measures can be tested. The scope of research indicates that this original research covers the traffic service resilience, but it does not include the physical resilience of transportation infrastructure. Another scope item indicates that dynamic resilience measures and methods are covered in this research and linkages to dynamic traffic control are 
identified. However, it is beyond the scope of this research to develop traffic control algorithms.

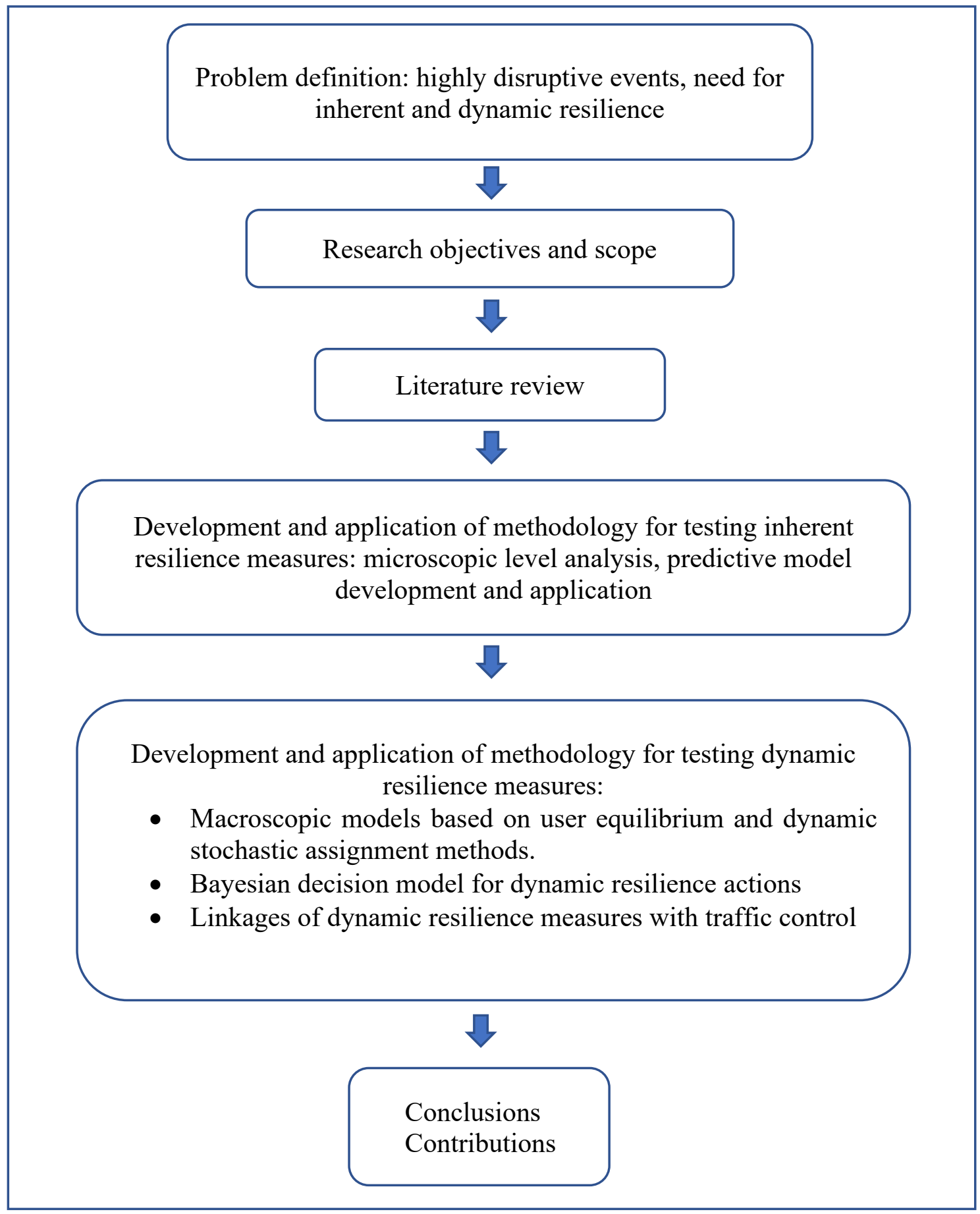

Figure 2.1: Research Methodology 
The literature review part serves an important function of assessing the state of knowledge in this field of inquiry. In addition, useful suggestions by previous researchers are taken into account in the development of research methods.

For the development of methodology for testing inherent resilience measures, microscopic level of investigation is necessary. Based on microscopic level simulations, predictive models of link performance are developed and applied for the quantification of resilience improvement.

Dynamic traffic assignment methods are implemented at the macroscopic level due to the necessity to study dynamic resilience measures at the network level. Macroscopic models based on dynamic stochastic assignment are investigated and compared with user equilibrium assignment methods.

Due to the uncertainties in traffic flow during highly disruptive events, Bayesian decision analysis method for assessing dynamic resilience actions is researched. These actions encompass combinations of user-equilibrium and stochastic assignment methods. These methodological developments lead to defining linkages of dynamic resilience measures with traffic control.

Finally, on the basis of advances in methods and their applications, conclusions are presented and contributions to knowledge are noted.

\subsection{RESEARCH GUIDING PRINCIPLES}

Philosophical and theoretical considerations noted below were instrumental in the development and implementation of the methodology.

- The theoretical foundation of methods and models are researched prior to their development and/or application. 
- The nature of complex link and network level analysis called for detailed simulations at the microscopic and macroscopic levels. The "PTV-software suite" was used for model development and application. Microsimulations were conducted using "PTV-Vissim" and "PTV-Visum" was used for macroscopic simulations. This software suite is well accepted in the research community and have all the necessary capabilities for implementing the research plan.

- For proof of concept and application of theories, the National Capital Region (NCR) (Ottawa-Gatineau, Canada) was used. Real-world data on travel demand, network, and traffic control were collected and used. Although the NCR data are used, the methodologies can be applied to any urban area. 


\section{LITERATURE REVIEW}

\subsection{INTRODUCTION}

Resilience has been defined in many disciplines in the literature including ecosystem (Holling, 1973), industry (Hollnagel et al., 2007), economics (Rose, 2004), freight transportation systems (Ta et al., 2009), and transportation network (MurrayTuite and Mahmassani, 2004; and Murray-tuite, 2006). Resilience is the process to oversee probable deficiencies in the transportation network and to reduce the time of recovery of the system to come back to normal operational condition after a disruption. The TDM Encyclopedia defined resilience as the "system's ability to accommodate variable and unexpected condition without catastrophic failure."

In addition, the resilience of the transportation network can be viewed as the ability of the network system to overcome an unforeseen abnormal congestion condition. Whether this condition caused by a natural disaster such as an earthquake, hurricane, or a situation like the giant sinkhole which swallowed three lanes of Rideau Street in Ottawa. The degree of road network resilience is the ability of the network to resist the deterioration of quality of flow through inherent resilience options; and to restore service flow capacity over short time by addressing dynamic and stochastic characteristics of traffic affected by a major disruptive event.

A study by Ouyang et al. (2012) produced a three-stage analysis framework(See Figure 3.1). The research paper divided the response performance process into three stages: stage one being the disaster prevention stage or the resistance capacity of the infrastructure to prevent possible hazards and reduce initial damage to the system. The second stage takes place as damage propagates; it reflects the system's ability to absorb 
the damaging impact and minimizes the consequences of the hazard. The maximum impact level is used to measure the absorptive capacity and regarded as the resilience in the second stage. The third stage is the assessment of damage and recovery, which reflects the restorative capacity of the performance. Recovery time and recovery cost characterize restorative capacity. The new performance state then is measured compared to the initial performance, and it might be better or worse.

To test the level of resilience of a transportation network, a disaster such as a closure of a main corridor will be assumed to take place, and the research will study the damage and recovery stage of the network. If the network can recover and serve traffic demand, then the system is defined to be resilient.

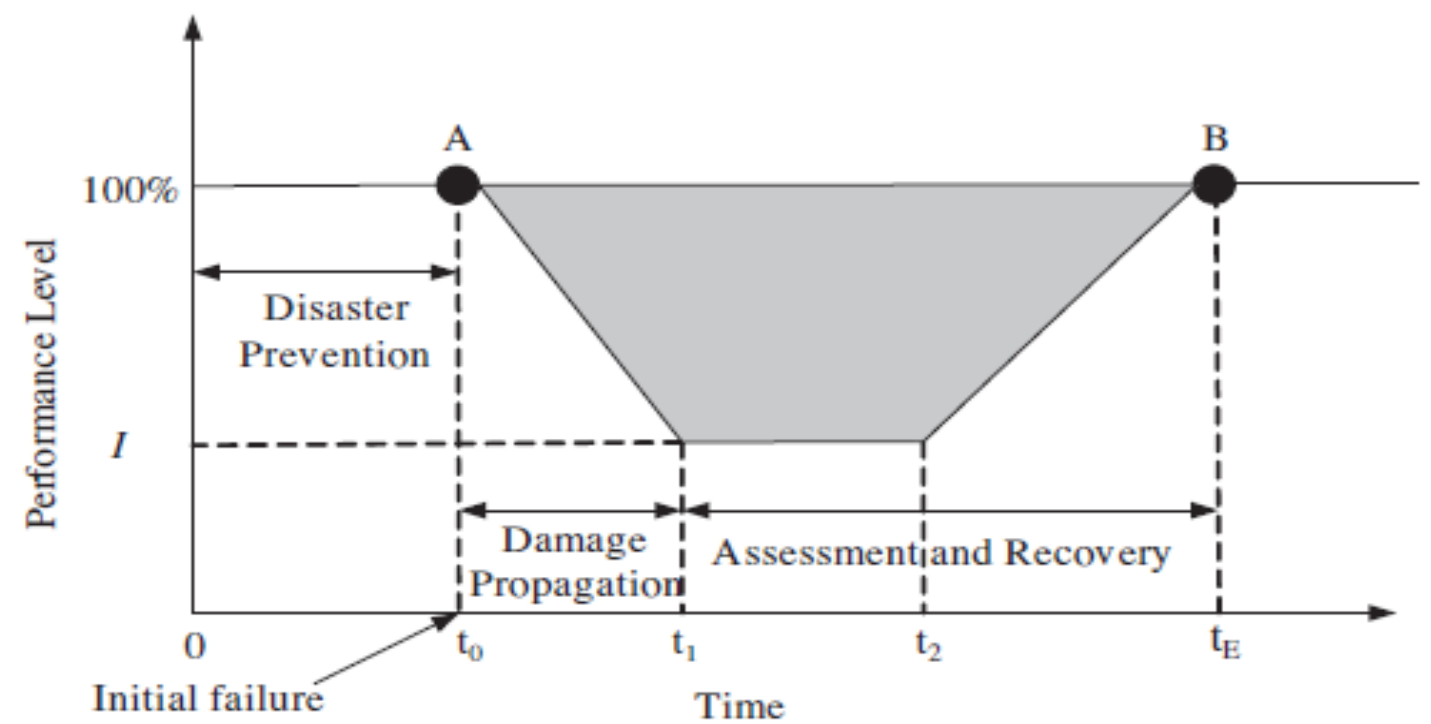

Figure 3.1: Typical performance response curve of an infrastructure system following a disruptive event. (Ouyang et al., 2012)

Another significant research in the general subject of this thesis carried out by (Murray-tuite, 2006) defines resilience as a characteristic that evaluates system performance in unusual condition. The recovery time, and the amount of outside 
assistance needed to resume original functional state are key players in the study. Murray-tuite suggests that a resilient transportation system has ten properties, which include redundancy, diversity, efficiency, autonomous components, strength, adaptability, collaboration, mobility, safety, and the ability to recover quickly. In addition, earlier work by Murray-Tuite \& Mahmassani (2004) used travel time and capacity to develop a disruption index for transportation network and pointed out vulnerable links, which are the most critical to the network from a connectivity standpoint. The study used a sample network consisting of 8 links and 6 nodes to apply the knowledge, which limits the use of the methodology on a real-world network. An implication of these literature items is that more research is required to set ground on measuring network resilience in real world.

\subsection{TRANSPORTATION NETWORK RESILIENCE}

Transportation network resilience is the network performance under unusual condition. Prediction of such performance is highly challenging and is also critical in a situation of emergency. It is important to predict how the transportation network will recover when emergency arises. From network planning perspective, it is highly important to draw scenarios of emergency preparedness to overcome safety, cost of ceased mobility (whether the cost is of human life, economy, accessibility, or infrastructure). If the transportation network is not resilient, then the system is susceptible to bargaining the cost of loss. Murray-Tuite (2006) study suggested, "system performance prediction must go beyond risk assessments and consider resilience."

Transportation network resilience is measured by its properties. Previous researches suggested properties for a resilient transportation system as follows: 
- Redundant, diverse, efficient, autonomous, strong, independent, adaptable, collaborative (Godschalk, 2003),

- Mobility (Victoria Transport Policy Institute, 2017)

- Safety, and the ability to recover quickly (Murray-tuite, 2006).

Definitions for the metrics of resilience are as follows: Definition of the first six terms are acknowledged from Godschalk (2002). The remaining terms are acknowledged from Murray-Tuite (2006).

1- Redundant system is a system with more than one component that serves the same function so that the system will not fail when one component fails.

2- Diverse system is a system with components that have diverse functions to serve the system from different threats.

3- Efficient system has an optimized ratio of input-output delivered dynamically.

4- Autonomous system has the ability to operate independently without outside assistance.

5- A strong system is a system that can withstand an outside event.

6- Independent system consists of connected links that will support each other at all time.

7- Collaborative system is a system that shares resources and infrastructure and to overcome an event by collaboration.

8- Adaptable system has the ability to learn from past events and provide flexibility to overcome an event.

9- Mobility is the measurement of road level of service, the ability of road users to reach their destination.

10-Safety of the system refers to the safety of road users.

11-Finally, the ability to recover quickly refers to the ability of the system to recover quickly with minimum outside assistance after an event occurs.

Previous research used simulation to compare “...the user equilibrium (UE) and system optimum (SO) traffic assignments with respect to adaptability, safety, mobility, 
and recovery." (Murray-Tuite, 2006). The study used DYNASMART-P software to generate both SO and UE traffic assignments for test networks. The output of the simulation was used to evaluate adaptability, safety, mobility, and recovery of the system. The study assumed human-made event, which required all residents of the test network to evacuate the city at the same time. The study tested the performance of two assignment methods. SO traffic assignment yielded better mobility and recovery, and UE performed slightly better regarding adaptability and safety. Similarly, this research will assume an event, test the consequences on roads and network, and test solution to increase mobility and recovery.

The following paragraphs show the measures used in the study of Murray-Tuite (2006):

Adaptability

“A network's adaptability to an event or its impacts can be measured through atypical uses of infrastructure, transportation modes, and demand management. This work considers atypical uses of infrastructure. For any arcs (A1rs) connecting origin node $r$ with destination node $s$ not normally used for general traffic, calculate the percentage of vehicles using these lanes, as in Equation (1). Note that special use lanes (such as high-occupancy vehicle) can be modeled as links separate from general use lanes."

$$
m_{1}=\frac{\sum_{w} \theta^{r s} \phi_{p} p_{w}^{r s}}{\sum_{w} \theta^{r s} p_{w}^{r s}} \times 100
$$

where

$p_{w}{ }^{r s}$ is the path of vehicle $w$ going from origin node $r$ to destination node $s$,

$\phi_{p}$ is a binary variable taking the value 1 if path $p$ contains one or more special use lanes and 0 otherwise,

$\theta^{r s}$ is a binary variable taking the value 1 if a path exists between origin node $r$ and destination node $s$ that includes a special use lane and 0 otherwise. 
Safety

“.... a rough estimate $(m 2=D \lambda)$ can be derived by multiplying the total vehicle miles traveled $(D)$ by the fatality or incident rate $(\lambda)$, publicly available from the National Highway Traffic Safety Administration (NHTSA). The units of the rate are often fatalities per million vehicle miles traveled."

Mobility

".... mobility is measured in six different ways. First is the amount of time $E$ required to evacuate a town's residents. Second is the ability of response vehicles, such as ambulances, to travel from one zone to another; ........ Third is the queue length $L a$ on directed arc $a, \ldots$. Fourth is the average queuing time $q$ per vehicle. Fifth is the amount of time ( $U a)$ link $a$ offers average speeds lower than a threshold $b$ of its posted speed limit $(u a)$. The final measure is the volume to capacity $(v / c) a$ for each link $a . "$

Recovery

"... If infrastructure is damaged, recovery can be measured by the amount of time, money, and outside assistance required to restore connectivity at an acceptable level of service, ....... In the case where no infrastructure damage occurs, $\ldots$, recovery is measured by the amount of time required to alleviate congestion.... three measures of recovery are used in this study. Let $t_{a}{ }^{l}$ be the time point at which the queue length on link $a$ returns to a predetermined range. Let $t_{a}{ }^{u}$ be the time at which the speed on link $a$ returns to or exceeds the posted speed limit. Finally, let $t_{a}{ }^{v}$ be the time at which the volume/capacity ratio on link $a$ returns to a pre-specified range." 


\subsection{CONGESTION}

In an event of disruption, the network experiences higher traffic surges which overload the network resulting in surges in delays. As a result, mobility decreases, and more time will be required to reach a new equilibrium. The resilience of a transportation network enhances the network's ability to decrease traffic delays in a shorter time. The relationship between traffic overload, mobility, and resilience could describe the level of network resilience and quantify the level of resilience. Increased efforts and time taken to ease traffic overload in the network means the network is less resilient.

More than a decade ago, an initial step was taken in the form of adaptive traffic control of intersections and ITS installations. The majority of all network delays are experienced at signalized intersections. Implementation of Traffic Adaptive Control (TAC) demonstrated the effectiveness and wide range of benefits related to auto speed and delays, transit speed and delays, left-turn delays, intersection delays, pedestrian delays, fuel consumption, emission levels, and traffic conflicts (Jagannathan and Khan, 2001).

A research paper by (Mucsi et al., 2011) proposed that the negative impact of congestion can be reduced by moving queues to predefined locations where the impact is minimized. Also, "to minimize total person delay and maximize vehicular capacity during congested conditions, the bottleneck intersection must always have sufficient number of vehicles on its approach during the green signal to maximize its capacity (i.e. it is never starved), but at the same time the queue of vehicles at 'the intersection' must be as short as possible to minimize transit delay." (Mucsi et al., 2011)

Congestion is also related to human behaviour. If we assume a technologyintensive, where vehicles can communicate with each other, then vehicles would follow 
each other closely at the speed limit without stopping unless needed. However, in the world where human fear and emotion is involved, the driver travels around the speed limit, and when the gap to the next vehicle shortens, the driver applies the brake (the pressure which the driver applies the brakes is dependent on emotions) even if the road in front of the next vehicle is clear. This creates a shock-wave. The driver behind him/her applies brakes, and the pressure builds up until it reaches a vehicle where the driver is forced to come to a complete stop, and the queues build up.

\subsection{VULNERABILITY OF TRANSPORTATION LINKS}

Vulnerable links in transportation network are those links that affect the transportation network the most. It is most likely to be targeted if an intended attack is to be planned, or the most valued in an incidence of a disaster. It could be referred as the connectivity link, the weak link, or the vulnerable link. It is a crucial link to a reliable network. In addressing the most vulnerable links, Murray-Tuite and Mahmassani (2004), proposed: "network reliability refers to the existence of a feasible connection between two network nodes. Reliability may be captured by the probability that the origin and destination are connected, given link failure probabilities."

The focus of transportation research on network reliability has been around the probability of the link being completely operational which exclude any damage to the network (Iida, 1999). To assess the network reliability (Bell, 1999) used game theory using pre-specified routes, pre-defined scenarios of route utilities, and user pessimism to measure the performance of the network. Another research has been conducted using different formulation to measure the performance or reliability of the network or to formulate the damage suffered by the network. In previously studied researches an 
assumption of vulnerable links is known prior, and the test is conducted on a small network with limited connectivity.

Past approach to determine vulnerable links was carried by Murray-Tuite and Mahmassani (2004), where the network reliability refers to the existence of a feasible connection between two nodes. In another word, the reliability is captured by the probability that the origin and destination are connected. The study developed a vulnerability index, which helps to identify the links that are most critical to the network from a connectivity standpoint and are most likely to be targeted if an evil entity had the intention to disrupt the traffic flow. On the other hand, Traffic Management Agency (TMA) will provide route guidance to road users in an emergency or a destructive situation.

The research by Murray-Tuite and Mahmassani (2004) addresses the importance of links in connecting origin-destination pairs using a game scenario; all links are studied, and a vulnerability index is specified for each link. "The vulnerability index accounts for the availability of alternate paths, excess capacity, and travel time.”(Murray-Tuite and Mahmassani, 2004). The vulnerability indices for a given link are then aggregated over all origin-destination pairs into a single measure of "the disruption index." The disruption index represents a network-level importance measure of a link. In addition, it is an indicator in which a harmful "evil entity" will use it as an indicator of relative damage to target an arc. General observations from the study are: the link with the highest disruption index connects most origin-destination $(\mathrm{O}-\mathrm{D})$ pairs in the sample network used. Second, if only one path connects O-D pair (and no alternate path can be used), then all links are marked with maximum vulnerability 1.0 on that path. Third, for the path to have 0.0 vulnerability index or disruption index, no 
traffic is assigned to that path. Fourth, low vulnerability index for the link means that an alternate path can accommodate the affected O-D flow from that link. Finally, the combination of high demand and network design (limited availability of alternate paths) may prevent routing affected vehicles around vulnerable links in a safe and timely manner.

The drawbacks of past experiments are that these are built on a hypothetical network and a restricted number of possibilities. The difference this research proposes is to analyse the state of traffic on the Ottawa-Hull area transportation network before and after a disruption. |Also, it is intended to examine possible inherent resilience options to be implemented and highlight dynamic resilience actions to ease traffic overload on the network.

\subsection{TRAVEL-TIME AND SPEED ESTIMATION (INHERENT RESILIENCE LITERATURE)}

\subsubsection{Introduction}

Recent advancement in traffic modelling and simulation software are expected to produce realistic speed and travel time estimates. Several approaches had been taken by researchers in the objective to predict flow-speed estimates. Some of these efforts are:

- Adjustment of coefficients of volume delay functions

- Calculation of Highway Capacity Manual-based approach for congestion delay estimation

- Traffic modelling and traffic simulation approach

- Compare speeds from field data and adjust VDFs 
For most research, the VDFs are generalized for a particular class of links in the transportation network e.g., highway speed estimation is given free-flow speed (FFS), the number of lanes, and flow. There has been little exploration of the effect of different road parameters on the flow speed, i.e., segment length, number of lanes, left and right turning bays, road class, and geometrics. Difficulty measures vary for different speed estimation approaches. Adjusting VDFs type functions can be easily implemented with the most current available travel demand forecasting software and require little or no adjustment to the coded network (Kurth et al., 1996). Implementation of calculationbased approaches is difficult to use for network-based estimation, as it requires a high amount of data, extensive link-specific details, high computation overhead, and significant changes to network coding and specialized software.

Uncertainty in inherent traffic serving capabilities (inherent resilience) limits the use of deterministic approach when modelling traffic demand in a transportation network. While browsing through literature, there has been more focus on determining the inherent flow speed and travel times of freeways as compared to that of networks consisting of arterials, collectors, and local links connected by intersections. This section will briefly describe relevant literature found on estimating the parameters of travel speed and travel times of different link types. The U.S. Bureau of Public Roads (BPR) equation was found to be the most extensively applied VDF used in practice. The scope of this research is to study network resilience and examine the range of application of BPR equation, which is used as the primary volume-delay function.

\subsubsection{Volume Delay Function}

Estimation of real flow condition has had an increasing concern for transportation modellers and researchers. Developing a new volume-delay function is 
complicated and implementing it require changes to network coding and processing procedures. On the other hand, improving adjustments to the BPR volume-delay function is more comfortable and implementing it require little or no changes to the currently available travel demand forecasting software. Numerous researches had been undertaken to predict adjustment factors for BPR equation to reflect field data and present the best fit for traffic behaviour under different conditions or link properties.

"The Bureau of Public Roads (BPR) equation and its variations are used by transportation demand modellers to predict speed as a simple function of volume/capacity ratio" (TRB, 1999). The standard BPR equation is:

$$
s=\frac{s_{f}}{1+a\left(\frac{v}{c}\right)^{B}}
$$

Where: $\mathrm{s}=$ predicted mean speed, $\mathrm{s}_{\mathrm{f}}=$ free flow speed, $\mathrm{v}=$ volume, $\mathrm{c}=$ practical capacity, $\mathrm{a}=0.15, \mathrm{~B}=4$

In a study on analysis of vehicle running speed and its influencing factors on urban major streets, Zi-lei et.al. (2010) used field data from Beijing, China. The base running speed was defined under base conditions and predicted speed was found from calibrated BPR Volume-delay functions. The findings on the relationship between segment length and the running speed, and number of lanes and the running speed for similar speed limit links are shown in Figure 3.2 and 3.3, respectively. The results show that running speed increases with an increase in segment length. This is an interesting finding from the perspective of resilience. The other result, namely improvement in speed due to increasing number of lanes, is what is commonly expected. However, it should be noted that both functions show diminishing marginal increase in speed. This research analyses the change in running speed on urban street with varying intersections 
characteristics. It also, quantifies the influence of different characteristics - left/right turn bay, and adaptive control - along with segment length on running speed.

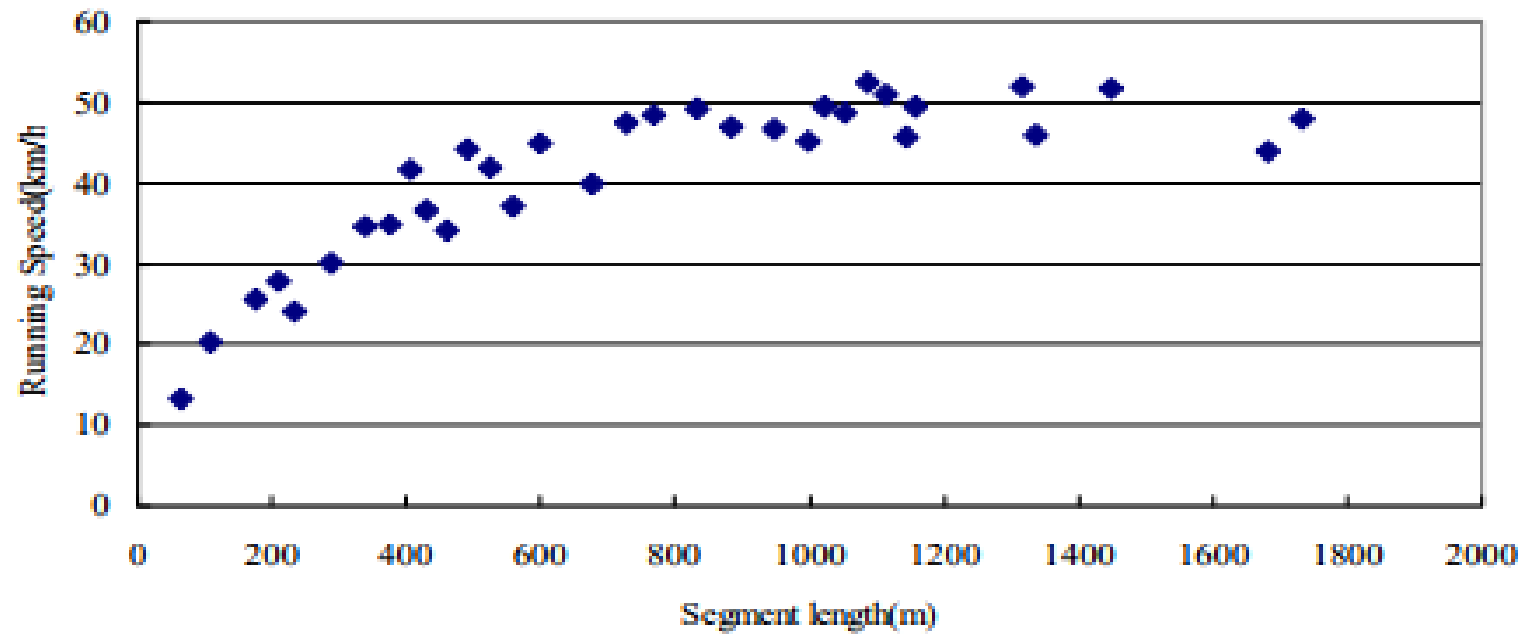

Figure 3.2: Relationship Between Running Speed and Segment Length (Zi-lei et al., 2010)

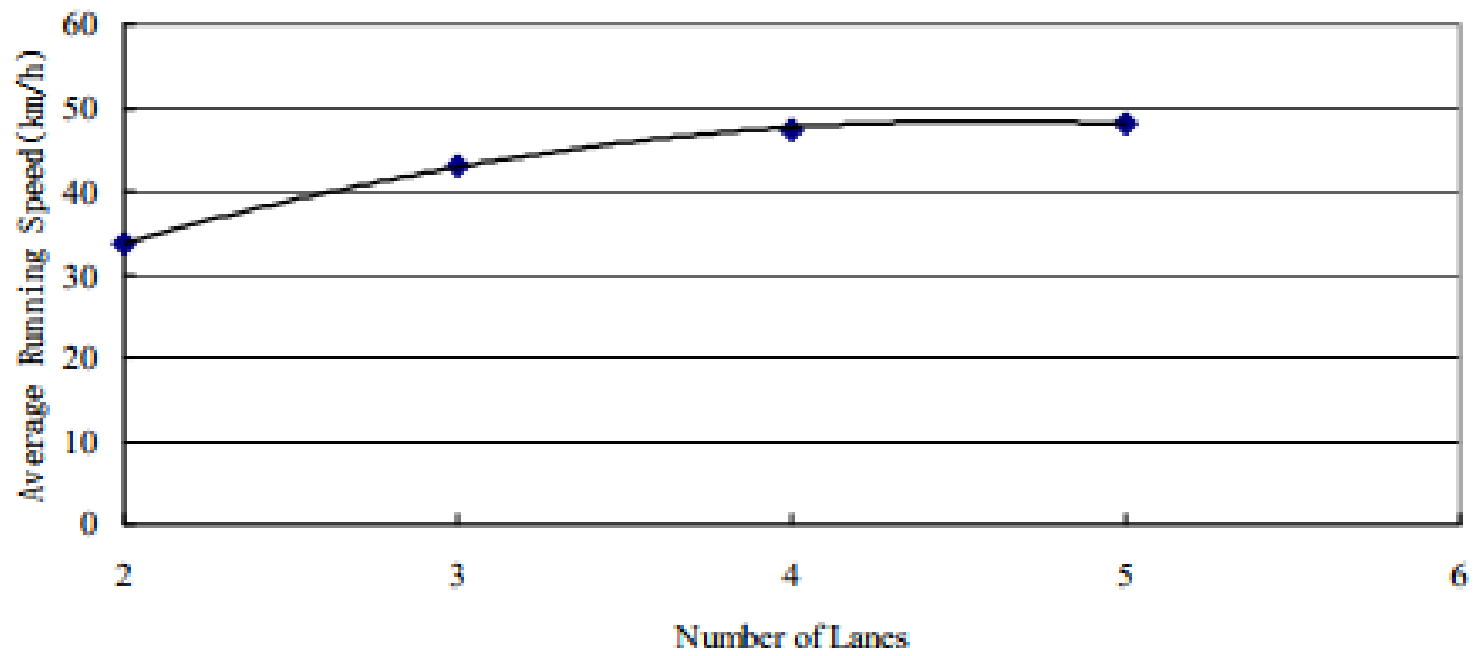

Figure 3.3: Relationship Between Number of Lanes and Average Running Speed (Zi-lei et al., 2010)

Skabardonis and Dowling (1997) proposed and tested improved speed-estimation techniques by comparing field data and simulation results. Their objective was to provide better accuracy of long-range transportation planning models for predicting the relationship between the average speed and flow on links (Skabardonis and Dowling, 1997). The model compared average speed of standard BPR, updated BPR, Akcelik Model equation; Highway Capacity Manual HCM- based model, and simulation data. 
The study concluded that the standard BPR curve predicts lower speed for volume/capacity $(\mathrm{v} / \mathrm{c})<1$ and higher speeds for $\mathrm{v} / \mathrm{c}>1$. In addition, the study found that the updated BPR curve for arterials significantly improved the accuracy of the estimated average speeds compared with the standard BPR curve. The updated generalized BPR volume-delay function which produced the best fit to the HCM-based model and FREQ model had the parameters value for $a=0.2$ and $b=10$. The summarized results are presented in the Figure 3.4, Figure 3.5, Figure 3.6, and Figure 3.7.

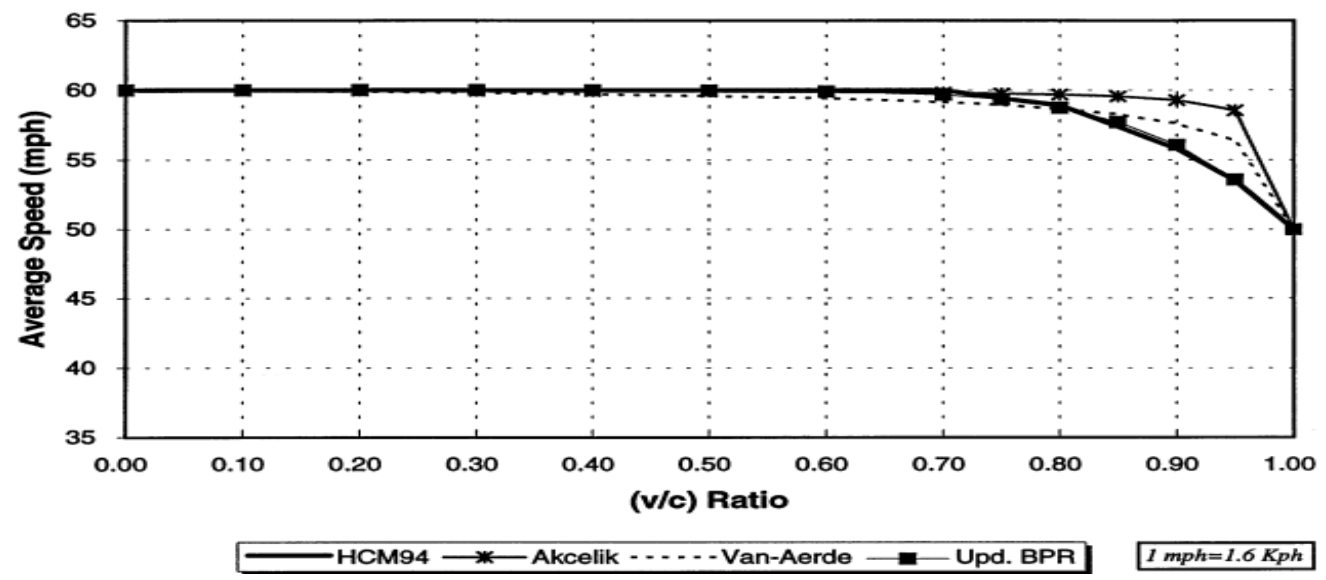

Figure 3.4: Comparison of Freeway Speed-Estimation Techniques (Skabardonis and Dowling, 1997)

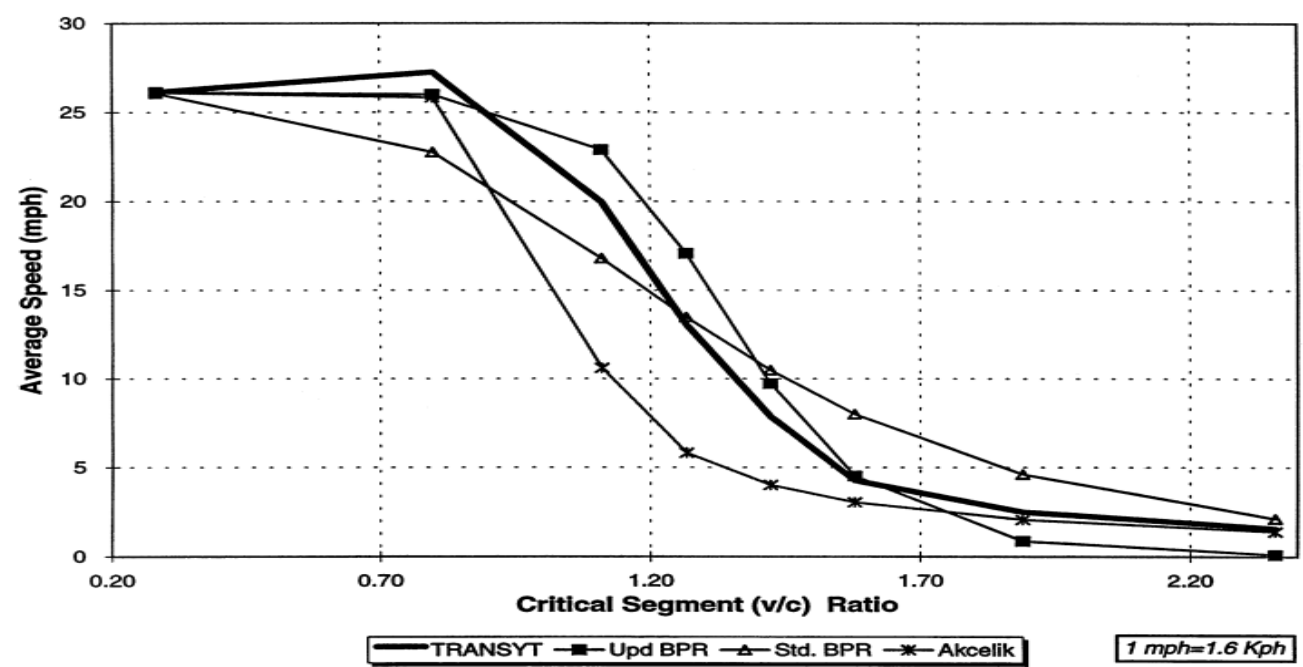

Figure 3.5: Comparison of arterial speed-prediction techniques, Ventura Boulevard, Los Angeles (Skabardonis and Dowling, 1997) 


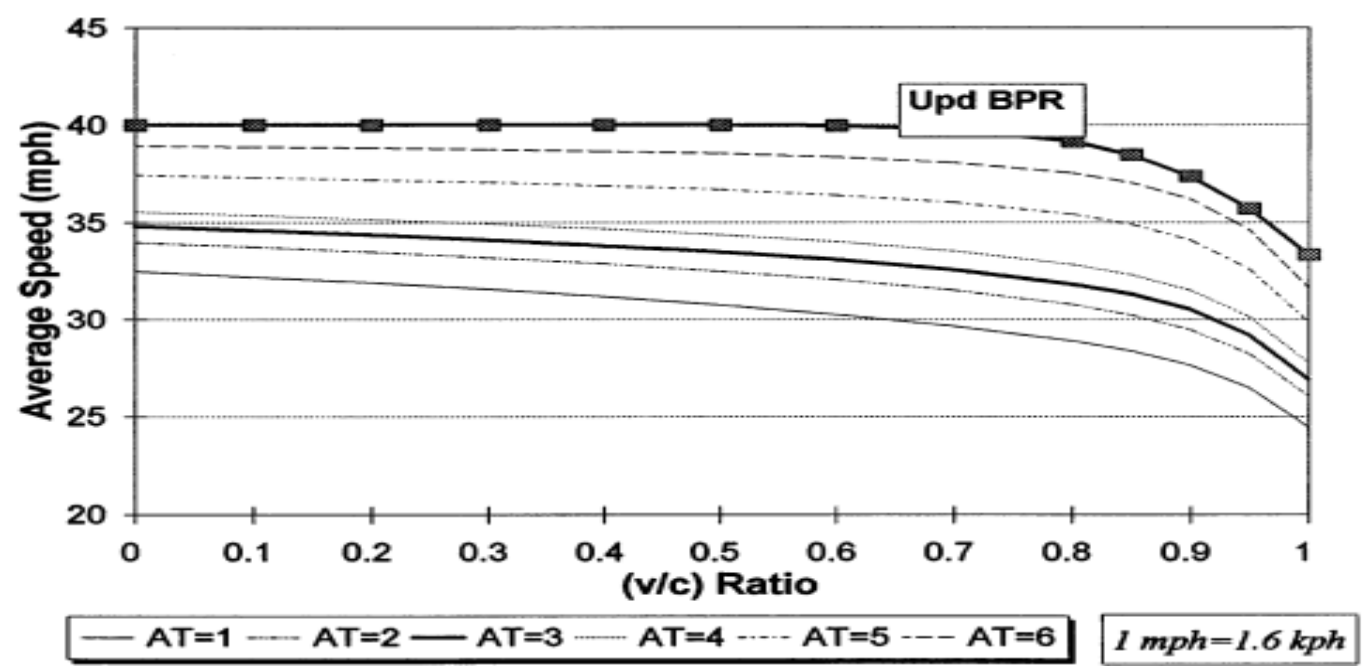

Figure 3.6: Sensitivity of HCM94 Estimated Arterial Speeds to AT (Skabardonis and Dowling, 1997)

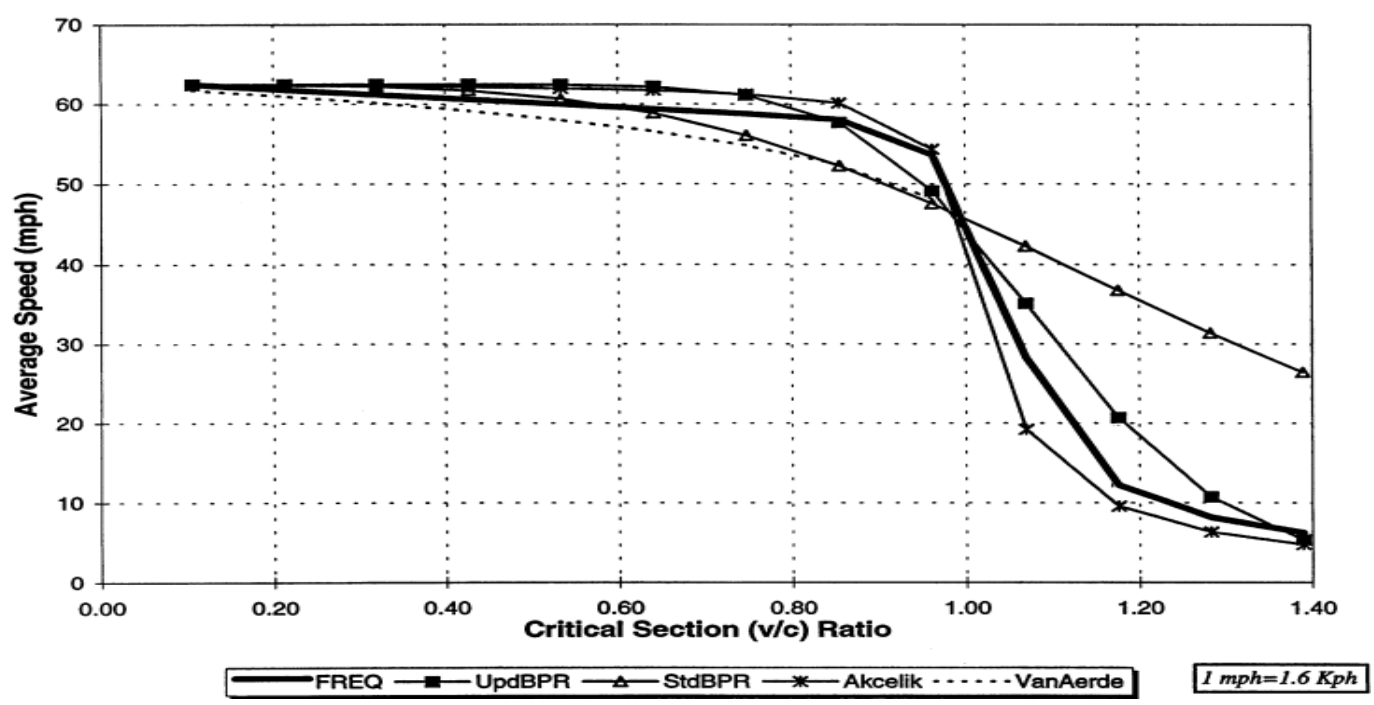

Figure 3.7: Comparison of Freeway Speed-Prediction Techniques: I-880 Freeway, Hayward, California (Skabardonis and Dowling, 1997)

Moreover, a research paper by Mtoi and Moses (2014) reported on calibration and evaluation of link congestion functions. The authors applied intrinsic sensitivity of link speed as a practical consideration to heterogeneous facility types within urban network. Public data were used to calibrate volume-delay functions namely, BPR curve, Davidson's delay model, Akcelik function and conical delay model. This process resulted in updated input parameters. Some results are presented in Table 3-1, which show the field estimate of FFS for different facilities. 
Table 3-1: Field Estimated Free-Flow Speeds and Capacities (Mtoi and Moses, 2014)

\begin{tabular}{cccccccc}
\hline Facility Type & Area Type & $\begin{array}{c}\text { Number of } \\
\text { Sites }\end{array}$ & Sample size & $\begin{array}{c}\text { Speed Limit } \\
(\mathbf{m p h})\end{array}$ & $\begin{array}{c}\text { Mean FFS } \\
(\mathbf{m p h})\end{array}$ & $q_{\operatorname{mar}(\mathbf{p c} / \mathbf{h} / \mathbf{l n})} \begin{array}{c}\text { Capacity } \\
(\mathbf{p c} / \mathbf{h} / \mathbf{l n})\end{array}$ \\
\hline Freeway & Urban & 3 & 6810 & 55 & 64.671 & 1891 & 1686 \\
Freeway & Urban & 6 & 13081 & 65 & 66.790 & 2384 & 2027 \\
Freeway & Residential & 3 & 12083 & 55 & 60.537 & 1632 & 1418 \\
Freeway & Residential & 4 & 14115 & 65 & 67.783 & 2108 & 1887 \\
Freeway & Residential & 17 & 71033 & 70 & 71.131 & 2435 & 1722 \\
Freeway & Rural & 4 & 14115 & 65 & 67.783 & 2108 & 1878 \\
Freeway & Rural & 17 & 71033 & 70 & 71.131 & 2435 & 1742 \\
Toll road & Urban & 2 & 24104 & 60 & 64.324 & 1916 & 1748 \\
Toll road & Urban & 3 & 35586 & 65 & 68.503 & 2315 & 1938 \\
Toll road & Residential & 2 & 33872 & 55 & 63.324 & 2235 & 2074 \\
Toll road & Residential & 2 & 52570 & 65 & 71.441 & 1877 & 1741 \\
Toll road & Residential & 2 & 36288 & 70 & 74.031 & 2183 & 2025 \\
Toll road & Rural & 2 & 54210 & 65 & 73.720 & 1802 & 1772 \\
Toll road & Rural & 4 & 68446 & 70 & 75.627 & 2377 & 2205 \\
HOV/HOT & Urban & 1 & 18445 & 65 & 71.116 & 1917 & 1857 \\
HOV/HOT & Residential & 2 & 15367 & 65 & 70.451 & 1823 & 1702 \\
Arterial & Urban & 4 & 16015 & 30 & 34.609 & 984 & 846 \\
Arterial & Urban & 3 & 10046 & 45 & 52.046 & 969 & 825 \\
Arterial & Residential & 4 & 12125 & 35 & 41.920 & 936 & 884 \\
\hline
\end{tabular}

Curve fitting was then conducted for four most commonly used VDFs. Parameters were estimated for four facility types namely freeways or expressways, toll roads, managed lanes (HOV or HOT lanes), and signalized facilities. Each category of facility type comprises of three area types distinguished by land uses: urban (1), residential (2) and rural (3). Results are shown in Table 3-2.

Table 3-2: Parameter Estimates for Fitted Models (Mtoi and Moses, 2014)

\begin{tabular}{|c|c|c|c|c|c|c|c|c|c|c|c|}
\hline \multirow[b]{3}{*}{ Function } & \multirow[b]{3}{*}{ Parameters } & \multicolumn{10}{|c|}{ Facility and Area Type } \\
\hline & & \multicolumn{3}{|c|}{ Freeways/Expressways } & \multicolumn{3}{|c|}{ Toll Roads } & \multicolumn{2}{|c|}{ HOV/HOT Lanes } & \multicolumn{2}{|c|}{ Signalized Arterials } \\
\hline & & 1 & 2 & 3 & 1 & 2 & 3 & 1 & 2 & 1 & 2 \\
\hline \multirow{2}{*}{ Fitted BPR } & $\alpha$ & 0.263 & 0.286 & 0.15 & 0.162 & 0.25 & 0.32 & 0.32 & 0.33 & 0.24 & 0.26 \\
\hline & $\beta$ & 6.869 & 5.091 & 5.61 & 6.34 & 7.9 & 6.71 & 8.4 & 8.6 & 7.50 & 8.20 \\
\hline \multirow{2}{*}{ Conical } & $\beta$ & 18.390 & 18.39 & 15.06 & 18.39 & 15.064 & 15.064 & 18.55 & 18.7 & 18.8 & 18.8 \\
\hline & $\alpha$ & 1.029 & 1.029 & 1.04 & 1.029 & 1.036 & 1.036 & 1.028 & 1.028 & 1.03 & 1.03 \\
\hline \multirow{2}{*}{$\begin{array}{l}\text { Modified } \\
\text { Davidson }\end{array}$} & $J$ & 0.009 & 0.0092 & 0.0099 & 0.008 & 0.0099 & 0.0099 & 0.009 & 0.0089 & 0.01 & 0.01 \\
\hline & $\mu$ & 0.950 & 0.949 & 0.951 & 0.94 & 0.952 & 0.940 & 0.95 & 0.947 & 0.95 & 0.95 \\
\hline Akcelik & $\tau$ & 0.100 & 0.101 & 0.099 & 0.11 & 0.098 & 0.097 & 0.09 & 0.08 & 0.10 & 0.10 \\
\hline
\end{tabular}


Notable findings of this research paper of interest to this research are:

- “... in a congested network, a VDF will perform differently given different facility types. For that reason, the selection of VDF for a particular facility type and area type needs sturdy knowledge of transportation network behavior under different congestion levels and different traffic controls." (Mtoi and Moses, 2014)

- "It is obvious that, the effect of change in congestion, near or at capacity, will have different impact on travel speed for a freeway link compared to a signalized arterial link. Speed tends to deteriorate faster in shorter links (urban signalized arterials) than in longer links (uninterrupted flow facilities such as freeways and expressways) when demand is close to capacity.... Conical, Akcelik and modified Davidson reach their steepest slopes at capacity $(\mathrm{x}=1.0)$ different from fitted BPR which reaches its steepest slope at a demand 20\% higher than capacity $(\mathrm{x}=1.2) \ldots$ a link is robust to change in demand if either the demand or travel speed is low - that is, changes in demand have lesser effect to travel speed if there are a few travelers in the link (free-flow condition), or if the link is already highly congested, and therefore the speed will not deteriorate much further." (Mtoi and Moses, 2014)

\subsection{TRAFFIC ASSIGNMENTS}

\subsubsection{Static Traffic Assignment and Introduction to Dynamic Assignment}

Static traffic assignment calculates spatial distributions of traffic volumes. It had been used for decades and still being used to produce a realistic traffic flow model. 
Static assignment determines the link volume of a given network using origindestination data of a given period. Various approaches for solving the static traffic assignment exist and range from simple procedures to equilibrium methods. (Friedrich et al., 2000)

In static assignment, the time at which vehicles enter the network or link on the network is ignored. Propagation of traffic over space and time is lacking in static assignment procedure. Travel time is the average travel time on all links. See Figure 3.8 for demonstration.

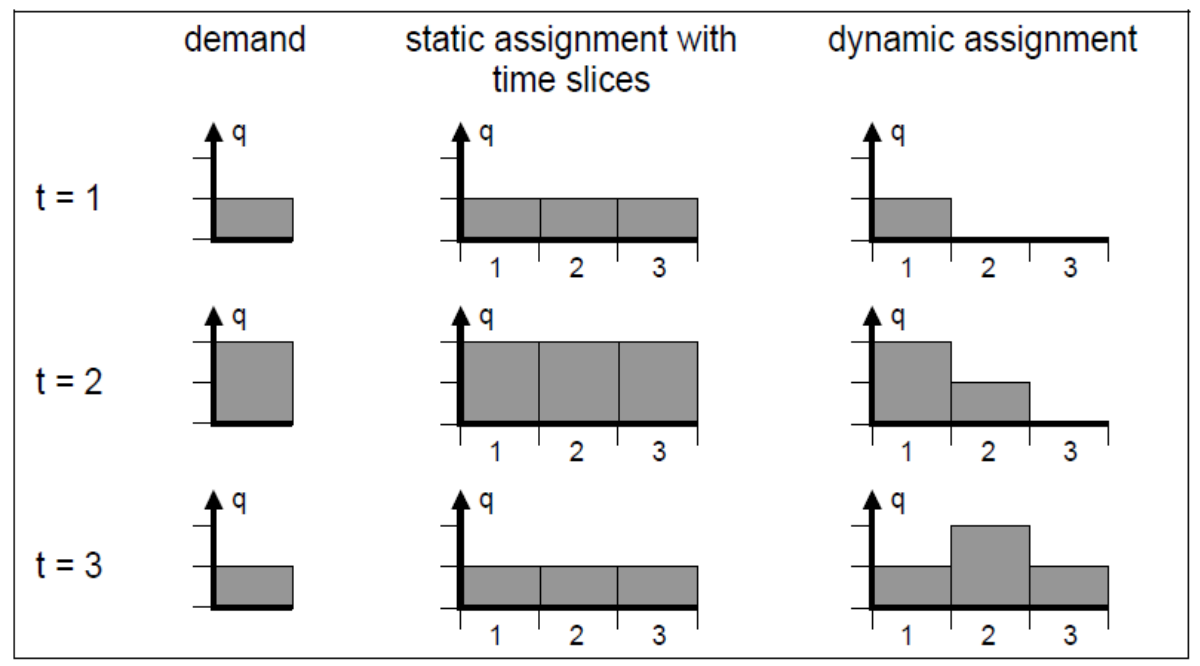

Figure 3.8: Assigning a Time-Dependent Demand Using a Static Assignment with Demand Slices and a Dynamic Assignment (Friedrich et al., 2000)

In contrast, dynamic assignment uses a time dynamic traffic flow model. The example in Figure 3.8 shows a simple network with three consecutive links, the demand on tile slice one moves to the next time slice 2 , while new demand is added to time slice 1. The travel time is the average travel time on the link. In the static assignment, it is assumed that all trips reach their destination within the assignment period. The static assignment is based on route choice, for example, shortest routes or minimum impedance for all alternatives. 
A good illustration of difference between static and dynamic assignment methods is contributed by Fried rich et al. (2000). See Figure 3.9 and 3.10.

Figure 3.9 illustrates the static assignment procedure using two routes. The route search in each iteration step is followed by the route distribution split, which distributes the trips evenly on the routes. Each iteration step adds one route, which is a new route or a route that is identified in the previous iteration. The iteration process terminates when link impedance difference is within a user-defined range.

\begin{tabular}{|c|c|l|l|l|r|}
\hline & \\
\hline
\end{tabular}

Figure 3.9: Example for the Static Learning Method (Friedrich et al., 2000) 


\subsubsection{Dynamic Traffic Assignment}

Dynamic traffic assignment captures the traffic flow propagation over space and time. According to Friedrich et, al. (2000) both static and dynamic assignment methods determine traffic volumes in the network resulting from travel demand, but the dynamic assignment provides answers for the case of time-dependent travel demand $\mathrm{D}(\mathrm{t})$ and time-dependent network $\mathrm{N}(\mathrm{t})$.

Route allocation and the movement of traffic with respect to time in the network are important in the dynamic traffic assignment. Dynamic traffic assignment procedure can generate varying travel demand matrices based on specific time interval, which describes the varying travel demand during the assignment period. A temporal resolution of travel demand and volumes in the network can be also be determined. Depending on the time-dependent capacity and time-dependent matrices different routes can be chosen at different times.

The dynamic traffic assignment results in more realistic temporal traffic assignment, which can be used to optimize congestion, evacuation plans, signal timing, and can be an asset to build more resilient and smart moving vehicles (autonomous vehicles). Due to the importance of dynamic traffic assignment to this thesis research, example applications are presented in this document.

A simple illustration of dynamic traffic assignment is shown in Figure 3.10 (Friedrich et al., 2000). The network consists of 3 zones and 24 links, which all have the same length $(2500 \mathrm{~m})$ and the same capacity (300 passenger-car-units). The FFS is 100 $\mathrm{km} / \mathrm{h}$ or $110 \mathrm{~km} / \mathrm{h}$. The different speed causes a shorter travel time in the unloaded network for route 1 (28.5 minutes from zone 100 to 300 ) compared to route 2 (30.0 minutes from zone 100 to 300 ). Route 2 may, nevertheless, provide a useful alternative 
as soon as the travel time for route 1 increases due to a growing traffic volume. The travel demand is given for two-time intervals $6: 00$ to $6: 15$ and $6: 15$ to $6: 30$.

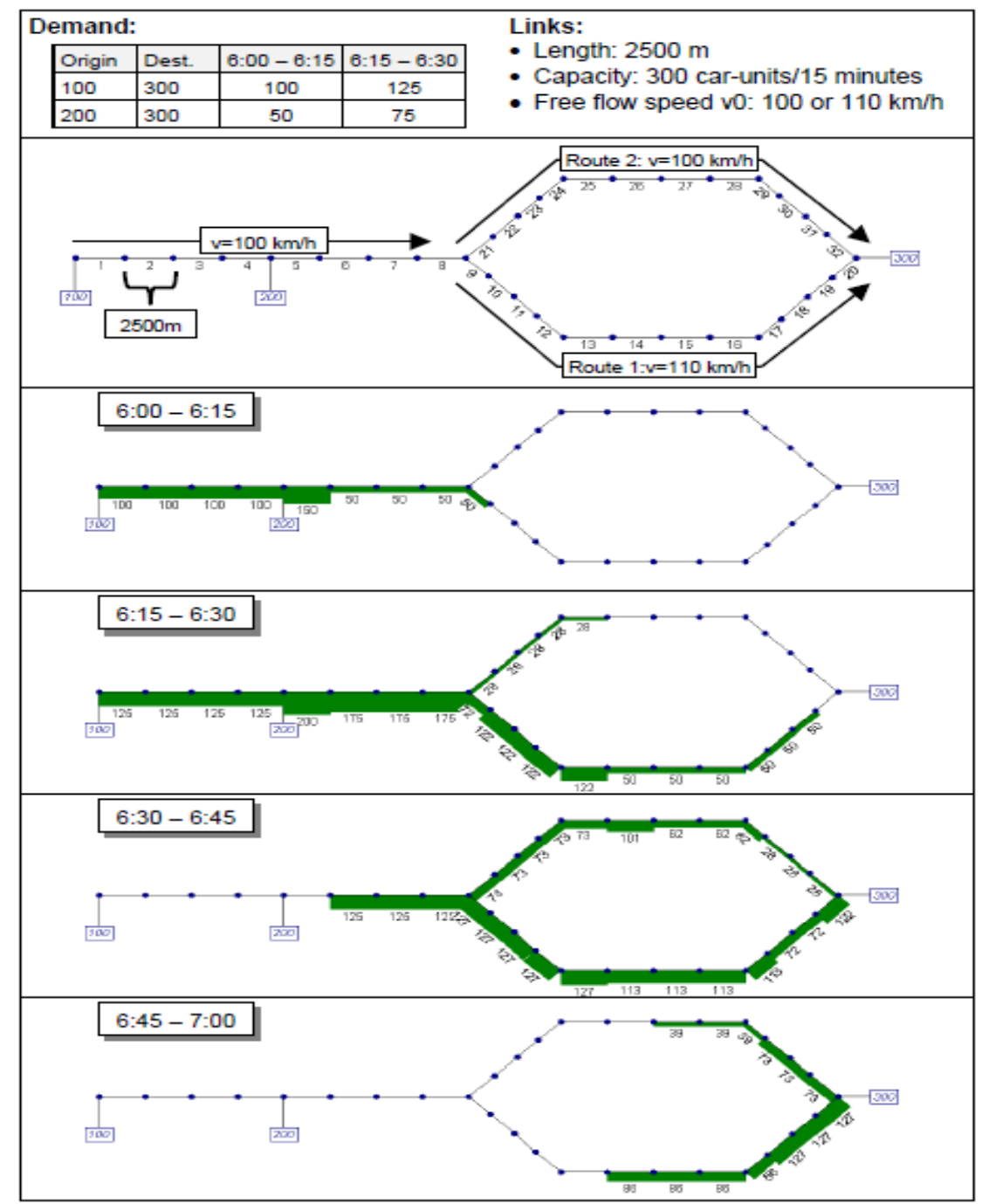

Figure 3.10:Example for a Dynamic Assignment with the Learning Method ((Friedrich et al., 2000)

\subsection{THE FUTURE OF TRANSPORTATION MANAGEMENT}

Given that dynamic resilience is likely to use the most advanced traffic management means, it is relevant to define the future of transportation management systems. Emerging technologies and ideas have been described in the literature. In 2014, NASA had shed the lights on using Unmanned Aerial System (UAS) for Unmanned traffic management (UTM) (Kopardekar, 2014). The unmanned aerial vehicle also 
referred to as DRONE has already found many potential applications in the transportation industry including delivery services of small parcels, traffic monitoring, and traffic network analysis. The method of using aircraft to collect information on congestion and traffic was initiated in 1965 by a transportation consultant in Maryland (Puri, 2005). It can be argued that inclusion of drones in the spectrum of traffic management technologies may not be appropriate, there is evidence from the literature that this technology may serve a useful and cost-effective role.

Various university and other researchers are working on improving the technology and methods to use aircraft for various applications in transportation management. In 2001, the Florida Department of Transportation (FDOT) started the "Proof of Concept for Using Unmanned Air Vehicles in Florida Dot ITS Application" (Srinivasan et al., 2004). The proposed project uses a UAV to transmit live video aimed for traffic surveillance to provide timely information on the transportation network. The project later was cancelled in 2005 because there is "no solution with 'see and avoid' and emergency safe landing" (Srinivasan et al., 2004). Research and development has taken place on fully autonomous UAV. "The WITAS Unmanned Aerial Vehicle Project" aimed at developing autonomous UAV which should be able to navigate autonomously at different altitude, take-off autonomously, land autonomously, plan for mission goals such as locating, identifying, tracking and monitoring of different vehicle types, and identify complex patterns of behavior such as vehicle overtaking, traversing of intersections, and parking lot activities (Doherty et al., 2000). The project ended in 2005 due to funding issues. Some projects aimed at using UAV towards traffic management followed, most of which use UAV for traffic surveillance, aerial mapping, and video recording of traffic conditions. 
In 2017, Cavaliere et. al. proposed a framework aimed to identify, label, and track objects to enhance scene understanding and awareness towards alarming situations such as fire detection, traffic, congestions, or accidents. (Cavaliere et al., 2018). Also, research by Khan et. al. proposed a methodological framework which uses UAV video recording to extract various traffic parameters or to analyze traffic safety situation. The UAV is used to video record a specific intersection. Then the gathered footage is processed into computer software to track the trajectory of the moving vehicle automatically. (Khan et al., 2017)

Previous research focused on video recording and GPS positioning to identify objects and vehicles toward developing the potential for using UAV in traffic management. These methods require processing time and a large amount of data saving. Traffic management requires a rapid time of response when the matter is related to traffic guidance and network analysis.

Using UAV as a traffic management tool is still in its infancy stage and developing the architectures of UAV, which can be used as a traffic management tool, require the following:

1. Rapid information exchange. i.e., sending information in the form of a digital scene which can be built on existing background

2. Development of tools to acquire scene understanding

3. Development of a tool to acquire object detection

4. Development of a tool to acquire object identification

5. Development of a tool to acquire object recognition. i.e., car, human, building

6. Use fixed point as a reference to position.

Limitation of UAVs:

1. Battery life

2. Limited distance to travel from receiver 


\section{Capacity to store data}

4. High-quality imagery and video is difficult to send wirelessly

5. Autonomous fly when fully charged and return before the battery is empty

6. Must be able to avoid a collision and act before it collides with another object

7. Must be able to function for the full span of time required

Traffic managers can use UAV in the meantime to provide a video recording of roads to analyze the network. However, this would require processing time by traffic managers and will not be effective in promoting actions toward changing the course of traffic or "autonomous vehicle - if the connection is available between UAV and autonomous vehicles" in the case of emergency or bridge collapse. Also, if UAV can be programmed to recognize scenes, detect deterioration of traffic serviceability, and report delay fluctuation on roads and between intersections; it would replace cameras installed on each traffic light. UAV would be a better fit to trace congestion to the bottleneck and watch over a wider area of more than one intersection.

There seems to be a missing link between the potential of UAVs and the way forward towards applications in transportation management. However, the promotors of technology have a road map. At first, UAVs can be used to carry parcels to eliminate the use of motor vehicles and minimize distance required to distribute small parcels or letters. It could even be used to deliver the parcel to the receiver doorstep. In addition, UAVs can provide an aerial image or video live stream to traffic manager who can alert others and appropriate action can be taken, if needed. Actions can be streamed through radio or inputted into navigation software, which is widely used by road users such as "Garmin Navigation" for example. To unlock the full potential of using UAVs as a traffic management tool, transportation agencies must work to overcome its limitations. 


\section{INHERENT RESILIENCE}

\subsection{INTRODUCTION}

The research aims to examine the inherent capability of transportation infrastructure and to examine the degree of benefits of added inherent resilience options. Nevertheless, the argument to be made is that transportation infrastructure can sustain traffic surges in case of an unusual event if more information about traffic conditions of a roadway becomes available such as surges of traffic delay. Both road conditions and delay can be passed to a traffic analyst to incorporate inherent resilience options that can resist further deterioration of the corridor's ability to serve traffic. Inherent resilience options are intended to enhance the travel time of road users and reduce environment and economic impacts. The study of the role of inherent resilience requires microsimulation of intersections using PTV-Vissim to extract information on driving behaviour, operating speed, travel time, road capacity, and adaptive control.

The transportation network consists of roads with different characteristics, such

as road access, mobility levels, and speed limits. Each road has a serving capability interpreted as a quantity of traffic flow per hour per lane. The simulator is provided with road characteristics and driving behaviour to observe the inherent resilience of a road; or the traffic serving capability of a road. Different road characteristics - such as segment length, the existence of a left / right turn bay, and green time over cycle ratio - can be tested in a simulation program and interpreted to calculate added benefits of these features in terms of operating speed, travel time, and capacity per lane per hour. The stochastic traffic assignment (Vissim) enables the study of traffic flow. The input 
variables for the traffic simulation model includes fixed infrastructures, vehicular flow, traffic signal control, and driver's behaviour.

The following sections will describe how the microsimulation-based approach is used to estimate the inherent resilience of roadways. Results and optimization methods will be discussed in the following chapter.

\subsection{SIMULATION DESIGN}

In order to quantify the effect of inherent resilience options, an analytical approach of variable intersection designs was chosen. Intersections with varying inherent resilience options are designed so as to evaluate the added benefits towards inherent resilience of a corridor - see Figure 4.1 in Section 4.5. Data will be collected from micro-simulated street segments with varying road characteristics. The objective is to study the effect of variables in improving the inherent resilience of a link or corridor. The output of the simulation will quantify over time the throughput and average driving speed. The driving behaviour will be set to reflect real-world naturalistic driving mode.

The Vissim modelling features were adopted from the Lousiana Department of Transportation and Development (Traffic Engineering VISSIM Modeling Guidance, n.d.). The Vissim Calibration Setting were obtained from North America's recommended parameters range ("VISSIM Calibration Settings," 2018). The inputs of the simulated intersections are noted next.

(1) Number of Lanes: The number of lanes correspond to the number of through movement lanes. One through lane will be modelled with varying option of right and left turn lanes. 
(2) Left Turn Bay: Availability of left-turn bay is important where left turning is allowed. To quantify the effect of left turns, left turn bay with sufficient storage will be included (if allowed). This approach minimizes the consequences where left-turn vehicles halt through movement.

(3) Right Turn Bay: The right turn is assumed to be allowed on red where exclusive right turn bay is available. Therefore, the effect of the right turn bay will be included in the study. To quantify the effect of right turns right turn bay with sufficient storage will be present.

(4) Segment Length: The proposed method is to build different road segments models and analyse travel speed and capacity of varying inherent resilience options. Effects of segment length on flow, and travel time/speed is analysed in this research. Segment lengths range from $300 \mathrm{~m}$ to $1000 \mathrm{~m}$. Distance between intersections has an impact on the FFS observed on the road.

(5) Green Time/Cycle ratio: Three levels of $\mathrm{g} / \mathrm{C}$ are pre-set to measure the added benefits of increased green time for inherent resilience purpose. The output is used to construct a relationship between traffic flow and $\mathrm{g} / \mathrm{C}$. More details are presented later in Section 4.6.

(6) Vehicle composition: The composition of traffic is an important input to the findings. The light-duty vehicles will make up to 97 percent of the vehicle composition, and the remaining 3 percent will be high occupancy vehicles (HOV).

\subsection{SIMULATION DESIGN ASSUMPTION}

The following are the model design assumptions:

1- 4 legs intersections are designed 
2- $50 \mathrm{~km} / \mathrm{hr}$ posted speed limit is assumed

3- All segments of road have the same number of through lanes

4- Only signal control is used

5- Exclusive left turns with protected phasing (10 sec for left turns)

6- Left turning and right turning traffic are $16 \%$ of the total traffic.

7- Lane width is $3.5 \mathrm{~m}$

8- Percentage of $\mathrm{HOV}=3 \%$

9- At level grade

10-Right turning movement on red (RTOR) is allowed

11-Pedestrian, bicycle, and bus stops are considered to be zero

12-Total of 96 road segments will be analyzed

13-Each simulation is run 3 times with different $\mathrm{g} / \mathrm{C}$ each run

14- Each result is the average of 30 simulation runs

15- Number of simulations runs analysed are 30 runs x 96 models

In support of assumption 2, it should be noted that it is not necessary to consider all possible combinations, and most roads analyzed have $50 \mathrm{~km} / \mathrm{h}$ speed limit.

\subsection{MODELS OUTPUT}

The output of the microscopic models is a predicted flow speed estimation and volume of traffic flowing through the designed corridor for 1 hour. Such prediction can be obtained with the help of PTV-Vissim. PTV-Vissim is a multi-modal traffic flow simulation software that simulates different modes of traffic and analyses their interactions and behaviour in detail. To practically measure the variable and random traffic congestion scenarios, predictive models are required. Results and the statistical analysis will be presented in a later chapter. 


\subsection{GRAPHICAL REPRESENTATION OF DESIGNED INTERSECTION}

As per sections above, eight intersections were designed in Vissim for processing of 32 links. Each link is simulated 3 times with $\mathrm{g} / \mathrm{C}$ 0.3, 0.4 and 0.5 . Total simulated links are $32 \times 3$. Figure 4.1 shows the intersection designed in Vissim. Figure 4.2 shows the data collections points in Vissim; and Travel time measurements in Vissim. Vehicle travel times are measured between the two blue points for vehicles passing the corridor; Vissim computes the average travel time/speed. Data collection point collect the vehicle count across the corridor. Links are identified in Figure 4.1. Characteristics of links designed in Vissim are as follows:

Link 1: 1 through lane, protected left turn bay, and right turn bay

Link 2: 1 through lane, and 1 right turn bay

Link 3: 1 through and right lane, and 1 protected left turn bay

Link 4: 1 through and right lane.

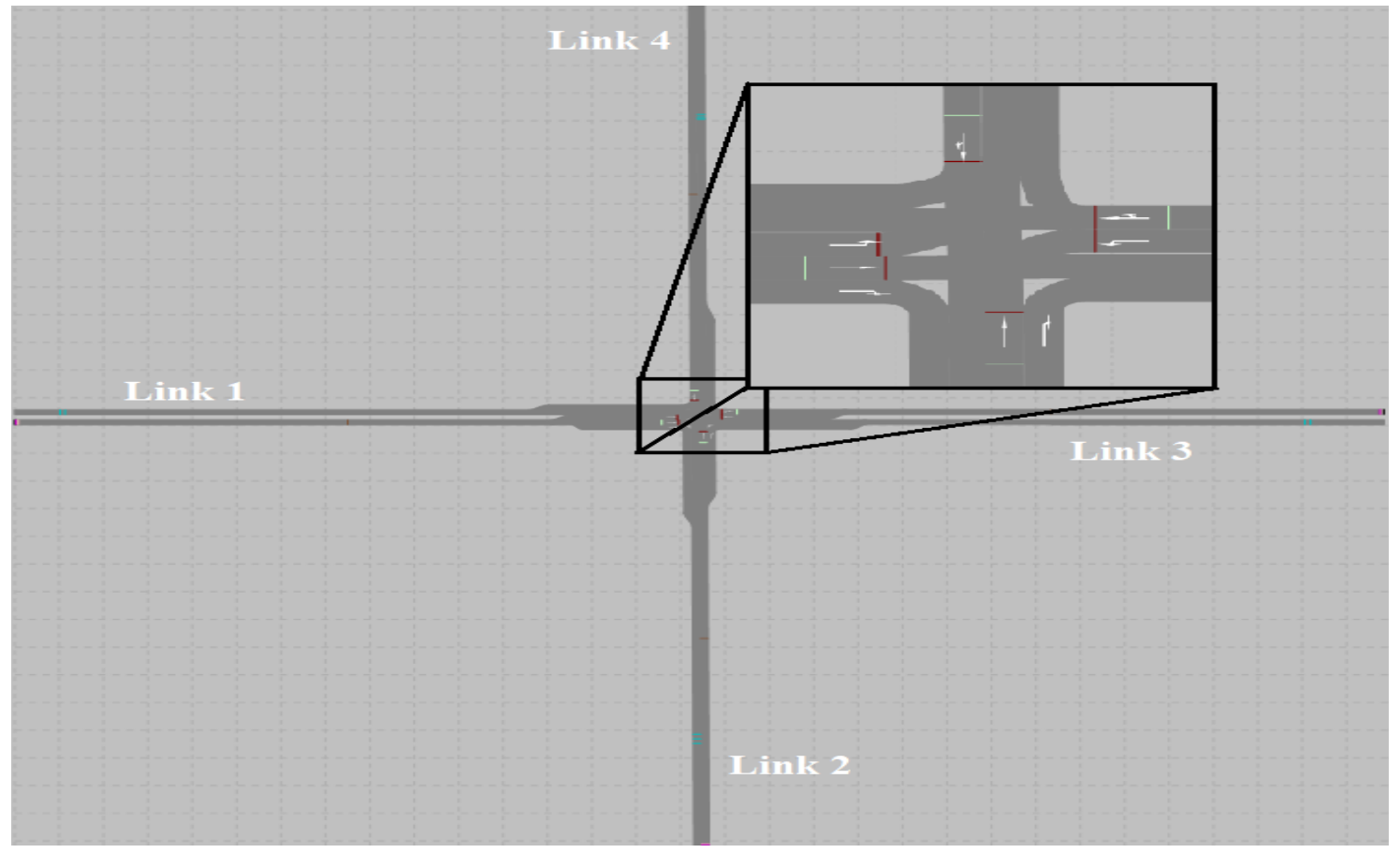

Figure 4.1: Intersection Design Used for Evaluation of Inherent Resilience Options in Vissim 


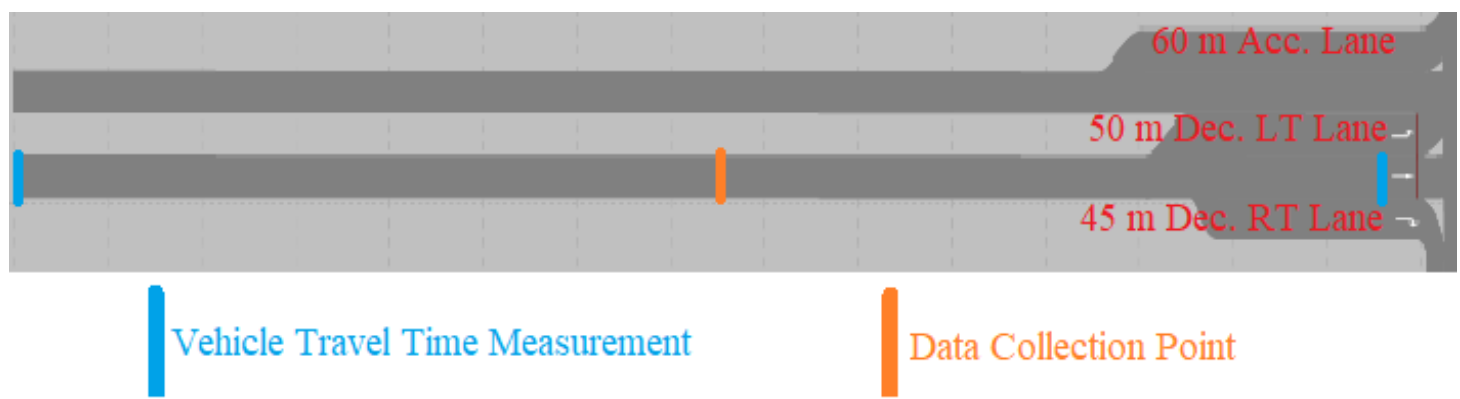

Figure 4.2: Detailed Link Design in Vissim

\subsection{DECISION MAKING ON VALUES OF VARIABLES}

\subsubsection{Lane Capacities}

The objectives of this research project are to investigate link and corridor-level means to enhance the inherent resilience in terms of sustained ability to serve traffic while resisting deterioration of quality of flow (see Figure 1.1: Level of inherent resilience). Specifically, the purpose is to identify static (inherent) resilience measures for increasing traffic serving ability of urban roads/corridors and develop a predictive model for testing such measures. The predictive model is intended to estimate improvements in service flow and operating speed as a result of changes in geometric design under given traffic control factors (i.e. segment length, turning bays, and g/C). The simulation models are used to predict the average traffic speed and the volume passing through a corridor during 1 hour of simulation.

Estimating lane capacities is an important aspect of evaluating the inherent resilience of transportation infrastructure. The lane capacity is the maximum number of vehicles that can pass a giving segment under the specific constraints. The process of evaluating lane capacity in this research is dependent upon results of models from microsimulations. 


\subsubsection{Design Models Speed}

The outputs of the flow models are used to predict the inherent resilience of the roadways. The posted speed limit analyzed is $50 \mathrm{~km} / \mathrm{h}$ across all corridors designed. The designed operating speed was selected based on the fact that the majority of corridors in Ottawa Central Business District (CBD) has a speed limit of $50 \mathrm{~km} / \mathrm{hr}$.

The desired speed upper limit will be set to $58 \mathrm{~km} / \mathrm{h}$ on $50 \mathrm{~km} / \mathrm{h}$ speed limit, according to HCM 2016 recommendation. "If posted speed limits are available, the posted speed limit may be adjusted by the analyst to estimate the free-flow speed. One approach is to assume the free-flow speed is 5 miles per hour greater than the posted speed limit." (Dowling et al., 2016). See Figure 4.3 below for desired speed distribution in Vissim. The variability in speed distribution allows a more realistic simulation of road users behaviour.

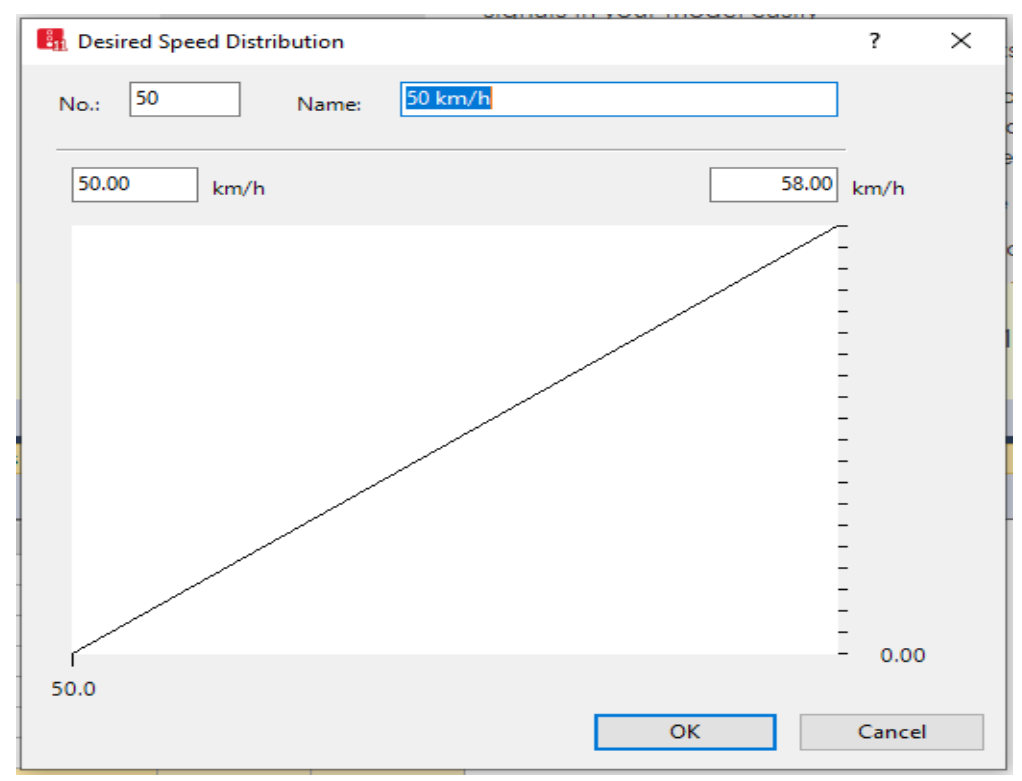

Figure 4.3: Vissim Desired Speed Distribution for $50 \mathrm{~km} / \mathrm{h}$

\subsubsection{Segment Lengths}

The models consist of different designs with varying segment lengths, and right and left turn bay availabilities. Urban roads segment length ranges from $100 \mathrm{~m}$ to 3000 
$\mathrm{m}$ in length. The majority of roads have more than $200 \mathrm{~m}$ of road segment length. Table 4-1 below lists the road segment lengths used for evaluation.

Table 4-1: Segment Lengths Used for Evaluation in Vissim

\begin{tabular}{|c|c|}
\hline Number & Road segment length \\
\hline 1 & $300 \mathrm{~m}$ \\
\hline 2 & $400 \mathrm{~m}$ \\
\hline 3 & $500 \mathrm{~m}$ \\
\hline 4 & $600 \mathrm{~m}$ \\
\hline 5 & $700 \mathrm{~m}$ \\
\hline 6 & $800 \mathrm{~m}$ \\
\hline 7 & $900 \mathrm{~m}$ \\
\hline 8 & $1000 \mathrm{~m}$ \\
\hline
\end{tabular}

\subsubsection{Right and Left Turns}

Right and left turns are a crucial part of roadway infrastructure. The added benefit of available left turn bay and right turn bay will be quantified as part of the inherent resilience objectives. The volumes of left and right turns were based on City of Ottawa Turning movement counts for the year of 2011 (City of Ottawa, n.d.). Average percentages were calculated from the data provided by the City of Ottawa; full data sheets are presented in Appendix B. Only links with permissible left and right turn were considered in the calculations. Also, links with access to parking lots were disregarded in the calculations. Table 4-2 below shows the average turning movements counts included in the calculations. According to the data provided, nearly $6 \%$ of the volume turns left in Ottawa CBD, and $10 \%$ of volume turns right.

Design of simulation links will include left-turn bays where a left turn is permissible to alleviate from deterioration of through movement caused by left-turn movement. Right turn movement, on the other hand, is permissible in all designed links, and the right turn is assumed to be allowed on red where right turn bay is available. 
Table 4-3 below shows the combination of right and left turns incorporated in the simulation.

Table 4-2: Turning Volume Movement Based on City of Ottawa 2011 Data

\begin{tabular}{|c|c|c|c|c|c|c|c|}
\hline Intersection & $\begin{array}{l}\text { Total } \\
\text { Vol. } \\
\text { (Veh) }\end{array}$ & $\begin{array}{l}\text { Thru. } \\
\text { Vol. } \\
\text { (Veh) }\end{array}$ & $\begin{array}{l}\text { Right } \\
\text { Turn } \\
\text { Vol. } \\
\text { (Veh) }\end{array}$ & $\begin{array}{l}\text { Left } \\
\text { Turn } \\
\text { Vol. } \\
\text { (Veh) }\end{array}$ & $\begin{array}{l}\text { Thru. } \\
\%\end{array}$ & $\begin{array}{l}\text { Right } \\
\text { Turn } \\
\%\end{array}$ & $\begin{array}{l}\text { Left } \\
\text { Turn } \\
\%\end{array}$ \\
\hline $\begin{array}{l}\text { BRONSON AVE @ } \\
\text { COMMISSIONER ST/ SLATER ST }\end{array}$ & 560 & 542 & 1 & 17 & 97 & 0 & 3 \\
\hline \multirow[t]{4}{*}{ BRONSONAVE@SOMERSET ST } & 545 & 482 & 42 & 21 & 88 & 8 & 4 \\
\hline & 160 & 113 & 29 & 18 & 71 & 18 & 11 \\
\hline & 637 & 524 & 50 & 63 & 82 & 8 & 10 \\
\hline & 273 & 178 & 15 & 80 & 65 & 5 & 29 \\
\hline \multirow{4}{*}{$\begin{array}{l}\text { BRONSON AVE@ GLADSTONE } \\
\text { AVE }\end{array}$} & 635 & 583 & 31 & 21 & 92 & 5 & 3 \\
\hline & 447 & 349 & 60 & 38 & 78 & 13 & 9 \\
\hline & 947 & 680 & 170 & 97 & 72 & 18 & 10 \\
\hline & 326 & 229 & 21 & 76 & 70 & 6 & 23 \\
\hline KENTST@LAURIER AVE & 934 & 729 & 138 & 67 & 78 & 15 & 7 \\
\hline KENT ST @ SOMERSET ST & 872 & 680 & 52 & 119 & 78 & 6 & 14 \\
\hline \multirow{2}{*}{ BANKST@WELLINGTON ST } & 992 & 939 & 41 & 12 & 95 & 4 & 1 \\
\hline & 737 & 666 & 12 & 59 & 90 & 2 & 8 \\
\hline \multirow[t]{2}{*}{ BANK ST@LAURIER AVE } & 323 & 254 & 68 & 1 & 79 & 21 & 0 \\
\hline & 341 & 258 & 82 & 1 & 76 & 24 & 0 \\
\hline \multirow[t]{3}{*}{ BANK ST @ SOMERSET ST } & 480 & 327 & 116 & 37 & 68 & 24 & 8 \\
\hline & 262 & 216 & 38 & 8 & 82 & 15 & 3 \\
\hline & 252 & 188 & 9 & 55 & 75 & 4 & 22 \\
\hline \multirow[t]{4}{*}{ BANK ST @ GLADSTONE AVE } & 534 & 502 & 19 & 1 & 94 & 4 & 0 \\
\hline & 370 & 288 & 58 & 19 & 78 & 16 & 5 \\
\hline & 500 & 414 & 50 & 36 & 83 & 10 & 7 \\
\hline & 321 & 250 & 53 & 18 & 78 & 17 & 6 \\
\hline LAURIER AVE@ O'CONNOR ST & 800 & 689 & 34 & 75 & 86 & 4 & 9 \\
\hline O'CONNOR ST@ SOMERSET ST & 1392 & 1216 & 108 & 64 & 87 & 8 & 5 \\
\hline $\begin{array}{l}\text { GLADSTONE AVE@O'CONNOR } \\
\text { ST }\end{array}$ & 1694 & 1456 & 131 & 83 & 86 & 8 & 5 \\
\hline \multirow[t]{2}{*}{ ELGIN ST @ SOMERSET ST } & 694 & 554 & 81 & 59 & 80 & 12 & 9 \\
\hline & 467 & 400 & 25 & 25 & 86 & 5 & 5 \\
\hline \multirow[t]{2}{*}{ ELGIN ST @ GLADSTONE AVE } & 819 & 707 & 98 & 7 & 86 & 12 & 1 \\
\hline & 486 & 398 & 25 & 63 & 82 & 5 & 13 \\
\hline \multirow{3}{*}{$\begin{array}{l}\text { KING EDWARD AVE @ RIDEAU } \\
\text { ST }\end{array}$} & 877 & 449 & 280 & 148 & 51 & 32 & 17 \\
\hline & 389 & 331 & 57 & 1 & 85 & 15 & 0 \\
\hline & 899 & 784 & 114 & 1 & 87 & 13 & 0 \\
\hline
\end{tabular}




\begin{tabular}{|l|l|l|l|l|l|l|l|}
\hline DALHOUSIE ST @ YORK ST & 461 & 337 & 78 & 23 & 73 & 17 & 5 \\
\cline { 2 - 8 } & 90 & 48 & 26 & 16 & 53 & 29 & 18 \\
\cline { 2 - 8 } & 265 & 210 & 21 & 32 & 79 & 8 & 12 \\
\hline KING EDWARD AVE @ YORK ST & 615 & 506 & 33 & 76 & 82 & 5 & 12 \\
\hline $\begin{array}{l}\text { KING EDWARD AVE @ SUSSEX } \\
\text { DR }\end{array}$ & 1019 & 799 & 210 & 5 & 78 & 21 & 0 \\
\hline $\begin{array}{l}\text { KING EDWARD AVE @ ST. } \\
\text { PATRICK ST }\end{array}$ & 2376 & 2284 & 82 & 10 & 96 & 3 & 0 \\
\cline { 2 - 9 } & 586 & 577 & 4 & 5 & 98 & 1 & 1 \\
\hline $\begin{array}{l}\text { KING EDWARD AVE @ LAURIER } \\
\text { AVE }\end{array}$ & 563 & 387 & 121 & 55 & 69 & 21 & 10 \\
\cline { 2 - 8 } & 385 & 290 & 23 & 72 & 75 & 6 & 19 \\
\cline { 2 - 8 } & 537 & 469 & 17 & 51 & 87 & 3 & 9 \\
\hline \multicolumn{1}{|c|}{ Average } & $\mathbf{2 6 3 3 0}$ & $\mathbf{2 1 8 5 0}$ & $\mathbf{2 7 0 0}$ & $\mathbf{1 6 5 8}$ & $\mathbf{8 3} \mathbf{\%}$ & $\mathbf{1 0} \%$ & $\mathbf{6 \%}$ \\
\hline
\end{tabular}

Table 4-3: Right and Left Turn Combination Used for Evaluation in Vissim

\begin{tabular}{|l|l|l|}
\hline Combination & Left Turn & Right Turn \\
\hline 1 & Protected Left Turn Bay & Right Turn Bay \\
\hline 2 & No Left Turn & Right Turn Bay \\
\hline 3 & Protected Left Turn Bay & No Right Turn Bay \\
\hline 4 & No Left Turn & No Right Turn Bay \\
\hline
\end{tabular}

\subsubsection{Design Combinations}

The design combinations of links were thought of to include all possible segment lengths, right turns, and left turns combinations to produce a thorough study on the effect of the variable on the inherent resilience of current infrastructures. Traffic control cycle length and number of cycles are the same across all intersections. For more information on signal controls, refer to section 4.6 .8 of traffic signal controls. Table 4-4 include all designed intersections combinations. Vissim design section includes a visual design of each intersection. The purpose of the simulated links is to observe the change in driving speed and link capacity given different inherent resilience factors. These factors had been discussed earlier in the chapter.

Each intersection will be simulated on three runs to account for the adaptive traffic implementation factor. Cycle length will remain constant across all simulations - 
90 seconds. Left turn $\mathrm{g} / \mathrm{C}$ will also remain constant across all simulations. Through movement will be simulated on three different levels of $\mathrm{g} / \mathrm{C}$. More on traffic light green times will be described later in the section 4.6.8.

Table 4-4: Link Design Combination for Evaluation in Vissim

\begin{tabular}{|c|l|l|c|c|}
\hline $\begin{array}{c}\text { LINK } \\
\#\end{array}$ & Segment Length $(\mathrm{m})$ & $\mathrm{g} / \mathrm{C}$ & $\begin{array}{c}\text { Left Turn } \\
\text { Bay }\end{array}$ & $\begin{array}{c}\text { Right } \\
\text { Turn Bay }\end{array}$ \\
\hline 1 & $300,400,500,600,700,800,900, \& 1000$ & $0.3,0.4, \& 0.5$ & 1 & 1 \\
\hline 2 & $300,400,500,600,700,800,900, \& 1000$ & $0.3,0.4, \& 0.5$ & 0 & 1 \\
\hline 3 & $300,400,500,600,700,800,900, \& 1000$ & $0.3,0.4, \& 0.5$ & 1 & 0 \\
\hline 4 & $300,400,500,600,700,800,900, \& 1000$ & $0.3,0.4, \& 0.5$ & 0 & 0 \\
\hline
\end{tabular}

- Number of through Lanes: 1 lane

- Left turn percentage $6 \%$ of volume

- Right Turn Percentage $10 \%$ of Volume

- HOV 3\% of Volume

\subsubsection{Deceleration Lanes}

The next important parameter in road geometric design is the deceleration lane length. Table 4-5 below represents AASHTO 2004 guidelines for deceleration length for various speed limit designs. The deceleration bay for left turn will be assumed $50 \mathrm{~m}$.

Table 4-5: AASHTO 2004 Deceleration Length for Various Speed Limits (AASHTO, 2004)

\begin{tabular}{|c|c|c|c|}
\hline $\begin{array}{c}\text { Design Speed } \\
(\mathrm{mph})\end{array}$ & $\begin{array}{c}\text { Deceleration } \\
\text { Length } \mathrm{ft}\end{array}$ & $\begin{array}{c}\text { Equivalent Design } \\
\text { Speed }(\mathrm{km} / \mathrm{h})\end{array}$ & $\begin{array}{c}\text { Equivalent Deceleration } \\
\text { Length } \mathrm{m}\end{array}$ \\
\hline 30 & 170 & 48.3 & 51.8 \\
\hline 40 & 275 & 64.4 & 83.8 \\
\hline 45 & 340 & 72.4 & 103.6 \\
\hline 50 & 410 & 80.4 & 124.9 \\
\hline 55 & 485 & 88.5 & 147.8 \\
\hline
\end{tabular}

Traffic Engineering Handbook (1999) suggests the design of left and right turn bays based on operational needs, as follows:(Yekhshatyan and Schnell, 2008)

- Lanes should be long enough to enable a driver to decelerate outside the higher speed lanes at rural intersections. 
- Lanes should be of enough length to store vehicles queued in the turn-lane at urban signalized intersections.

According to the Traffic Engineering Handbook the sufficient length of left turn is given by the following formula:

$$
\mathrm{L}=\mathrm{V} * \mathrm{~K} * 25 *(1+\mathrm{p}) / \mathrm{Nc}
$$

Where: $\mathrm{L}$ - storage length, in feet,

$\mathrm{V}$ - peak 15-min flow rate, in vph,

$\mathrm{K}$ - constant to reflect random arrival of vehicles, usually 2 ,

$\mathrm{Nc}-$ number of cycles per hour, and

$\mathrm{p}-$ percentage of trucks and buses.

For evaluation of right-turn bays, the formula is:

$$
\mathrm{L}=(1-\mathrm{G} / \mathrm{C}) * \mathrm{~V} *(1+\mathrm{p}) * \mathrm{~K} * 25 / \mathrm{Nc} * \mathrm{n}
$$

Where: $\mathrm{L}$ - storage length, in feet,

$\mathrm{G}$ - green time,

$\mathrm{C}$ - cycle length,

$\mathrm{K}$ - random arrival for vehicles equals 2 when right-turn-on-red is not permitted and 1.5 when right-turn-on-red is allowed,

$\mathrm{n}$ - number of traffic lanes,

$\mathrm{V}$ - peak 15-min flow rate, in vph,

$\mathrm{Nc}-$ number of cycles per hour, and

$\mathrm{P}-$ percentage of trucks and buses.

Table 4-6 represents the deceleration lane lengths for right and left turn bay using the above formulas with 120 seconds cycle length and 46 seconds green time, 10 seconds for left turn signal and 4 seconds of green and amber.

\begin{tabular}{|c|c|c|c|c|c|}
\hline $\begin{array}{l}\text { Number } \\
\text { of lanes }\end{array}$ & $\begin{array}{l}\text { Peak } 15 \\
\text { min } \\
\text { Volume } \\
\text { vph }\end{array}$ & $\begin{array}{l}\text { Left Turn } \\
\text { Deceleration } \\
\text { Length (ft) }\end{array}$ & $\begin{array}{l}\text { Right } \\
\text { Turn } \\
\text { Storage } \\
\text { length (ft) }\end{array}$ & $\begin{array}{l}\text { Left Turn } \\
\text { Deceleration } \\
\text { Length (m) }\end{array}$ & $\begin{array}{l}\text { Right } \\
\text { Turn } \\
\text { Storage } \\
\text { length (m) }\end{array}$ \\
\hline 1 & 200 & 257 & 149 & 78 & 45 \\
\hline 2 & 400 & 515 & 149 & 156 & 45 \\
\hline
\end{tabular}

Table 4-6:Deceleration Lane Lengths (Pline and Institute of Transportation Engineers, 1999) 
For simplicity, the deceleration lane for right turn will be assumed $45 \mathrm{~m}$ long according to Traffic Engineering Handbook for Vissim link designs.

\subsubsection{Acceleration Lane Length}

The acceleration lane is an important parameter of roadway geometric design. According to the U.S. Department of Transportation (U.S DOT, 2004) the acceleration lane length is tabulated below in Table 4-7.

Table 4-7:Acceleration Lane length (U.S DOT, 2004)

\begin{tabular}{|c|c|}
\hline Design Speed $(\mathrm{km} / \mathrm{hr})$ & $*$ Accelerating lane distance $(\mathrm{m})$ \\
\hline 50 & 60 \\
\hline 60 & 100 \\
\hline 80 & 220 \\
\hline
\end{tabular}

*Distances were rounded to nearest length in $\mathrm{m}$.

The acceleration lane for right turning vehicles will be assumed $60 \mathrm{~m}$ long according to according to AASHTO 2004 for Vissim link designs.

\subsubsection{Traffic Signal Control}

Traffic signal controls are designed to satisfy the requirements set by Signal Timing Manual 2015. Each signal phase consists of green time, yellow time, and 1 second all red. According to Signal Timing Manual 2015, “...The yellow change interval should last approximately 3 to 6 seconds, with longer intervals being used on higher speed approaches". Therefore, the yellow interval is set to 3 seconds. The minimum green to satisfy driver expectancy is shown in Table 4-8 below. Red clearance intervals are shown in Table 4-9 below. Designed simulation intersections width reaches up to a maximum of 60 feet. Therefore 1-second red clearance is sufficient based on Signal Timing Manual 2015. 
Table 4-8: Typical Minimum Green Interval Duration Needed to Satisfy Driver Expectancy.(National Academies of Sciences, 2015)

\begin{tabular}{|c|c|c|}
\hline \multirow{1}{*}{ Phase Type } & Facility Type & $\begin{array}{l}\text { Minimum Green Needed to Satisfy } \\
\text { Driver Expectancy (Ge), s }\end{array}$ \\
\hline \multirow{3}{*}{ Through } & $\begin{array}{c}\text { Major Arterial (speed } \\
\text { limit exceeds 40 mph) }\end{array}$ & 10 to 15 \\
\cline { 2 - 3 } & $\begin{array}{c}\text { Major Arterial (speed } \\
\text { limit is } 40 \text { mph or less) }\end{array}$ & 7 to 15 \\
\cline { 2 - 3 } & Minor Arterial & 4 to 10 \\
\cline { 2 - 3 } & Collector, Local, \\
Driveway & 2 to 10 \\
\hline Left Turn & Any & 2 to 5 \\
\hline
\end{tabular}

Table 4-9: Red Clearance Interval (Signal Timing Manual - Second Edition, 2015) (National Academies of Sciences, 2015)

\begin{tabular}{c|ccccc}
\hline \multirow{2}{*}{$\begin{array}{c}\text { Approach } \\
\text { Speed } \\
\text { (MPH) }\end{array}$} & \multicolumn{5}{|c}{ Red Clearance $^{\mathbf{1}}$ (Seconds) } \\
\cline { 2 - 6 } & 30 & 50 & 70 & 90 & 110 \\
\hline 25 & 0.4 & 0.9 & 1.5 & 2.0 & 2.5 \\
\hline 30 & 0.1 & 0.6 & 1.0 & 1.5 & 2.0 \\
\hline 35 & 0.0 & 0.4 & 0.8 & 1.1 & 1.5 \\
\hline 40 & 0.0 & 0.2 & 0.5 & 0.9 & 1.2 \\
\hline 45 & 0.0 & 0.1 & 0.4 & 0.7 & 1.0 \\
\hline 50 & 0.0 & 0.0 & 0.2 & 0.5 & 0.8 \\
\hline 55 & 0.0 & 0.0 & 0.1 & 0.4 & 0.6 \\
\hline 60 & 0.0 & 0.0 & 0.0 & 0.2 & 0.5 \\
\hline
\end{tabular}

${ }^{1}$ Based on recent research reported in NCHRP 731 (6), the calculated red clearance values have been reduced by 1 second.

Before selecting a signal control duration, it is important to decide on the link capacity used. For this purpose, the link capacity was based on data provided by the City of Ottawa study report (City of Ottawa, 2011). Appendix D - Provide listing (categorized by section) of major study area roadways, their classification, right of way, number of lanes, assumed directional capacity, and existing traffic volumes. The 
information used to populate the table was obtained by referring to the city of Ottawa and available intersection turning movement data. According to the city of Ottawa one lane capacity in Ottawa CBD have a capacity of 800 vehicles/hour/lane, except for Dalhousie Street which has a capacity of 600 vehicles/hour/lane. Table 4-10 below shows the calculated through, right, and left movement volumes per hour per lane.

Table 4-10: Lane Capacity

\begin{tabular}{|l|l|l|l|}
\hline $\begin{array}{l}\text { Total Vol. } \\
(\mathrm{Veh} / \mathrm{Hr} / \mathrm{L})\end{array}$ & Thr. Vol. (Veh/Hr/L) & Left Vol. (Veh/Hr/L) & $\begin{array}{l}\text { Right Vol. } \\
(\mathrm{Veh} / \mathrm{Hr} / \mathrm{L})\end{array}$ \\
\hline $100 \%$ & $84 \%$ & $6 \%$ & $10 \%$ \\
\hline 800 & 672 & 48 & 80 \\
\hline Volumes where of links with no left turn movement allowed \\
\hline $100 \%$ & $0 \% \%$ & $0 \%$ & $10 \%$ \\
\hline 800 & 720 & & 80 \\
\hline
\end{tabular}

The above data were used in HCS 2010 software to analyze signal control cycle length, phases, and green time allocation. The results are shown in Table 4-11. The cycle length was chosen to be 90 seconds with equal green time for through movement and 10 seconds for the left turn. The design intersection is designed to carry three phases with amber of 3 seconds and all red of 1 second. Please refer to Table 4-11 for more details on intersection capacities. Figure 4.4 below shows the signal control program 1 in Vissim.

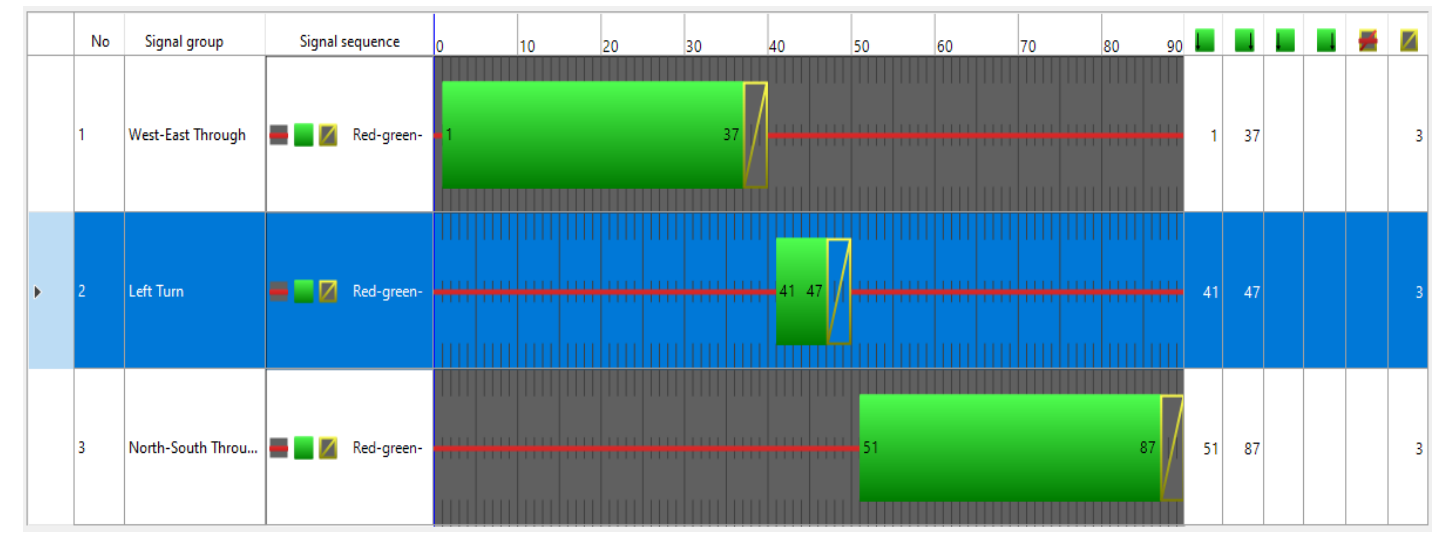

Figure 4.4: Signal Control Program 1 
Table 4-11:HCS signalized Intersection Results in HCS 2010

\begin{tabular}{|c|c|c|c|c|c|c|c|c|c|c|c|c|c|c|c|}
\hline & & $2010 \mathrm{H}$ & CS S & ignaliz & zed In & nterse & ection & Res! & sults St & umma & ary & & & & \\
\hline General Inform & nation & & & & & & & & Intersecti & tion Info & ormatio & & & tant & 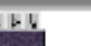 \\
\hline Agency & & & & & & & & & Duration, & & 0.25 & & & r & \\
\hline Analyst & & & & Analysi & is Date & Oct 8 & 2018 & & Area Type & & CBD & & $\Rightarrow$ & & \\
\hline Jurisdiction & & & & Time $\mathrm{Pe}$ & eriod & & & & $\mathrm{PHF}$ & & 0.82 & & $\vec{a}$ & $\therefore$ & \\
\hline Intersection & & & & Analysi & is Year & 2018 & & & Analysis $\mathrm{F}$ & Period & $1>7: 0$ & & 7 & & \\
\hline File Name & & Signals1.xus & & & & & & & & & & & & 11 & \\
\hline Project Descript & tion & & & & & & & & & & & & & 1 & \\
\hline Demand Inform & mation & & & & $E B$ & & & WB & & & NB & & & SB & \\
\hline Approach Move & ement & & & L & $T$ & $\mathrm{R}$ & L & $T$ & $\mathrm{R}$ & L & $T$ & $\mathrm{R}$ & L & $T$ & $R$ \\
\hline Demand ( $(v)$, ve & & & & 48 & 672 & 80 & 48 & 672 & 80 & & 672 & 80 & & 672 & 80 \\
\hline Signal Informa & ation & & & & & & 刃 & & & & & & & & \\
\hline Cycle, $\mathbf{s}$ & 90.0 & Reference Phase & 2 & & & $\sqrt[x]{ }$ & & & & & & & & & \\
\hline Offset, 5 & 0 & Reference Point & End & Green & 6.0 & 36.0 & 36.0 & 0.0 & 0.0 & 0.0 & & & & & \\
\hline Uncoordinated & No & Simult. Gap E/W & On & Yellow & 3.0 & 3.0 & 3.0 & 0.0 & 0.0 & 0.0 & & & & & 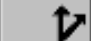 \\
\hline Force Mode & Fixed & Simult. Gap N/S & On & Red & 1.0 & 1.0 & 1.0 & 0.0 & 0.0 & 0.0 & & $=1$ & 5 & II & \\
\hline Timer Results & & & & EBL & & EBT & WBL & & WBT & NBL & & NBT & SBL & & SBT \\
\hline Assigned Phase & & & & 5 & & 2 & 1 & & 6 & 3 & & 8 & 7 & & 4 \\
\hline Case Number & & & & 2.0 & & 3.0 & 2.0 & & 3.0 & 11.0 & & 3.0 & 2.0 & & 3.0 \\
\hline Phase Duration & & & & 10.0 & & 40.0 & 10.0 & & 40.0 & 0.0 & & 40.0 & 0.0 & & 40.0 \\
\hline Change Period, & $(Y+R c)$ & & & 4.0 & & 4.0 & 4.0 & & 4.0 & 4.0 & & 4.0 & 4.0 & & 4.0 \\
\hline Max Allow Heac & dway (N & $(A H), \mathrm{s}$ & & 1.2 & & 0.0 & 1.2 & & 0.0 & 0.0 & & 1.1 & 0.0 & & 1.1 \\
\hline Queve Clearan & ice Time & $(g s) ; s$ & & 4.8 & & & 4.8 & & & & & 38.0 & & & 38.0 \\
\hline Green Extensio & on Time & $(g e)_{2} \mathbf{5}$ & & 0.0 & & 0.0 & 0.0 & & 0.0 & 0.0 & & 0.0 & 0.0 & & 0.0 \\
\hline Phase Call Prot & bability & & & 1.00 & & & 1.00 & & & & & 1.00 & & & 1.00 \\
\hline Max Out Probak & bility & & & 0.82 & & & 0.82 & & & & & 1.00 & & & 1.00 \\
\hline Movement Gro & oup Res & sults & & & EB & & & WB & & & NB & & & SB & \\
\hline Approach Move & ement & & & L & $T$ & $R$ & L & $T$ & $\mathrm{R}$ & L & $T$ & $\mathrm{R}$ & L & $T$ & $\mathrm{R}$ \\
\hline Assigned Move & ement & & & 5 & 2 & 12 & 1 & 6 & 16 & 3 & 8 & 18 & 7 & 4 & 14 \\
\hline Adjusted Flow F & Rate (v) & veh/h & & 52 & 730 & 87 & 52 & 730 & 87 & 0 & 730 & 87 & 0 & 730 & 87 \\
\hline Adjusted Satura & ation $\mathrm{Flc}$ & ow Rate (s), veh/h/ln & & 1629 & 1710 & 1449 & 1628 & 1710 & 1449 & 1810 & 1710 & 1449 & 1810 & 1710 & 1449 \\
\hline Queue Service & time $(g$ : & s), 5 & & 2.8 & 36.0 & 3.4 & 2.8 & 36.0 & 3.4 & 0.0 & 36.0 & 3.4 & 0.0 & 36.0 & 3.4 \\
\hline Cycle Queue $\mathrm{Cl}$ & learanc & e Time $(g c), s$ & & 2.8 & 36.0 & 3.4 & 2.8 & 36.0 & 3.4 & 0.0 & 36.0 & 3.4 & 0.0 & 36.0 & 3.4 \\
\hline Capacity (c), ve & & & & 109 & 684 & 580 & 109 & 684 & 580 & & 684 & 580 & & 684 & 580 \\
\hline Volume-to-Caps & acity $R z$ & atio $(x)$ & & 0.481 & 1.068 & 0.150 & 0.481 & 1.068 & 0.150 & 0.000 & 1.068 & 0.150 & 0.000 & 1.068 & 0.150 \\
\hline Available Capac & city (cs) & veh/h & & 109 & 684 & 580 & 109 & 684 & 580 & & 684 & 580 & & 684 & 580 \\
\hline Back of Queve & (Q), vel & & & 1.5 & 24.0 & 1.2 & 1.5 & 24.0 & 1.2 & & 24.0 & 1.2 & & 24.0 & 1.2 \\
\hline Overflow Queue & e $(Q s)$, & veh/ln & & 0.0 & 0.0 & 0.0 & 0.0 & 0.0 & 0.0 & 0.0 & 0.0 & 0.0 & 0.0 & 0.0 & 0.0 \\
\hline Queve Storage & Ratio ( & $R Q)$ & & 0.0 & 0.0 & 0.0 & 0.0 & 0.0 & 0.0 & 0.0 & 0.0 & 0.0 & 0.0 & 0.0 & 0.0 \\
\hline Uniform Delay & $\left(d_{1}\right), s / v$ & & & 40.5 & 27.0 & 17.2 & 40.5 & 27.0 & 17.2 & & 27.0 & 17.2 & & 27.0 & 17.2 \\
\hline Incremental Del & lay $(d z)$. & s/veh & & 14.4 & 54.0 & 0.5 & 14.4 & 54.0 & 0.5 & 0.0 & 54.0 & 0.5 & 0.0 & 54.0 & 0.5 \\
\hline Initial Queue De & elay $\left(d_{3}\right.$ & , s/veh & & 0.0 & 0.0 & 0.0 & 0.0 & 0.0 & 0.0 & 0.0 & 0.0 & 0.0 & 0.0 & 0.0 & 0.0 \\
\hline Control Delay (c & d), sivel & & & 54.8 & 81.0 & 17.8 & 54.9 & 81.0 & 17.8 & & 81.0 & 17.8 & & 81.0 & 17.8 \\
\hline Level of Service & e (LOS) & & & $\mathrm{D}$ & $F$ & $B$ & $\mathrm{D}$ & $F$ & $B$ & & $F$ & $B$ & & $F$ & $B$ \\
\hline Approach Delay & y, s/veh & ILOS & & 73.1 & & $\mathrm{E}$ & 73.1 & & $E$ & 74.3 & & $\mathrm{E}$ & 74.3 & & $\mathrm{E}$ \\
\hline Intersection Del & lay $s / v e$ & h / LOS & & & & 73. & 8.7 & & & & & & $E$ & & \\
\hline MultiModal Re & sults & & & & $\mathrm{EB}$ & & & WB & & & NB & & & $\mathrm{SB}$ & \\
\hline Pedestrian LOS & 5 Score & ILOS & & 2.3 & & $B$ & 2.3 & & $B$ & 2.4 & & $B$ & 2.4 & & $B$ \\
\hline Bicycle LOS Sc & core / LC & & & 1.8 & & A & 1.8 & & A & 1.8 & & A & 1.8 & & A \\
\hline
\end{tabular}


Two more signal timing programs are designed to quantify the effect of adaptive control. Adaptive control is a signal timing strategy in which traffic signal timing is changed to adapt to increased traffic surges. Figure 4.5 and Figure 4.6 below shows the two added signal timing programs. Traffic flow will be simulated to measure the traffic flow changes over different $\mathrm{g} / \mathrm{C}$, then a relationship between traffic flow and different levels of $\mathrm{g} / \mathrm{C}$ will be based on microsimulation results. This part of the research is designed to measure traffic flow with higher/lower $\mathrm{g} / \mathrm{C}$ for each link. The green time duration for through movement is to be increased or decreased by 8 seconds on opposite directions.

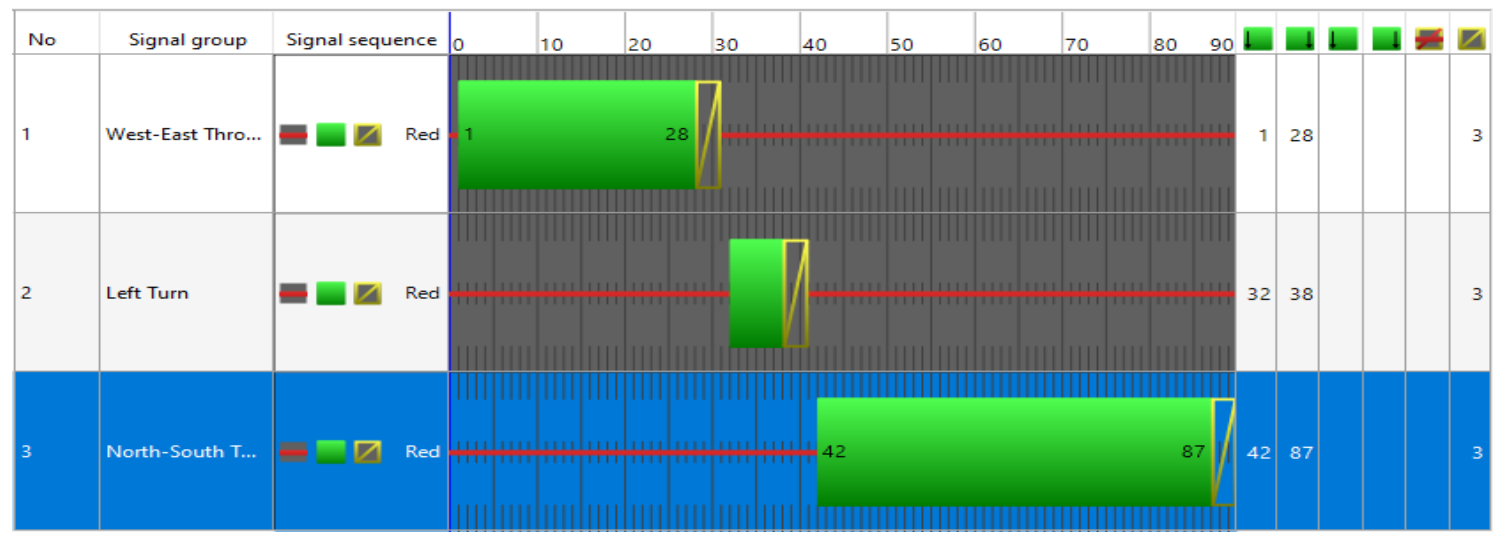

Figure 4.5: Alternate Signal Program 2

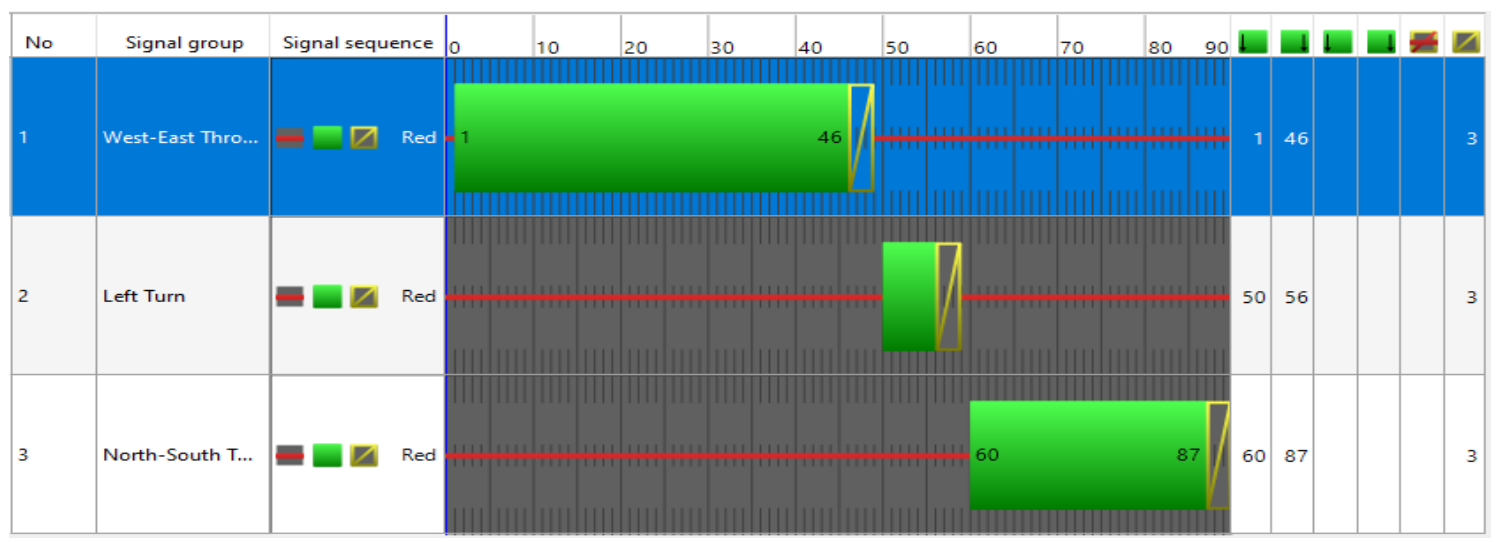

Figure 4.6: Alternate Signal Program 3 


\section{ANALYSIS OF SIMULATION RUNS}

\subsection{INTRODUCTION}

The analysis of simulation runs is described in detail in this chapter. Simulation model design parameters were used to reflect real-world conditions. This includes driving behaviour, vehicle class breakdown, right turn/left turning vehicles, turning speed, percentage of right turn vehicles, percentage of left-turn vehicles, and desired speed distribution, etc. Microsimulation of traffic behaviour was carried out using PTVVissim.

Effect of inherent resilience measures include the effect of different road geometrics (i.e. segment length, availability of left-turn bay, availability of right turn bay) on maximum flow "capacity," and the average travel speed /travel time in a corridor. Also, the effect of $\mathrm{g} / \mathrm{C}$ on maximum flow and travel time in a corridor with different road designs is quantified.

The analysis method adopted quantifies the effect of design features on throughput and service quality factors. Illustrative graphs present the relationship between various road designs, maximum traffic flow, and mean travel time/mean travel speed. In this chapter, developed models are presented and also effectiveness of adding inherent resilience measures are reported.

\subsection{RESULTS OF SIMULATION MODELS}

This part of the research describes simulation results and proposes new simulationbased models for estimating speed and demand distributions of roadways with different characteristics. In addition to the input factors listed above, vehicle flow was increased 
incrementally until convergence was reached or the maximum flow was obtained. Results extracted from simulation runs in PTV-Vissim include average vehicle travel time/ average speed of all vehicles passing between two points, and flow (throughput). The results of the simulation modelling provide valuable insights into relative capacities under different geometric configurations and traffic flow. The next (future) step in this part of research can be to calibrate the models to actual field measurements/counts.

There are 4 links variations. Each has 8 segment length variations, which are simulated with $3 \mathrm{~g} / \mathrm{C}$ variations. Thus, a total of 96 scenarios were simulated and analyzed. Each scenario was simulated 30 times.

Table 5-1 shows the simulation results. Figure 5.1 illustrates the demand data distribution over time for link 1 configuration with a segment length of $500 \mathrm{~m}$ and $\mathrm{g} / \mathrm{C}$ of 0.4 , and the error bars show the speed standard deviation. All individual simulation results are presented below.

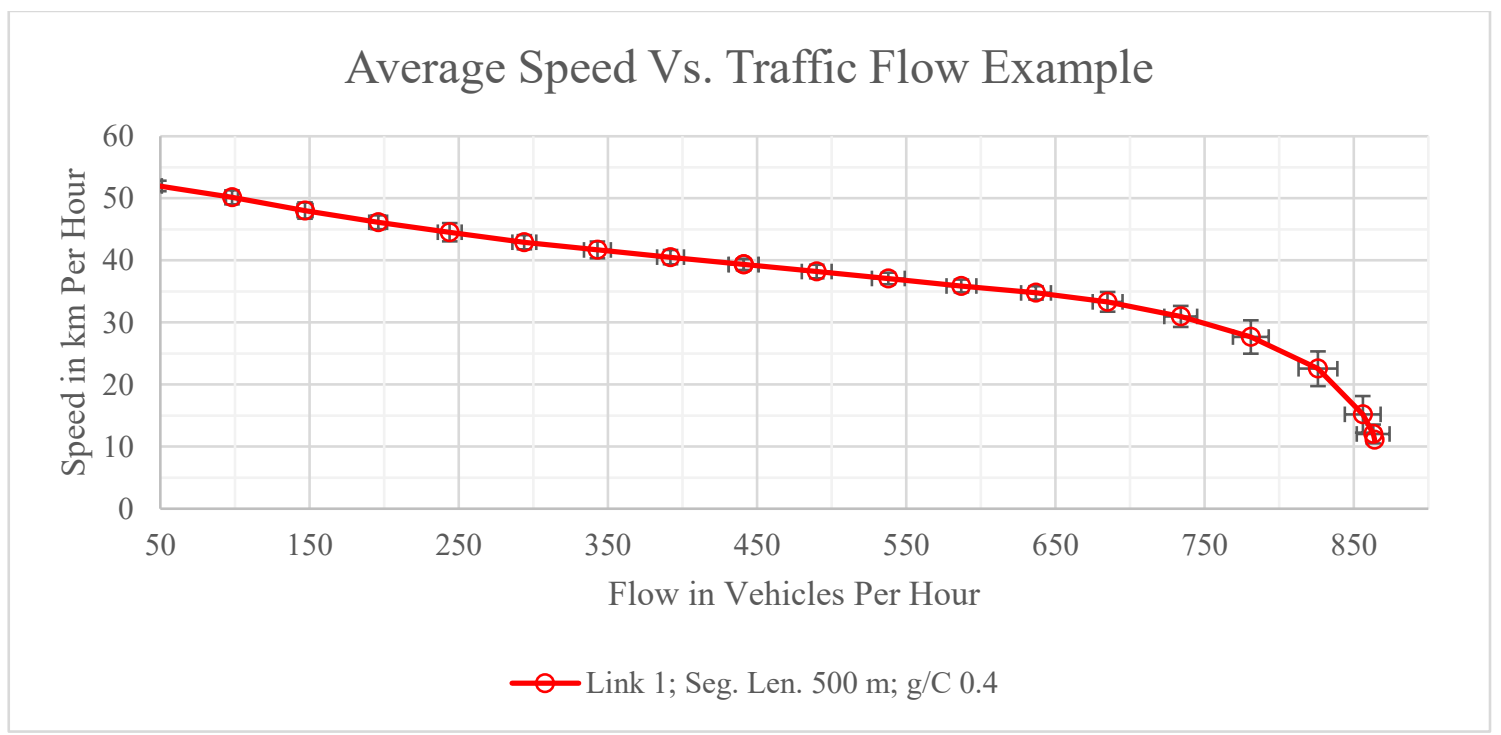

Figure 5.1: Link 1 with Segment Length $500 \mathrm{~m}$ and $\mathrm{g} / \mathrm{C} 0.4$ Graph (Note: See Table 4.4 for Link Characteristics) 
Table 5-1 shows the simulation results. Figure 5.1 illustrates the demand data distribution over time for link 1 configuration with a segment length of $500 \mathrm{~m}$ and $\mathrm{g} / \mathrm{C}$ of 0.4 , and the error bars show the speed standard deviation. All individual simulation results are presented below.

Table 5-1: Link 1 with Segment Length $500 \mathrm{~m}$ and g/C 0.4 Simulation Results

\begin{tabular}{|c|c|c|c|}
\hline $\begin{array}{c}\text { Flow in Vehicles Per } \\
\text { Hour }\end{array}$ & $\begin{array}{c}\text { Speed in km } \\
\text { Per Hour }\end{array}$ & $\begin{array}{c}\text { Flow Standard } \\
\text { Deviation (Veh) }\end{array}$ & $\begin{array}{c}\text { Speed Standard } \\
\text { Deviation }(\mathrm{km} / \mathrm{h})\end{array}$ \\
\hline 49 & 52.0 & 2 & 0.8 \\
\hline 98 & 50.2 & 4 & 1.1 \\
\hline 147 & 48.0 & 5 & 1.3 \\
\hline 196 & 46.1 & 6 & 1.5 \\
\hline 244 & 44.5 & 8 & 1.1 \\
\hline 294 & 42.9 & 8 & 1.4 \\
\hline 343 & 41.7 & 9 & 1.1 \\
\hline 392 & 40.5 & 9 & 0.9 \\
\hline 441 & 39.3 & 10 & 0.9 \\
\hline 441 & 39.3 & 10 & 1.1 \\
\hline 490 & 38.2 & 10 & 0.9 \\
\hline 538 & 37.1 & 11 & 1.0 \\
\hline 587 & 35.9 & 10 & 1.1 \\
\hline 637 & 34.8 & 10 & 1.6 \\
\hline 685 & 33.3 & 10 & 2.7 \\
\hline 734 & 31.0 & 11 & 2.8 \\
\hline 781 & 27.7 & 12 & 1.5 \\
\hline 826 & 22.5 & 13 & \\
\hline 856 & 15.2 & 12 & 11 \\
\hline 863 & 12.0 & & 2.9 \\
\hline
\end{tabular}

(Note: See Table 4.4 for Link Characteristics)

Graphical presentation of all simulation configurations are displayed below in Figure 5.3

- Figure 5.14. Through analyzing demand speed relationship graphs below, observation is as follow:

- A direct variation is observed between segment length and travel speed: As segment length increases, travel speed increases. 
- A direct variation is observed between $\mathrm{g} / \mathrm{C}$, travel speed, and capacity: Increasing $\mathrm{g} / \mathrm{C}$ directly increases travel speed and the maximum flow of vehicles per hour per lane.

- The availability of the right turn bay has a more considerable direct variation with travel speed and capacity due to higher turning volume and permissible right turn on red where applicable. In contrast, the availability of the left-turn bay proposes a slight direct variation with travel speed and capacity. See Figure 5.2 below.

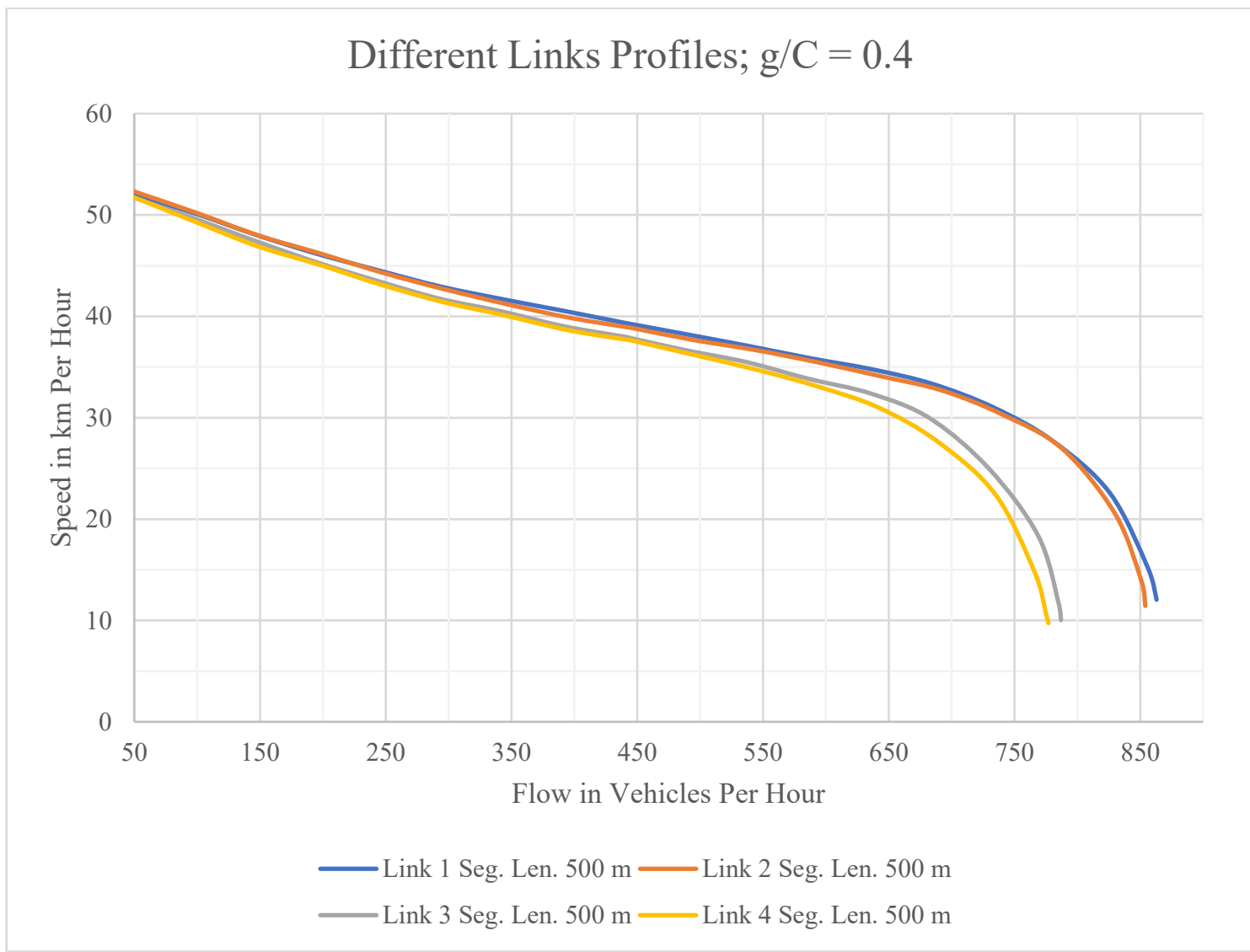

Figure 5.2: Effect of Left Turn Bay and Right Turn Bay on Travel Speed (Note: See Table 4.4 for Link Characteristics) 


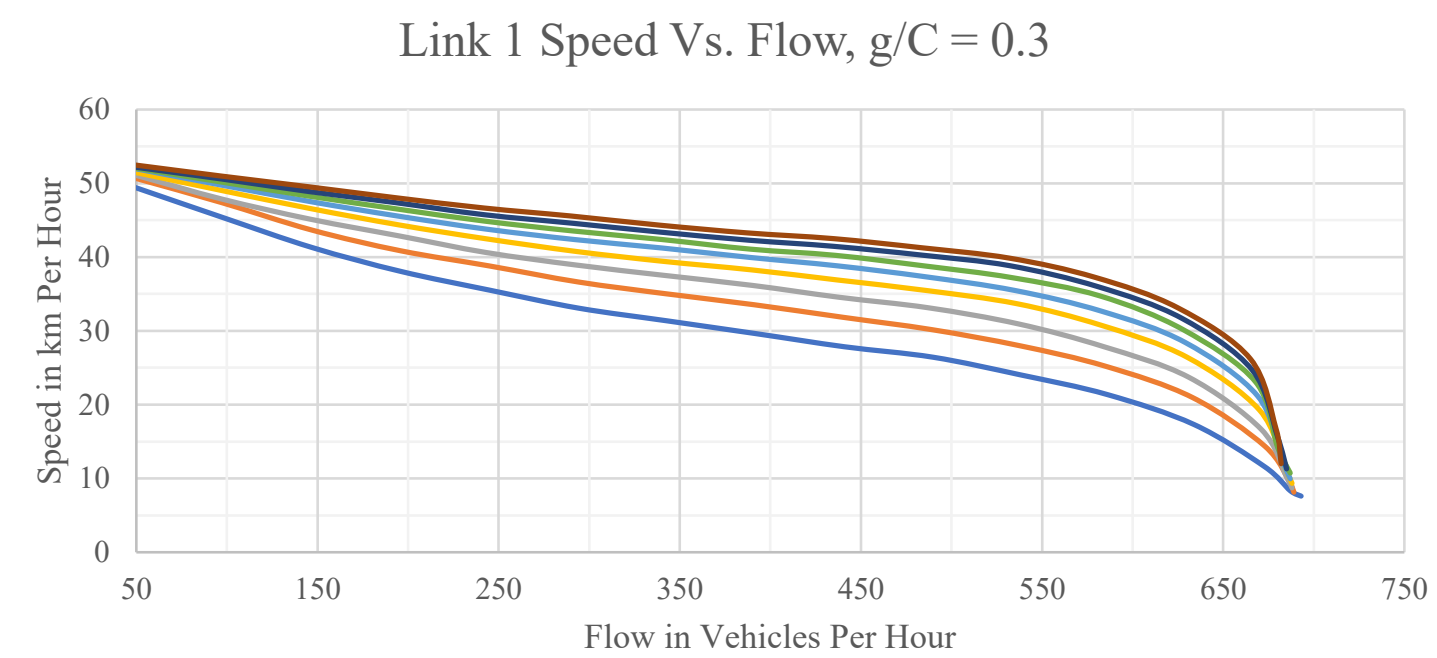

$\longrightarrow$ Seg. Len. $300 \mathrm{~m} \longrightarrow$ Seg. Len. $400 \mathrm{~m} \longrightarrow$ Seg. Len. $500 \mathrm{~m} \longrightarrow$ Seg. Len. $600 \mathrm{~m}$

$\longrightarrow$ Seg. Len. $700 \mathrm{~m} \longrightarrow$ Seg. Len. $800 \mathrm{~m}$ — Seg. Len. $900 \mathrm{~m}$ - Seg. Len. $1000 \mathrm{~m}$

Figure 5.3: Link 1 All Segments Lengths and g/C 0.3 Simulation Results (Note: See Table 4.4 for Link Characteristics)

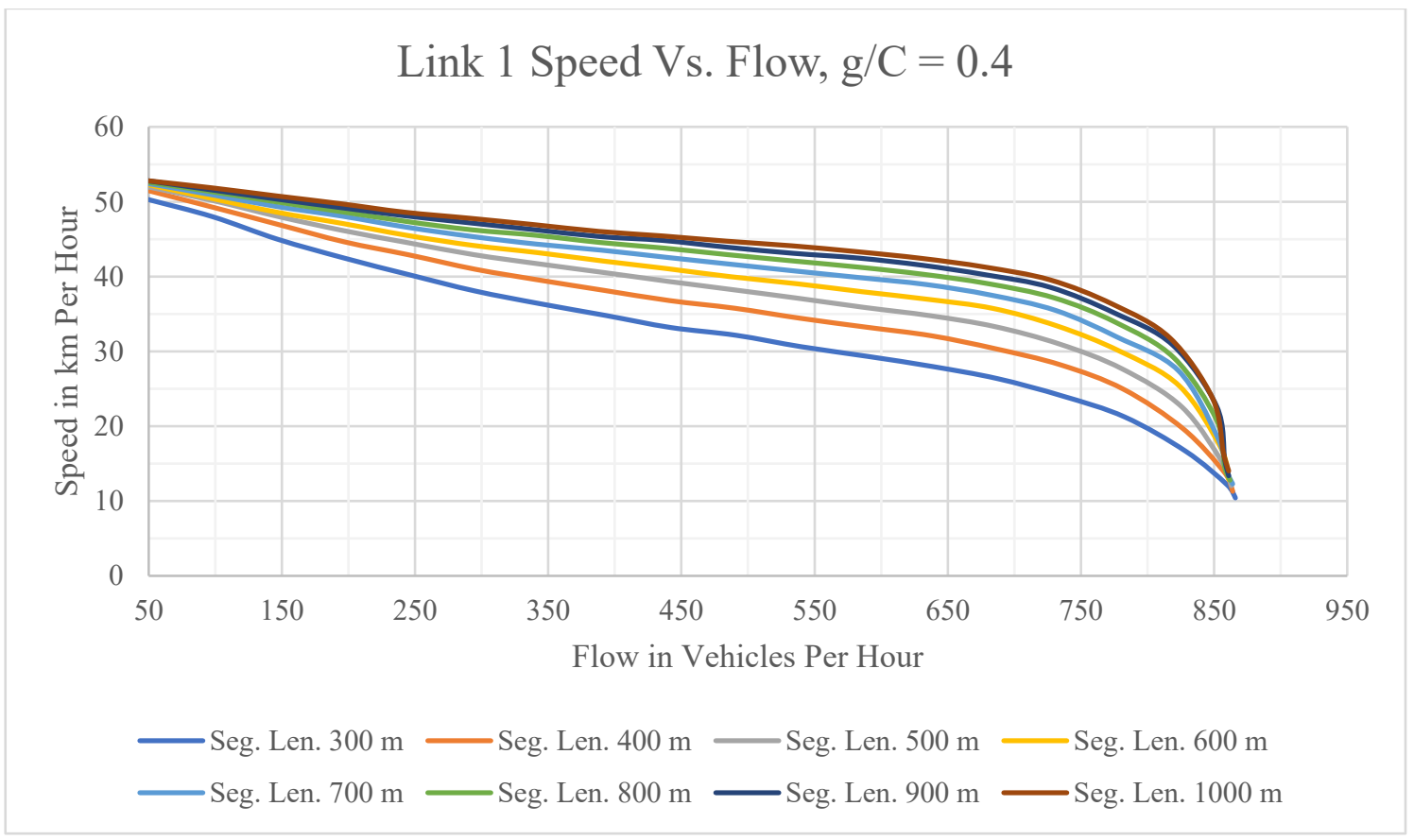

Figure 5.4: Link 1 All Segments Lengths and g/C 0.4 Simulation Results (Note: See Table 4.4 for Link Characteristics) 


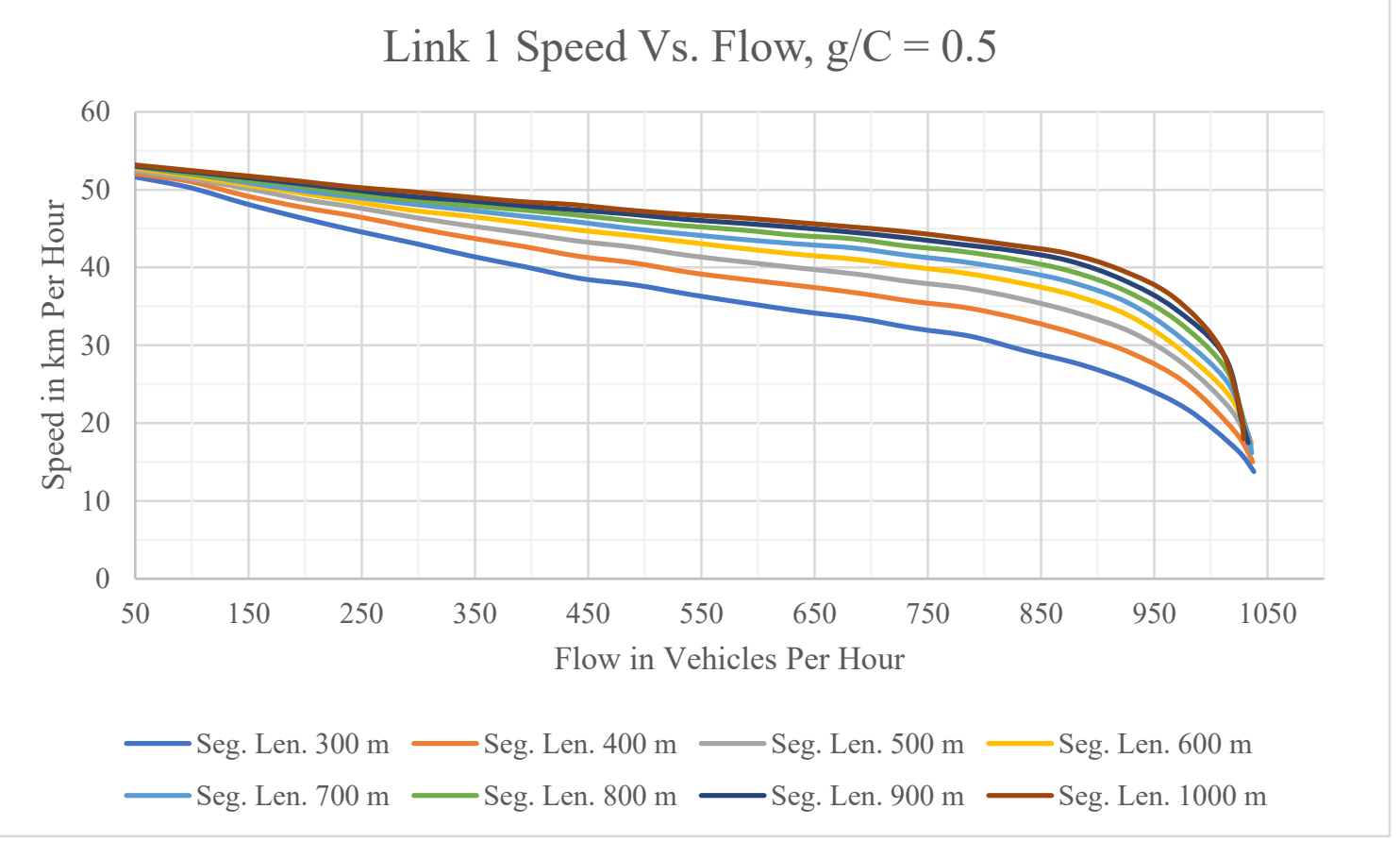

Figure 5.5: Link 1 All Segments Lengths and g/C 0.5 Simulation Results (Note: See Table 4.4 for Link Characteristics)

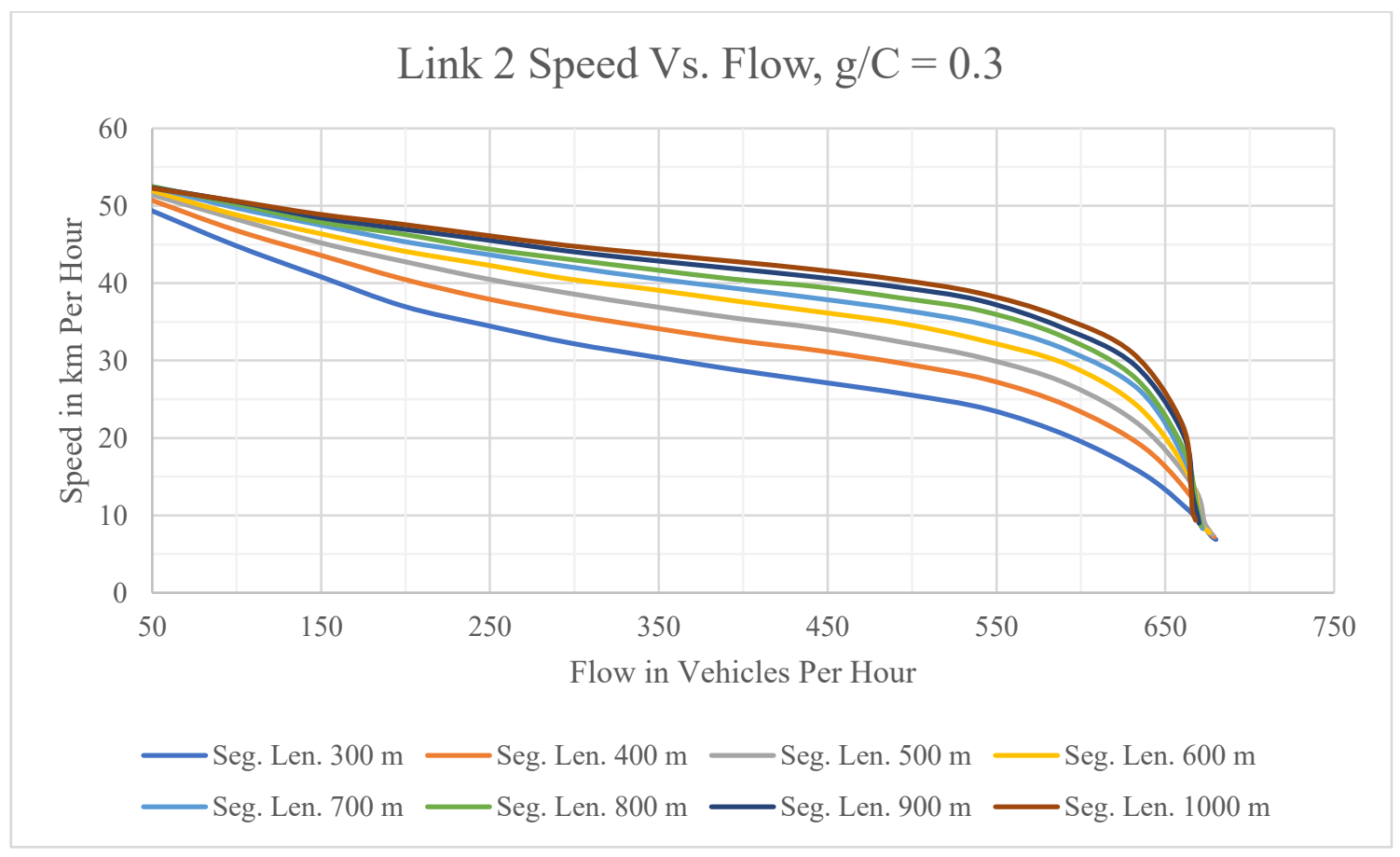

Figure 5.6: Link 2 All Segments Lengths and g/C 0.3 Simulation Results (Note: See Table 4.4 for Link Characteristics) 


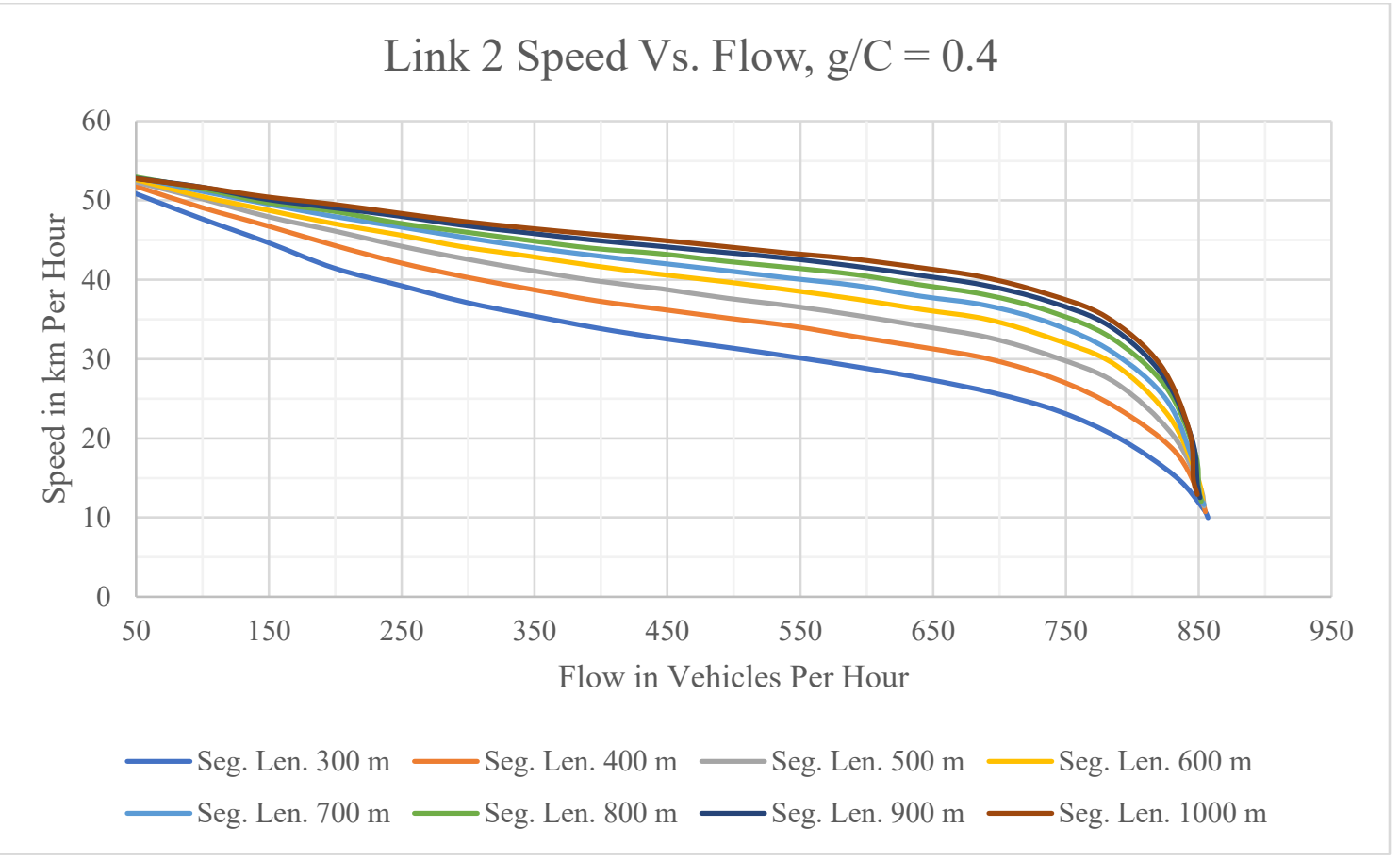

Figure 5.7: Link 2 All Segments Lengths and g/C 0.4 Simulation Results (Note: See Table 4.4 for Link Characteristics)

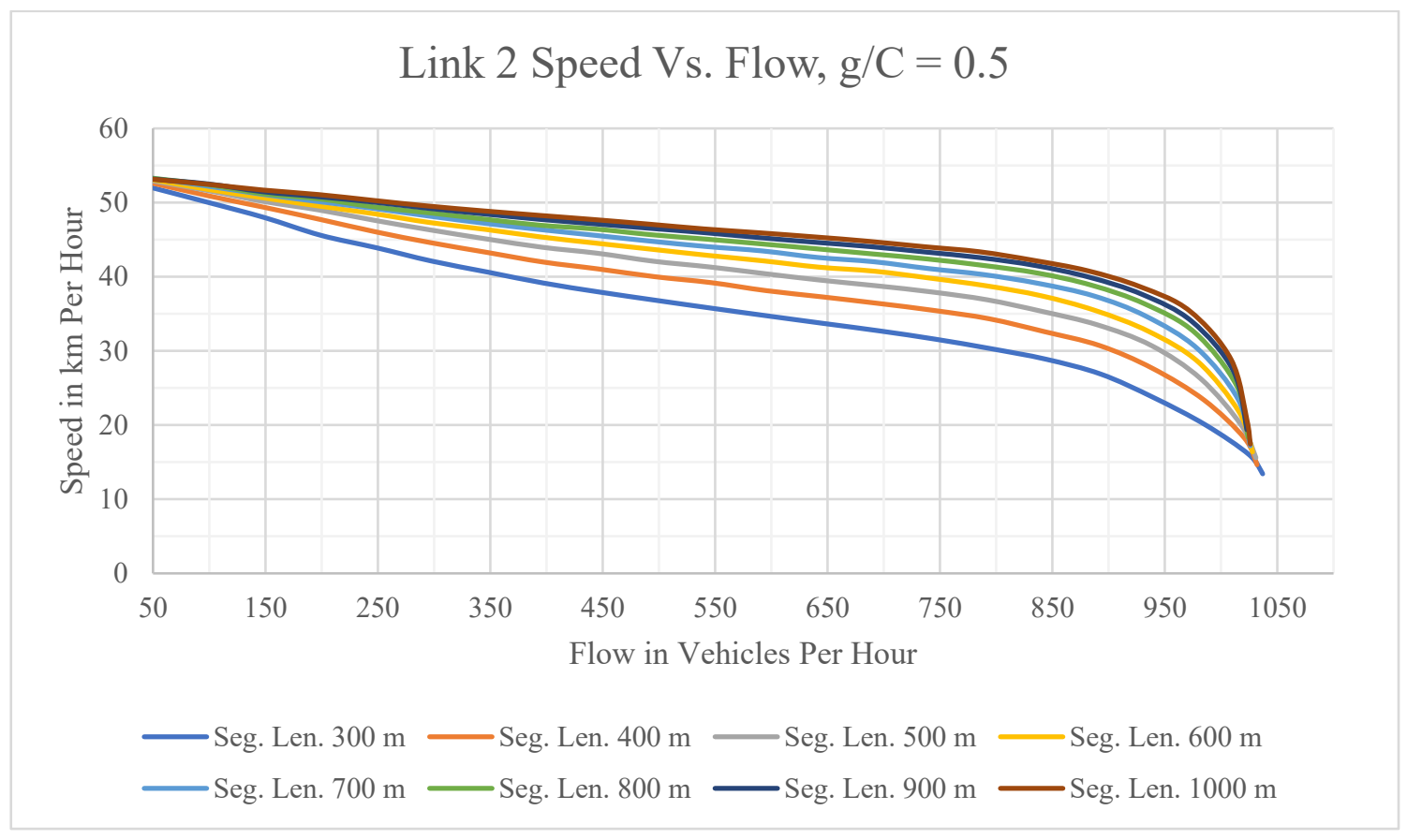

Figure 5.8: Link 2 All Segments Lengths and g/C 0.5 Simulation Results (Note: See Table 4.4 for Link Characteristics) 


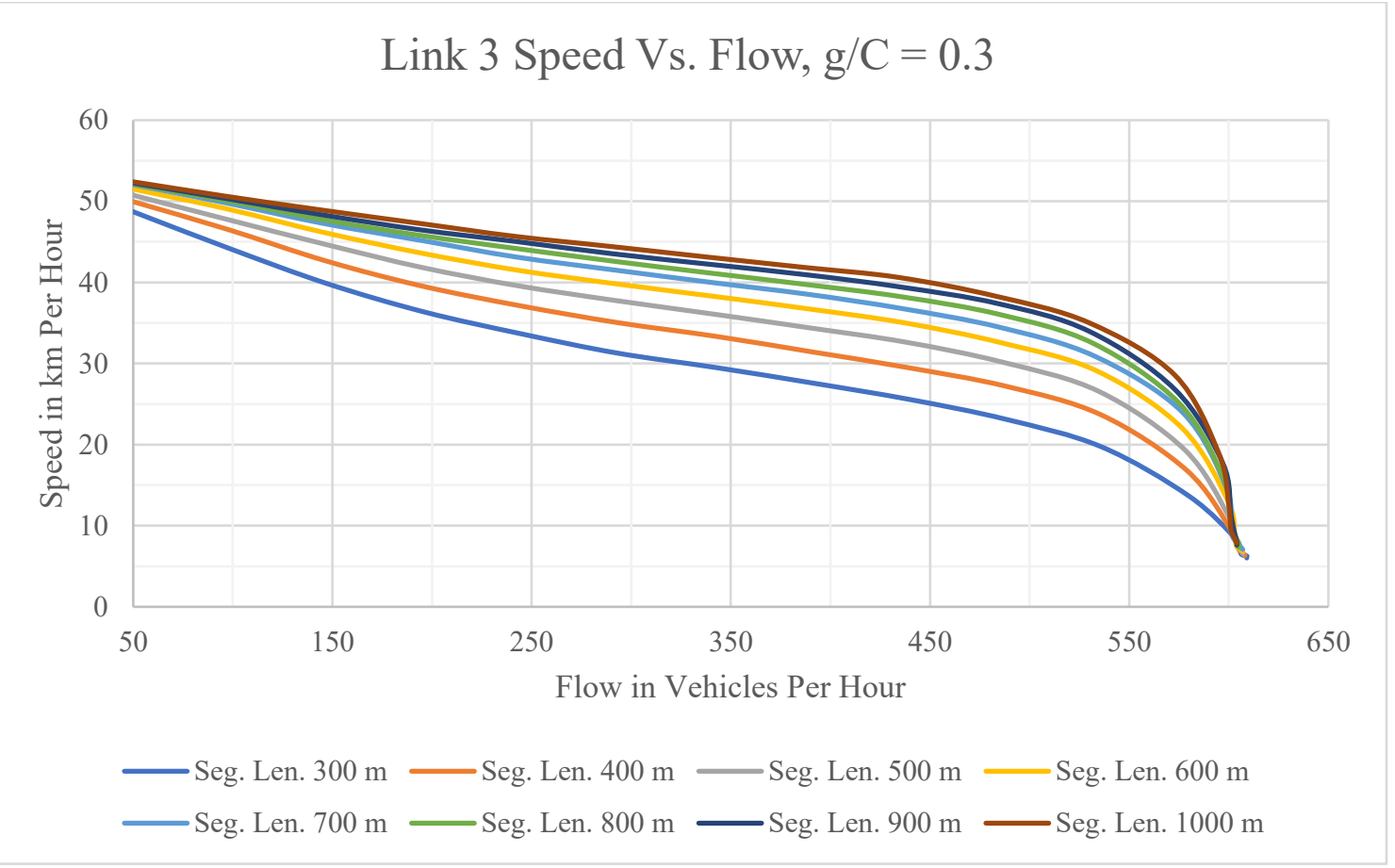

Figure 5.9: Link 3 All Segments Lengths and g/C 0.3 Simulation Results (Note: See Table 4.4 for Link Characteristics)

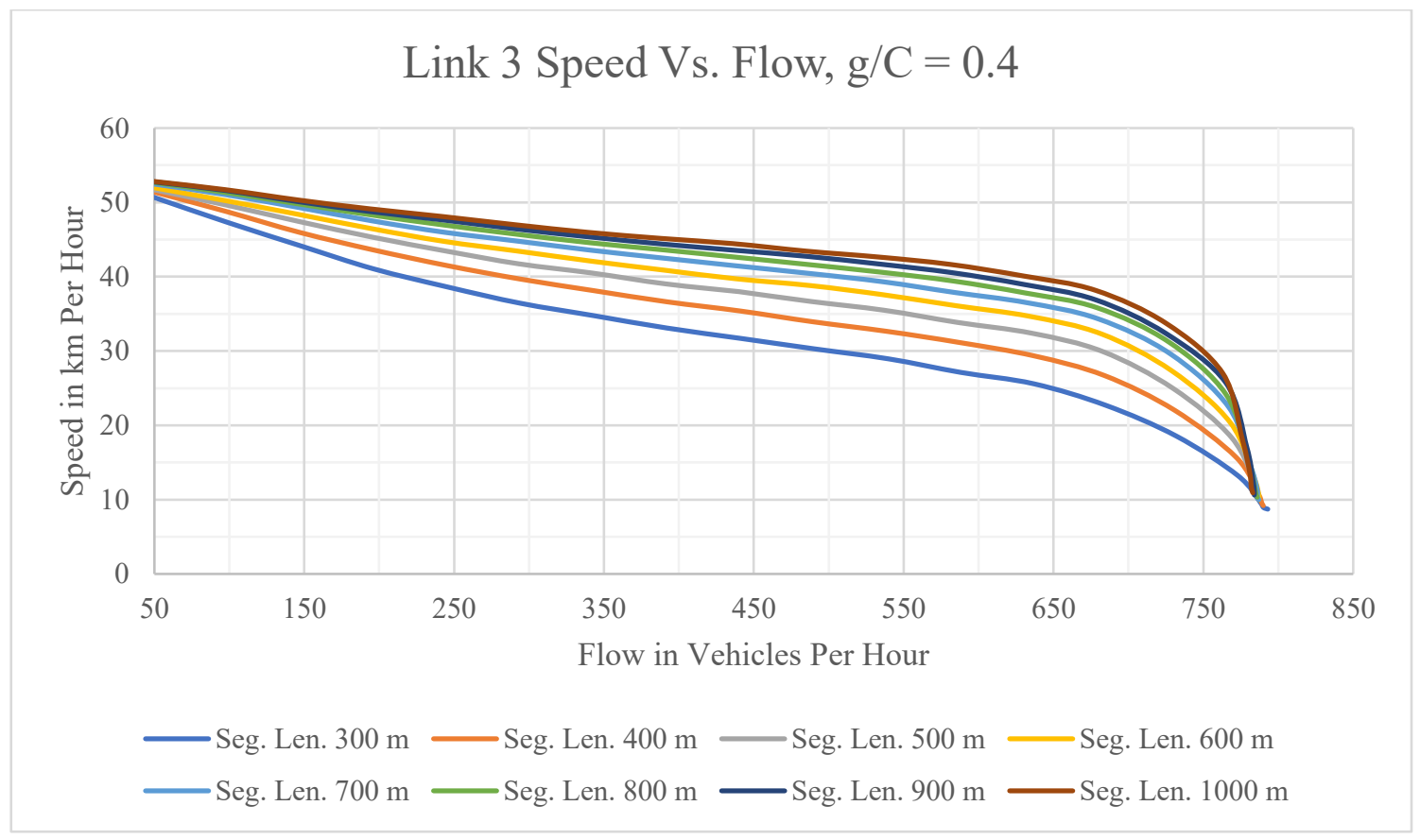

Figure 5.10: Link 3 All Segments Lengths and g/C 0.4 Simulation Results (Note: See Table 4.4 for Link Characteristics) 


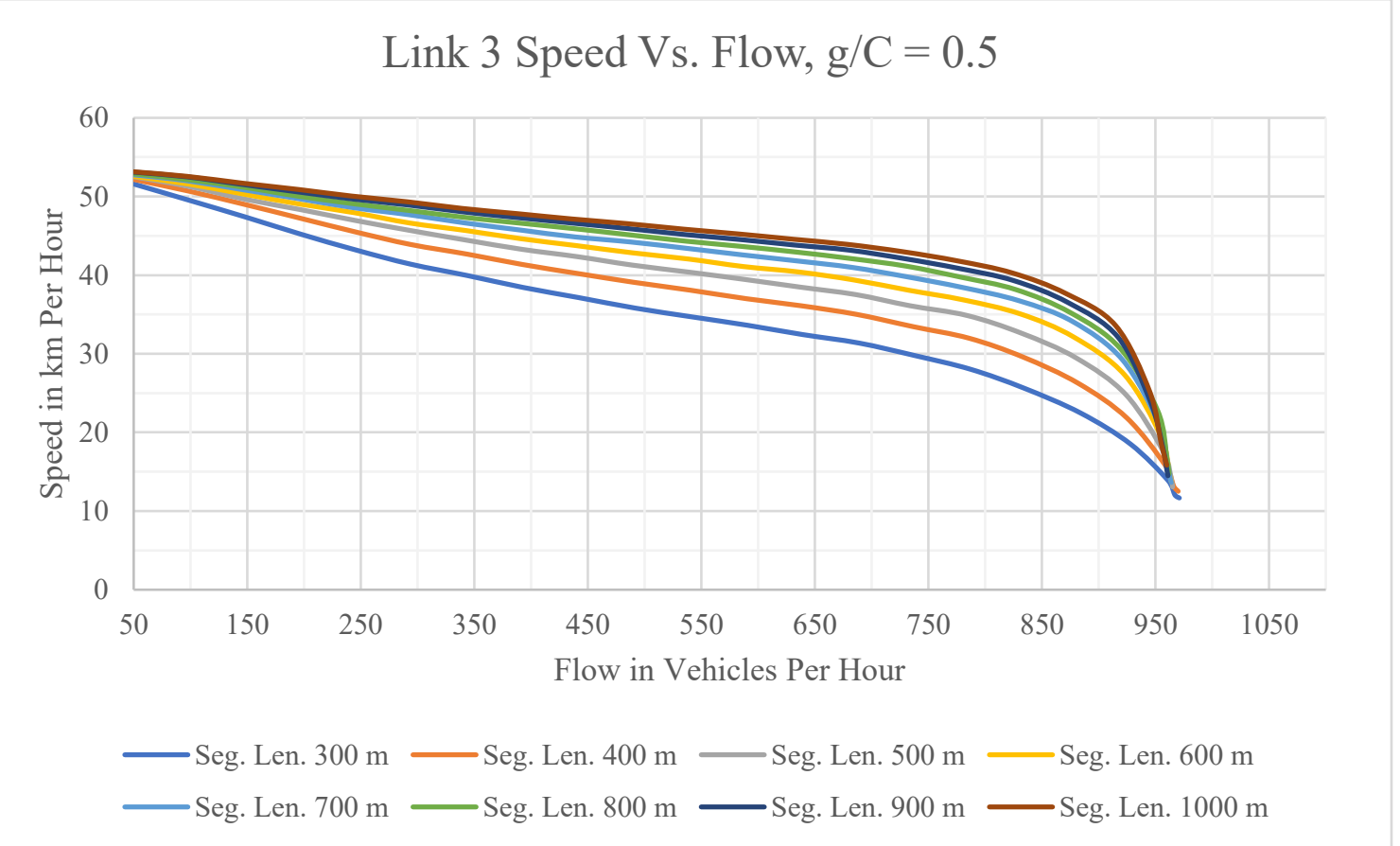

Figure 5.11: Link 3 All Segments Lengths and g/C 0.5 Simulation Results (Note: See Table 4.4 for Link Characteristics)

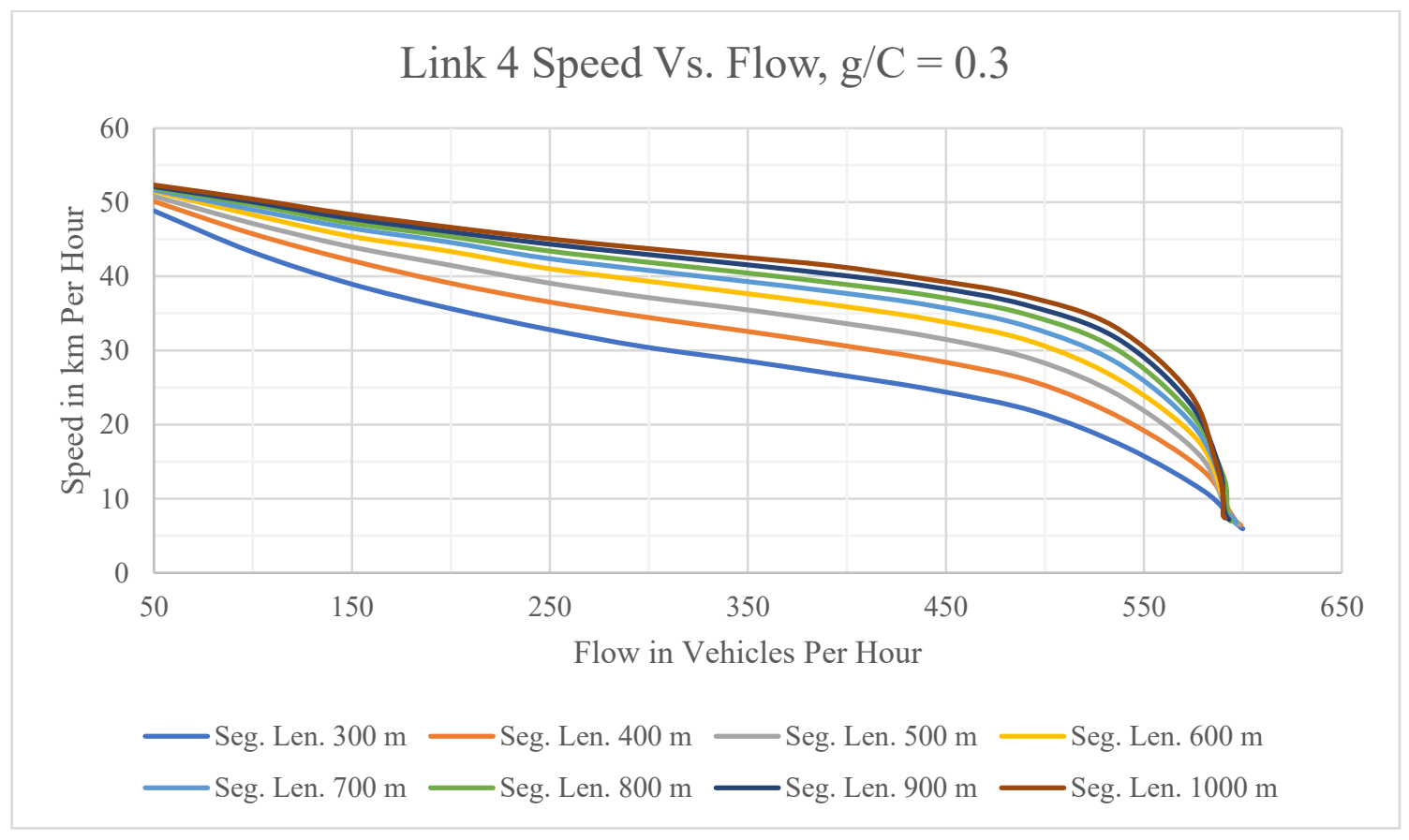

Figure 5.12: Link 4 All Segments Lengths and g/C 0.3 Simulation Results (Note: See Table 4.4 for Link Characteristics) 


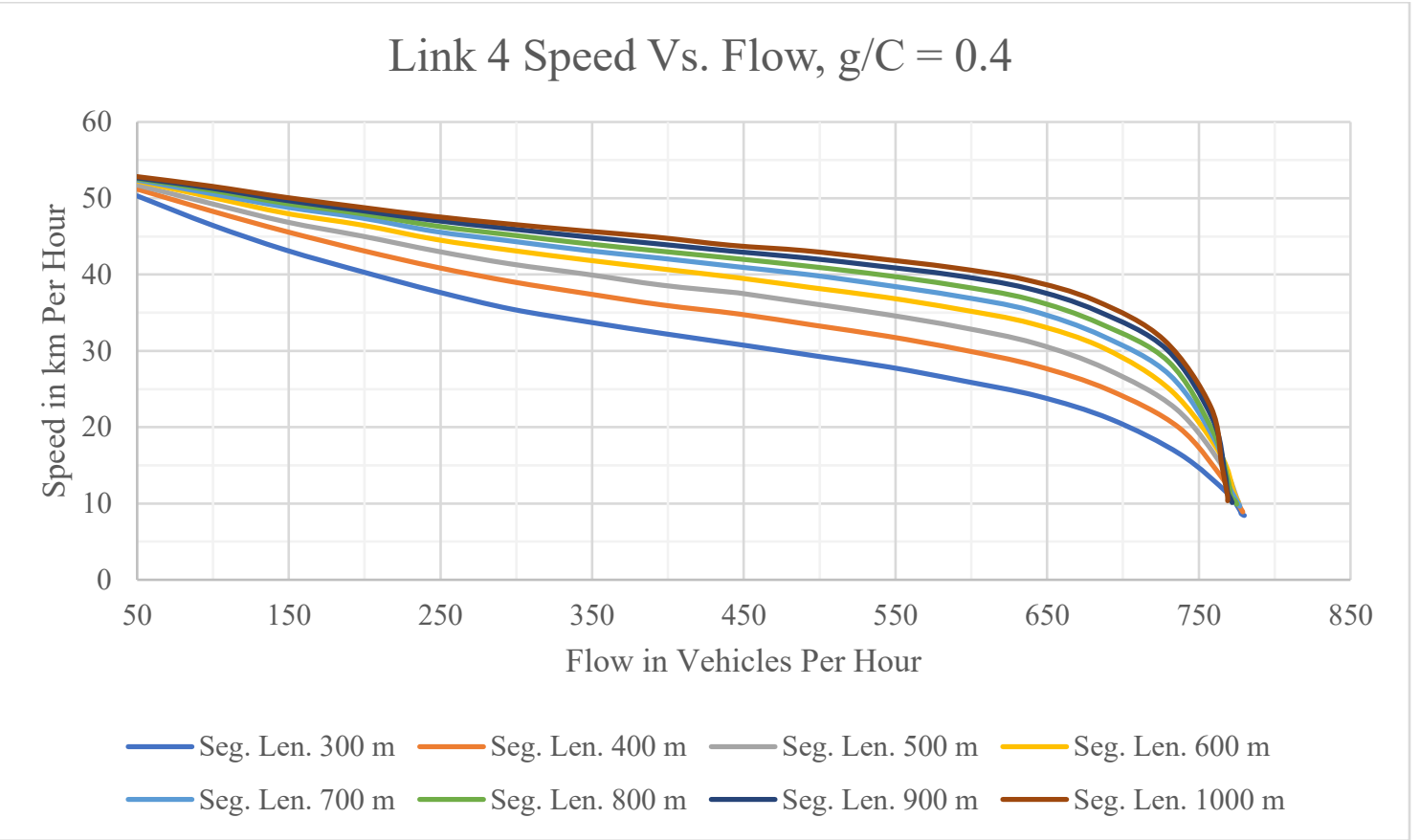

Figure 5.13: Link 4 All Segments Lengths and g/C 0.4 Simulation Results (Note: See Table 4.4 for Link Characteristics)

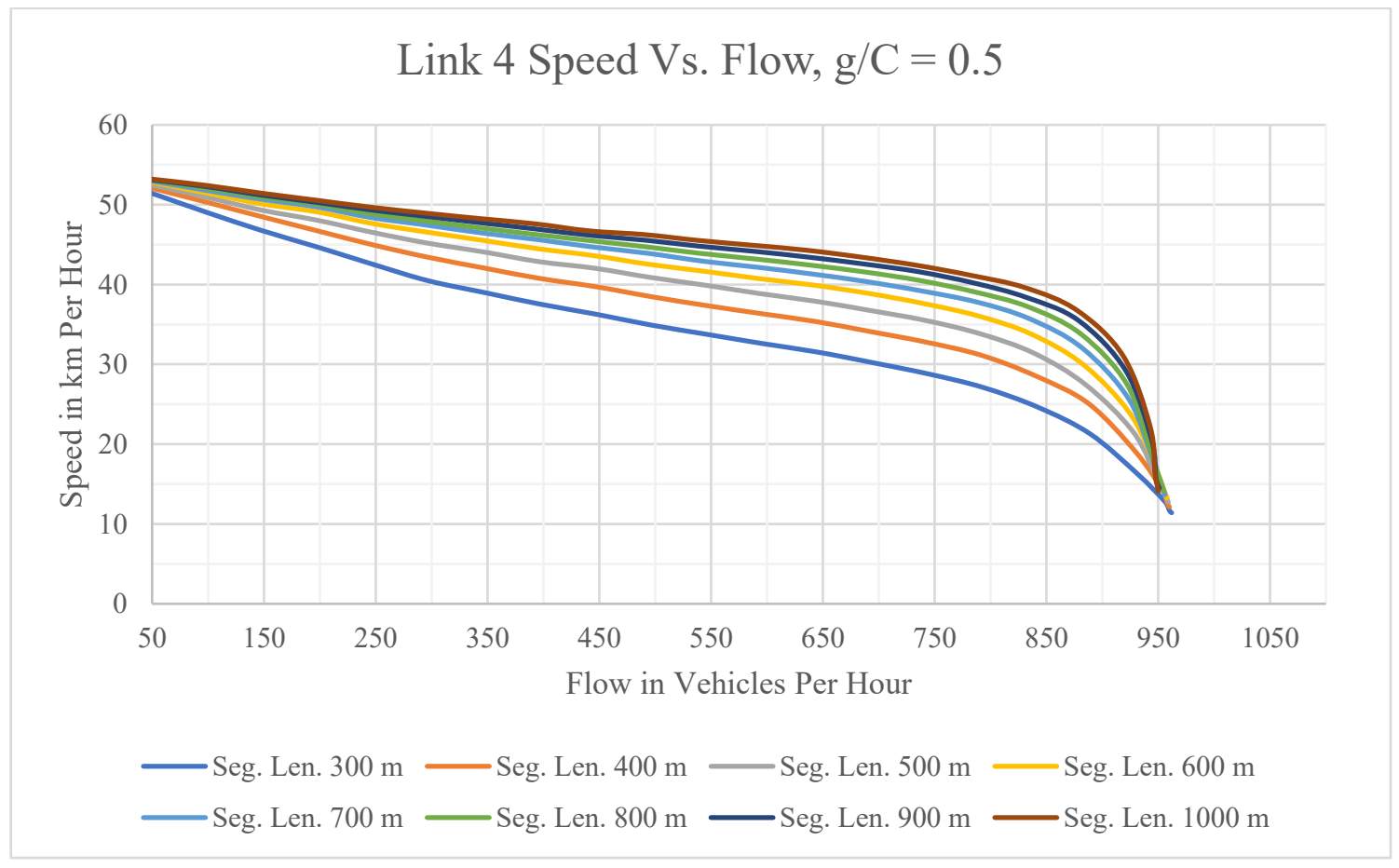

Figure 5.14: Link 4 All Segments Lengths and g/C 0.5 Simulation Results (Note: See Table 4.4 for Link Characteristics) 


\subsection{EFFECTIVENESS OF RESILIENCE MEASURES ON TRAVEL TIME /TRAVEL SPEED}

Microsimulation results shown in Figures 5.3 to 5.14 summarize the flowspeed relationship for different link configurations and g/C. In order to explain the relationship between travel speed, and segment length, $\mathrm{g} / \mathrm{C}$, and the existence of left-turn bay / right turn bay, multiple regression analysis was carried out on the data set extracted using SPSS. Details of SPSS analysis results can be seen in Appendix G.

Table 5-2 shown below presents the model summary. The $\mathrm{R}^{2}$ is 0.781 (78.1\%), which means that the predictors' segment length, left-turn bay, right turn bay, and $\mathrm{g} / \mathrm{C}$ account for $78.1 \%$ of the variance. The ANOVA test presented in

Table 5-3 for the analysis shows that the predictors are able to account for a significant amount of variance in travel speed. In other words, the overall regression model was significant, $\mathrm{F}(5,1866)=1332.4, \mathrm{p}<0.001, \mathrm{R}^{2}=0.781$.

Variables, namely $\mathrm{g} / \mathrm{C}$, and segment length, show a positive correlation with average travel speed; right turn bay, and left-turn bay show a fairly low positive correlation with average travel speed. In contrast, as expected, flow shows a negative correlation with the dependent variable. The values of correlation with the dependent variable are $0.246,0.215,0.109,0.032$, and -0.727 respectively. As expected, the $\mathrm{g} / \mathrm{C}$ represents the highest unique predictive capacity of the dependent variable, followed by segment length, then right turn bay.

Table 5-4 shows the coefficients' results. Segment length, right turn bay, and g/C are statistically significant with $p<0.001$; left turn value is also statistically significant with $p=0.01$. Multicollinearity is not a problem. More work is needed to produce a predictive equation of travel time/ travel speed using the variables listed above. 
Table 5-2: SPSS Model Summary

\begin{tabular}{|c|c|c|c|c|}
\hline Model & $\mathrm{R}$ & $\mathrm{R}$ Square & Adjusted R Square & Std. Error of the Estimate \\
\hline 1 & $.884^{\mathrm{a}}$ & .781 & .781 & 6.115 \\
\hline
\end{tabular}

a. Predictors: (Constant), Flow, LeftTurnBay, segmentLength, RightTurnBay, GreenOverCycle

b. Dependent Variable: Speed

Table 5-3: ANOVA Table Results

ANOVA $^{\mathrm{a}}$

\begin{tabular}{|c|c|c|c|c|c|c|}
\hline Model & & Sum of Squares & df & Mean Square & $F$ & Sig. \\
\hline \multirow{3}{*}{1} & Regression & 249126.4 & 5 & 49825.2 & 1332.404 & $.000^{b}$ \\
\hline & Residual & 69779.1 & 1866 & 37.3 & & \\
\hline & Total & 318905.5 & 1871 & & & \\
\hline
\end{tabular}

a. Dependent Variable: Speed

b. Predictors: (Constant), Flow, LeftTurnBay, segmentLength, RightTurnBay, GreenOverCycle

Table 5-4: SPSS Coefficient Results

\begin{tabular}{|c|c|c|c|c|c|c|c|c|c|c|c|c|}
\hline \multirow[t]{2}{*}{ Model } & \multicolumn{2}{|c|}{$\begin{array}{l}\text { Unstandardized } \\
\text { Coefficients }\end{array}$} & \multirow{2}{*}{$\begin{array}{l}\text { Stand. } \\
\text { Coeff. } \\
\text { Beta }\end{array}$} & \multirow[t]{2}{*}{$\mathrm{t}$} & \multirow[t]{2}{*}{ Sig. } & \multicolumn{2}{|c|}{$\begin{array}{c}95.0 \% \\
\text { Confidence } \\
\text { Interval for B }\end{array}$} & \multicolumn{3}{|c|}{ Correlations } & \multicolumn{2}{|c|}{$\begin{array}{l}\text { Collinearity } \\
\text { Statistics }\end{array}$} \\
\hline & B & $\begin{array}{l}\text { Std. } \\
\text { Error }\end{array}$ & & & & $\begin{array}{l}\text { Lower } \\
\text { Bound }\end{array}$ & $\begin{array}{l}\text { Upper } \\
\text { Bound }\end{array}$ & $\begin{array}{l}\text { Zero- } \\
\text { order }\end{array}$ & $\begin{array}{c}\text { Partia } \\
1 \\
\end{array}$ & Part & $\begin{array}{c}\text { Toleran } \\
\text { ce }\end{array}$ & VIF \\
\hline (Constant) & 16.383 & .858 & & 19.090 & .000 & 14.699 & 18.066 & & & & & \\
\hline segmentLength & .013 & .001 & .223 & 20.608 & .000 & .011 & .014 & .215 & .431 & .223 & 1.000 & 1.000 \\
\hline LeftTurnBay & .728 & .283 & .028 & 2.576 & .010 & .174 & 1.283 & .032 & .060 & .028 & 1.000 & 1.000 \\
\hline RightTurnBay & 3.488 & .283 & .134 & 12.334 & .000 & 2.933 & 4.043 & .109 & .275 & .134 & .999 & 1.001 \\
\hline GreenOverCycle & 71.190 & 1.794 & .442 & 39.683 & .000 & 67.672 & 74.709 & .246 & .677 & .430 & .944 & 1.059 \\
\hline Flow & -.041 & .001 & -.837 & -75.118 & .000 & -.042 & -.040 & -.727 & -.867 & -.813 & .944 & 1.060 \\
\hline
\end{tabular}

a. Dependent Variable: Speed 


\subsection{EFFECTIVENESS OF INHERENT RESILIENCE MEASURES ON THROUGHPUT}

Graphs of flow-speed relationships reveal that segment lengths do not contribute to change in maximum flow per hour per lane. In contrast, the existence of left-turn bay, right-turn bay, and $\mathrm{g} / \mathrm{C}$ contribute to change in the capacity of the roadway segment. The maximum flow or capacity is measured by counting the number of vehicles that enters and exits the road segment. Vehicles that remain on the road segment by the end of the one-hour simulation are not included in the count. The flow is considered at its max when the maximum flow of vehicles per hour does not change, regardless of the increase in vehicles input in the simulation software. The maximum flow of each simulation run was gathered and linear regression analysis of capacity against segment length, right turn lane, left turn lane, and $\mathrm{g} / \mathrm{C}$ variables was carried using SPSS. A simplified result of maximum flow is presented in Table 5-5 below. Figure 5.15 shows a graphical representation of maximum flow means. Detailed results are presented in Appendix F.

\section{Table 5-5: Max Flow Mean Breakdown}

\begin{tabular}{|c|c|c|c|c|c|c|}
\hline Link & $\begin{array}{c}\text { Segment } \\
\text { length } \\
(\mathrm{m})\end{array}$ & $\begin{array}{c}\text { Left } \\
\text { Bay }\end{array}$ & $\begin{array}{c}\text { Right } \\
\text { Bay }\end{array}$ & $\mathrm{g} / \mathrm{C}$ & $\begin{array}{c}\text { Max. } \\
\text { Flow } \\
\text { Mean }\end{array}$ & $\begin{array}{c}\text { Max. } \\
\text { Flow } \\
\text { Standard } \\
\text { Deviation }\end{array}$ \\
\hline 1 & All & 1 & 1 & 0.3 & 687 & 3 \\
\hline 2 & All & 0 & 1 & 0.3 & 674 & 5 \\
\hline 3 & All & 1 & 0 & 0.3 & 606 & 2 \\
\hline 4 & All & 0 & 0 & 0.3 & 596 & 3 \\
\hline 1 & All & 1 & 1 & 0.4 & 863 & 2 \\
\hline 2 & All & 0 & 1 & 0.4 & 853 & 2 \\
\hline 3 & All & 1 & 0 & 0.4 & 787 & 3 \\
\hline 4 & All & 0 & 0 & 0.4 & 776 & 4 \\
\hline 1 & All & 1 & 1 & 0.5 & 1034 & 3 \\
\hline 2 & All & 0 & 1 & 0.5 & 1028 & 5 \\
\hline 3 & All & 1 & 0 & 0.5 & 965 & 4 \\
\hline 4 & All & 0 & 0 & 0.5 & 956 & 4 \\
\hline
\end{tabular}




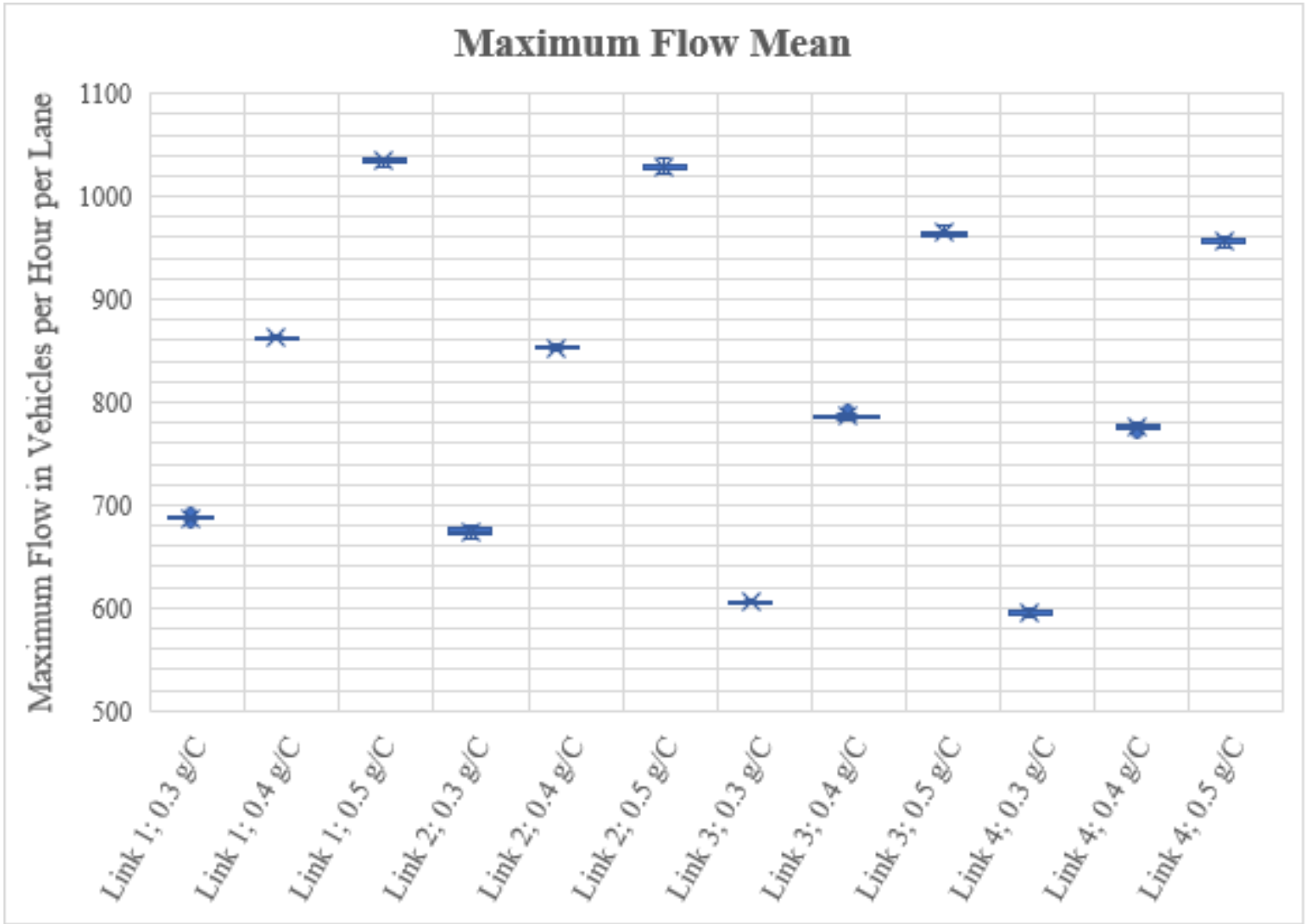

Figure 5.15: Graphical Representation of Maximum Flow of Different Links Structure and g/C (Note: See Table 4.4 for Link Characteristics)

A total of 96 input values were analyzed in SPSS. The output of the regression analysis from SPSS shows a linear relationship between capacity, the existence of leftturn bay, existence of right-turn bay, and g/C. Table 5-6 below shows the model summary from SPSS. The R squared value shows that over $99 \%$ of predicted capacity can be accounted for by the predictors. Full SPSS report is presented in Appendix M. Its recommended that more variations of left-turn and right-turn vehicles flow be accounted for in future research. Figure 5.16 below shows the estimated capacity for links 1, 2, 3, and 4 for different $\mathrm{g} / \mathrm{C}$. availability of the right turn bay has a more significant impact on capacity through the bottleneck. 
Table 5-6: SPSS Capacity Model Summary

\begin{tabular}{|l|r|r|r|c|}
\hline Model & R & R Square & \multicolumn{1}{|c|}{$\begin{array}{c}\text { Adjusted R } \\
\text { Square }\end{array}$} & $\begin{array}{c}\text { Std. Error of the } \\
\text { Estimate }\end{array}$ \\
\hline 1 & $1.000^{\mathrm{a}}$ & .999 & .999 & 3.99953 \\
\hline
\end{tabular}

a. Predictors: (Constant), GreenOverCycle, RightBay, LeftBay

b. Dependent Variable: MaxFlow

The following equation estimates capacity through road segments with different geometrics:

$$
\text { Capacity }=66.333+9.792 * \mathrm{LTB}+75.667 * \mathrm{RTB}+1774.531 * \mathrm{~g} / \mathrm{C}
$$

The above equation can be rewritten to include number of through lanes as:

$$
\text { Capacity }=[66.333+1774.531 * \mathrm{~g} / \mathrm{C}] * \mathrm{~N}+9.792 * \mathrm{LTB}+75.667 * \mathrm{RTB}
$$

Where: $\mathrm{g} / \mathrm{C}=$ Green time over cycle length,

$$
\mathrm{N}=\text { number of through lanes, }
$$

$\mathrm{LTB}=1$ if LTB is available,

$$
\mathrm{RTB}=1 \text { if } \mathrm{RTB} \text { is available }
$$

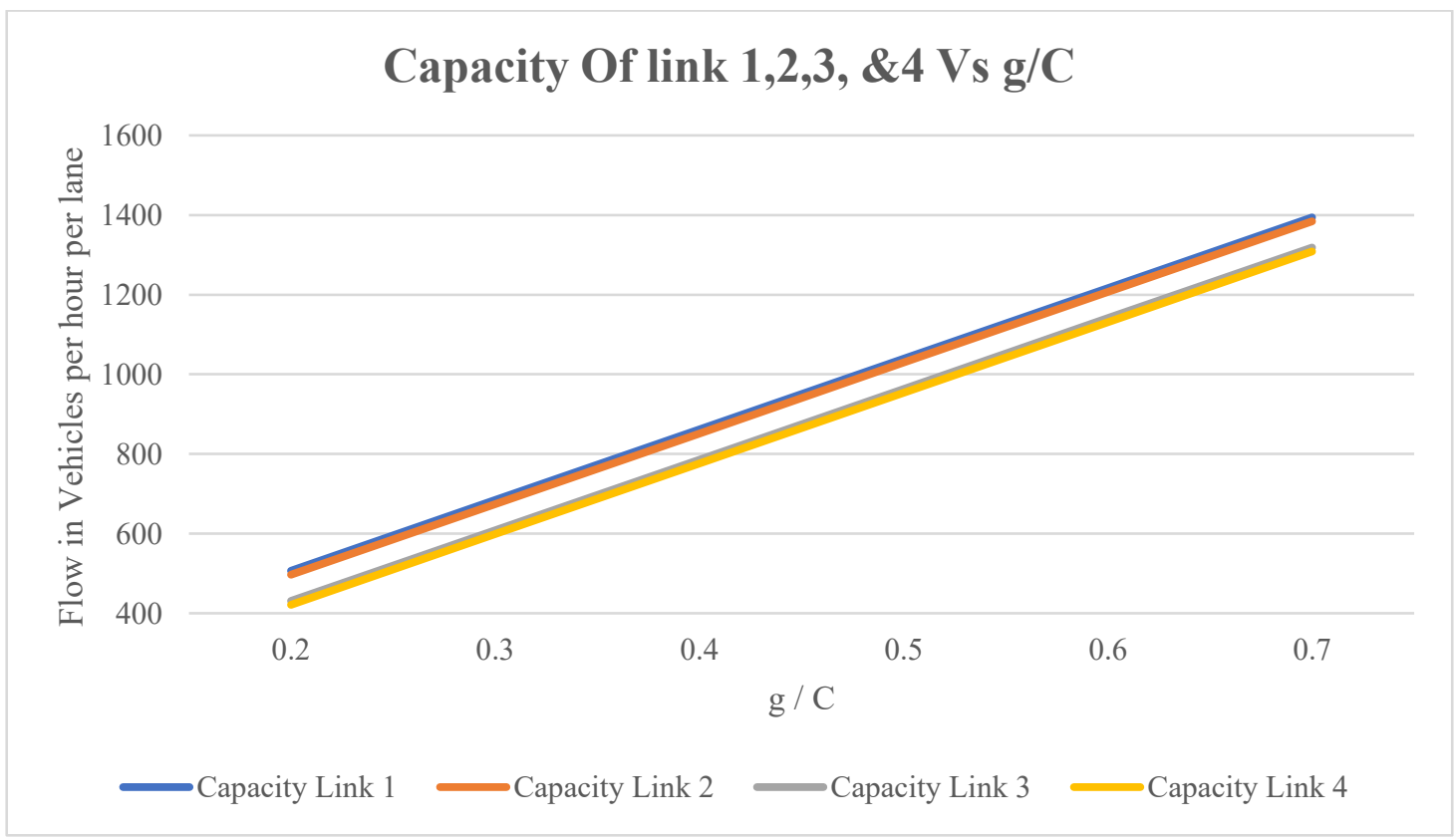

Figure 5.16: Capacity vs g/C for All Links (Note: See Table 4.4 for Link Characteristics) 


\section{TESTING INHERENT RESILIENCE IN AN}

\section{IMPACTED NETWORK}

\subsection{PURPOSE AND VARIABLES}

Chapters 4 and 5 covered the theoretical foundation of inherent resilience, and the role of inherent resilience measures was investigated by link-level simulations. Models developed were found to be satisfactory for explaining traffic behaviour and road capacity. In addition to adapting traffic control, geometric characteristics of the link can enhance the ability of the link to resist loss of traffic serving capability. The geometric design characteristics that can serve as measures of inherent resilience include distance between intersections, left turn bay, and right turn bay. The link level research results can be applied to an important link within a corridor.

The next step in testing the effectiveness of inherent resilience measures is at a real-world network level. In addition to a base case, the impacted network can be simulated with and without inherent resilience features. Of course, in a real-world network that is already built, it may not be possible to code all measures of inherent resilience. However, there is still much merit to quantify the effectiveness of inherent resilience measures that can be coded in the network. This chapter reports research in inherent resilience at the network level.

\subsection{TEST NETWORK}

The study area is part of the Ottawa Central Business District (CBD), measuring $1.1 \mathrm{~km}$ by $1.725 \mathrm{~km}$. See Figure 6.2 below. It consists of 23 intersections and 96 links. The intersections are between $65 \mathrm{~m}$ up to $625 \mathrm{~m}$ apart. The posted speed limit is $50 \mathrm{~km} / \mathrm{h}$. 
Details of characterizing speed distribution and vehicle composition are described in previous sections of this document. A disruptive event that resulted in the closure of the Chaudière bridge was assumed. Despite bridge closure, the Ottawa-hull area is considered connected through an alternate route. In this illustration, the connectedness is established through a secondary bridge - Portage bridge.

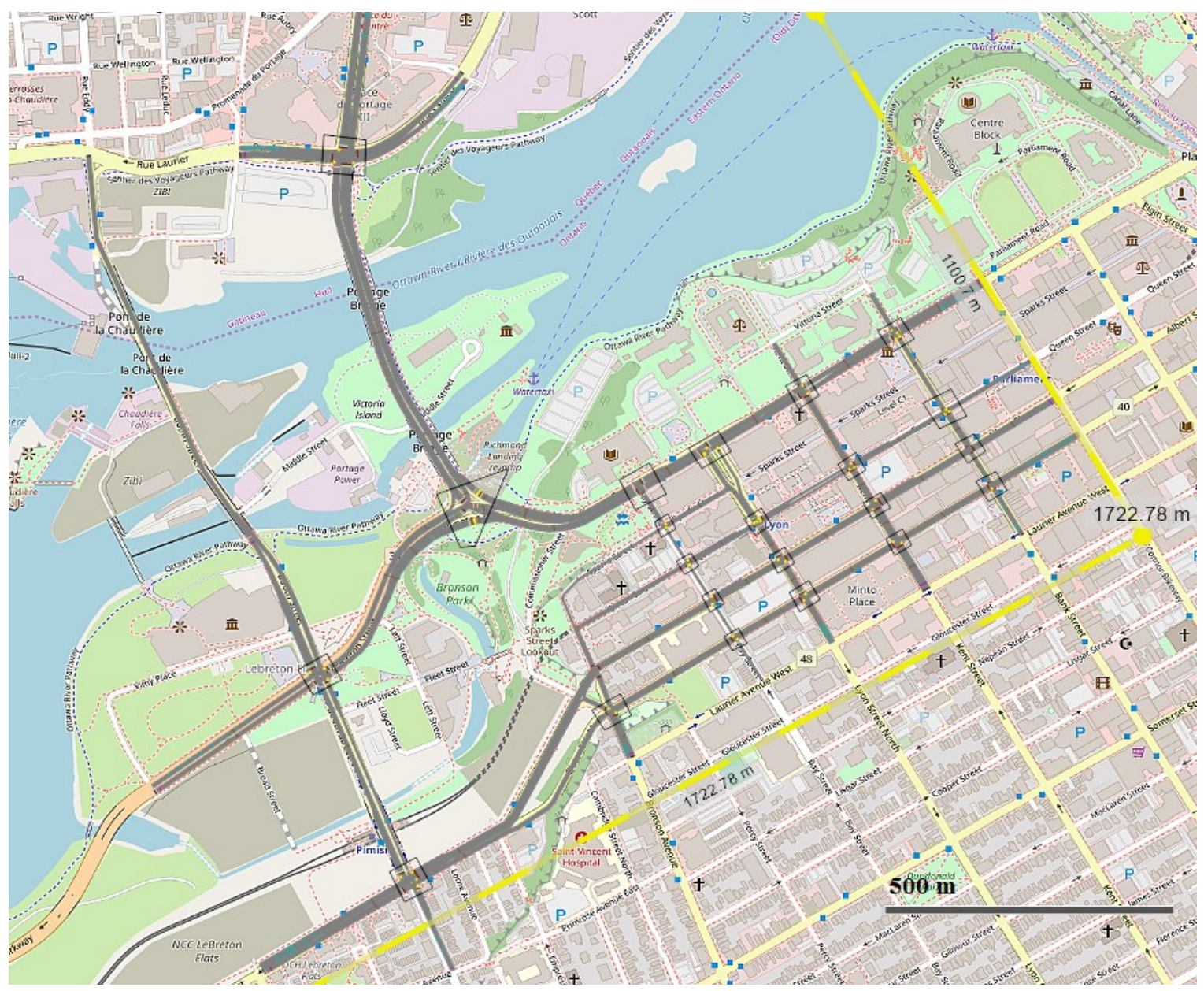

Figure 6.1: Ottawa-Gatineau Case Study Area

\subsection{METHODOLOGICAL FRAMEWORK FOR ASSESSING NETWORK RESILIENCE UNDER DISRUPTION}

The methodological framework for assessing the network resilience under disruption is presented in Figure 6.2. The offline optimization-simulation approach is selected for the investigation of means to enhance inherent resilience. The inherent 
resilience options to be tested include adding a left-turn bay, adding a right-turn bay, and optimization of traffic signal control. The model was run on 15 minutes of time-sliced data. The methodological framework for inherent resilience optimization and analysis is shown in Figure 6.3 below.

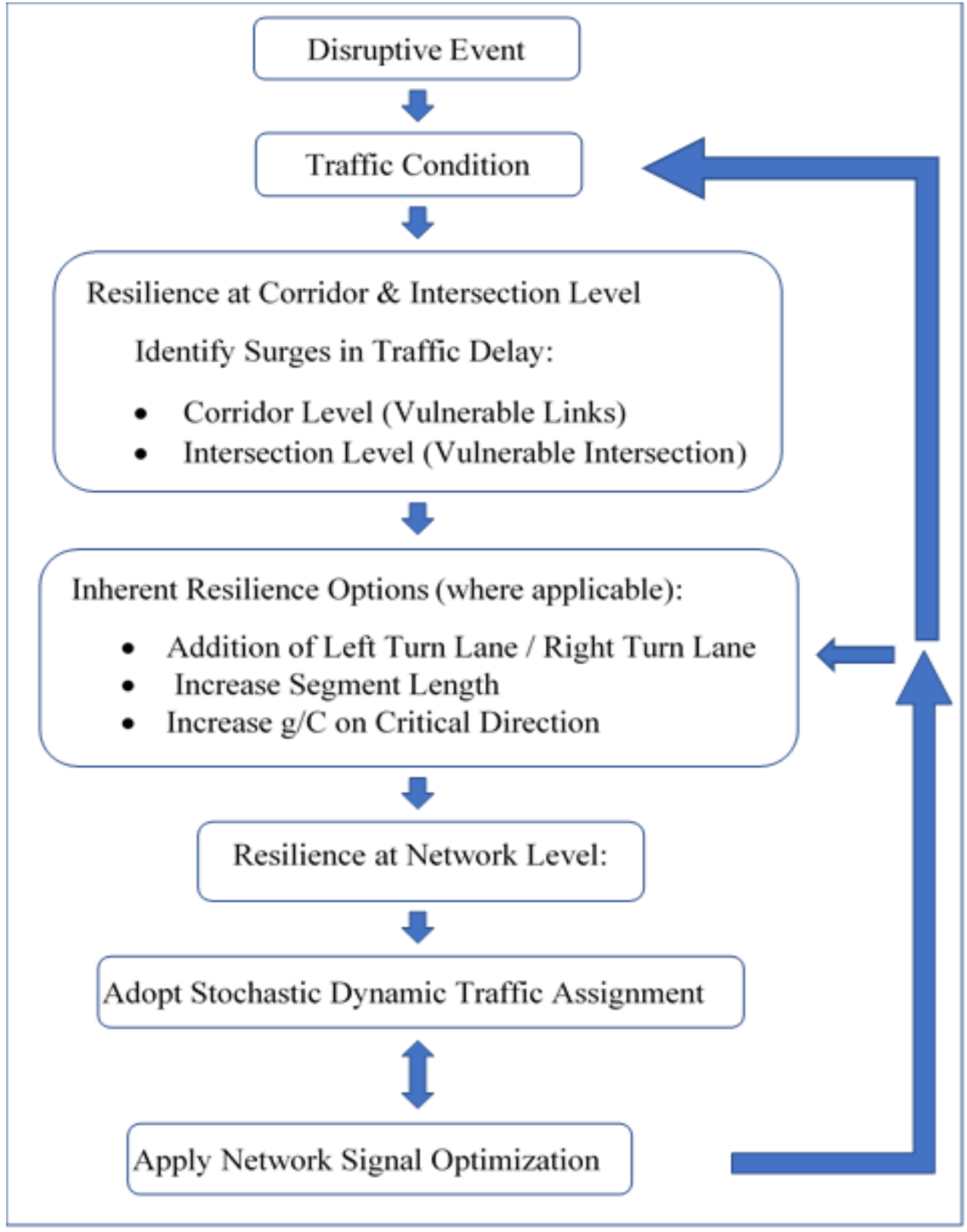

Figure 6.2: Methodological Framework for Assessing Network Resilience 


\subsection{METHODOLOGY FOR ASSESSING BEFORE \& AFTER INHERENT RESILIENCE APPLICATION}

The methodology for inherent resilience optimization and analysis is shown in Figure 6.3. The components of the methodology include characterizing the case study area, scenario definitions, simulation with PTV Vissim, analysis, and compilation of results. The goal is to enhance the network ability to resist loss of traffic serving capability owed to geometric design and control system design.

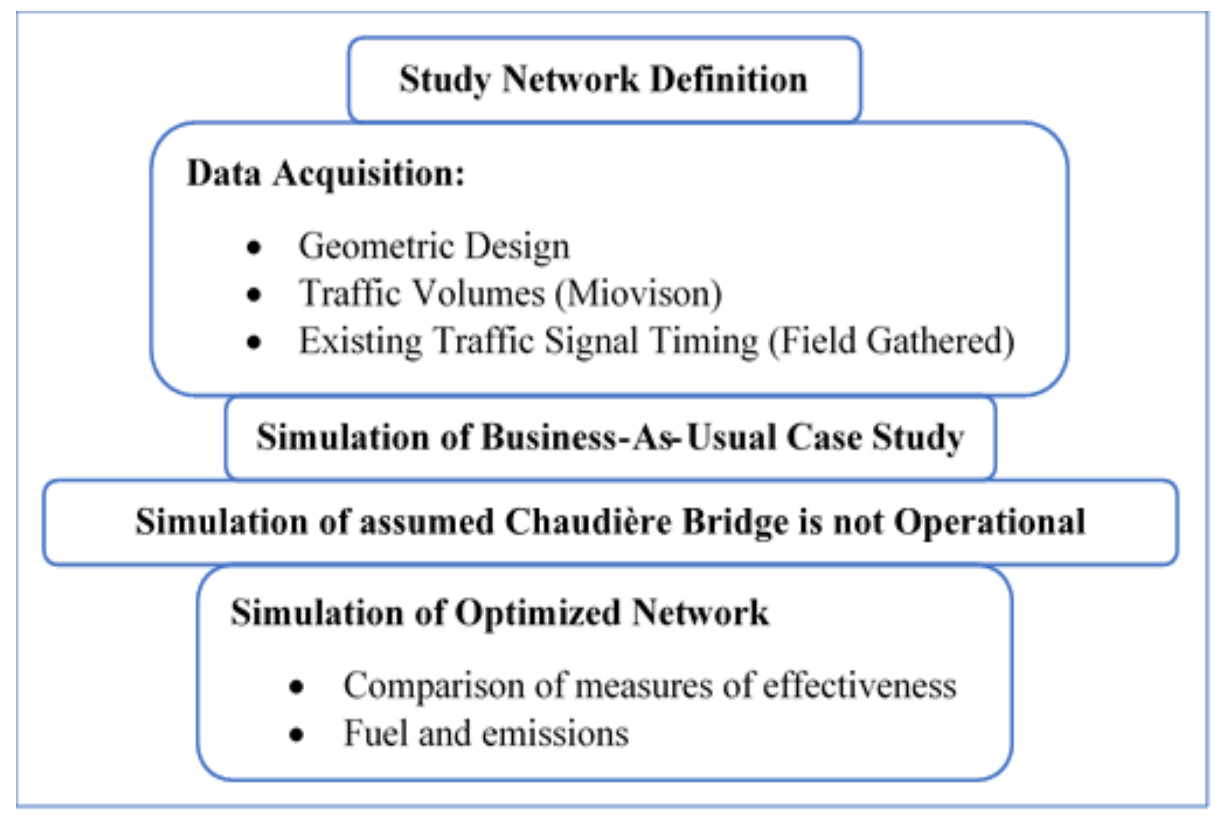

Figure 6.3: Inherent Resilience Methodology

Three networks were designed and analyzed for assessing before, during, and after a disruption event. Case 1 represents the study area under regular operation and is called the Business-As-Usual case study. Case 2 represents the Do-Nothing scenario when a catastrophic failure impacts the major bridge - Chaudière Bridge. On the other hand, in case 3, profoundly impacted corridors and intersections are identified, and inherent resilience options are implemented to reduce the total impact on the network. For cases 2 and 3 network traffic flow and condition is a result of route choices that 
travellers make. Thus, UE traffic assignment is used to redistribute traffic under the disrupted condition to quantify the added benefits of inherent resilience options. Travellers are assumed to have full knowledge of the network condition. For further information about UE traffic assignment refer to section 7.3.

\subsection{SCENARIO DEFINITIONS AND ANALYSIS}

The scenarios for network level test of inherent resilience were defined as noted next:

- Traffic volumes on corridors were gathered for the Ottawa region from Miovison Traffic Data Online Portal.

- Origin-Destination values were manually calculated from traffic counts on each segment.

- Case 2 and 3 traffic routing and O-D data were based on the PTV-Visum user equilibrium traffic assignment.

- A 15-minute time period was used in the simulation.

- Each simulation was carried 30 times, and average values were used for analysis.

The first step of the study was to test the base-case option (considered as the Business-As-Usual option). That is, it involved using traffic counts obtained from Miovison and traffic signals data measured in the field during the PM peak period. The evaluation was undertaken using PTV-Vissim. Appendix A contains traffic signal control programs for both case 1 , case 2 , and case 3 .

Case 2 represents an assumed condition where Chaudière Bridge is closed for traffic. Closure of Chaudière took place during 2019 spring floods due to the high 
Ottawa river water level. The signal control program remained unchanged from case 1. In the analysis of traffic changes, the following were undertaken:

- Traffic movement was monitored, and traffic congestion areas were identified.

- During Case 2, traffic congestion areas were identified, as shown in Figure 6.4 and described below:

- Booth St / Albert St intersection had an increased delay due to queue spill back from vehicles turning right on Wellington St at Booth St./ Wellington St. Intersection.

- Increased intersection delays on Wellington St/ Portage Bridge, Wellington St/Bay St. and Wellington Booth St. all intersection were on one route.

- High right turning movement on Slater coming from Bronson St.

- Only areas of higher delay surges were tested for improvement in this study. These areas are: Booth St./ Wellington St. Intersection, Wellington St./ Portage Bridge intersection, Wellington St/Bay St. intersection, and Slater St. /Bronson St. intersection.

- For the intersections Booth St./ Wellington St. and Slater St. /Bronson St. higher right turning movement caused queue spillback. Exclusive right turn lane was added to ease the congestion.

- Due to the disruption of the Chaudière bridge, more traffic is observed to be heading southbound on Portage Bridge toward Lyon St. To prevent traffic spillback, the capacity equation shown in Section 5.4, was used to calculate the intersection capacity and required $\mathrm{g} / \mathrm{C}$ to increase traffic flow through Portage Bridge southbound direction and passing through Willington St. and Lyon St. intersection. See Table 6-2.

- Case 3 was constructed using the above measures to illustrate the benefits of inherent resilience options. Further improvements can be carried out to reach full network optimization. Inherent resilience options implemented resulted in improved traffic flow over the test network.

- Average intersection delays are presented in Figure 6.5. 
- Snapshots of intersections taken after 2 hours of the simulation are presented in Figure 6.6 to 6.9 .

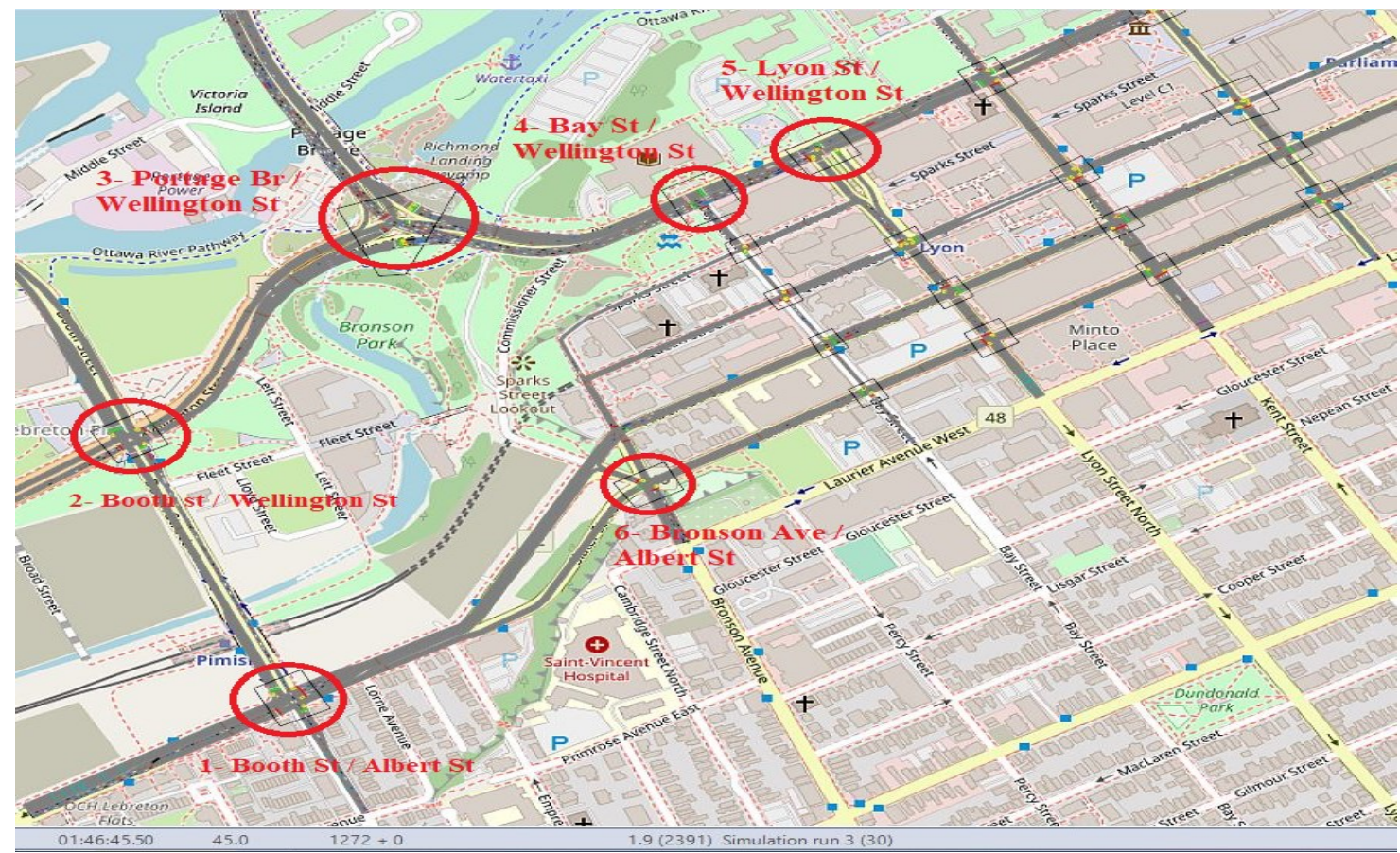

Figure 6.4: Highly Impacted Intersection Due to Disruption

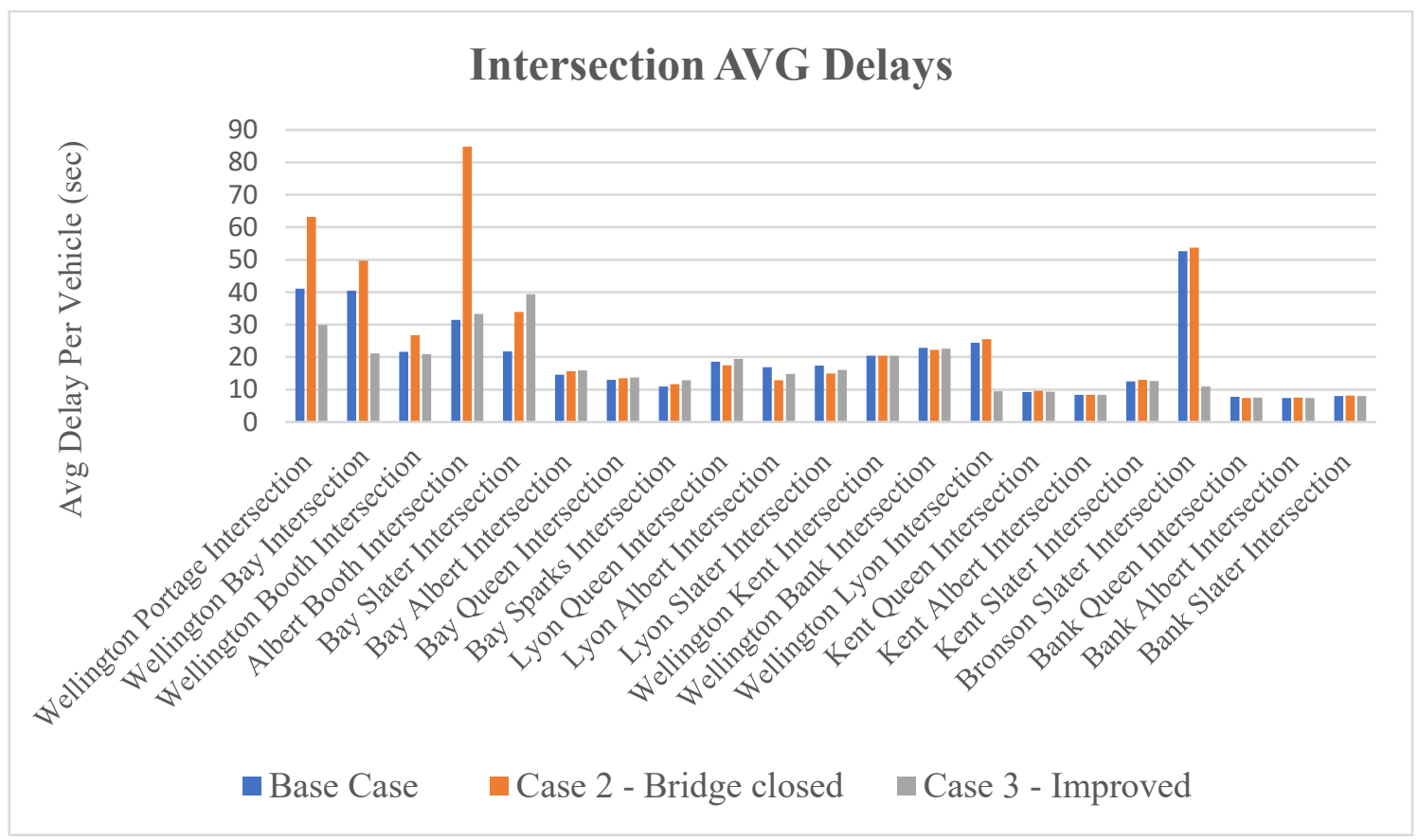

Figure 6.5: Intersection Delays Results 


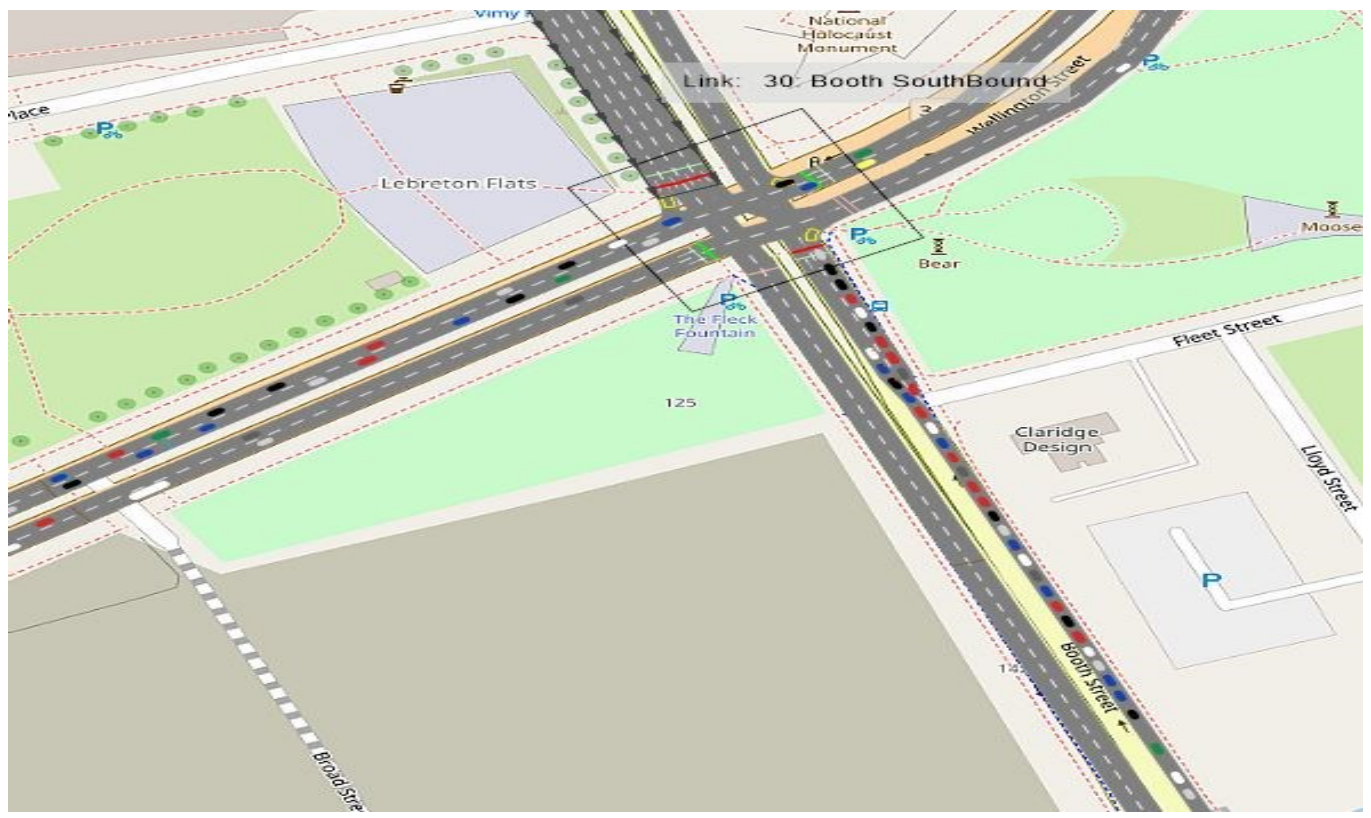

Figure 6.6: Booth St./ Wellington St. Intersection During Disruption - Case 2

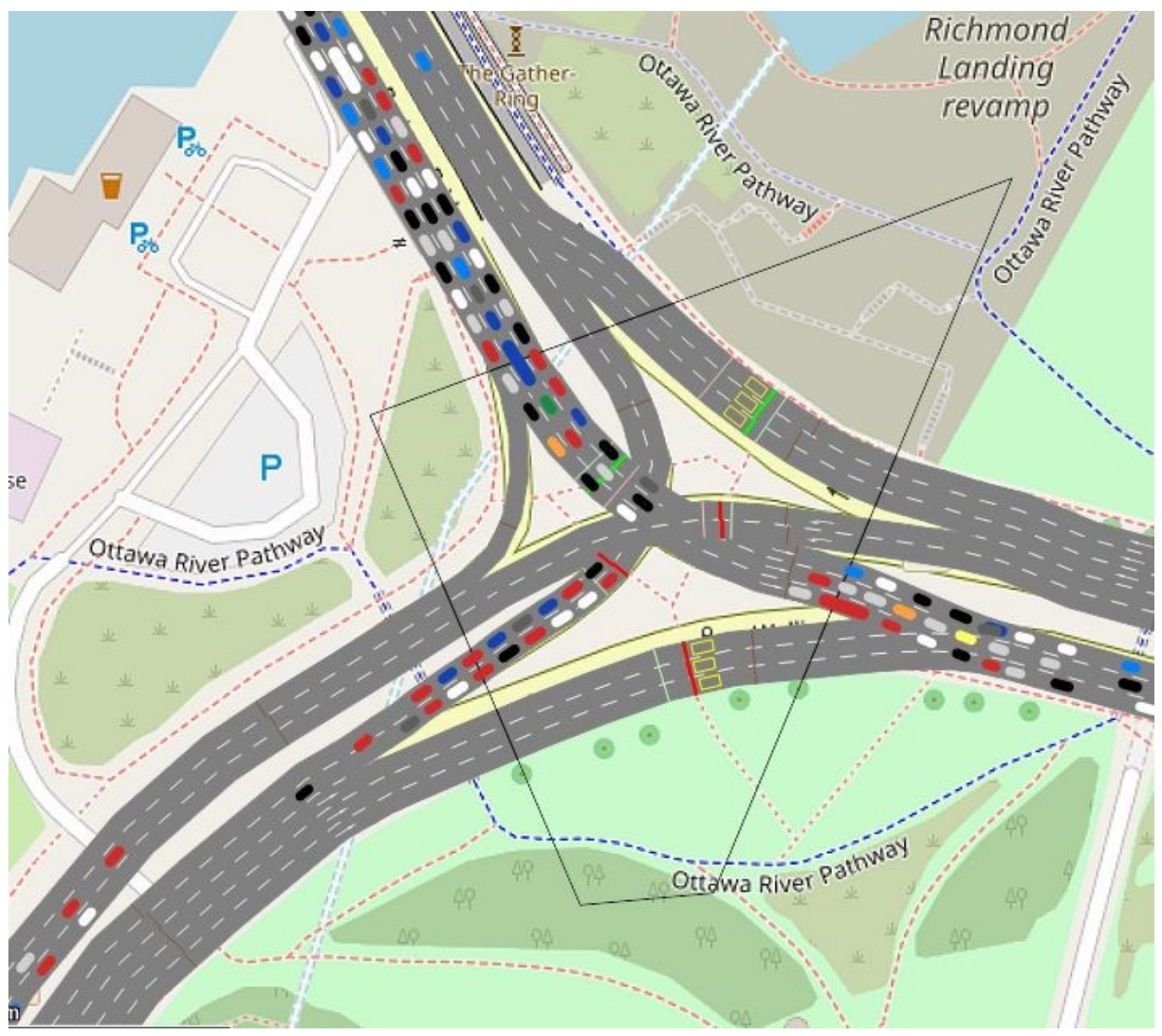

Figure 6.7: Wellington St./Portage Br. Intersection During Disruption - Case 2 


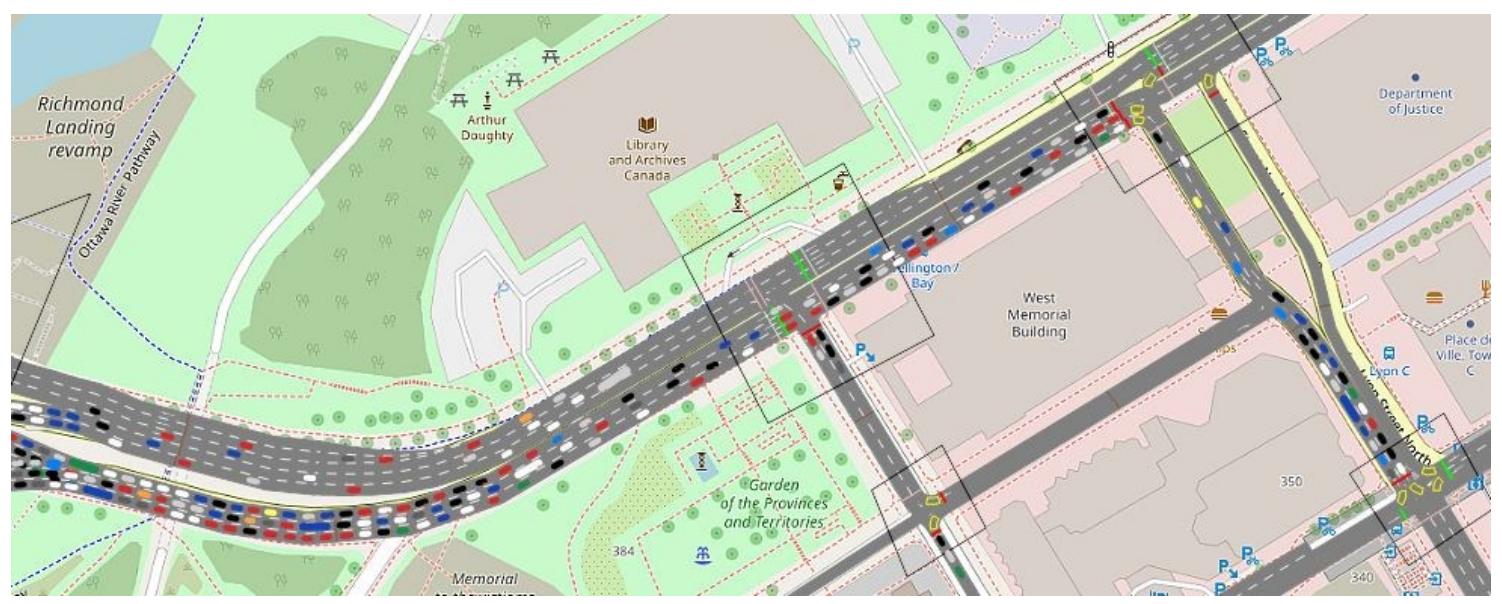

Figure 6.8: Wellington St. / Bay St. and Lyon St. Intersections During Disruption - Case 2

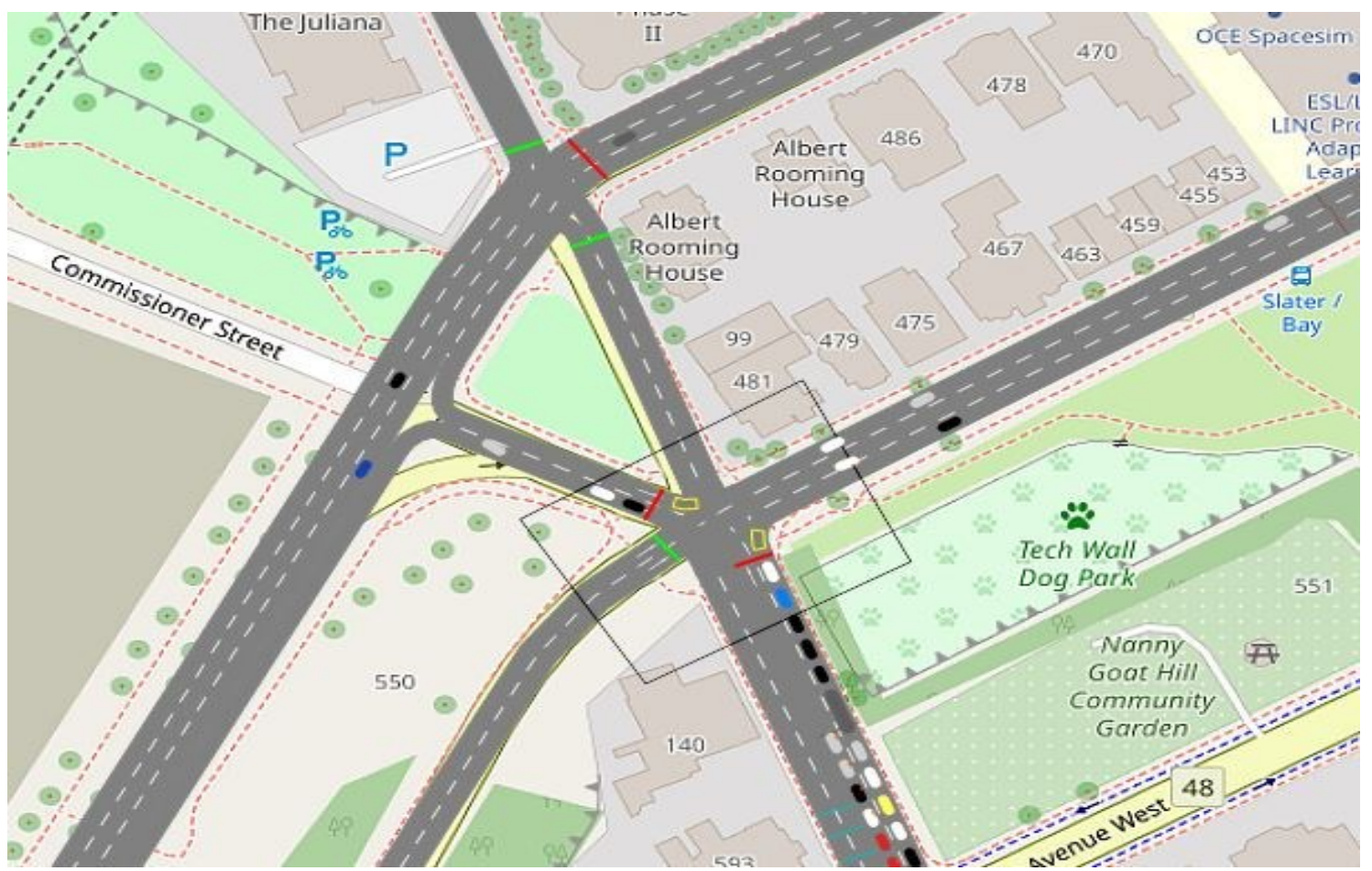

Figure 6.9: Bronson Ave./ Slater St. Intersection During Disruption - Case 2

Case 3 represents an enhanced version of Case 2, where inherent resilience measures were implemented. The following steps were undertaken in this test case.

- Congestion areas were identified from Case 2 simulation runs. 
- Surges in average vehicle delay at the corridor level were identified and traced to bottleneck areas.

- The specific bottlenecks for congestion areas were then identified. Four bottlenecks identified were: 1- right turning movement from Booth $\mathrm{St}$ Northbound; 2- right turning movement from Bronson St Northbound, 3Through movement on Wellington St Eastbound intersecting with Lyon St. 4Portage Bridge southbound to Wellington St.

Further actions taken in testing Case 3 are as follows. Table 6-1 below shows the inherent resilience measures implemented. Intersection hourly volumes for the study time are graphically represented in Figure 6.10. Capacity equation (noted in Section 5.4) was used to calculate $\mathrm{g} / \mathrm{C}$ required to allow for hourly flow to pass the intersection. See Table 6-2. The use of adaptive control accounts for increased traffic demand, at the same time, continous distribution of green time should be equitable for all traffic movements through the intersection. Adaptive control uses real time data to adjest traffic flow in order to maximize the capacity of the intersection.

Table 6-1: Inherent resilience measures implemented

\begin{tabular}{|l|l|}
\multicolumn{1}{c}{ Intersection } & \multicolumn{1}{c|}{ Inherent Resilience Option } \\
\hline Wellington Portage Intersection & Increased g/C Southbound Direction \\
\hline Wellington Bay Intersection & Traffic Control Improved \\
\hline Wellington Booth Intersection & Addition of RTB \\
\hline Wellington Lyon Intersection & Increased g/C Eastbound Direction \\
\hline Bronson Slater Intersection & Addition of RTB \\
\hline
\end{tabular}




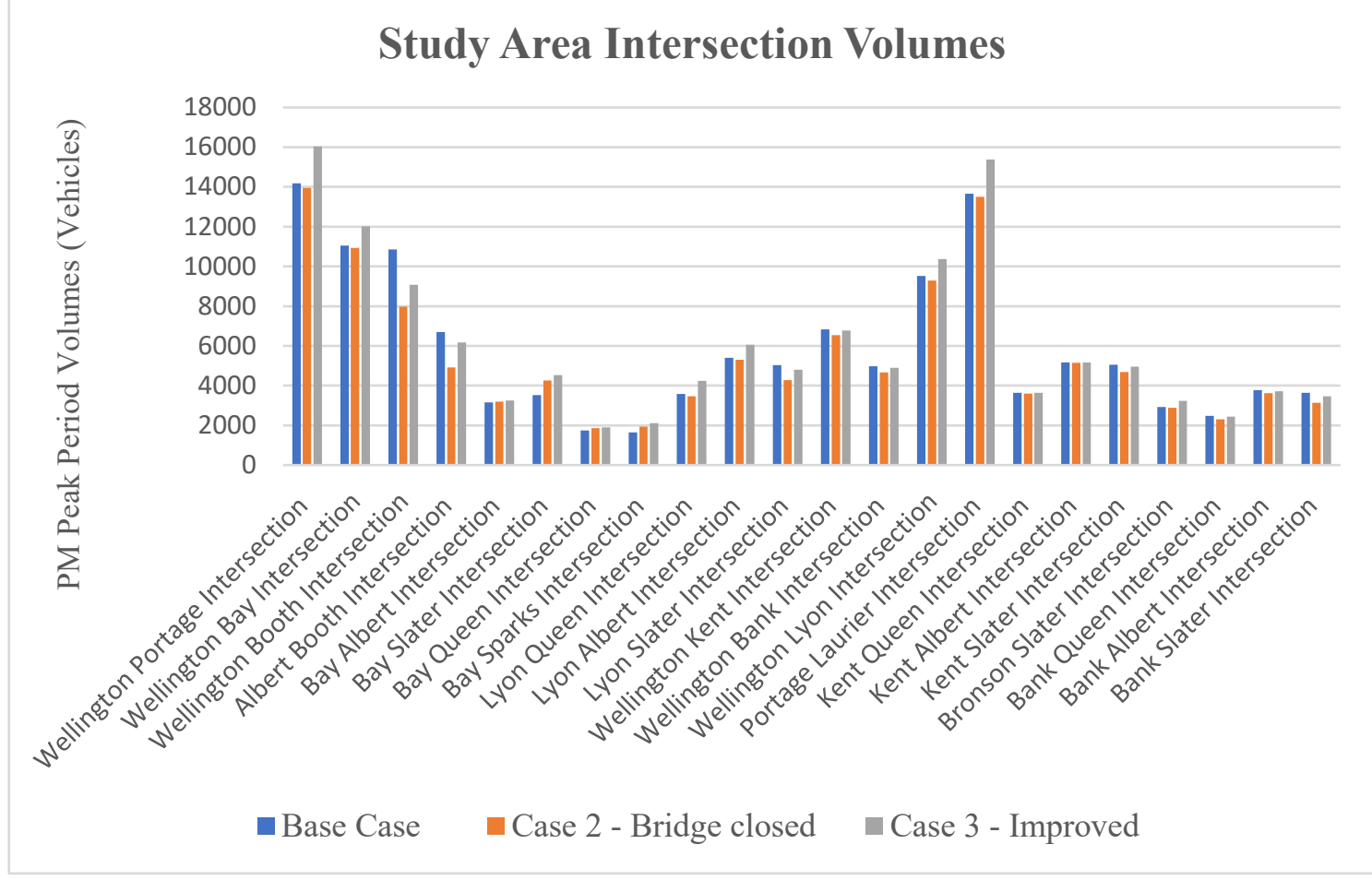

Figure 6.10: Study Area Intersections Volumes

Table 6-2: Study Area Calculated g/C Table

\begin{tabular}{|l|l|l|c|c|c|c|}
\hline \# & Link & $\begin{array}{l}\text { Number of } \\
\text { Lanes }\end{array}$ & $\begin{array}{c}\text { Hourly } \\
\text { Flow } \\
\text { (Veh) }\end{array}$ & $\begin{array}{c}\text { Current } \\
\text { g/C }\end{array}$ & $\begin{array}{c}\text { calculated } \\
\text { g/C }\end{array}$ & $\begin{array}{c}\text { Updated } \\
\text { g/C }\end{array}$ \\
\hline 1 & Portage Southbound & 3 Through Lanes & 1822 & 0.28 & 0.32 & 0.32 \\
\hline & $\begin{array}{l}\text { Wellington St EastBound } \\
\text { Right }\end{array}$ & 3 Through lanes & 744 & 0.63 & 0.10 & 0.60 \\
\hline $\begin{array}{l}\text { Wellington St EastBound } \\
\text { Left }\end{array}$ & 2 Through Lanes & 1364 & 0.30 & 0.35 & 0.30 \\
\hline $\begin{array}{l}\text { Wellington St Westbound } \\
\text { Right }\end{array}$ & 3 Through lanes & 1224 & 0.62 & 0.19 & 0.60 \\
\hline $\begin{array}{l}\text { Wellington St Westbound } \\
\text { Left }\end{array}$ & 2 Through Lanes & 1284 & 0.29 & 0.32 & 0.283 \\
\hline 2 & $\begin{array}{l}\text { Wellington St East Bound } \\
\text { Intersecting with Bay St }\end{array}$ & 3 Through Lanes & 1868 & 0.63 & 0.31 & 0.63 \\
\hline $\begin{array}{l}\text { Wellington St WestBound } \\
\text { Intersecting with Bay St }\end{array}$ & 3 Through Lanes & 1840 & 0.63 & 0.31 & 0.63 \\
\hline & Bay St Northbound & 2 Through Lanes & 644 & 0.28 & 0.14 & 0.28 \\
\hline 3 & $\begin{array}{l}\text { Wellington St East Bound } \\
\text { Intersecting with Lyon St }\end{array}$ & $\begin{array}{l}\text { 2 Thr. + 1 Left } \\
\text { Bay }\end{array}$ & 2649 & 0.50 & 0.69 & 0.70 \\
\hline & $\begin{array}{l}\text { Wellington St WestBound } \\
\text { Intersecting with Lyon St }\end{array}$ & $\begin{array}{l}\text { 2 Thr. + 1 Right } \\
\text { Bay }\end{array}$ & 1864 & 0.90 & 0.47 & 0.90 \\
\hline & Lyon Northbound & 300 & 0.21 & 0.09 & 0.15 \\
\hline
\end{tabular}


Emissions data are recorded in Table 6-3 below. Vissim uses standard formulas to calculate emissions for fuel consumption values of vehicles based on TRANSYT 7-F (University of Florida Transportation Institute, n.d.), as well as data on emissions sourced from the Oak Ridge National Laboratory of the U.S. Department of Energy (“Oak Ridge National Laboratory," n.d.). The data refer to a typical North American vehicle fleet and do not differentiate between individual vehicle types.

Table 6-3: Study Time Total Emissions

\begin{tabular}{|r|l|l|l|l|l|}
\hline & & \multicolumn{3}{|l|}{ Study Time Total Emissions } \\
\cline { 3 - 7 } \# & Study Scenario & $\begin{array}{l}\text { Carbon } \\
\text { Monoxide } \\
\text { (kilograms) }\end{array}$ & $\begin{array}{l}\text { Nitrogen } \\
\text { Oxides } \\
\text { (kilograms) }\end{array}$ & $\begin{array}{l}\text { VOC } \\
\text { (kilograms) }\end{array}$ & $\begin{array}{l}\text { Fuel } \\
\text { Consumption } \\
\text { (US liquid } \\
\text { gallon) }\end{array}$ \\
\hline 1 & Base Case & 30.6 & 5.9 & 7.1 & 438 \\
\hline 2 & Case 2 - Bridge closed & 41.6 & 8.1 & 9.6 & 596 \\
\hline 3 & Case 3 - Optimized & 23.8 & 4.6 & 5.5 & 341 \\
\hline
\end{tabular}

\subsection{EFFECTIVENESS OF RESULTS}

(1) Total average vehicles delay after applying inherent resilience measures improved by $15 \%$ as compared to Case 1 (base case).

(2) Average intersections queue length is graphically presented in Figure 6.11. These show reduction in queue length due to application of inherent resilience measures.

(3) Table 6-3 shows that inherent resilience reduced fuel consumption and emissions.

(4) Results presented in Table 6-4 show that in Case 3 as compared to base case, improvements occurred in throughput, average queue length, and average delay. These enhancements are attributable to inherent resilience. 


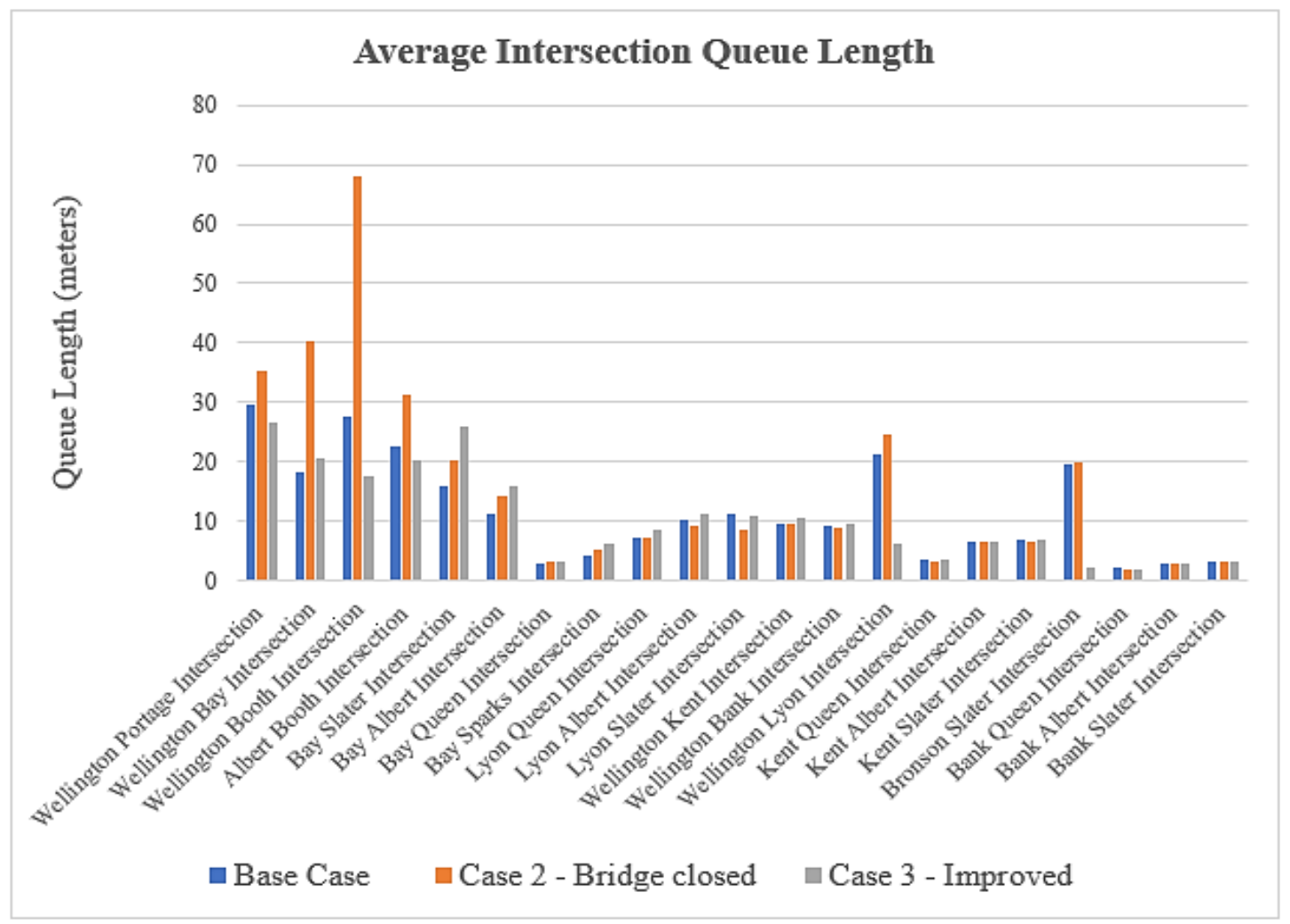

Figure 6.11: Average Intersection Queue Length Base on Vissim Simulation

Table 6-4: Total volumes, Total Average Queue Lengths, and Total Average Delay for the Study Period

\begin{tabular}{|r|l|l|l|l|}
\hline$\#$ & Study Scenario & $\begin{array}{l}\text { Total Volumes } \\
\text { across Intersections } \\
\text { during Study period } \\
\text { (Vehicles) }\end{array}$ & $\begin{array}{l}\text { Summed } \\
\text { Average Queue } \\
\text { length for all } \\
\text { intersections (m) }\end{array}$ & $\begin{array}{l}\text { Total Avg. } \\
\text { Vehicle Delay } \\
\text { (seconds) }\end{array}$ \\
\hline 1 & Base Case & 45952 & 245.58 & 421 \\
\hline 2 & Case 2 - Bridge closed & 43172 & 330.41 & 521 \\
\hline 3 & Case 3 - Optimized & 47516 & 221.38 & 354 \\
\hline
\end{tabular}

\subsection{LIMITATIONS}

(1) Microsimulation requires a lot of information to truly be reflective of real world traffic conditions. In this research, comparing results with real-world data was out of scope. Even if data can be found after a major disruption, the effect of testing the role of resilience measures cannot be done.

(2) Simulations requires powerful computing ability. In the case of this research, computing ability was limited, which made the simulation time-consuming. 


\section{DYNAMIC RESILIENCE METHODS}

\subsection{METHODS FOR DEVELOPING AND ASSESSING DYNAMIC RESILIENCE ACTIONS}

Dynamic resilience actions can be defined by using three types of tools. The first one is the dynamic stochastic model for network analysis. The second one is a Bayesian decision model for assessing the relative merits of dynamic resilience actions. The third tool produces information for the implementation of dynamic resilience action via traffic control.

The first method (dynamic stochastic model for network analysis) has the following network analysis capabilities:

(1) Ability to work with short time slices - to approach almost real time traffic management,

(2) Searching for alternative routes so as to avoid overloads on some links/corridors and utilized available capacity on other links/corridors,

(3) Assigning traffic to multiple paths and routes in order to reduce delay,

(4) Treating the stochastic nature of traffic throughout a network,

(5) Ability to produce total delay to traffic during selected time durations.

The second method (Bayesian decision model for assessing the relative merits of dynamic resilience actions) is required to produce decision-making guides for traffic control and management personnel for the implementation of selected dynamic resilience action. This decision aid should have the following capabilities: 
(1) Treat the total delay result obtained from the dynamic network analysis model as uncertain and apply Bayesian probability models to identify the preferred dynamic resilience action,

(2) Capability to update probabilities by using new information as it becomes available,

(3) Selection of preferred dynamic resilience actions should be based on the criterion of minimization of delay.

The third method is intended to link dynamic resilience action with a traffic control model so that the resilience enhancing action can be implemented.

The following sections (7.2 to 7.4$)$ cover the above noted methods.

\subsection{DYNAMIC NETWORK ANALYSIS}

Over the years, progress has occurred in traffic network analysis models and software has become available for implementing models. This research calls for identifying if dynamic network analysis is warranted or if the frequently used user equilibrium method will produce the information required for developing dynamic resilience actions. Since the dynamic network analysis implemented by a dynamic assignment model is relatively new, as compared to user equilibrium model, the dynamic assignment is described below.

Dynamic traffic assignment models distribute demand per time interval. Dynamic assignment can also use time-varying attribute at each time interval - e.g., 15 minutes - to load the network according to travel time in an unloaded link, travel time in a loaded link, volume / capacity ratio per time interval, and capacity. It is important to note how users perceive their route choices. A high percentage of travellers, whether 
they rely on following GPS travel routes or individual travel decision to get to their destination, tend to follow the shortest path or shortest-time path.

A research article titled "Do People Use the Shortest Path? An Empirical Test of Wardrop's First Principle" (Zhu and Levinson, 2015) captured the actual routes travellers followed during eight-week study period using GPS data/detailed GIS roadmap, which was then compared to the shortest time path predicted by the model. The trips were divided into commute and non-commute trips. Interestingly, the study research found that almost $40 \%$ of all trips follow the shortest time path; "About $55 \%$ of non-commute and $30 \%$ of commute trips follow a route that is almost as good as the shortest time path (less than 5\% longer in time). Although about $80 \%$ of non-commute trips and $70 \%$ of commute trips follow a route that has a travel time less than $20 \%$ higher than the shortest time path, the number of trips that follow a much longer route is still significant." (Zhu and Levinson, 2015) see Figure 7.1 below.

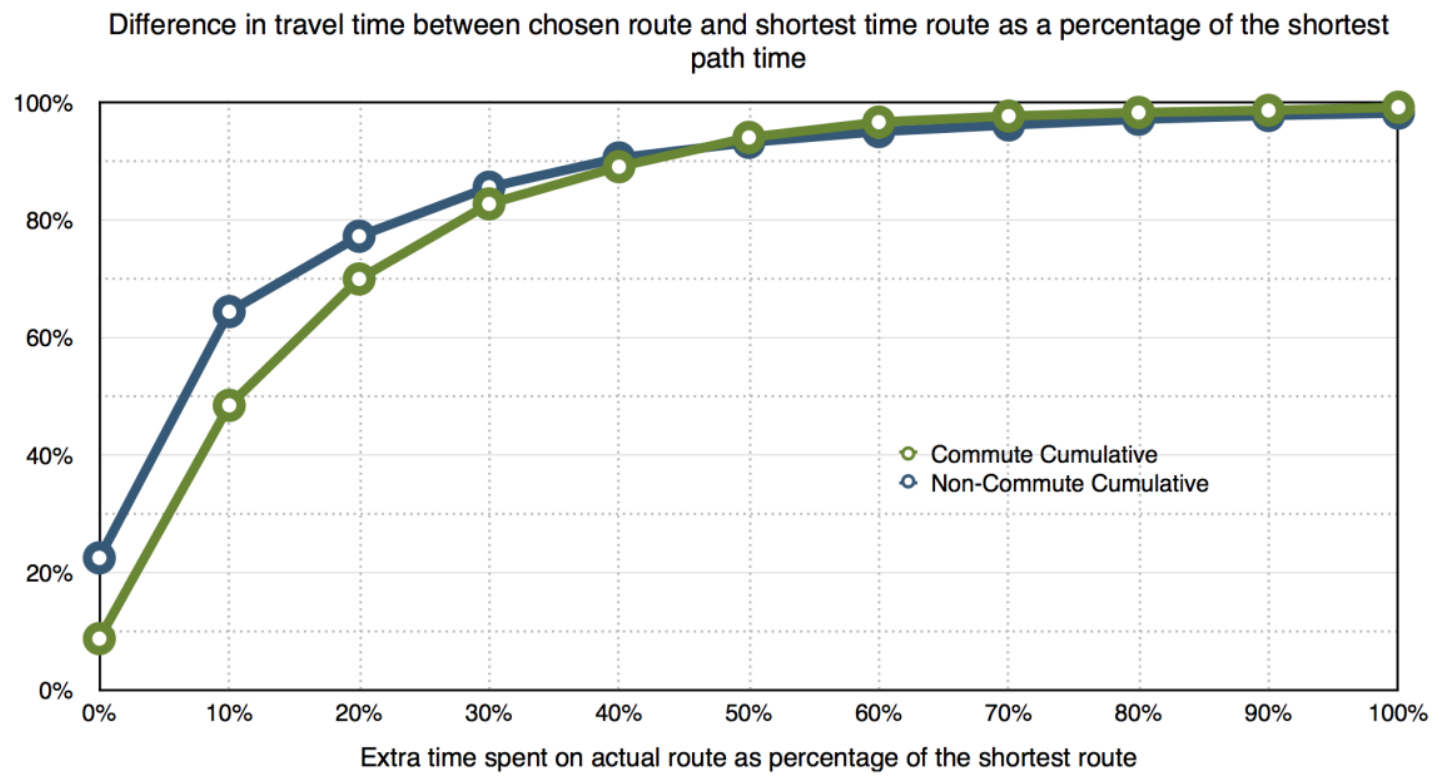

Figure 7.1: Difference in Travel Time Between Chosen Route and Shortest Time Route (Zhu and Levinson, 2015). 
A high percentage of commuters use the same route almost every day to get from origin to destination. Travellers use their intellect to decide which route to take and which route would save them some time. However, as travel conditions change commuters' route would stay the same, and that is because travellers have a limited amount of information on the route ahead. This research aims to facilitate information exchange to travelers.

We can create a sound argument built on current transportation infrastructures available, reliable prediction of link flow, travellers behaviour, and travel times of different route alternatives. Knowledge about travel conditions ahead and travel times ahead of the travellers could lead to heterogeneity in route choices. Travellers differ in attributes such as, the value of time, the value of budget or willingness to pay more for a longer route which is shorter in time, willingness to try a new route with potential saving - whether saving time or money. To create fully dynamic resilient system, road users should have access to the maximum amount of information about the route choices. To overcome limitations, the following could be done:

1- Prepare for an alternative for possible network disturbance or disasters (covered in this research).

2- Prediction of route alternative travel-time and volume (covered in this research).

3- Continuous collection of road users' data and location.

4- Create a connected navigation system, which updates the road users' location and volumes based on real time.

5- Develop turn-by-turn guidance based on "shortest travel time - and not shortest travel distance" to guide road users to best route alternative systematically. 


\subsection{MODELING OF USER EQUILIBRIUM TRAFFIC ASSIGNMENT VS DYNAMIC STOCHASTIC TRAFFIC ASSIGNMENT}

User equilibrium assignment models the driver's increasing knowledge of journey with each iteration. The demand is distributed according to Wardrop's first principle, which is based on an equal cost of travel routes for all drivers. The driver cannot save on travel cost by taking another route. Equilibrium equations set every road user in such a way that the impedance/travel cost on all alternative routes are the same. The static assignment of equilibrium has an overload effect in the network, and it assumes homogeneous travellers and their knowledge of travel time on all routes. The overload effect happens when volume over capacity ratio becomes greater than one, which means that traffic needs more time to discharge than the anticipated study period.

The goal of traffic modelling is to determine the network traffic flow and conditions which result from the route choices that travellers make. In practice, travellers try to choose the least travel time route between their O-D. Overtime every traveller succeeds in finding the route, and every used route has the minimum impedance or travel cost for each O-D pair. This condition is known as user equilibrium. According to the technical transportation board report (Technical Activities Division et al., 2011) the concept of equilibrium is useful for several reasons. First, it is a reasonable approximation of traveller choice. Second, it assumes that travellers have discovered the shortest routes for their trips. Third, technological advances in the Advanced Traveller Information Systems (ATIS) and other ITS technologies make travellers more aware of network conditions. Finally, the equilibrium principle makes available methods for evaluating potential benefits that accrue to travellers following a change in travel 
conditions due to the implementation of certain transportation projects or policies. "Thus, when comparative analysis is required, these features have made equilibriumbased traffic modelling the predominant approach used in practice to date." (Technical Activities Division et al., 2011)

The dynamic stochastic assignment is a transportation model implemented in PTV-Visum. Figure 7.2 represent the dynamic stochastic traffic assignment procedure used in PTV-Visum. It provides calculated results of impedance or volume and their traversed network objects (links and turns) for each time interval. The assignment period $\mathrm{T}$ (e.g., 1 hour) is then divided into time slices $\mathrm{Ti}(5 \mathrm{~min}$ each). The procedure initially calculates the route impedance in an unloaded state. Internal iterations search for alternative routes, volume, and capacity for each network element are stored for every time slice. Internal iteration assigns traffic to routs with each iteration. The progress time of the trip through the network is decremented along with the route. The system chooses different routes based on time-dependent traffic flow parameters.

The dynamic stochastic assignment takes into consideration the dynamic behaviour of traffic entering and exiting a link. It predicts the volume and travel time across the network without overloading each link. Traffic movement is dynamic by nature and for this reason, using a dynamic traffic assignment model is more accurate to predict route choices and volumes of a transportation network better.

\subsection{DYNAMIC STOCHASTIC ASSIGNMENT MODEL PROCEDURE}

The dynamic stochastic assignment model is introduced in the form of its theoretical foundation, supplemented by a detailed description based on Visum 18 User manual (PTV AG, 2019). It uses time varying attributes. These attributes include: speed, 
capacity, and travel time. The assignment period is divided into individual time slices, with volume and impedance separated for each time slice. For each departure time interval, the demand is distributed across the available connections (= route + departure time) based on an assignment model as in the case of the stochastic assignment. With this modeling approach, temporary overload conditions in the network are displayed, a varying choice of routes results in the course of the day, and possibly also a shift of departure time with respect to the desired time.

Assignment procedures are based on a short-route algorithm that determines low impedance routes. Travel times are determined by the saturation of links and turns which result from the traffic volume and the capacity of these network objects. For free traffic flow, the travel time $t_{0}$ of a link can be determined from the link length and the free-flow speed $v_{0}$. For turns at an intersection, the turn time $t_{0}$ is specified directly. In loaded networks, the link travel time and the turn time is determined by volume-delay function. This capacity restraint function describes the correlation between the current traffic volume $q$ and the capacity $\mathrm{q}_{\mathrm{MAX}}$. The result of the Volume Delay function is the travel time in the loaded network tcur.

$\mathrm{q}$ is the volume of a network object [car units/time interval] $=$ sum of volumes of all transport systems including basic volume (preloaded volume):

$$
q=\sum_{i=1}^{\text {NumTsys }}\left(q i x P C U_{i}\right)+q_{\text {PreloadedVol }}
$$

Where $\mathrm{t}_{0}=$ free flow travel time $[\mathrm{s}]$

$\mathrm{v}_{0}=$ free flow speed $[\mathrm{km} / \mathrm{h}]$

$\mathrm{t}_{\mathrm{cur}}=$ travel time in loaded network $[\mathrm{s}]$

$\mathrm{q}_{\max }=$ capacity [car units/time interval]

$\mathrm{PCU}=$ passenger car units 
Dynamic stochastic assignment procedure is structured as follows: First, a number of alternatives (routes or connections) is determined. Then the total demand per origin-destination pair is distributed across these alternatives.

A distribution model determines the share of demand which is assigned to a certain route. This portion depends on the impedance of a route. In all cases, percentage $P_{i}^{a}$, of route $i$, is determined based on the demand of an OD pair within time interval $a$, so that impedance $R_{i}^{a}$ is applied in a distribution function, allowing the program to calculate utility $U_{i}^{a}$ of the route. For this distribution function the Kirchhoff, Logit, BoxCox, Lohse models and Lohse with variable Beta are available.

1- Impedance $R_{i}^{a}$ is converted to the utility $U_{i}^{a}$ of route $i$ in the time interval $a$

$$
U_{i}^{a}=f\left(R_{i}^{a}\right)
$$

2- From this utility $U_{i}^{a}$ the percentage of demand $P_{i}^{a}$ is calculated (where $n$ is the total number of routes).

$$
P_{i}^{a}=\frac{U_{i}^{a}}{\sum_{j=1}^{n} U_{i}^{a}}
$$

The models reveal differences in the functional relation $f$ of impedance and utility.

3- Distribution models are:

\section{- The Kirchhoff model in the assignment}

The utility is as follows:

where $\beta=4$.

$$
U_{i}^{a}=\left(R_{i}^{a}\right)^{-\beta}
$$


The sum of all routes $j$ is taken and $\beta$ is used as a parameter for modeling the impedance sensitivity. In this distribution method, the ratios of the various impedances are decisive. It does not matter, therefore, whether two routes have impedances of 5 and 10 minutes, for example, or 50 and 100 minutes - the distribution is the same.

\section{- The Logit model in the assignment}

In this model, instead of the ratio between the impedances, their difference is used for the distribution rule. The impedance is additionally divided by a scaling divisor. The utility is as follows:

$$
U_{i}^{a}=e^{-\beta * R_{i}^{a}}
$$

Where $\beta=0.25$.

Parameter $\beta$ describes the sensitivity of passengers towards increased impedances. As in this case the differences rather than the ratios of the impedances are considered, it does not matter whether two routes have impedances of 5 and 10 minutes, for example, or 95 and 100 minutes.

\section{- The Box-Cox model in the assignment}

This distribution model is based on the Box-Cox transformation. For the given $\tau$ $\geq 0$, the Box-Cox transformation is explained as follows:

$$
b^{(\tau)}(x)= \begin{cases}\frac{x^{\tau}-1}{\tau} & \text { if } \tau \neq 0 \\ \log (x) & \text { if } \tau=0\end{cases}
$$

When calculating the utility, $b(t)(\mathrm{R} i a)$ is now included in the Logit model instead of Ria, thus the result is: 


$$
U_{i}^{a}=e^{-\beta * b^{(\tau) *\left(R_{i}^{a}\right)}}
$$

Where $\beta=1$, and $\tau=0.5$

The importance of the Box-Cox model is illustrated by the two special cases below:

○ $\tau=0$ (leads to the Kirchhoff distribution)

○ $\tau=1$ (leads to the Logit distribution)

- The Lohse model in the assignment

$$
U_{i}^{a}=e^{-\left(\beta\left(\frac{R_{i}^{a}}{\operatorname{Rmin}_{i}^{a}}-1\right)\right)^{2}}
$$

Where $\operatorname{Rmin}_{i}^{a}=$ minimum impedance of all connections per OD pair, and $\beta=4$.

In this case, the impedance of a route is related to the minimum impedance, which therefore measures the relative difference from the optimum. Due to this different approach, the Lohse model can be used as an alternative to Kirchhoff and Logit.

Dynamic Stochastic assignment procedures assume that road users in principle select the best route but evaluate the individual routes differently due to incomplete and different information. In addition, in a Dynamic stochastic assignment the demand is distributed to the found routes using a distribution model (e.g. Logit, Kirchhoff, BoxCox, Lohse or Lohse with variable beta).

In order to take the spatial similarities of the routes into account during the distribution, a similarity measure is determined from overlapping routes - it is called the Commonality Factor $(\Rightarrow$ "C-Logit") - or the independence of each route (Ben-Akiva and Bierlaire, 1999) is determined. This results in the following sequence: 
1- Route search for all traffic cells for current impedance.

2- Commonality Factor or independence calculated from overlapping of all routes of an origin/destination pair.

3- Distribution of demand to the routes of each OD pair, taking the Commonality Factor or independence into account.

4- Repeat from step 3 until demand for all OD pairs is in equilibrium.

5- Repeat steps $1-4$ until no new routes are found or until the change in the link volumes between two iteration steps is very small.

During the route search, the number of possible routes can be increased in that it is not just the shortest route that is found, but a number of alternatives are found using a multiple best path search and a variation in the link impedances. The procedure for dynamic stochastic assignment is given in Figure 7.2.

\subsubsection{Similarity of Routes and Commonality Factor}

In the case of the dynamic stochastic assignment, alternative routes are generated - based on another assignment as initial solution - for an OD pair by varying the impedances of the network objects based on a distribution, in order to model the incomplete information supplied to the road-users and their individual differences in terms of perception and preferences. In this way, it is possible to calculate in one step not only the shortest route in terms of impedance, but also alternative routes with higher impedances. After completion of the route search, depending on the route impedance based on an assignment model (Logit, Box-Cox, Kirchhoff, Lohse or Lohse with variable beta), the demand is distributed across the alternatives. The similarity of the routes is to be taken into account during the distribution process. The C-Logit approach proposed by (Cascetta et al., 1996) is a suitable way of overcoming this problem. To do 
this, a so-called commonality factor $C$ is introduced to measure the overlapping of the two routes $r$ and $s$ as follows:

$$
C_{r s}=\frac{t_{0 r s}}{\sqrt{t_{0 r^{*}} t_{0 s}}} \text { or } C_{r s}=\frac{l_{r s}}{\sqrt{l_{r} * l_{s}}}
$$

Where: $C r s=$ Similarity of the routes $r$ and $s$ (Commonality factor)

$t_{\text {ors }}=$ Time $t 0$ of the common sections of the routes $r$ and $s$

$t_{0 r}=$ Time $t 0$ of route $r$

$l_{r s}=$ Length $l$ of the common sections of the routes $r$ and $s$

$l_{r}=$ Length $l$ of route $r$

Thus, $C r s$ equals 1 , if the two routes are identical, and will be 0 , if the two routes do not overlap. The commonality factor Crs is determined for all route combinations. Then, the correction factor $C F r$ of a route $r$ compared to any other route $s$ is defined as follows:

$$
C F_{r}=\frac{1}{\sum_{s} C_{r s}}=\frac{1}{1+\sum_{r \neq s} C_{r s}}
$$

The correction factor of a route $r$ is 1 if the commonality factors Crs for all routes $s$ have the value 0 , i.e. the route has no overlap with another route. In any other case it is below 1 .

Alternatively, the correction factor $C F r$ can be determined with a simpler approach according to Ben Akiva. It is then defined as:

Or

$$
C F_{r}=\sum_{a \in P r}\left(\frac{t_{0 a}}{t_{0 r}} * \frac{1}{N_{i j a}}\right)
$$

Where: $t_{0 a}=$ Time $t 0$ of link $a$

$$
C F_{r}=\sum_{a \in P r}\left(\frac{l_{a}}{l_{r}} * \frac{1}{N_{i j a}}\right)
$$

$t_{0 r}=$ Time $t 0$ of route $r$

$l a=$ Length $l$ of link $a$

$l r=$ Length $l$ of route $r$

$N_{i j a}=$ Number of routes of the OD pair $i j$ that lead across link $a$ 


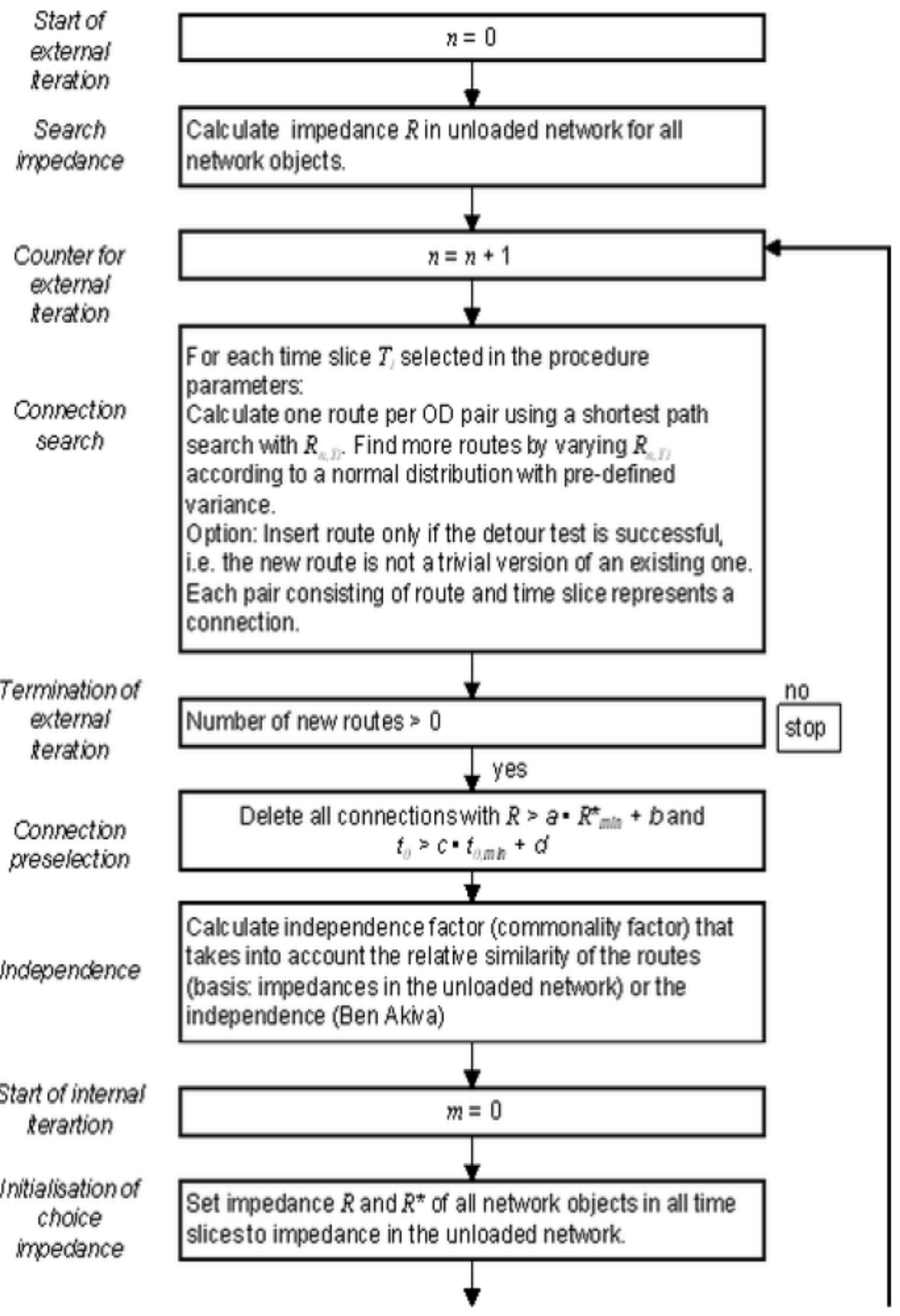


Counter for

internal

keration

Chaice

impedance

Connection

choice

Update search

impedance

Termination

criterion for

interna!

zeration

\section{Termination of \\ extema! \\ keration}

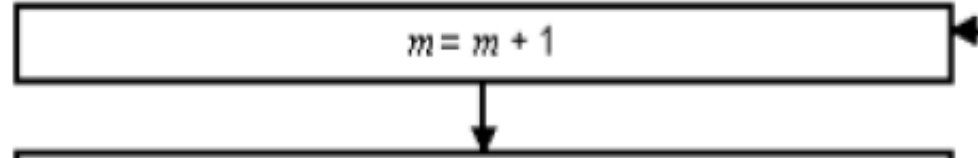

Calculate $R^{*}$ of all connections as total $R^{*}$ for all traversed network objects in each time slice affected. Inc rease impedance using deviation from desired departure time slice and correct using impedance factor.

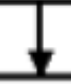

Assignment of demand across connections in acc ordance with Logit, Box-Cox, Kirchhoff, Lohse or Lohse with variable beta results in connection volumes $Q$. *

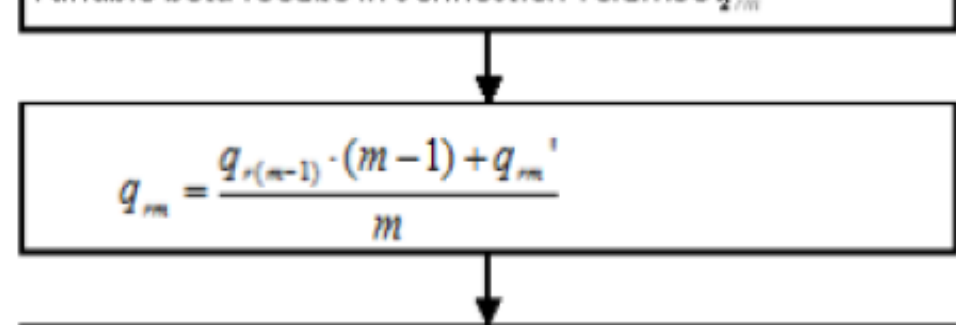

Calculate $R^{*}$ for all network objects in all time slices from the volumes that result from the connection choice. The search impedance is an estimated $R^{*}$ value that is calculated as in the learning procedure:

$$
R_{\text {sew }}^{*}=R_{\text {eid }}^{*}+\Delta \times\left(R_{\text {oew }}-R_{\text {oid }}^{*}\right)
$$

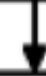

$m=$ max. number of internal iterations or

$$
\left|R_{m}^{*}-R_{m-1}^{*}\right| \leq \min \left(E_{1} \cdot \max \left(R_{m}^{*}, R_{m-1}^{*}\right)+E_{2}, E_{3}\right)
$$

is valid for the impedance of all network elements in all time slices, and

$$
\left|q_{m}-q_{r(m-1)}\right| \leq \min \left(E_{4} \cdot \max \left(q_{m}, q_{r(m-1)}\right)+E_{5}, E_{6}\right)
$$

is valid for the volume of all connections

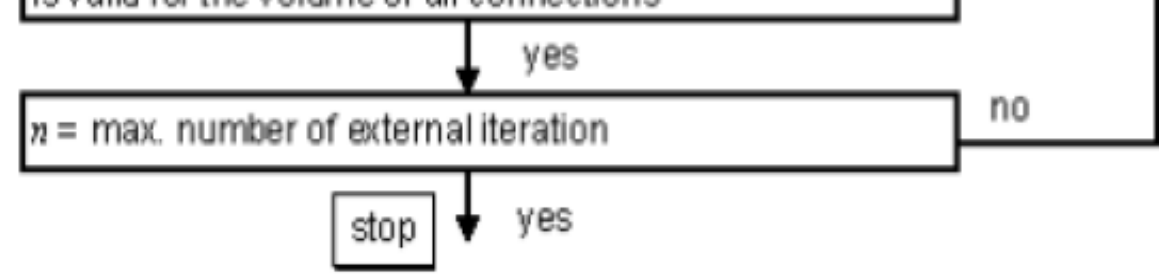

Figure 7.2: The Procedure of Dynamic Stochastic Assignment (PTV AG, 2019) 


\subsection{PROCESS OF CREATING DYNAMIC RESILIENT TRANSPORTATION SYSTEM}

In the process of creating a dynamic transportation system, a macro-simulation model was created using PTV-Visum. PTV-Visum allows for the analysis of traffic distribution over the network. The traffic distribution analysis provides feedback on how road users can use the network to travel between two points. Knowledge of travel times and route alternatives will increase the knowledge of how to guide road users and create a more resilient traffic serving capability. The study of different traffic distribution models will help traffic manager to make better decisions. The two traffic distribution models used for comparison are User Equilibrium, which has been used in research since the 1950s, and dynamic stochastic assignment. The output of this research is to analyze the dynamic resilience features (e.g., routing) which can be analyzed through the dynamic stochastic assignment and eliminate the conservative approach of user equilibrium which leads to overload in some parts of the transportation network.

\subsection{MODEL INPUTS}

The model inputs were data acquired from the City of Ottawa on road capacities, volumes, posted speed limit, and demand distribution (origin-destination matrixes). Satellite images and Google maps were used to obtain accurate information on the infrastructures of the transportation network such as segment length, intersection locations, and intersections type.

\subsubsection{Link Characteristics}

The variables of link characteristics were gathered from the City of Ottawa past survey data. Classification, number of lanes, directional capacity and demand matrix 
input data into PTV-Visum software. The initial step of the test was taken to provide proof of concept of the dynamic resilience. In the initial step, the standard BPR parameters were considered to compare traffic distribution of dynamic stochastic assignment method to the conventional user equilibrium assignment.

\subsubsection{Model Output}

A comparative approach to user equilibrium traffic distribution and dynamic stochastic assignment traffic distribution is to understand the difference between user equilibrium traffic assignment and dynamic stochastic assignment. Application of the proposed methodology will produce results of interest for a follow-up step in research. 


\section{COMPARISON OF SIMULATION RESULTS}

\subsection{INTRODUCTION}

This chapter presents the results of traffic distribution using both Equilibrium Traffic Assignment and Dynamic Stochastic Traffic Assignment. The following chapter will discuss the possible applications of the research toward creating dynamic resilient transportation network. The comparison is based on link volumes, travel times, and distance. A small virtual network was created to help with delivering the concept, and Ottawa-Hull CBD network served this function. It was created to reflect a real-world scenario. Traffic assignment algorithm applications were carried out in Visum. The ultimate purpose was to create a better understanding of traffic assignment over the transportation network and introduce the possible usage of simulation results toward activating capacity enhancing measures or dynamic resilience.

The comparison consists of two parts. The first part is an "example network" for illustrating dynamic assignment over the static assignment. The second part discusses the added benefit of using the dynamic assignment in a real-world network. Definitions and differences of Equilibrium assignment and dynamic stochastic assignment were discussed in previous chapters. The following chapter describes research that produced satisfactory results.

\subsection{THEORETICAL MINI NETWORK}

The following network was developed to illustrate the benefit of using a dynamic assignment over static traffic assignment. Since the length of the links on the test network is small and ranges between $(60 \mathrm{~m}-1 \mathrm{~km})$ with average link length of around 
$120 \mathrm{~m}$, the theoretical network was created to represent the movement of vehicles across the network better as time passes.

A small network of two villages $(1 \& 2)$ is constructed in PTV-Visum to illustrate how each assignment works. 2000 vehicles are assigned to travel from village 1 to village 2 in the time span of 1 hour. Three routes of different characteristics are assumed in Figure 8.1 as follows:

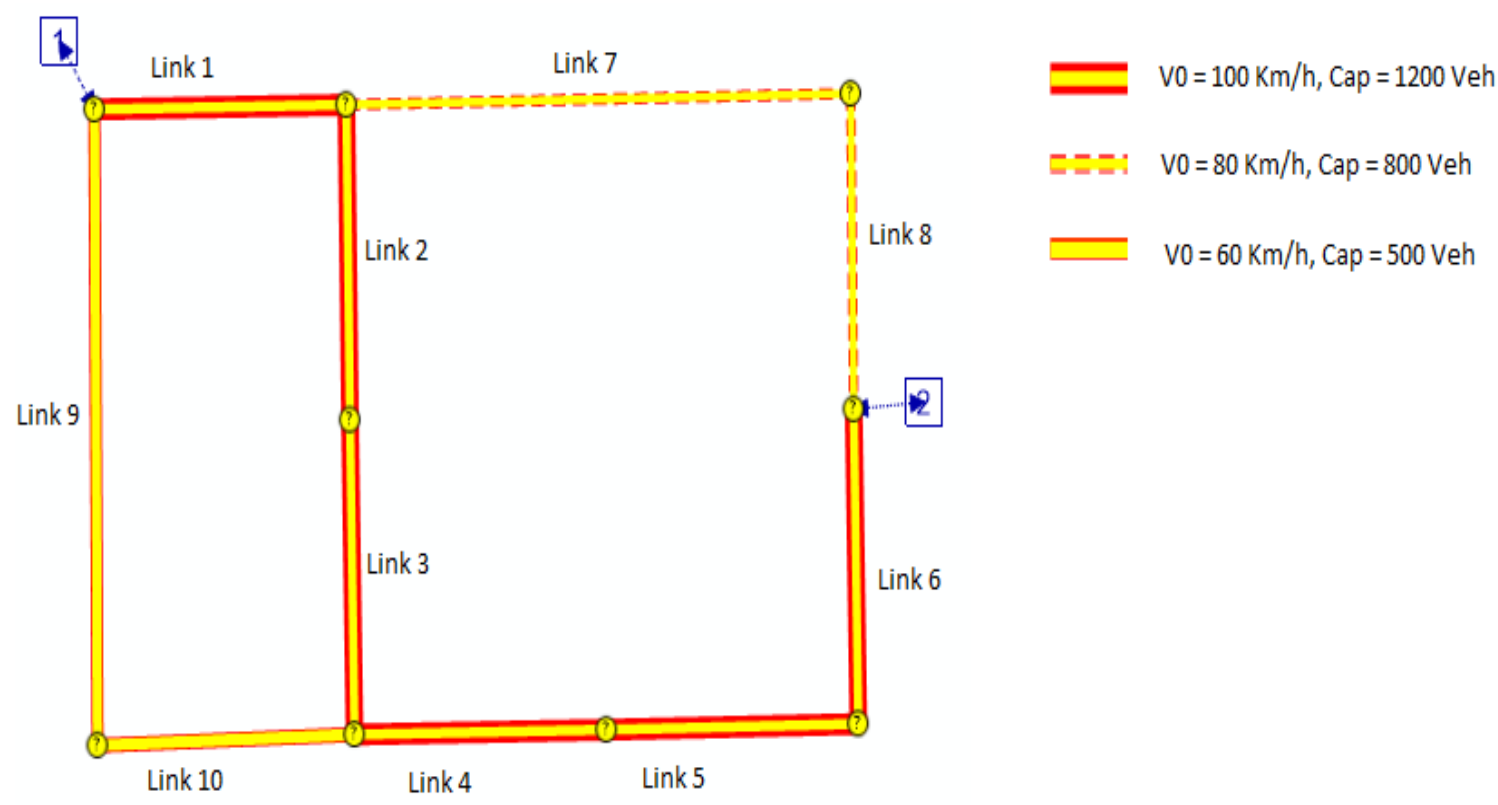

Figure 8.1: Example Network

Long segment length was used which better represents the effect of the dynamic behaviour of traffic when using dynamic stochastic assignment. The segment length properties and the speed limit is summarized in the following Table $8-1$.

\begin{tabular}{|l|l|l|}
\hline & Link Length & Speed Limit \\
\hline EQ Link 1 & $5 \mathrm{~km}$ & $100 \mathrm{~km} / \mathrm{h}$ \\
\hline EQ Link 2 & $5 \mathrm{~km}$ & $100 \mathrm{~km} / \mathrm{h}$ \\
\hline EQ Link 3 & $5 \mathrm{~km}$ & $100 \mathrm{~km} / \mathrm{h}$ \\
\hline EQ Link 4 & $5 \mathrm{~km}$ & $100 \mathrm{~km} / \mathrm{h}$ \\
\hline EQ Link 5 & $5 \mathrm{~km}$ & $100 \mathrm{~km} / \mathrm{h}$ \\
\hline
\end{tabular}




\begin{tabular}{|l|l|l|} 
EQ Link 6 & $16 \mathrm{~km}$ & $100 \mathrm{~km} / \mathrm{h}$ \\
\hline EQ Link 7 & $5 \mathrm{~km}$ & $80 \mathrm{~km} / \mathrm{h}$ \\
\hline EQ Link 8 & $5 \mathrm{~km}$ & $80 \mathrm{~km} / \mathrm{h}$ \\
\hline EQ Link 9 & $10 \mathrm{~km}$ & $60 \mathrm{~km} / \mathrm{h}$ \\
\hline EQ Link 10 & $5 \mathrm{~km}$ & $60 \mathrm{~km} / \mathrm{h}$ \\
\hline
\end{tabular}

The initial step was carried out to calculate the routes, which are used by travellers to travel from village 1 to village 2 . Since this is a finite model, all routes can be accounted for and compared. In contrast, the routes in a larger network are hard to record, since there is much more possibility of travel routes. The Input BPR function parameters used for the evaluation were $a=0.15, b=4$, and capacity was taken as shown in Figure 8.1 above. A summary of route choices and $t_{0}$ were recorded in Table 8-2 below.

Table 8-2: Travel Times

\begin{tabular}{|l|l|l|l|}
\hline Route & Links & Length & $\mathrm{t}_{0}$ \\
\hline 1 & $1+2+3+4+5+6$ & $30 \mathrm{~km}$ & $18 \mathrm{~min}$ \\
\hline 2 & $1+7+8$ & $26 \mathrm{~km}$ & $18 \mathrm{~min} 45 \mathrm{sec}$ \\
\hline 3 & $1+9+10+4+5+6$ & $30 \mathrm{~km}$ & $24 \mathrm{~min}$ \\
\hline
\end{tabular}

\subsubsection{Equilibrium Assignment Results}

Figure 8.2 below shows the equilibrium traffic assignment model. 2000 vehicles were distributed over the network to travel between two villages. A small network was used for comparison to evaluate the findings easily and directly. The same conclusion can be obtained by a more extensive network with more routes and destination points.

Table 8-3 below summarizes the travel times on each link in a loaded network. 


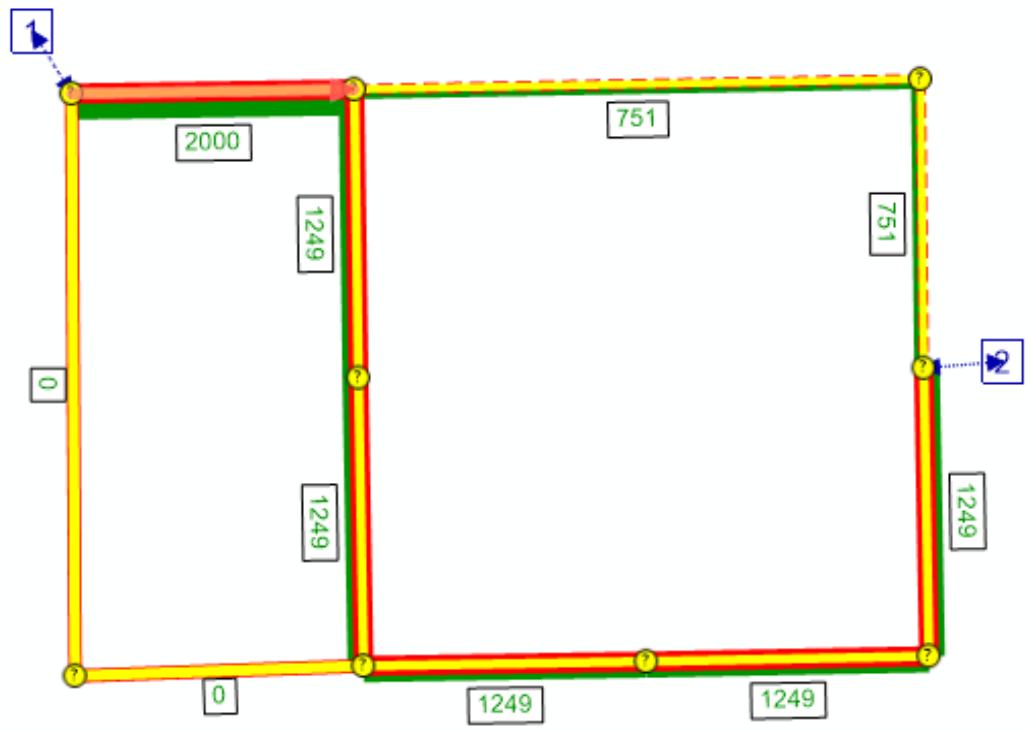

Figure 8.2: Equilibrium Assignment Results

Table 8-3: Travel Times of Links in a Loaded Network

\begin{tabular}{|c|c|c|}
\hline & $\begin{array}{lr}\text { Travel } & \text { Time in } \\
\text { unloaded } & \text { network } \\
\text { (seconds) } & \end{array}$ & $\begin{array}{l}\text { Travel Time in loaded } \\
\text { network (seconds) }\end{array}$ \\
\hline EQ Link 1 & 180 & 388 \\
\hline EQ Link 2 & 180 & 212 \\
\hline EQ Link 3 & 180 & 212 \\
\hline EQ Link 4 & 180 & 212 \\
\hline EQ Link 5 & 180 & 212 \\
\hline EQ Link 6 & 180 & 212 \\
\hline EQ Link 7 & 720 & 804 \\
\hline EQ Link 8 & 225 & 251 \\
\hline EQ Link 9 & 600 & 600 \\
\hline EQ Link 10 & 300 & 300 \\
\hline
\end{tabular}

\subsubsection{Dynamic Stochastic Assignment}

Figure 8.3 below shows the dynamic stochastic assignment model result after 20 minutes of simulation. Since the dynamic assignment takes into account vehicles entering and exiting a link, the traffic count was taken after 20 minutes of the assignment. 


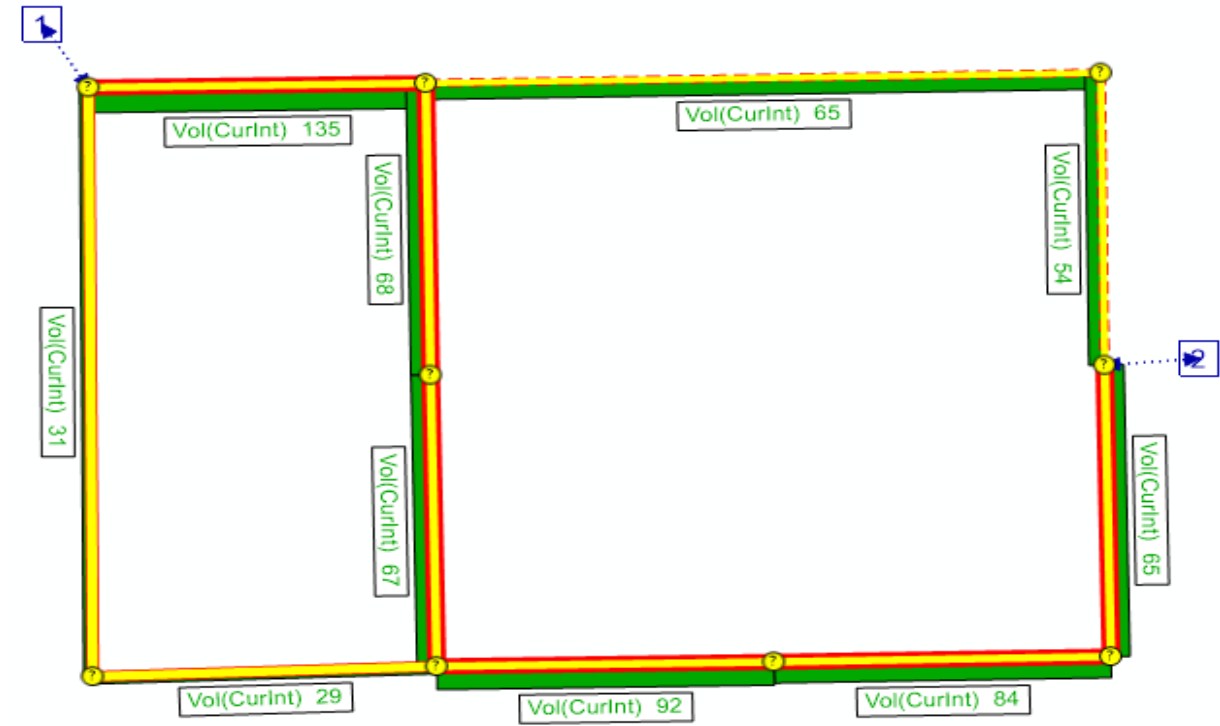

Figure 8.3: DAS Results

To compare the results the number of vehicles flowing on a link was taken every 5 minutes and multiplied by 12 . The result is summarized in Figure 8.4 below. The travel times on each link was summarized in Figure 8.5 below.

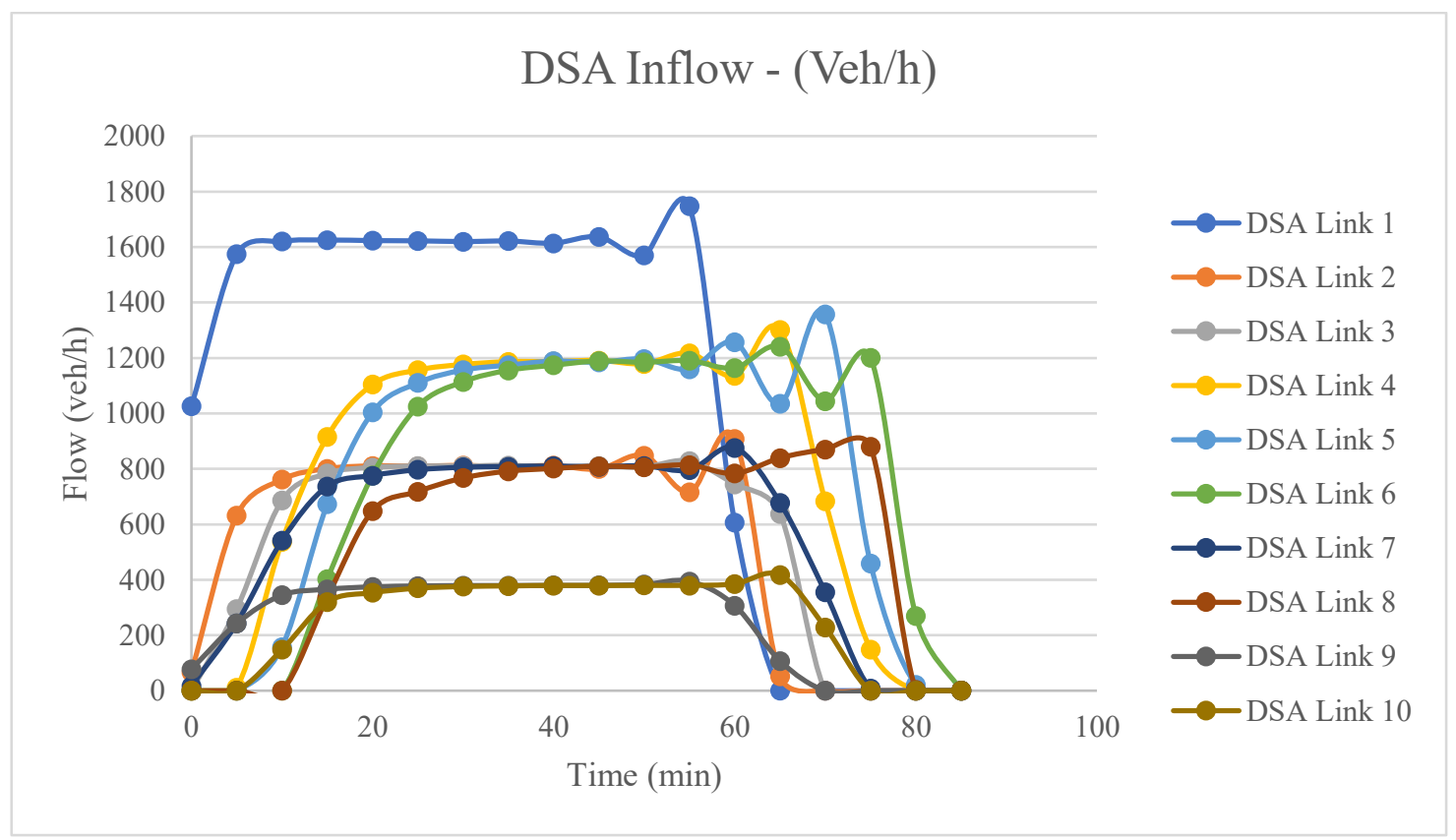

Figure 8.4: Dynamic Stochastic Assignment Vehicle Inflow Every 5 Minutes 


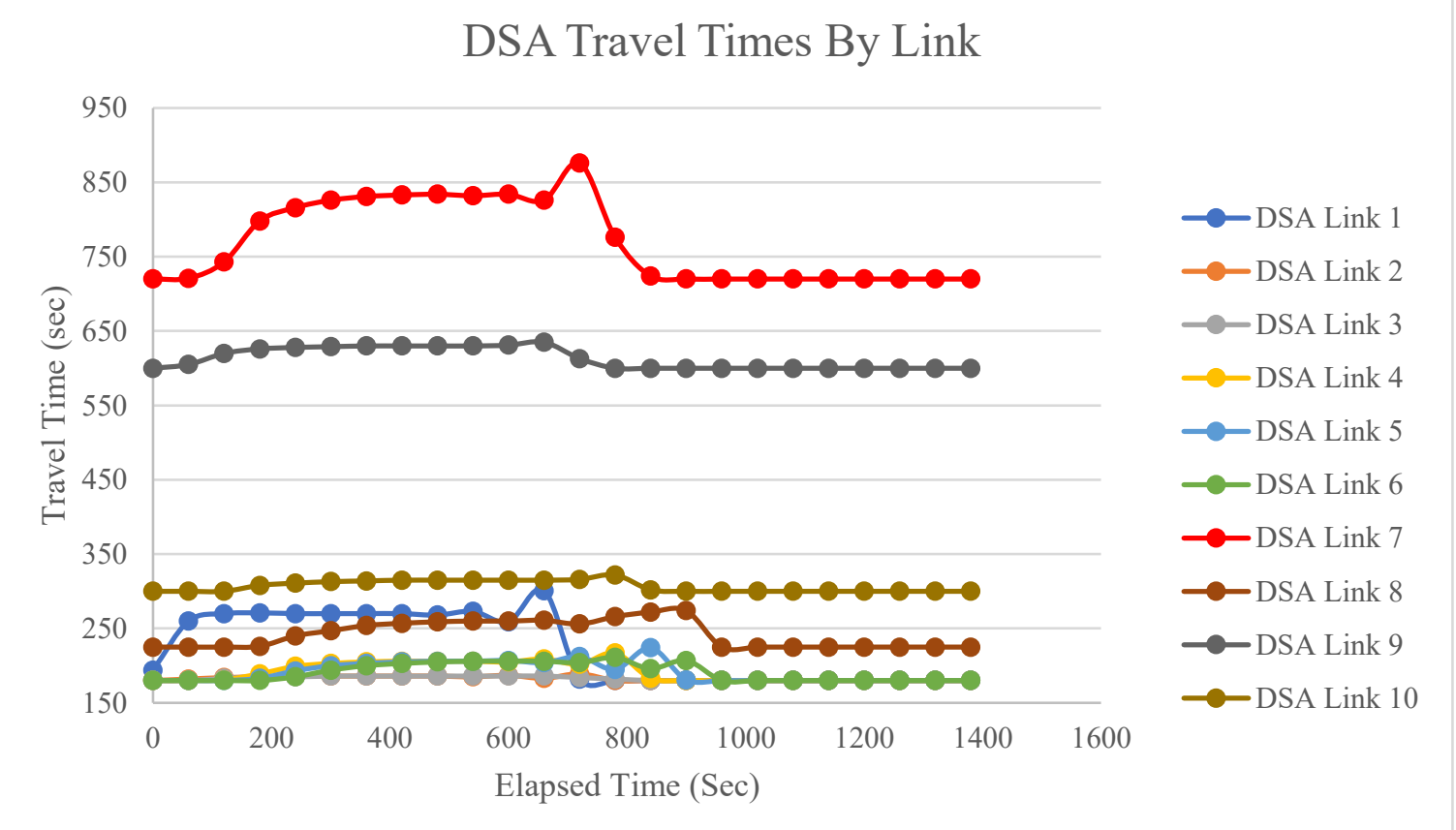

Figure 8.5: Travel Time on Each Link for the Simulation Period

\subsubsection{Comparing the results}

In the dynamic stochastic assignment, the link capacity constraints were better considered, and all routes were considered. The static equilibrium assignment chose 2 routs out of 3 resulting in oversaturation of the flow. As for the average travel time, dynamic stochastic assignment yielded a $20 \mathrm{~min} 57 \mathrm{sec}$ on route 1 while equilibrium assignment yielded $24 \min 7 \mathrm{sec}$ on the same route. Overall dynamic assignment yielded significantly better delay time and more evenly distributed traffic over the network while equilibrium assignment results were based on the shortest path, see Table 8-4.

Table 8-4: Average Tarvel Time on all Routes

\begin{tabular}{|l|l|l|l|l|l|}
\hline Rout & Links & Length & t0 & $\begin{array}{l}\text { DSA Avg } \\
\text { Travel Time }\end{array}$ & $\begin{array}{l}\text { EQ Avg Travel } \\
\text { Time }\end{array}$ \\
\hline 1 & $1+2+3+4+5+6$ & $30 \mathrm{~km}$ & $18 \mathrm{~min}$ & $20 \mathrm{~min} 57 \mathrm{sec}$ & $24 \mathrm{~min} 7 \mathrm{sec}$ \\
\hline 2 & $1+7+8$ & $26 \mathrm{~km}$ & $18 \mathrm{~min} 45 \mathrm{sec}$ & $22 \mathrm{~min} 54 \mathrm{sec}$ & $24 \mathrm{~min} 3 \mathrm{sec}$ \\
\hline 3 & $1+9+10+4+5+6$ & $30 \mathrm{~km}$ & $24 \mathrm{~min}$ & $25 \mathrm{~min} 58 \mathrm{sec}$ & $\mathrm{X}$ \\
\hline
\end{tabular}


The dynamic stochastic assignment can explain the dynamic nature of the roads network; where there are many possible routes between origin A and destination $\mathrm{B}$. The dynamic stochastic assignment better considers re-planning (re-routing) of the traffic by considering more route options. In contrast, static equilibrium assignment focused on the shortest route and caused oversaturation of flow.

Using the dynamic assignment approach, one can draw the temporal demand distribution over a link on the network, route or even an area. Moreover, the departure time of demand can be divided into user-defined time slices (in the example above the traffic demand for 1 hour was divided into $25 \%$ portions and distributed over $15 \mathrm{~min}$ time slices). By reducing time slices period and assigning better demand data over the time slice will undoubtedly yield a better result but requires more computing time and machine power. In contrast, static assignment relies on the selection of shortest routes in comparison to the comprehensive modeling of traffic flow. The static assignment uses the volume-delay function and assigns the traffic as a single demand. The dynamic assignment better represents the real-life scenario effect of the movement and flow of traffic in and out of the network. The temporal distribution better considers the flow of demand and route choices. 


\section{PROOF OF CONCEPT}

\subsection{INTRODUCTION}

The proof of concept chapter covers the development of User Equilibrium Traffic Assignment (UE) and Dynamic Stochastic Traffic Assignment (DSA) models for the Ottawa-Hull Area roadway network.

In the implementation of the models, guidance was obtained from the literature review on UE and DSA models and application. The development and results of the network are documented along with the necessary model calibration. PTV-Visum was adopted for developing of the network. It is an advanced software for traffic analysis, forecasting, and it is able to perform several traffic assignment procedures for the transportation model. The static assignment procedure (UE) and time dynamic traffic flow model (DSA) were computed by using PTV-Visum.

\subsection{BACKGROUND}

This chapter examines the application of DSA and UE models for the Ottawahull area. The application of these models required updated and up-to-date information about the roadway network. Some difficulties arose in validating route choices and travel patterns in DSA. The validation process carried out in this research includes but is not limited to:

1. Travel forecasting

2. Delay time estimation

3. Impacts of major disruption over time

4. Travel supply over time-interval and its effects on the network 


\subsection{CHARACTERISTICS}

\subsubsection{User Equilibrium (UE) Assignment}

User Equilibrium (UE) traffic assignment can refer to traveler's behavior in the network for everyday recurring traffic congestions. UE assignment underlies the assumption that every road user would experience the same impedance on all alternative routes. Demand is distributed according to Wardrop's first Principle, which uses static time slices. Capacities must be specified according to the total length of time interval for which demand data is available. Departure time of road users is irrelevant. This research aims to introduce a new travel planning aspect which investigates the short-time surge in traffic supply, bottlenecks, and mitigation of non-recurring traffic congestion caused by possible disruption happening.

\subsubsection{Dynamic Stochastic Assignment (DSA)}

As previously, noted, Dynamic Stochastic Assignment (DSA) differs from UE traffic assignment. Capacities are set to the hourly value, and not regarding the time interval (TI) the demand data is available. The assignment period can be divided up into time slice TI of equal lengths. Departure time can be specified for road users. Searches for several shortest time paths with network impedance is carried out after each time interval. Demand temporal distribution curve can be calculated. The volumes and capacities - time-varying attribute - the network element is stored for every time slice. Road user's choice of shortest time path is dependent upon the traffic demand on alternative routes at time slice.

The time-varying attribute can be considered with DSA for road capacity and posted speed limit. Using the time-varying attribute, the DSA model provides calculated results of volumes or impedance with link capacity constraint for the time interval. For 
example, an accident, which caused lane closure on a three-lane highway, has taken place at 5:45 pm and the lane was closed for 30 minutes.

The DSA simulates changes in network per time-interval (e.g.15 minutes) and over the analysis period ( 2 hours and 30 minutes for example). Vehicles inflow over time and impact of incidents over time can be analyzed, and temporal distribution curves of traffic can be drawn and observed. Prediction of changes in flow patterns over the entire roadway network serves as an important component in transportation planning and management (Tian et al., 2014).

\subsubsection{Re-Visiting Definition of Resilience}

Resilience of a transportation system is the ability of transportation roadway system to accommodate traffic demand during an unexpected event resulting surges of traffic demand. Resilience can be divided into two elements:

1. Inherent Resilience: inherent resilience is the ability to resist the loss of trafficserving capability owing to geometric and control system. Inherent resilience is discussed in previous chapters. Application of inherent resilience achieves a sustainable network.

2. Dynamic resilience: the application of dynamically activating of capacity-enhancing measures achieve a resilient network. For example, a two-way corridor is transformed to one-way corridor to serve increased traffic for a specific time. Dynamic resilience observes viable solutions to a problem, which might happen.

Dynamic resilience actions: Based on available information, the traffic control and management personnel will be in a position to evaluate alternative dynamic resilience actions and select the best alternative for implementation. The alternative 
actions are to be pre-defined based on analyses such as the ones presented in this thesis research. The evaluation is to be carried out using Bayesian decision model (explained in a later chapter).

Figure 9.1 below illustrates the infrastructure response curve over time during a disruptive event.

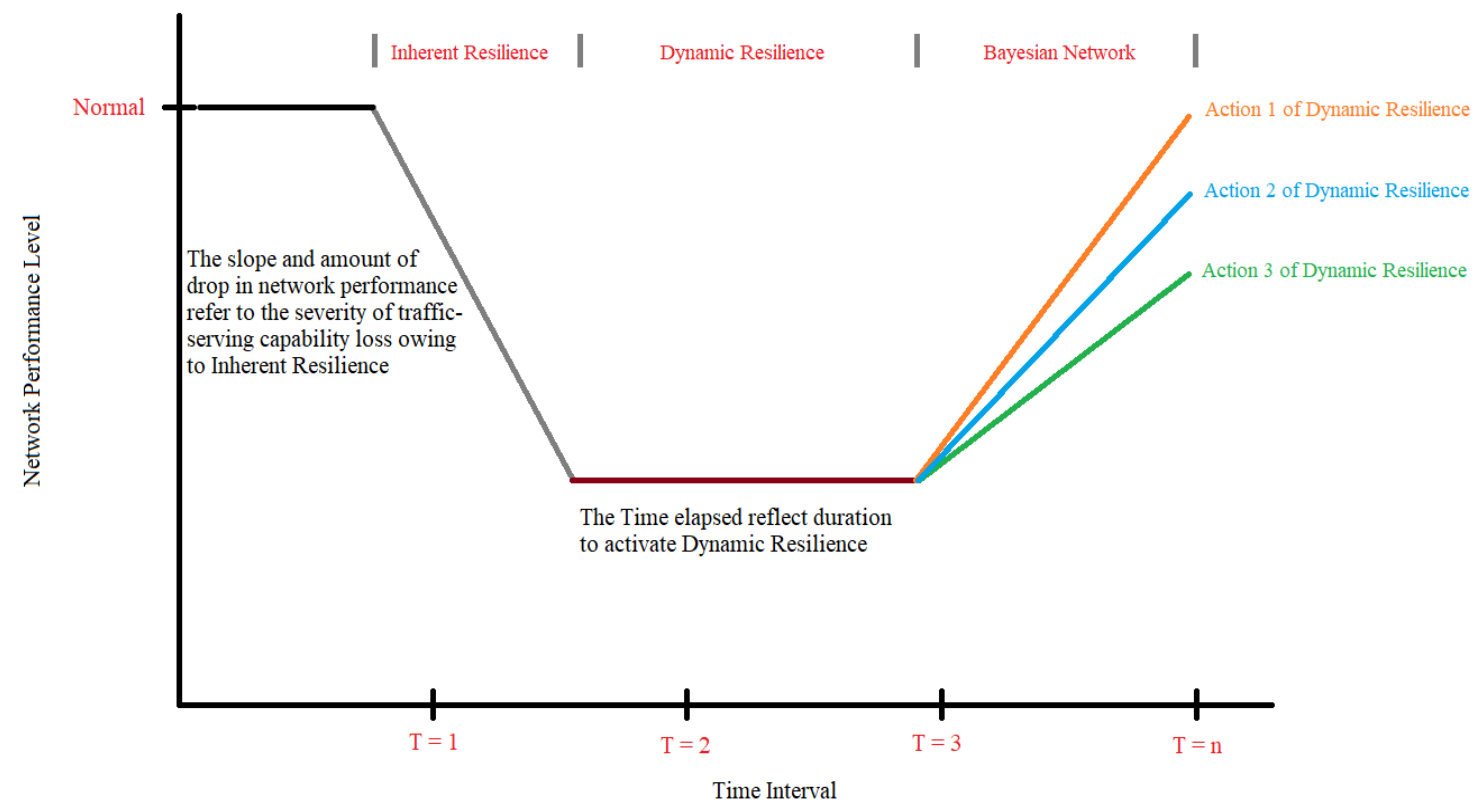

Figure 9.1: Infrastructure Response Curve During Disruptive Event

\subsection{APPLICATION OF METHODOLOGY}

\subsubsection{Network}

The Data used in Ottawa-Hull network was collected from the City of Ottawa, Google Maps (“Google Maps," n.d.), Ottawa Transportation Master Plan (City of Ottawa, 2013), and Trans Committee (IBI Group, 2016). A screenshot of the network with PTV-Visum is presented in Figure 9.2 below. Visum employs simulation-based macroscopic dynamic traffic assignment framework by using link-based simulation to incorporate the time-dependent demand data matrices, and time varying attribute $\left(\mathrm{t}_{0}, \mathrm{v}_{0}\right.$, and capacity) to capture the dynamic traffic flow in the network over time. 


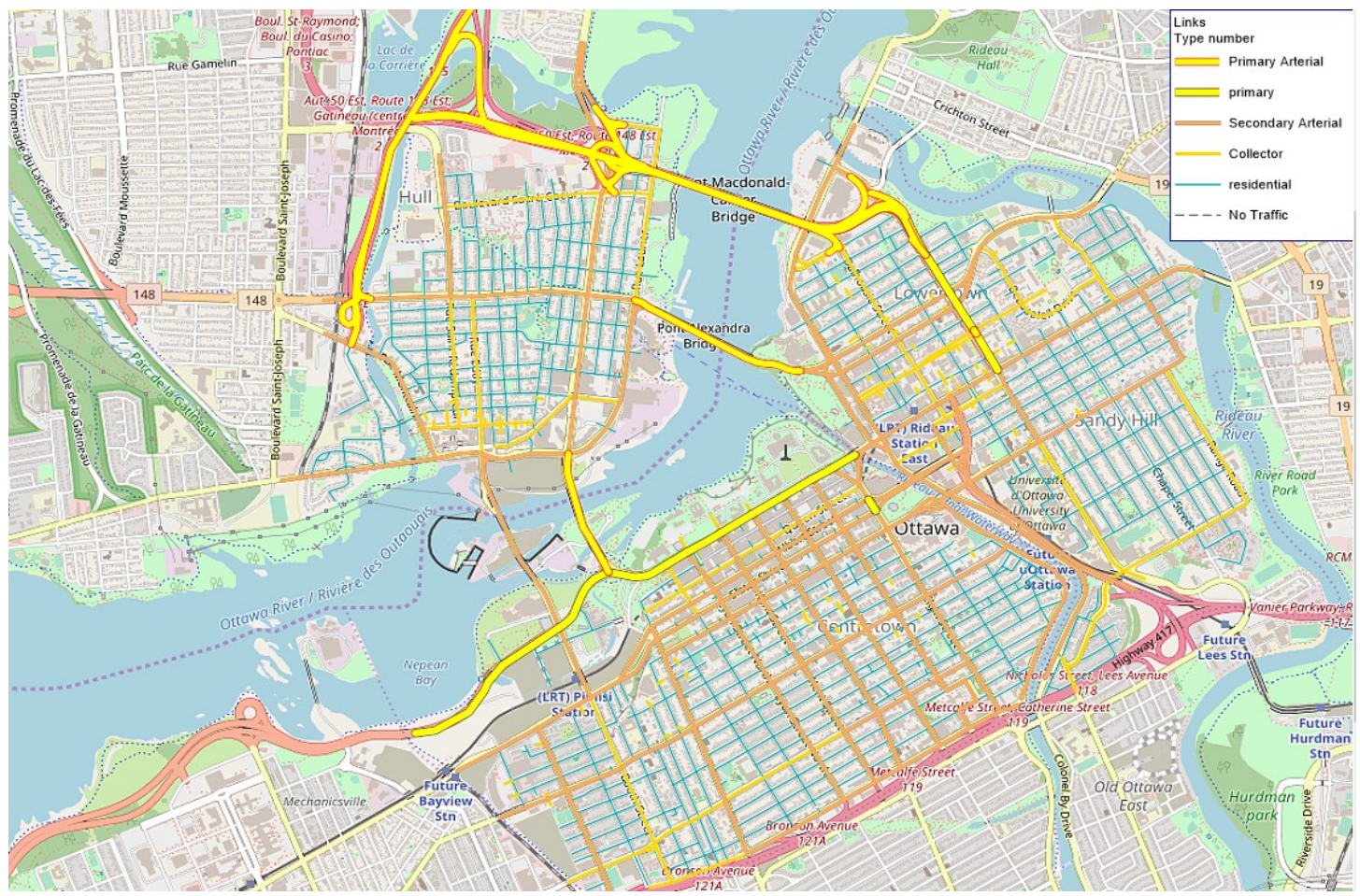

Figure 9.2: Computer Screen of Ottawa-Hull Study Area in Visum

\subsubsection{Travel Demand Data}

The time-dependent demand data was inputted into Visum O-D matrix. The analysis covers 1-hour PM Peak hour, PM Peak Period (two and Half-hours). Demand data for 2011 and forecasts for 2018 and 2031 were used.

Table 9-1 provides time periods of demand data, departure-time and peak hour scaling factor used in Visum.

Table 9-1: Time Periods of Demand Data

\begin{tabular}{|c|l|c|}
\hline Name & Time of Day & Peak Hour Scaling Factor \\
\hline PM Peak Hour & $15: 30-16: 30^{1}$ & 1 \\
\hline PM Peak Period & $15: 00-17: 30^{1}$ & $2.38^{1}$ \\
\hline $\begin{array}{c}{ }^{1} \text { Source: IBI Group, 2016. National Capital Region Travel Trends. Trans } \\
\text { Committee. }\end{array}$
\end{tabular}


Demand growth was calculated using the Transportation Master Plan data prepared by the City of Ottawa. The equations below were used to obtain projected travel demand for 2018, and 2031 using projected growth in number of trips.

$$
\begin{aligned}
& \text { Demand }_{2018}=\text { Demand }_{2011}(1+0.01475)^{8} \\
& \text { Demand }_{2031}=\text { Demand }_{2011}(1+0.01475)^{21}
\end{aligned}
$$

Number of trips in Passenger car units are displayed in

Table 9-2 below.

Table 9-2: Number of Trips in Passenger Car Units

\begin{tabular}{|l|l|l|}
\hline Year & Peak Hour Volumes & Peak Period Volumes \\
\hline 2011 & 89,112 & 212,086 \\
\hline 2018 & 100,146 & 238,347 \\
\hline 2031 & 121,192 & 288,436 \\
\hline
\end{tabular}

9.4.3 Time-Interval and Trip Distribution

Based on "National Capital Region Travel Trends" report by (IBI Group, 2016), trip distribution by departure time was calculate. See Figure 9.3 - below.

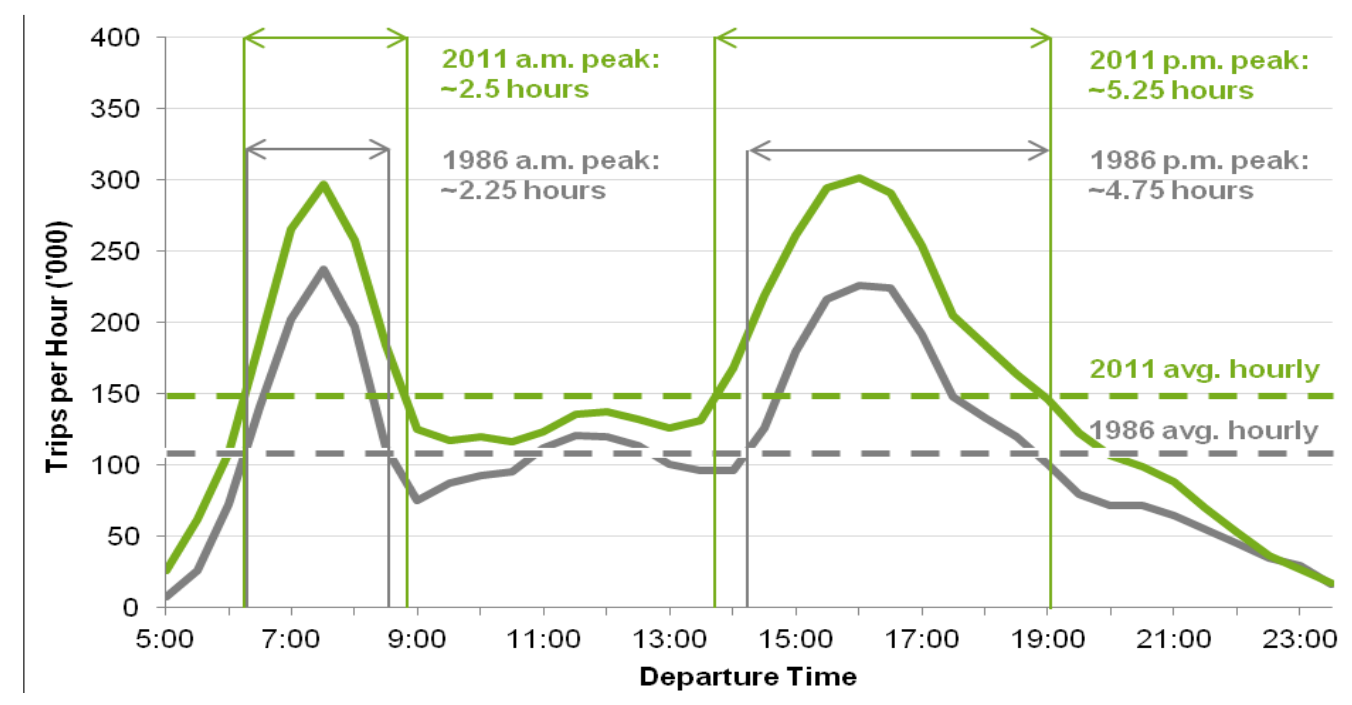

Figure 9.3: Trip Start Time Distribution and Peak Period Trips (IBI Group, 2016) 
For UE traffic assignment, and other static traffic assignments, road capacity inputs must be specified according to the time length of the demand data. i.e. the capacity of road segments for 1-hour Analysis-Period is equivalent to 1-hour capacity per road segment, and 2.5 hours analysis-period road segment capacity is equivalent to 2.5 x 1-hour capacity per road segment. Volumes and resultant impedances are superimposed upon each other at the individual network objects.

In contrast, dynamic stochastic traffic assignment in PTV-Visum considers the temporal distribution of demand data as well as the temporal distribution of departuretime of the entire network. Figure 9.4 below shows a screenshot of DSA time-intervals (TI) used in Visum for DSA procedure. Departure-time of road users is also specified accordingto (IBI Group, 2016). Figure 9.4 also shows a screenshot of the 2.5-hour demand data departure time percentage distribution while Figure 9.5 shows DSA Departure time distribution in Visum.

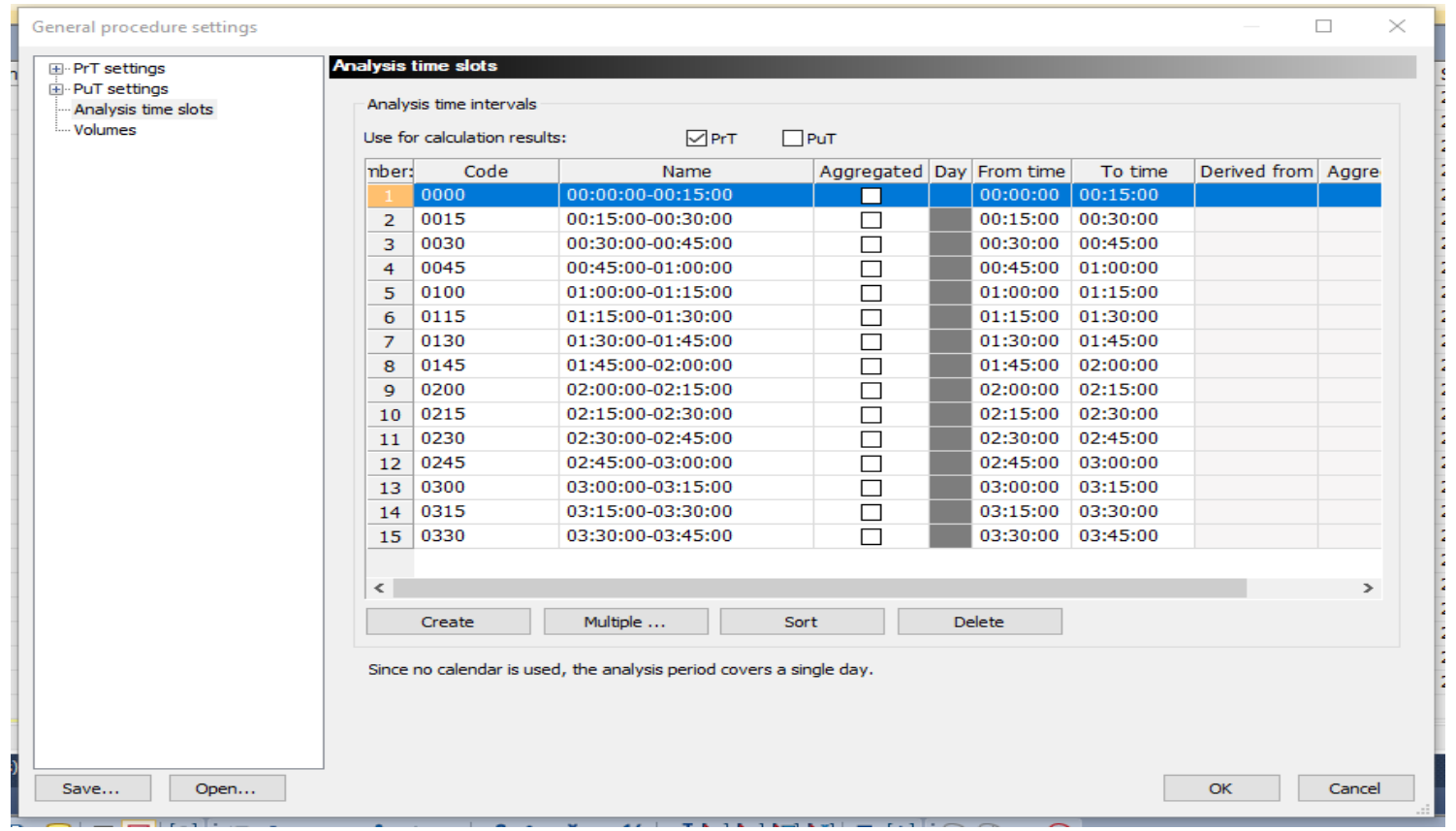

Figure 9.4: Computer Shot of DSA Analysis Time-Intervals 


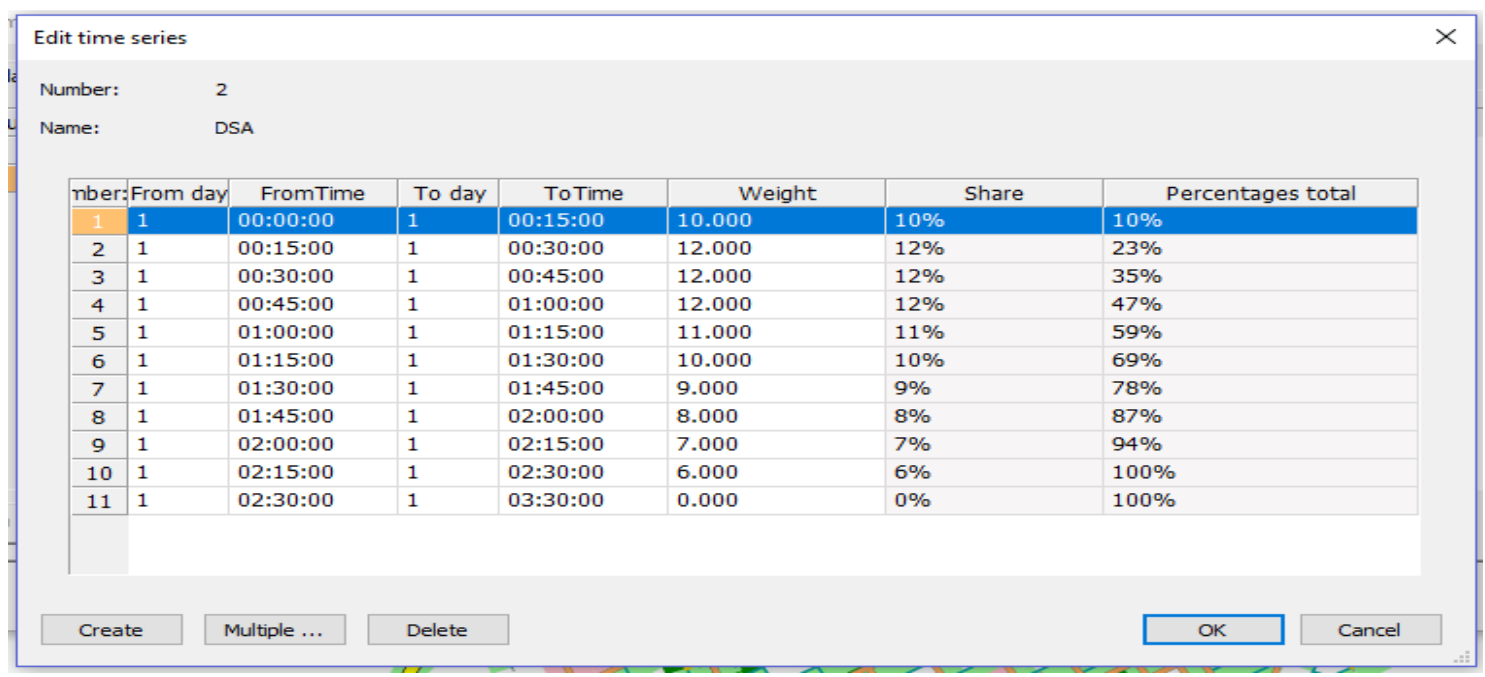

Figure 9.5: DSA Departure Time Distribution in Visum

\subsection{NETWORK RESULTS}

An overview of the Ottawa-Hull area network data is provided in Table 9-3 below.

Table 9-3: Network Data Overview

\begin{tabular}{|l|r|}
\hline Name & \multicolumn{1}{|l|}{ Value } \\
\hline Nodes & 1370 \\
\hline Links & 3802 \\
\hline Zones & 67 \\
\hline Link Types & 19 \\
\hline
\end{tabular}

Table 9-4 summarizes the simulation run differences. Figure 9.6, shows the traffic flow in and out of the network as result of dynamic stochastic traffic model.

Table 9-4: Model Describtion

\begin{tabular}{|l|l|l|l|c|}
\hline $\begin{array}{l}\text { Assignment } \\
\text { Procedure }\end{array}$ & Analysis-Period & $\begin{array}{l}\text { Time- } \\
\text { Interval (TI) } \\
\text { (Minutes) }\end{array}$ & Departure Time & $\begin{array}{l}\text { Base } \\
\text { Demand } \\
\text { Data Year }\end{array}$ \\
\hline UE & 1-Hour, PM peak hour & 60 minutes & Superimposed & 2011 \\
\hline DSA & 1-Hour, PM peak hour & 15 minutes & \% of Road users per TI & 2011 \\
\hline UE & 2.5-Hrs, PM peak period & 150 minutes & Superimposed & 2011 \\
\hline DSA & 2.5-Hrs, PM peak period & 15 minutes & \% of Road users per TI & 2011 \\
\hline
\end{tabular}




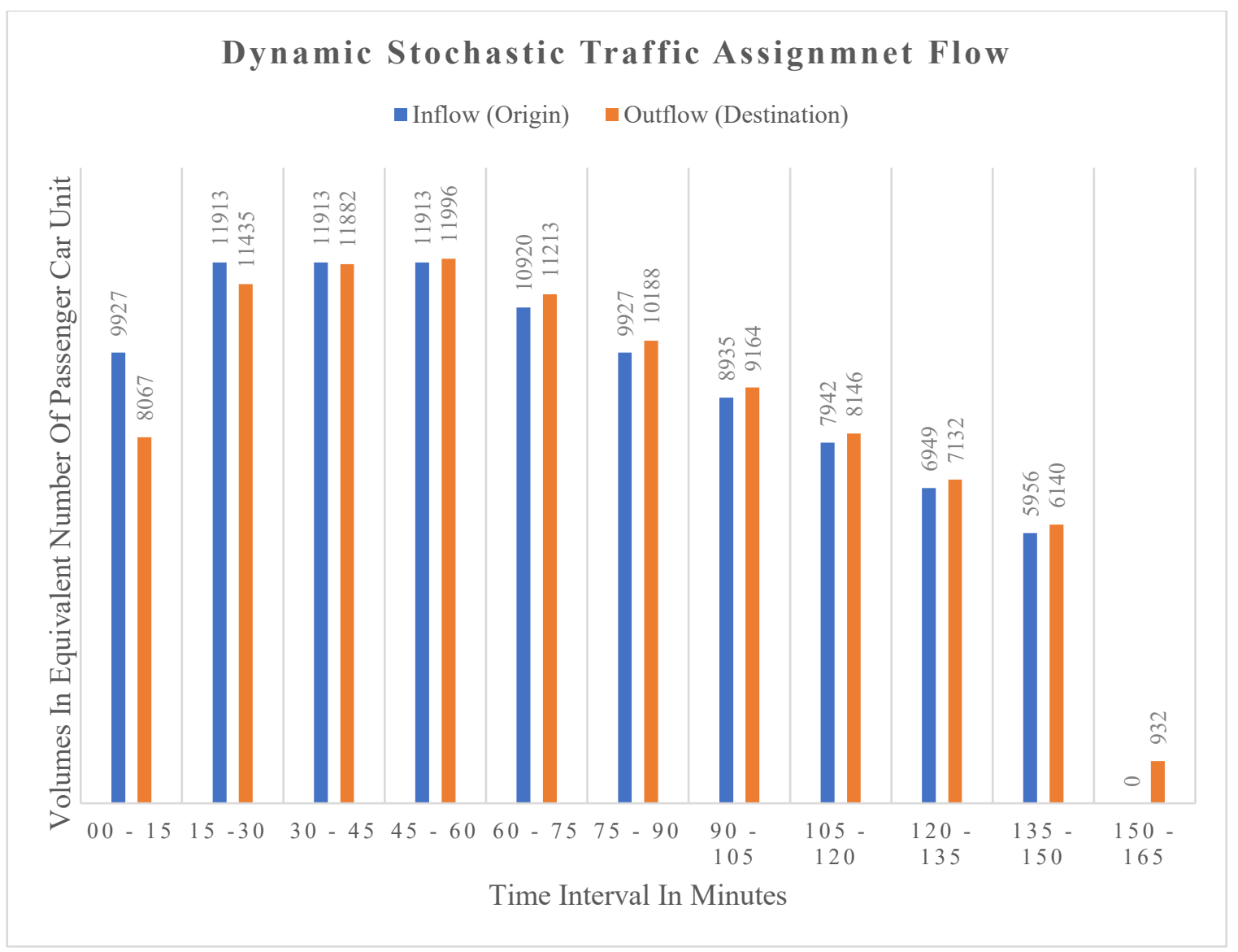

Figure 9.6: DSA Traffic Flow in and out of the Network - 2018 Traffic Data (model 6).

\subsection{FLOW DISTRIBUTION}

Figures below show the volume of traffic for PM peak hour distributed over links. Figure 9.7 shows all link volume comparison between UE assignment and DSA assignment. In case of the static UE, assignment traffic was distributed over a smaller number of links, wherein the case of DSA, flows are distributed more equally over the whole network, traffic was more likely to choose a less congested faster but sometimes farther routes than at the UE assignment. Figure 9.8 and Figure 9.9, zoom into the low volume links, which show that travellers were more likely to choose alternative routes in the case of DSA assignment. 


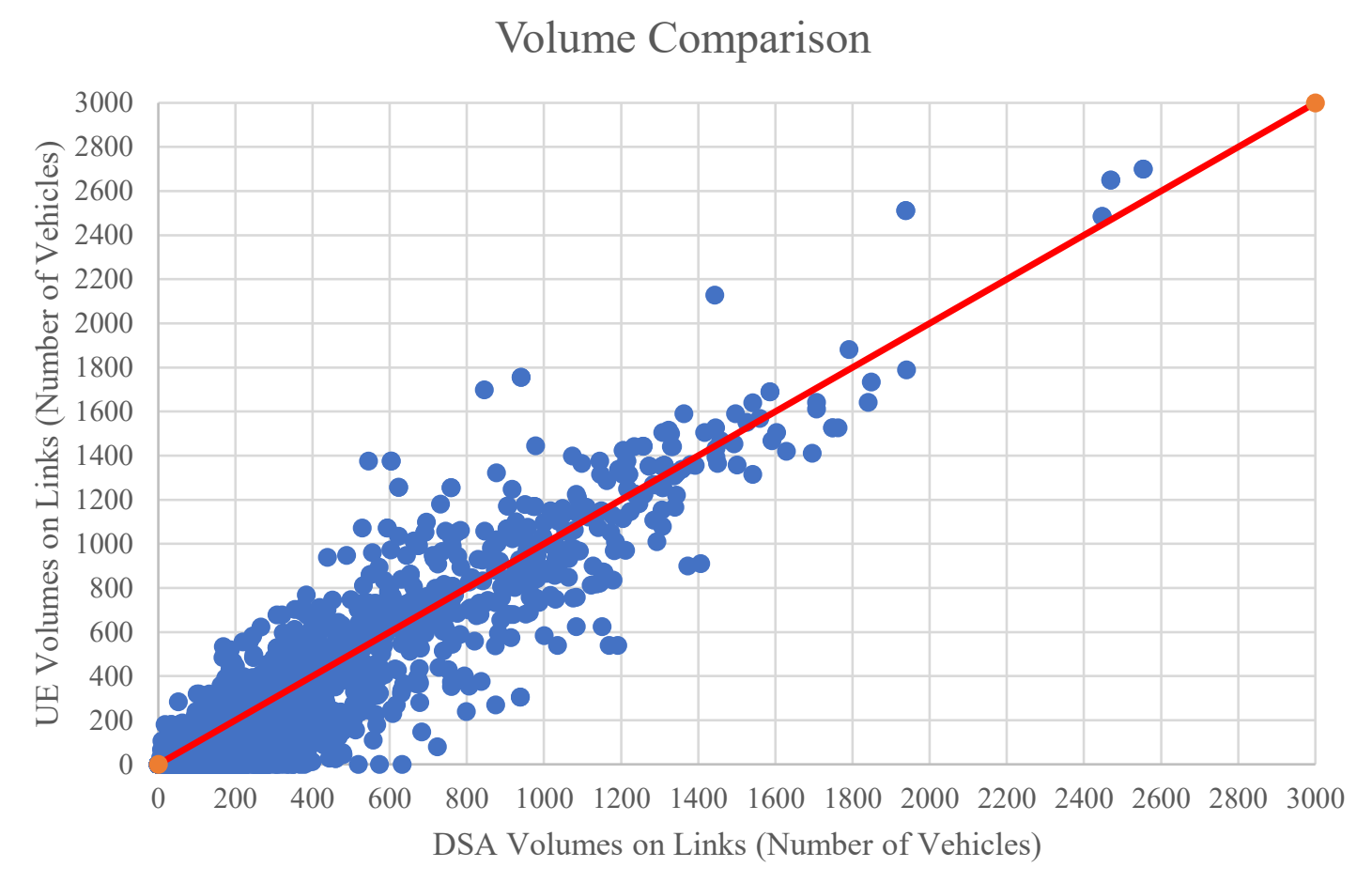

Figure 9.7: Comparing of Link Volumes in Visum

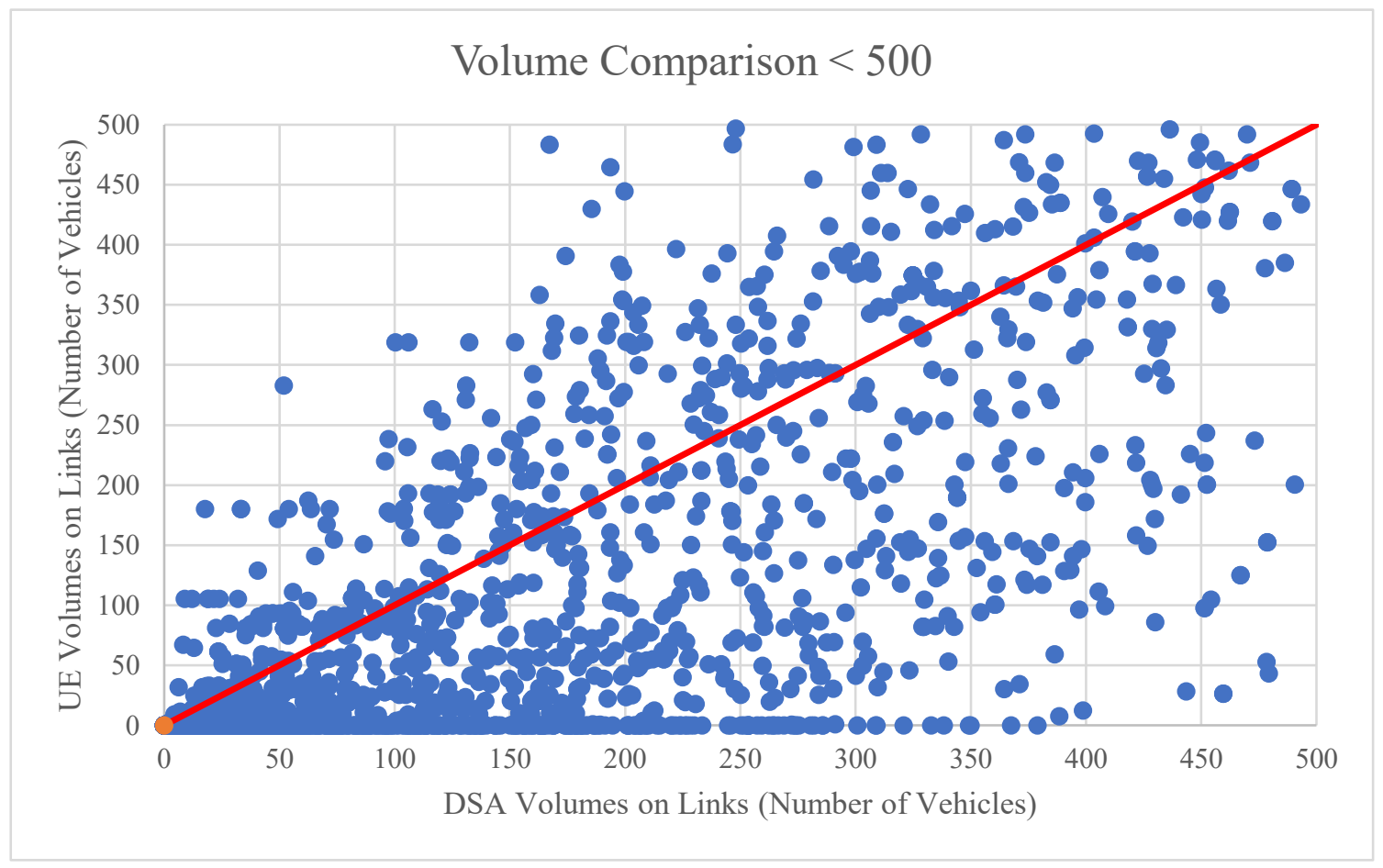

Figure 9.8: Zoom in of Comparison of Link Volumes $<500$ Vehicles in Visum 


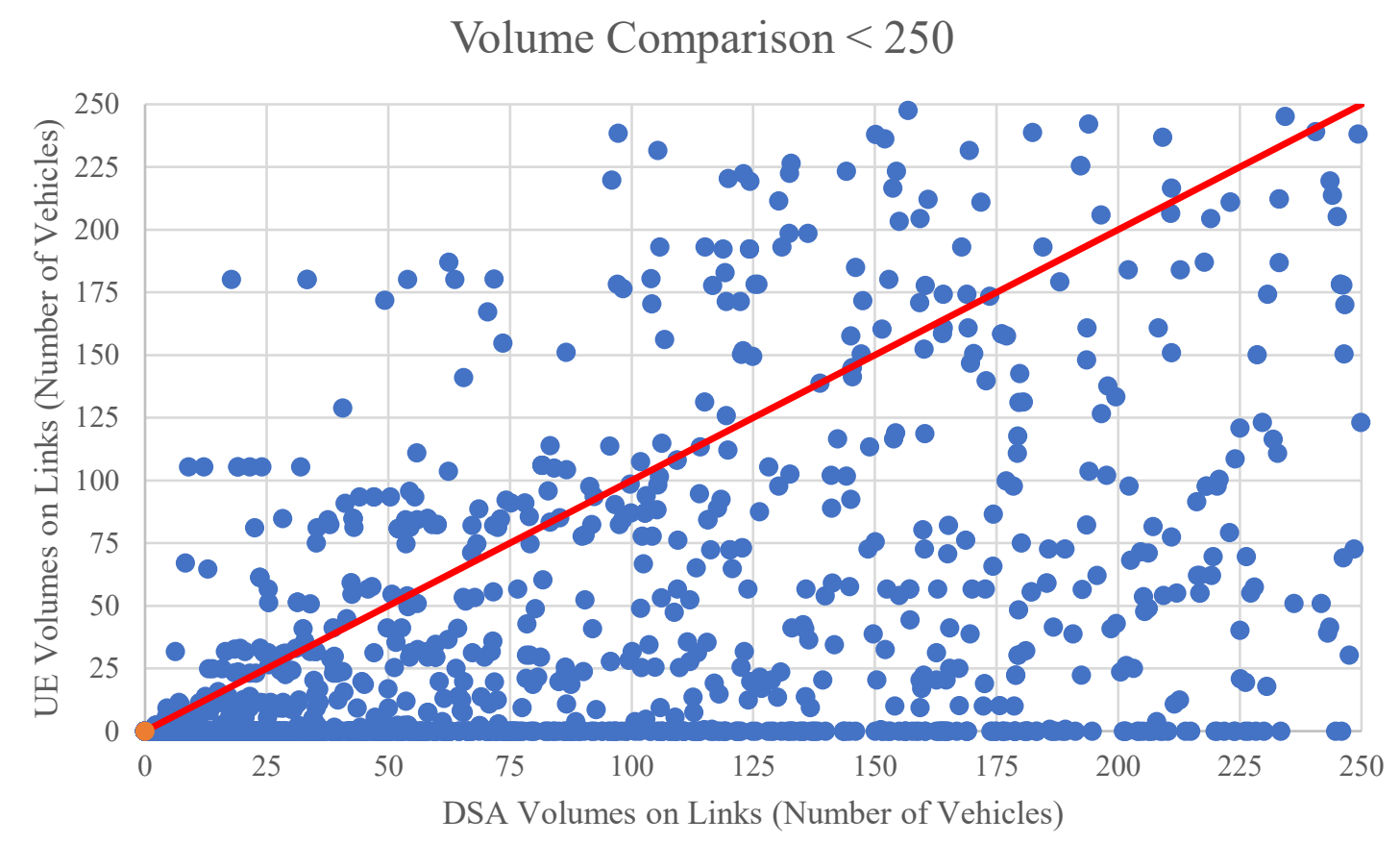

Figure 9.9: Zoom in of Comparison of Link Volumes $<250$ Vehicles in Visum

\subsection{TRAFFIC CROSSING SCREEN LINES DURING PEAK HOUR}

To fairly compare traffic volumes, both traffic assignment screen lines were embedded in Visum. See Figure 9.10 for illustration. The screen lines aggregate the number of vehicles passing the links that it intersects. The number of passenger car units crossing the screen lines are presented in Table 9-5. More volumes cross Cordon 3 screen line both in forward and backward direction; the percentage increase is 24.2 percent and 11.0 percent, respectively.

Table 9-5: Volumes Crossing Screen Lines - 2018 Peak Hour Traffic Flow (Model 4 \& 6)

\begin{tabular}{|c|c|c|c|c|}
\hline \multirow{2}{*}{ Screen Line } & \multicolumn{2}{|c|}{$\begin{array}{c}\text { Forward Volumes in Number of } \\
\text { Passenger Vehicles }\end{array}$} & \multicolumn{2}{c|}{$\begin{array}{c}\text { Backward Volumes in Number of } \\
\text { Passenger Vehicles }\end{array}$} \\
\cline { 2 - 5 } & $\begin{array}{c}\text { DSA (\% } \\
\text { increase) }\end{array}$ & UE & $\begin{array}{c}\text { DSA (\% } \\
\text { increase) }\end{array}$ & UE \\
\hline Cordon 3 & $15378(24.2)$ & 12383 & $23054(11.0)$ & 20767 \\
\hline Bridges Screen Line & $8111(0)$ & 8092 & $4436(0)$ & 4417 \\
\hline
\end{tabular}




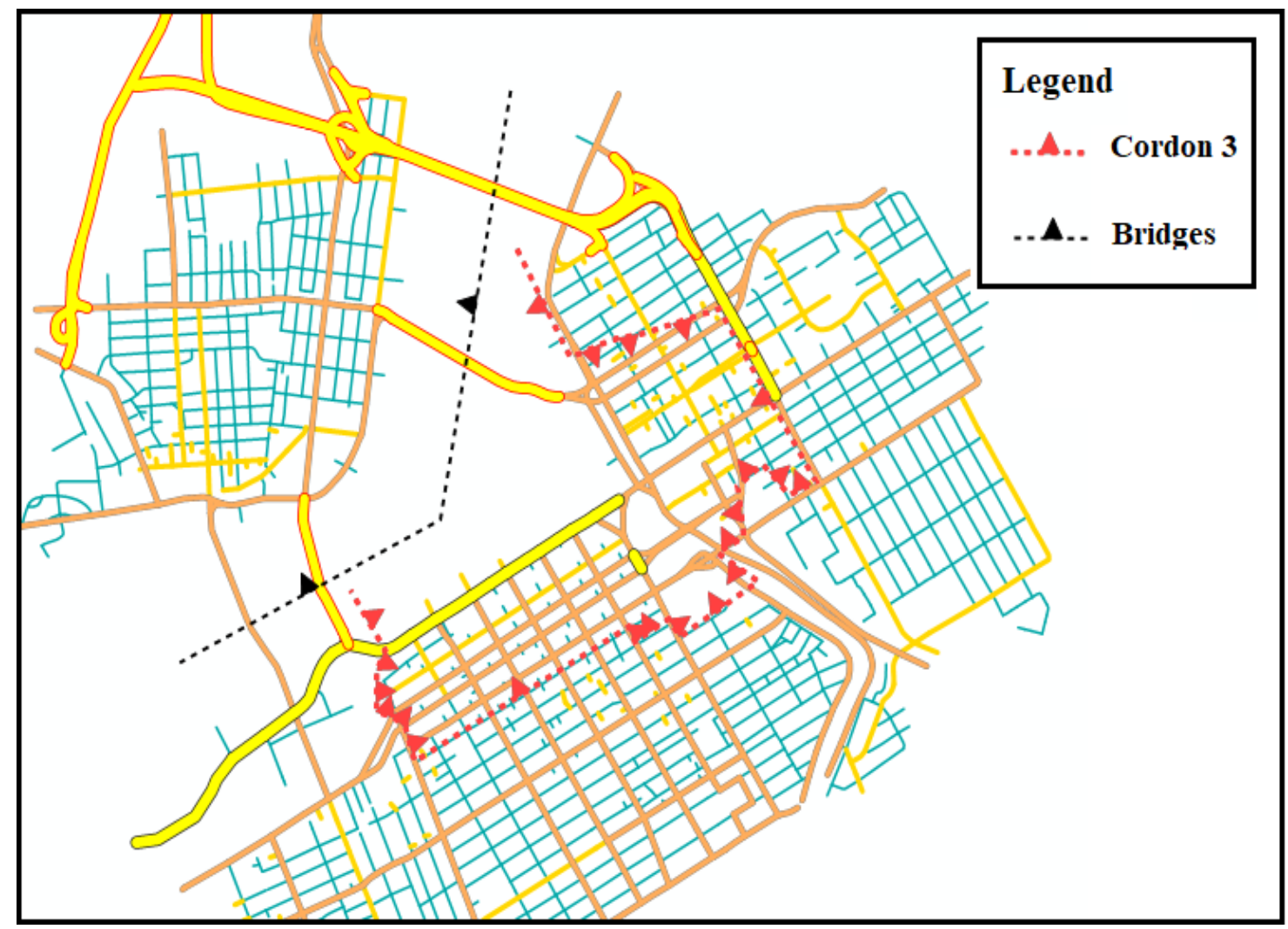

Figure 9.10: Screen Lines in PTV-Visum

\subsection{TRAFFIC BEHAVIOR DURING PEAK PERIOD}

Figure 9.11 and Figure 9.12 below illustrate the change in flows in and out of major bridges in the case of DSA assignment (model 6, Section 9.10.11). While in the case of UE assignment (model 4, Section 9.10.11), flow of vehicle and travel time is treated as lump sum over the links - see Table 9-6 - which shown in the previous example leads to oversaturation of the network. The effect of oversaturation is even exaggerated when the traffic flowing is over capacity. 


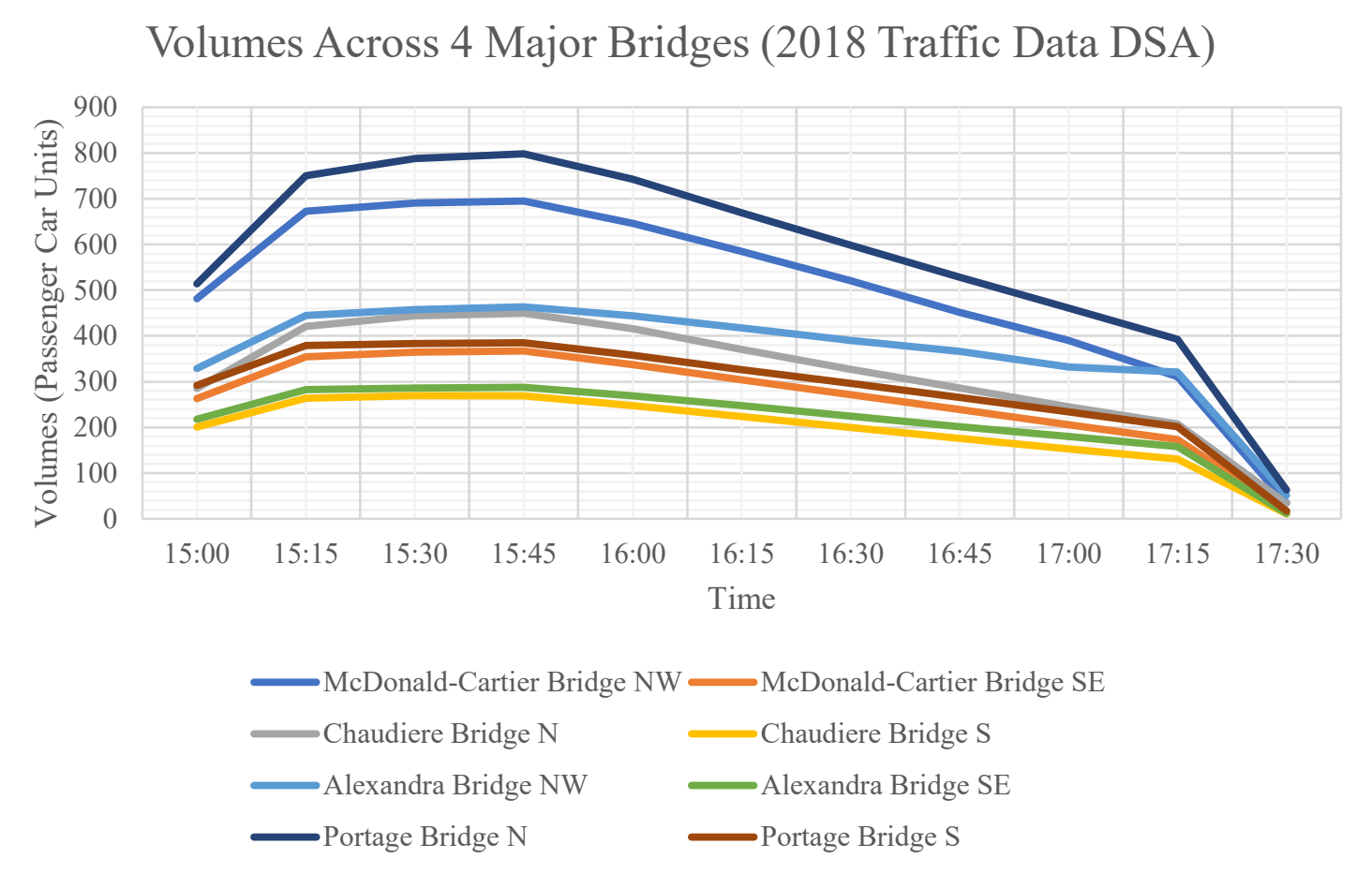

Figure 9.11: Bridges Volumes Over Time for PM Peak Period

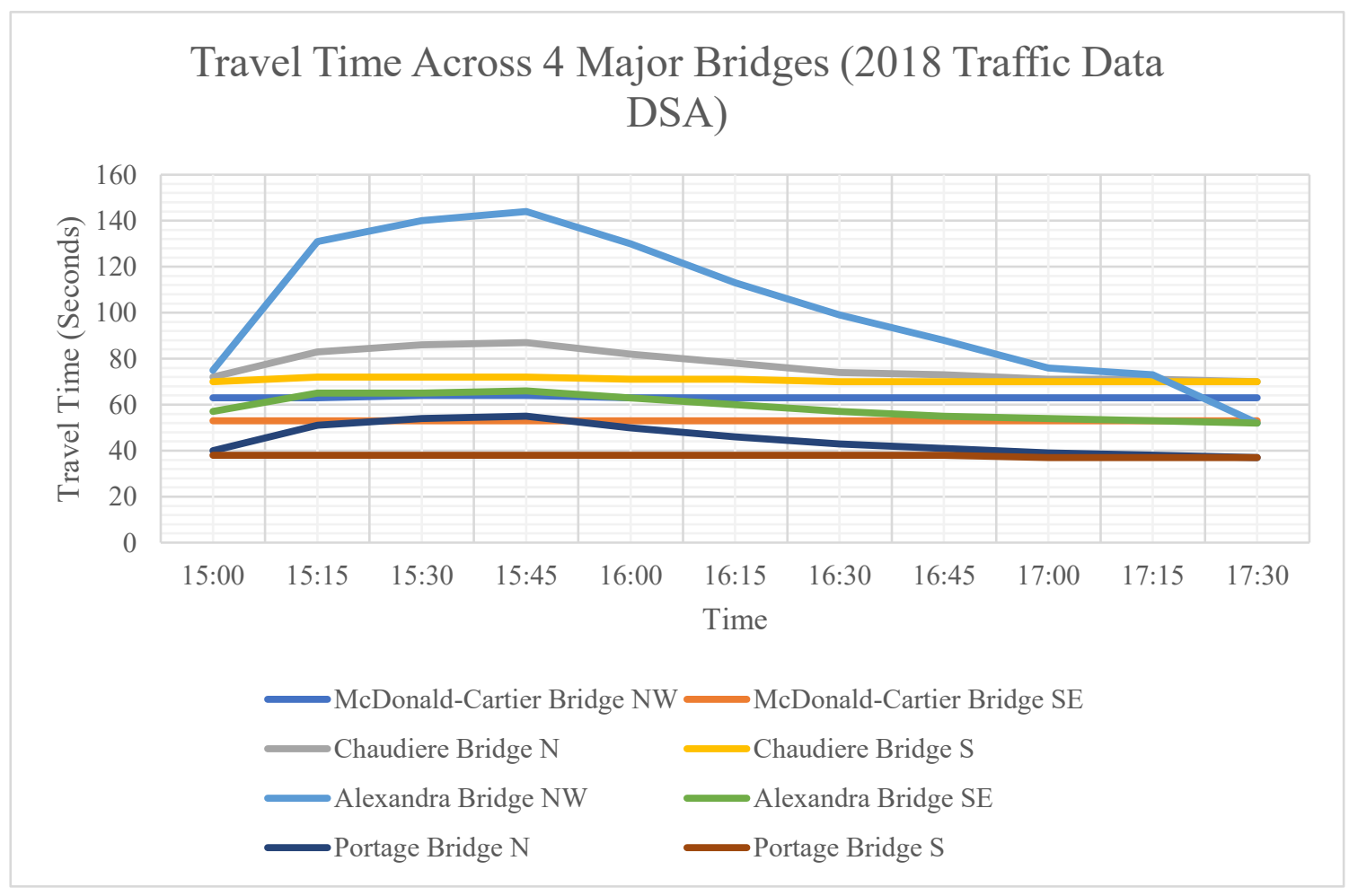

Figure 9.12: Bridges Travel Time over PM Peak Period 
Table 9-6: Flow and Travel Times Across Major Bridges for 2018 Traffic Data (UE Traffic Assignment)

\begin{tabular}{|l|c|c|}
\hline Crossing & $\begin{array}{l}\text { Peak Period Flow ( /15 } \\
\text { minutes) }\end{array}$ & Travel Time (Seconds) \\
\hline McDonald-Cartier Bridge NW & $5971(597)$ & 63 \\
\hline McDonald-Cartier Bridge SE & $3180(318)$ & 53 \\
\hline Chaudière Bridge N & $2943(294)$ & 79 \\
\hline Chaudière Bridge S & $2540(254)$ & 75 \\
\hline Alexandra Bridge NW & $3569(357)$ & 84 \\
\hline Alexandra Bridge SE & $2048(205)$ & 56 \\
\hline Portage Bridge N & $6776(678)$ & 46 \\
\hline Portage Bridge S & $2745(274)$ & 38 \\
\hline
\end{tabular}

\subsection{Sample Delay Time Calculation}

The standard BPR equation is:

$$
t_{c u r}=t_{0} \times\left(1+a\left(\frac{v}{c}\right)^{B}\right)
$$

Where: $\mathrm{t}_{\mathrm{cur}}=$ predicted travel time, $\mathrm{t}_{0}=$ free flow speed travel time, $\mathrm{v}=$ volume, $\mathrm{c}$ $=$ practical capacity, $\mathrm{a}=0.15$, and $\mathrm{B}=4$

The practical capacity for Portage Bridge is 2400 Vehicles/1-hour for the PM peak hour UE traffic assignment, and 6000 vehicles/2.5-hours for the PM peak period UE traffic assignment. In contrast, 2400 vehicles capacity is used for DSA regardless to the simulation period. Capacity per TI is calculated as Capacity /60 minutes/TI.

Equations of delay time over roadway segment is presented below:

1- UE Traffic Assignment

Delay time $=$ Volume $\mathrm{x}\left(\mathrm{t}_{\mathrm{cur}}-\mathrm{t}_{0}\right)$

2- DSA Traffic Assignment

Delay time $_{\mathrm{TI}}=$ Volume $_{\mathrm{TI}} \mathrm{x}\left(\mathrm{t}_{\mathrm{curTI}}-\mathrm{t}_{0}\right)$

Total Delay Time over link $=\sum_{T I}^{A P}$ Delay $_{\text {Time }}$ TI 


\subsection{RESULTS FOR OTTAWA-HULL REGIONAL UE AND DSA SIMULATION}

Differences between UE and DSA traffic assignment impedance and delay time calculation is reviewed in previous sections. Identical networks have been used to compare the results of both traffic assignments. Ten models are used for the comparison. Matrices calibration for all models were discussed in previous section of this chapter. Demand data from 2018 was used in all models. The models and differences among them are as follows:

\subsubsection{Model 1 - UE Traffic Assignment for PM Peak Hour}

UE traffic assignment for PM peak hour 15:30 - 16:30. The Link capacities is specified for 1-hour link capacity. Figure 9.13 and Figure 9.14 below show the traffic over network and capacity values for link types.

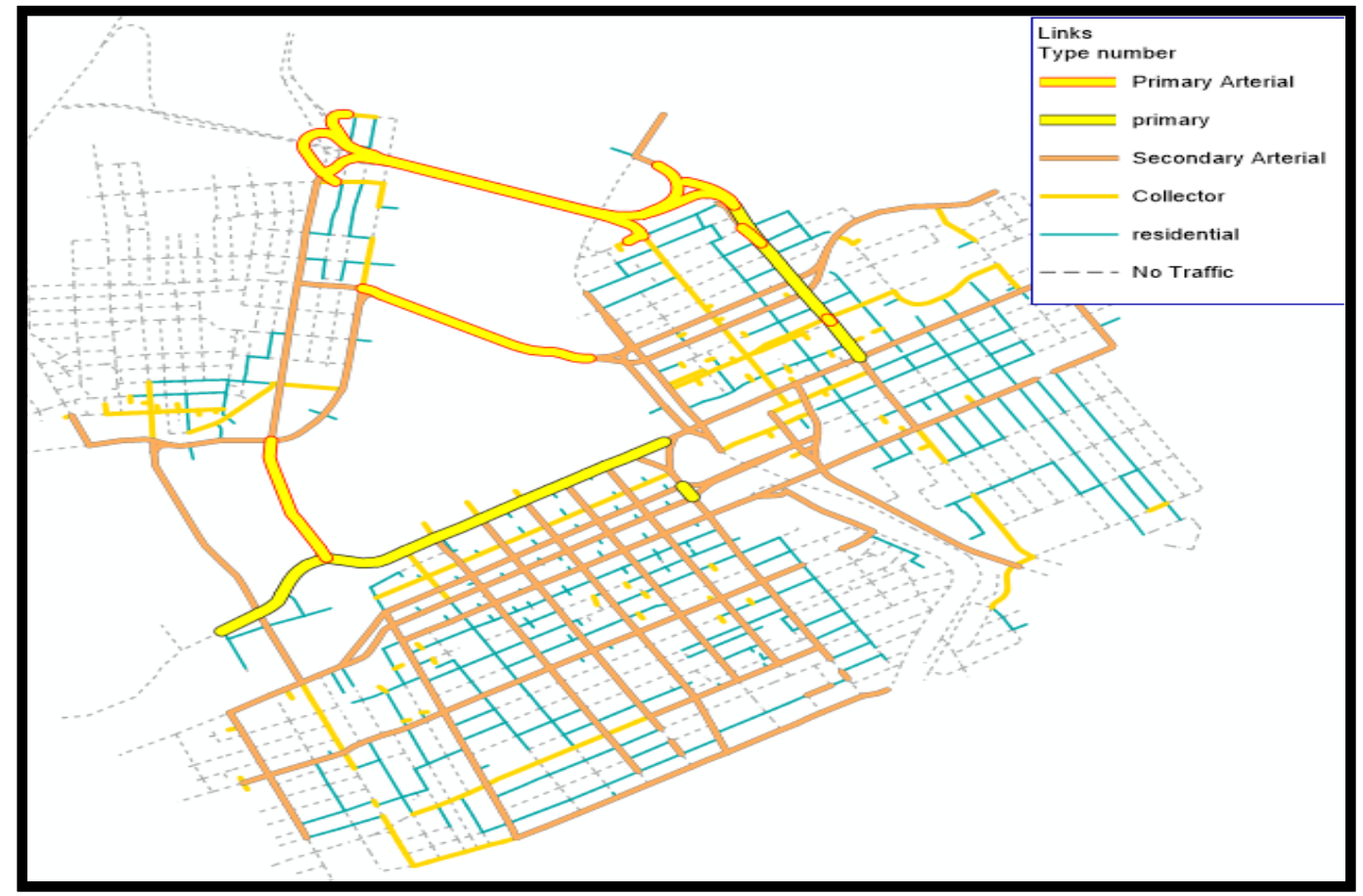

Figure 9.13: Model 1 UE Traffic Assignment 


\begin{tabular}{|c|c|c|c|c|c|c|c|c|c|c|}
\hline Count: 100 & No & Name & Strict & Rank & TSysSet & NumLanes & CapPrT & VOPrT & VMinPrT & VMax_PrTSys(CAR) \\
\hline 11 & 10 & Motorway, 1 lane & $\square$ & 1 & CAR,HGV & 1 & 1500 & $100 \mathrm{~km} / \mathrm{h}$ & $0 \mathrm{~km} / \mathrm{h}$ & $110 \mathrm{~km} / \mathrm{h}$ \\
\hline 12 & 11 & Motorway, 2 lanes & $\square$ & 1 & CAR,HGV & 2 & 3000 & $100 \mathrm{~km} / \mathrm{h}$ & $0 \mathrm{~km} / \mathrm{h}$ & $110 \mathrm{~km} / \mathrm{h}$ \\
\hline 13 & 12 & Motorway, 3 lanes & $\square$ & 1 & CAR,HGV & 3 & 4500 & $100 \mathrm{~km} / \mathrm{h}$ & $0 \mathrm{~km} / \mathrm{h}$ & $110 \mathrm{~km} / \mathrm{h}$ \\
\hline 14 & 13 & Motorway, 4 lanes & $\square$ & 1 & CAR,HGV & 4 & 6000 & $100 \mathrm{~km} / \mathrm{h}$ & $0 \mathrm{~km} / \mathrm{h}$ & $110 \mathrm{~km} / \mathrm{h}$ \\
\hline 15 & 14 & NA & $\square$ & 1 & CAR,HGV & 0 & 0 & $0 \mathrm{~km} / \mathrm{h}$ & $0 \mathrm{~km} / \mathrm{h}$ & $0 \mathrm{~km} / \mathrm{h}$ \\
\hline 16 & 15 & NA & $\square$ & 1 & CAR,HGV & 0 & 0 & $0 \mathrm{~km} / \mathrm{h}$ & $0 \mathrm{~km} / \mathrm{h}$ & $0 \mathrm{~km} / \mathrm{h}$ \\
\hline 17 & 16 & NA & $\square$ & 1 & CAR,HGV & 0 & 0 & $0 \mathrm{~km} / \mathrm{h}$ & $0 \mathrm{~km} / \mathrm{h}$ & $0 \mathrm{~km} / \mathrm{h}$ \\
\hline 18 & 17 & NA & $\square$ & 1 & CAR,HGV & 0 & 0 & $\mathrm{Okm} / \mathrm{h}$ & $0 \mathrm{~km} / \mathrm{h}$ & $\mathrm{Okm} / \mathrm{h}$ \\
\hline 19 & 18 & Motorway_link, 1 lane & $\square$ & 1 & CAR,HGV & 1 & 1100 & $80 \mathrm{~km} / \mathrm{h}$ & $0 \mathrm{~km} / \mathrm{h}$ & $80 \mathrm{~km} / \mathrm{h}$ \\
\hline 20 & 19 & Motorway_link, 2 lanes & $\square$ & 1 & CAR,HGV & 2 & 2200 & $80 \mathrm{~km} / \mathrm{h}$ & $0 \mathrm{~km} / \mathrm{h}$ & $80 \mathrm{~km} / \mathrm{h}$ \\
\hline 21 & 20 & Trunk, 1 lane & $\square$ & 1 & BUS,CAR,HGV & 1 & 1000 & $60 \mathrm{~km} / \mathrm{h}$ & $0 \mathrm{~km} / \mathrm{h}$ & $70 \mathrm{~km} / \mathrm{h}$ \\
\hline 22 & 21 & Trunk, 2 lanes & $\square$ & 1 & BUS,CAR,HGV & 2 & 2000 & $60 \mathrm{~km} / \mathrm{h}$ & $0 \mathrm{~km} / \mathrm{h}$ & $70 \mathrm{~km} / \mathrm{h}$ \\
\hline 23 & 22 & Trunk, 3 lanes & $\square$ & 1 & BUS,CAR,HGV & 3 & 3000 & $60 \mathrm{~km} / \mathrm{h}$ & $0 \mathrm{~km} / \mathrm{h}$ & $70 \mathrm{~km} / \mathrm{h}$ \\
\hline 24 & 23 & NCC Roadway, 1 lane 60 & $\square$ & 1 & BUS,CAR,HGV & 1 & 1000 & $60 \mathrm{~km} / \mathrm{h}$ & $0 \mathrm{~km} / \mathrm{h}$ & $60 \mathrm{~km} / \mathrm{h}$ \\
\hline 25 & 24 & NCC Roadway, 2 lanes 60 & $\square$ & 1 & BUS,CAR,HGV & 2 & 2400 & $60 \mathrm{~km} / \mathrm{h}$ & $0 \mathrm{~km} / \mathrm{h}$ & $60 \mathrm{~km} / \mathrm{h}$ \\
\hline 26 & 25 & NCC Roadway, 3 lanes 60 & $\square$ & 1 & BUS,CAR,HGV & 3 & 4800 & $60 \mathrm{~km} / \mathrm{h}$ & $0 \mathrm{~km} / \mathrm{h}$ & $60 \mathrm{~km} / \mathrm{h}$ \\
\hline 27 & 26 & NA & $\square$ & 1 & BUS,CAR,HGV & 0 & 0 & $0 \mathrm{~km} / \mathrm{h}$ & $0 \mathrm{~km} / \mathrm{h}$ & $0 \mathrm{~km} / \mathrm{h}$ \\
\hline 28 & 27 & NA & $\square$ & 1 & BUS,CAR,HGV & 0 & 0 & $0 \mathrm{~km} / \mathrm{h}$ & $0 \mathrm{~km} / \mathrm{h}$ & $0 \mathrm{~km} / \mathrm{h}$ \\
\hline 29 & 28 & Trunk_link, 1 lane & $\square$ & 1 & BUS,CAR,HGV & 1 & 800 & $60 \mathrm{~km} / \mathrm{h}$ & $0 \mathrm{~km} / \mathrm{h}$ & $60 \mathrm{~km} / \mathrm{h}$ \\
\hline 30 & 29 & Trunk_link, 2 lanes & $\square$ & 1 & BUS,CAR,HGV & 2 & 1200 & $60 \mathrm{~km} / \mathrm{h}$ & $0 \mathrm{~km} / \mathrm{h}$ & $60 \mathrm{~km} / \mathrm{h}$ \\
\hline 31 & 30 & Primary Arterial, 1 lane & $\square$ & 1 & BUS,CAR,HGV,PUTW & 1 & 1000 & $50 \mathrm{~km} / \mathrm{h}$ & $0 \mathrm{~km} / \mathrm{h}$ & $50 \mathrm{~km} / \mathrm{h}$ \\
\hline 32 & 31 & Primary Arteria, 2 lanes & $\square$ & 1 & BUS,CAR,HGV,PUTW & 2 & 2500 & $50 \mathrm{~km} / \mathrm{h}$ & $0 \mathrm{~km} / \mathrm{h}$ & $50 \mathrm{~km} / \mathrm{h}$ \\
\hline 33 & 32 & Primary Arteria, 3 lanes & $\square$ & 1 & BUS,CAR,HGV,PUTW & 3 & 3400 & $50 \mathrm{~km} / \mathrm{h}$ & $0 \mathrm{~km} / \mathrm{h}$ & $50 \mathrm{~km} / \mathrm{h}$ \\
\hline 34 & 33 & Primary Arteria, 4 lanes & $\square$ & 1 & BUS,CAR,HGV,PUTW & 4 & 4000 & $50 \mathrm{~km} / \mathrm{h}$ & $0 \mathrm{~km} / \mathrm{h}$ & $50 \mathrm{~km} / \mathrm{h}$ \\
\hline 35 & 34 & Primary Arteria, 5 lanes & $\square$ & 1 & BUS,CAR,HGV,PUTW & 5 & 5000 & $50 \mathrm{~km} / \mathrm{h}$ & $0 \mathrm{~km} / \mathrm{h}$ & $50 \mathrm{~km} / \mathrm{h}$ \\
\hline 36 & 35 & NA & $\square$ & 1 & BUS,CAR,HGV,PUTW & 2 & 0 & $0 \mathrm{~km} / \mathrm{h}$ & $0 \mathrm{~km} / \mathrm{h}$ & $0 \mathrm{~km} / \mathrm{h}$ \\
\hline 37 & 36 & NA & $\square$ & 1 & BUS,CAR,HGV,PUTW & 1 & 0 & $0 \mathrm{~km} / \mathrm{h}$ & $0 \mathrm{~km} / \mathrm{h}$ & $\mathrm{Okm} / \mathrm{h}$ \\
\hline 38 & 37 & NA & $\square$ & 1 & BUS,CAR,HGV,PUTW & 1 & 0 & $0 \mathrm{~km} / \mathrm{h}$ & $0 \mathrm{~km} / \mathrm{h}$ & $0 \mathrm{~km} / \mathrm{h}$ \\
\hline 39 & 38 & NA & $\square$ & 1 & BUS,CAR,HGV,PUTW & 1 & 0 & $0 \mathrm{~km} / \mathrm{h}$ & $0 \mathrm{~km} / \mathrm{h}$ & $\mathrm{Okm} / \mathrm{h}$ \\
\hline 40 & 39 & Primary_link & $\square$ & 1 & BUS,CAR,HGV,PUTW & 1 & 800 & $40 \mathrm{~km} / \mathrm{h}$ & $0 \mathrm{~km} / \mathrm{h}$ & $40 \mathrm{~km} / \mathrm{h}$ \\
\hline 41 & 40 & Secondary Arterial, 1 lane & $\square$ & 1 & BUS,CAR,HGV & 1 & 800 & $50 \mathrm{~km} / \mathrm{h}$ & $0 \mathrm{~km} / \mathrm{h}$ & $50 \mathrm{~km} / \mathrm{h}$ \\
\hline 42 & 41 & Secondary Avterial, 2 lanes & $\square$ & 1 & BUS,CAR,HGV & 2 & 1200 & $50 \mathrm{~km} / \mathrm{h}$ & $0 \mathrm{~km} / \mathrm{h}$ & $50 \mathrm{~km} / \mathrm{h}$ \\
\hline 43 & 42 & Secondary Avterial, 3 lanes & $\square$ & 1 & BUS,CAR,HGV & 3 & 1600 & $50 \mathrm{~km} / \mathrm{h}$ & $0 \mathrm{~km} / \mathrm{h}$ & $50 \mathrm{~km} / \mathrm{h}$ \\
\hline 44 & 43 & Secondary Avterial, 4 lanes & $\square$ & 1 & BUS,CAR,HGV & 4 & 2000 & $50 \mathrm{~km} / \mathrm{h}$ & $0 \mathrm{~km} / \mathrm{h}$ & $50 \mathrm{~km} / \mathrm{h}$ \\
\hline 45 & 44 & NA & $\square$ & 1 & BUS,CAR,HGV & 0 & 0 & $0 \mathrm{~km} / \mathrm{h}$ & $0 \mathrm{~km} / \mathrm{h}$ & $0 \mathrm{~km} / \mathrm{h}$ \\
\hline 46 & 45 & NA & $\square$ & 1 & BUS,CAR,HGV & 0 & 0 & $0 \mathrm{~km} / \mathrm{h}$ & $0 \mathrm{~km} / \mathrm{h}$ & $\mathrm{Okm} / \mathrm{h}$ \\
\hline 47 & 46 & NA & $\square$ & 1 & BUS,CAR,HGV & 0 & 0 & $0 \mathrm{~km} / \mathrm{h}$ & $0 \mathrm{~km} / \mathrm{h}$ & $0 \mathrm{~km} / \mathrm{h}$ \\
\hline 48 & 47 & NA & $\square$ & 1 & BUS,CAR,HGV & 0 & 0 & $0 \mathrm{~km} / \mathrm{h}$ & $0 \mathrm{~km} / \mathrm{h}$ & $0 \mathrm{~km} / \mathrm{h}$ \\
\hline 49 & 48 & NA & $\square$ & 1 & BUS,CAR,HGV & 0 & 0 & $0 \mathrm{~km} / \mathrm{h}$ & $0 \mathrm{~km} / \mathrm{h}$ & $0 \mathrm{~km} / \mathrm{h}$ \\
\hline 50 & 49 & NA & $\square$ & 1 & CAR,HGV & 0 & 0 & $0 \mathrm{~km} / \mathrm{h}$ & $0 \mathrm{~km} / \mathrm{h}$ & $0 \mathrm{~km} / \mathrm{h}$ \\
\hline 51 & 50 & collector, 1 lane & $\square$ & 1 & BUS,CAR,HGV & 1 & 600 & $40 \mathrm{~km} / \mathrm{h}$ & $0 \mathrm{~km} / \mathrm{h}$ & $40 \mathrm{~km} / \mathrm{h}$ \\
\hline 52 & 51 & Collector, 2 lanes & $\square$ & 1 & BUS,CAR,HGV & 2 & 800 & $40 \mathrm{~km} / \mathrm{h}$ & $0 \mathrm{~km} / \mathrm{h}$ & $40 \mathrm{~km} / \mathrm{h}$ \\
\hline 53 & 52 & NA & $\square$ & 1 & BUS,CAR,HGV & 0 & 0 & $0 \mathrm{~km} / \mathrm{h}$ & $0 \mathrm{~km} / \mathrm{h}$ & $0 \mathrm{~km} / \mathrm{h}$ \\
\hline 54 & 53 & NA & $\square$ & 1 & BUS,CAR,HGV & 0 & 0 & $0 \mathrm{~km} / \mathrm{h}$ & $0 \mathrm{~km} / \mathrm{h}$ & $0 \mathrm{~km} / \mathrm{h}$ \\
\hline
\end{tabular}

Figure 9.14: Model 1 - Link Types Capacities

\subsubsection{Model 2 - DSA Traffic Assignment for PM Peak Hour}

DSA traffic assignment for PM peak hour 15:30 - 16:30. The time intervals (TI)

for the assignment is 15 minutes. See Figure 9.15. Demand data or departure time of

roadway users is divided equally among time intervals. See Figure 9.16. Traffic over the

network is presented in Figure 9.17. Capacities per link type is identical to model 1 - see

Figure 9.14 above. 


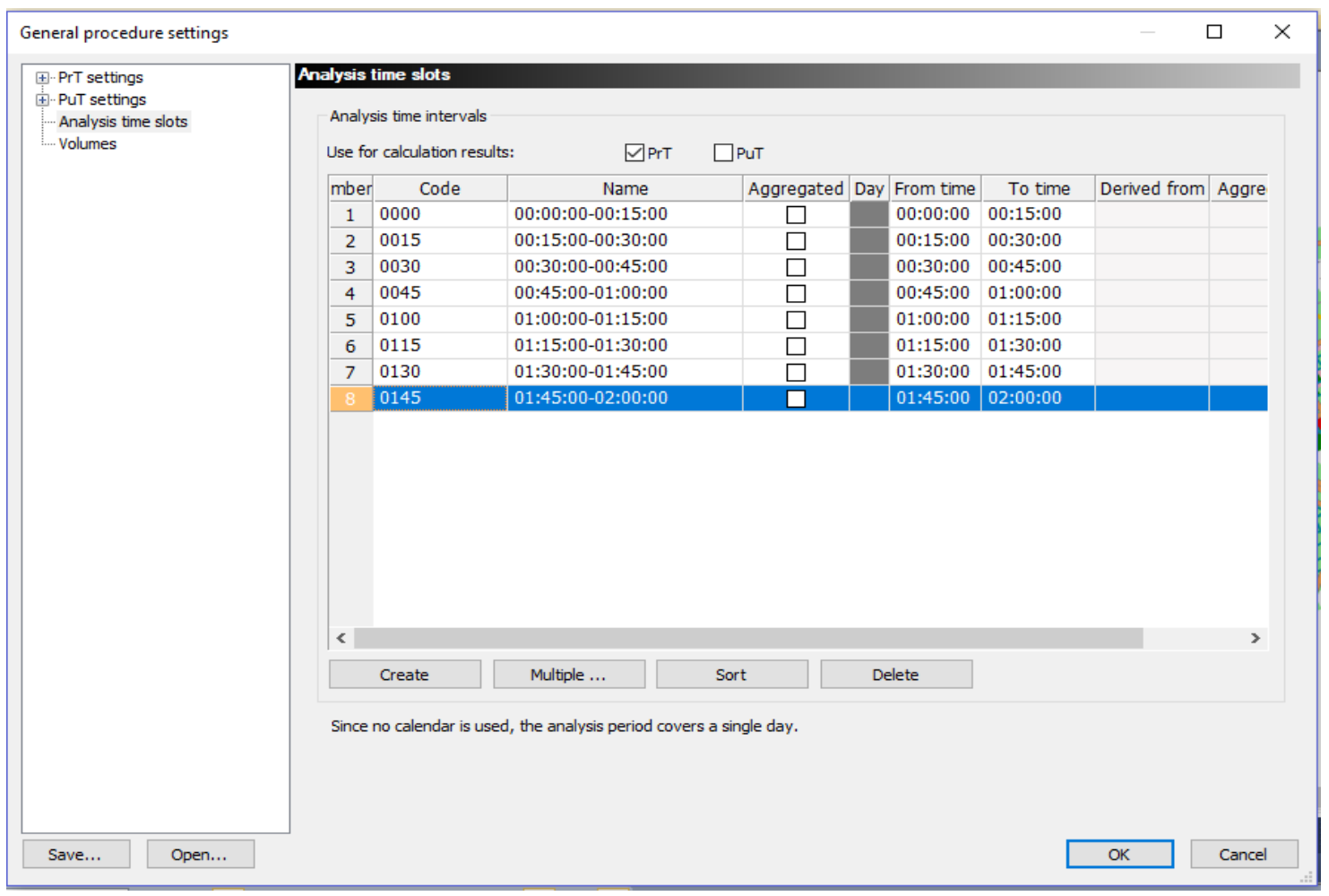

Figure 9.15: Model 2 - DSA TI of 15 Minutes

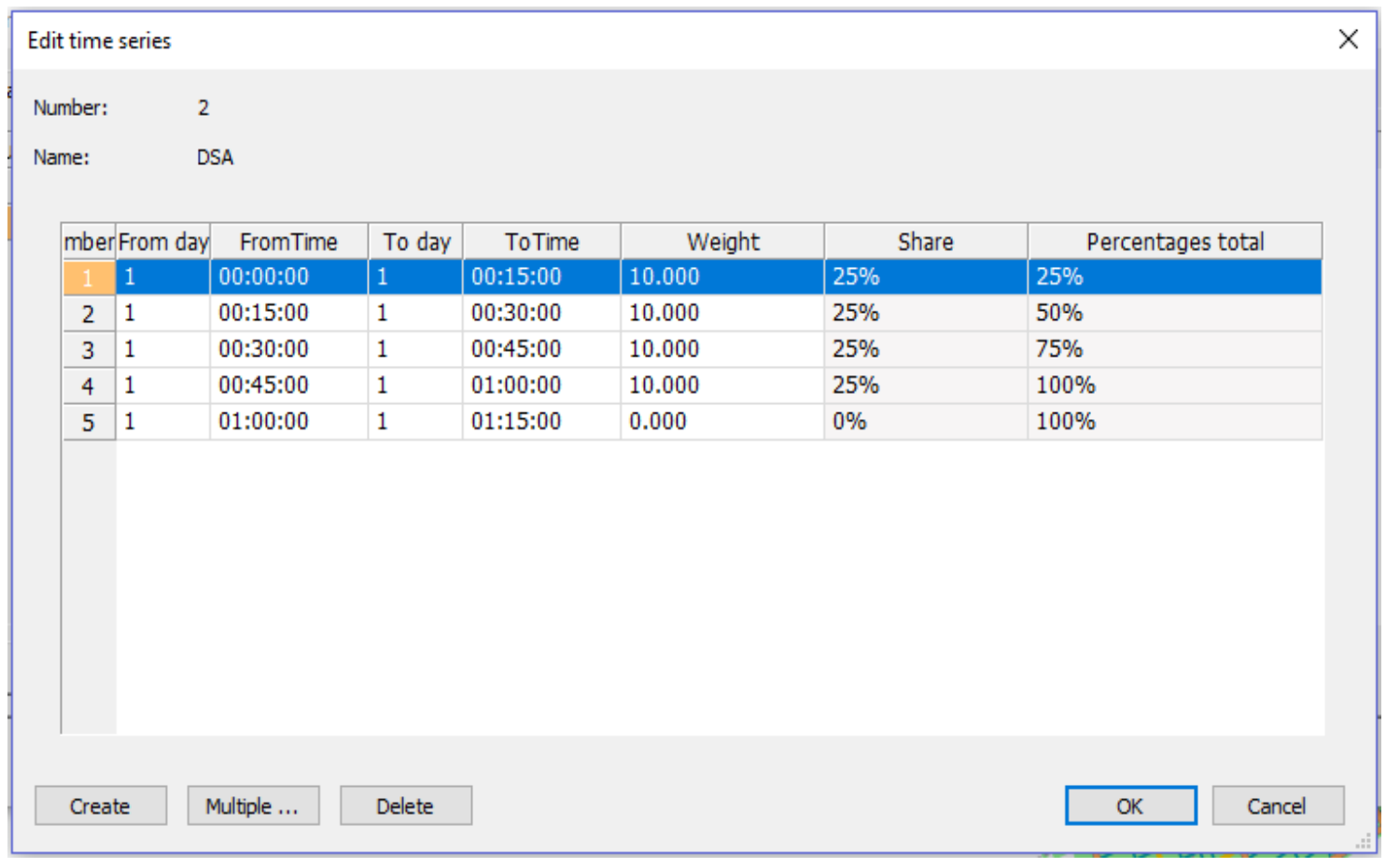

Figure 9.16: Model 2- DSA 15 Minutes TI Departure Time per TI 


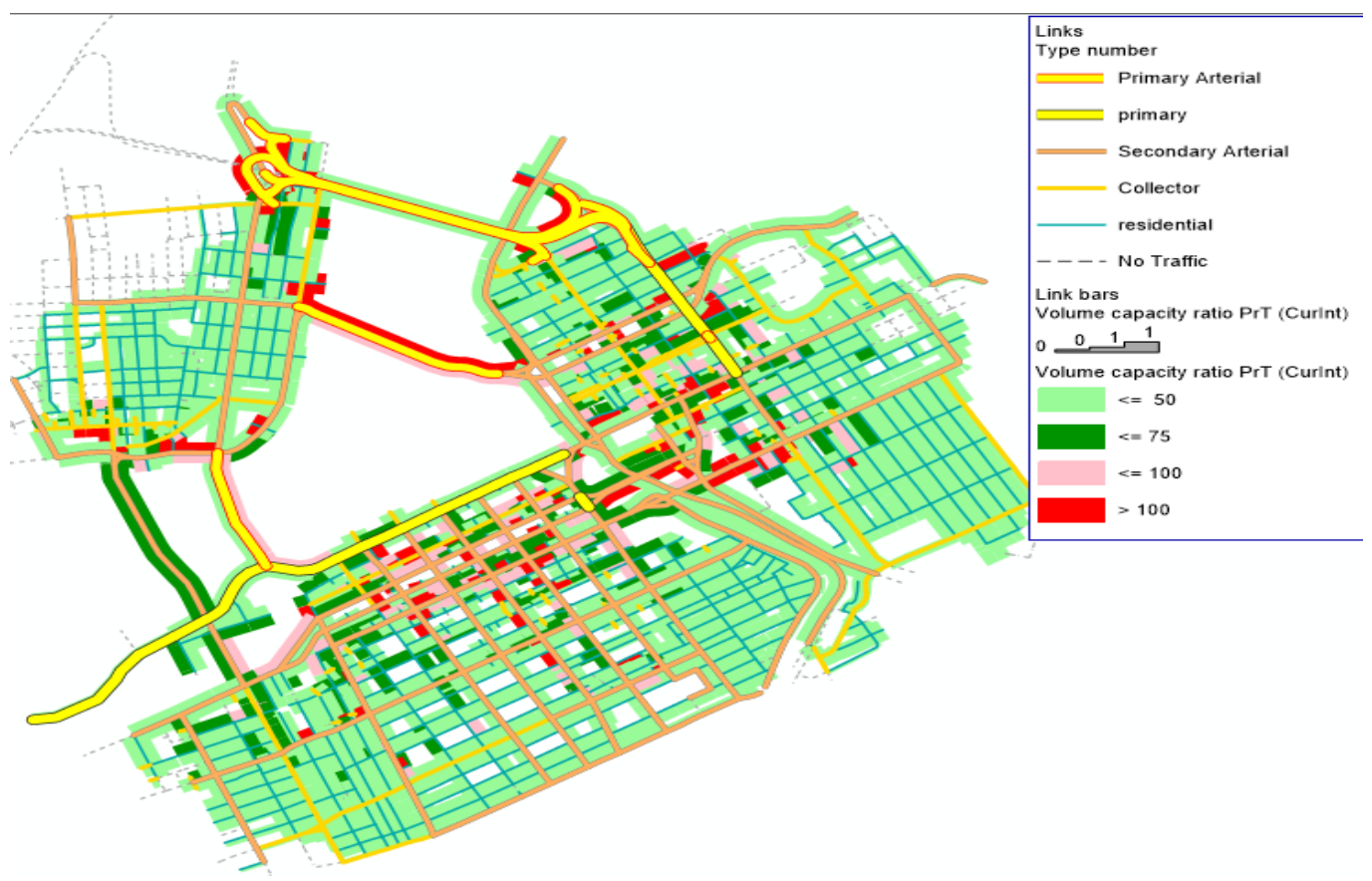

Figure 9.17: Model 2 - DSA Traffic Distribition 15 Minutes TI

\subsubsection{Model 3 - DSA Traffic Assignment for PM Peak Hour}

DSA traffic assignment for PM peak hour 15:30 - 16:30. The time intervals (TI) for the assignment is 5 minutes (Figure 9.18). Demand data or departure time of roadway users is divided equally among Time intervals. See Figure 9.19. Capacities per link type is identical to model $1-$ see Figure 9.14 above.

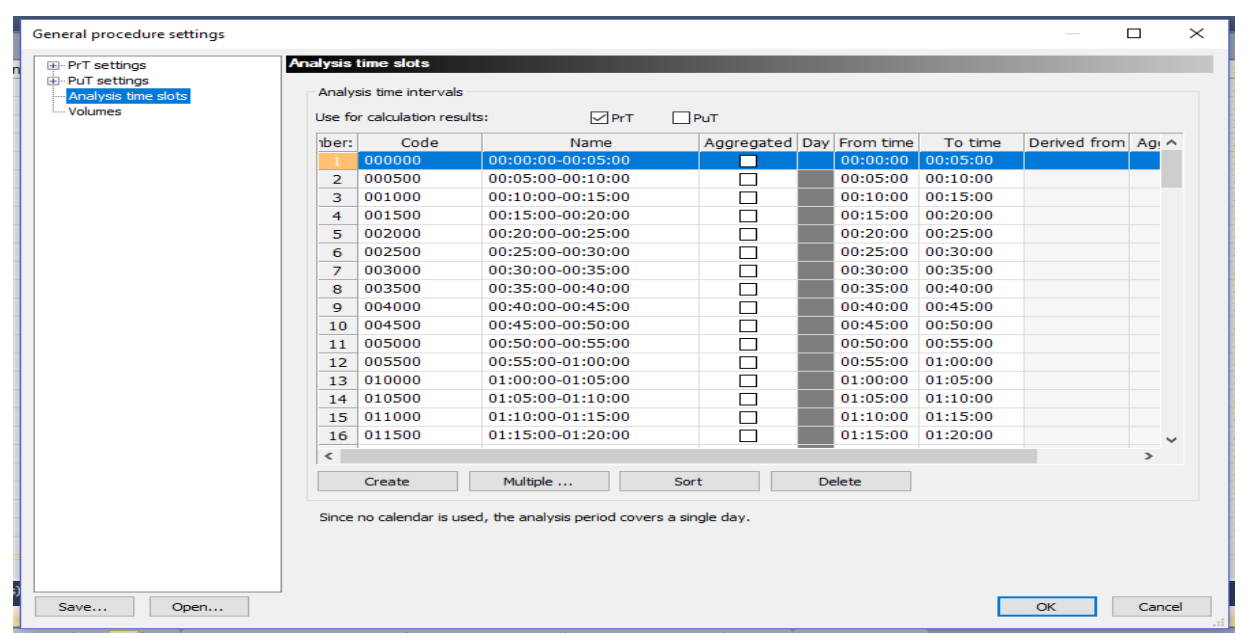

Figure 9.18: model 3 - DSA TI of 5 Minutes 


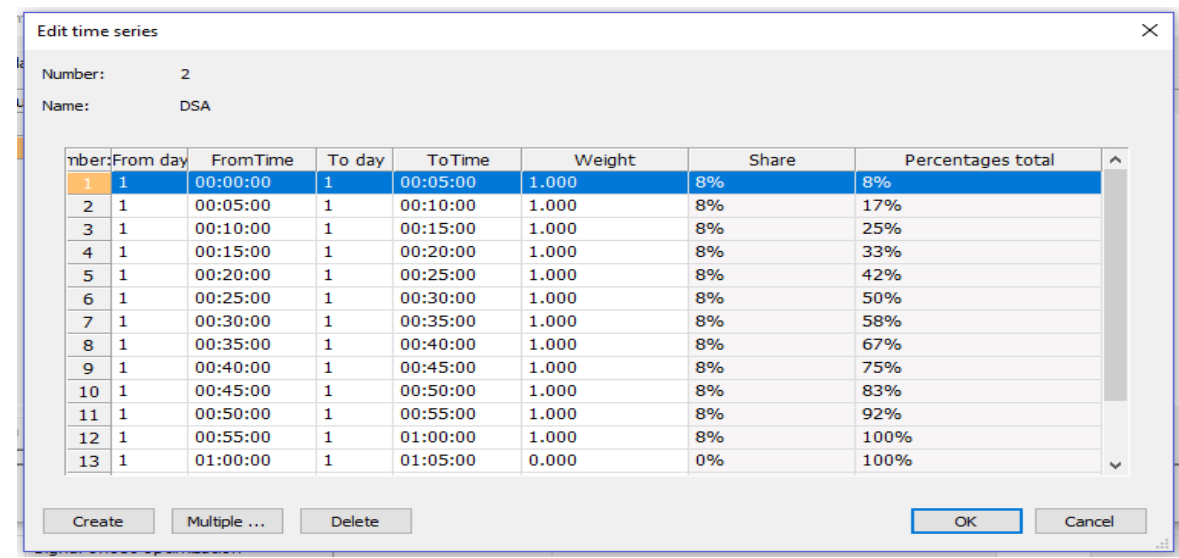

Figure 9.19:Model 3 - DSA Peak Hour 5 Minutes TI Departure Time per TI

\subsubsection{Model 4 - UE Traffic Assignment for PM Peak Period}

UE traffic assignment for PM peak period: 15:00 - 17:30. The link capacities is

specified as 2.5 -hours link capacity. Figure 9.20 below shows capacity values for each

link type.

\begin{tabular}{|c|c|c|c|c|c|c|c|c|c|c|}
\hline Count: 100 & No & Name & Strict & Rank & TSysSet & NumLanes & CapPrT & VOPrT & VMinPrT & VMax_PrTSys(CAR) \\
\hline 11 & 10 & Motorway. 1 lane & $\square$ & 1 & CAR,HGV & 1 & 3750 & $100 \mathrm{~km} / \mathrm{h}$ & $0 \mathrm{~km} / \mathrm{h}$ & $110 \mathrm{~km} / \mathrm{h}$ \\
\hline 12 & 11 & Motorway. 2 lanes & $\square$ & 1 & CAR,HGV & 2 & 7500 & $100 \mathrm{~km} / \mathrm{h}$ & $0 \mathrm{~km} / \mathrm{h}$ & $110 \mathrm{~km} / \mathrm{h}$ \\
\hline 13 & 12 & Motorway. 3 lanes & $\square$ & 1 & CAR,HGV & 3 & 11250 & $100 \mathrm{~km} / \mathrm{h}$ & $0 \mathrm{~km} / \mathrm{h}$ & $110 \mathrm{~km} / \mathrm{h}$ \\
\hline 14 & 13 & Motorway. 4 lanes & $\square$ & 1 & CAR,HGV & 4 & 15000 & $100 \mathrm{~km} / \mathrm{h}$ & $0 \mathrm{~km} / \mathrm{h}$ & $110 \mathrm{~km} / \mathrm{h}$ \\
\hline 15 & 14 & NA & $\square$ & 1 & CAR,HGV & 0 & 0 & $0 \mathrm{~km} / \mathrm{h}$ & $0 \mathrm{~km} / \mathrm{h}$ & $0 \mathrm{~km} / \mathrm{h}$ \\
\hline 16 & 15 & NA & $\square$ & 1 & CAR,HGV & 0 & 0 & $0 \mathrm{~km} / \mathrm{h}$ & $0 \mathrm{~km} / \mathrm{h}$ & $0 \mathrm{~km} / \mathrm{h}$ \\
\hline 17 & 16 & NA & $\square$ & 1 & CAR,HGV & 0 & 0 & $0 \mathrm{~km} / \mathrm{h}$ & $0 \mathrm{~km} / \mathrm{h}$ & $0 \mathrm{~km} / \mathrm{h}$ \\
\hline 18 & 17 & NA & $\square$ & 1 & CAR,HGV & 0 & 0 & $0 \mathrm{~km} / \mathrm{h}$ & $0 \mathrm{~km} / \mathrm{h}$ & $0 \mathrm{~km} / \mathrm{h}$ \\
\hline 19 & 18 & Motorway_link. 1 lane & $\square$ & 1 & CAR,HGV & 1 & 2750 & $80 \mathrm{~km} / \mathrm{h}$ & $0 \mathrm{~km} / \mathrm{h}$ & $80 \mathrm{~km} / \mathrm{h}$ \\
\hline 20 & 19 & Motorway_link. 2 lanes & $\square$ & 1 & CAR,HGV & 2 & 5500 & $80 \mathrm{~km} / \mathrm{h}$ & $0 \mathrm{~km} / \mathrm{h}$ & $80 \mathrm{~km} / \mathrm{h}$ \\
\hline 21 & 20 & Trunk. 1 lane & $\square$ & 1 & BUS.CAR.HGV & 1 & 2500 & $60 \mathrm{~km} / \mathrm{h}$ & $0 \mathrm{~km} / \mathrm{h}$ & $70 \mathrm{~km} / \mathrm{h}$ \\
\hline 22 & 21 & Trunk. 2 lanes & $\square$ & 1 & BUS.CAR.HGV & 2 & 5000 & $60 \mathrm{~km} / \mathrm{h}$ & $0 \mathrm{~km} / \mathrm{h}$ & $70 \mathrm{~km} / \mathrm{h}$ \\
\hline 23 & 22 & Trunk. 3 lanes & $\square$ & 1 & BUS.CAR.HGV & 3 & 7500 & $60 \mathrm{~km} / \mathrm{h}$ & $0 \mathrm{~km} / \mathrm{h}$ & $70 \mathrm{~km} / \mathrm{h}$ \\
\hline 24 & 23 & NCC Roadway. 1 lane 60 & $\square$ & 1 & BUS.CAR.HGV & 1 & 2500 & $60 \mathrm{~km} / \mathrm{h}$ & $0 \mathrm{~km} / \mathrm{h}$ & $60 \mathrm{~km} / \mathrm{h}$ \\
\hline 25 & 24 & NCC Roadway, 2 lanes 60 & $\square$ & 1 & BUS.CAR,HGV & 2 & 6000 & $60 \mathrm{~km} / \mathrm{h}$ & $0 \mathrm{~km} / \mathrm{h}$ & $60 \mathrm{~km} / \mathrm{h}$ \\
\hline 26 & 25 & NCC Roadway. 3 lanes 60 & $\square$ & 1 & BUS.CAR,HGV & 3 & 12000 & $60 \mathrm{~km} / \mathrm{h}$ & $0 \mathrm{~km} / \mathrm{h}$ & $60 \mathrm{~km} / \mathrm{h}$ \\
\hline 27 & 26 & NA & $\square$ & 1 & BUS.CAR,HGV & 0 & 0 & $0 \mathrm{~km} / \mathrm{h}$ & $0 \mathrm{~km} / \mathrm{h}$ & $0 \mathrm{~km} / \mathrm{h}$ \\
\hline 28 & 27 & NA & $\square$ & 1 & BUS,CAR,HGV & 0 & 0 & $0 \mathrm{~km} / \mathrm{h}$ & $0 \mathrm{~km} / \mathrm{h}$ & $0 \mathrm{~km} / \mathrm{h}$ \\
\hline 29 & 28 & Trunk_link. 1 lane & $\square$ & 1 & BUS.CAR,HGV & 1 & 2000 & $60 \mathrm{~km} / \mathrm{h}$ & $0 \mathrm{~km} / \mathrm{h}$ & $60 \mathrm{~km} / \mathrm{h}$ \\
\hline 30 & 29 & Trunk_link. 2 lanes & $\square$ & 1 & BUS.CAR.HGV & 2 & 3000 & $60 \mathrm{~km} / \mathrm{h}$ & $0 \mathrm{~km} / \mathrm{h}$ & $60 \mathrm{~km} / \mathrm{h}$ \\
\hline 31 & 30 & Primary Avterial, 1 lane & $\square$ & 1 & BUS.CAR,HGV.PUTW & 1 & 2500 & $50 \mathrm{~km} / \mathrm{h}$ & $0 \mathrm{~km} / \mathrm{h}$ & $50 \mathrm{~km} / \mathrm{h}$ \\
\hline 32 & 31 & Primary Avteria, 2 lanes & $\square$ & 1 & BUS,CAR,HGV.PUTW & 2 & 6250 & $50 \mathrm{~km} / \mathrm{h}$ & $0 \mathrm{~km} / \mathrm{h}$ & $50 \mathrm{~km} / \mathrm{h}$ \\
\hline 33 & 32 & Primary Arteria, 3 lanes & $\square$ & 1 & BUS.CAR,HGV.PUTW & 3 & 8500 & $50 \mathrm{~km} / \mathrm{h}$ & $0 \mathrm{~km} / \mathrm{h}$ & $50 \mathrm{~km} / \mathrm{h}$ \\
\hline 34 & 33 & Primary Avteria, 4 lanes & $\square$ & 1 & BUS.CAR,HGV.PUTW & 4 & 10000 & $50 \mathrm{~km} / \mathrm{h}$ & $0 \mathrm{~km} / \mathrm{h}$ & $50 \mathrm{~km} / \mathrm{h}$ \\
\hline 35 & 34 & Primary Avteria. 5 lanes & $\square$ & 1 & BUS.CAR.HGV.PUTW & 5 & 12500 & $50 \mathrm{~km} / \mathrm{h}$ & $0 \mathrm{~km} / \mathrm{h}$ & $50 \mathrm{~km} / \mathrm{h}$ \\
\hline 36 & 35 & NA & $\square$ & 1 & BUS.CAR,HGV.PUTW & 2 & 0 & $0 \mathrm{~km} / \mathrm{h}$ & $0 \mathrm{~km} / \mathrm{h}$ & $0 \mathrm{~km} / \mathrm{h}$ \\
\hline 37 & 36 & NA & $\square$ & 1 & BUS.CAR,HGV.PUTW & 1 & 0 & $0 \mathrm{~km} / \mathrm{h}$ & $0 \mathrm{~km} / \mathrm{h}$ & $0 \mathrm{~km} / \mathrm{h}$ \\
\hline 38 & 37 & NA & $\square$ & 1 & BUS.CAR,HGV.PUTW & 1 & 0 & $0 \mathrm{~km} / \mathrm{h}$ & $0 \mathrm{~km} / \mathrm{h}$ & $0 \mathrm{~km} / \mathrm{h}$ \\
\hline 39 & 38 & NA & $\square$ & 1 & BUS,CAR,HGV.PUTW & 1 & 0 & $0 \mathrm{~km} / \mathrm{h}$ & $0 \mathrm{~km} / \mathrm{h}$ & $0 \mathrm{~km} / \mathrm{h}$ \\
\hline 40 & 39 & Primary_link & $\square$ & 1 & BUS.CAR,HGV.PUTW & 1 & 2000 & $40 \mathrm{~km} / \mathrm{h}$ & $0 \mathrm{~km} / \mathrm{h}$ & $40 \mathrm{~km} / \mathrm{h}$ \\
\hline 41 & 40 & Secondary Avterial, 1 lane & 口 & 1 & BUS,CAR,HGV & 1 & 2000 & $50 \mathrm{~km} / \mathrm{h}$ & $0 \mathrm{~km} / \mathrm{h}$ & $50 \mathrm{~km} / \mathrm{h}$ \\
\hline 42 & 41 & Secondary Arterial, 2 lanes & $\square$ & 1 & BUS.CAR,HGV & 2 & 3000 & $50 \mathrm{~km} / \mathrm{h}$ & $0 \mathrm{~km} / \mathrm{h}$ & $50 \mathrm{~km} / \mathrm{h}$ \\
\hline 43 & 42 & Secondary Arterial, 3 lanes & $\square$ & 1 & BUS.CAR,HGV & 3 & 4000 & $50 \mathrm{~km} / \mathrm{h}$ & $0 \mathrm{~km} / \mathrm{h}$ & $50 \mathrm{~km} / \mathrm{h}$ \\
\hline 44 & 43 & Secondary Arterial. 4 lanes & $\square$ & 1 & BUS.CAR,HGV & 4 & 5000 & $50 \mathrm{~km} / \mathrm{h}$ & $0 \mathrm{~km} / \mathrm{h}$ & $50 \mathrm{~km} / \mathrm{h}$ \\
\hline 45 & 44 & NA & $\square$ & 1 & BUS.CAR.HGV & 0 & 0 & $0 \mathrm{~km} / \mathrm{h}$ & $0 \mathrm{~km} / \mathrm{h}$ & $0 \mathrm{~km} / \mathrm{h}$ \\
\hline 46 & 45 & NA & $\square$ & 1 & BUS.CAR.HGV & 0 & 0 & $0 \mathrm{~km} / \mathrm{h}$ & $0 \mathrm{~km} / \mathrm{h}$ & $0 \mathrm{~km} / \mathrm{h}$ \\
\hline 47 & 46 & NA & $\square$ & 1 & BUS.CAR,HGV & 0 & 0 & $0 \mathrm{~km} / \mathrm{h}$ & $0 \mathrm{~km} / \mathrm{h}$ & $0 \mathrm{~km} / \mathrm{h}$ \\
\hline 48 & 47 & NA & $\square$ & 1 & BUS.CAR.HGV & 0 & 0 & $0 \mathrm{~km} / \mathrm{h}$ & $0 \mathrm{~km} / \mathrm{h}$ & $0 \mathrm{~km} / \mathrm{h}$ \\
\hline 49 & 48 & NA & $\square$ & 1 & BUS.CAR,HGV & 0 & 0 & $0 \mathrm{~km} / \mathrm{h}$ & $0 \mathrm{~km} / \mathrm{h}$ & $0 \mathrm{~km} / \mathrm{h}$ \\
\hline 50 & 49 & NA & $\square$ & 1 & CAR,HGV & 0 & 0 & $0 \mathrm{~km} / \mathrm{h}$ & $0 \mathrm{~km} / \mathrm{h}$ & $0 \mathrm{~km} / \mathrm{h}$ \\
\hline 51 & 50 & collector, 1 lane & $\square$ & 1 & BUS.CAR,HGV & 1 & 1500 & $40 \mathrm{~km} / \mathrm{h}$ & $0 \mathrm{~km} / \mathrm{h}$ & $40 \mathrm{~km} / \mathrm{h}$ \\
\hline 52 & 51 & Collector. 2 lanes & $\square$ & 1 & BUS.CAR,HGV & 2 & 2000 & $40 \mathrm{~km} / \mathrm{h}$ & $0 \mathrm{~km} / \mathrm{h}$ & $40 \mathrm{~km} / \mathrm{h}$ \\
\hline 53 & 52 & NA & $\square$ & 1 & BUS.CAR,HGV & 0 & 0 & $0 \mathrm{~km} / \mathrm{h}$ & $0 \mathrm{~km} / \mathrm{h}$ & $0 \mathrm{~km} / \mathrm{h}$ \\
\hline
\end{tabular}

Figure 9.20: Model 4 - UE 2.5 Peak Period Link Types and Capacities 


\subsubsection{Model 5 - DSA Traffic Assignment for PM Peak Period}

DSA traffic assignment for PM peak period 15:00 - 17:30. The time intervals

(TI) for the assignment is 15 minutes, see Figure 9.21. Demand data or departure time of

roadway users is divided equally among Time intervals. See Figure 9.22. Capacities per

link type is identical to model 1 - see Figure 9.14 above.

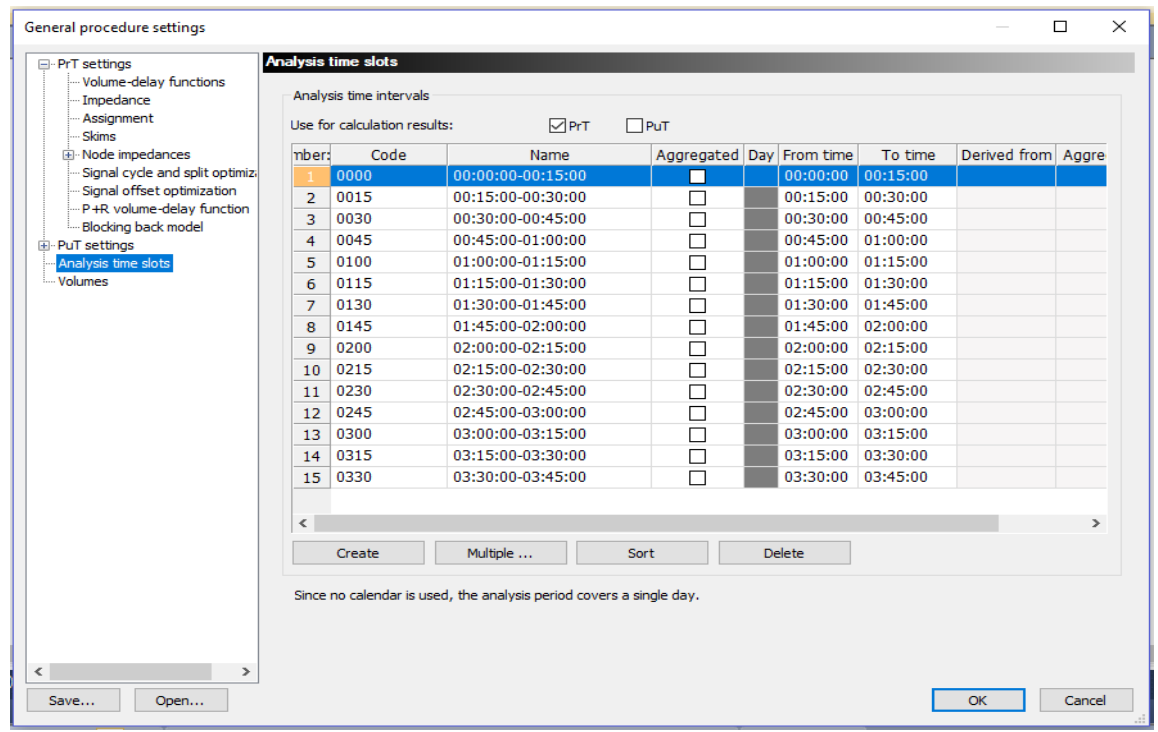

Figure 9.21: Model 5 - DSA TI of 15 Minutes

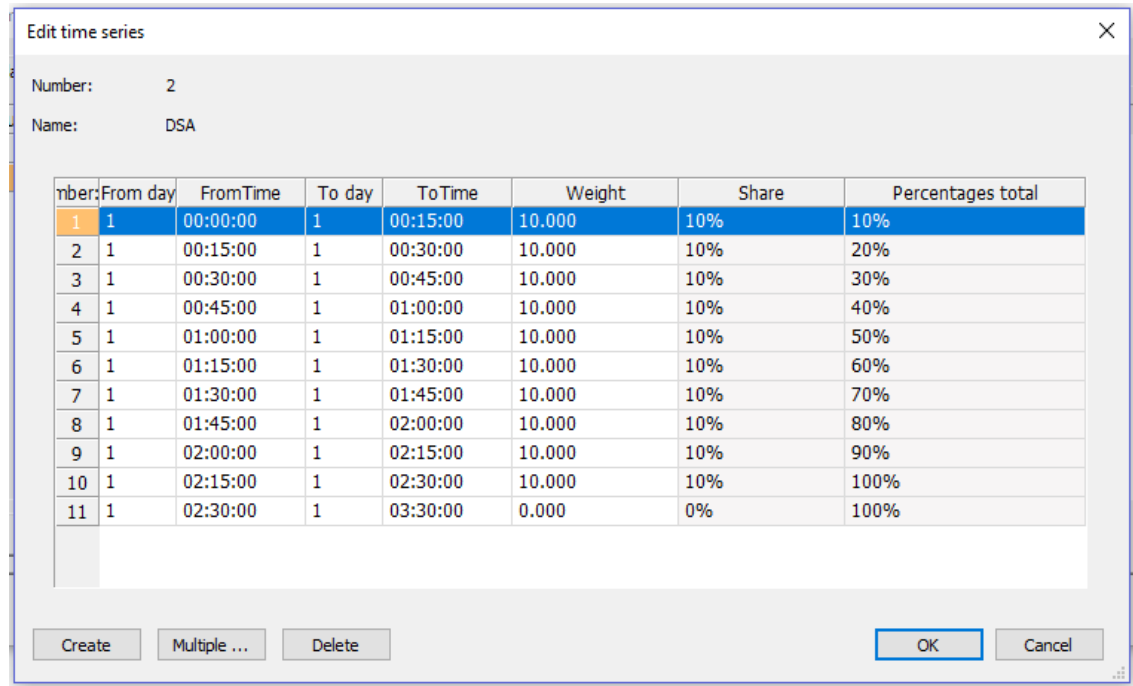

Figure 9.22: Model 5 - DSA Peak Period 15 Minutes TI Departure Time per TI 


\subsubsection{Model 6 - DSA Traffic Assignment for PM Peak Period}

DSA traffic assignment for PM peak period 15:00 - 17:30. The time intervals

(TI) for the assignment is 15 minutes. Demand data or departure time of roadway users is divided among Time intervals to reflect realistic traffic flow (Figure 9.23). Model 6 differ from model 5 with the amount of traffic released into the network over time. Table 9-7 below shows the percentage difference of traffic over the network. Capacities per link type is identical to model 1 - see Figure 9.14 above.

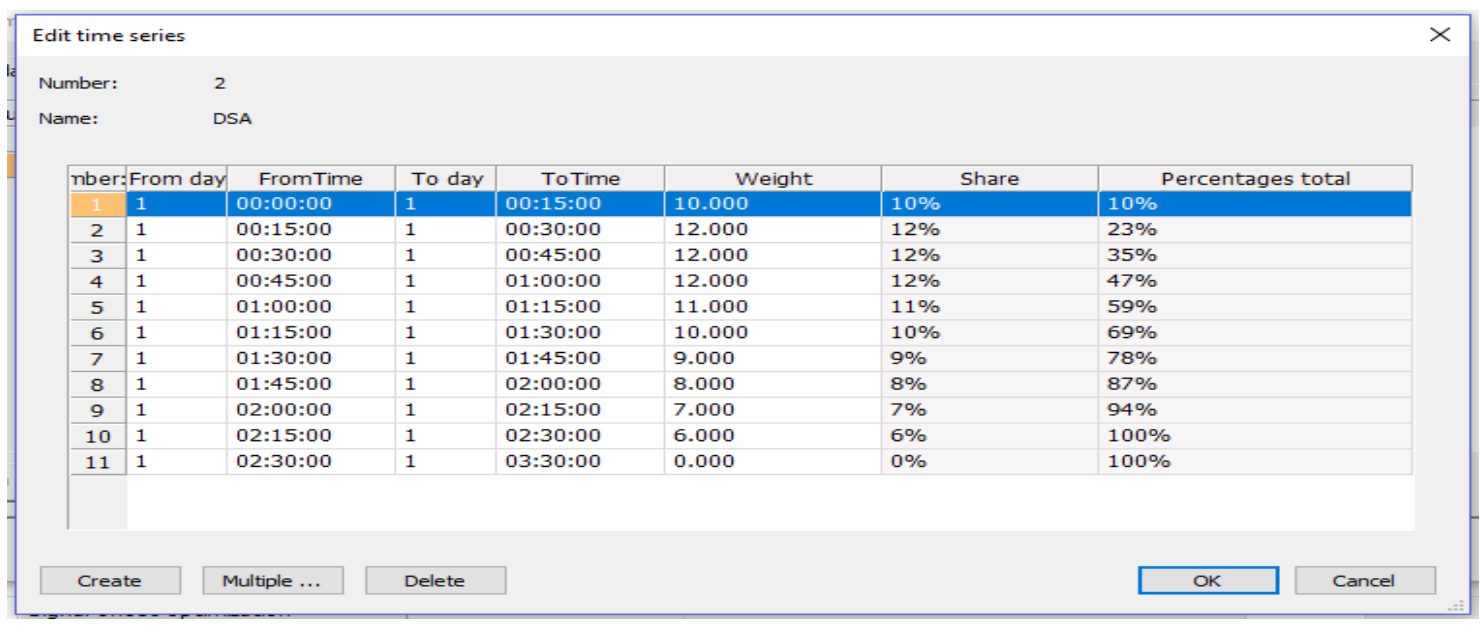

Figure 9.23: Model 6 - DSA Departure Time per TI to Reflect Realistic Scenario

Table 9-7: Model 5 and Model 6 Traffic Inflow Percentage Difference

\begin{tabular}{|l|l|l|l|}
\hline Departure Time & $\begin{array}{l}\text { Model 5 - Cumulative } \\
\text { Volume Percentage }\end{array}$ & $\begin{array}{l}\text { Model 6 - } \\
\text { Cumulative Volume } \\
\text { Percentage }\end{array}$ & $\begin{array}{l}\text { Volumes } \\
\text { Difference }\end{array}$ \\
\hline $15: 00$ & $10 \%$ & $10 \%$ & $0 \%$ \\
\hline $15: 15$ & $20 \%$ & $23 \%$ & $3 \%$ \\
\hline $15: 30$ & $30 \%$ & $35 \%$ & $5 \%$ \\
\hline $15: 45$ & $40 \%$ & $47 \%$ & $7 \%$ \\
\hline $16: 00$ & $50 \%$ & $59 \%$ & $9 \%$ \\
\hline $16: 15$ & $60 \%$ & $69 \%$ & $9 \%$ \\
\hline $16: 30$ & $70 \%$ & $78 \%$ & $8 \%$ \\
\hline $16: 45$ & $80 \%$ & $87 \%$ & $7 \%$ \\
\hline $17: 00$ & $90 \%$ & $94 \%$ & $4 \%$ \\
\hline $17: 15$ & $100 \%$ & $100 \%$ & $0 \%$ \\
\hline
\end{tabular}




\subsubsection{Model 7 - UE Traffic Assignment for PM Peak Hour}

UE traffic assignment for PM peak hour 15:30 - 16:30. In this model, Portage

Bridge is assumed to be closed for traffic for the entire analysis period See Figure 9.24.

Capacities per link type is identical to model 1 - see Figure 9.14 above.

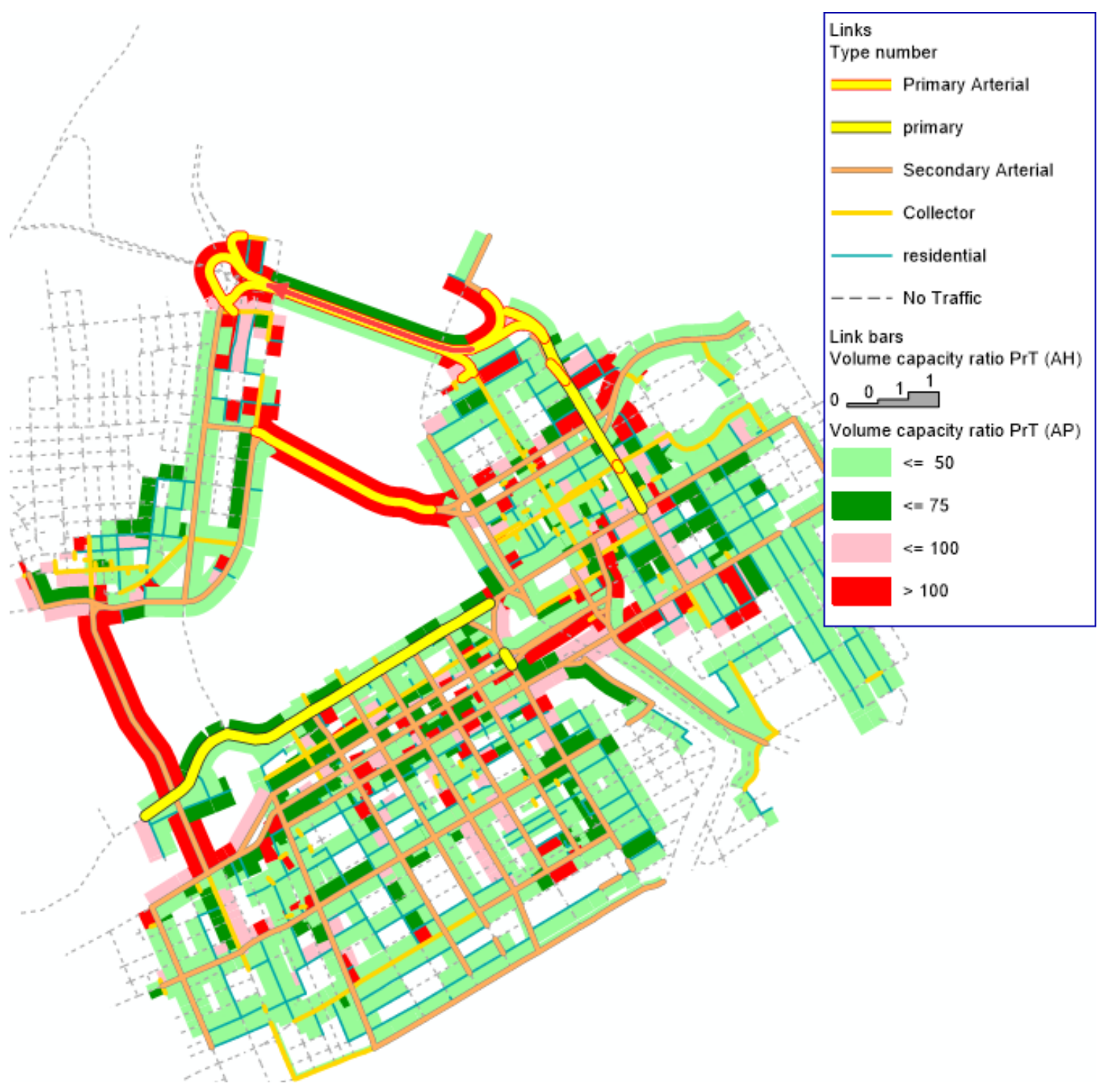

Figure 9.24: Model 7 - Peak Hour UE Traffic Flow with Portage Bridge Closed 


\subsubsection{Model 8 - DSA Traffic Assignment for PM Peak Hour}

DSA traffic assignment for PM peak hour 15:30 - 16:30. In this model, Portage

Bridge is assumed to be closed for traffic for the entire analysis period, see Figure 9.25.

Time intervals (TI) for the assignment is 15 minutes. Capacities per link type is identical to model 1 - see Figure 9.14 above.

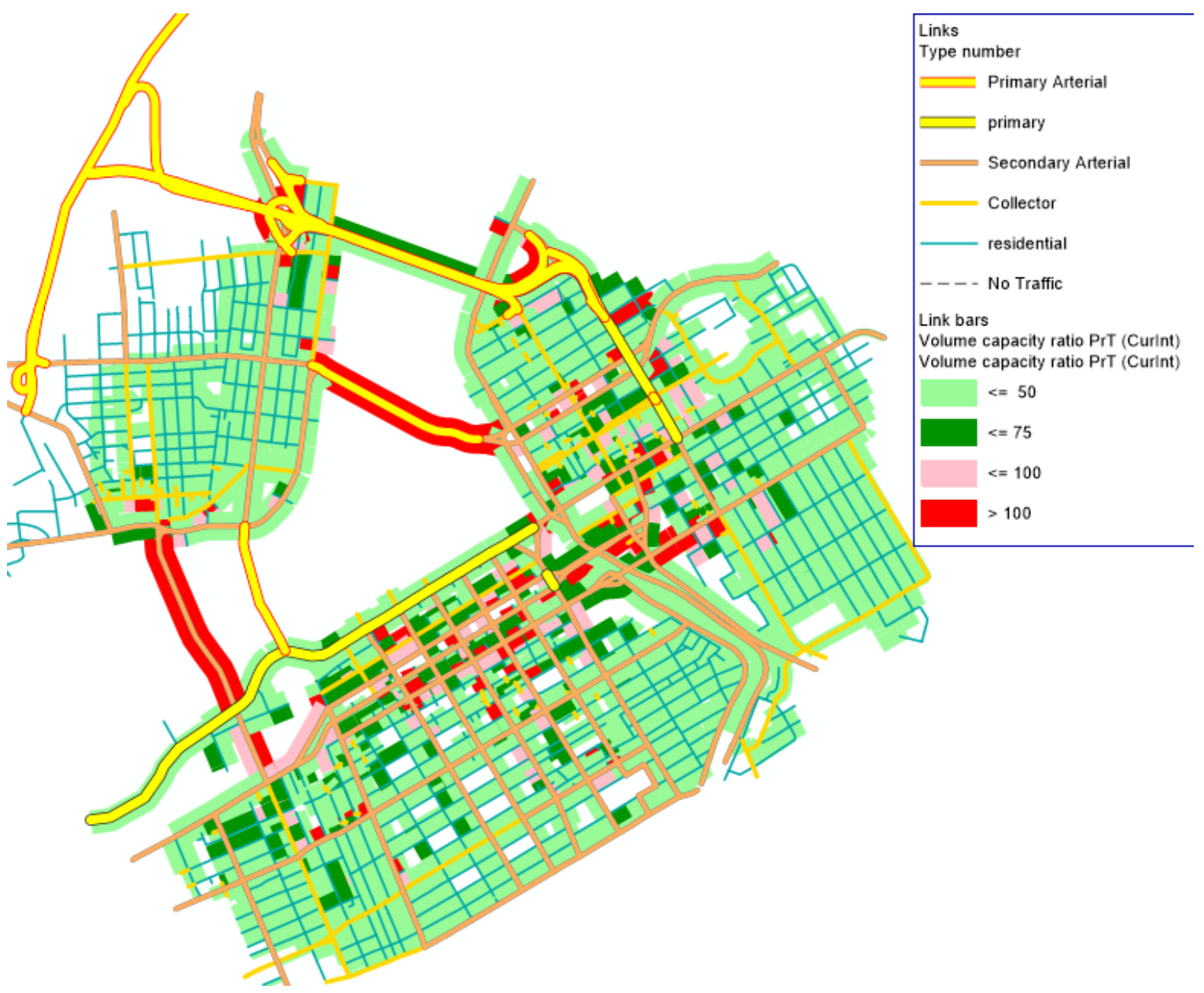

Figure 9.25: Model 8 - Peak Hour DSA Traffic Flow with Portage Bridge Closed, TI = 15 minutes 


\subsubsection{Model 9 - UE Traffic Assignment for PM Peak Period}

UE traffic assignment for PM peak period 15:00 - 17:30: In this model, Portage

Bridge is assumed to be closed for traffic for the entire analysis period, see Figure 9.26.

Capacities per link type is identical to model 4 - see Figure 9.20 above.

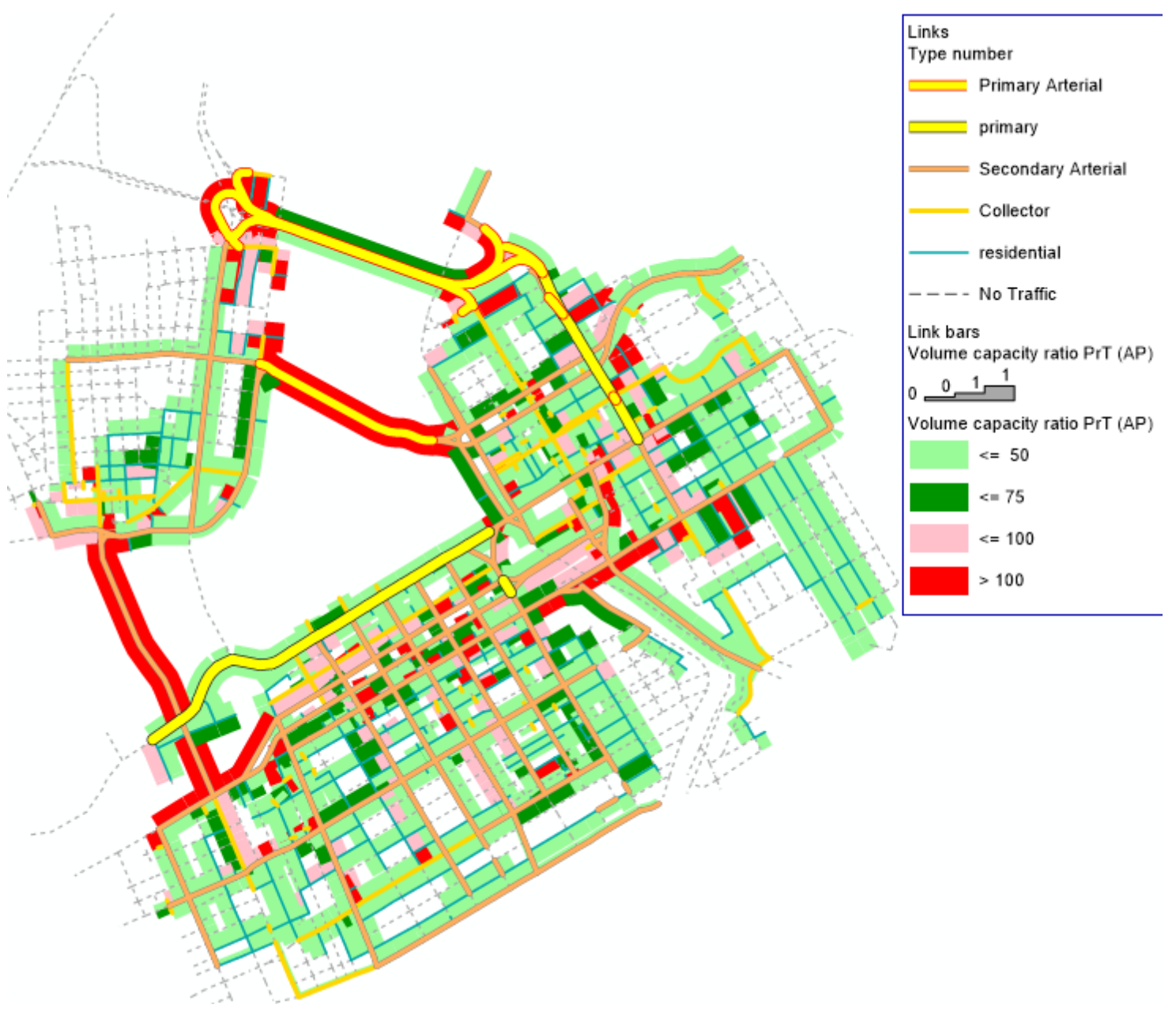

Figure 9.26:Model 9 - Peak Period UE Traffic Flow with Portage Bridge Closed 


\subsubsection{Model 10 - DSA Traffic Assignment for PM Peak Period}

DSA traffic assignment for PM peak period 15:00 - 17:30: Time intervals (TI) for the assignment is 15 minutes. Demand data or departure time of roadway users is divided among Time intervals to reflect realistic demand data, see Figure 9.27. In this model Portage Bridge is assumed to be closed to traffic for the entire analysis period. Capacities per link type is identical to model 1 - see Figure 9.14 above.

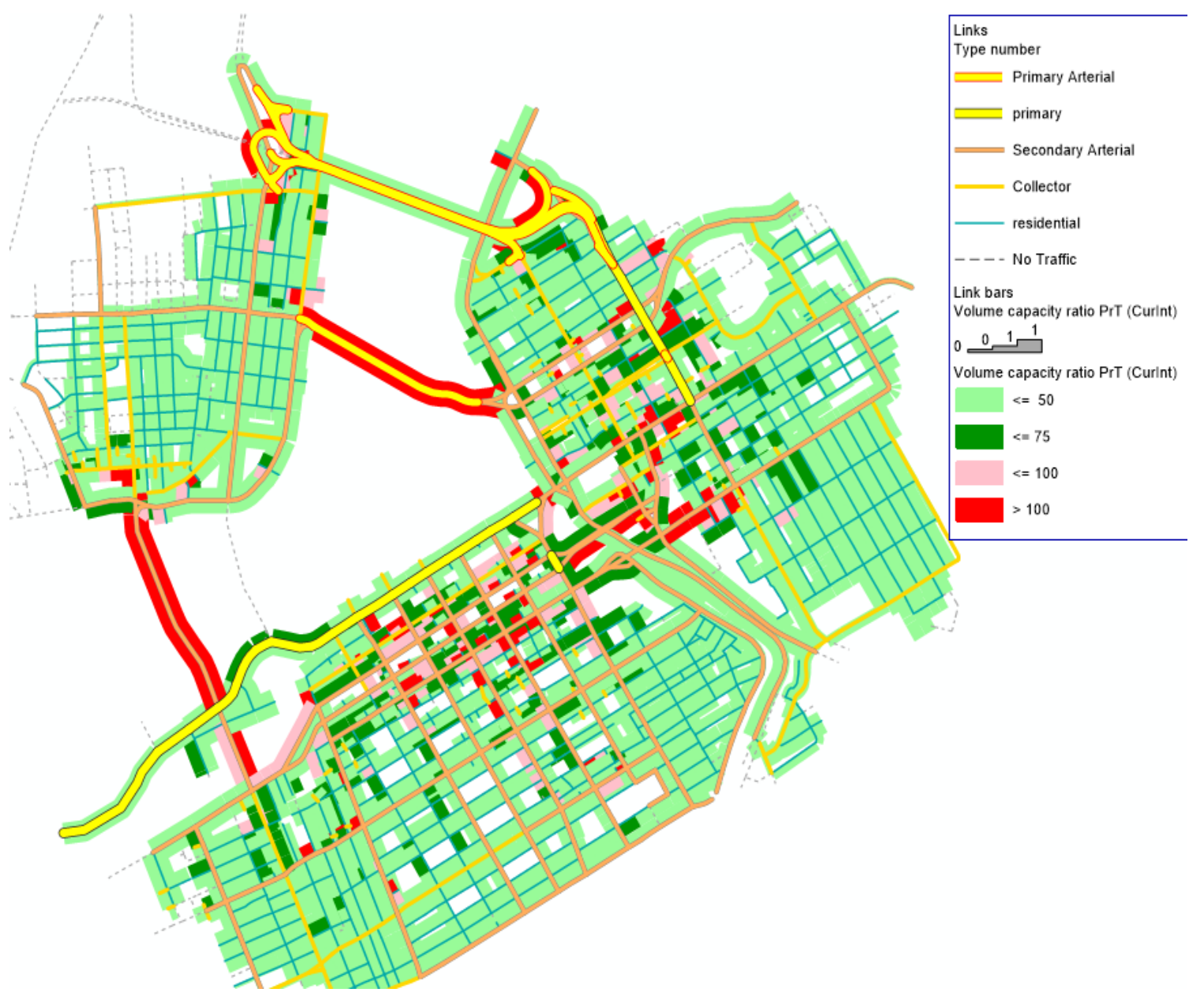

Figure 9.27: Model 10 - Peak Period DSA Traffic Flow with Portage Bridge Closed, TI = 15 minutes 


\subsubsection{Models Summary}

Table 9-8 below present all models and the differences among them.

Table 9-8: Models Differences Summary

\begin{tabular}{|c|c|c|c|c|c|}
\hline \multicolumn{6}{|c|}{ Group 1} \\
\hline Model & $\begin{array}{l}\text { Assignment } \\
\text { Procedure }\end{array}$ & $\begin{array}{l}\text { Assignment } \\
\text { Duration }\end{array}$ & Time interval & $\begin{array}{l}\text { Demand Data } \\
\text { Distribution }\end{array}$ & Disruptive Event \\
\hline 1 & UE & 1-hour & NA & NA & None \\
\hline 2 & DSA & 1-hour & 15 minutes & Evenly & None \\
\hline 3 & DSA & 1-hour & 5 minutes & Evenly & None \\
\hline \multicolumn{6}{|c|}{ Group 2} \\
\hline 4 & $\overline{\mathrm{UE}}$ & 2.5-hours & NA & NA & None \\
\hline 5 & DSA & 2.5-hours & 15 minutes & Evenly & None \\
\hline 6 & DSA & 2.5-hours & 15 minutes & Realistic & None \\
\hline \multicolumn{6}{|c|}{ Group 3} \\
\hline 7 & $\overline{\mathrm{UE}}$ & 1-hour & NA & NA & Portage Closed \\
\hline 8 & DSA & 1-hour & 15 minutes & Evenly & Portage Closed \\
\hline \multicolumn{6}{|c|}{ Group 4} \\
\hline 9 & UE & 2.5-hours & NA & NA & Portage Closed \\
\hline 10 & DSA & 2.5-hours & 15 minutes & Realistic & Portage Closed \\
\hline
\end{tabular}

\subsection{TOTAL DELAY TIME RESULTS}

Table 9-9: Total Delay over the Network for 2011, 2018 Demand Data

\begin{tabular}{|c|c|c|c|}
\hline Model & $\begin{array}{c}\text { 2011 Demand Data } \\
\text { Delay (Hours) }\end{array}$ & $\begin{array}{c}\text { 2018 Demand Data } \\
\text { Delay (Hours) }\end{array}$ & $\begin{array}{c}\text { Increase in Total } \\
\text { Delay (Hours) }\end{array}$ \\
\hline \multicolumn{4}{|c|}{ Group 1 } \\
\hline Model 1 & 171 & 258 & 87 \\
\hline Model 2 & 171 & 267 & 97 \\
\hline Model 3 & 173 & 270 & 191 \\
\hline \multicolumn{5}{|c|}{ Group 2 } \\
\hline Model 4 & 366 & 557 & 174 \\
\hline Model 5 & 324 & 498 & 198 \\
\hline Model 6 & 406 & 629 & 194 \\
\hline \multicolumn{5}{|c|}{ Group 3 } \\
\hline Model 7 & 313 & 511 & 552 \\
\hline Model 8 & 303 & 497 & 496 \\
\hline \multicolumn{5}{|c|}{ Group 4 } \\
\hline Model 9 & 867 & 1419 & 1276 \\
\hline Model 10 & 780 & & \\
\hline
\end{tabular}




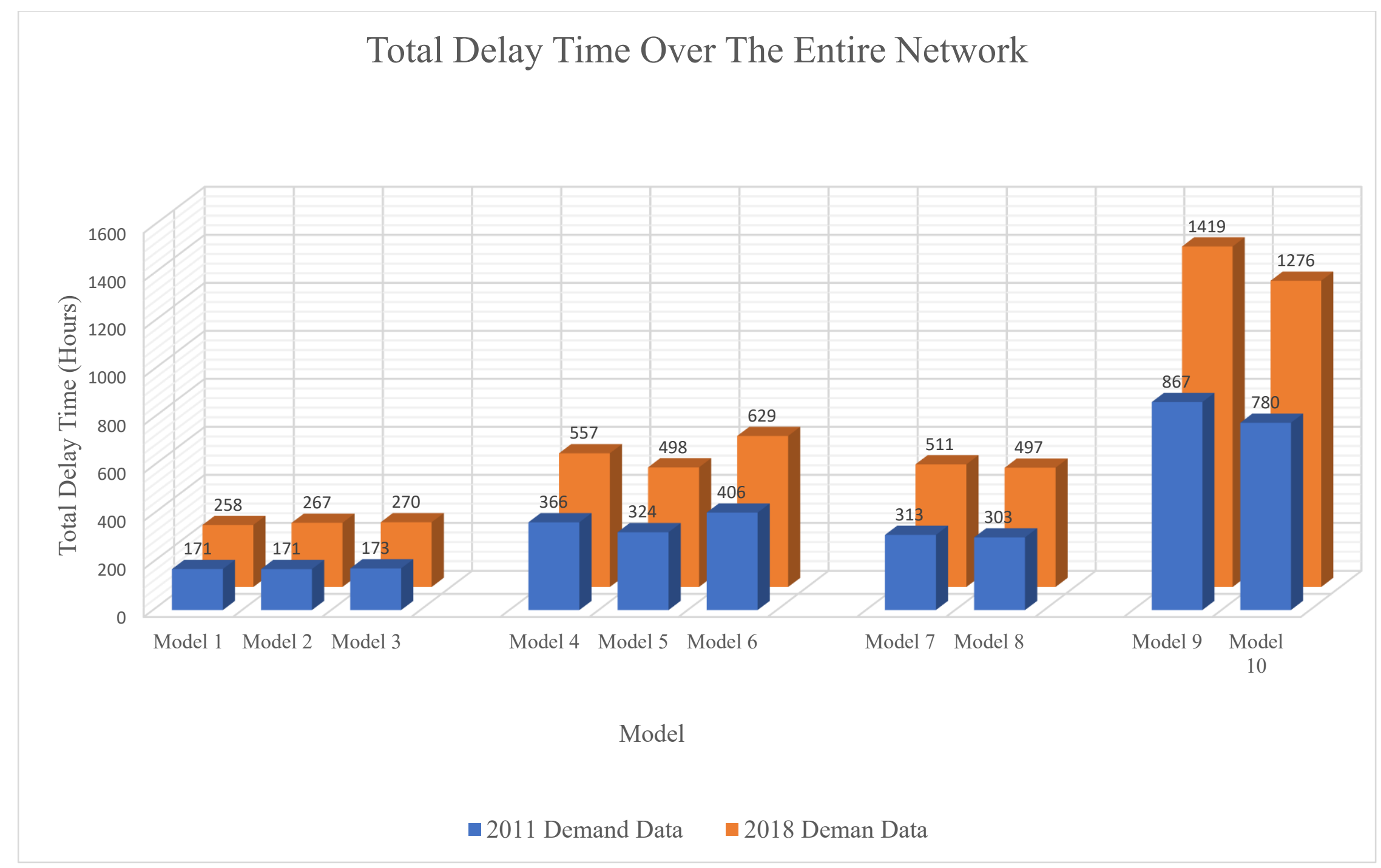

Figure 9.28: Total Delay Times over the Network for All Models 


\subsection{DISCUSSION}

The research thesis is intended to identify measures to enhance the ability of the traffic network to continue to serve traffic following a major disruption. Both micro- and macro- simulation techniques and associated developed models are used. This current section discusses the findings of macrosimulation using PTV-Visum. The Ottawa-Hull area was used in all models described in Chapter 7. Please refer to previous sections in the chapter for model differences, and demand data distribution. The two traffic assignment techniques used are the traditional User Equilibrium Traffic assignment (UE), and the Dynamic Stochastic Traffic Assignment (DSA).

Traffic flow is distributed over more links in the case of DSA. See Figure 9.7 to 9.9. Although more delay time is observed in case of DSA, it is also notable that up to 24 percent more total volume crosses Cordon 3 screen line in the network in case of DSA over UE traffic assignment during peak hour traffic simulation (Table 9-5). Temporal distribution of DSA traffic flow across 4 major bridges in the study area is represented in Figure 9.11.

During normal peak period, traffic suffer less total delay when following UE traffic routes (model 4) - 557 hours - as compared to DSA routes (model 6) - 629 hours. During normal operation, the hypothesis of Wardrop's first principle is that every road user is fully informed about the network state. The information is gained by each driver through time and experiments of trying different routes. A fully informed driver hypothesis gives a methodological advantage for UE traffic assignment over DSA.

In contrast, in the event of non-recurring traffic surge caused by closed Portage Bridge delay times increase to 1419 hours for UE (model 9), and 1276 hours for DSA (model 10) (Figure 9.28). As expected, the difference between total delay times summed

for all road users is observed to increase more as traffic increases (model 9 and 10) Figure 9.28. 


\section{APPLICATION OF METHODOLOGY TO ALL FOUR}

\section{BRIDGES}

\subsection{INTRODUCTION}

This chapter provides additional information in order to further examine the merit of DSA over UE traffic assignment. A disruptive incident is assumed causing one of the main corridors connecting Ottawa to Hull is left out of service to the public. The four cases are then compared to UE traffic assignment with all main corridors in operation. Model 4 and model 6 described in Chapter 9 are used as the basis for the analysis based on 2018 demand data with changes due to the event taking place. Models 4 and 5 described in Chapter 9 are used in the analysis based on 2031 demand data. Given that projected future traffic is uncertain, the models with even temporal demand were chosen.

The analysis examines the change in volume, $\mathrm{v} / \mathrm{c}$ ratio, travel speed, and total delay in alternative corridors. The effect of future projection of traffic demand for the year 2031 is also to be examined. A comparison of analysis of all 10 cases with traffic assignment is also presented.

The list of disruptive events is as follow:

Event 1: Macdonald-Cartier Bridge impaired

Event 2: Alexandra Bridge Impaired

Event 3: Portage Bridge Impaired

Event 4: Chaudière Bridge Impaired

Event 5: All Bridges Operational

The purpose of analyses presented in this chapter is to further illustrate the effect of DSA on main corridors connecting Ottawa-Hull area. This comprehensive coverage 
of disruptive events is to give the evidence that the approach and methods developed in this research can be applied to any location in an urban traffic network. In the case of Ottawa-Hull (Gatineau), the vulnerable corridors are the bridges and in other cities, the approach and methods can be applied to major arterials and highways.

Returning to the present application example, because more traffic travels from Ottawa to Hull and across the four main bridges connecting the two areas during the P.M. peak period, the study focused on the direction of traffic travelling to the Hull area. Detailed graphs of all 10 networks are presented for an appreciation of the results obtained. All 10 networks analyzed are identical except for travel assignment method used.

\subsection{INDIVIDUAL COMPARISON OF FACTORS}

\subsubsection{Volume/Capacity Ratio}

Based on 2018 demand data, around 19250 Passenger Car Units (PCU) crossed the 4 main corridors travelling from Ottawa to Hull area during the 2.5 hours PM Peak Period (15:00 to 17:30 hour); and around 23300 PCU crossed the bridges based on 2031 demand data projection. Detailed v/c ratio for the 15 minutes time-intervals (TI) from DSA were composed in the figures shown later in this chapter. Although the procedure of DSA (Dynamic Stochastic Traffic Assignment) had demand time between 15:00 17:30, excess traffic sprawled into 17:30 - 17:45 TI (See figures 10.1 to 10.58 of DSA). This is a useful property of dynamic traffic assignment, which led to reduce the average $\mathrm{v} / \mathrm{c}$ ratio on alternative corridors and hence on other links in the network. Individual $\mathrm{v} / \mathrm{c}$ ratios were gathered per TI as seen in figures presented later in this chapter, then summed, and divided by 11 TI to account for the sprawled traffic into the TI of 17:30 - 
17:45. The same was done for other comparison factors. In UE traffic assignment procedure, the total value was divided by 10 since the UE distributes traffic on exactly 2.5 hours of the methodology.

Generally, distributing traffic according to DSA yielded better - lower- v/c ratio than the UE (User Equilibrium traffic assignment), except for Alexandra bridge in Event 4 and Event 5, which had insignificant 2\% increase in v/c ratio over the UE network for 2018 demand data. Table 10-1 below shows the percentage of v/c ratio of using DSA compared to using UE traffic distribution procedure. In contrast, the maximum decrease in the $\mathrm{v} / \mathrm{c}$ ratio was 21.86 .

Table 10-1: Average v/c Ratio Percentage per TI Comparison of DSA and UE

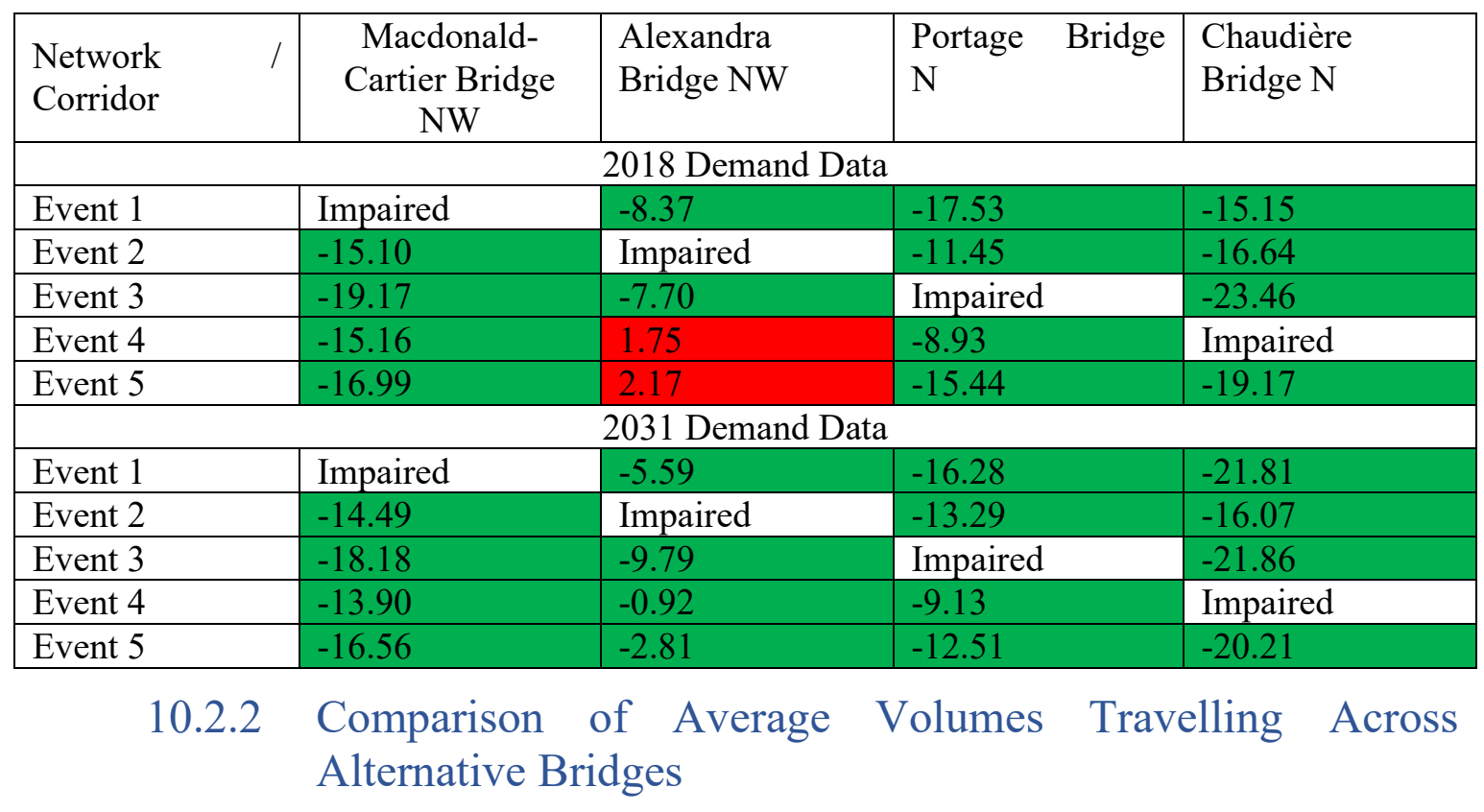

A comparison of DSA and UE shown in Table 10-2 shows that generally, less average volumes travel across alternatives per TI. But the Chaudière bridge experienced more average volumes traveling per TI. The green color indicated less average volumes travel across alternatives. Detailed volumes per TI can be seen later in this chapter. 
Table 10-2: Average Volumes Percentage Traveling per TI Comparison of DSA and UE (\%)

\begin{tabular}{|c|c|c|c|c|}
\hline $\begin{array}{l}\text { Network } \\
\text { Corridor }\end{array}$ & $\begin{array}{c}\text { Macdonald- } \\
\text { Cartier Bridge } \\
\text { NW }\end{array}$ & $\begin{array}{l}\text { Alexandra } \\
\text { Bridge NW }\end{array}$ & $\begin{array}{l}\text { Portage Bridge } \\
\mathrm{N}\end{array}$ & $\begin{array}{l}\text { Chaudière } \\
\text { Bridge N }\end{array}$ \\
\hline \multicolumn{5}{|c|}{2018 Demand Data } \\
\hline Event 1 & Impaired & -8.67 & -17.54 & 12.61 \\
\hline Event 2 & -15.24 & Impaired & -11.46 & 11.53 \\
\hline Event 3 & -18.97 & -7.51 & Impaired & 2.21 \\
\hline Event 4 & -15.83 & 1.75 & -8.74 & Impaired \\
\hline Event 5 & -16.57 & 2.32 & -15.44 & 7.78 \\
\hline \multicolumn{5}{|c|}{2031 Demand Data } \\
\hline Event 1 & Impaired & -5.75 & -16.28 & 4.46 \\
\hline Event 2 & -13.92 & Impaired & -13.46 & 11.9 \\
\hline Event 3 & -18.42 & -10.03 & Impaired & 4.05 \\
\hline Event 4 & -13.45 & -1.03 & -9.13 & Impaired \\
\hline Event 5 & -16.21 & -3.16 & -12.72 & 6.68 \\
\hline
\end{tabular}

Generally average travel speed per TI improved when traffic is assigned using DSA method. Better analysis results were observed in the projected 2031 demand data. Table 10-3 shows the average travel speed percentage of DSA over UE. The green indicates better travel speed per TI experienced by road users.

Table 10-3: Average Travel Speed Percentage per TI Comparison of DSA and UE (\%)

\begin{tabular}{|l|l|l|l|l|}
\hline $\begin{array}{l}\text { Network } \\
\text { Corridor }\end{array}$ & $\begin{array}{l}\text { Macdonald- } \\
\text { Cartier } \\
\text { Bridge NW }\end{array}$ & $\begin{array}{l}\text { Alexandra } \\
\text { Bridge NW }\end{array}$ & $\begin{array}{l}\text { Portage Bridge } \\
\mathrm{N}\end{array}$ & $\begin{array}{l}\text { Chaudière } \\
\text { Bridge N }\end{array}$ \\
\hline \multicolumn{5}{|c|}{2018 Demand Data } \\
\hline Event 1 & Impaired & 39.49 & 35.35 & 7.83 \\
\hline Event 2 & 2.05 & Impaired & 7.05 & 3.33 \\
\hline Event 3 & 0.98 & 23.72 & Impaired & 97.70 \\
\hline Event 4 & 0.38 & -6.78 & 8.89 & Impaired \\
\hline Event 5 & 0.67 & -8.54 & 5.79 & 3.64 \\
\hline \multicolumn{7}{|l|}{2031 Demand Data } \\
\hline Event 1 & Impaired & 33.29 & 59.33 & 45.05 \\
\hline Event 2 & 1.72 & Impaired & 25.84 & 15.98 \\
\hline Event 3 & 2.54 & 51.50 & Impaired & 137.62 \\
\hline Event 4 & -0.33 & 1.84 & 23.63 & Impaired \\
\hline Event 5 & 0.67 & 2.35 & 11.74 & 14.47 \\
\hline
\end{tabular}




\subsubsection{Comparison of Average Delay Time per TI on Alternative Corridors}

Comparison of average delay per TI has been composed in Table 10-4 below. Two colours are used - green refers to fewer delays experienced by road users when DSA is used, and red refers to fewer delays experienced by road users per TI when UE is used. Generally, road users experience fewer delays following UE traffic assignment in 2018, and vice versa in 2031.

to 10-9 show the total delay (in hours) on each alternative for all events. Table 10-10 and 10-11 show the total delay over the whole networks for all events. While distributing traffic over the network using DSA traffic assignment is debatable for 2018 demand data, it is apparent that for future projected traffic demand, DSA traffic method performs better in distributing traffic over the network.

Table 10-4: Average Delay Percentage per TI Comparison of DSA and UE (\%)

\begin{tabular}{|l|l|l|l|l|}
\hline $\begin{array}{l}\text { Network } \\
\text { Corridor }\end{array}$ & $\begin{array}{l}\text { Macdonald-Cartier } \\
\text { Bridge NW }\end{array}$ & $\begin{array}{l}\text { Alexandra } \\
\text { Bridge NW }\end{array}$ & $\begin{array}{l}\text { Portage Bridge } \\
\text { N }\end{array}$ & $\begin{array}{l}\text { Chaudière } \\
\text { Bridge N }\end{array}$ \\
\hline \multicolumn{7}{|l|}{ 2018 Demand Data } \\
\hline Event 1 & Impaired & 0.53 & -18.97 & 43.73 \\
\hline Event 2 & -26.45 & Impaired & 14.11 & 26.37 \\
\hline Event 3 & -16.35 & 17.73 & Impaired & -33.66 \\
\hline Event 4 & 13.92 & 82.41 & 29.19 & Impaired \\
\hline Event 5 & -1.87 & 81.91 & -10.67 & 1.23 \\
\hline \multicolumn{7}{|l|}{ 2031 Demand Data } \\
\hline Event 1 & Impaired & 5.03 & -42.28 & -43.65 \\
\hline Event 2 & -28.48 & Impaired & -32.39 & -21.68 \\
\hline Event 3 & -47.52 & -15.57 & Impaired & -45.44 \\
\hline Event 4 & -21.10 & 32.61 & -13.38 & Impaired \\
\hline Event 5 & -95.70 & 19.36 & -29.38 & -38.58 \\
\hline
\end{tabular}


Table 10-5: Event 1 - Comparison of Total Delay Across Alternatives for Vehicles Traveling from Ottawa to Hull

\begin{tabular}{|c|c|c|r|r|r|r|}
\hline Alternative & $\begin{array}{c}\text { UE 2018 } \\
\text { Demand } \\
\text { Data Delay } \\
\text { Ottawa to } \\
\text { Hull } \\
\text { (Hours) }\end{array}$ & $\begin{array}{c}\text { DAS 2018 } \\
\text { Demand } \\
\text { Data Delay } \\
\text { Ottawa to } \\
\text { Hull } \\
\text { (Hours) }\end{array}$ & $\begin{array}{c}\text { Increase / } \\
\text { Decrease } \\
\%\end{array}$ & $\begin{array}{c}\text { UE 2031 } \\
\text { Demand } \\
\text { Data Delay } \\
\text { Ottawa to } \\
\text { Hull } \\
\text { (Hours) }\end{array}$ & $\begin{array}{c}\text { DAS 2031 } \\
\text { Demand } \\
\text { Data Delay } \\
\text { Ottawa to } \\
\text { Hull } \\
\text { (Hours) }\end{array}$ & $\begin{array}{c}\text { Increase / } \\
\text { Decrease } \\
\%\end{array}$ \\
\hline Alexandra & 252.00 & 278.68 & 10.59 & 400.08 & 462.15 & 15.51 \\
\hline Portage & 124.58 & 111.12 & -10.80 & 337.42 & 214.18 & -36.52 \\
\hline Chaudière & 28.25 & 44.55 & 57.70 & 122.43 & 75.93 & -37.98 \\
\hline All Alt. & 404.83 & 434.35 & 7.29 & 859.93 & 752.26 & -12.52 \\
\hline
\end{tabular}

Table 10-6: Event 2 - Comparison of Total Delay Across Alternatives for Vehicles Traveling from Ottawa to Hull

\begin{tabular}{|c|c|c|c|c|c|c|}
\hline \multirow{2}{*}{ Alternative } & $\begin{array}{c}\text { UE 2018 } \\
\text { Demand } \\
\text { Data } \\
\text { Delay } \\
\text { Ottawa to } \\
\text { Hull } \\
\text { (Hours) }\end{array}$ & $\begin{array}{c}\text { DAS 2018 } \\
\text { Demand } \\
\text { Data } \\
\text { Delay } \\
\text { Ottawa to } \\
\text { Hull } \\
\text { (Hours) }\end{array}$ & $\begin{array}{c}\text { Increase / } \\
\text { Decrease } \\
\%\end{array}$ & $\begin{array}{c}\text { UE 2031 } \\
\text { Demand } \\
\text { Data } \\
\text { Delay } \\
\text { Ottawa to } \\
\text { Hull } \\
\text { (Hours) }\end{array}$ & $\begin{array}{c}\text { DAS 2031 } \\
\text { Demand } \\
\text { Data } \\
\text { Delay } \\
\text { Ottawa to } \\
\text { Hull } \\
\text { (Hours) }\end{array}$ & $\begin{array}{c}\text { Increase / } \\
\text { Decrease } \\
\%\end{array}$ \\
\hline Macdonald-Cartier & 3.63 & 3.00 & -17.36 & 7.20 & 5.50 & -23.61 \\
\hline Portage & 41.93 & 52.75 & 25.80 & 129.43 & 96.30 & -25.60 \\
\hline Chaudière & 15.24 & 21.10 & 38.45 & 46.75 & 40.35 & -13.69 \\
\hline All Alt. & 60.80 & 76.85 & 26.40 & 183.38 & 142.15 & -22.48 \\
\hline
\end{tabular}

Table 10-7: Event 3 - Comparison of Total Delay Across Alternatives for Vehicles Traveling from Ottawa to Hull

\begin{tabular}{|c|c|c|c|c|c|c|}
\hline Alternative & $\begin{array}{c}\text { UE 2018 } \\
\text { Demand } \\
\text { Data Delay } \\
\text { Ottawa to } \\
\text { Hull } \\
\text { (Hours) }\end{array}$ & $\begin{array}{c}\text { DAS 2018 } \\
\text { Demand } \\
\text { Data Delay } \\
\text { Ottawa to } \\
\text { Hull } \\
\text { (Hours) }\end{array}$ & $\begin{array}{c}\text { Increase / } \\
\text { Decrease } \\
\%\end{array}$ & $\begin{array}{c}\text { UE 2031 } \\
\text { Demand } \\
\text { Data Delay } \\
\text { Ottawa to } \\
\text { Hull } \\
\text { (Hours) }\end{array}$ & $\begin{array}{c}\text { DAS 2031 } \\
\text { Demand } \\
\text { Data Delay } \\
\text { Ottawa to } \\
\text { Hull } \\
\text { (Hours) }\end{array}$ & $\begin{array}{c}\text { Increase / } \\
\text { Decrease } \\
\%\end{array}$ \\
\hline Macdonald-Cartier & 4.18 & 3.83 & -8.37 & 13.25 & 7.70 & -41.89 \\
\hline Alexandra & 139.98 & 181.30 & 29.52 & 329.90 & 306.33 & -7.14 \\
\hline Chaudière & 399.13 & 291.27 & -27.02 & 855.18 & 513.28 & -39.98 \\
\hline All Alt. & 543.29 & 476.40 & -12.31 & 1198.33 & 827.31 & -30.96 \\
\hline
\end{tabular}


Table 10-8: Event 4 - Comparison of Total Delay Across Alternatives for Vehicles Traveling from Ottawa to Hull

\begin{tabular}{|c|c|c|c|c|c|c|}
\hline Alternative & $\begin{array}{c}\text { UE 2018 } \\
\text { Demand } \\
\text { Data Delay } \\
\text { Ottawa to } \\
\text { Hull } \\
\text { (Hours) }\end{array}$ & $\begin{array}{c}\text { DAS 2018 } \\
\text { Demand } \\
\text { Data Delay } \\
\text { Ottawa to } \\
\text { Hull } \\
\text { (Hours) }\end{array}$ & $\begin{array}{c}\text { Increase / } \\
\text { Decrease } \\
\%\end{array}$ & $\begin{array}{c}\text { UE 2031 } \\
\text { Demand } \\
\text { Data Delay } \\
\text { Ottawa to } \\
\text { Hull } \\
\text { (Hours) }\end{array}$ & $\begin{array}{c}\text { DAS 2031 } \\
\text { Demand } \\
\text { Data Delay } \\
\text { Ottawa to } \\
\text { Hull } \\
\text { (Hours) }\end{array}$ & $\begin{array}{c}\text { Increase / } \\
\text { Decrease } \\
\%\end{array}$ \\
\hline Macdonald-Cartier & 1.23 & 1.55 & 26.02 & 3.28 & 2.75 & -16.16 \\
\hline Alexandra & 41.07 & 82.27 & 100.32 & 94.88 & 138.33 & 45.79 \\
\hline Portage & 79.92 & 113.68 & 42.24 & 213.25 & 203.25 & -4.69 \\
\hline All Alt. & 122.22 & 197.50 & 61.59 & 311.41 & 344.33 & 10.57 \\
\hline
\end{tabular}

Table 10-9: Event 5 - Comparison of Total Delay Across Alternatives for Vehicles Traveling from Ottawa to Hull

\begin{tabular}{|c|c|c|c|c|c|c|}
\hline Alternative & $\begin{array}{c}\text { UE 2018 } \\
\text { Demand } \\
\text { Data Delay } \\
\text { Ottawa to } \\
\text { Hull } \\
\text { (Hours) }\end{array}$ & $\begin{array}{c}\text { DAS 2018 } \\
\text { Demand } \\
\text { Data Delay } \\
\text { Ottawa to } \\
\text { Hull } \\
\text { (Hours) }\end{array}$ & $\begin{array}{c}\text { Increase / } \\
\text { Decrease } \\
\%\end{array}$ & $\begin{array}{c}\text { UE 2031 } \\
\text { Demand } \\
\text { Data Delay } \\
\text { Ottawa to } \\
\text { Hull } \\
\text { (Hours) }\end{array}$ & $\begin{array}{c}\text { DAS 2031 } \\
\text { Demand } \\
\text { Data Delay } \\
\text { Ottawa to } \\
\text { Hull } \\
\text { (Hours) }\end{array}$ & $\begin{array}{c}\text { Increase / } \\
\text { Decrease } \\
\%\end{array}$ \\
\hline Macdonald-Cartier & 0.95 & 1.08 & 13.68 & 2.58 & 1.23 & -52.33 \\
\hline Alexandra & 32.15 & 64.37 & 100.22 & 75.72 & 99.35 & 31.21 \\
\hline Portage & 17.13 & 16.87 & -1.52 & 40.78 & 31.72 & -22.22 \\
\hline Chaudière & 7.93 & 8.91 & 12.36 & 25.37 & 17.12 & -32.52 \\
\hline All Alt. & 58.16 & 91.23 & 56.86 & 144.45 & 149.42 & 3.44 \\
\hline
\end{tabular}

Table 10-10: Comparison of Total Network Delay During Events - 2018 Demand

\begin{tabular}{|l|l|l|l|}
\hline Event & $\begin{array}{l}\text { UE 2018 Demand Total Delay } \\
\text { Over All Links (Hours) }\end{array}$ & $\begin{array}{l}\text { DAS 2018 Demand Total } \\
\text { Delay Over All Links (Hours) }\end{array}$ & $\begin{array}{l}\text { Increase / } \\
\text { Decrease \% }\end{array}$ \\
\hline Network 1 & 1496.42 & 1574.20 & 5.20 \\
\hline Network 2 & 864.37 & 853.44 & -1.26 \\
\hline Network 3 & 1419 & 1276 & -10.08 \\
\hline Network 4 & 734.38 & 808.85 & 10.14 \\
\hline Network 5 & 557 & 629 & 12.93 \\
\hline
\end{tabular}


Table 10-11:Comparison of Total Network Delay During Events - 2031 Demand

\begin{tabular}{|c|c|c|r|}
\hline Event & $\begin{array}{c}\text { UE 2031 Demand } \\
\text { Data Delay (Hours) }\end{array}$ & $\begin{array}{c}\text { DAS 2031 Demand } \\
\text { Data Delay (Hours) }\end{array}$ & $\begin{array}{c}\text { Increase / } \\
\text { Decrease \% }\end{array}$ \\
\hline Network 1 & 2763.88 & 2601.67 & -5.87 \\
\hline Network 2 & 1670.27 & 1435.14 & -14.08 \\
\hline Network 3 & 3209.14 & 2192.49 & -31.68 \\
\hline Network 4 & 1530.25 & 1340.62 & -12.39 \\
\hline Network 5 & 1153.75 & 1016.21 & -11.92 \\
\hline
\end{tabular}

\subsection{VIABILITY OF THE METHODOLOGY}

The example network of Ottawa - Hull area was used to prove the suitability of the DSA method to distribute traffic over the network compared to the UE procedure. The DSA method has been explained in earlier chapters. The temporal information, which can be extracted from the DSA, is far more detailed and can be an asset to travel planners to draw the stochastic and temporal flow pattern of vehicles. This information can be collected, analyzed and used to alter traffic control in order to guide road users. The procedure can be applied to any network to analyze the effect of distributed traffic. Future research in traffic control can establish how to utilize the information extracted in a timely manner as opposed to what has been done through the research. Computer codes can also be added to Visum to automatically draw the flow patterns of traffic and provide detailed feedback on traffic movement and location per time interval.

\subsection{ILLUSTRATIONS OF ANALYSIS RESULTS}

A comparison of traffic distribution across main corridors connecting Ottawa to Hull Area is described next. The following sections compare traffic travelling on the Ottawa-Hull area transportation network for all events assumed. The figures illustrate a graphical representation of the intensity of volumes, and compares volumes/capacity ratios, volumes, travel speeds, and delays per time intervals over alternative bridges connecting Ottawa to Hull area. 


\subsubsection{Event 1 - Macdonald-Cartier Bridge under Stress - 2018 Demand Data}

Traffic assignments were carried out as discussed in Chapter 9. The network analyzed is displayed in Figure 10.1 below. Selected results are illustrated in follow-up figures.

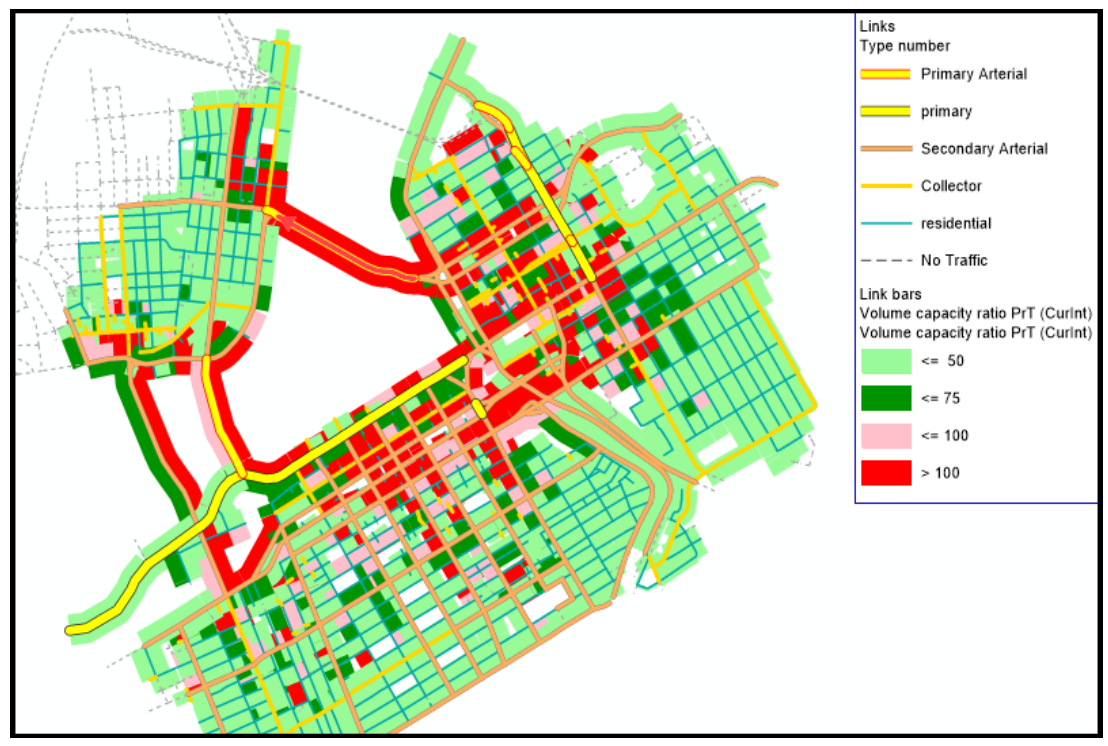

Figure 10.1: DSA of 2018 Data for Event 1 - 15:45 to 16:00 TI Simulation

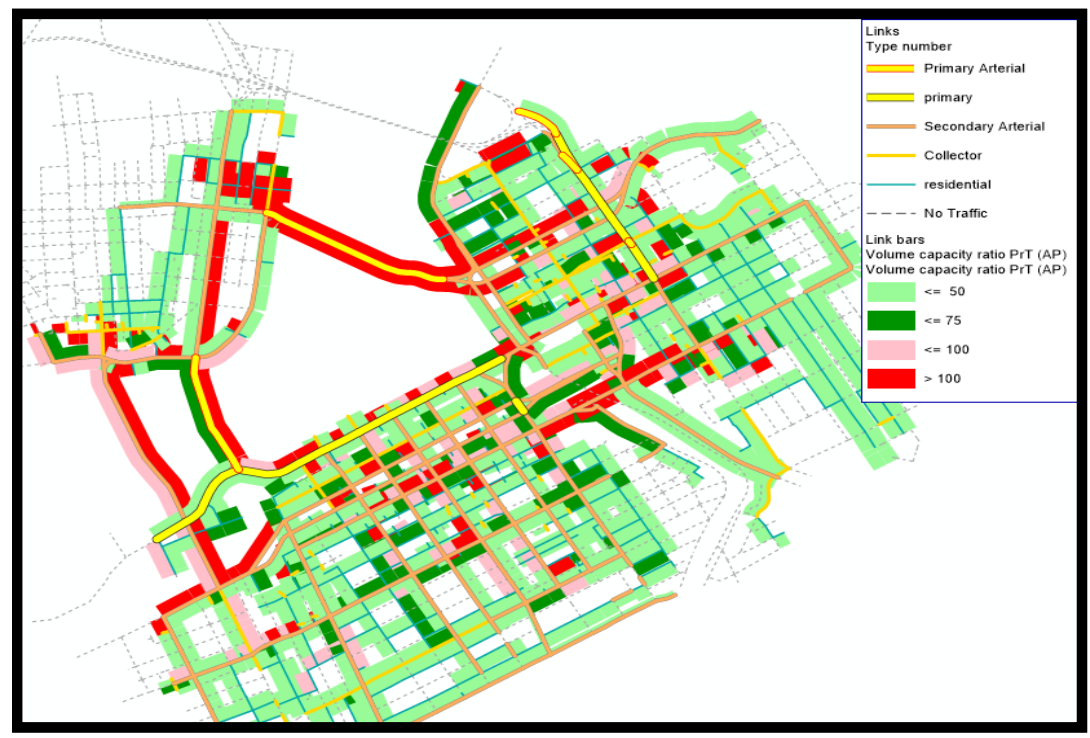

Figure 10.2: UE of 2018 Data for Event 1 


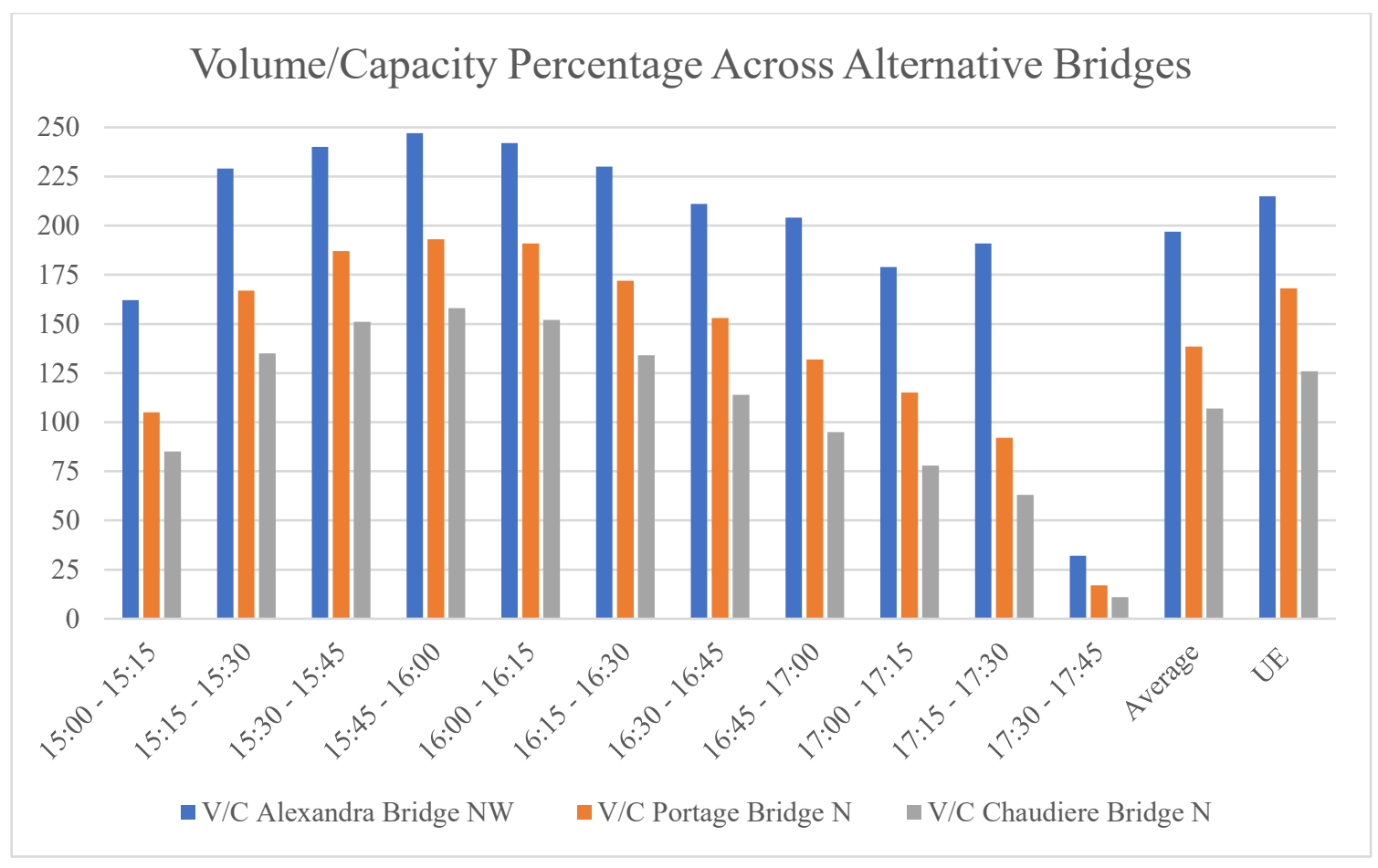

Figure 10.3: Event 1 v/c Ratio per TI - 2018 Demand

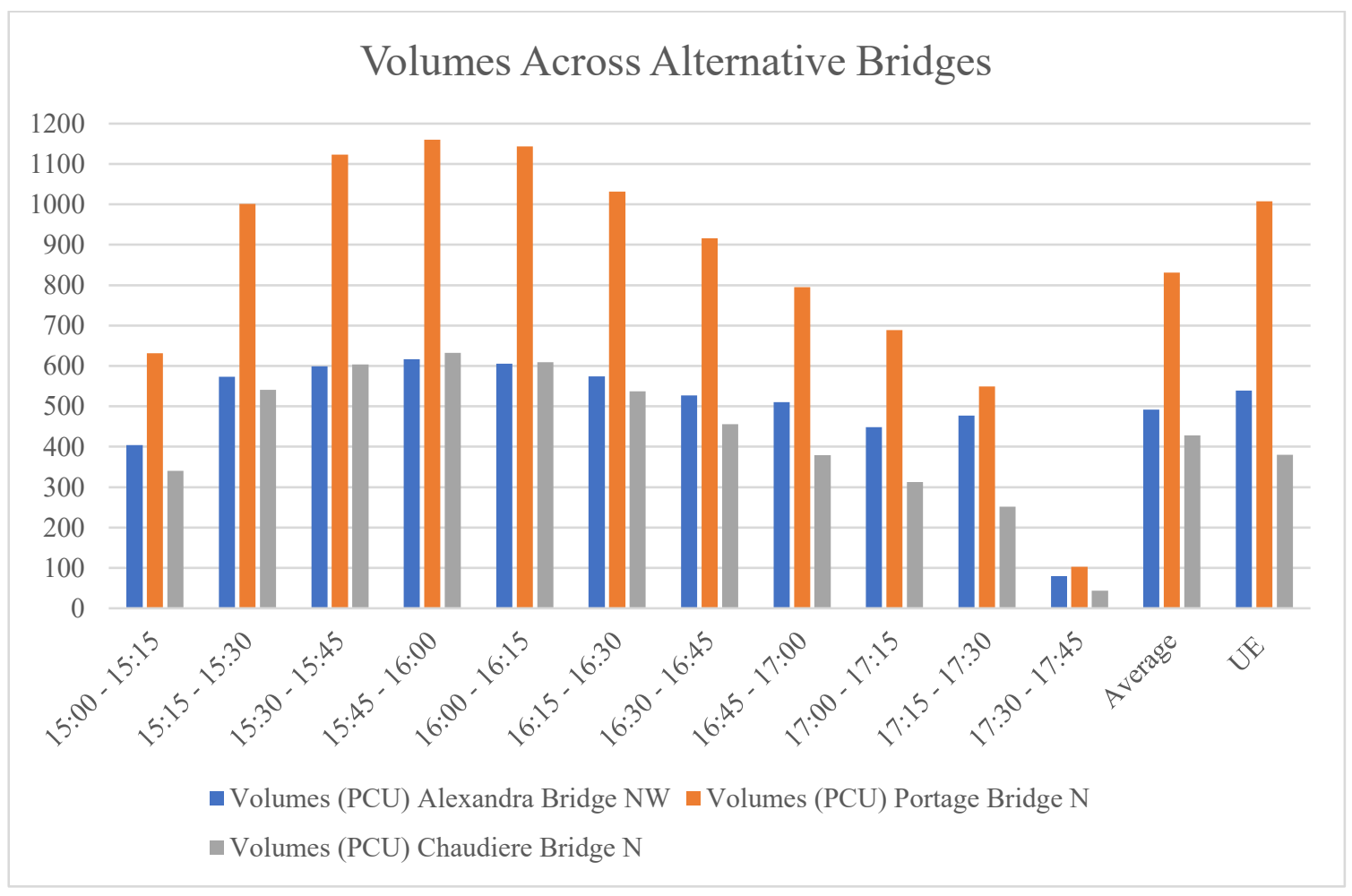

Figure 10.4: Event 1 Volumes Across Alternatives - 2018 Demand 


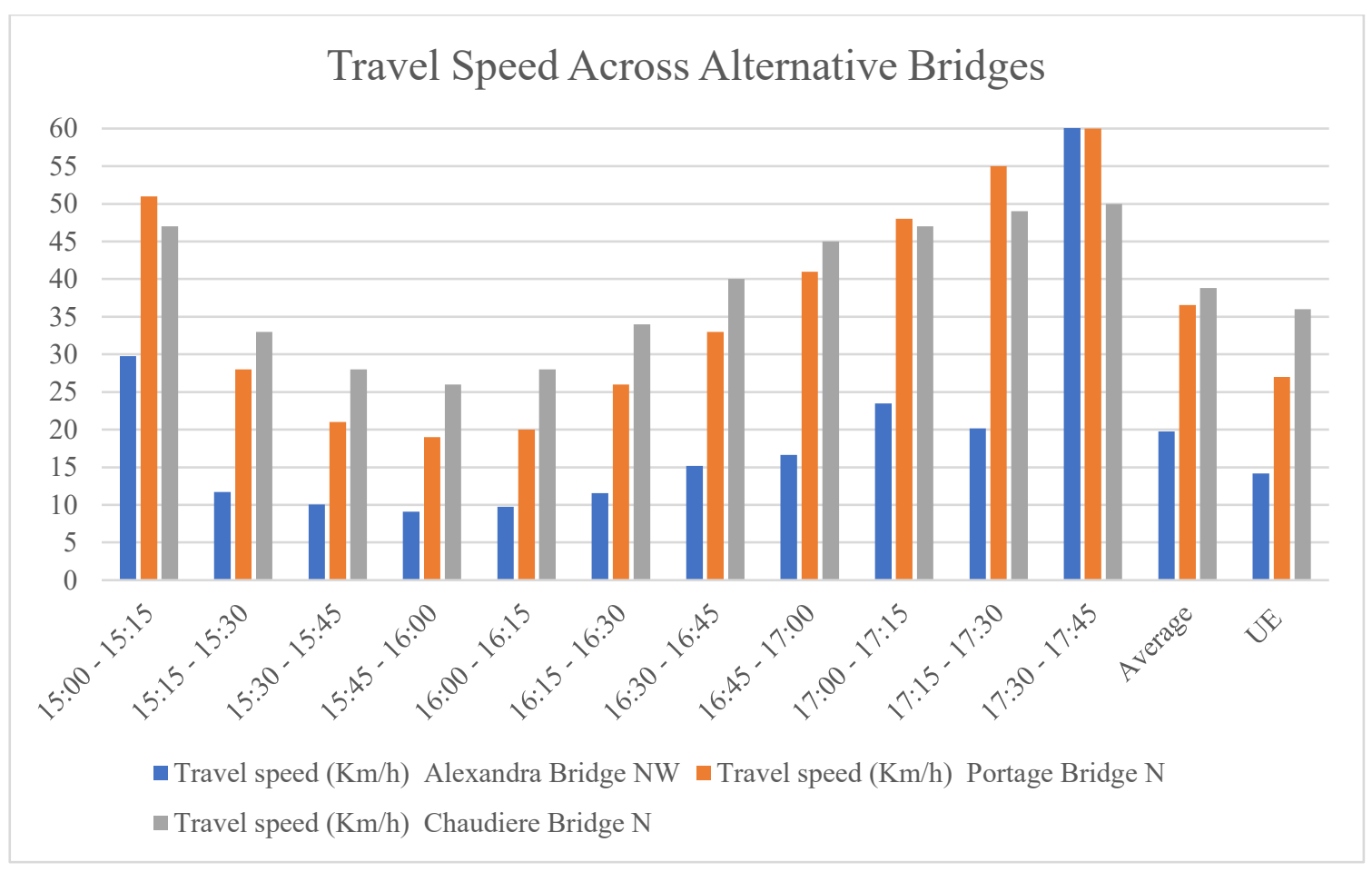

Figure 10.5: Event 1 Travel Speed Across Alternatives - 2018 Data

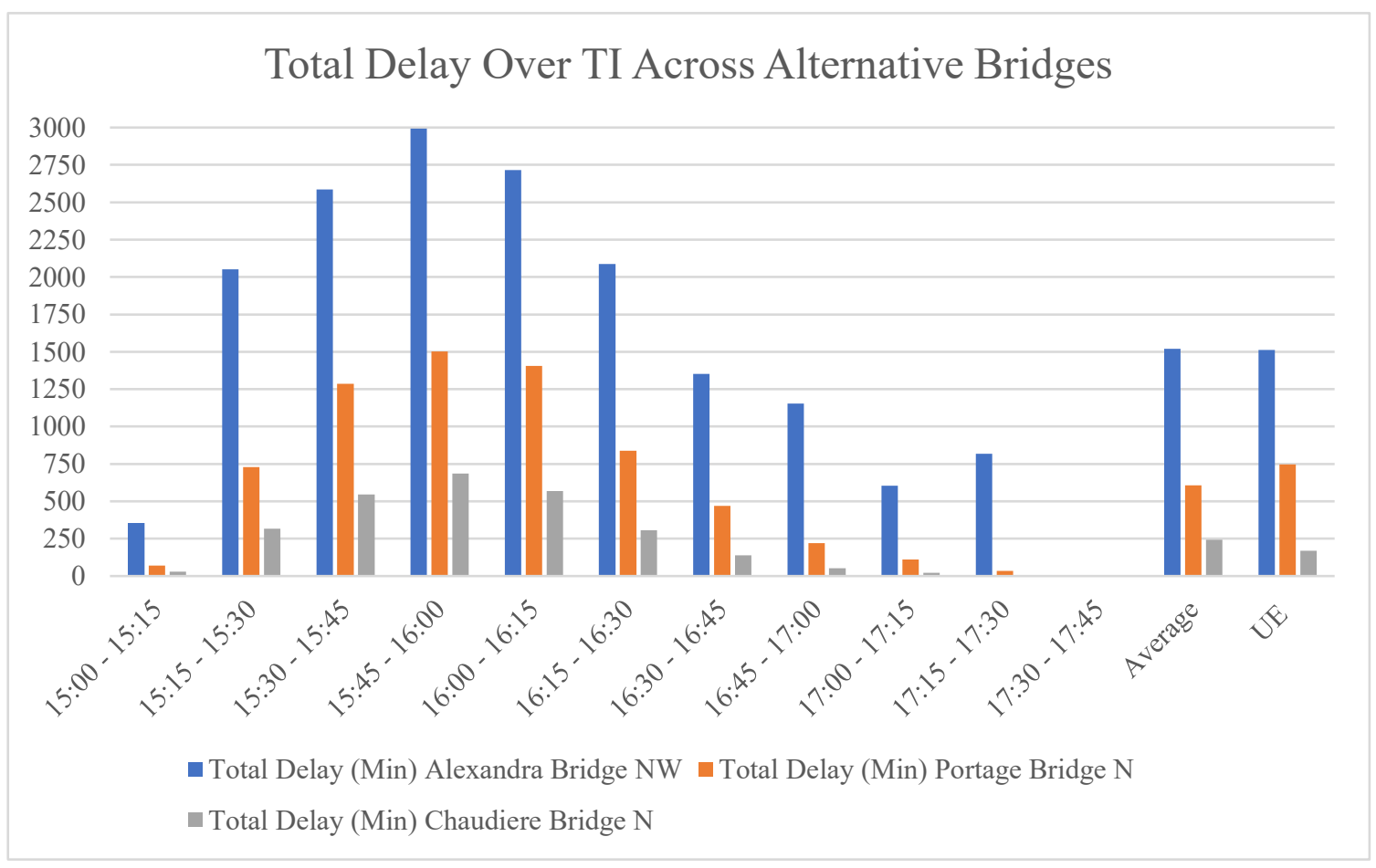

Figure 10.6: Event 1 Delay per TI Across Alternatives - 2018 Data 
10.4.2 Event 1 - Macdonald-Cartier Bridge under Stress - 2031 Demand Data

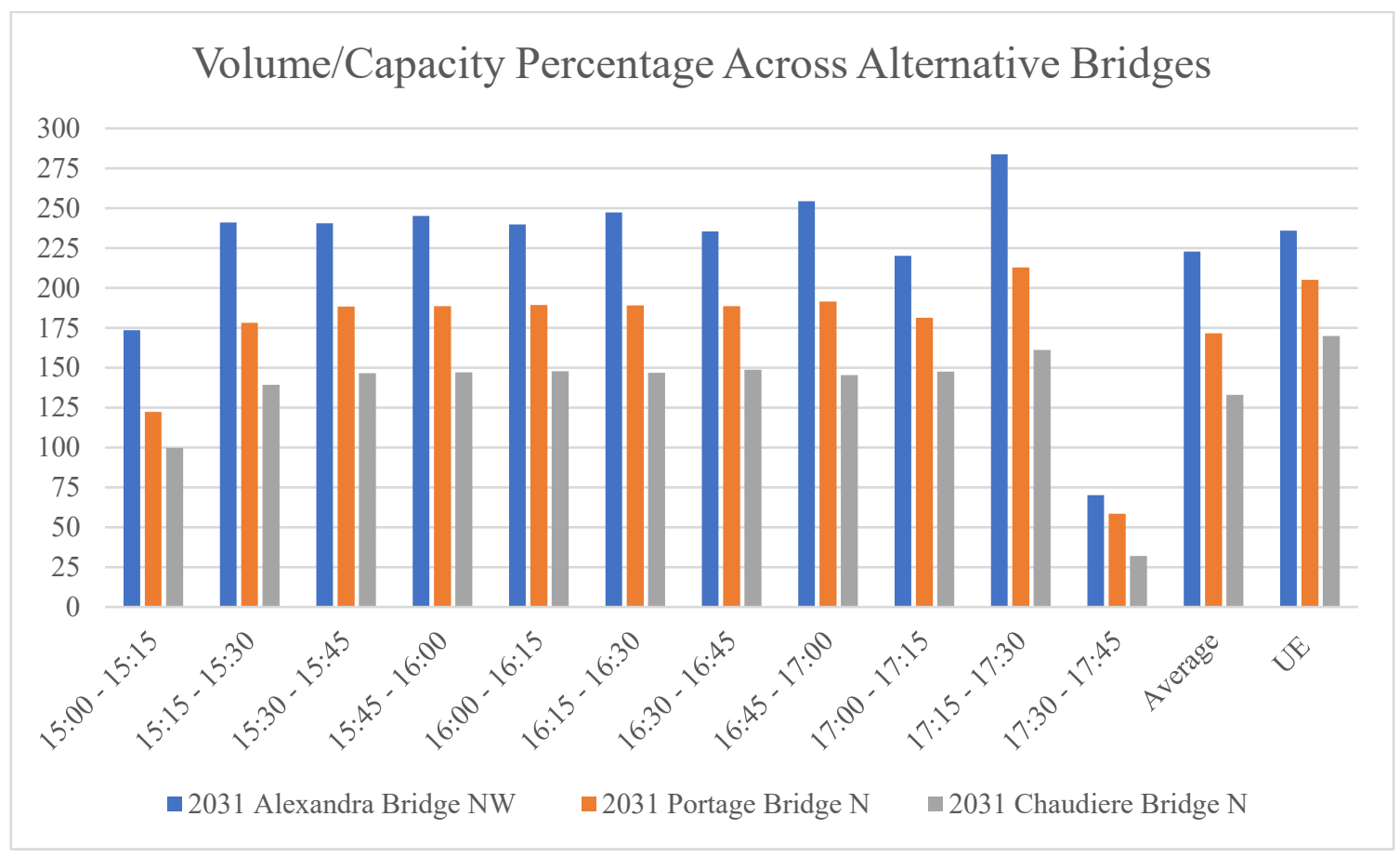

Figure 10.7: V/C Ratio per TI - 2031 Demand

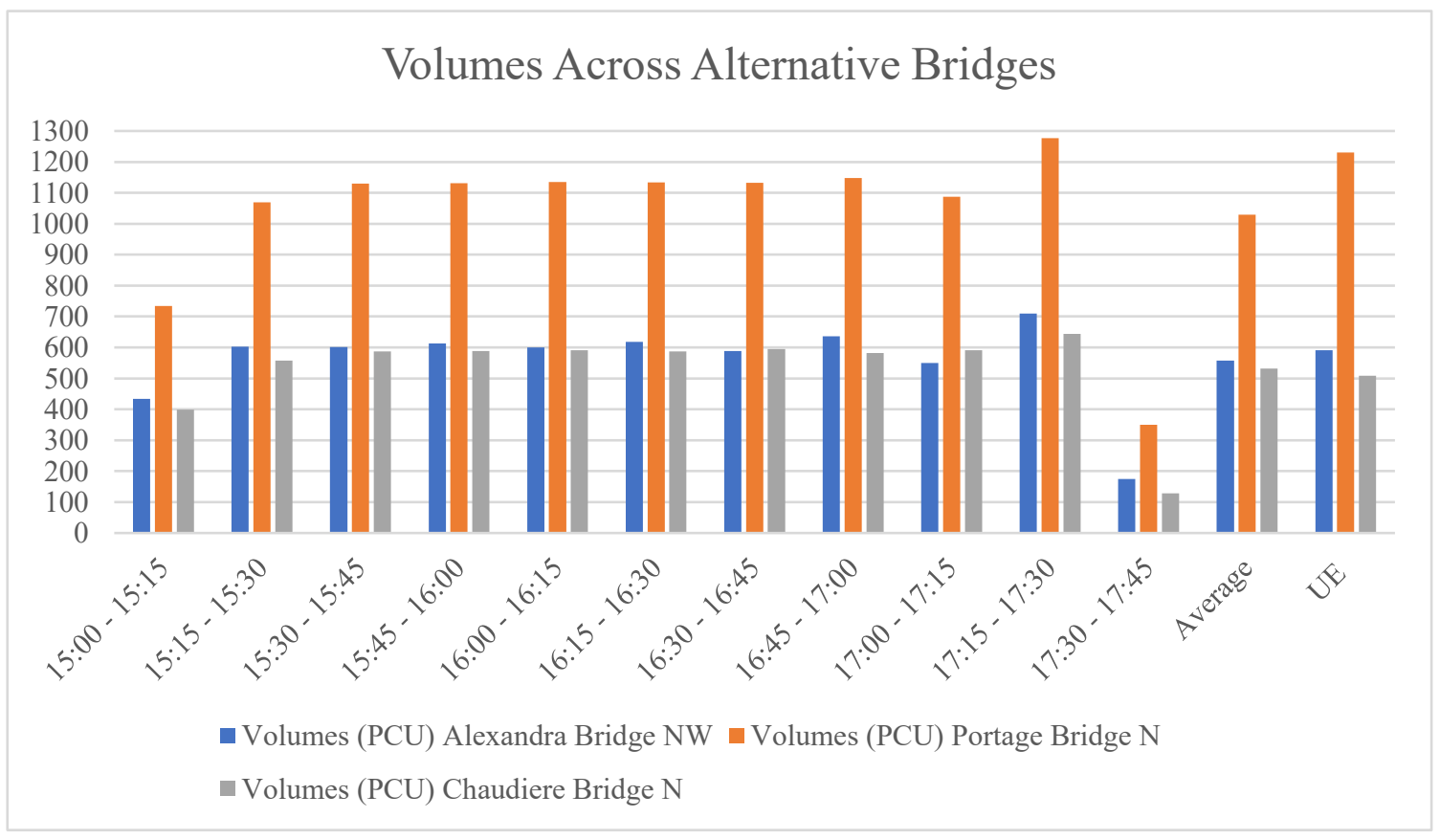

Figure 10.8: Volumes Across Alternatives - 2031 Demand 


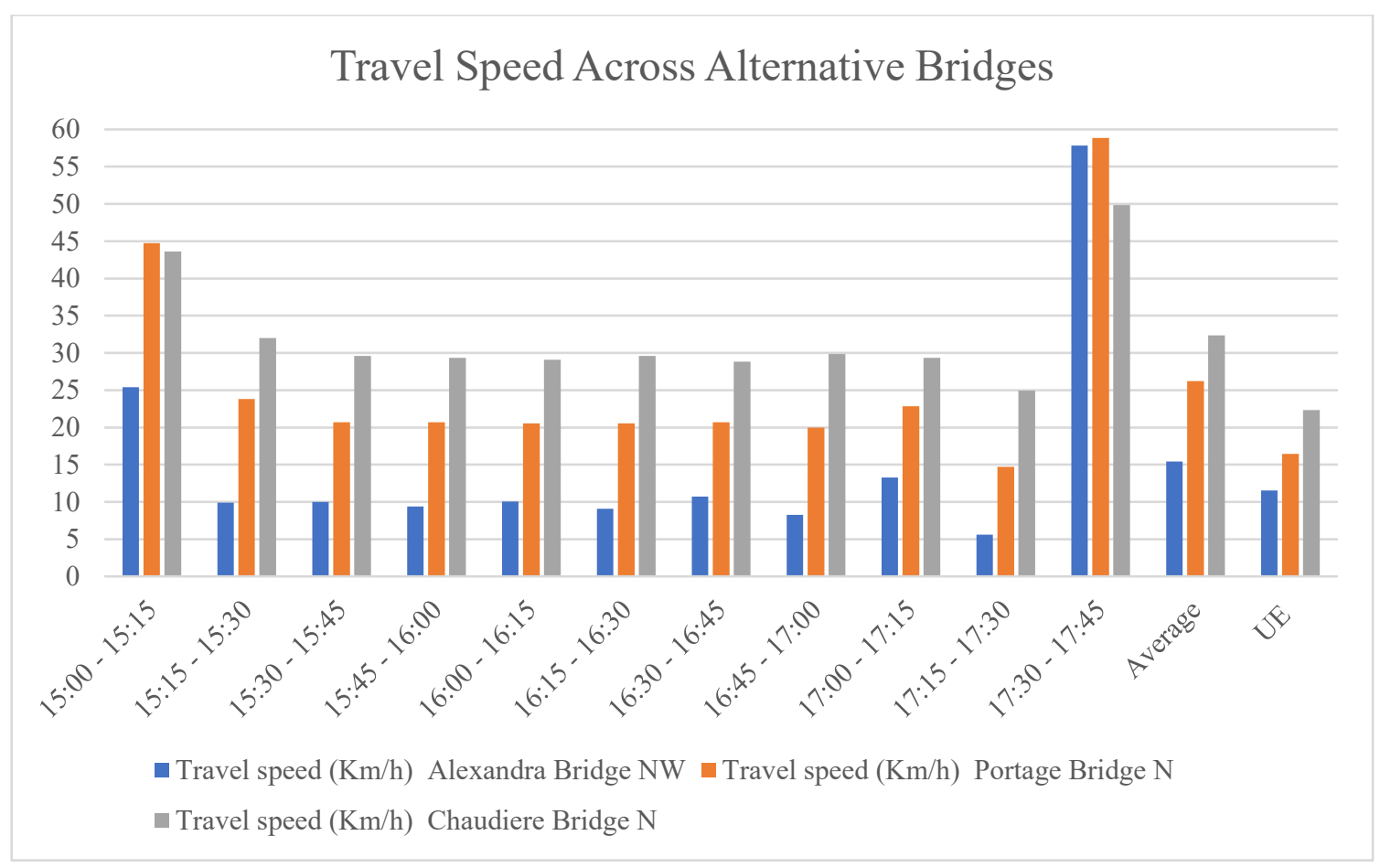

Figure 10.9: Travel Speed Across Alternatives - 2031 Data

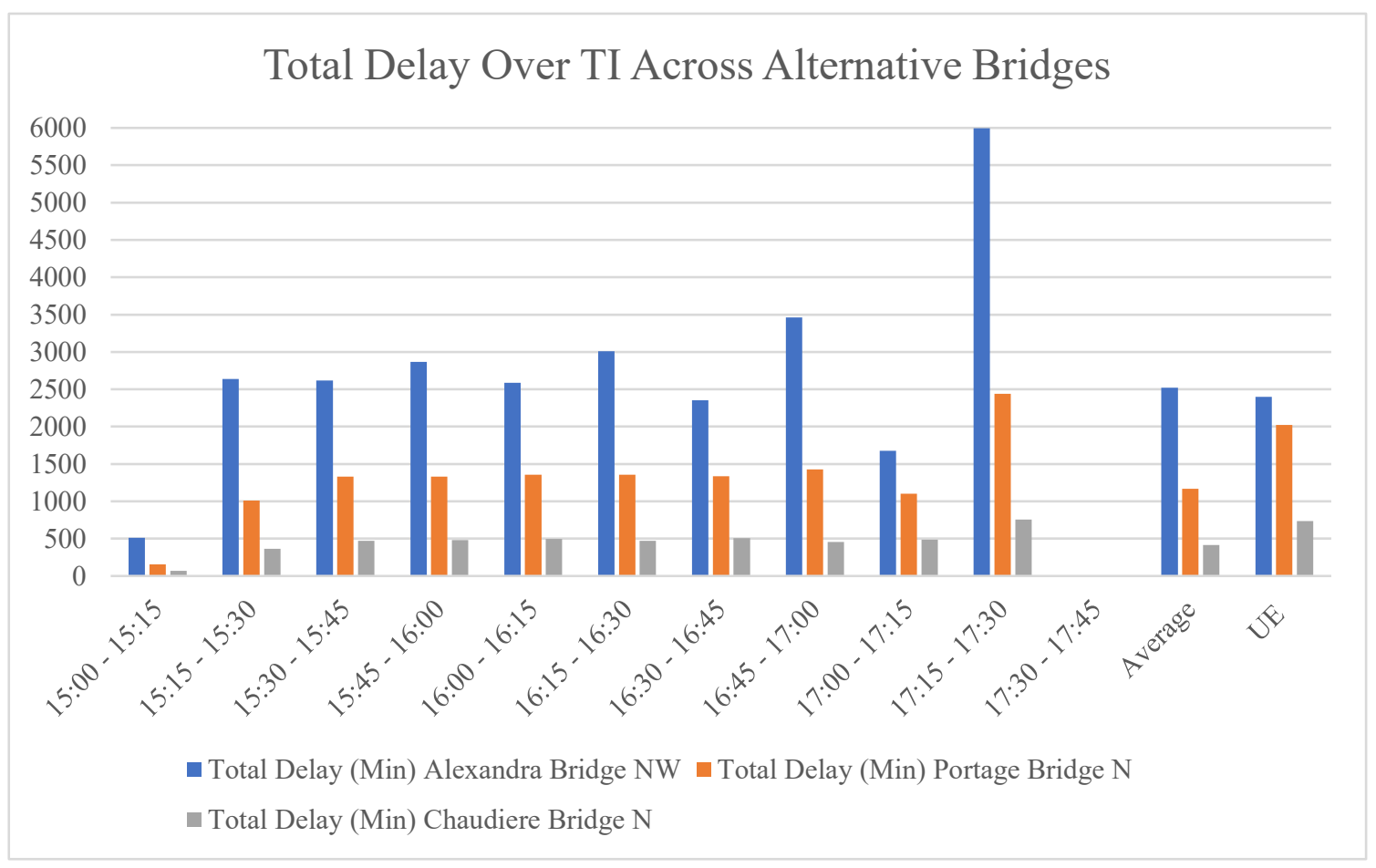

Figure 10.10: Delay per TI Across Alternatives - 2031 Data 


\subsubsection{Event 1 - Summary}

Table 10-12: Comparison of Volumes of Vehicles Traveling from Ottawa to Hull Across Alternatives -

Event 1

\begin{tabular}{|c|c|c|c|c|}
\hline Alternative & $\begin{array}{c}\text { UE 2018 } \\
\text { Demand } \\
\text { Volumes Ottawa } \\
\text { to Hull (PCU) }\end{array}$ & $\begin{array}{c}\text { DAS 2018 } \\
\text { Demand } \\
\text { Volumes Ottawa } \\
\text { to Hull (PCU) }\end{array}$ & $\begin{array}{c}\text { UE 2031 } \\
\text { Demand } \\
\text { Volumes Ottawa } \\
\text { to Hull (PCU) }\end{array}$ & $\begin{array}{c}\text { DAS 2031 } \\
\text { Demand } \\
\text { Volumes Ottawa } \\
\text { to Hull (PCU) }\end{array}$ \\
\hline 2: Alexandra & 5387 & 5416 & 5909 & 6127 \\
\hline 3: Portage & 10077 & 9142 & 12300 & 11328 \\
\hline 4: Chaudière & 3795 & 4708 & 5088 & 5849 \\
\hline Total & 19259 & 19266 & 23297 & 23304 \\
\hline
\end{tabular}

Table 10-13: Comparison of Total Delay Across Alternatives for Vehicles Traveling from Ottawa to Hull - Event 1

\begin{tabular}{|c|c|c|r|r|r|r|}
\hline Alternative & $\begin{array}{c}\text { UE 2018 } \\
\text { Demand } \\
\text { Data Delay } \\
\text { Ottawa to } \\
\text { Hull } \\
\text { (Hours) }\end{array}$ & $\begin{array}{c}\text { DAS 2018 } \\
\text { Demand } \\
\text { Data Delay } \\
\text { Ottawa to } \\
\text { Hull } \\
\text { (Hours) }\end{array}$ & $\begin{array}{c}\text { Increase } \\
/ \\
\text { Decreas } \\
\mathrm{e} \%\end{array}$ & $\begin{array}{c}\text { UE 2031 } \\
\text { Demand } \\
\text { Data Delay } \\
\text { Ottawa to } \\
\text { Hull (Hours) }\end{array}$ & $\begin{array}{c}\text { DAS 2031 } \\
\text { Demand } \\
\text { Data Delay } \\
\text { Ottawa to } \\
\text { Hull (Hours) }\end{array}$ & $\begin{array}{c}\text { Increase / } \\
\text { Decrease } \\
\%\end{array}$ \\
\hline Alexandra & 252.00 & 278.68 & 10.59 & 400.08 & 462.15 & 15.51 \\
\hline Portage & 124.58 & 111.12 & -10.80 & 337.42 & 214.18 & -36.52 \\
\hline Chaudière & 28.25 & 44.55 & 57.70 & 122.43 & 75.93 & -37.98 \\
\hline All Alt. & 404.83 & 434.35 & 7.29 & 859.93 & 752.26 & -12.52 \\
\hline
\end{tabular}




\subsubsection{Event 2 - Alexandra Bridge under Stress - 2018 Demand Data}

Figures and tables below shows the comparison results on alternative corridors if Alexandra Bridge where to be out of service to road users.

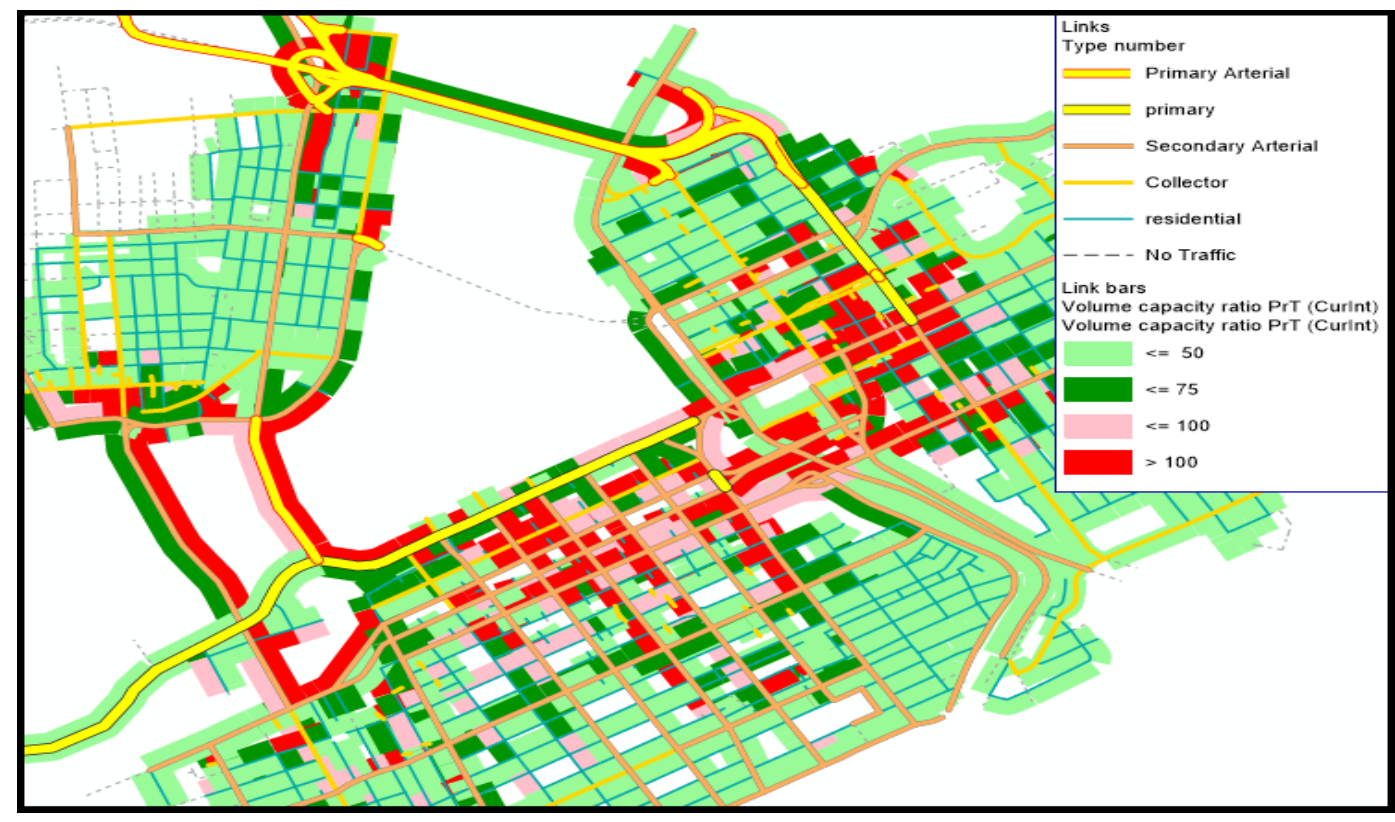

Figure 10.11: DSA of 2018 Data for Event 2 - 15:45 to 16:00 TI Simulation

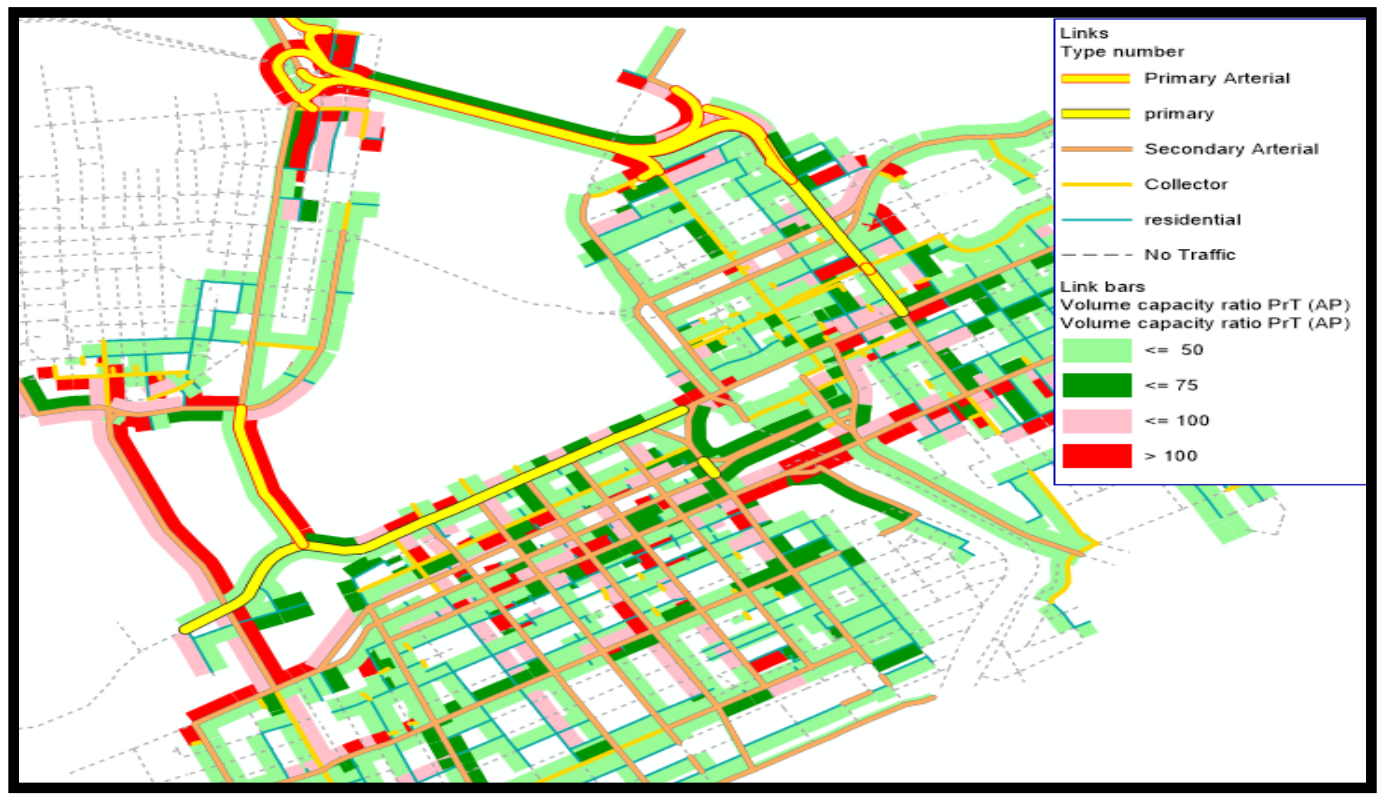

Figure 10.12: UE of 2018 Data for Event 2 - Simulation 


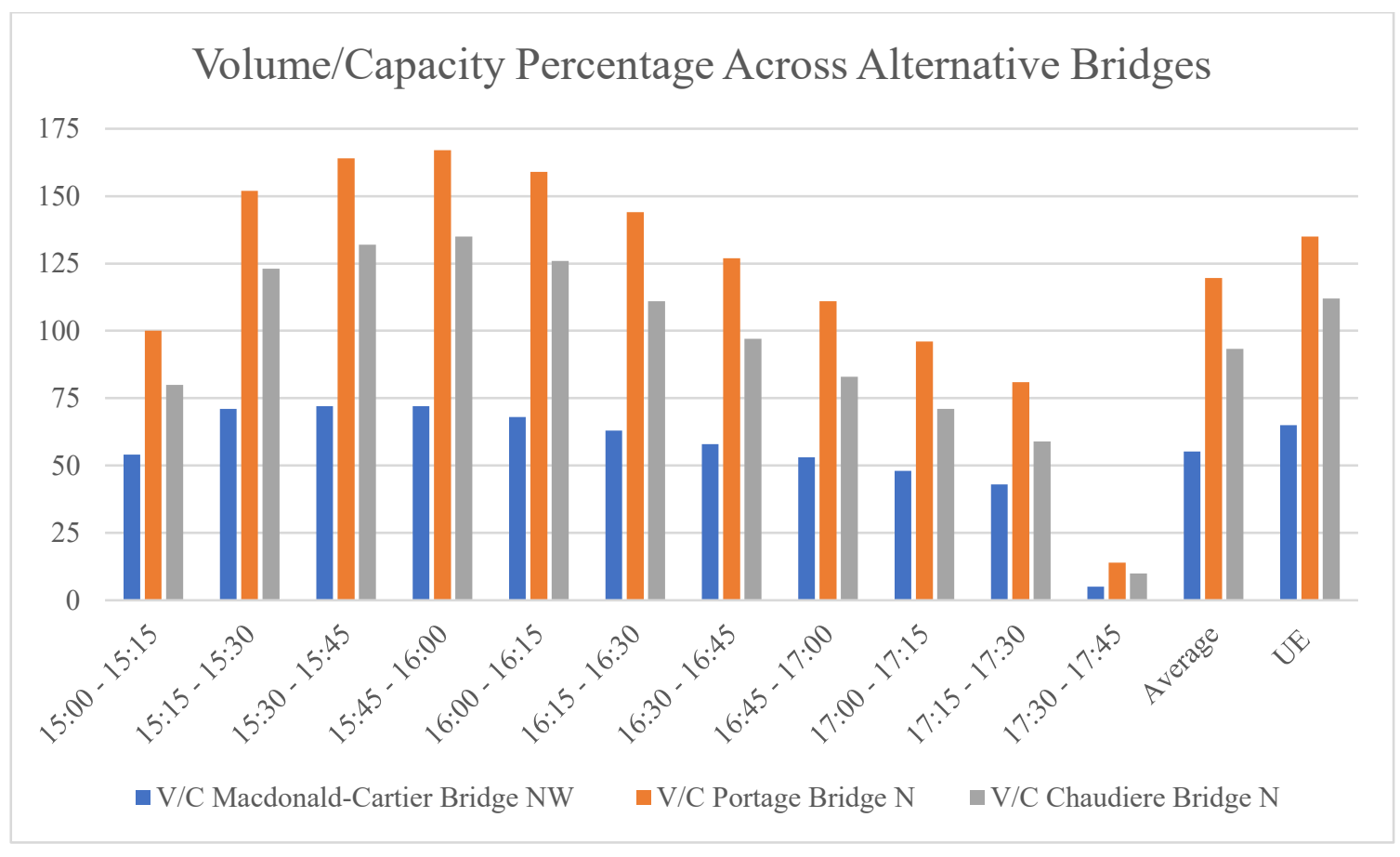

Figure 10.13: Event 2 v/c Ratio per TI - 2018 Demand

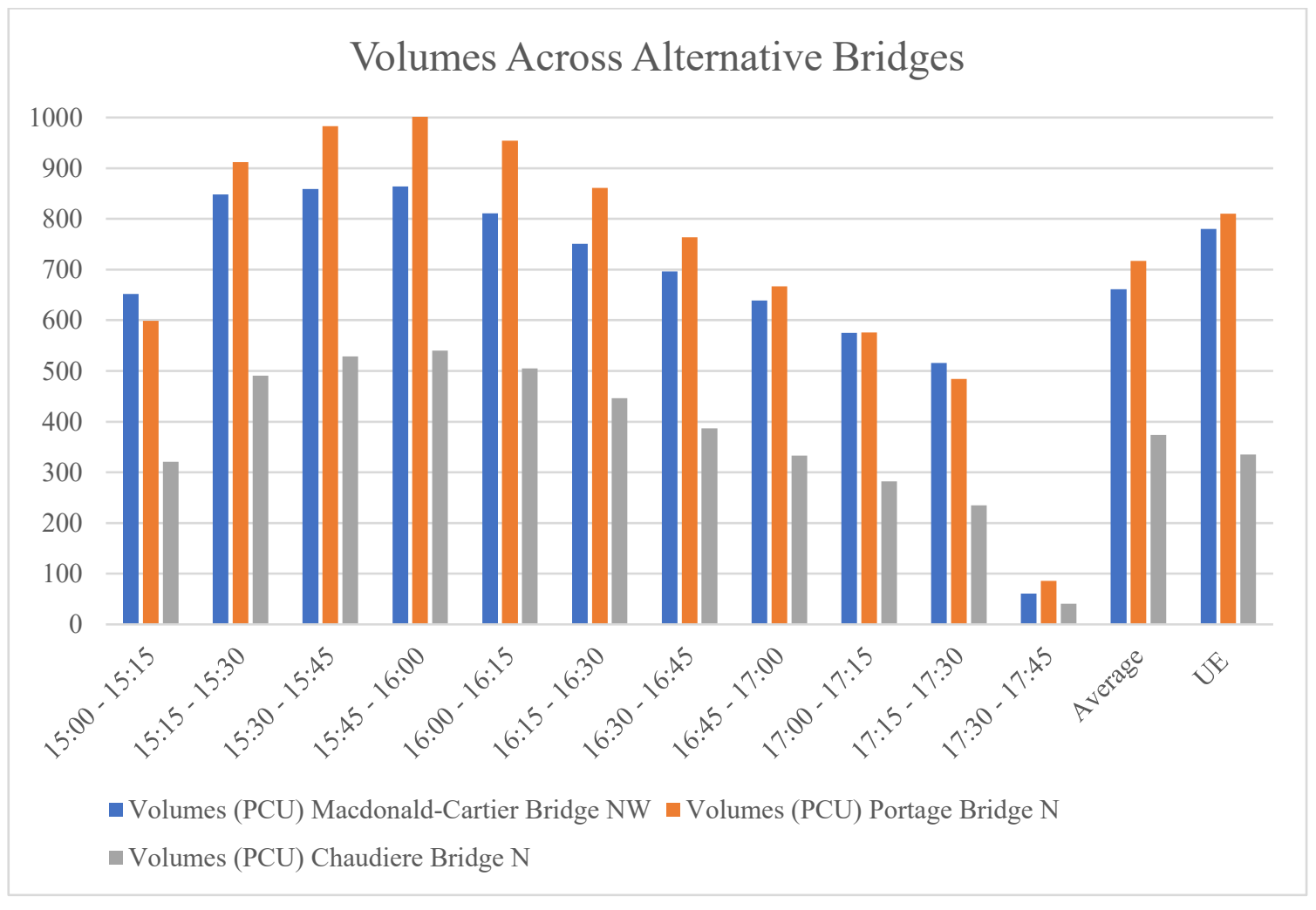

Figure 10.14: Event 2 Volumes Across Alternatives - 2018 Demand 


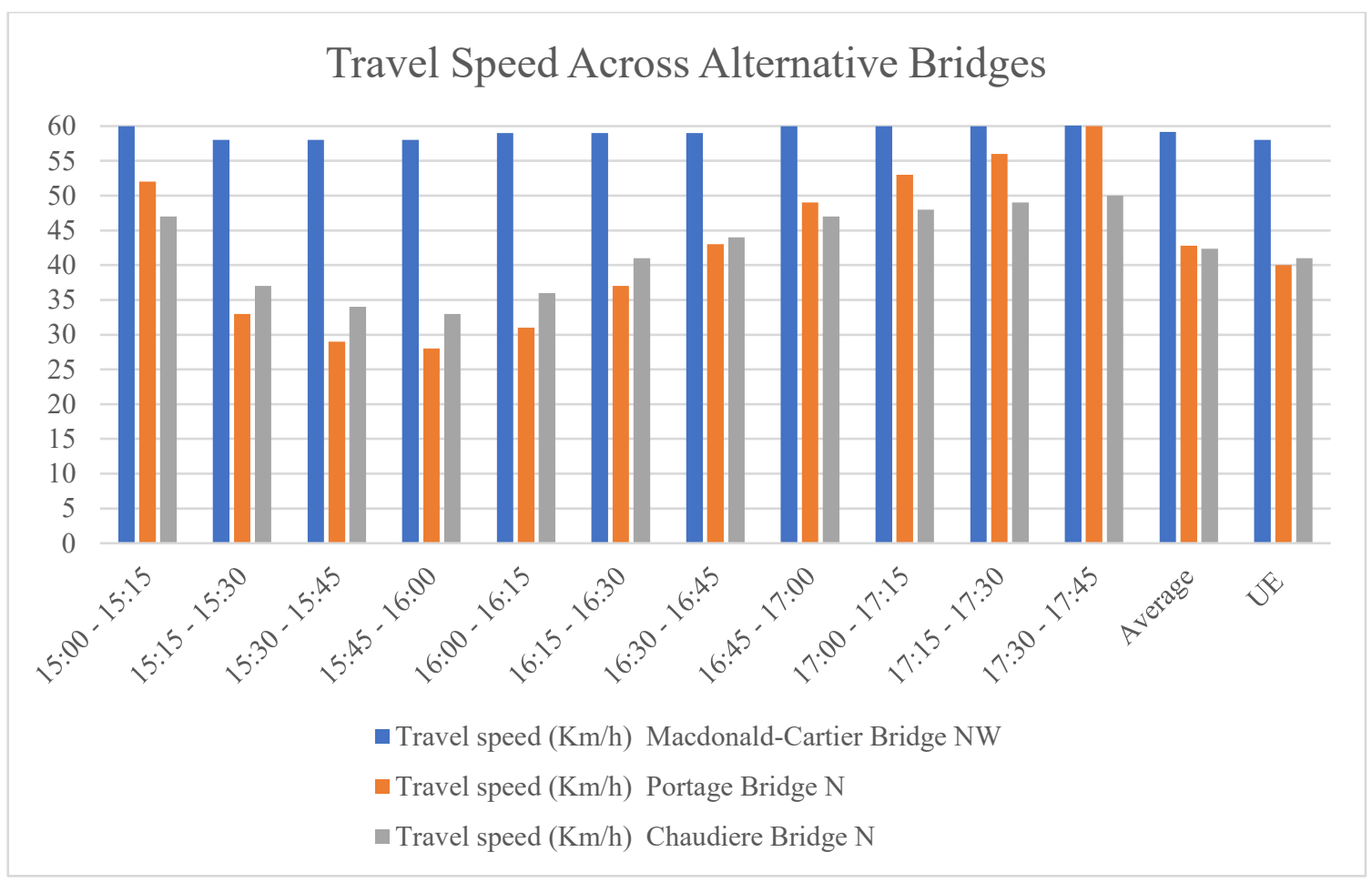

Figure 10.15: Event 2 Travel Speed Across Alternatives - 2018 Data

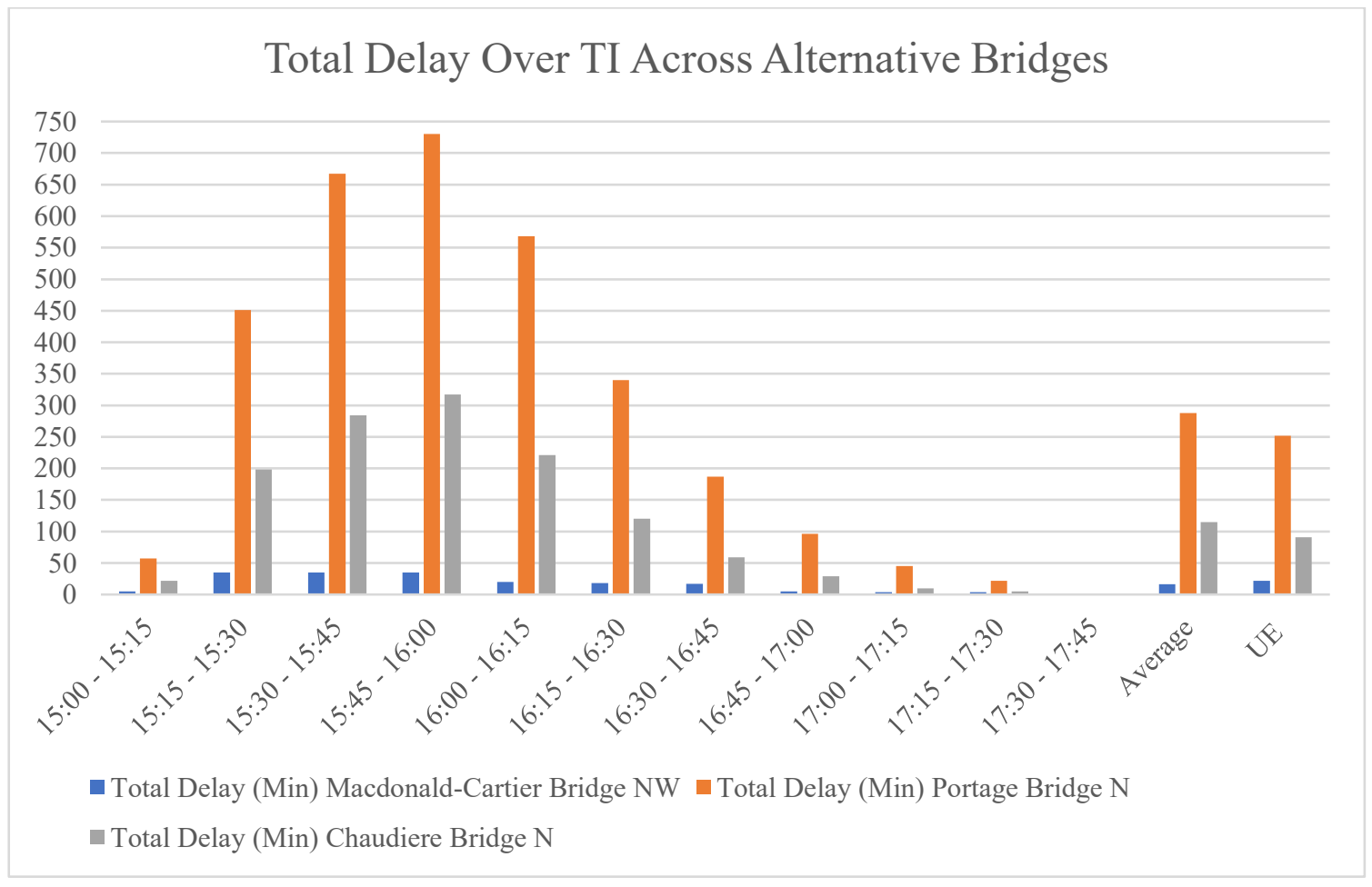

Figure 10.16: Event 2 Delay per TI Across Alternatives - 2018 Data 
10.4.5 Event 2 - Alexandra Bridge under Stress - 2031 Demand Data

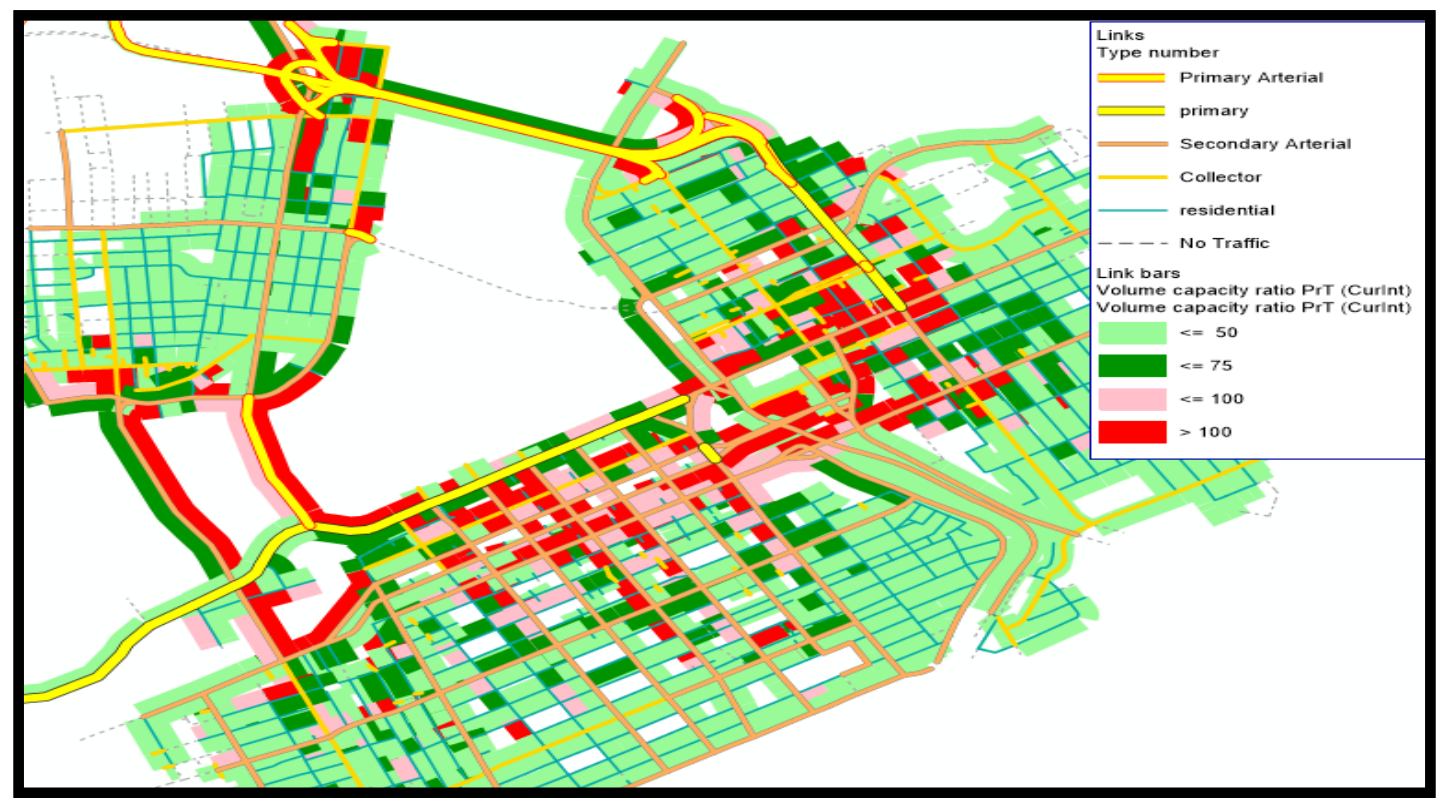

Figure 10.17: DSA of 2031 Data for Event 2 - 15:45 to 16:00 TI Simulation

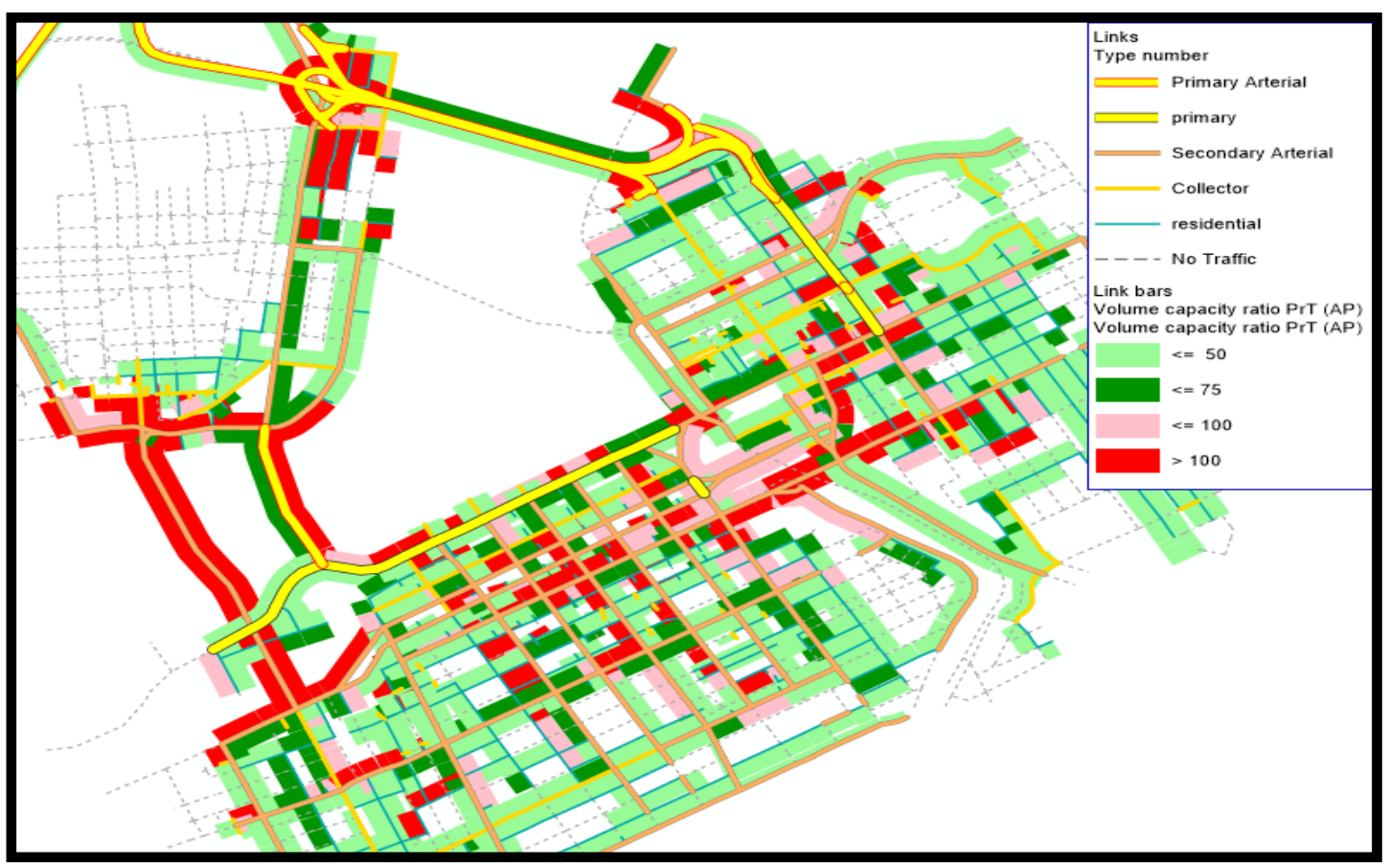

Figure 10.18: UE of 2031 Data for Event 2 - Simulation 


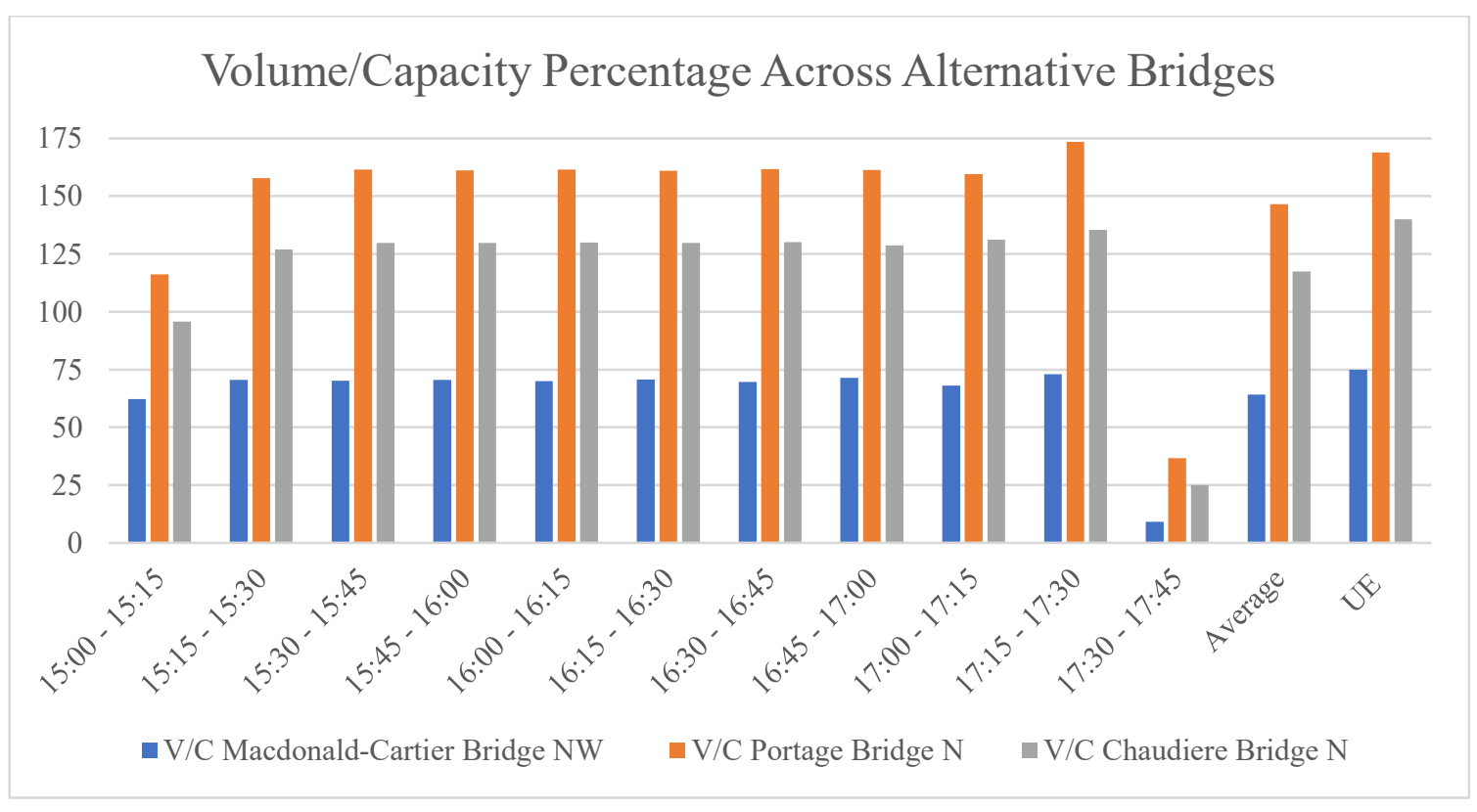

Figure 10.19: Event 2 V/C Ratio per TI-2031 Demand

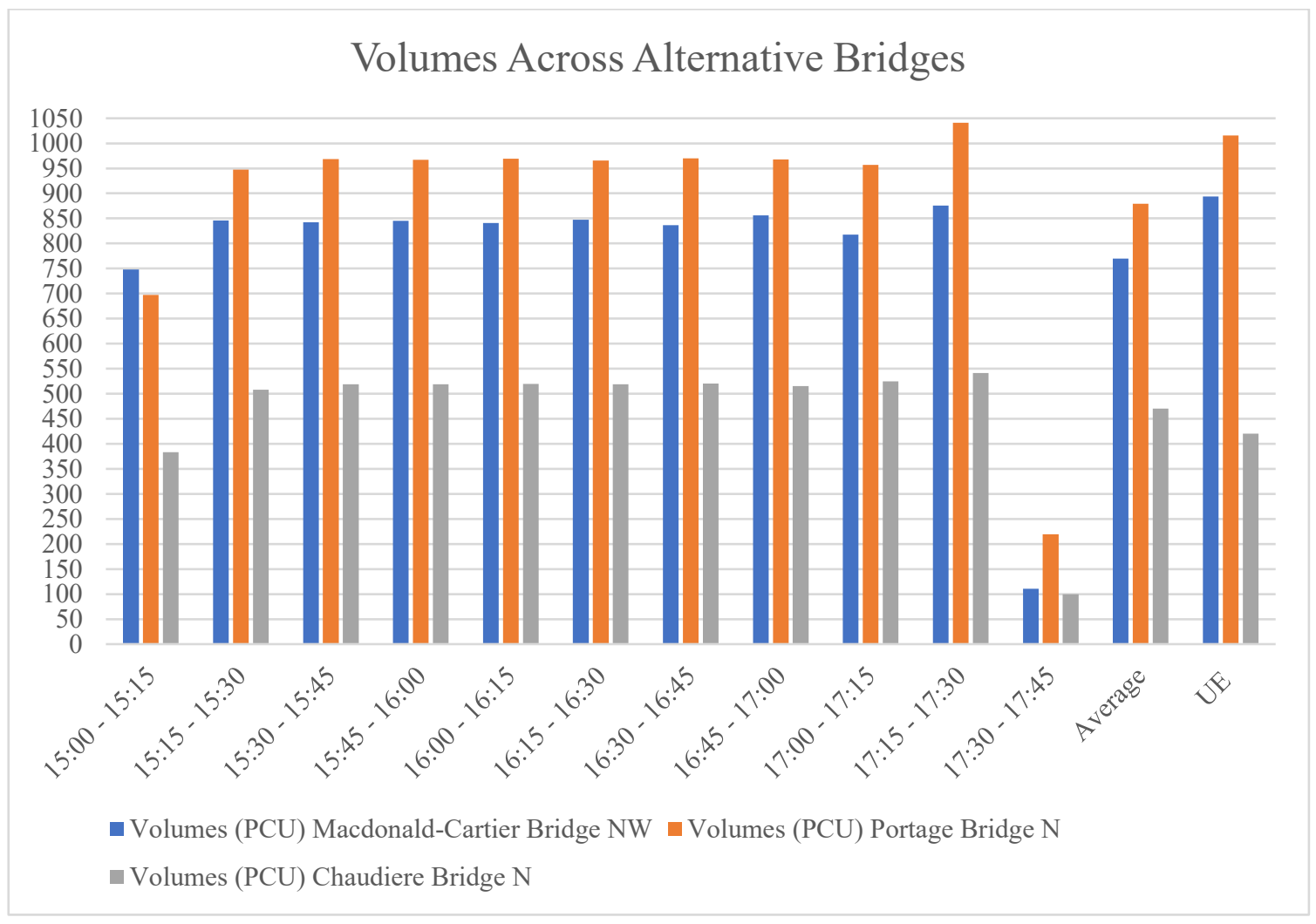

Figure 10.20: Event 2 Volumes Across Alternatives - 2031 Demand 


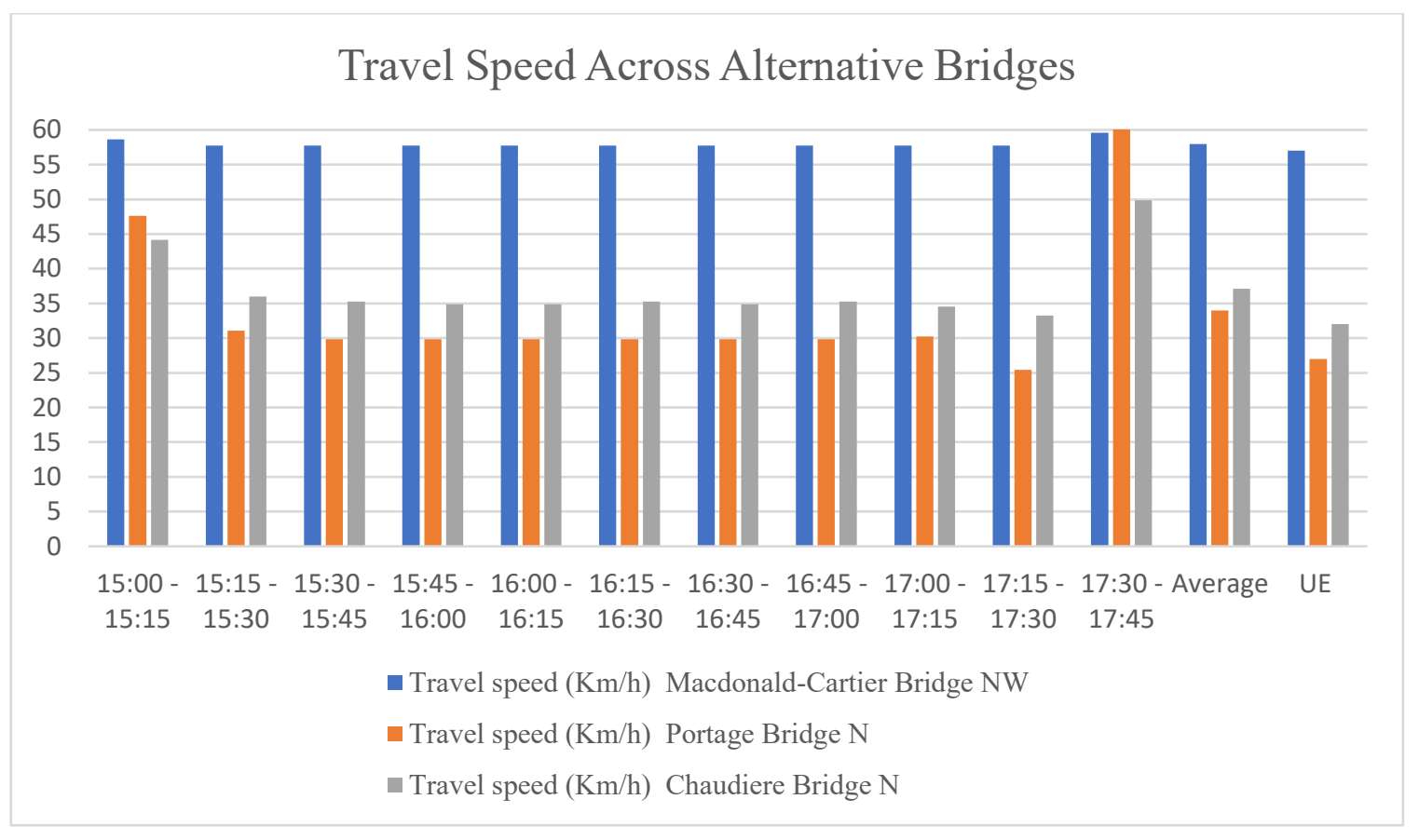

Figure 10.21: Event 2 Travel Speed Across Alternatives - 2031 Data

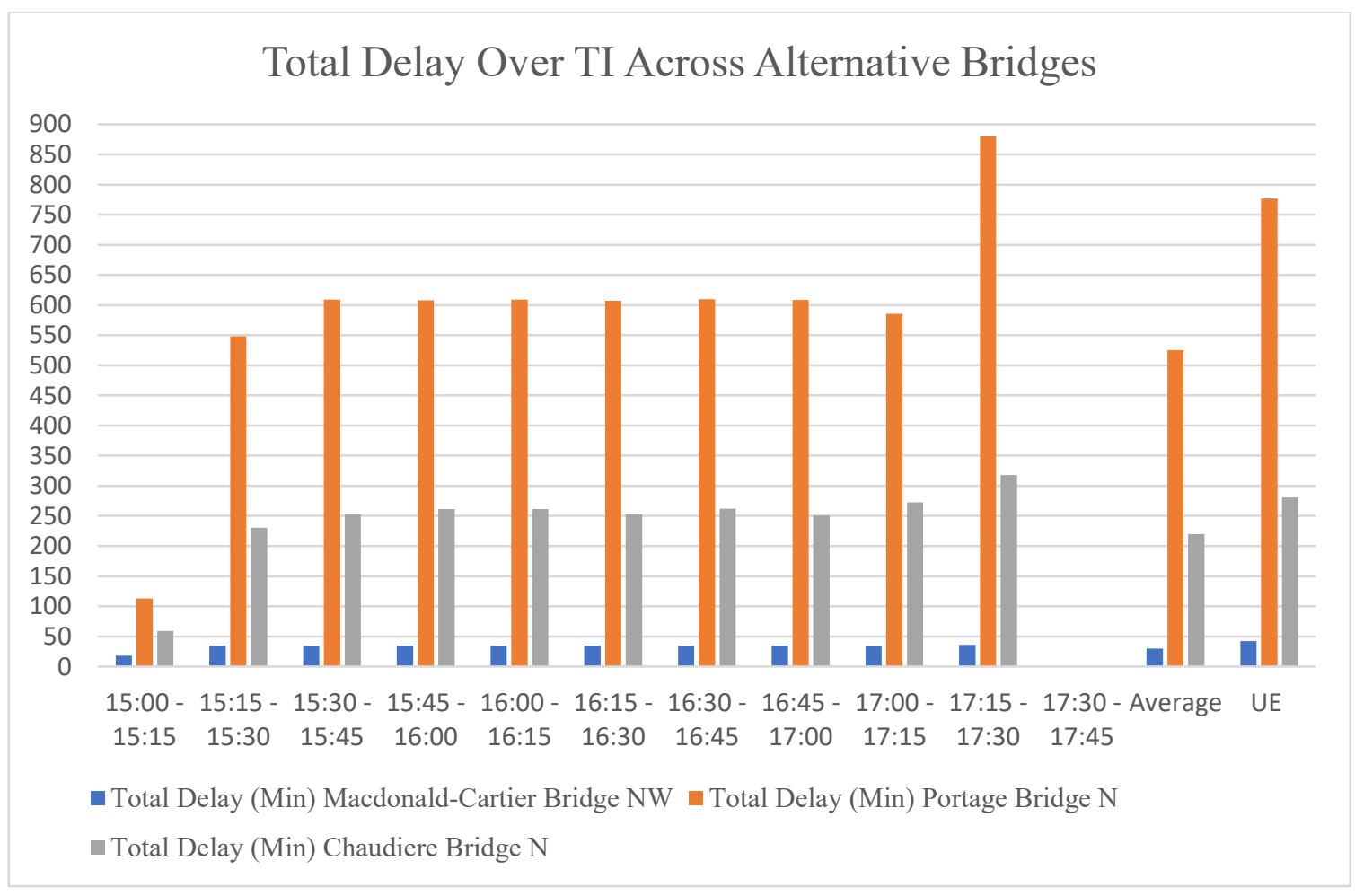

Figure 10.22: Event 2 Delay per TI Across Alternatives - 2031 Data 


\subsubsection{Event 2 - Summary}

Table 10-14: 2018 Demand Volumes Across Alternatives - Event 2

\begin{tabular}{|c|c|c|c|c|}
\hline Alternative & $\begin{array}{c}\text { UE 2018 } \\
\text { Demand } \\
\text { Volumes } \\
\text { Ottawa to Hull } \\
\text { (PCU) }\end{array}$ & $\begin{array}{c}\text { DAS 2018 } \\
\text { Demand } \\
\text { Volumes } \\
\text { Ottawa to Hull } \\
\text { (PCU) }\end{array}$ & $\begin{array}{c}\text { UE 2031 } \\
\text { Demand } \\
\text { Volumes } \\
\text { Ottawa to Hull } \\
\text { (PCU) }\end{array}$ & $\begin{array}{c}\text { DAS 2031 } \\
\text { Demand } \\
\text { Volumes } \\
\text { Ottawa to } \\
\text { Hull (PCU) }\end{array}$ \\
\hline 2: Macdonald-Cartier & 7800 & 7272 & 8945 & 8466 \\
\hline 3: Portage & 8105 & 7890 & 10155 & 9672 \\
\hline 4: Chaudière & 3354 & 4110 & 4197 & 5170 \\
\hline Total & 19259 & 19272 & 23297 & 23308 \\
\hline
\end{tabular}

Table 10-15: Event 2 - Comparison of Total Delay Across Alternatives for Vehicles Traveling from Ottawa to Hull

\begin{tabular}{|c|c|c|c|c|c|c|}
\hline Alternative & $\begin{array}{c}\text { UE 2018 } \\
\text { Demand } \\
\text { Data Delay } \\
\text { Ottawa to } \\
\text { Hull } \\
\text { (Hours) }\end{array}$ & $\begin{array}{c}\text { DAS 2018 } \\
\text { Demand } \\
\text { Data Delay } \\
\text { Ottawa to } \\
\text { Hull } \\
\text { (Hours) }\end{array}$ & $\begin{array}{c}\text { Increase / } \\
\text { Decrease } \\
\%\end{array}$ & $\begin{array}{c}\text { UE 2031 } \\
\text { Demand } \\
\text { Data Delay } \\
\text { Ottawa to } \\
\text { Hull } \\
\text { (Hours) }\end{array}$ & $\begin{array}{c}\text { DAS 2031 } \\
\text { Demand } \\
\text { Data } \\
\text { Delay } \\
\text { Ottawa to } \\
\text { Hull } \\
\text { (Hours) }\end{array}$ & $\begin{array}{c}\text { Increase } \\
/ \\
\text { Decrease } \\
\%\end{array}$ \\
\hline Macdonald-Cartier & 3.63 & 3.00 & -17.36 & 7.20 & 5.50 & -23.61 \\
\hline Portage & 41.93 & 52.75 & 25.80 & 129.43 & 96.30 & -25.60 \\
\hline Chaudière & 15.24 & 21.10 & 38.45 & 46.75 & 40.35 & -13.69 \\
\hline All Alt. & 60.80 & 76.85 & 26.40 & 183.38 & 142.15 & -22.48 \\
\hline
\end{tabular}




\subsubsection{Event 3 - Portage Bridge under Stress - 2018 Demand Data}

Figures and tables below shows the comparison results on alternative corridors if

Portage Bridge were to be out of service to road users.

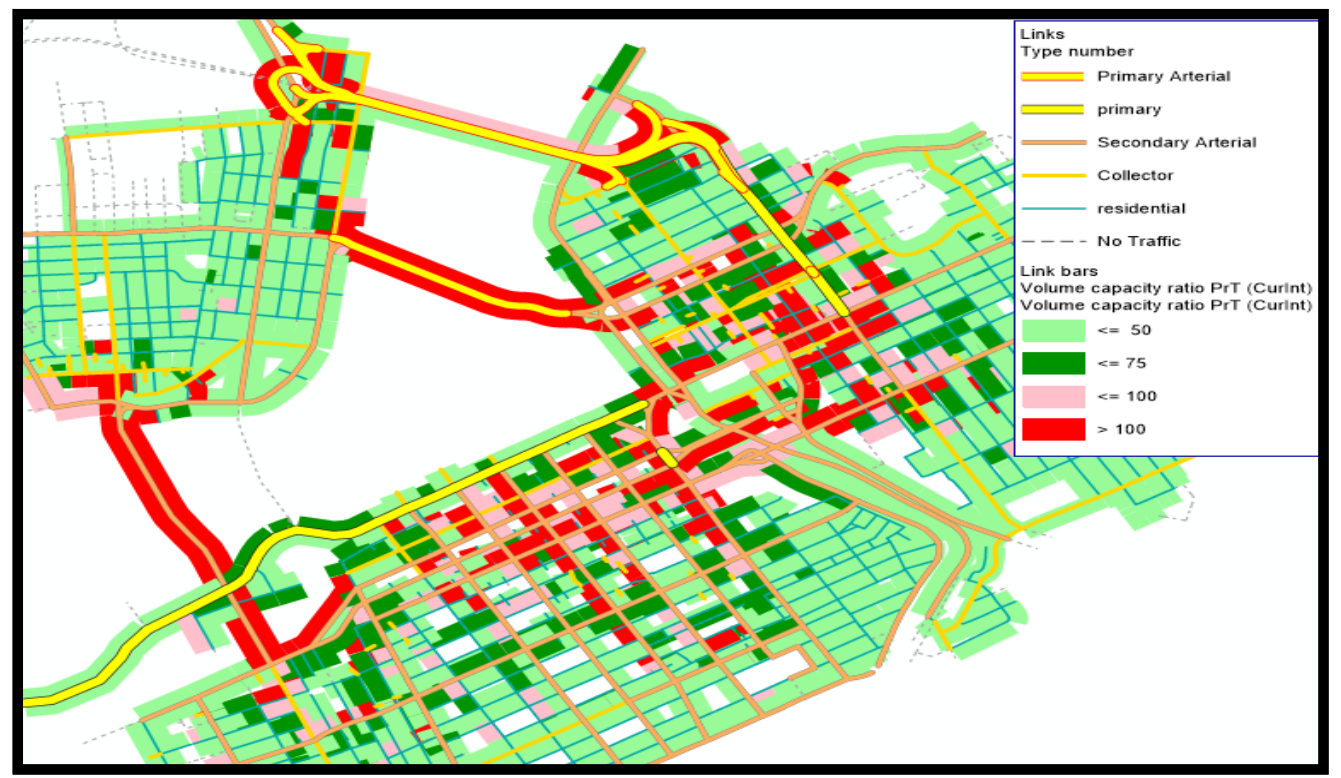

Figure 10.23: DSA of 2018 Data for Event 3 - 15:45 to 16:00 TI Simulation

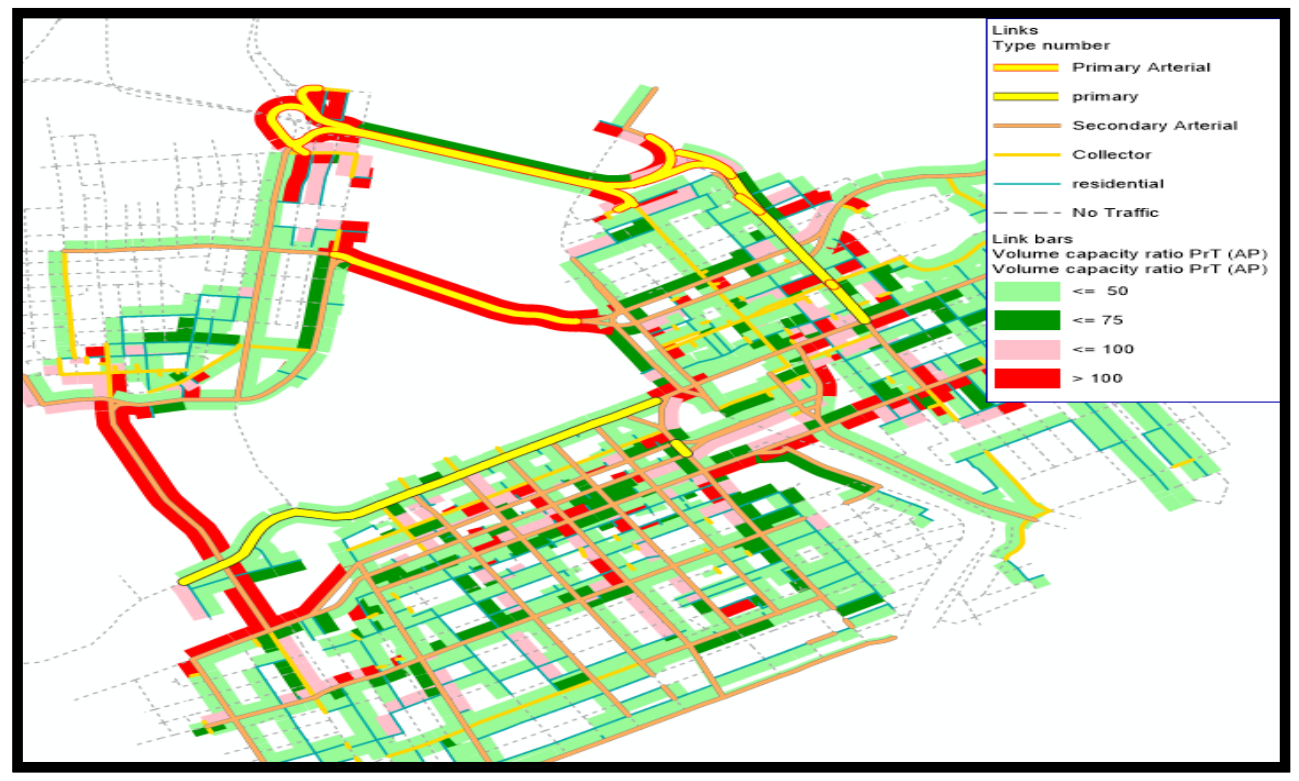

Figure 10.24: UE of 2018 Data for Event 3 Simulation 


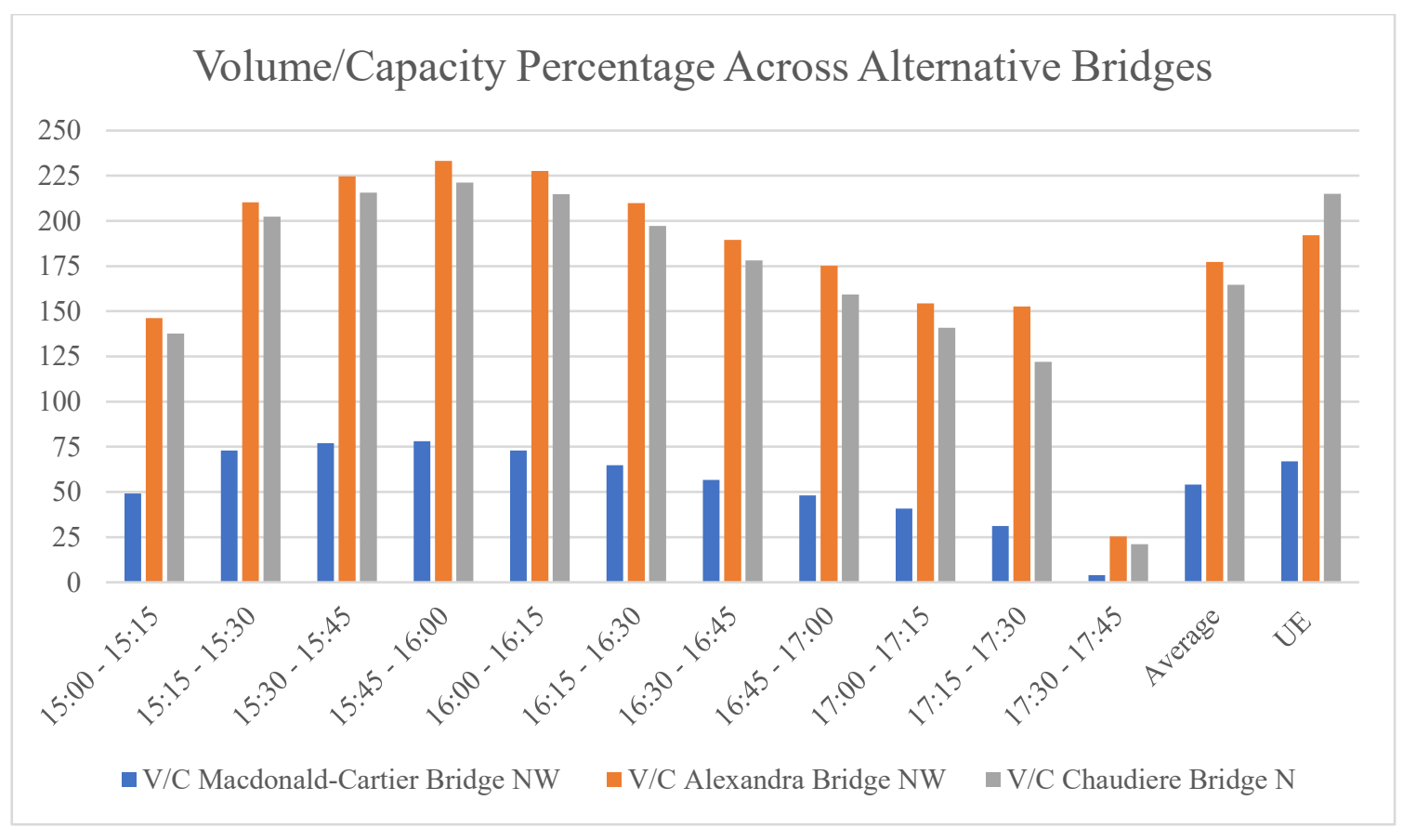

Figure 10.25: Event 3 v/c Ratio per TI - 2018 Demand

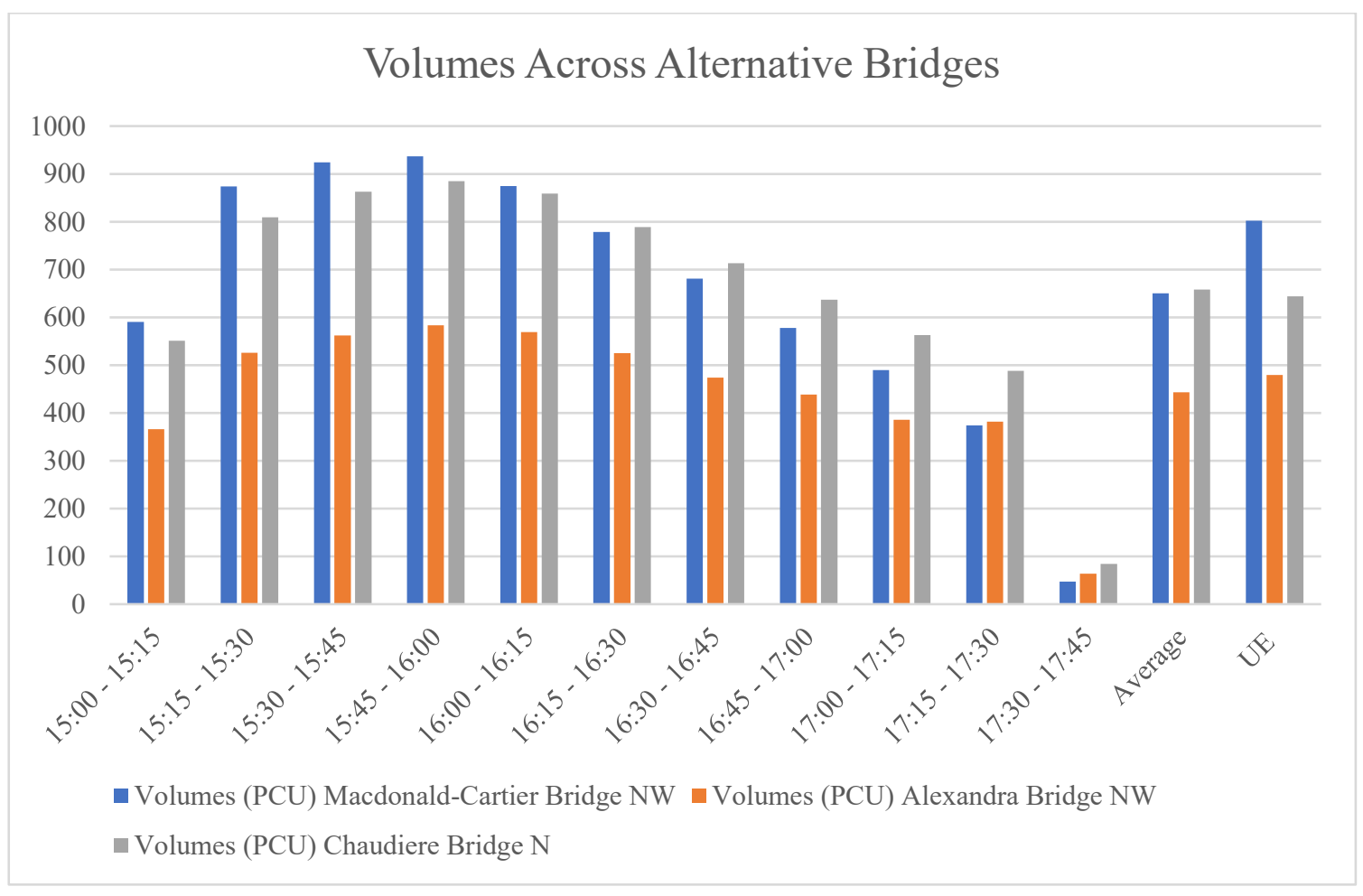

Figure 10.26: Event 3 Volumes Across Alternatives - 2018 Demand 


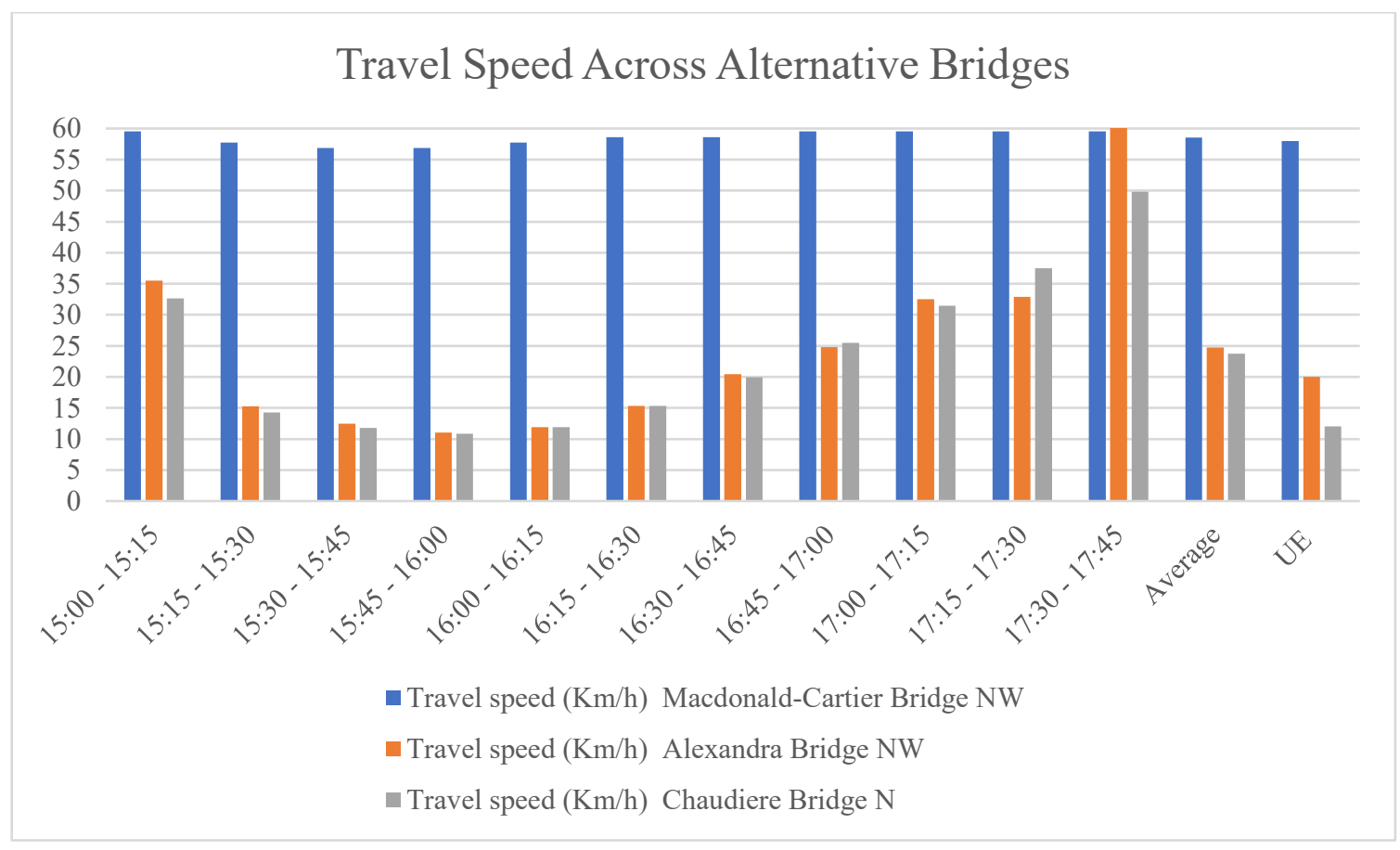

Figure 10.27: Event 3 Travel Speed Across Alternatives - 2018 Data

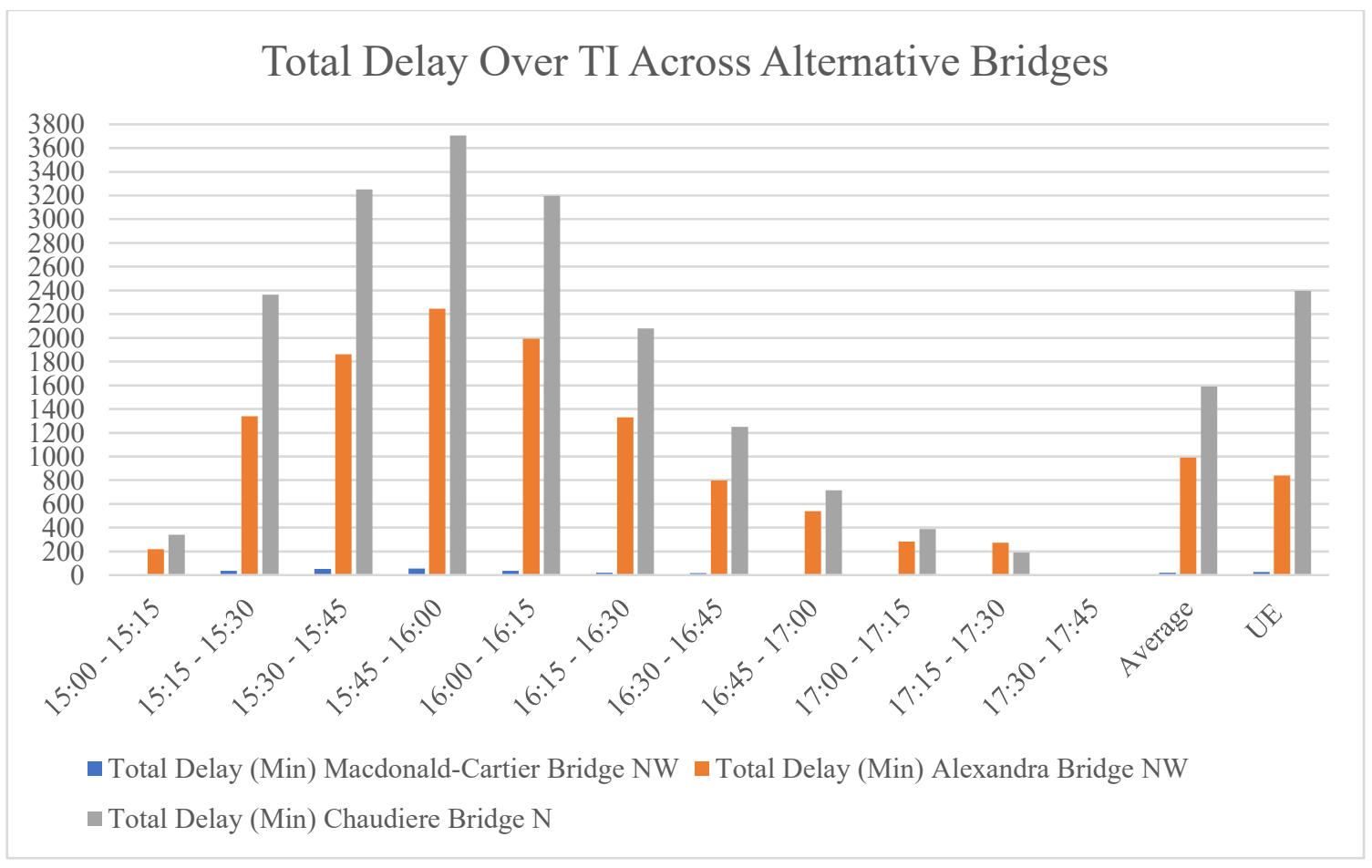

Figure 10.28: Event 3 Delay per TI Across Alternatives - 2018 Data 
10.4.8 Event 3 - Portage Bridge under Stress - 2031 Demand Data

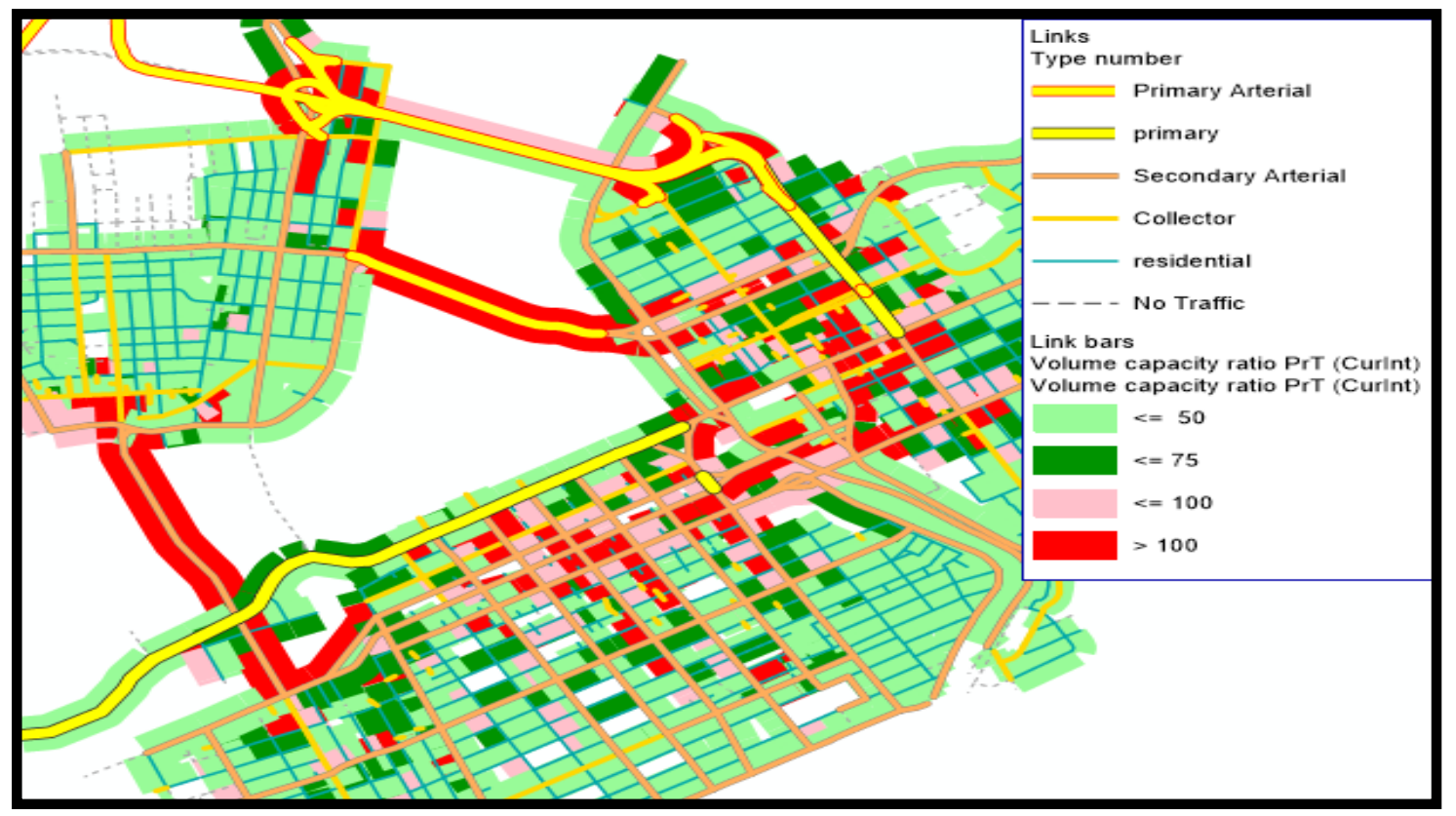

Figure 10.29: DSA of 2031 Data for Event 3 - 15:45 to 16:00 TI Simulation

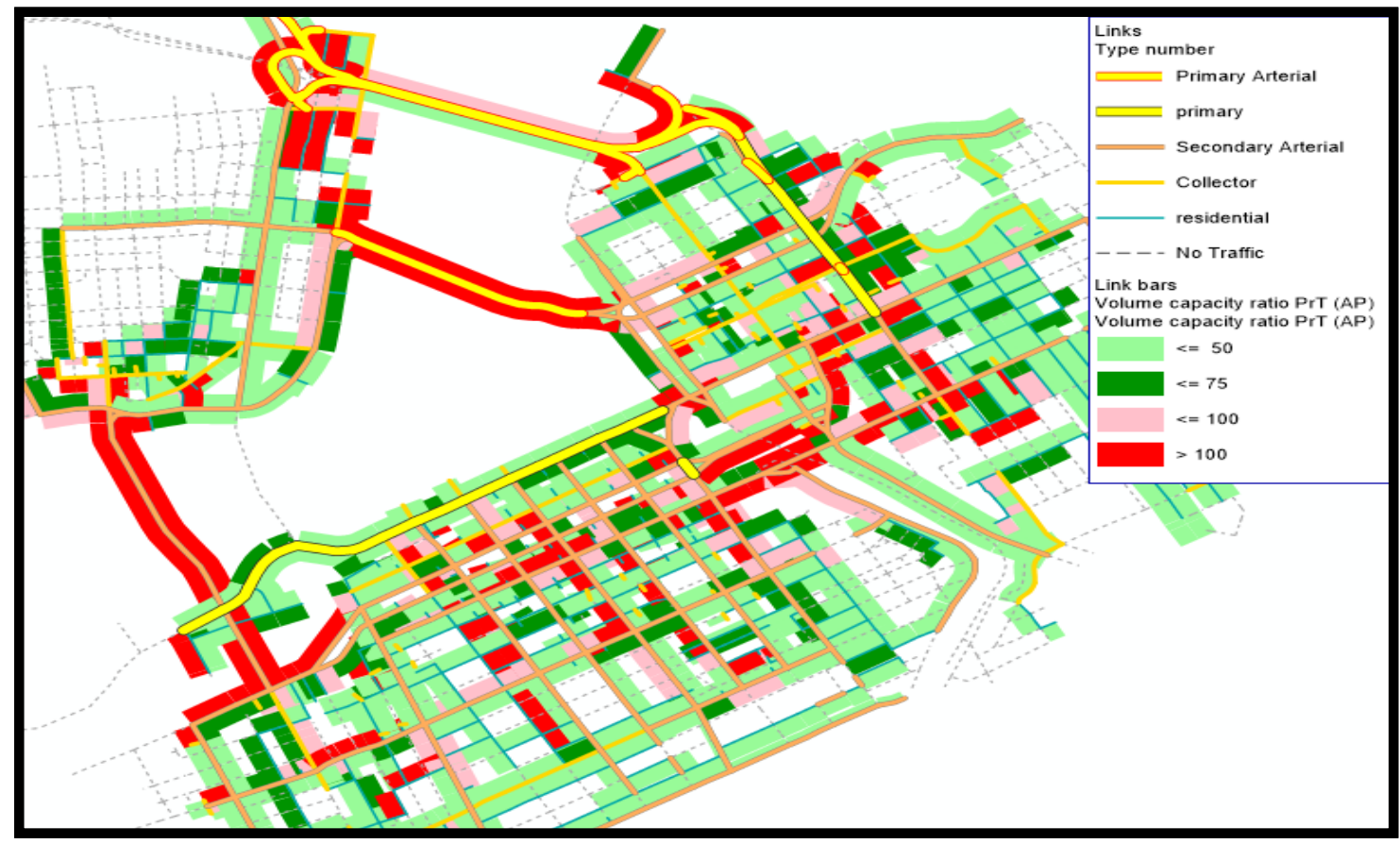

Figure 10.30: UE of 2031 Data for Event 3 Simulation 


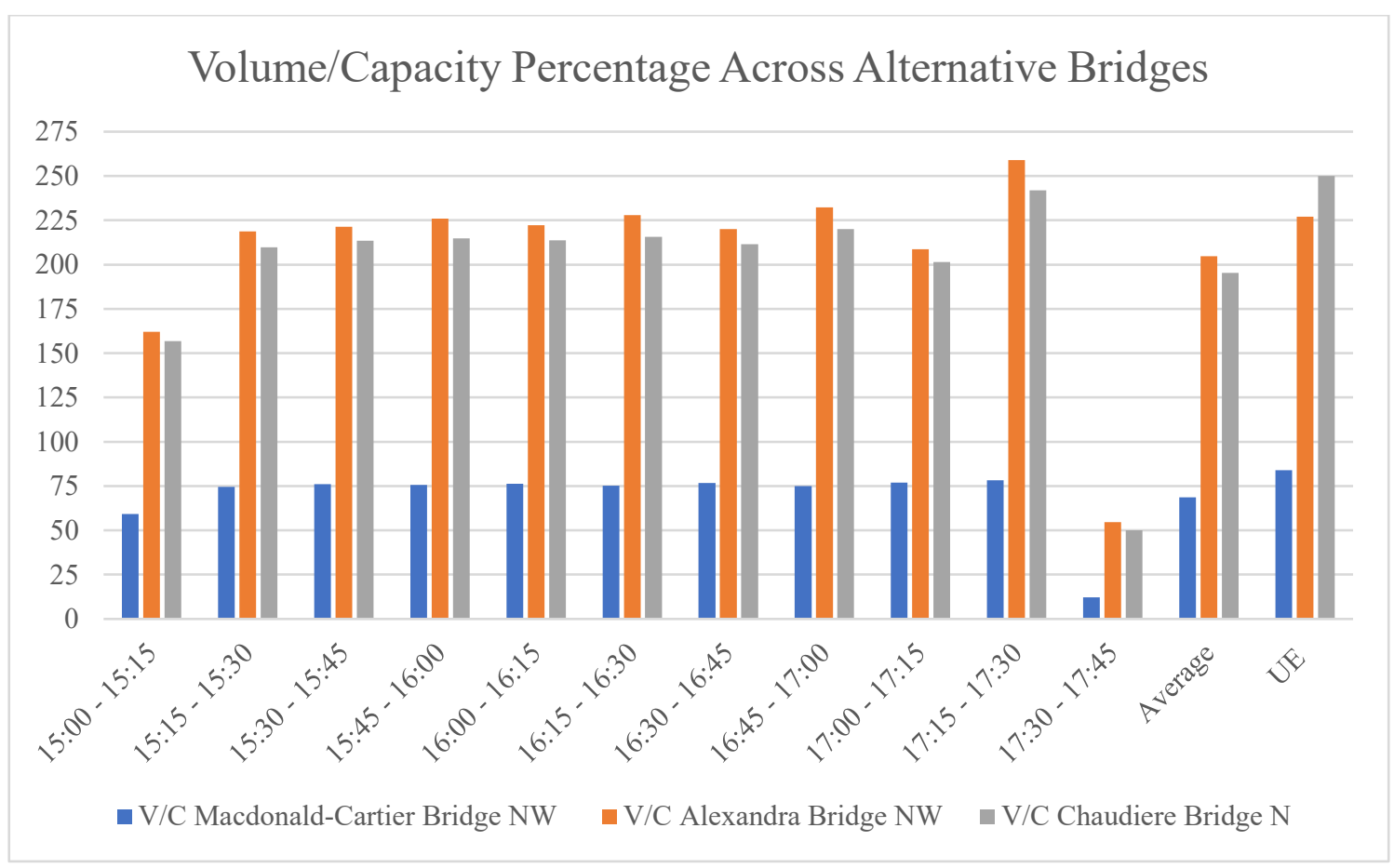

Figure 10.31: Event 3 v/c Ratio per TI - 2031 Demand

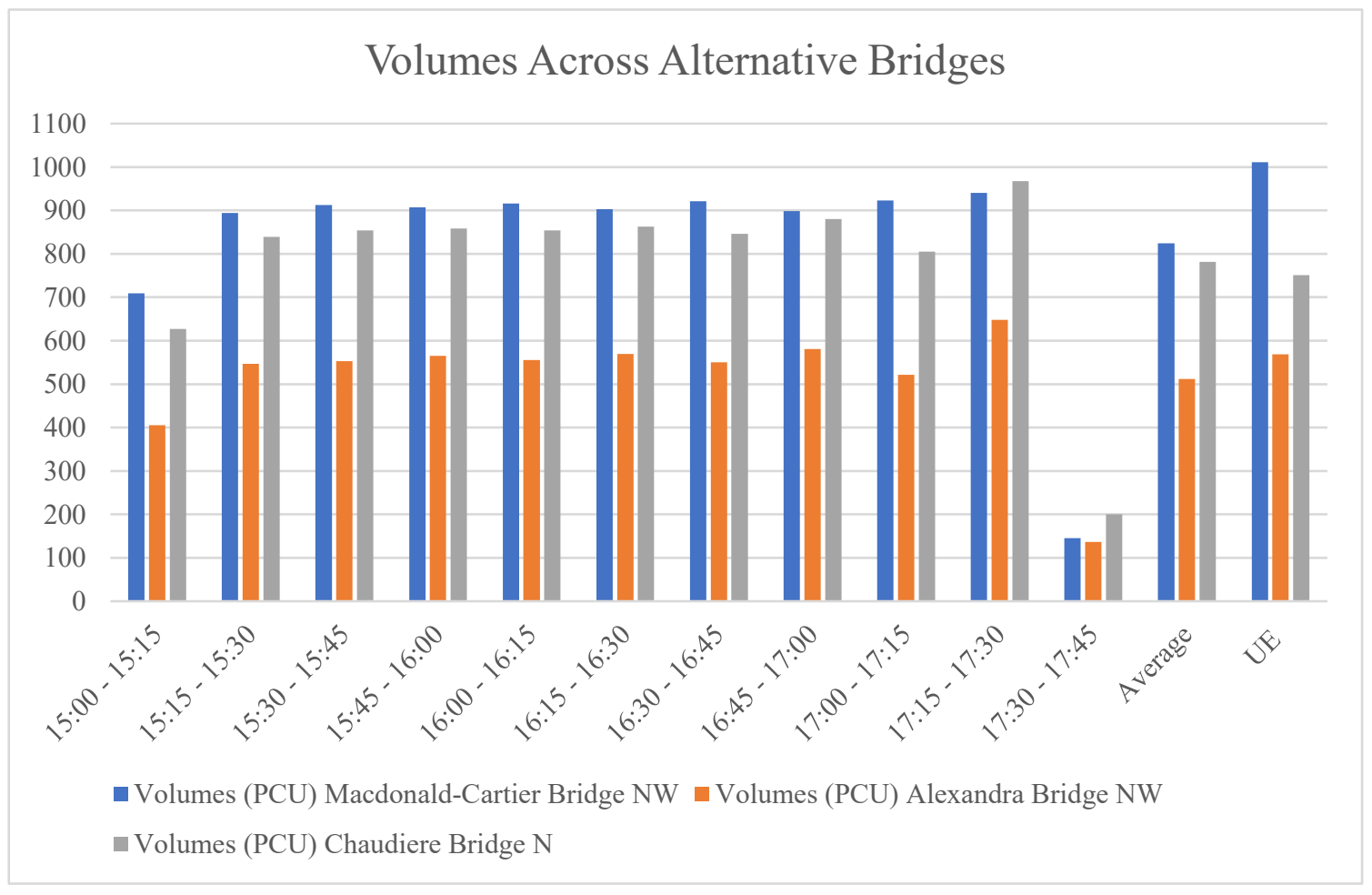

Figure 10.32: Event 3 Volumes Across Alternatives - 2031 Demand 


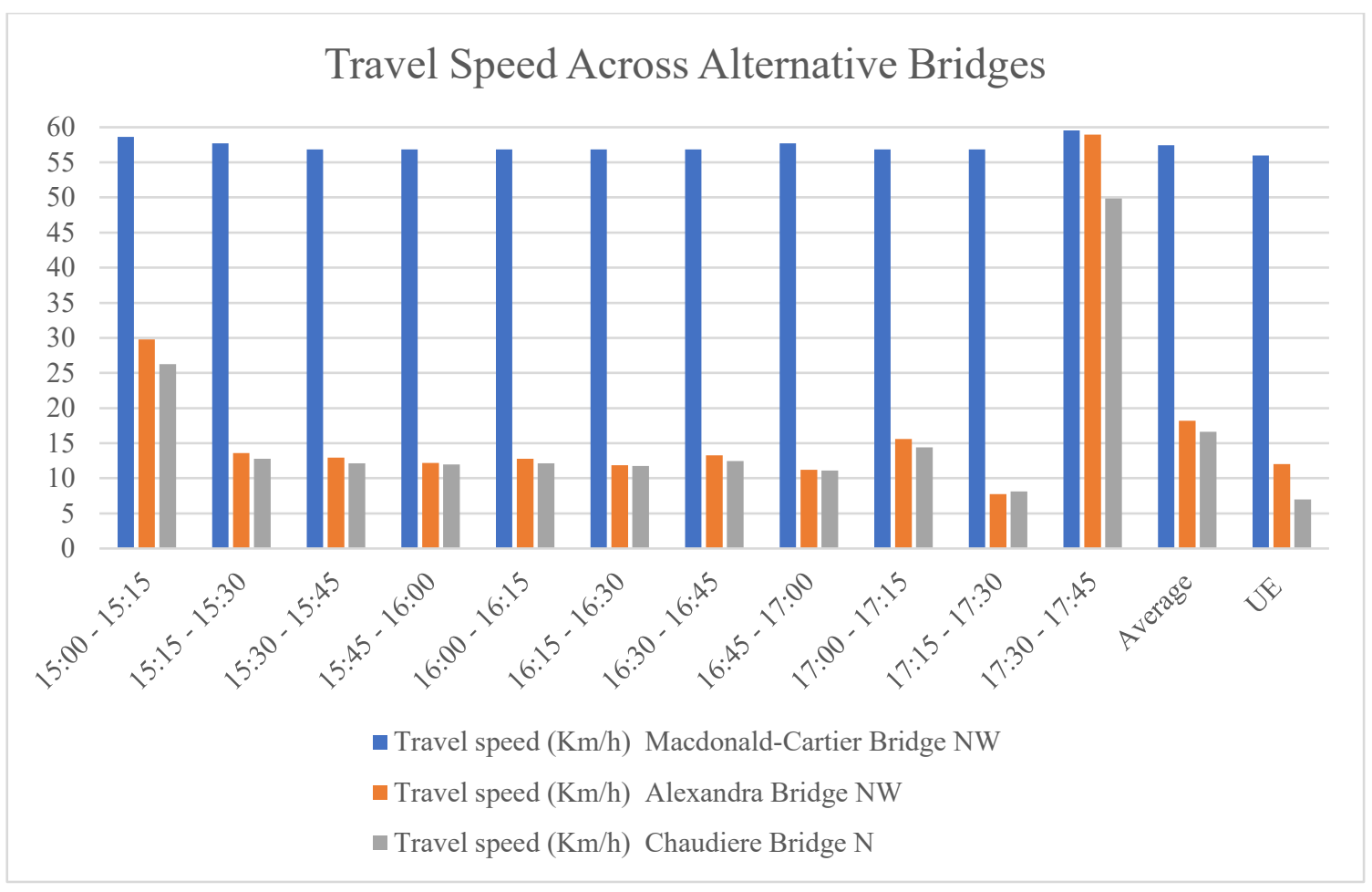

Figure 10.33: Event 3 Travel Speed Across Alternatives - 2031 Data

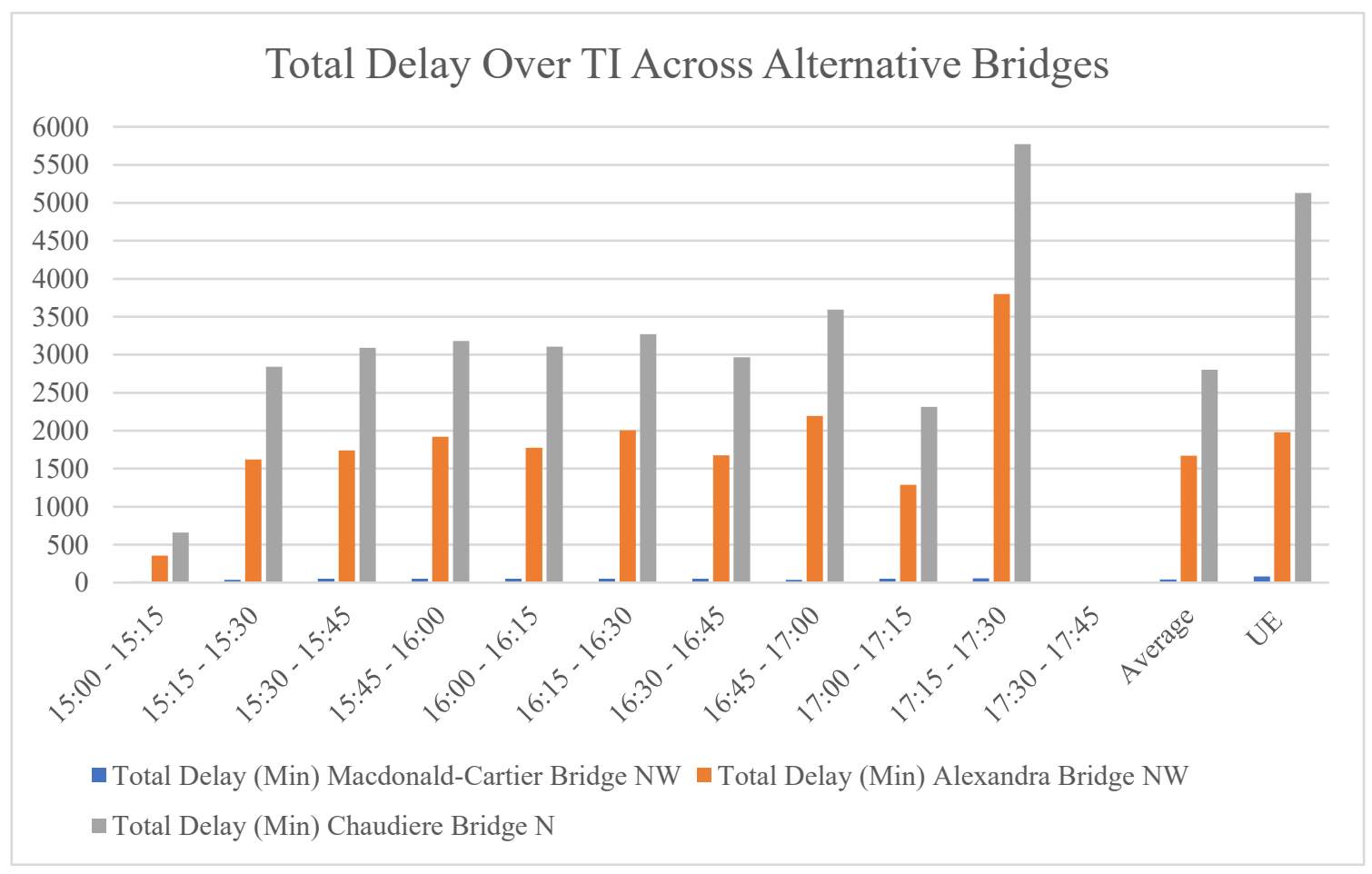

Figure 10.34: Event 2 Delay per TI Across Alternatives - 2031 Data 


\subsubsection{Event 3 - Summary}

Table 10-16: 2018 Demand Volumes Across Alternatives - Event 3

\begin{tabular}{|c|c|c|c|c|}
\hline Alternative & $\begin{array}{c}\text { UE 2018 } \\
\text { Demand } \\
\text { Volumes } \\
\text { Ottawa to Hull } \\
\text { (PCU) }\end{array}$ & $\begin{array}{c}\text { DAS 2018 } \\
\text { Demand } \\
\text { Volumes Ottawa } \\
\text { to Hull (PCU) }\end{array}$ & $\begin{array}{c}\text { UE 2031 } \\
\text { Demand } \\
\text { Volumes } \\
\text { Ottawa to Hull } \\
\text { (PCU) }\end{array}$ & $\begin{array}{c}\text { DAS 2031 } \\
\text { Demand } \\
\text { Volumes } \\
\text { Ottawa to } \\
\text { Hull (PCU) }\end{array}$ \\
\hline 1: Macdonald-Cartier & 8025 & 7148 & 10106 & 9072 \\
\hline 2: Alexandra & 4789 & 4873 & 5685 & 5631 \\
\hline 4: Chaudière & 6445 & 7241 & 7506 & 8595 \\
\hline Total & 19259 & 19262 & 23297 & 23298 \\
\hline
\end{tabular}

Table 10-17: Event 3 - Comparison of Total Delay Across Alternatives for Vehicles Traveling from Ottawa to Hull

\begin{tabular}{|c|c|c|c|c|c|c|}
\hline Alternative & $\begin{array}{c}\text { UE 2018 } \\
\text { Demand } \\
\text { Data Delay } \\
\text { Ottawa to } \\
\text { Hull } \\
\text { (Hours) }\end{array}$ & $\begin{array}{c}\text { DAS 2018 } \\
\text { Demand } \\
\text { Data Delay } \\
\text { Ottawa to } \\
\text { Hull } \\
\text { (Hours) }\end{array}$ & $\begin{array}{c}\text { Increase / } \\
\text { Decrease } \\
\%\end{array}$ & $\begin{array}{c}\text { UE 2031 } \\
\text { Demand } \\
\text { Data Delay } \\
\text { Ottawa to } \\
\text { Hull } \\
\text { (Hours) }\end{array}$ & $\begin{array}{c}\text { DAS 2031 } \\
\text { Demand } \\
\text { Data Delay } \\
\text { Ottawa to } \\
\text { Hull } \\
\text { (Hours) }\end{array}$ & $\begin{array}{c}\text { Increase / } \\
\text { Decrease } \\
\%\end{array}$ \\
\hline Macdonald-Cartier & 4.18 & 3.83 & -8.37 & 13.25 & 7.70 & -41.89 \\
\hline Alexandra & 139.98 & 181.30 & 29.52 & 329.90 & 306.33 & -7.14 \\
\hline Chaudière & 399.13 & 291.27 & -27.02 & 855.18 & 513.28 & -39.98 \\
\hline All Alt. & 543.29 & 476.40 & -12.31 & 1198.33 & 827.31 & -30.96 \\
\hline
\end{tabular}




\subsubsection{Event 4 - Chaudière Bridge under Stress - 2018 Demand Data}

Figures and tables below show the comparison results on alternative corridors if

Chaudière Bridge were to be out of service to road users.

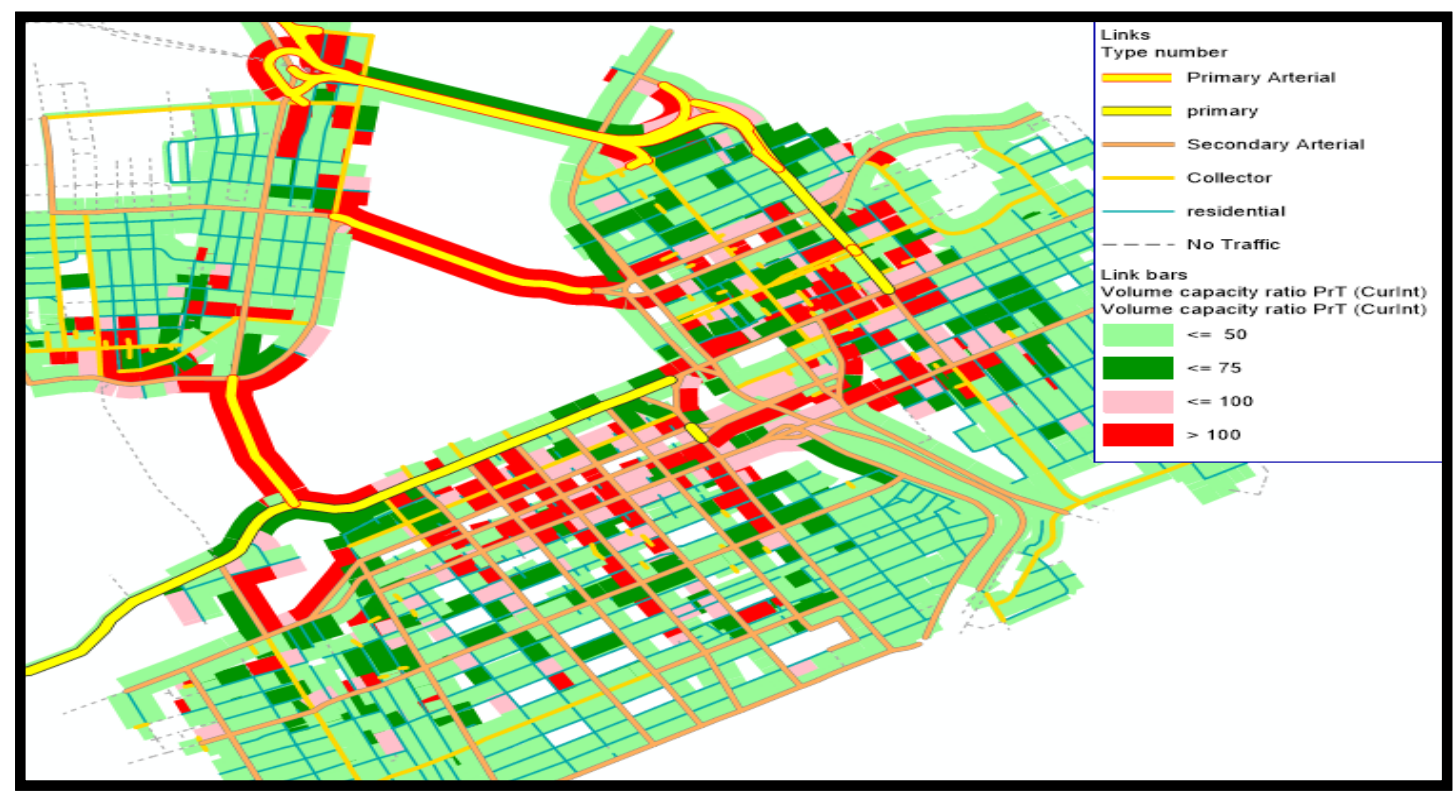

Figure 10.35: DSA of 2018 Data for Event 4 - 15:45 to 16:00 TI Simulation

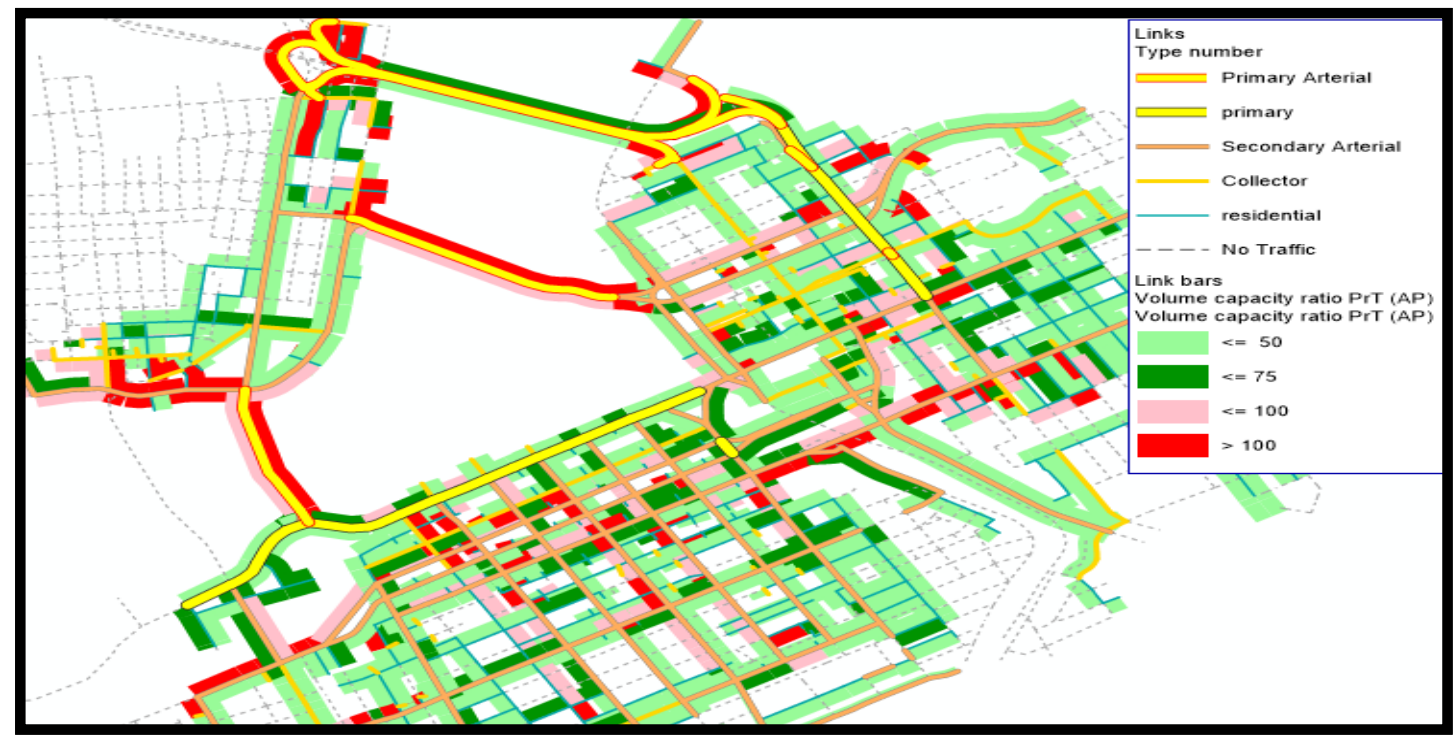

Figure 10.36: UE of 2018 Data for Event 4 Simulation 


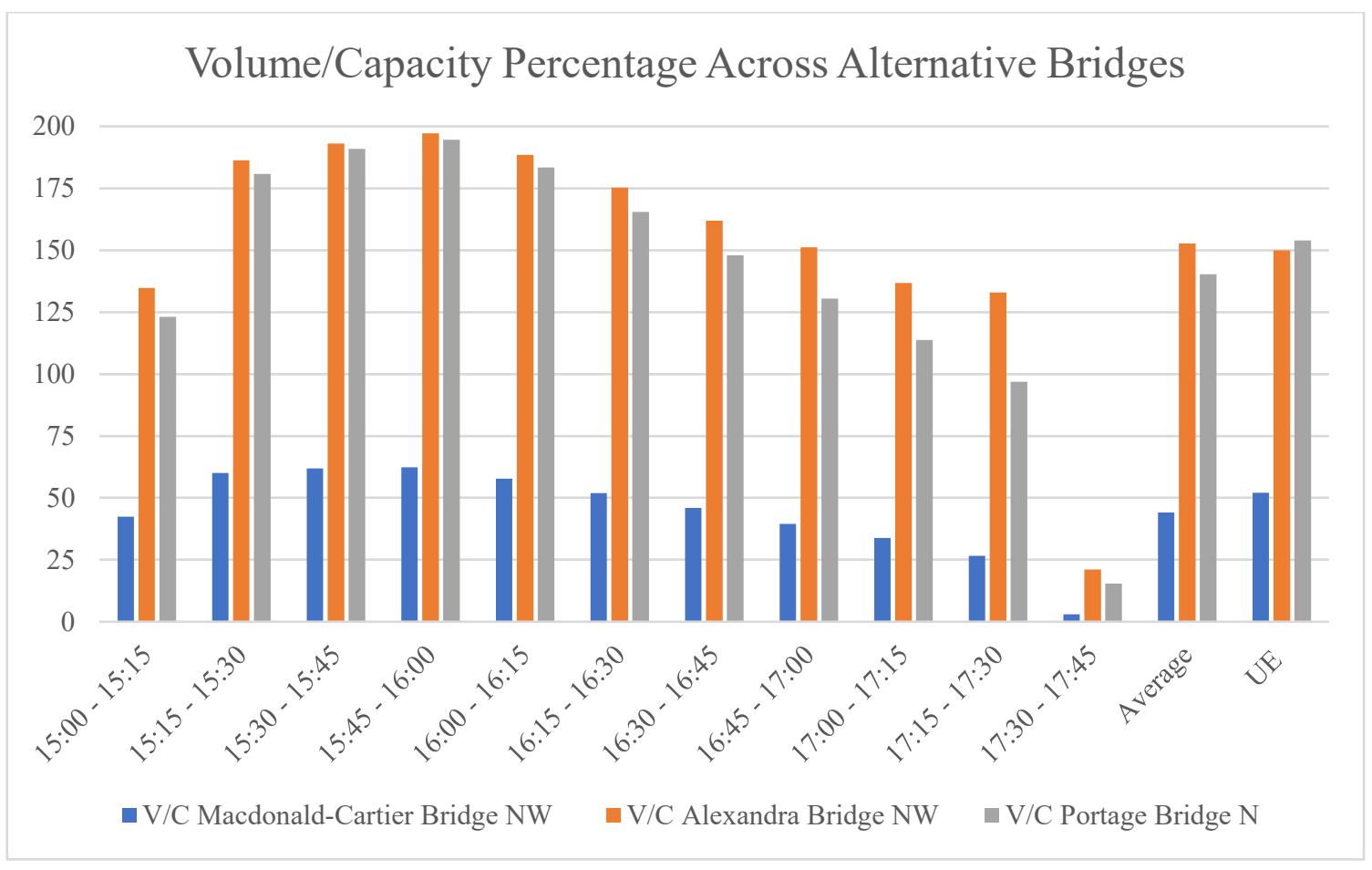

Figure 10.37: Event 4 v/c Ratio per TI - 2018 Demand

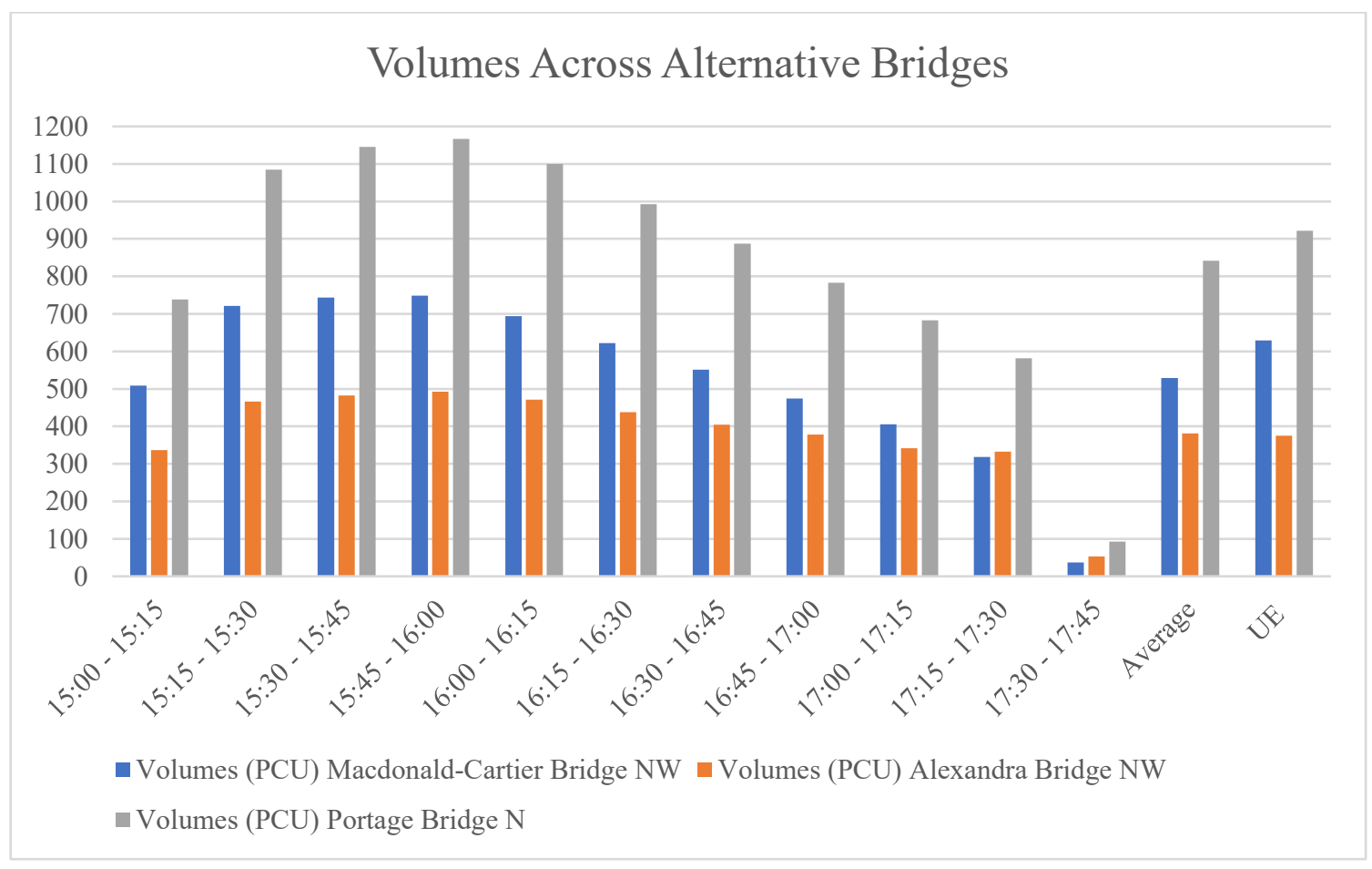

Figure 10.38: Event 4 Volumes Across Alternatives - 2018 Demand 


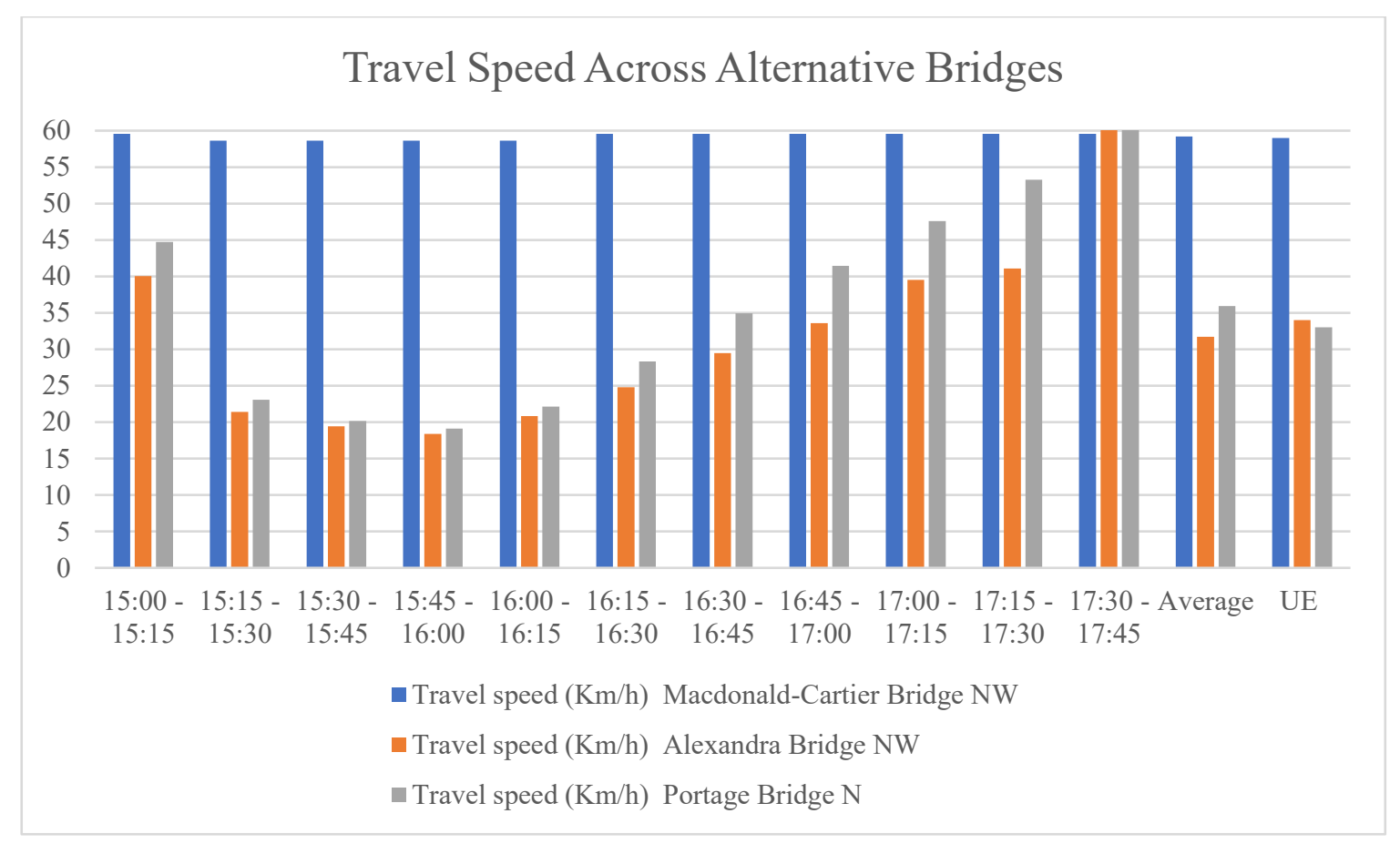

Figure 10.39: Event 4 Travel Speed Across Alternatives - 2018 Data

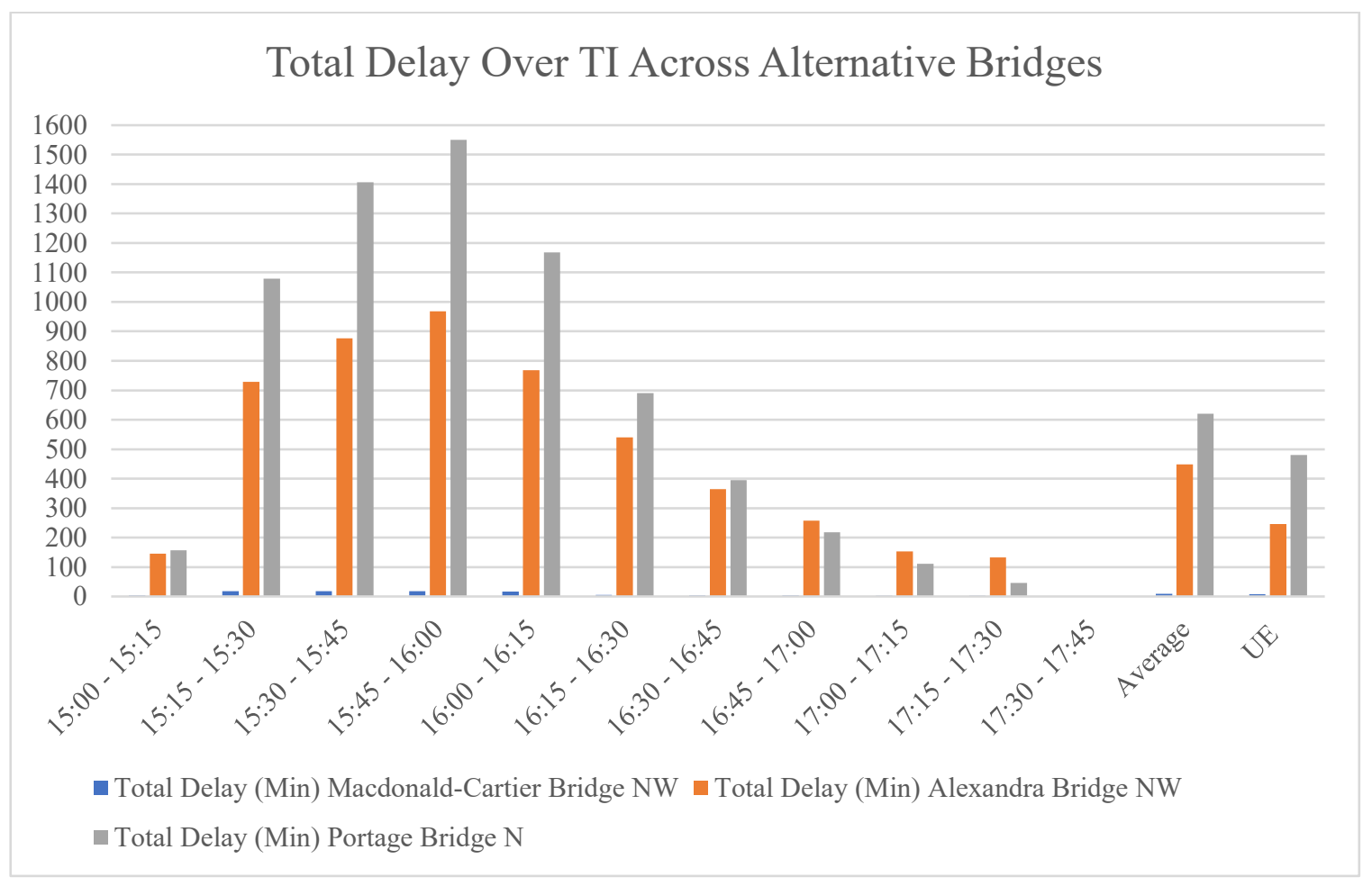

Figure 10.40: Event 4 Delay per TI Across Alternatives - 2018 Data 
10.4.11 Event 4 - Chaudière Bridge under Stress - 2031 Demand Data

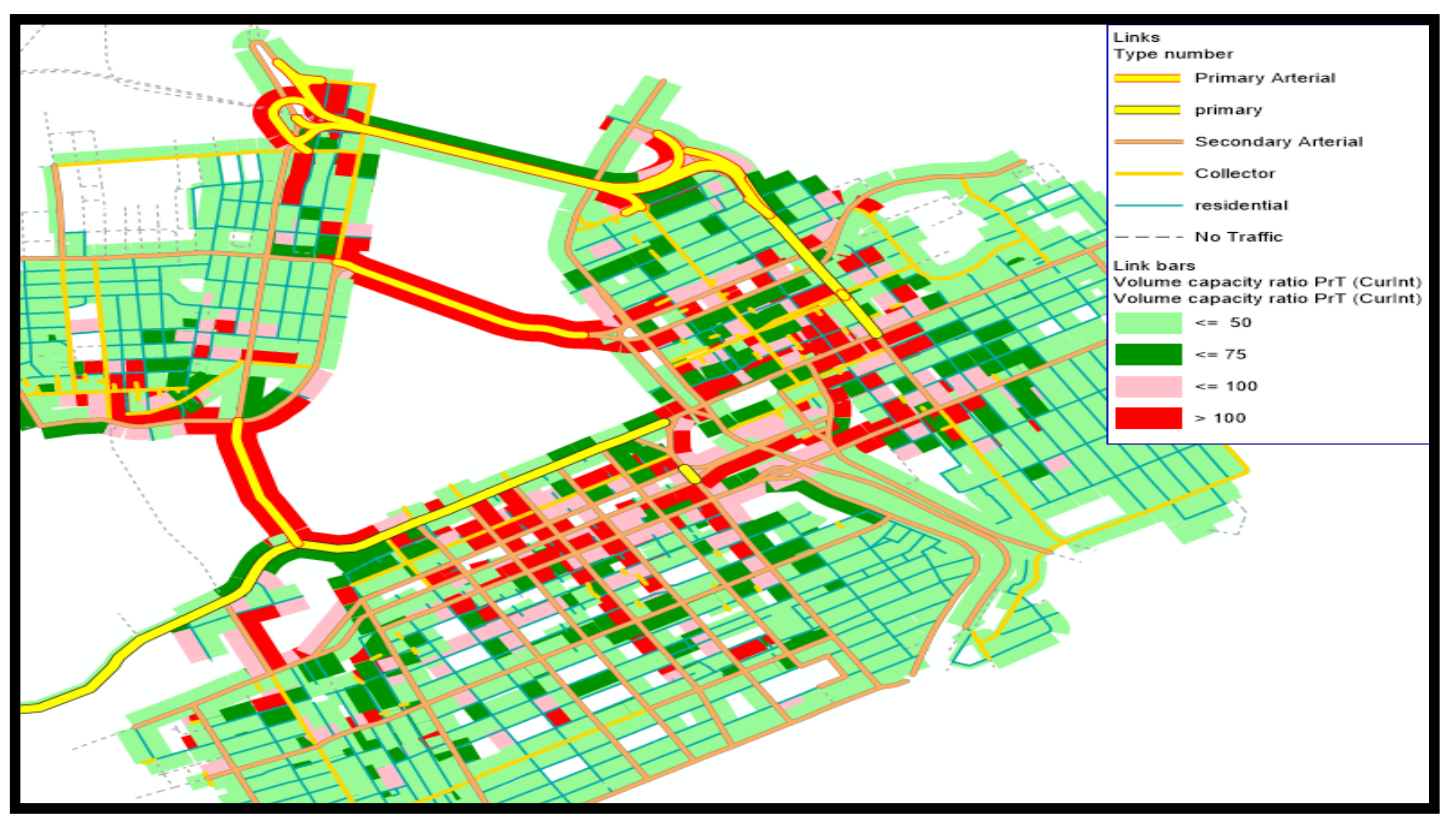

Figure 10.41: DSA of 2031 Data for Event 4 - 15:45 to 16:00 TI Simulation

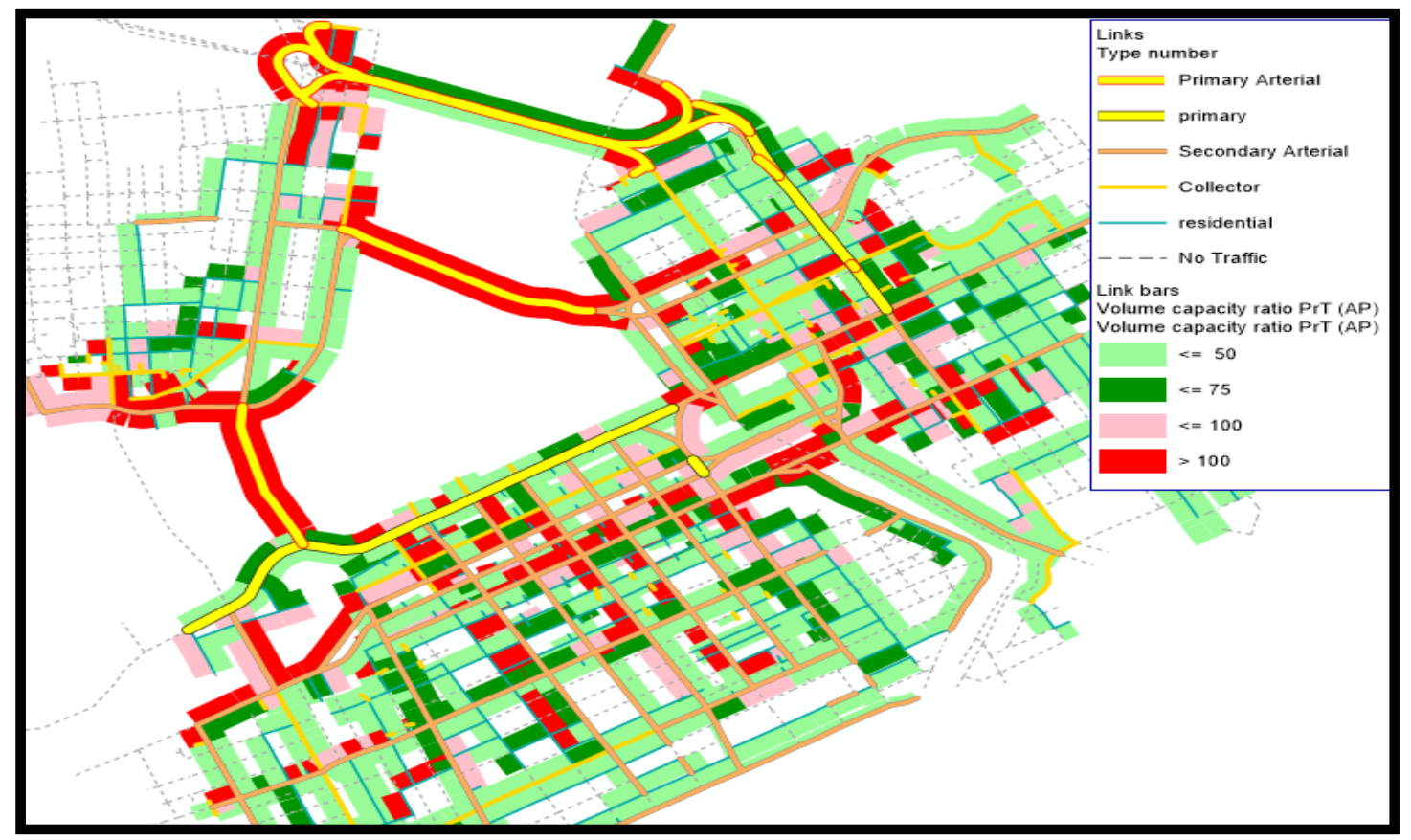

Figure 10.42: UE of 2031 Data for Event 4 Simulation 


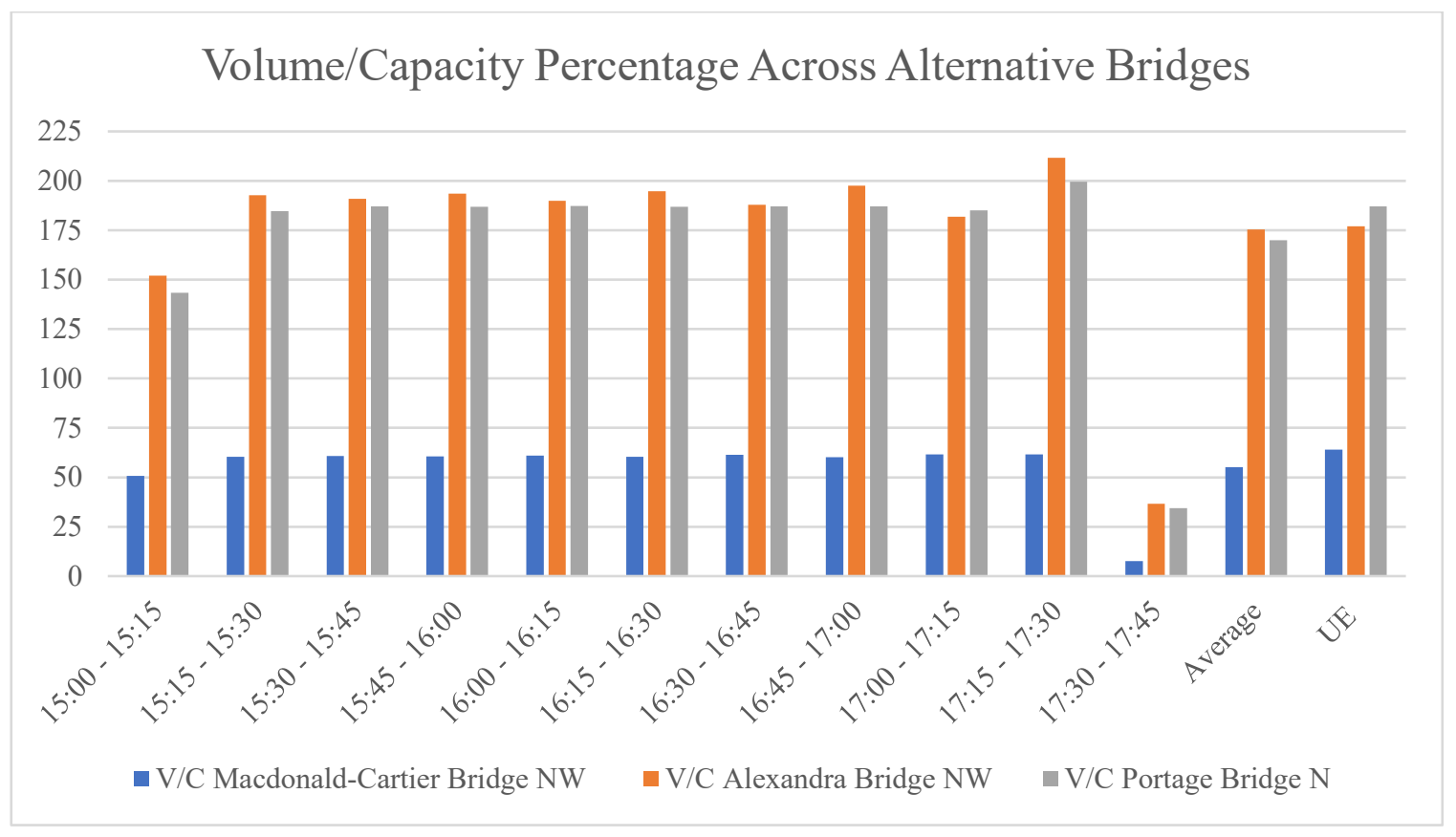

Figure 10.43: Event 4 v/c Ratio per TI-2031 Demand

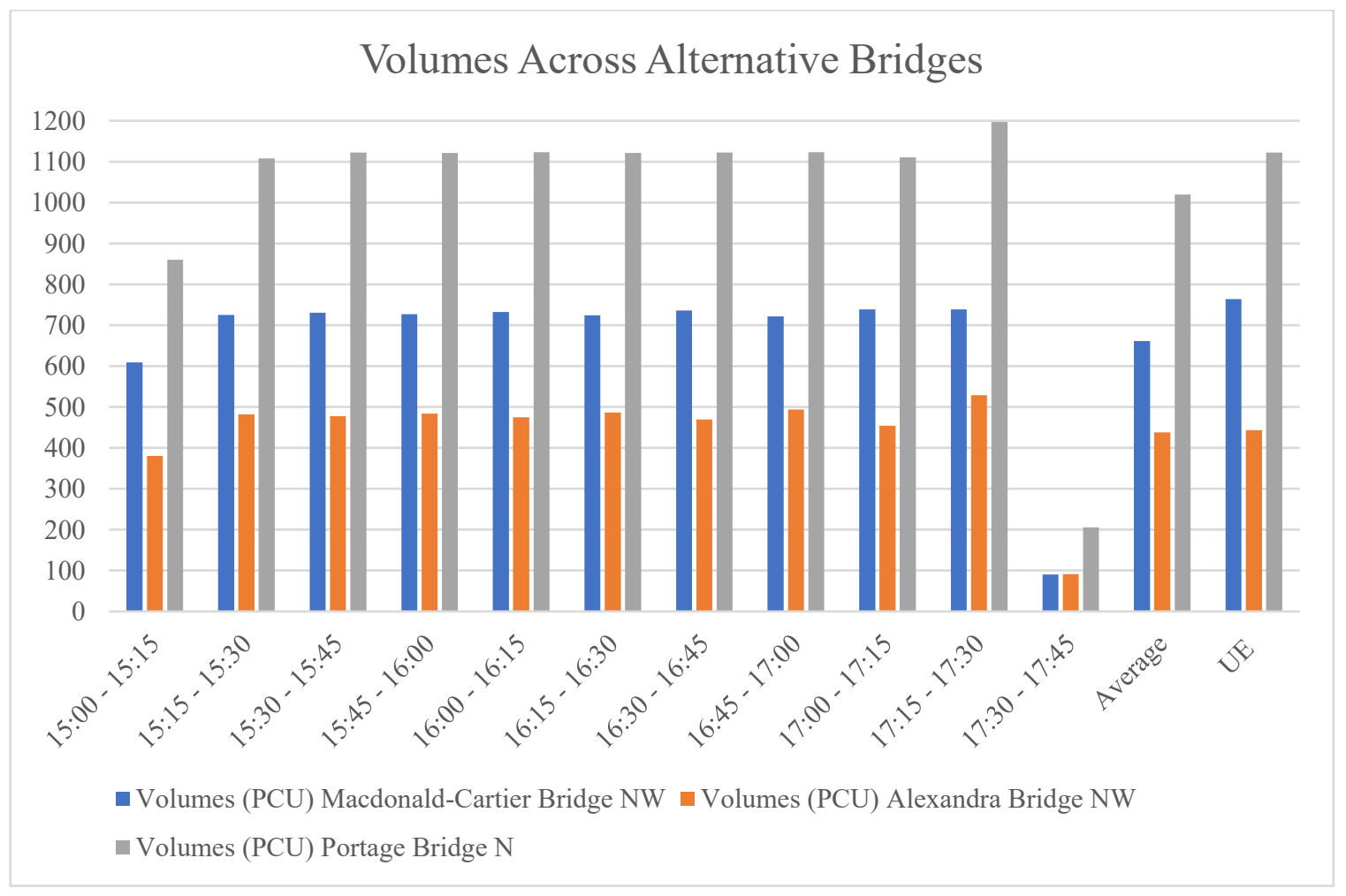

Figure 10.44: Event 4 Volumes Across Alternatives - 2031 Demand 


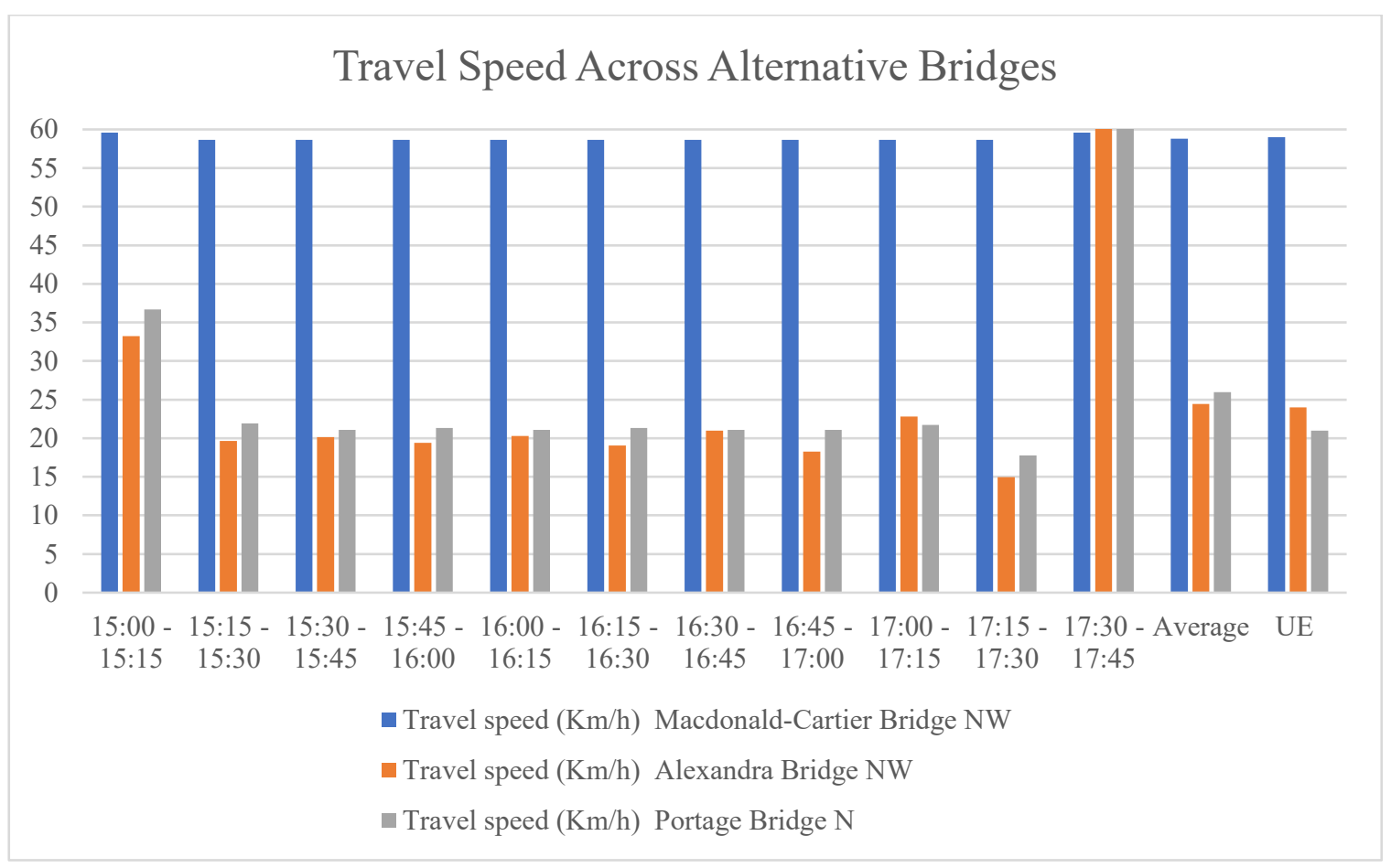

Figure 10.45: Event 4 Travel Speed Across Alternatives - 2031 Data

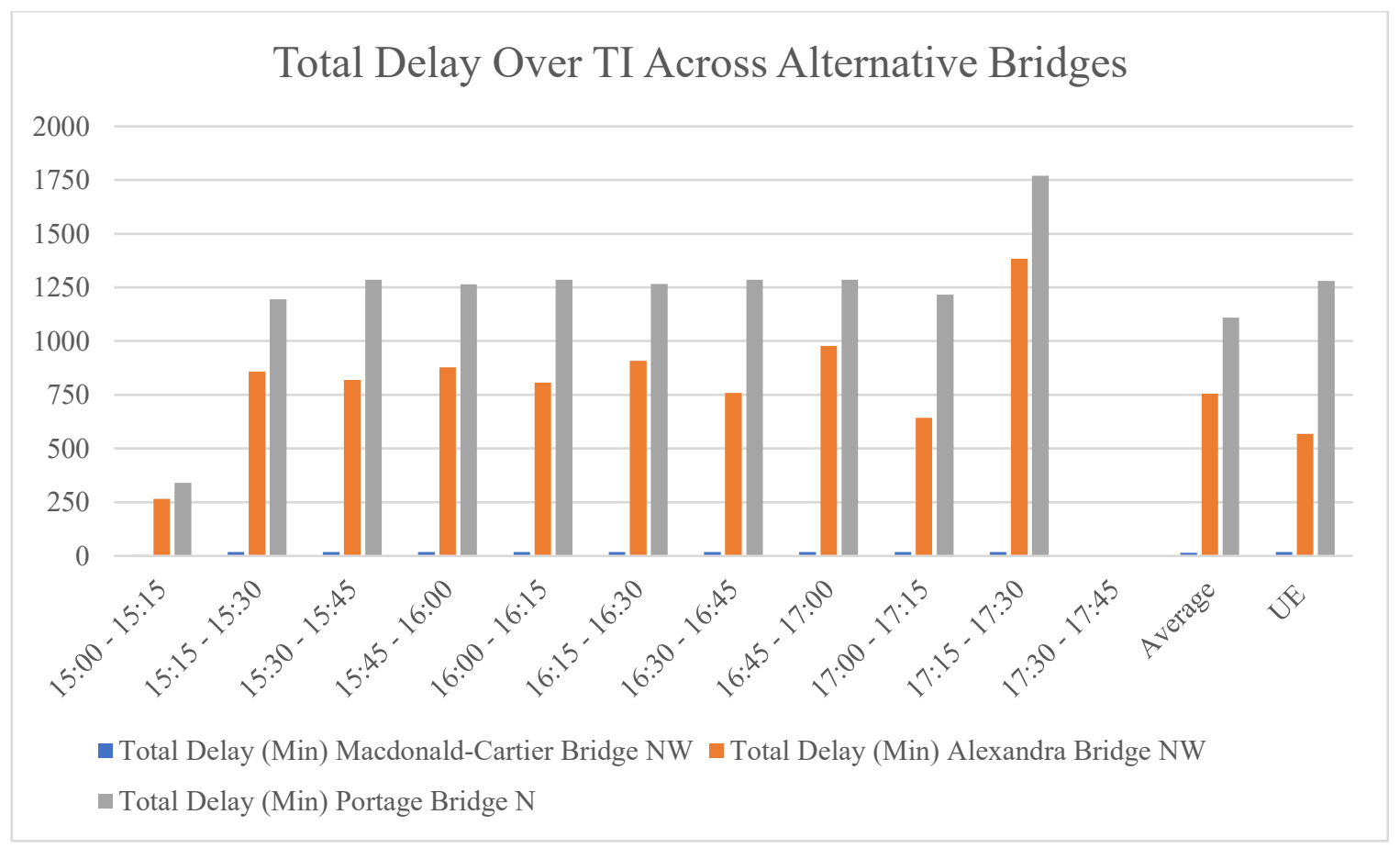

Figure 10.46: Event 4 Delay per TI Across Alternatives - 2031 Data 


\subsubsection{Event 4 - Summary}

Table 10-18: 2018 Demand Volumes Across Alternatives - Event 4

\begin{tabular}{|c|c|c|c|c|}
\hline Alternative & $\begin{array}{c}\text { UE 2018 Demand } \\
\text { Volumes Ottawa } \\
\text { to Hull (PCU) }\end{array}$ & $\begin{array}{c}\text { DAS 2018 } \\
\text { Demand Volumes } \\
\text { Ottawa to Hull } \\
\text { (PCU) }\end{array}$ & $\begin{array}{c}\text { UE 2031 } \\
\text { Demand } \\
\text { Volumes } \\
\text { Ottawa to } \\
\text { Hull (PCU) }\end{array}$ & $\begin{array}{c}\text { DAS } \\
2031 \\
\text { Demand } \\
\text { Volumes } \\
\text { Ottawa } \\
\text { to Hull } \\
\text { (PCU) }\end{array}$ \\
\hline 1: Macdonald-Cartier & 6290 & 5824 & 7644 & 7274 \\
\hline 2: Alexandra & 3748 & 4197 & 4431 & 4823 \\
\hline 3: Portage & 9221 & 9256 & 11221 & 11216 \\
\hline Total & 19259 & 19277 & 23296 & 23313 \\
\hline
\end{tabular}

Table 10-19: Event 4-Comparison of Total Delay Across Alternatives for Vehicles Traveling from Ottawa to Hull

\begin{tabular}{|c|c|c|c|c|c|c|}
\hline Alternative & $\begin{array}{c}\text { UE 2018 } \\
\text { Demand } \\
\text { Data Delay } \\
\text { Ottawa to } \\
\text { Hull } \\
\text { (Hours) }\end{array}$ & $\begin{array}{c}\text { DAS 2018 } \\
\text { Demand } \\
\text { Data Delay } \\
\text { Ottawa to } \\
\text { Hull } \\
\text { (Hours) }\end{array}$ & $\begin{array}{c}\text { Increase / } \\
\text { Decrease } \\
\%\end{array}$ & $\begin{array}{c}\text { UE 2031 } \\
\text { Demand } \\
\text { Data Delay } \\
\text { Ottawa to } \\
\text { Hull } \\
\text { (Hours) }\end{array}$ & $\begin{array}{c}\text { DAS 2031 } \\
\text { Demand } \\
\text { Data Delay } \\
\text { Ottawa to } \\
\text { Hull } \\
\text { (Hours) }\end{array}$ & $\begin{array}{c}\text { Increase / } \\
\text { Decrease } \\
\%\end{array}$ \\
\hline Macdonald-Cartier & 1.23 & 1.55 & 26.02 & 3.28 & 2.75 & -16.16 \\
\hline Alexandra & 41.07 & 82.27 & 100.32 & 94.88 & 138.33 & 45.79 \\
\hline Portage & 79.92 & 113.68 & 42.24 & 213.25 & 203.25 & -4.69 \\
\hline All Alt. & 122.22 & 197.50 & 61.59 & 311.41 & 344.33 & 10.57 \\
\hline
\end{tabular}




\subsubsection{Event 5 - Analysis of main Corridors connecting Ottawa - Hull Area - 2018 Demand Data}

Figures and tables below shows the comparison results on 4 main bridges connecting Ottawa-Hull area.

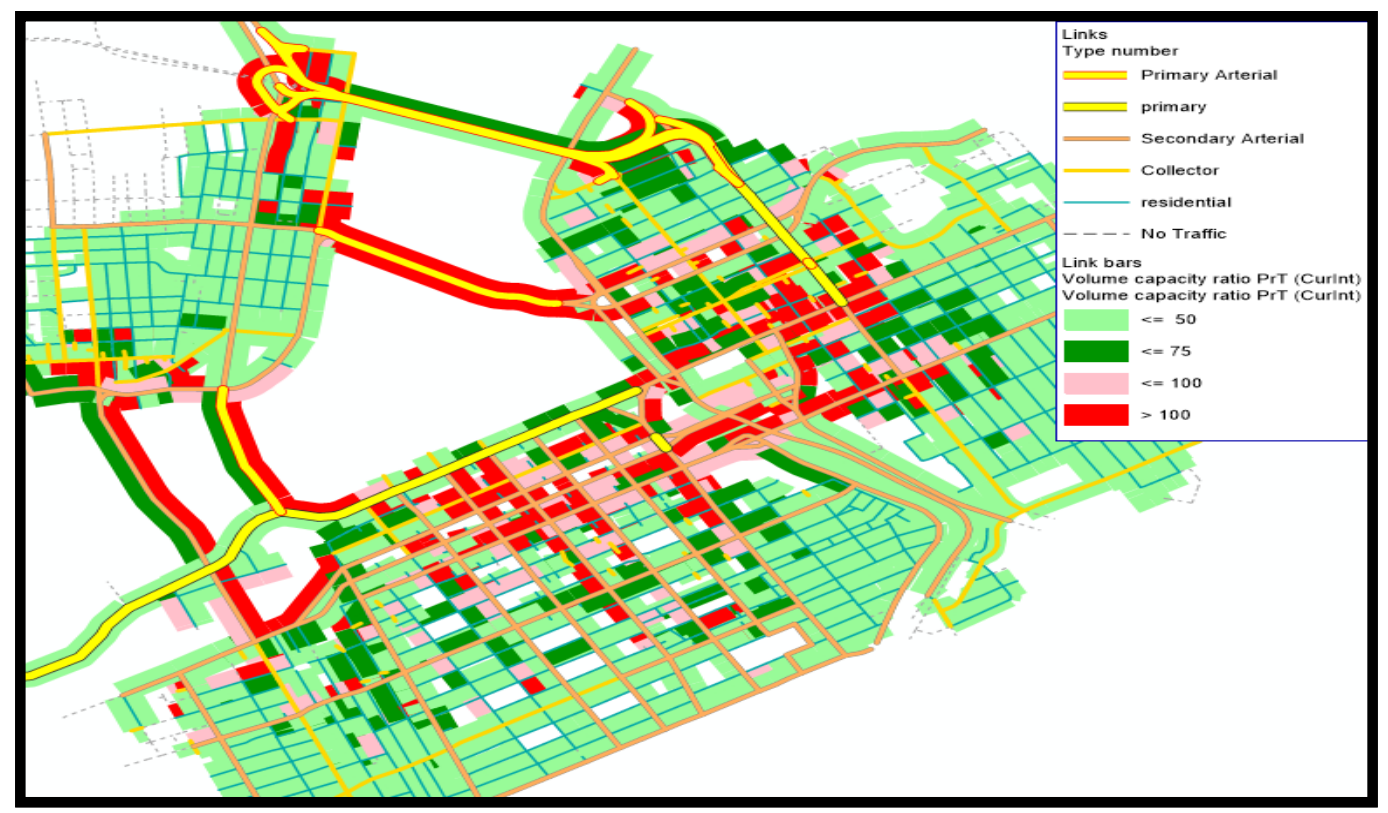

Figure 10.47: DSA of 2018 Data for Event 5 - 15:45 to 16:00 TI Simulation

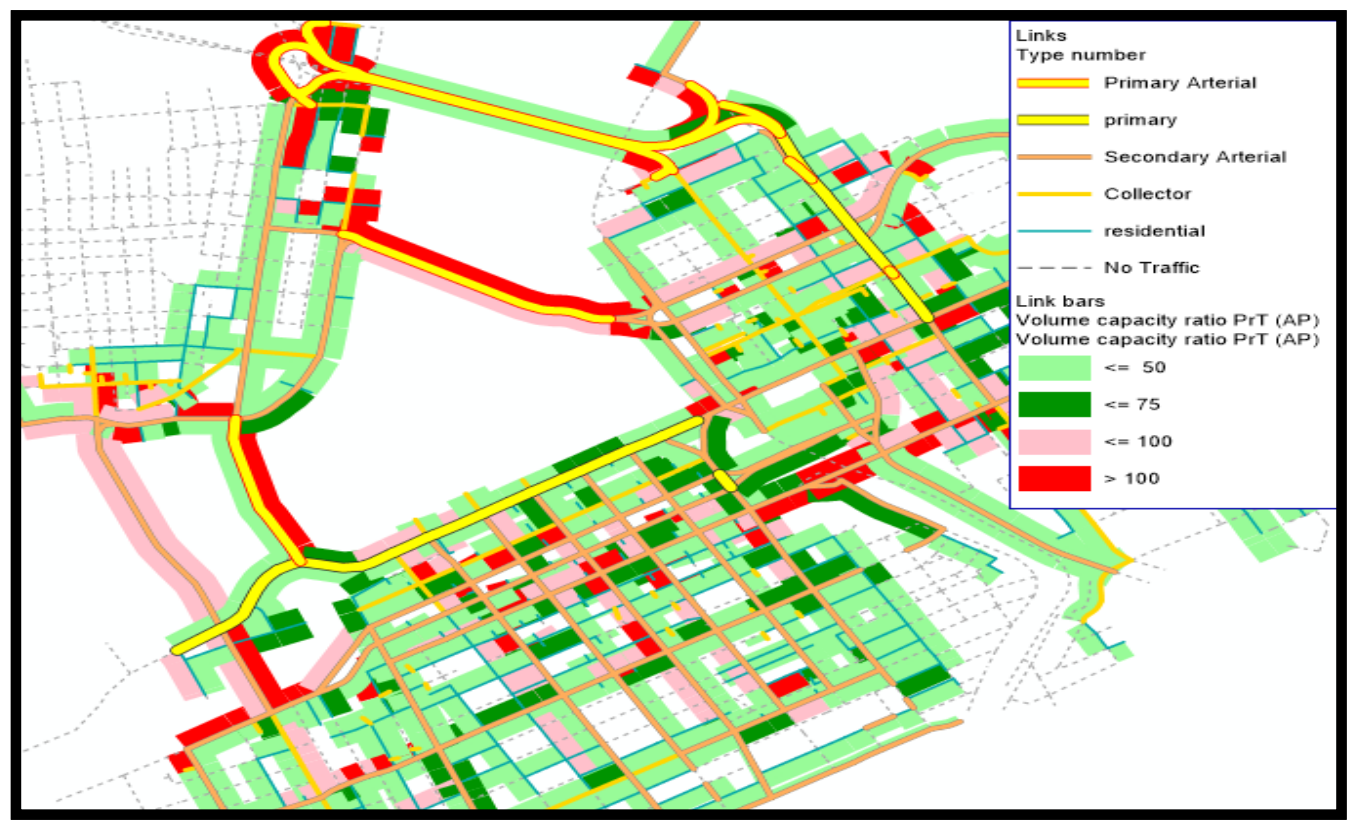

Figure 10.48: UE of 2018 Data for Event 5 Simulation 


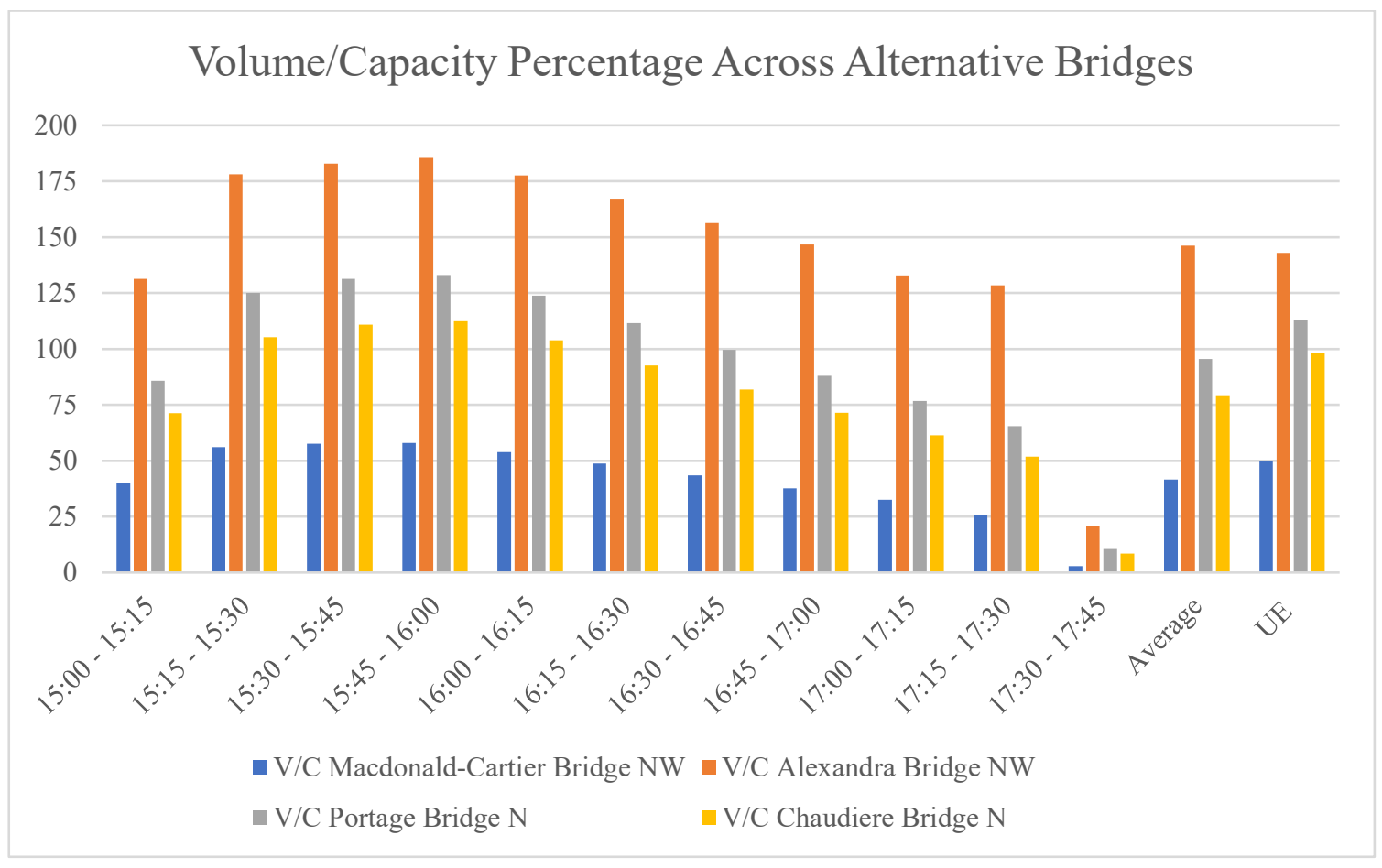

Figure 10.49: Event 5 v/c Ratio per TI - 2018 Demand

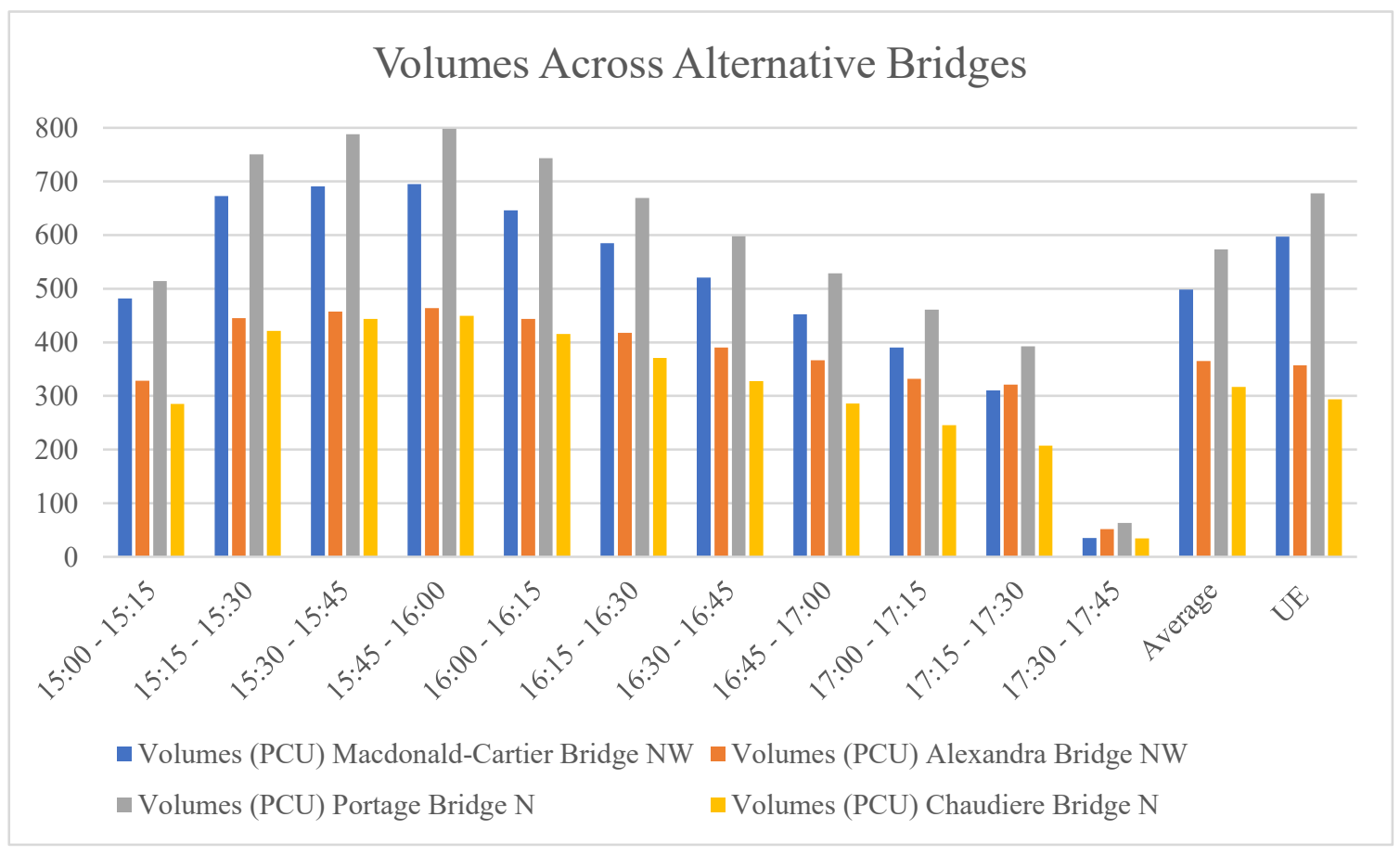

Figure 10.50: Event 5 Volumes Across Alternatives - 2018 Demand 


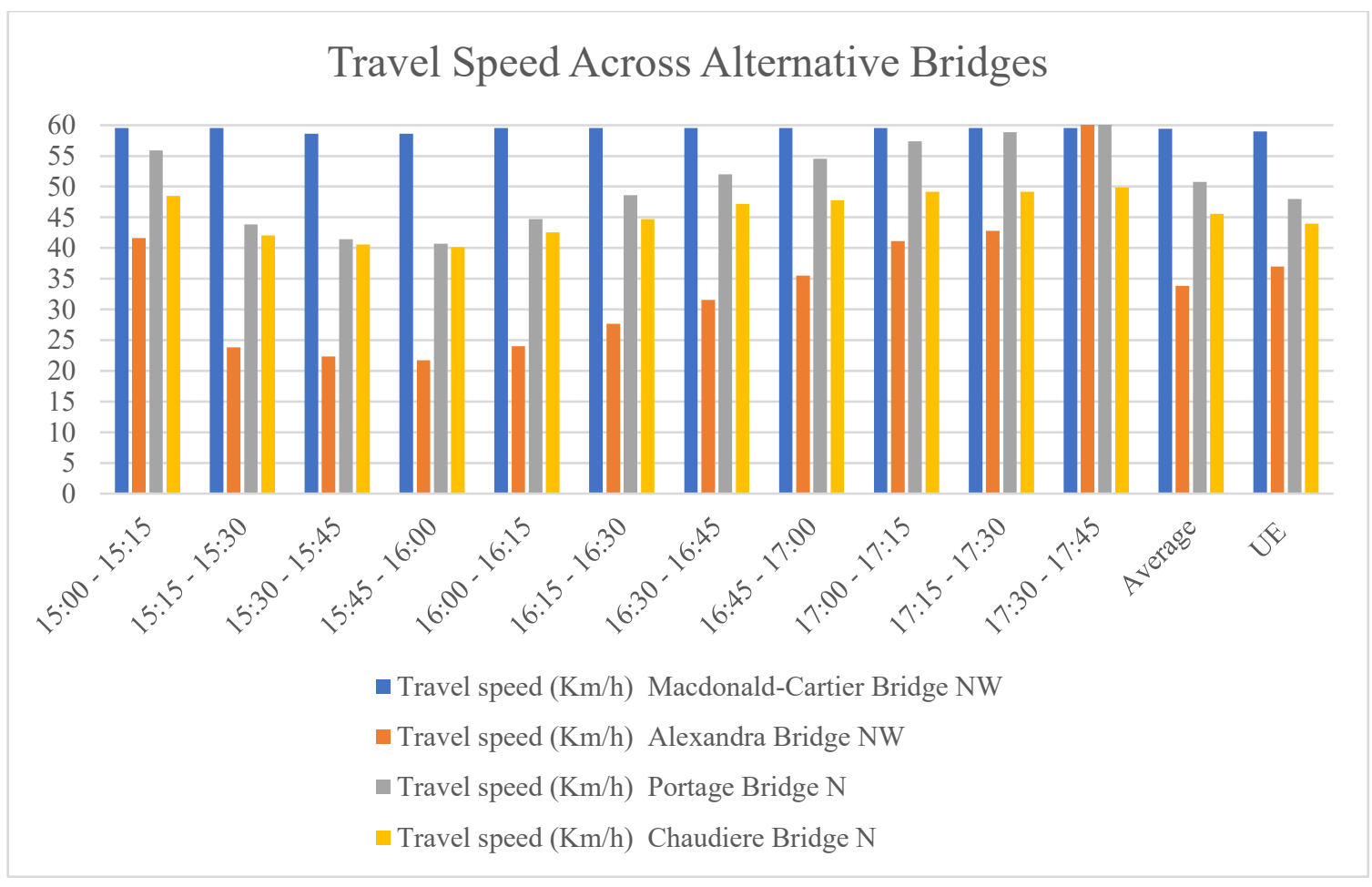

Figure 10.51: Event 5 Travel Speed Across Alternatives - 2018 Data

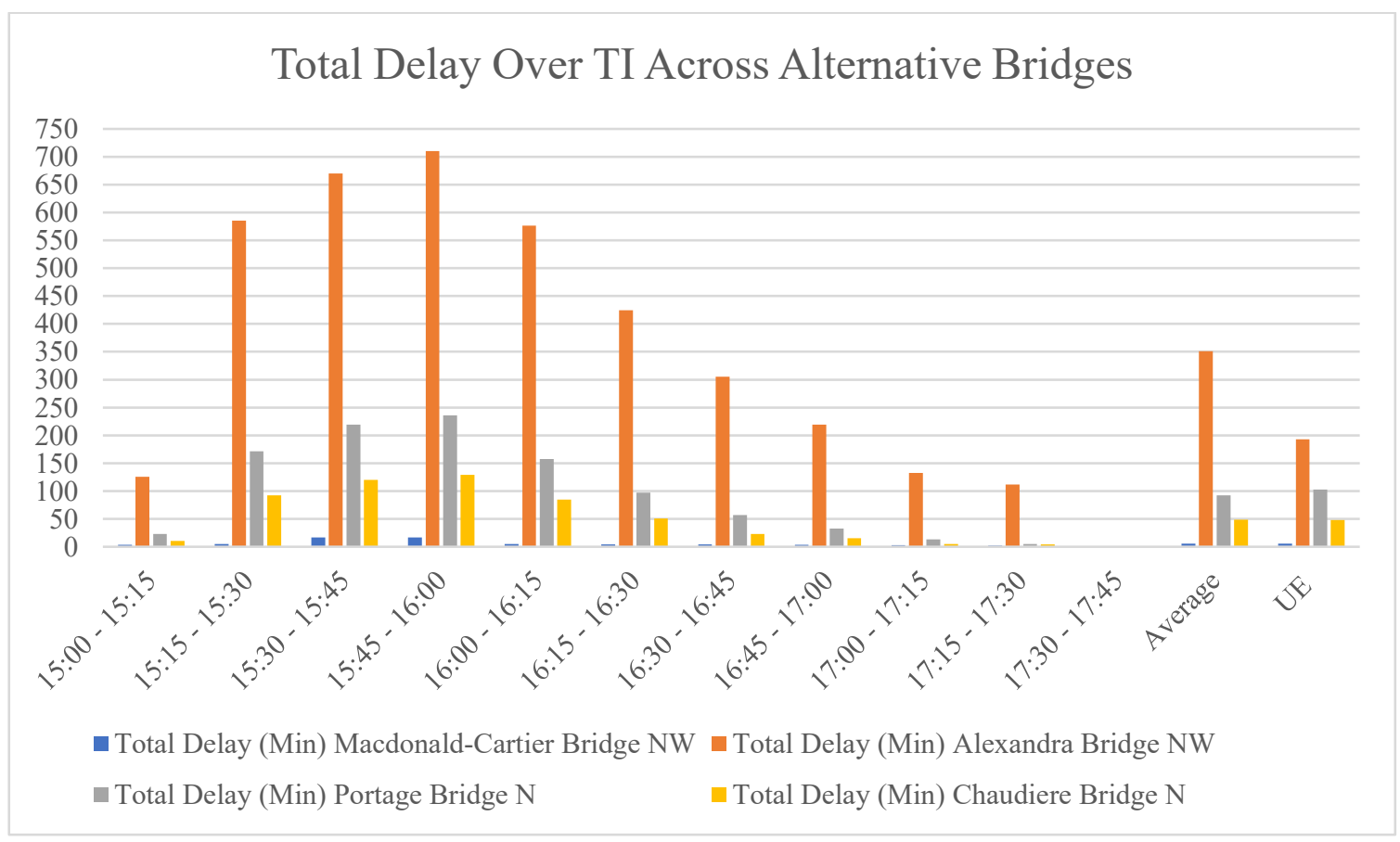

Figure 10.52: Event 5 Delay per TI Across Alternatives - 2018 Data 
10.4.14 Event 5 - Analysis of main Corridors connecting Ottawa Hull Area - 2031 Demand Data

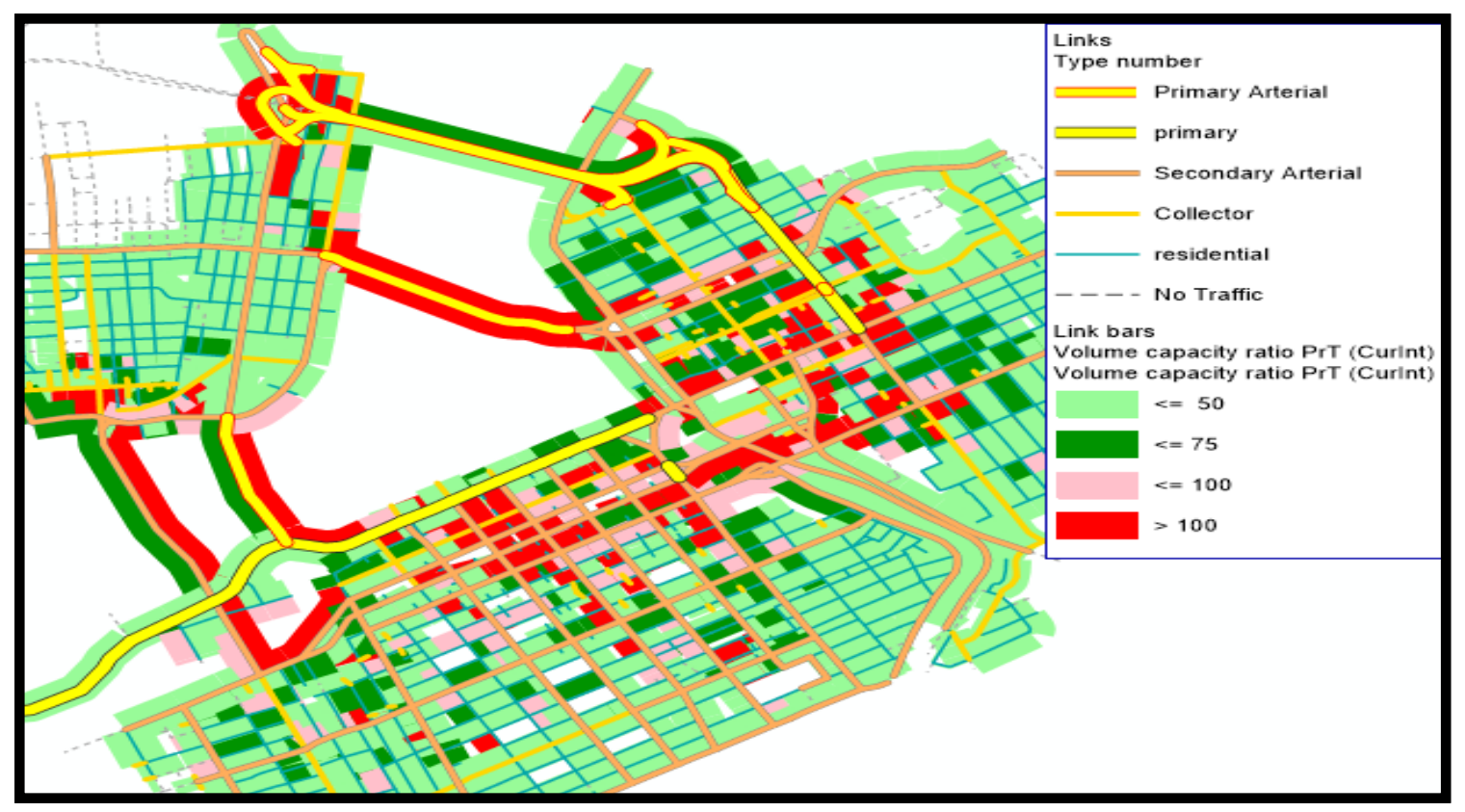

Figure 10.53: DSA of 2031 Data for Event 5 - 15:45 to 16:00 TI Simulation

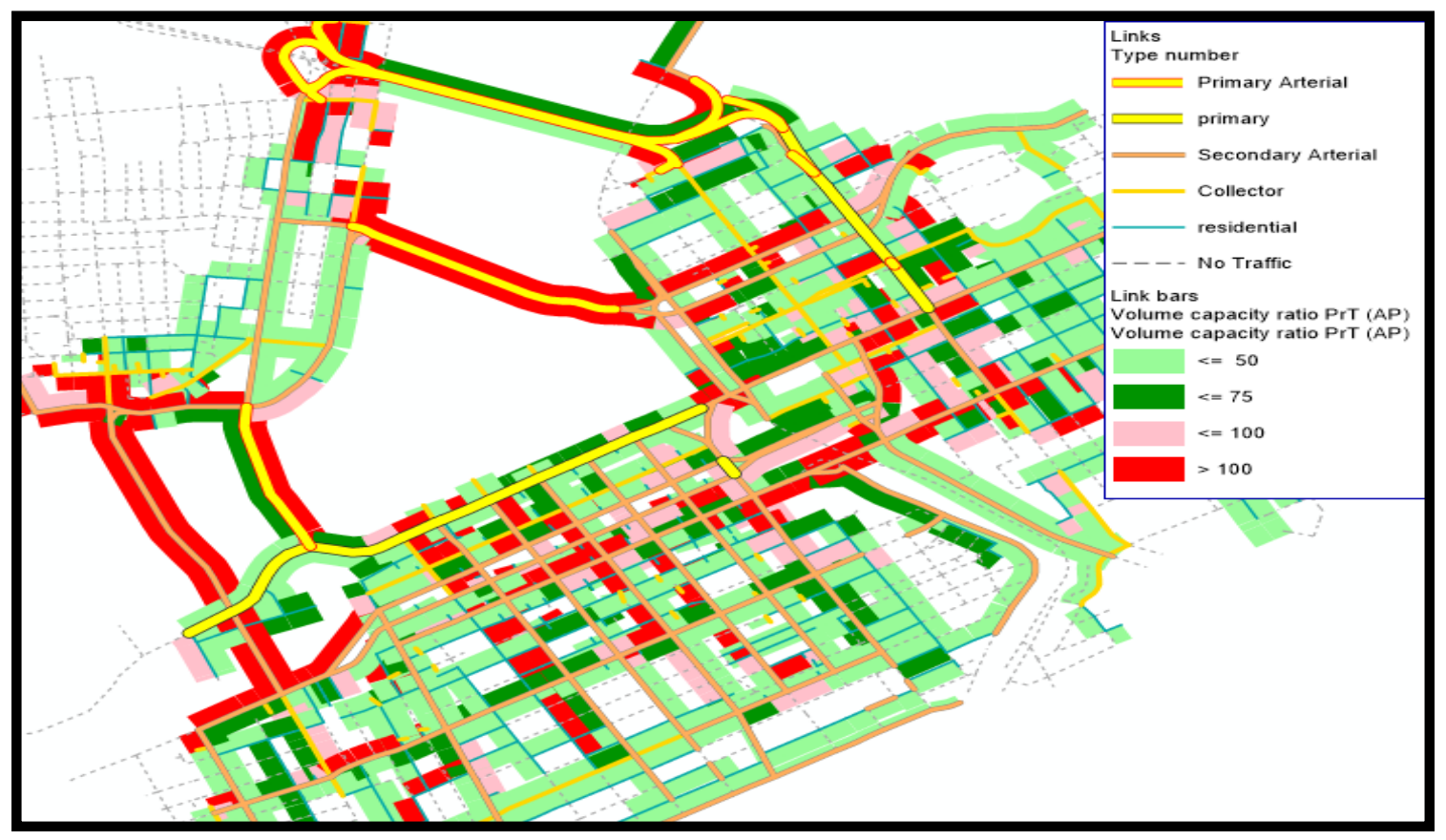

Figure 10.54: UE of 2031 Data for Event 5 Simulation 


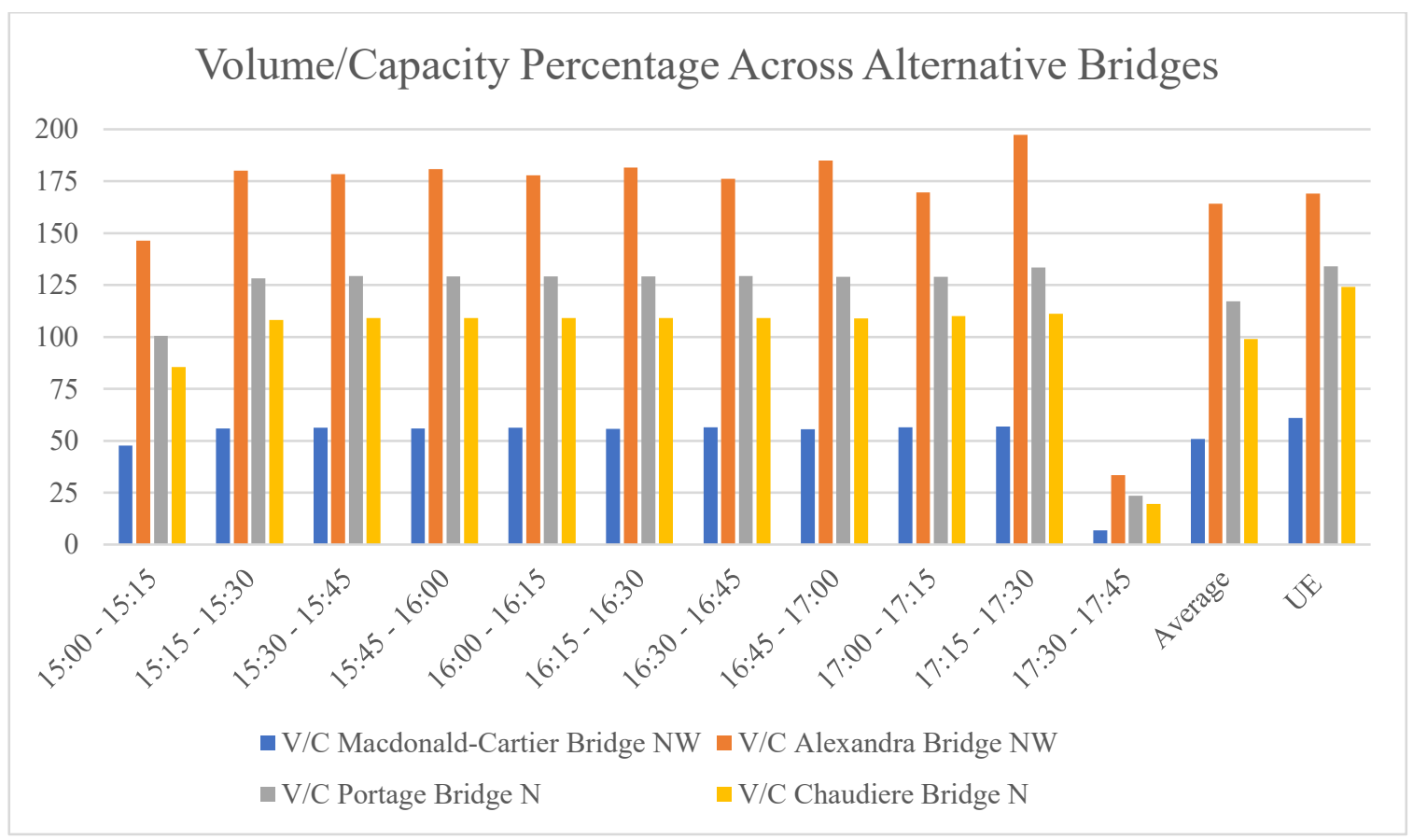

Figure 10.55: Event 5 v/c Ratio per TI-2031 Demand

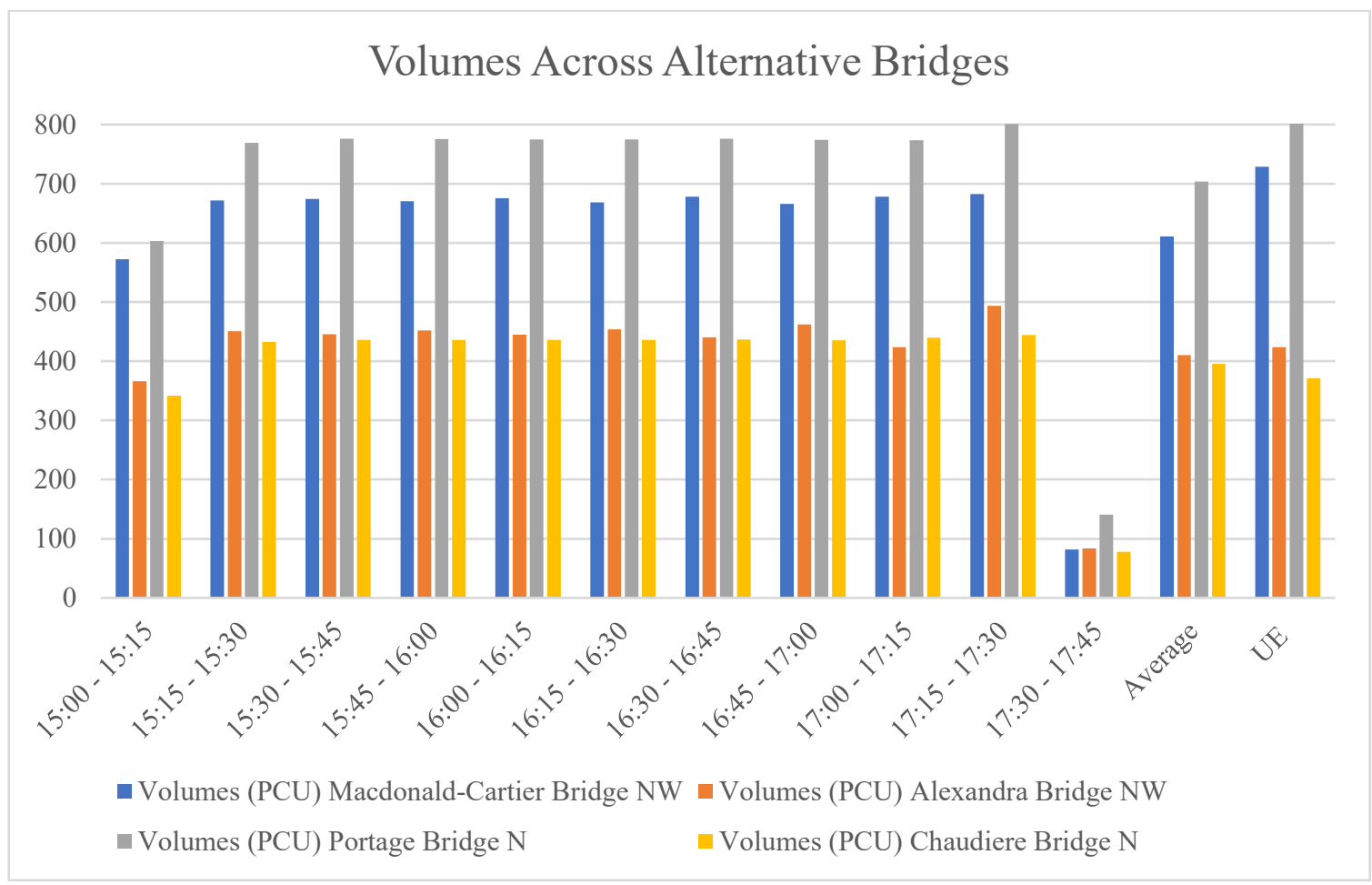

Figure 10.56: Event 5 Volumes Across Alternatives - 2031 Demand 


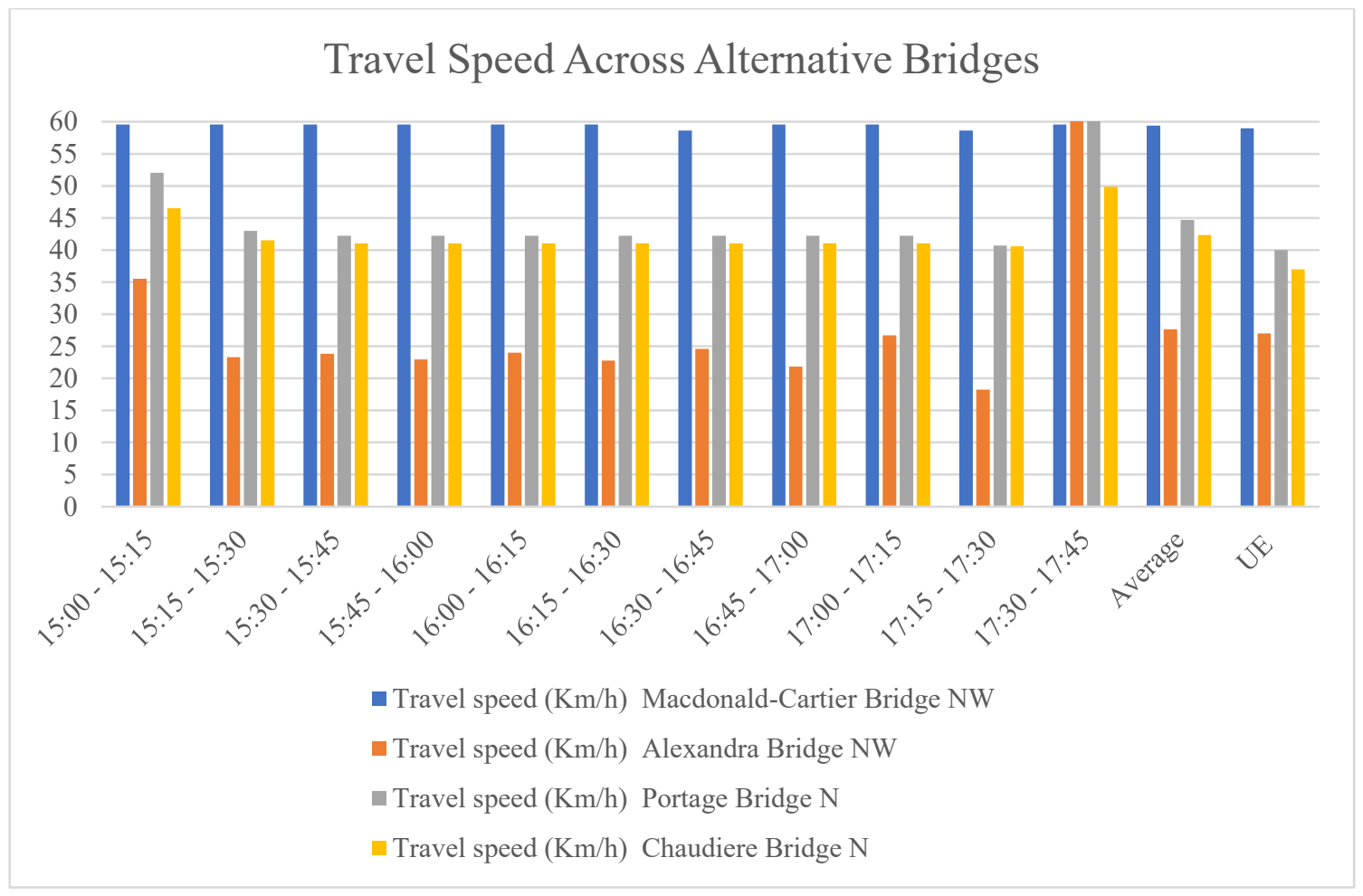

Figure 10.57: Event 5 Travel Speed Across Alternatives - 2031 Data

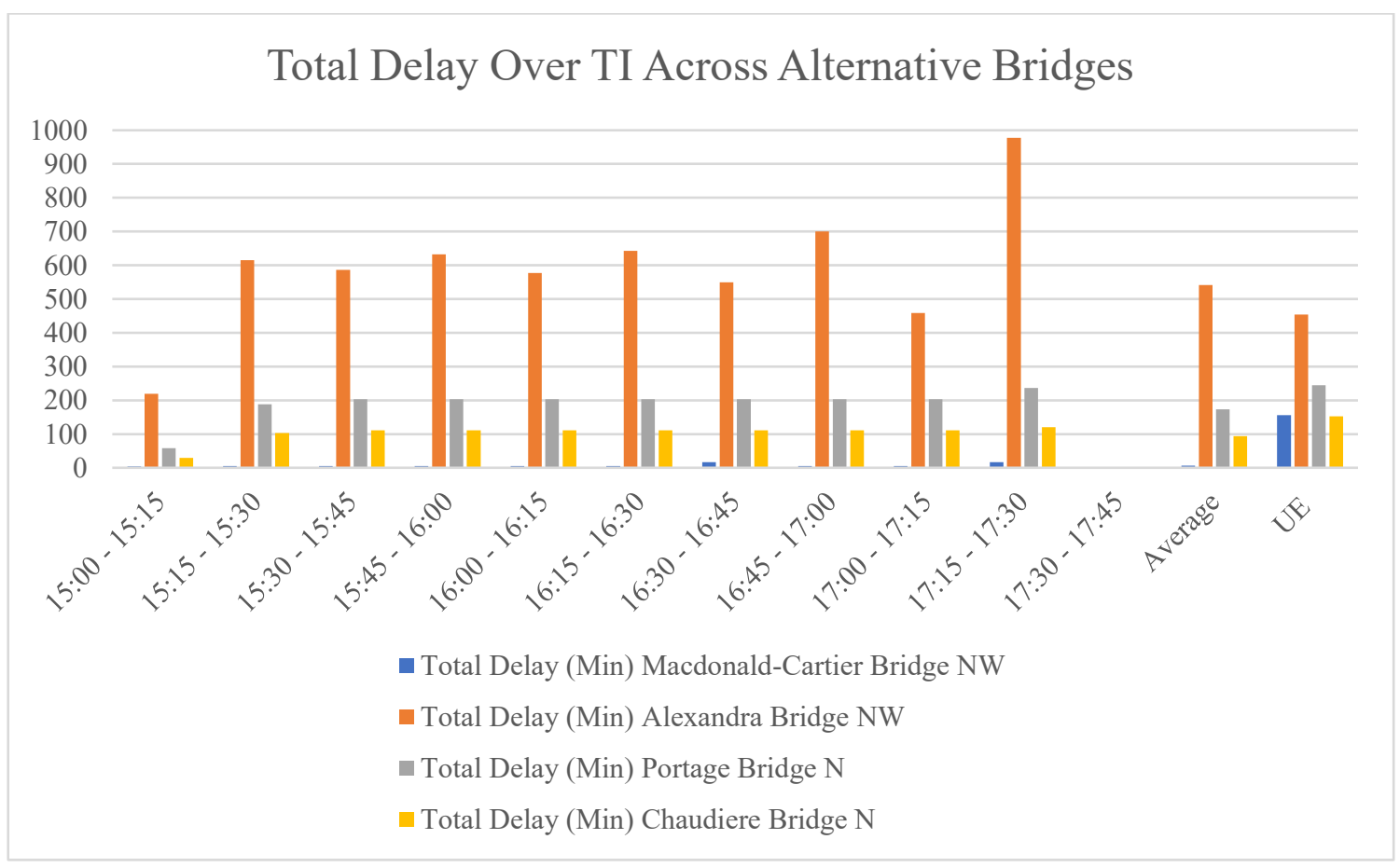

Figure 10.58: Event 5 Delay per TI Across Alternatives - 2031 Data 


\subsubsection{Analysis of main Corridors connecting Ottawa - Hull Area - Demand Data Summary:}

Table 10-20: 2018 Demand Volumes Across Alternatives - Event 5

\begin{tabular}{|c|c|c|c|c|}
\hline Alternative & $\begin{array}{c}\text { UE 2018 } \\
\text { Demand } \\
\text { Volumes } \\
\text { Ottawa to Hull } \\
\text { (PCU) }\end{array}$ & $\begin{array}{c}\text { DAS 2018 } \\
\text { Demand } \\
\text { Volumes } \\
\text { Ottawa to Hull } \\
\text { (PCU) }\end{array}$ & $\begin{array}{c}\text { UE 2031 } \\
\text { Demand } \\
\text { Volumes } \\
\text { Ottawa to Hull } \\
\text { (PCU) }\end{array}$ & $\begin{array}{c}\text { DAS 2031 } \\
\text { Demand } \\
\text { Volumes } \\
\text { Ottawa to } \\
\text { Hull (PCU) }\end{array}$ \\
\hline 1: Macdonald-Cartier & 5971 & 5479 & 7287 & 6719 \\
\hline 2: Alexandra & 3569 & 4018 & 4236 & 4517 \\
\hline 3: Portage & 6776 & 6306 & 8060 & 7738 \\
\hline 4: Chaudière & 2943 & 3486 & 3714 & 4353 \\
\hline Total & 19259 & 19289 & 23297 & 23327 \\
\hline
\end{tabular}

Table 10-21: Event 5 - Comparison of Total Delay Across Alternatives for Vehicles Traveling from Ottawa to Hull

\begin{tabular}{|c|c|c|c|c|c|c|}
\hline Alternative & $\begin{array}{c}\text { UE 2018 } \\
\text { Demand } \\
\text { Data Delay } \\
\text { Ottawa to } \\
\text { Hull } \\
\text { (Hours) }\end{array}$ & $\begin{array}{c}\text { DAS 2018 } \\
\text { Demand } \\
\text { Data Delay } \\
\text { Ottawa to } \\
\text { Hull } \\
\text { (Hours) }\end{array}$ & $\begin{array}{c}\text { Increase / } \\
\text { Decrease } \\
\%\end{array}$ & $\begin{array}{c}\text { UE 2031 } \\
\text { Demand } \\
\text { Data Delay } \\
\text { Ottawa to } \\
\text { Hull } \\
\text { (Hours) }\end{array}$ & $\begin{array}{c}\text { DAS 2031 } \\
\text { Demand } \\
\text { Data Delay } \\
\text { Ottawa to } \\
\text { Hull } \\
\text { (Hours) }\end{array}$ & $\begin{array}{c}\text { Increase / } \\
\text { Decrease } \\
\%\end{array}$ \\
\hline Macdonald-Cartier & 0.95 & 1.08 & 13.68 & 2.58 & 1.23 & -52.33 \\
\hline Alexandra & 32.15 & 64.37 & 100.22 & 75.72 & 99.35 & 31.21 \\
\hline Portage & 17.13 & 16.87 & -1.52 & 40.78 & 31.72 & -22.22 \\
\hline Chaudière & 7.93 & 8.91 & 12.36 & 25.37 & 17.12 & -32.52 \\
\hline All Alt. & 58.16 & 91.23 & 56.86 & 144.45 & 149.42 & 3.44 \\
\hline
\end{tabular}

\subsection{TOTAL DELAY OVER NETWORK}

Table 10-22: Comparison of Total Network Delay During Events - 2018 Demand

\begin{tabular}{|c|c|c|c|}
\hline Event & $\begin{array}{c}\text { UE 2018 Demand Total Delay } \\
\text { Over All Links (Hours) }\end{array}$ & $\begin{array}{c}\text { DAS 2018 Demand Total } \\
\text { Delay Over All Links (Hours) }\end{array}$ & $\begin{array}{c}\text { Increase / } \\
\text { Decrease \% }\end{array}$ \\
\hline Network 1 & 1496.42 & 1574.20 & 5.20 \\
\hline Network 2 & 864.37 & 853.44 & -1.26 \\
\hline Network 3 & 1419 & 1276 & -10.08 \\
\hline Network 4 & 734.38 & 808.85 & 10.14 \\
\hline Network 5 & 557 & 629 & 12.93 \\
\hline
\end{tabular}


Table 10-23: Comparison of Total Network Delay During Events - 2031 Demand

\begin{tabular}{|l|l|l|l|}
\hline Event & $\begin{array}{l}\text { UE 2031 Demand Data } \\
\text { Delay (Hours) }\end{array}$ & $\begin{array}{l}\text { DAS 2031 Demand Data } \\
\text { Delay (Hours) }\end{array}$ & $\begin{array}{l}\text { Increase / } \\
\text { Decrease \% }\end{array}$ \\
\hline Network 1 & 2763.88 & 2601.67 & -5.87 \\
\hline Network 2 & 1670.27 & 1435.14 & -14.08 \\
\hline Network 3 & 3209.14 & 2192.49 & -31.68 \\
\hline Network 4 & 1530.25 & 1340.62 & -12.39 \\
\hline Network 5 & 1153.75 & 1016.21 & -11.92 \\
\hline
\end{tabular}

\subsection{DISCUSSION}

This part of the research analyzed traffic behaviour if a disruptive event caused one of the main corridors connecting Ottawa and Hull to close for traffic. Two assumptions are in place in case of disruption: (1) traffic models presented represent traffic under disrupted condition, and (2) response based on dynamic resilience measures can be applied after disruption happens.

Two possible outcomes are expected. (1) Travellers are aware of the damage to the network and choose their route based on experience which leads to equal impedances for all alternatives connecting origin A to destination B. (2) Travellers receive information to follow the best routes based on DSA procedure.

Based on previously analyzed networks of disrupted bridges between Ottawa and Hull, the analysis is divided into two parts. The first part is the traffic assignment results for alternative main corridors (i.e. the remaining three bridges which maintain the connectedness property of the area). The second part uses results of traffic assignment UE and DSA - on the entire road network affected by the disruption during the study period. 
Four disruptive events have been simulated and data outputs are presented in previous sections of this chapter. The information can then be used later in the Bayesian method as useful aid for decision selection - whether UE, DSA or hybrid traffic routing. Information extracted also can be tailored to specific sub-area or route within the study area - this has not been done in this research due to the lack of technical capability to compile and report information. Analysis results on travel speed, volume, v/c, delay per time interval are examples of useful information that can be used in support of the Bayesian method. The role of the Bayesian method is to decide on the best traffic management measure which results in economic savings for the travellers.

The first disrupted bridge was Macdonald-Cartier Bridge. The results are explained below.

1- The average travel speed per TI experienced by travellers across all three alternatives is higher when the DSA procedure is activated for 2018 demand data; the increase in travel speed is $7.83 \%$ on Chaudière Bridge, $35.35 \%$ on Portage, and $39.49 \%$ on Alexandra Bridge, compared to UE. For 2031 demand projected data, travellers experience higher travel speed on all three alternatives as well.

2- Although the average travel time per TI is better, the travellers experience a total delay change of $7.29 \%$ when following the DSA procedure for 2018 demand. This is due to the fluctuation of departure time caused by travellers. But as travel volumes grow DSA procedure yields a $12.52 \%$ decrease in total delay across all alternatives for 2031 demand.

3- The total network delay experienced by all travellers during the study period yields similar outcomes as total delays on alternative corridors also, due to fluctuation of travellers' departure time and volumes. For 2018 data total delay of the network is increased by $5.2 \%$ when following the DSA procedure. For 2031 demand data the network delay decreased by $5.87 \%$ when following the DSA procedure. 
The second disrupted bridge analyzed was Alexandra Bridge. The results are as follows.

1- The average travel speed per TI experienced by travellers across all three alternatives is higher when DSA procedure is activated for 2018 demand data; the increase in travel speed is $2.05 \%$ on Macdonald-Cartier Bridge, $7.05 \%$ on Portage Bridge, and $3.33 \%$ on Chaudière Bridge, compared to UE. For 2031 demand projected data, travellers experience higher travel speed on all three alternatives as well.

2- Although the average travel time per TI is better, the travellers experience a total delay of $26.4 \%$ when following the DSA procedure for 2018 demand. This is due to the fluctuation of departure time caused by travellers. But as travel volumes grow DSA procedure yields a $22.48 \%$ decrease in total delay across all alternatives for 2031 demand.

3- The total network delay experienced by all travellers during the study period yields a decrease of $1.26 \%$ in delay for 2018 demand data, and $14.08 \%$ for 2031 demand data when following the DSA procedure.

4- Although delay increases over the other three bridges, it decreases for all road users in the network by $-1.26 \%$. Cost analysis of savings would lead to whether to use DSA procedure or UE procedure.

The third disrupted bridge analyzed was Portage Bridge. The results are noted next.

1- An increase in average speed per TI across all alternatives of $0.98 \%$ on Macdonald-Cartier Bridge., $23.72 \%$ on Alexandra Bridge, and $97.7 \%$ on Chaudière Bridge for 2018 demand data and following DSA procedure. Higher values are observed for 2031 demand data.

2- Total delay across alternatives is decrease by $12.31 \%$ in 2018 , and $30.96 \%$ in 2031 when following the DSA procedure.

3- Total network delay is also decreased by $10.08 \%$ for 2018 demand data, and $31.68 \%$ for 2031 demand data.

4- DSA procedure produces more benefits for travellers if Portage Bridge closed for traffic for both simulated traffic demands of 2018, and 2031.

The fourth disrupted bridge analyzed was Chaudière Bridge. The results are noted next. 
1- An increase was estimated in average speed per TI of $0.38 \%$ on MacdonaldCartier Bridge, and $8.89 \%$ on Portage Bridge for 2018 demand data and following the DSA procedure. While average speed is observed to decrease on Alexandra bridge by $6.78 \%$ following DSA procedure, better estimates in favour of DSA procedure are observed for the projected demand data of 2031. An increase in average speed per TI of $1.84 \%$ on Alexandra Bridge and $23.63 \%$ on Portage Bridge was estimated for 2018 demand data and following DSA procedure.

2- Total delay across all alternatives increases by $61.59 \%$ for 2018 demand, and $10.57 \%$ for 2031 when following the DSA procedure.

3- Total network delay increases by $10.14 \%$ for 2018 demand, while decreases by $12.39 \%$ for 2031 demand data when following DSA procedure.

In the case of all bridges are operational, the results are described next.

1- An increase in average speed per TI of $0.67 \%$ on Macdonald-Cartier Bridgr, $5.79 \%$ on Portage Bridge, and $3.64 \%$ on Chaudière Bridge for 2018 demand data and following the DSA procedure. While average speed is observed to decrease on Alexandra bridge by $8.54 \%$ following DSA procedure, better estimates towards DSA procedure are observed for the projected demand data of 2031. An increase in average speed per TI of $0.67 \%$ on Macdonald-Cartier Bridge, $2.35 \%$ on Alexandra Bridge, $11.74 \%$ on Portage Bridgr, and $14.47 \%$ on Chaudière Bridge for 2031 demand data and following DSA procedure.

2- Total delay across all alternatives increase by $56.86 \%$ for 2018 demand, and $3.44 \%$ for 2031 when following DSA procedure.

3- Total network delay increases by $12.93 \%$ for 2018 demand, while decreases by $11.92 \%$ for 2031 demand data when following DSA procedure.

In an event of disruption, the temporal distribution of $\mathrm{v} / \mathrm{c}$, volumes on roads, delay times, and average speed should be taken into consideration to decide when to activate dynamic resilience actions. This can be done using Bayesian methods to decide 
whether to balance impedances across alternatives using the UE procedure or provide route guidance using the DSA procedure.

It is important to mention, in an event of disruptive event to Portage Bridge, better average speed per TI across alternatives was observed if following DSA procedure. This also was the case when projecting 2031 demand data of higher traffic volumes over the existing road network. The results translate in economic savings to the traveller and the environment.

\subsection{EFFECTIVENESS OF DYNAMIC STOCHASTIC ASSIGNMENT VERSUS USER EQUILIBRIUM ASSIGNMENT UNDER DISRUPTION CONDITION: SUMMARY OF RESULTS}

This chapter presented detailed results on the comparison of effectiveness of DSA and UE assignments under disruption condition. It should be noted that that the objective of a dynamic resilience measure is to maintain throughput (i.e. to serve demand). Another objective is to maintain the service quality, but this objective is not as important as serving demand under disruption conditions.

The simulation results at 2031 traffic levels show that under all five events, the DSA performed better than the UE assignment in serving demand. In all cases, the throughput for DSA was higher than for the UE. In the case of network level delay, the DSA showed better results in most cases, except for Event 5. In that case, the delay for DSA was slightly higher than for UE due to a very high delay experienced at the Alexandra Bridge. 


\section{UNCERTAIN TOTAL DELAY AND CHOICE OF}

\section{DYNAMIC RESILIENCE ACTION}

\subsection{EFFECT OF TRAFFIC LEVEL AND NETWORK LEVEL DELAY UNDER DISRUPTION CONDITION}

Analyses reported in Chapter 8 suggest that, in general, network level delays rise with traffic level. This is expected, according to theory that as demand volume rises, the ability of the network to handle volume drops. The inherent resilience helps to reduce the effect of traffic surges, but this capability cannot go very far, and delay rises with traffic. Under disruption, delays rise due to capacity reduction on a key corridor or key corridors if area-wide disruptions are encountered.

Under normal traffic operating conditions, the traffic control settings are influenced by the User Equilibrium (UE) assignment results. The UE assignment results are supplemented with current traffic counts. Under major disruption conditions, the UEbased traffic control system may perform well to a certain level, but high traffic level will call for dynamic resilience actions based on dynamic traffic assignment results. In some urban areas, traffic control system in major corridors has demand-actuated and traffic-adaptive designs and therefore a limited amount of capability exists to absorb shocks in traffic due to major disruption. However, it is inevitable that dynamic resilience actions will be required in order to reduce delays and bring the traffic service capability of links and corridors back to normal. 


\subsection{INACCURACY IN TRAVEL FORECASTS}

Since this research is focused on forecasting travel behavior for probable network distress, it is important to take into account uncertainties in the various parts of the modelling and analysis tasks. The Bayesian decision model described in this chapter accounts for the uncertainty in delay estimates produced by network analyses. Here, a brief coverage is provided on uncertainty in a roadway network travel forecast, and prediction of high imbalances of demand versus capacity.

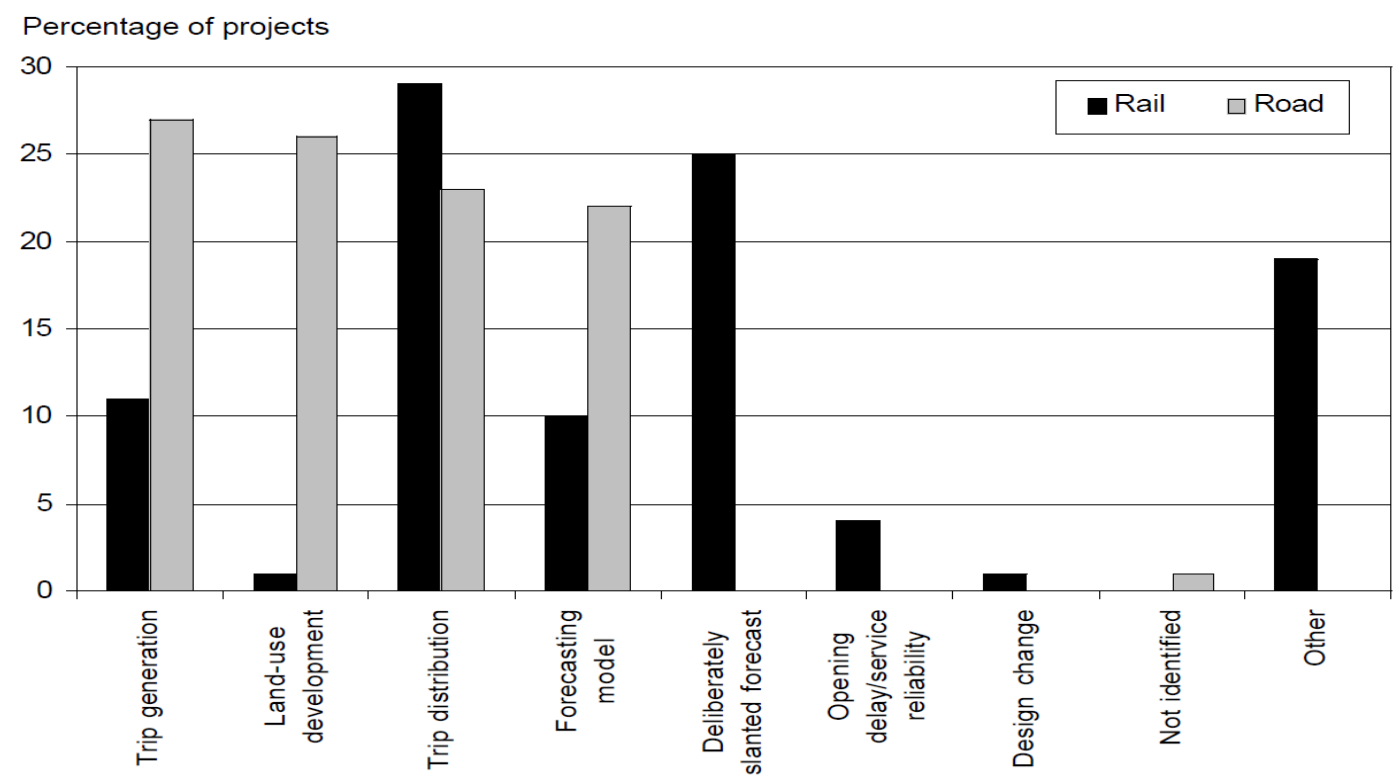

Figure 11.1: Stated Causes of Inaccuracies in Traffic Forecasts (Flyvbjerg et al., 2007)

Uncertainty in traffic forecast can be a result of many reasons. Flyvbierg et al. (2007) identified causes of inaccuracy for 234 transportation projects (Figure 11.1). Granato (1998) reported that traffic forecasting error based on AADT range from 11.6 percent for high volume counts to $45.6 \%$ for low volume counts. Armoogum et al. identified three main sources of errors in long-term traffic forecasting: "errors in the calibration of the model; uncertainty of the behaviour of future generations, and errors in population projections." (Armoogum et al., 2009). 
Although the scope of this research does not allow the study of causes and effects of inaccurate demand predictions, it is essential to treat uncertain demand predictions.

\subsection{COPING WITH UNCERTAINTIES IN NETWORK LEVEL DELAYS}

It is generally accepted in the professional and research circles that link and corridor level traffic is uncertain. Detailed traffic variation factors are not available for use in time of the day simulations carried out in this research. Thus, an assumed traffic variation with a lower limit of $75 \%$ of traffic in 2018 counts and an upper limit of 125 $\%$ is considered.

The models with calibrated traffic volumes were run in Visum and delay times are presented in Figure 11.2 below.

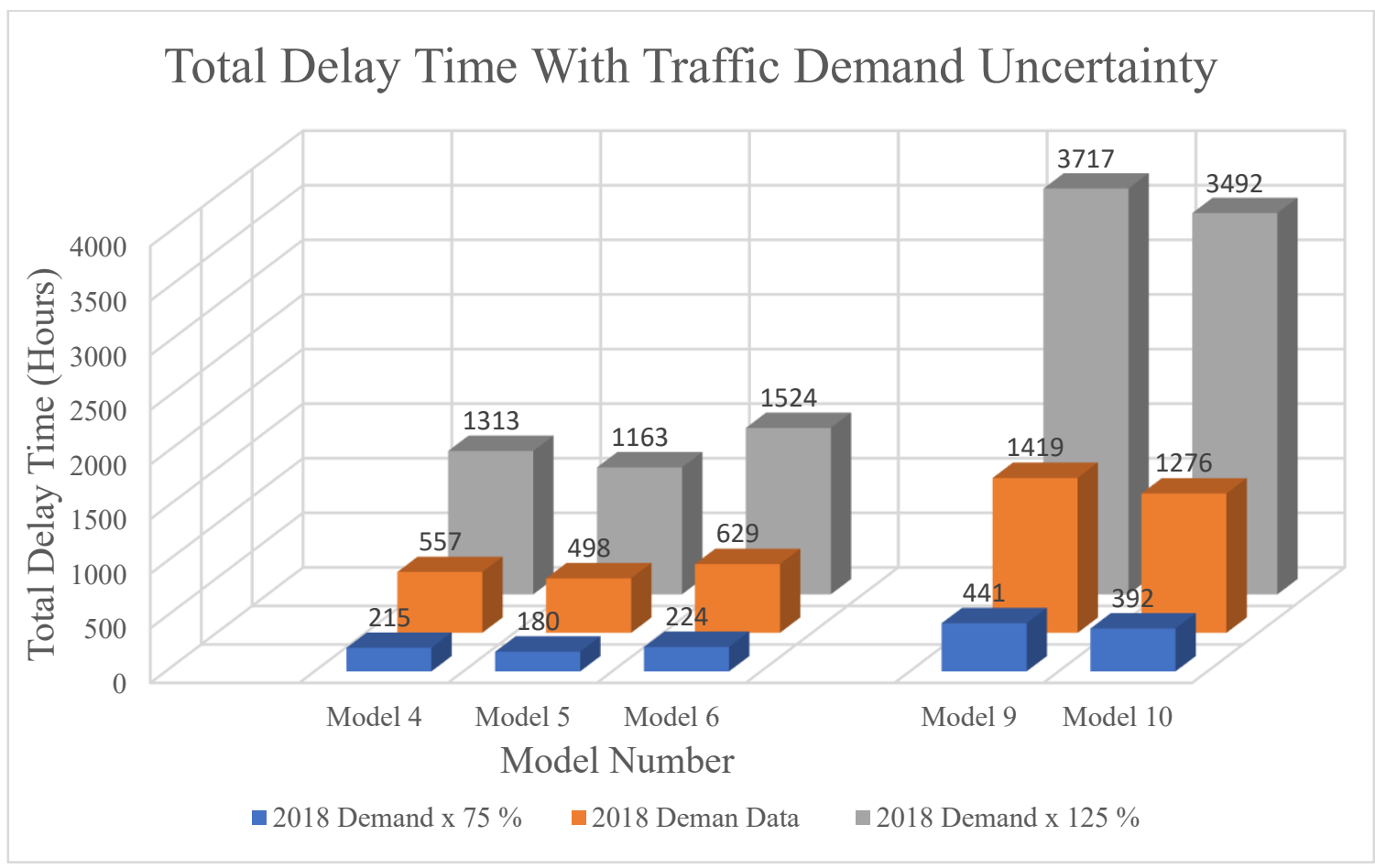

Figure 11.2: Total Delay Time with Traffic Demand Uncertainty 
There are two challenges in coping with uncertainties in network delays caused by a major disruption such as the Portage bridge corridor outage:

(1) A decision analysis on whether to apply dynamic resilience measures and at if yes, when these actions should be applied. This decision model has to work with uncertain delay levels and should have the ability to update probabilities in response to new information that may be obtainable from the use of ITS and other advanced technology means.

(2) There is a need to develop traffic control strategies and tactics that can be used to implement dynamic stochastic assignment results. In terms of the process, this will be similar to process followed by traffic management experts to develop Time of Day (TOD) traffic control plans based on user-equilibrium (UE) assignment results.

\subsection{BAYESIAN DECISION MODEL}

The principles of decision theory offer an opportunity to develop a model for the identification and choice of a preferred dynamic resilience alternative among a set of alternatives. In the following pages of this thesis, the theoretical aspects of the decision model are described, and the model is applied to the Portage Bridge Corridor case for illustration purposes.

\subsubsection{Structuring the Decision Problem}

Decision-theoretic models are required that will treat network level total delay as probabilistic. See Portage Bridge analysis results for an example.

The variables of the decision model as applied in this research are:

- Dynamic resilience action alternatives $\left(\mathrm{A}_{1}, \mathrm{~A}_{2}, \mathrm{~A}_{3}\right)$

- The states of network level delay $\left(\mathrm{D}_{1}, \mathrm{D}_{2}, \mathrm{D}_{3}\right)$ 
- The total delay magnitude for each A \& D combination.

Decision will be based on Expected total delay:

$E(D i)=\sum_{j=1}^{n}\left[D i j \times P_{j}\right]$

Where:

$E\left(D_{i}\right)=$ the expected Delay of alternative $A_{i} ; i=1,2, \ldots, m$

$D_{i j}=$ the delay alternative $A_{i}$, under state of network level delay called state-of-nature

$D j, j=1,2, \ldots, n$

$\mathrm{P}_{\mathrm{j}}=$ probability of state of nature $D_{j}$

An example application of the decision model is presented next, based on Portage Bridge Corridor (See Figure 10.23).

Table 11-1: Delay Matrix

\begin{tabular}{|l|c|c|c|}
\hline & $\begin{array}{c}\text { Total delay state 1 } \\
\text { (Hours) }\end{array}$ & $\begin{array}{c}\text { Total delay state 2 } \\
\text { (Hours) }\end{array}$ & $\begin{array}{c}\text { Total delay state 3 } \\
\text { (Hours) }\end{array}$ \\
\hline A1 UE & 441 & 1419 & 3717 \\
\hline A2 DSA & 392 & 1276 & 3492 \\
\hline
\end{tabular}

Considering 2.5 hours duration after it became known that Portage bridge is no longer available to traffic, the following decision alternatives are available:

Table 11-2: Decision Alternative

\begin{tabular}{|l|l|}
\hline Time following disruption & $\begin{array}{l}\text { Decision alternatives: } \\
\text { Keep time of day (TOD) alternative based on UE } \\
\text { assignment or implement dynamic resilience alternative. }\end{array}$ \\
\hline At the time of disruption & $\begin{array}{l}\text { - Scan for new information? } \\
\text { - Implement dynamic resilience action? } \\
\text { - Stay with UE-based control? }\end{array}$ \\
\hline 6 minutes after disruption & $\begin{array}{l}\text { - Scan for new information? } \\
\text { - Implement dynamic resilience action? } \\
\text { - Apply UE-based control for 6 minutes and then } \\
\end{array}$ \\
& implement dynamic resilience action? \\
\hline
\end{tabular}




\begin{tabular}{|c|c|}
\hline 18 minutes after disruption & $\begin{array}{l}\text { - Scan for new information? } \\
\text { - Implement dynamic resilience action? } \\
\text { - Apply UE-based control for } 18 \text { minutes and then } \\
\text { implement dynamic resilience action? }\end{array}$ \\
\hline 30 minutes after disruption & $\begin{array}{l}\text { - Scan for new information? } \\
\text { - Implement dynamic resilience action? } \\
\text { - Apply UE-based control for } 30 \text { minutes and then } \\
\text { implement dynamic resilience action? }\end{array}$ \\
\hline
\end{tabular}

Another illustration of uncertain total delay and decision alternatives are based on Network 4 analyses presented earlier. See tables below.

Table 11-3: Comparison of Total Network Delay During Network 4 Event: Traffic Demand at 2018 \& 2031 Levels

\begin{tabular}{|c|c|c|c|}
\hline Event & $\begin{array}{c}\text { UE 2018 Demand Total } \\
\text { Delay Over All Links } \\
\text { (Hours) }\end{array}$ & $\begin{array}{c}\text { DAS 2018 Demand } \\
\text { Total Delay Over All } \\
\text { Links (Hours) }\end{array}$ & $\begin{array}{c}\text { Increase } \\
/ \\
\text { Decrease } \\
\%\end{array}$ \\
\hline Network 4 & 734.38 & 808.85 & 10.14 \\
\hline Event & $\begin{array}{c}\text { UE 2031 Demand Total } \\
\text { Delay Over All Links } \\
\text { (Hours) }\end{array}$ & $\begin{array}{c}\text { DAS 2031 Demand } \\
\text { Total Delay Over All } \\
\text { Links (Hours) }\end{array}$ & $\begin{array}{c}\text { Increase } \\
/ \\
\text { Decrease } \\
\%\end{array}$ \\
\hline Network 4 & 1530.25 & 1340.62 & -12.39 \\
\hline
\end{tabular}

Table 11-4: Delay Matrix Network 4

\begin{tabular}{|l|c|c|}
\hline Actions & $\begin{array}{c}\text { Total delay state D1 } \\
\text { (Hours) }\end{array}$ & $\begin{array}{c}\text { Total delay state D2 } \\
\text { (Hours) }\end{array}$ \\
\hline A1 UE & 735 & 1530 \\
\hline A2 DSA & 8018 demand and delay level & 1341 \\
\hline
\end{tabular}

The following are the decision alternatives. 


\begin{tabular}{|l|l|}
\hline Time following disruption & $\begin{array}{l}\text { Decision alternatives: } \\
\text { Keep time of day (TOD) alternative based on UE } \\
\text { assignment or implement dynamic resilience } \\
\text { alternative. }\end{array}$ \\
\hline At the time of disruption & $\begin{array}{l}\text { - Scan for new information? } \\
\text { - Stay with UE-based control? }\end{array}$ \\
\hline At the time of disruption & $\begin{array}{l}\text { - Scan for new information? } \\
\text { - Implement dynamic resilience action? }\end{array}$ \\
\hline
\end{tabular}

\subsubsection{Bayesian Statistical Decision Model - Variables and Basic Formulation}

The Bayesian approach is suitable for decision-making regarding the implementation of dynamic resilience actions in order to achieve the lowest possible total delay in the traffic network. It identifies the trade-offs between various decisions using probabilities and delay to travellers that are associated with such decisions. The decision-maker can take into account new data/information in modifying the initial probabilities.

The basic data required to solve a decision problem as defined by Raiffa and Schlaifer (1968) are noted below:

1. A set of alternative terminal actions: $A 1, A 2, \ldots \varepsilon a$, wherein the decision is to be made by selecting a single act $A$, from some domain $a$ of potential acts. In this research, these are dynamic resilience alternatives based mainly on DSA results, including staying with the UE-based traffic control.

2. The possible states of nature (in this research, demand and delay states): $\mathrm{D}_{1}, D_{2}, \ldots \varepsilon$ d. The states of nature are probabilistic and prior probabilities have to be assigned to each state in the set of states of nature. The decision maker or the decision-making 
system follows the philosophy that the selection of an alternative $A$ from the set $a$ is dependent upon the actual state of nature which is not known with certainty.

3. The set of alternative information acquisition measures implies experiments (in decision theory language) or scans to obtain readings on traffic conditions): e $0, e l$, $\ldots \varepsilon E$. The decision maker (or system) may elect to use one experiment from the set $E$ for the purpose of obtaining more information about the actual state of nature (i.e. traffic) prior to selection of an action.

4. The sample space or the set of outcomes or results of information acquisition experiment: $r_{0}, r_{1} \ldots \ldots \varepsilon R$. For each experiment $e$, there is a space of possible outcomes for that scan. The space of possible outcomes $R$, is defined to encompass any outcome of any $e$ in $E$.

5. The cost values, dis-utilities $\mathrm{C}(e, r, A, D)$ represent the decision maker's preferences for all $e, r, A, S$ combinations. The sequence of a course of action is as follows. The decision maker selects an information acquisition means $e$ (including no new information), observes a result $r$, selects a particular $A$, and then a particular state of nature, D, occurs.

It is assumed that a single valued cost function (dis-utility function) is defined over the space, expressed as $\mathrm{C}(e, r, A, D)$, and that in accordance with the principles of utility/value theory, the Cost $\mathrm{C}(e, r)$ and $\mathrm{C}(A, D)$ are additive. In this research, these costs will be in hours of delay.

The cost functions is intended to reflect the value structure of the decision maker (i.e. traffic control and management organization).

6. The probability distributions of $P(D)$ and $P(r \mid D, e)$, portray a joint probability measure $P(D, r \mid e)$ over the space for each information acquisition tactic. The $P(D)$ 
(a prior probability) represents the decision maker's judgment about the relative likelihood of values of $\mathrm{D}$, and $P(r \mid D, e)$ (a conditional probability) characterizes each information acquisition tactic. It is the probability that the outcome $r$, will be observed if the experiment $e$, is performed and $\mathrm{D}$ is the value of the state of nature variable. Additional information on probability measures is provided next.

\subsubsection{Probability Measures}

Solution to the Bayesian decision problem calls for the assignment, either directly or indirectly, a joint probability $P(D, r \mid e)$ to the joint distribution of $\mathrm{D}, r$, over the space $\mathrm{d} \times R$ for each information acquisition tactic $e$. This implies that the decision maker (or the decision system) should define the reliability of each possible information outcome $r$ in predicting the true state of nature (i.e. demand and traffic) $\mathrm{D}$, for each information acquisition tactic $e$.

From the joint probability measure, four other probability measures are obtained. These are explained below.

1. The prior measure $P^{\prime}(D)$ on the states of nature that the decision system would assign to D prior to observing the outcome $\mathrm{r}$ of tactic (experiment) $e$.

2. The conditional measure $P(r \mid D, e)$ on the space $R$-- the probability that the outcome $r$ will be observed if the tactic (experiment) $e$ is performed and $\mathrm{D}$ is the true value of the state of nature.

3. The marginal measure $P(r \mid e)$ on the space $R$ for all $\mathrm{S}$ or the probability of observing outcome $r$ from tactic $e$. It is computed using the following:

$P(r \mid e)=\Sigma P^{\prime}(D) P(r \mid D, e)$ 
4. The posterior measure $P$ " $(D \mid r, e)$ on the space $d$ represents the likelihood of different states $\mathrm{D}$, given $r$ and $e$. Although it is computed using known components, it is based on the philosophy that the decision maker assigns this probability measure to the space $\mathrm{d}$ after knowing the outcome $r$ of the experiment $e$. It is computed using the following equation:

$P^{\prime \prime}(D \mid r, e)$

$=\frac{P(r \mid D, e) P^{\prime}(D)}{P(r \mid e)}$

According to the Bayesian philosophy, each $e$ can be characterized by a conditional probability distribution $P(r \mid D$, e. Its composition and structure is defined by the relationship between the prior and posterior distribution in accordance with the Bayesian Theorem.

\subsubsection{Solving the Decision Problem}

The solution approach is based on the defining the sequence of $(e, r, A, D)$. The cost of a course of action (i.e. the sequence) is represented by the cost matrix $\mathrm{C}(e, r, A$, D).

The decision maker wishes to choose an information acquisition tactic $e$ (including the "null" tactic $e_{0}$ ) and therefore has to evaluate all the possible sequences or courses of action.

The analysis method that involves the evaluation of alternative courses of action to determine the most desirable information acquisition tactic $e$ is known as preposterior analysis. In this thesis, to determine if additional information should be obtained, the pre-posterior analysis mode is assessed. However, if it is intended to find 
the optimal $e$ and the purpose of the analysis is to compare results of analysis under prior and posterior probability distribution, then the mode of analysis can be termed posterior analysis.

In this research, the pre-posterior analysis is used for the purposes of finding out if it is desirable to obtain additional information on the uncertain states (i.e. total network level delay) and the amount of delay is incurred due to information acquisition. In addition, the optimal dynamic resilience alternative can be identified by using the identification of minimum delay.

The sequence of operations required in Pre-posterior analysis are as follows.

1. The likelihood of different states of nature, D, is expressed in the form of prior probability distribution $P^{\prime}(D)$.

2. The conditional probability characteristics $P(r \mid D, e)$, is determined for each experiment.

3. The marginal measures $P(r \mid e)$, for each experiment is computed as noted above. For the null alternative $\left(e_{o}\right)$, the probability is equal to one $P\left(r_{o} \mid e_{o}\right)=1.0$

4. The posterior probability distribution $P$ "' $(D \mid r, e)$ is computed for each combination as defined above.

5. For each combination of $e, r, A, D$, its relative total delay found: $C(e, r, A, D)$.

6. The expected total delay for each action $A$, for each $(e, r)$ combination is as follows: The expected delay for the posterior branch: $C^{*}(A, r, e)=\sum s P^{\prime \prime}(D \mid r, e) C(e, r, A, D)$ However, for the prior branch, where no new experiment is acquired, $C^{*}\left(A, r_{0}, e_{0}\right)=\sum_{s} P^{\prime}(D) C\left(e_{0}, r_{0}, A, D\right)$ 
7. For each $(e, r)$ combination, the optimal action is determined and its associated total delay is noted:

$C^{*}(r, e)=\operatorname{Min}_{A} C^{*}(A, r, e)$

8. For each information acquisition tactic $e$, the expected cost can be computed:

$C^{*}(e)=\sum_{r} P(r \mid e) C^{*}(r, e)$

9. The optimal experiment $e^{*}$ is that $\mathrm{e}$ for which $\mathrm{C}^{*}(e)$ is a minimum total delay. That is: $C^{*}\left(e^{*}\right)=\operatorname{Min}_{e} C^{*}(e)$

\subsubsection{Value of Information}

If the least total delay (optimal) experiment is found not to be the 'null' case, the value of information acquired from scanning/sampling should be calculated. In this research, an assumption is made that the sampling and terminal gains/delays are additive. That is, instead of calculating the total delay $\mathrm{C}(e, r)$ for each possible experimental outcome, it is possible to compute the decrease in delay, which would result for each $r$ if the prior choice of a terminal action after learning about it were changed. A weighted average of these total delay decreases can be calculated as follows:

$C(e, r, A, D)=C_{s}(e, r)+C_{t}(A, D)$

Where subscript $\mathrm{D}$ is used for "additional data" obtained and $t$ is used for "terminal" increase in delay.

The expected total delay disutility of an information acquisition tactic $e$ is:

$C^{*}(e)=\sum_{r} P(r \mid e) C^{*}(r, e)=\sum_{r} P(r \mid e)\left[\operatorname{Min}_{A} \sum_{D} P^{\prime \prime}(D \mid r, e) G(e, r, A, D)\right]$

From the above, we can find

$C^{*}(e)=\sum_{r} P(r \mid e)\left[\operatorname{Min}_{A} \sum_{D} P^{\prime \prime}(D \mid r, e)\left[C_{D}(e, r)+C_{t}(A, D)\right]\right]$ 


$$
=\sum_{r} P(r \mid e)\left[C_{D}(e, r)+\operatorname{Min}_{A} \sum D{ }_{D}{ }^{\prime}(D \mid r, e) C_{t}(A, D)\right]
$$

Or

$C_{D} *(e)=\sum_{r} P(r \mid e) C_{D}(e, r)$

and

$C_{t}^{*}(e)=\sum_{r} P(r \mid e)\left[\operatorname{Min}_{A} \sum_{D} P "(D \mid r, e) C_{t}(A, D)\right]$

If $A$ ' is an optimal action under prior conditions of $\mathrm{D}$ :

$\sum_{S} P^{\prime}(D) G_{t}\left(A^{\prime}, D\right) \geq \sum_{D} P^{\prime}(D) C_{t}(A, D)$

and letting $A r$ be defined as the optimal action under the posterior conditions of $D$ is determined by:

$\sum_{D} P^{\prime \prime}(D \mid r, e) C_{t}(A r, D)=\operatorname{Min}_{A} \sum_{D} P^{\prime \prime}(D \mid r, e) C_{t}(A, D)$

If instead of choosing the action $A$ directly (i.e., based on prior probabilities), the decision maker performs tactic $e$, observes $r$, and then chooses $A_{r}$, the terminal reduction in total delay will be:

$V_{t}(e, r)=\sum{ }_{D} P^{\prime \prime}(D \mid r, e) C_{t}\left(A_{r}, D\right)-\sum D P^{\prime \prime}(D \mid r, e) C_{t}\left(A^{\prime}, D\right)$

The term $V_{t}(e, r)$ is known as the conditional value of additional information $r$. However, before $r$ is observed, the expected value of additional information is given by: $V_{t} *(e)=\sum_{r} P(r \mid e) V_{t}(e, r)$

It can also be interpreted as the amount of total delay that can be reduced because of acquiring additional information for the purpose of reducing total network level delay. Therefore, the expected terminal cost of a particular experiment is the expected terminal cost of an immediate terminal action plus the expected value of additional information. Written in equation form, gives the following:

$G_{t}^{*}(e)=G_{t}^{*}\left(e_{0}\right)+V_{t}^{*}(e)$ 
Now, the expected net gain of information acquisition is therefore determined to be the expected value of additional information less the expected penalty of obtaining it. The penalty of obtaining the information is translated into delays until the information is available. In equation form: $v^{*}(e)=V_{t}^{*}(e)-c_{D} *(e)$

$$
\text { where, } c_{D} *(e)=C_{D} *(e)=\sum r P(r \mid e) C_{D}(e, r)
$$

Notes:

(1) $V_{t}^{*}(e)$ can be considered as the expected reduction in total delay.

(2) If $V_{t}^{*}(e)$ is equal to zero or it is found to be negative, then $\mathrm{e}_{0}$ is the best course of action (i.e., it is not desirable to acquire additional information in support of decision-making).

\subsubsection{Application to Portage Bridge Corridor Disruptive Event}

The inputs are:

- The Total Delay matrix

- Prior probabilities

- The conditional probabilities are set on the basis that if additional information is obtained, it can be reasonably reliable (i.e. $\mathrm{P}(\mathrm{r} \mid \mathrm{D}=0.7)$ ).

The software computes:

- Marginal probabilities

- Posterior probabilities

- Expected Total delay based on prior probabilities \& minimum total delay obtainable from corresponding alternative

- Expected total delay based on posterior probabilities, minimum delay based on result of additional information acquisition $e$ (i.e. r1,r2, r3) and corresponding alternative

- Value of information

- Expected total delay (taking into account marginal probabilities) 


\subsubsection{Alternatives: UE-based and DSA-based}

Prior probabilities P'(D)

\begin{tabular}{|l|l|}
\hline P'(D1) $^{\prime}$ & 0.2 \\
\hline P'(D2) $^{\prime}$ & 0.6 \\
\hline P'(D3) $^{\prime}$ & 0.2 \\
\hline Sum & 1.0 \\
\hline
\end{tabular}

Conditional probabilities $\mathrm{P}(\mathrm{r} \mid \mathrm{D}, \mathrm{e})$

\begin{tabular}{|l|l|l|l|}
\hline & D1 & D2 & D3 \\
\hline r1 & 0.7 & 0.15 & 0.1 \\
\hline r2 & 0.2 & 0.7 & 0.2 \\
\hline r3 & 0.1 & 0.15 & 0.7 \\
\hline Sum & 1.0 & 1.0 & 1.0 \\
\hline
\end{tabular}

Marginal probabilities $\mathrm{P}(\mathrm{r} \mid \mathrm{e})$

\begin{tabular}{|l|l|}
\hline $\mathbf{r}$ & $\mathbf{P}(\mathbf{r} \mid \mathbf{e})$ \\
\hline $\mathbf{r 1}$ & 0.25 \\
\hline $\mathbf{r 2}$ & 0.5 \\
\hline r3 & 0.25 \\
\hline Sum & 1.0 \\
\hline
\end{tabular}

Posterior probabilities P"(D|r,e)

\begin{tabular}{|l|l|l|l|l|}
\hline & D1 & D2 & D3 & Sum \\
\hline r1 & 0.56 & 0.36 & 0.08 & 1.0 \\
\hline r2 & 0.08 & 0.84 & 0.08 & 1.0 \\
\hline r3 & 0.08 & 0.36 & 0.56 & 1.0 \\
\hline
\end{tabular}

Total delay matrix C(A,D) (Hours)

\begin{tabular}{|l|l|l|l|}
\hline Alternative & D1 & D2 & D3 \\
\hline A1 UE-based & 441 & 1419 & 3717 \\
\hline A2 DSA-based & 392 & 1276 & 3492 \\
\hline
\end{tabular}

Expected Delay

\begin{tabular}{|c|c|c|}
\hline Priors & Expected delay & Minimum delay \\
\hline C*(A1) & 1683 & \\
\hline$C *(A 2)$ & 1542.4 & 1542.4 \\
\hline \multicolumn{3}{|l|}{ Posteriors } \\
\hline$C^{*}(\mathrm{~A} 1, \mathrm{r} 1, \mathrm{e})$ & 1055.16 & \\
\hline$C^{*}(\mathrm{~A} 2, \mathrm{r} 1, \mathrm{e})$ & 958.24 & 958.24 \\
\hline$C^{*}(\mathrm{~A} 1, \mathrm{r} 2, \mathrm{e})$ & 1524.6 & \\
\hline$C *(A 2, r 2, e)$ & 1382.56 & 1382.56 \\
\hline$C^{*}(\mathrm{~A} 1, \mathrm{r} 3, \mathrm{e})$ & 2627.64 & \\
\hline$C^{*}(\mathrm{~A} 2, \mathrm{r} 3, \mathrm{e})$ & 2446.24 & 2446.24 \\
\hline
\end{tabular}

Value of information calculations

\begin{tabular}{|c|c|c|c|}
\hline & r1 & r2 & r3 \\
\hline $\mathbf{A r}$ & 958.24 & 1382.56 & 2446.24 \\
\hline $\mathbf{A}^{\prime}$ & 1542.4 & 1542.4 & 1542.4 \\
\hline $\mathbf{A}^{\prime}-\mathbf{A r}$ & 584.16 & 159.84 & -903.84 \\
\hline $\mathbf{P}(\mathbf{r} \mid \mathbf{e})$ & 0.25 & 0.5 & 0.25 \\
\hline
\end{tabular}




\section{Key Results}

\begin{tabular}{|l|c|c|}
\hline $\begin{array}{c}\text { Expected delay (A1) } \\
\text { Hours }\end{array}$ & 1683 & \multicolumn{1}{c|}{ Comment } \\
\hline $\begin{array}{c}\text { Expected delay (A2) } \\
\text { Hours }\end{array}$ & 1542.4 & DSA-based is the choice \\
\hline $\begin{array}{l}\text { Value of additional } \\
\text { information Vt*(e) } \\
\text { (Reduction of delay -- } \\
\text { hours) }\end{array}$ & 0 & $\begin{array}{l}\text { Do not initiate additional scan of } \\
\text { traffic; implement the dynamic } \\
\text { resilience action. }\end{array}$ \\
\hline
\end{tabular}

11.4.3.3 Alternatives: Hybrid of 6 minutes of UE-based and then DSA-based vs. DSA-based

Prior probabilities P'(D)

\begin{tabular}{|l|l|}
\hline P'(D1) $^{\prime}$ & 0.2 \\
\hline P'(D2) $^{\prime}$ & 0.6 \\
\hline P'(D3) & 0.2 \\
\hline Sum & 1.0 \\
\hline
\end{tabular}

Conditional probabilities $\mathrm{P}(\mathrm{r} \mid \mathrm{D}, \mathrm{e})$

\begin{tabular}{|l|l|l|l|}
\hline & D1 & D2 & D3 \\
\hline r1 & 0.7 & 0.15 & 0.1 \\
\hline r2 & 0.2 & 0.7 & 0.2 \\
\hline r3 & 0.1 & 0.15 & 0.7 \\
\hline Sum & 1.0 & 1.0 & 1.0 \\
\hline
\end{tabular}

Marginal probabilities $\mathrm{P}(\mathrm{r} \mid \mathrm{e})$

\begin{tabular}{|l|l|}
\hline $\mathbf{r}$ & $\mathbf{P}(\mathbf{r} \mid \mathbf{e})$ \\
\hline $\mathbf{r 1}$ & 0.25 \\
\hline r2 & 0.5 \\
\hline r3 & 0.25 \\
\hline Sum & 1.0 \\
\hline
\end{tabular}

Posterior probabilities P"(D|r,e)

\begin{tabular}{|l|l|l|l|l|}
\hline & D1 & D2 & D3 & Sum \\
\hline r1 & 0.56 & 0.36 & 0.08 & 1.0 \\
\hline r2 & 0.08 & 0.84 & 0.08 & 1.0 \\
\hline r3 & 0.08 & 0.36 & 0.56 & 1.0 \\
\hline
\end{tabular}

Total delay matrix C(A,D) (Hours)

\begin{tabular}{|l|l|l|l|}
\hline Alternative & D1 & D2 & D3 \\
\hline $\begin{array}{l}\text { A1 Hybrid (6 minutes of UE-based } \\
\text { \& then DSA-based) }\end{array}$ & 394 & 1281 & 3538 \\
\hline A2 DSA-based & 392 & 1276 & 3492 \\
\hline
\end{tabular}


Expected Delay

\begin{tabular}{|c|c|c|}
\hline Priors & Expected delay & Minimum delay \\
\hline C*(A1) & 1555 & \\
\hline$C^{*}(\mathrm{~A} 2)$ & 1542.4 & 1542.4 \\
\hline \multicolumn{3}{|l|}{ Posteriors } \\
\hline$C *(A 1, r 1, e)$ & 964.84 & \\
\hline C*(A2,r1,e) & 958.24 & 958.24 \\
\hline$C^{*}(\mathrm{~A} 1, \mathrm{r} 2, \mathrm{e})$ & 1390.6 & \\
\hline$C *(A 2, r 2, e)$ & 1382.56 & 1382.56 \\
\hline$C *(A 1, r 3, e)$ & 2473.96 & \\
\hline$C *(A 2, r 3, e)$ & 2446.24 & 2446.24 \\
\hline
\end{tabular}

Value of information calculations

\begin{tabular}{|l|l|l|l|}
\hline & r1 & r2 & r3 \\
\hline $\mathbf{A r}$ & 958.24 & 1382.56 & 2446.24 \\
\hline $\mathbf{A}^{\prime}$ & 1542.4 & 1542.4 & 1542.4 \\
\hline $\mathbf{A}^{\prime}-\mathbf{A r}$ & 584.16 & 159.84 & -903.84 \\
\hline $\mathbf{P}(\mathbf{r} \mid \mathbf{e})$ & 0.25 & 0.5 & 0.25 \\
\hline
\end{tabular}

\section{$\underline{\text { Key Results }}$}

\begin{tabular}{|l|c|l|}
\hline Expected delay (A1) Hours & 1555 & Comment \\
\hline $\begin{array}{l}\text { Expected delay (A2) } \\
\text { Hours }\end{array}$ & 1542.4 & DSA-based is the choice \\
\hline $\begin{array}{l}\text { Value of additional information } \\
\text { Vt*(e) } \\
\text { (Reduction of delay --hours) }\end{array}$ & 0 & $\begin{array}{l}\text { Do not initiate additional scan of } \\
\text { traffic; implement the dynamic } \\
\text { resilience action. . }\end{array}$ \\
\hline
\end{tabular}

11.4.3.5 Alternatives: Hybrid of 18 minutes of UE-based and then DSA-based vs. DSA-based

Prior probabilities P'(D)

\begin{tabular}{|l|l|}
\hline P'(D1) & 0.2 \\
\hline P'(D2) & 0.6 \\
\hline P'(D3) & 0.2 \\
\hline Sum & 1.0 \\
\hline
\end{tabular}

Conditional probabilities $\mathrm{P}(\mathrm{r} \mid \mathrm{D}, \mathrm{e})$

\begin{tabular}{|l|l|l|l|}
\hline & D1 & D2 & D3 \\
\hline r1 & 0.7 & 0.15 & 0.1 \\
\hline r2 & 0.2 & 0.7 & 0.2 \\
\hline
\end{tabular}




\begin{tabular}{|l|l|l|l|}
\hline r3 & 0.1 & 0.15 & 0.7 \\
\hline Sum & 1.0 & 1.0 & 1.0 \\
\hline
\end{tabular}

Marginal probabilities $\mathrm{P}(\mathrm{r} \mid \mathrm{e})$

\begin{tabular}{|l|l|}
\hline $\mathbf{r}$ & $\mathbf{P}(\mathbf{r} \mid \mathbf{e})$ \\
\hline $\mathbf{r 1}$ & 0.25 \\
\hline $\mathbf{r 2}$ & 0.5 \\
\hline r3 & 0.25 \\
\hline Sum & 1.0 \\
\hline
\end{tabular}

Posterior probabilities P"( $(\mathrm{D} \mid \mathrm{r}, \mathrm{e})$

\begin{tabular}{|l|l|l|l|l|}
\hline & D1 & D2 & D3 & Sum \\
\hline r1 & 0.56 & 0.36 & 0.08 & 1.0 \\
\hline r2 & 0.08 & 0.84 & 0.08 & 1.0 \\
\hline r3 & 0.08 & 0.36 & 0.56 & 1.0 \\
\hline
\end{tabular}

Total delay matrix C(A,D) (Hours)

\begin{tabular}{|l|l|l|l|}
\hline Alternative & D1 & D2 & D3 \\
\hline $\begin{array}{l}\text { A1 Hybrid (18 minutes of UE-based } \\
\text { \& then DSA-based) }\end{array}$ & 397 & 1298 & 3515 \\
\hline A2 DSA-based & 392 & 1276 & 3492 \\
\hline
\end{tabular}

Expected Delay

\begin{tabular}{|l|l|l|}
\hline Priors & Expected delay & Minimum delay \\
\hline$C^{*}(\mathbf{A 1})$ & 1561.2 & \\
\hline$C^{*}(\mathbf{A 2})$ & 1542.4 & 1542.4 \\
\hline & & \\
\hline Posteriors & & \\
\hline$C^{*}(\mathbf{A 1}, \mathbf{r 1}, \mathbf{e})$ & 970.8 & 958.24 \\
\hline$C^{*}(\mathbf{A 2}, \mathbf{r 1 , e )}$ & 958.24 & \\
\hline & & \\
\hline$C^{*}(\mathbf{A 1}, \mathbf{r 2 , e})$ & 1403.28 & 1382.56 \\
\hline$C^{*}(\mathbf{A 2}, \mathbf{r 2}, \mathbf{e})$ & 1382.56 & \\
\hline & & \\
\hline$C^{*}(\mathbf{A 1}, \mathbf{r 3 , e})$ & 2467.44 & 2446.24 \\
\hline$C^{*}(\mathbf{A 2}, \mathbf{r 3 , e )}$ & 2446.24 & \\
\hline
\end{tabular}

Value of information calculations

\begin{tabular}{|l|l|l|l|}
\hline & $\mathbf{r 1}$ & $\mathbf{r 2}$ & $\mathbf{r 3}$ \\
\hline $\mathbf{A r}$ & 958.24 & 1382.56 & 2446.24 \\
\hline $\mathbf{A}^{\prime}$ & 1542.4 & 1542.4 & 1542.4 \\
\hline $\mathbf{A}^{\prime}-\mathbf{A r}$ & 584.16 & 159.84 & -903.84 \\
\hline $\mathbf{P}(\mathbf{r} \mid \mathbf{e})$ & 0.25 & 0.5 & 0.25 \\
\hline
\end{tabular}


$\underline{\text { Key Results }}$

\begin{tabular}{|l|l|l|}
\hline $\begin{array}{l}\text { Expected delay (A1) } \\
\text { Hours }\end{array}$ & $\mathbf{1 5 6 1 . 2}$ & Comment \\
\hline $\begin{array}{l}\text { Expected delay (A2) } \\
\text { Hours }\end{array}$ & 1542.4 & DSA-based is the choice \\
\hline $\begin{array}{l}\text { Value of additional } \\
\text { information Vt*(e) } \\
\text { (Reduction of delay -- } \\
\text { hours) }\end{array}$ & 0 & $\begin{array}{l}\text { Do not initiate additional scan } \\
\text { of traffic; implement the } \\
\text { dynamic resilience action. . }\end{array}$ \\
\hline
\end{tabular}

\subsubsection{Alternatives: Hybrid of 30 minutes of UE-based and}

then DSA-based vs. DSA-based

Prior probabilities P'(D)

\begin{tabular}{|l|l|}
\hline P'(D1) $^{\prime}$ & 0.2 \\
\hline P'(D2) $^{\prime}$ & 0.6 \\
\hline P'(D3) & 0.2 \\
\hline Sum & 1.0 \\
\hline
\end{tabular}

Conditional probabilities $\mathrm{P}(\mathrm{r} \mid \mathrm{D}, \mathrm{e})$

\begin{tabular}{|l|l|l|l|}
\hline & D1 & D2 & D3 \\
\hline r1 & 0.7 & 0.15 & 0.1 \\
\hline r2 & 0.2 & 0.7 & 0.2 \\
\hline r3 & 0.1 & 0.15 & 0.7 \\
\hline Sum & 1.0 & 1.0 & 1.0 \\
\hline
\end{tabular}

Marginal probabilities $\mathrm{P}(\mathrm{r} \mid \mathrm{e})$

\begin{tabular}{|l|l|}
\hline $\mathbf{r}$ & $\mathbf{P}(\mathbf{r} \mid \mathbf{e})$ \\
\hline $\mathbf{r 1}$ & 0.25 \\
\hline r2 & 0.5 \\
\hline r3 & 0.25 \\
\hline Sum & 1.0 \\
\hline
\end{tabular}

Posterior probabilities P' $(\mathrm{D} \mid \mathrm{r}, \mathrm{e})$

\begin{tabular}{|l|l|l|l|l|}
\hline & D1 & D2 & D3 & Sum \\
\hline r1 & 0.56 & 0.36 & 0.08 & 1.0 \\
\hline r2 & 0.08 & 0.84 & 0.08 & 1.0 \\
\hline r3 & 0.08 & 0.36 & 0.56 & 1.0 \\
\hline
\end{tabular}

Total delay matrix C(A,D) (Hours)

\begin{tabular}{|l|l|l|l|}
\hline Alternative & D1 & D2 & D3 \\
\hline $\begin{array}{l}\text { A1 Hybrid (30 minutes of UE-based } \\
\text { \& then DSA-based) }\end{array}$ & 400 & 1300 & 3530 \\
\hline A2 DSA-based & 392 & 1276 & 3492 \\
\hline
\end{tabular}




\begin{tabular}{|c|c|c|}
\hline Priors & Fxnected delay & Minimum delay \\
\hline$C *(A 1)$ & 1566 & \\
\hline$C *(A 2)$ & 1542.4 & 1542.4 \\
\hline \multicolumn{3}{|l|}{ Posteriors } \\
\hline$C^{*}(\mathrm{~A} 1, \mathrm{r} 1, \mathrm{e})$ & 974.4 & \\
\hline$C^{*}(\mathrm{~A} 2, \mathrm{r} 1, \mathrm{e})$ & 958.24 & 958.24 \\
\hline$C^{*}(\mathrm{~A} 1, \mathrm{r} 2, \mathrm{e})$ & 1406.4 & \\
\hline$C^{*}(\mathrm{~A} 2, \mathrm{r} 2, \mathrm{e})$ & 1382.56 & 1382.56 \\
\hline$C^{*}(\mathrm{~A} 1, \mathrm{r3}, \mathrm{e})$ & 2476.8 & \\
\hline$C^{*}(\mathrm{~A} 2, \mathrm{r3}, \mathrm{e})$ & 2446.24 & 2446.24 \\
\hline
\end{tabular}

Value of information calculations

\begin{tabular}{|l|l|l|l|}
\hline & $\mathbf{r}$ & $\mathbf{r 2}$ & $\mathbf{r 3}$ \\
\hline $\mathbf{A r}$ & 958.24 & 1382.56 & 2446.24 \\
\hline $\mathbf{A}^{\prime}$ & 1542.4 & 1542.4 & 1542.4 \\
\hline $\mathbf{A}^{\prime}-\mathbf{A r}$ & 584.16 & 159.84 & -903.84 \\
\hline $\mathbf{P}(\mathbf{r} \mid \mathbf{e})$ & 0.25 & 0.5 & 0.25 \\
\hline
\end{tabular}

\section{$\underline{\text { Key Results }}$}

\begin{tabular}{|l|l|l|}
\hline Expected delay (A1) Hours & 1566 & Comment \\
\hline $\begin{array}{l}\text { Expected delay (A2) } \\
\text { Hours }\end{array}$ & 1542.4 & DSA-based is the choice \\
\hline $\begin{array}{l}\text { Value of additional } \\
\text { information Vt*(e) } \\
\text { (Reduction of delay --hours) }\end{array}$ & 0 & $\begin{array}{l}\text { Do not initiate additional scan of traffic; } \\
\text { implement the dynamic resilience action. . }\end{array}$ \\
\hline
\end{tabular}

\subsubsection{Comments on Results}

In this application, three traffic levels and corresponding total delays were analyzed using the Bayesian decision model. For all traffic states, the DSA produced lower total delays as compared to UE assignment. A number of hybrid UE-DSA alternatives were analyzed and results were observed. Owing to clear superiority of the DSA under the severe disruption condition as compared to the UE assignment, the optimal courses of action in all cases tested confirmed that: 
(1) The acquisition of additional information before decision-making will not lower the uncertainty regarding total network delay.

(2) Dynamic resilience action based on DSA-based control will be needed.

In the present application, sensitivity tests were not carried out. However, as a part of further work, prior and conditional probabilities will be systematically altered in order to find out if there is a change in the current conclusion that DSA-based control will be desirable as a dynamic resilience measure.

\subsubsection{Application to Network 4 Disruption Event \\ 11.4.4.1 Network 4 Case Alternatives: UE-based and DSA- based}

Prior probabilities P'(D)

\begin{tabular}{|l|l|}
\hline P'(D1) & 0.95 \\
\hline P'(D2) & 0.05 \\
\hline Sum & 1.0 \\
\hline
\end{tabular}

Conditional probabilities $\mathrm{P}(\mathrm{r} \mid \mathrm{D}, \mathrm{e})$

\begin{tabular}{|c|c|c|}
\hline & D1 & D2 \\
\hline r1 & 0.7 & 0.3 \\
\hline r2 & 0.3 & 0.7 \\
\hline & & \\
\hline Sum & 1.0 & 1.0 \\
\hline
\end{tabular}

Marginal probabilities $\mathrm{P}(\mathrm{r} \mid \mathrm{e})$

\begin{tabular}{|c|c|}
\hline $\mathbf{r}$ & $\mathbf{P}(\mathbf{r} \mid \mathbf{e})$ \\
\hline $\mathbf{r 1}$ & 0.68 \\
\hline $\mathbf{r 2}$ & 0.32 \\
\hline & \\
\hline Sum & 1.0 \\
\hline
\end{tabular}

Posterior probabilities P"' $(\mathrm{D} \mid \mathrm{r}, \mathrm{e})$

\begin{tabular}{|c|c|c|c|}
\hline & D1 & D2 & Sum \\
\hline r1 & 0.978 & 0.022 & 1.0 \\
\hline r2 & 0.890 & 0.110 & 1.0 \\
\hline
\end{tabular}


Total delay matrix C(A,D) (Hours)

\begin{tabular}{|l|c|c|}
\hline Alternative & D1 & D2 \\
\hline A1 UE-based & 735 & 1530 \\
\hline A2 DSA-based & 809 & 1341 \\
\hline
\end{tabular}

Expected Delay

\begin{tabular}{|l|l|l|l|}
\hline Priors & Expected delay & Minimum delay & \\
\hline C*(A1) & 774.75 & 774.75 & \\
\hline C*(A2) & 835.6 & & \\
\hline & & & \\
\hline Posteriors & & & \\
\hline$C^{*}(\mathbf{A 1}, \mathbf{r 1 , e )}$ & 752.537 & 752.537 & \\
\hline C*(A2,r1,e) & 820.735 & & \\
\hline & & & \\
\hline$C^{*}(\mathbf{A 1}, \mathbf{r 2 , e )}$ & 821.953 & 821.953 & \\
\hline $\mathbf{C}^{*}(\mathbf{A 2}, \mathbf{r 2 , e )}$ & 867.188 & 1382.56 & \\
\hline
\end{tabular}

Value of information calculations

\begin{tabular}{|l|l|l|}
\hline & r1 & r2 \\
\hline $\mathbf{A r}$ & 752.537 & 821.953 \\
\hline $\mathbf{A}^{\prime}$ & 774.75 & 774.75 \\
\hline $\mathbf{A}^{\prime}-\mathbf{A r}$ & 22.213 & -47.203 \\
\hline $\mathbf{P}(\mathbf{r} \mid \mathbf{e})$ & 0.68 & 0.32 \\
\hline
\end{tabular}

\section{$\underline{\text { Key Results }}$}

\begin{tabular}{|l|l|l|}
\hline Expected delay (A1) Hours & 774.75 & Comment \\
\hline $\begin{array}{l}\text { Expected delay (A2) } \\
\text { Hours }\end{array}$ & 835.6 & UE-based is the choice \\
\hline $\begin{array}{l}\text { Value of additional } \\
\text { information Vt*(e) } \\
\text { (Reduction of delay --hours) }\end{array}$ & 0 & $\begin{array}{l}\text { Do not initiate additional scan of traffic; } \\
\text { keep the UE-based control. }\end{array}$ \\
\hline
\end{tabular}

11.4.4.3 Network 4 Case Alternatives: UE-based and DSAbased

In the following application, prior probabilities are modified.

Prior probabilities P'(D)

\begin{tabular}{|l|l|}
\hline P'(D1) $^{\prime}$ & 0.9 \\
\hline P'(D2) $^{\prime}$ & 0.1 \\
\hline & \\
\hline Sum & 1.0 \\
\hline
\end{tabular}


Conditional probabilities $\mathrm{P}(\mathrm{r} \mid \mathrm{D}, \mathrm{e})$

\begin{tabular}{|l|l|l|}
\hline & D1 & D2 \\
\hline r1 & 0.7 & 0.3 \\
\hline r2 & 0.3 & 0.7 \\
\hline & & \\
\hline Sum & 1.0 & 1.0 \\
\hline
\end{tabular}

Marginal probabilities $\mathrm{P}(\mathrm{r} \mid \mathrm{e})$

\begin{tabular}{|l|l|}
\hline $\mathbf{r}$ & $\mathbf{P}(\mathbf{r} \mid \mathbf{e})$ \\
\hline $\mathbf{r 1}$ & 0.66 \\
\hline $\mathbf{r 2}$ & 0.34 \\
\hline & \\
\hline Sum & 1.0 \\
\hline
\end{tabular}

Posterior probabilities P'(D|r,e)

\begin{tabular}{|l|l|l|l|l|}
\hline & D1 & D2 & & Sum \\
\hline r1 & 0.955 & 0.045 & & 1.0 \\
\hline r2 & 0.794 & 0.206 & & 1.0 \\
\hline & & & & \\
\hline
\end{tabular}

Total delay matrix C(A,D) (Hours)

\begin{tabular}{|l|l|l|}
\hline Alternative & D1 & D2 \\
\hline A1 UE-based & 735 & 1530 \\
\hline A2 DSA-based & 809 & 1341 \\
\hline
\end{tabular}

\begin{tabular}{|c|c|c|}
\hline \multicolumn{3}{|c|}{ Expected Delay } \\
\hline Priors & Expected delay & Minimum delay \\
\hline$C^{*}(\mathrm{~A} 1)$ & 814.5 & 814.5 \\
\hline$C *(\mathrm{~A} 2)$ & 862.2 & \\
\hline \multicolumn{3}{|l|}{ Posteriors } \\
\hline$C^{*}(\mathrm{~A} 1, \mathrm{r} 1, \mathrm{e})$ & 771.136 & 771.136 \\
\hline$C^{*}(\mathrm{~A} 2, \mathrm{r} 1, \mathrm{e})$ & 833.182 & \\
\hline$C^{*}(\mathrm{~A} 1, \mathrm{r} 2, \mathrm{e})$ & 898.676 & 898.677 \\
\hline$C^{*}(\mathrm{~A} 2, \mathrm{r} 2, \mathrm{e})$ & 918.529 & \\
\hline
\end{tabular}

Value of information calculations

\begin{tabular}{|l|l|l|}
\hline & r1 & r2 \\
\hline $\mathbf{A r}$ & 771.136 & 898.676 \\
\hline $\mathbf{A}^{\prime}$ & 814.5 & 814.5 \\
\hline $\mathbf{A}^{\prime}-\mathbf{A r}$ & 43.364 & -84.177 \\
\hline $\mathbf{P}(\mathbf{r} \mid \mathbf{e})$ & 0.66 & 0.34 \\
\hline
\end{tabular}


Key Results

\begin{tabular}{|l|l|l|}
\hline Expected delay (A1) Hours & 814.5 & Comment \\
\hline $\begin{array}{l}\text { Expected delay (A2) } \\
\text { Hours }\end{array}$ & 862.2 & UE-based is the choice \\
\hline $\begin{array}{l}\text { Value of additional } \\
\text { information Vt*(e) } \\
\text { (Reduction of delay --hours) }\end{array}$ & $1.350 \mathrm{E}-13$ & $\begin{array}{l}\text { Do not initiate additional scan } \\
\text { of traffic; keep the UE-based } \\
\text { control. }\end{array}$ \\
\hline
\end{tabular}

11.4.4.5 Network 4 Case Alternatives: UE-based and DSA-

based

In the following application, prior probabilities are modified.

Prior probabilities P'(D)

\begin{tabular}{|l|l|}
\hline P'(D1) & 0.8 \\
\hline P'(D2) & 0.2 \\
\hline & \\
\hline Sum & 1.0 \\
\hline
\end{tabular}

Conditional probabilities $\mathrm{P}(\mathrm{r} \mid \mathrm{D}, \mathrm{e})$

\begin{tabular}{|l|l|l|l|}
\hline & D1 & D2 & \\
\hline r1 & 0.7 & 0.3 & \\
\hline r2 & 0.3 & 0.7 & \\
\hline & & & \\
\hline Sum & 1.0 & 1.0 & \\
\hline
\end{tabular}

Marginal probabilities $\mathrm{P}(\mathrm{r} \mid \mathrm{e})$

\begin{tabular}{|l|l|}
\hline $\mathbf{r}$ & $\mathbf{P}(\mathbf{r} \mid \mathbf{e})$ \\
\hline $\mathbf{r 1}$ & 0.66 \\
\hline $\mathbf{r 2}$ & 0.34 \\
\hline & \\
\hline Sum & 1.0 \\
\hline
\end{tabular}

Posterior probabilities P'(D $\mid$ r,e $)$

\begin{tabular}{|l|l|l|l|l|}
\hline & D1 & D2 & & Sum \\
\hline r1 & 0.903 & 0.097 & & 1.0 \\
\hline r2 & 0.632 & 0.368 & & 1.0 \\
\hline
\end{tabular}

Total delay matrix C(A,D) (Hours)

\begin{tabular}{|l|l|l|}
\hline Alternative & D1 & D2 \\
\hline A1 UE-based & 735 & 1530 \\
\hline A2 DSA-based & 809 & 1341 \\
\hline
\end{tabular}


Expected Delay

\begin{tabular}{|l|l|l|}
\hline Priors & Expected delay & Minimum delay \\
\hline$C^{*}(\mathbf{A 1})$ & 894 & 894 \\
\hline$C^{*}(\mathbf{A 2})$ & 915.4 & \\
\hline & & \\
\hline Posteriors & & \\
\hline$C^{*}(\mathbf{A 1}, \mathbf{r 1 , e )}$ & 811.935 & 811.935 \\
\hline C*(A2,r1,e) $^{*}$ & 860.484 & \\
\hline & & \\
\hline $\mathbf{C}^{*}(\mathbf{A 1}, \mathbf{r 2}, \mathbf{e})$ & 1027.894 & 1005 \\
\hline $\mathbf{C}^{*}(\mathbf{A 2}, \mathbf{r 2}, \mathbf{e})$ & 1005 & \\
\hline
\end{tabular}

Value of information calculations

\begin{tabular}{|l|l|l|}
\hline & r1 & r2 \\
\hline Ar & 811.935 & 1005 \\
\hline $\mathbf{A}^{\prime}$ & 894 & 894 \\
\hline $\mathbf{A}^{\prime}-\mathbf{A r}$ & 82.064 & -111 \\
\hline $\mathbf{P}(\mathbf{r} \mid \mathbf{e})$ & 0.62 & 0.38 \\
\hline
\end{tabular}

Key Results

\begin{tabular}{|l|l|l|}
\hline Expected delay (A1) Hours & 894 & Comment \\
\hline $\begin{array}{l}\text { Expected delay (A2) } \\
\text { Hours }\end{array}$ & 915.4 & UE-based is the choice \\
\hline $\begin{array}{l}\text { Value of additional } \\
\text { information Vt*(e) } \\
\text { (Reduction of delay --hours) }\end{array}$ & 8.7 & $\begin{array}{l}\text { Initiate additional scan of traffic; keep the } \\
\text { UE-based control. }\end{array}$ \\
\hline
\end{tabular}

\subsubsection{Network 4 Case Alternatives: UE-based and DSA-}

based

In the following application, prior probabilities are modified.

Prior probabilities P'(D)

\begin{tabular}{|l|c|}
\hline P'(D1) $^{\prime}$ & 0.75 \\
\hline P'(D2) $^{\prime}$ & 0.25 \\
\hline & \\
\hline Sum & 1.0 \\
\hline
\end{tabular}

Conditional probabilities $\mathrm{P}(\mathrm{r} \mid \mathrm{D}, \mathrm{e})$

\begin{tabular}{|c|c|c|}
\hline & D1 & D2 \\
\hline r1 & 0.7 & 0.3 \\
\hline r2 & 0.3 & 0.7 \\
\hline & & \\
\hline Sum & 1.0 & 1.0 \\
\hline
\end{tabular}




\begin{tabular}{|c|c|c|c|}
\hline \multicolumn{3}{|c|}{ Marginal probabilities $\mathrm{P}(\mathrm{r} \mid \mathrm{e})$} & \\
\hline $\mathbf{r}$ & \multicolumn{2}{|c|}{$P(r \mid e)$} & \\
\hline $\mathbf{r 1}$ & \multicolumn{2}{|c|}{0.6} & \\
\hline $\mathbf{r 2}$ & \multicolumn{2}{|c|}{0.4} & \\
\hline Sum & \multicolumn{2}{|c|}{1.0} & \\
\hline \multicolumn{4}{|c|}{ Posterior probabilities P' $(\mathrm{D} \mid \mathrm{r}, \mathrm{e})$} \\
\hline & D1 & D2 & Sum \\
\hline r1 & 0.875 & 0.125 & 1.0 \\
\hline $\mathbf{r 2}$ & 0.563 & 0.437 & 1.0 \\
\hline & & & \\
\hline
\end{tabular}

Total delay matrix C(A,D) (Hours)

\begin{tabular}{|l|l|l|}
\hline Alternative & D1 & D2 \\
\hline A1 UE-based & 735 & 1530 \\
\hline A2 DSA-based & 809 & 1341 \\
\hline
\end{tabular}

\section{Expected Delay}

\begin{tabular}{|l|l|l|}
\hline Priors & Expected delay & Minimum delay \\
\hline$C^{*}(\mathbf{A 1})$ & 933.75 & 933.75 \\
\hline $\mathbf{C}^{*}(\mathbf{A 2})$ & 942 & \\
\hline Posteriors & & \\
\hline $\mathbf{C}^{*}(\mathbf{A 1}, \mathbf{r 1 , e )}$ & 834.375 & 834.375 \\
\hline $\mathbf{C}^{*}(\mathbf{A 2}, \mathbf{r 1 , e )}$ & 875.5 & \\
\hline & & \\
\hline $\mathbf{C}^{*}(\mathbf{A 1}, \mathbf{r 2}, \mathbf{e})$ & 1082.813 & \\
\hline$C^{*}(\mathbf{A 2}, \mathbf{r 2}, \mathbf{e})$ & 1041.75 & 1041.75 \\
\hline & & \\
\hline
\end{tabular}

Value of information calculations

\begin{tabular}{|l|l|l|}
\hline & r1 & r2 \\
\hline $\mathbf{A r}$ & 834.375 & 1041.75 \\
\hline $\mathbf{A}^{\prime}$ & 933.75 & 933.75 \\
\hline $\mathbf{A}^{\prime}-\mathbf{A r}$ & 99.375 & -108 \\
\hline $\mathbf{P}(\mathbf{r} \mid \mathbf{e})$ & 0.6 & 0.4 \\
\hline
\end{tabular}

\section{Key Results}

\begin{tabular}{|l|l|l|}
\hline Expected delay (A1) Hours & 933.75 & Comment \\
\hline $\begin{array}{l}\text { Expected delay (A2) } \\
\text { Hours }\end{array}$ & 942 & UE-based is the choice \\
\hline $\begin{array}{l}\text { Value of additional } \\
\text { information Vt*(e) } \\
\text { (Reduction of delay --hours) }\end{array}$ & 16.425 & $\begin{array}{l}\text { Initiate additional scan of traffic; keep the } \\
\text { UE-based control. }\end{array}$ \\
\hline
\end{tabular}


In the following application, prior probabilities are modified.

Prior probabilities P'(D)

\begin{tabular}{|l|l|}
\hline P'(D1) & 0.7 \\
\hline P'(D2) $^{\prime}$ & 0.3 \\
\hline & \\
\hline Sum & 1.0 \\
\hline
\end{tabular}

Conditional probabilities $\mathrm{P}(\mathrm{r} \mid \mathrm{D}, \mathrm{e})$

\begin{tabular}{|l|l|l|}
\hline & D1 & D2 \\
\hline r1 & 0.7 & 0.3 \\
\hline r2 & 0.3 & 0.7 \\
\hline & & \\
\hline Sum & 1.0 & 1.0 \\
\hline
\end{tabular}

Marginal probabilities $\mathrm{P}(\mathrm{r} \mid \mathrm{e})$

\begin{tabular}{|l|l|}
\hline $\mathbf{r}$ & $\mathbf{P}(\mathbf{r} \mid \mathbf{e})$ \\
\hline $\mathbf{r 1}$ & 0.58 \\
\hline $\mathbf{r} 2$ & 0.42 \\
\hline & 1.0 \\
\hline Sum & \\
\hline
\end{tabular}

Posterior probabilities P" $(\mathrm{D} \mid \mathrm{r}, \mathrm{e})$

\begin{tabular}{|l|l|l|l|l|}
\hline & D1 & D2 & & Sum \\
\hline r1 & 0.84 & 0.16 & & 1.0 \\
\hline r2 & 0.5 & 0.5 & & 1.0 \\
\hline
\end{tabular}

Total delay matrix C(A,D) (Hours)

\begin{tabular}{|l|l|l|}
\hline Alternative & D1 & D2 \\
\hline A1 UE-based & 735 & 1530 \\
\hline A2 DSA-based & 809 & 1341 \\
\hline
\end{tabular}

Expected Delay

\begin{tabular}{|l|l|l|}
\hline Priors & Expected delay & Minimum delay \\
\hline $\mathbf{C}^{*}(\mathbf{A 1})$ & 973.5 & \\
\hline $\mathbf{C}^{*}(\mathbf{A 2})$ & 968.6 & 968.6 \\
\hline & & \\
\hline Posteriors & & 858.36 \\
\hline $\mathbf{C}^{*}(\mathbf{A 1}, \mathbf{r 1 , e )}$ & 858.36 & \\
\hline $\mathbf{C}^{*}(\mathbf{A 2}, \mathbf{r 1}, \mathbf{e})$ & 891.55 & \\
\hline & & \\
\hline $\mathbf{C}^{*}(\mathbf{A 1}, \mathbf{r 2 , e})$ & 1132.5 & 1075 \\
\hline $\mathbf{C}^{*} \mathbf{( A 2 , r 2 , e )}$ & 1075 & \\
\hline
\end{tabular}


Value of information calculations

\begin{tabular}{|l|l|l|}
\hline & r1 & r2 \\
\hline $\mathbf{A r}$ & 858.36 & 1075 \\
\hline $\mathbf{A}^{\prime}$ & 968.6 & 968.6 \\
\hline $\mathbf{A}^{\prime}-\mathbf{A r}$ & 110.24 & -106.4 \\
\hline $\mathbf{P}(\mathbf{r} \mid \mathbf{e})$ & 0.58 & 0.42 \\
\hline
\end{tabular}

\section{$\underline{\text { Key Results }}$}

\begin{tabular}{|c|c|c|}
\hline Expected delay (A1) Hours & 973.5 & Comment \\
\hline Expected delay (A2) Hours & 968.6 & DSA-based is the choice \\
\hline $\begin{array}{l}\text { Value of additional } \\
\text { information } \mathrm{Vt}^{*}(\mathrm{e}) \\
\text { (Reduction of delay --hours) }\end{array}$ & 19.25 & $\begin{array}{l}\text { Initiate additional scan of } \\
\text { traffic; Implement DSA- } \\
\text { based control. }\end{array}$ \\
\hline
\end{tabular}

\subsubsection{Network 4 Case Alternatives: UE-based and DSA-}

\section{based}

In the following application, prior probabilities are modified.

Prior probabilities $\mathrm{P}^{\prime}(\mathrm{D})$

\begin{tabular}{|l|l|}
\hline P'(D1) & 0.6 \\
\hline P'(D2) & 0.4 \\
\hline & \\
\hline Sum & 1.0 \\
\hline
\end{tabular}

Conditional probabilities $\mathrm{P}(\mathrm{r} \mid \mathrm{D}, \mathrm{e})$

\begin{tabular}{|c|c|c|}
\hline & D1 & D2 \\
\hline r1 & 0.7 & 0.3 \\
\hline r2 & 0.3 & 0.7 \\
\hline & & \\
\hline Sum & 1.0 & 1.0 \\
\hline
\end{tabular}

Marginal probabilities $\mathrm{P}(\mathrm{r} \mid \mathrm{e})$

\begin{tabular}{|c|c|}
\hline $\mathbf{r}$ & $\mathbf{P}(\mathbf{r} \mid \mathbf{e})$ \\
\hline $\mathbf{r 1}$ & 0.54 \\
\hline $\mathbf{r 2}$ & 0.46 \\
\hline Sum & 1.0 \\
\hline
\end{tabular}

Posterior probabilities P'(D|r,e)

\begin{tabular}{|c|c|c|c|}
\hline & D1 & D2 & Sum \\
\hline r1 & 0.78 & 0.22 & 1.0 \\
\hline r2 & 0.39 & 0.61 & 1.0 \\
\hline
\end{tabular}


Total delay matrix C(A,D) (Hours)

\begin{tabular}{|l|l|l|}
\hline Alternative & D1 & D2 \\
\hline A1 UE-based & 735 & 1530 \\
\hline A2 DSA-based & 809 & 1341 \\
\hline
\end{tabular}

Expected Delay

\begin{tabular}{|c|c|c|}
\hline Priors & Expected delay & Minimum delay \\
\hline C*(A1) & 1053 & \\
\hline$C *(A 2)$ & 1021.8 & 1021.8 \\
\hline \multicolumn{3}{|l|}{ Posteriors } \\
\hline$C^{*}(\mathrm{~A} 1, \mathrm{r} 1, \mathrm{e})$ & 911.67 & 911.67 \\
\hline$C *(A 2, r 1, e)$ & 927.22 & \\
\hline$C^{*}(\mathrm{~A} 1, \mathrm{r} 2, \mathrm{e})$ & 1218.91 & \\
\hline$C *(A 2, r 2, e)$ & 1132.83 & 1132.83 \\
\hline
\end{tabular}

Value of information calculations

\begin{tabular}{|c|c|c|}
\hline & r1 & r2 \\
\hline $\mathbf{A r}$ & 911.67 & 1132.83 \\
\hline $\mathbf{A}^{\prime}$ & 1021.8 & 1021.8 \\
\hline $\mathbf{A}^{\prime}-\mathbf{A r}$ & 110.13 & -111.03 \\
\hline $\mathbf{P}(\mathbf{r} \mid \mathbf{e})$ & 0.54 & 0.46 \\
\hline
\end{tabular}

\section{$\underline{\text { Key Results }}$}

\begin{tabular}{|l|c|l|}
\hline Expected delay (A1) Hours & 1053 & Comment \\
\hline $\begin{array}{l}\text { Expected delay (A2) } \\
\text { Hours }\end{array}$ & 1021.8 & DSA-based is the choice \\
\hline $\begin{array}{l}\text { Value of additional } \\
\text { information Vt*(e) } \\
\text { (Reduction of delay --hours) }\end{array}$ & 8.4 & $\begin{array}{l}\text { Initiate additional scan of } \\
\text { traffic; Implement DSA-based } \\
\text { control. }\end{array}$ \\
\hline
\end{tabular}

\subsubsection{Network 4 Case Alternatives: UE-based and DSA-}

based

In the following application, prior probabilities are modified.

Prior probabilities P'(D)

\begin{tabular}{|l|l|}
\hline P'(D1) & 0.5 \\
\hline P'(D2) & 0.5 \\
\hline & \\
\hline Sum & 1.0 \\
\hline
\end{tabular}


Conditional probabilities $\mathrm{P}(\mathrm{r} \mid \mathrm{D}, \mathrm{e})$

\begin{tabular}{|c|c|c|}
\hline & D1 & D2 \\
\hline r1 & 0.7 & 0.3 \\
\hline r2 & 0.3 & 0.7 \\
\hline & & \\
\hline Sum & 1.0 & 1.0 \\
\hline
\end{tabular}

Marginal probabilities $\mathrm{P}(\mathrm{r} \mid \mathrm{e})$

\begin{tabular}{|c|c|}
\hline $\mathbf{r}$ & $\mathbf{P}(\mathbf{r} \mid \mathbf{e})$ \\
\hline $\mathbf{r 1}$ & 0.5 \\
\hline r2 & 0.5 \\
\hline Sum & 1.0 \\
\hline
\end{tabular}

Posterior probabilities P'(D|r,e)

\begin{tabular}{|l|l|l|l|l|}
\hline & D1 & D2 & & Sum \\
\hline r1 & 0.7 & 0.3 & & 1.0 \\
\hline r2 & 0.3 & 0.7 & & 1.0 \\
\hline
\end{tabular}

Total delay matrix C(A,D) (Hours)

\begin{tabular}{|l|l|l|}
\hline Alternative & D1 & D2 \\
\hline A1 UE-based & 735 & 1530 \\
\hline A2 DSA-based & 809 & 1341 \\
\hline
\end{tabular}

Expected Delay

\begin{tabular}{|l|l|l|}
\hline Priors & Expected delay & Minimum delay \\
\hline$C^{*}(\mathbf{A 1})$ & 1132.5 & \\
\hline $\mathbf{C}^{*}(\mathbf{A 2})$ & 1075 & 1075 \\
\hline & & \\
\hline Posteriors & & \\
\hline $\mathbf{C}^{*}(\mathbf{A 1}, \mathbf{r 1 , e )}$ & 973.5 & \\
\hline $\mathbf{C}^{*}(\mathbf{A 2}, \mathbf{r 1 , e )}$ & 968.6 & 968.6 \\
\hline & & \\
\hline $\mathbf{C}^{*}(\mathbf{A 1}, \mathbf{r 2 , e )}$ & 1291.5 & \\
\hline $\mathbf{C}^{*}(\mathbf{A 2}, \mathbf{r 2}, \mathbf{e})$ & 1181.4 & 1181.4 \\
\hline & & \\
\hline
\end{tabular}

Value of information calculations

\begin{tabular}{|l|l|l|}
\hline & r1 & r2 \\
\hline $\mathbf{A r}$ & 968.6 & 1181.4 \\
\hline $\mathbf{A}^{\prime}$ & 1075 & 1075. \\
\hline $\mathbf{A}^{\prime}-\mathbf{A r}$ & 106.4 & -106.4 \\
\hline $\mathbf{P}(\mathbf{r} \mid \mathbf{e})$ & 0.5 & 0.5 \\
\hline
\end{tabular}

\section{$\underline{\text { Key Results }}$}

\begin{tabular}{|l|l|l|}
\hline Expected delay (A1) Hours & 1132.5 & Comment \\
\hline $\begin{array}{l}\text { Expected delay (A2) } \\
\text { Hours }\end{array}$ & 1075 & DSA-based is the choice \\
\hline $\begin{array}{l}\text { Value of additional information } \\
\begin{array}{l}\text { Vt*(e) } \\
\text { (Reduction of delay --hours) }\end{array}\end{array}$ & $1.137 \mathrm{E}-13$ & $\begin{array}{l}\text { Do not initiate additional scan of } \\
\text { traffic; Implement DSA-based } \\
\text { control. }\end{array}$ \\
\hline
\end{tabular}




\subsubsection{Comments on Results}

In this Network 4 disruption case, it was noted that at the 2018 traffic level, the total delay was lower for the UE assignment as compared to Dynamic Stochastic Assignment (DSA) case. On the other hand, for the 2031 traffic level, the DSA resulted in lower total delay. This presented an interesting opportunity to find the most suitable traffic control by considering the two traffic levels as uncertain traffic states and apply the Bayesian analysis to the corridor network. In this application, we are working with two traffic and total delay states, D1 and D2. In the case of UE assignment, the D2 level total delay is 2.1 times the D1 level. Based on DSA assignment, the ratio is 1.7. Given that traffic surges on a given day are stochastic and can fluctuate to the extent that is characterized by S1 and S2, it is useful to study the role of dynamic resilience actions for the Network 4 disruption case.

In this application, the decision analyses were repeated by altering prior probabilities and results were compiled. Specifically, two results were of interest:

(1) The value of additional information obtainable from traffic scanning before making a decision on dynamic resilience action (i.e. scan traffic before making a decision).

(2) Should UE-based control continue or should the DSA-based control be initiated? Results obtained are very logical. These suggest that:

(1) The value of information is positive and relatively high if the uncertainty can be lowered regarding the level of total delay.

(2) The UE-based control results in lower total delay under low traffic conditions.

(3) The DSA-based control is effective in lowering total delay if a disruption occurred under high traffic condition. As previously noted, the DSA-based control is a dynamic resilience action. 


\section{CONCLUSIONS}

\subsection{KEY FINDINGS AND MAJOR CONCLUSIONS}

This research investigated design factors that can contribute inherent resilience to the transportation network in order to reduce the effect of highly disruptive incidents and it also studied dynamic resilience measures with potential to restore throughput and level of service. Methodological frameworks were developed and implemented for each type of resilience. Inherent resilience research defined and tested the effectiveness of measures using microsimulations and predictive models that were developed from simulation results. The dynamic resilience research applied User Equilibrium (UE) and Dynamic Stochastic Assignment (DSA) models, supplemented with Bayesian methodology. The National Capital Region (Ottawa-Gatineau, Canada) transportation system served as both a source of data and as a testbed for proof of concept applications of products of this research. However, the methods developed are applicable to transportation network of any city.

Key findings and major conclusions are noted next.

- Link level inherent resilience measures were identified and tested using the microsimulation tool. Predictive models were developed for quantifying and verifying the effectiveness of link design features, namely right turn and left turn bays in contributing inherent resilience. The availability of the right turn bay has a considerable direct variation with travel speed and capacity. In contrast, the availability of the left-turn bay has a slight direct effect on travel speed and capacity. 
- Increasing the link length also proved to be a resiliency-enhancing measure. Further, as expected, adapting traffic control in the form incrementally increasing green time/cycle ratio in response to traffic surges enhanced inherent resilience.

- Simulation of a traffic network with and without inherent resilience measures resulted in further confirmation that inherent resilience measures can be specified for improving throughput, quality of flow and reducing fuel consumption and emissions under major disruptive events. As compared to the base case (without resilience treatments), total average delay increased by $24 \%$ when a major incident occurred. After implementing inherent resilience options, as compared to the base case, the throughput increased by $3.4 \%$, average delay decreased by $15 \%$, total emissions dropped, and average queue lengths across intersections reduced by $10 \%$.

- Research in the role of Dynamic Stochastic Assignment (DSA) as a dynamic resilience tool proved to be fruitful. Comparisons of the effectiveness of DSA and UE assignments under disruption condition confirmed the role of DSA under high traffic levels in stabilizing throughput (i.e. demand to be served) and restoring network level quality of flow (i.e. preventing increase in delay). The UE-based control results in lower total delay under low traffic conditions. On the other hand, the DSA-based control is effective in lowering total delay if a disruption occurs under high traffic condition. As previously noted, the DSA-based control is a dynamic resilience action. 
A Bayesian decision model was used to assess the relative merits of dynamic resilience actions. The Bayesian model answers can be used by the traffic management system in order to cope with uncertainty in traffic level during disruptive events. This model can analyze alternatives based on DSA or hybrids of DSA and UE assignment methods. In addition, its ability to quantify the merits of sampling additional information for updating probabilities and to quantify the value of additional information provides further guidance in selecting a dynamic resilience measure for implementation in real time. Results obtained are very logical and suggest that the value of information is positive and relatively high if the uncertainty can be lowered regarding the level of total delay.

\subsection{CONTRIBUTIONS OF THESIS RESEARCH}

- The resilience of a traffic network to serve its function when impacted by a major event is a new research subject. Methodological advances are achieved in both inherent and dynamic resilience of traffic network. In addition, information gaps in this subject of importance to travellers and city officials are addressed by detailed original proof of concept applications in a realworld setting.

- The quantification of the effectiveness of inherent resilience at link as well as network level is a contribution to knowledge for use by the traffic engineering profession.

- In the dynamic resilience part of the research, with the application of advanced methods, namely the dynamic stochastic and user equilibrium assignment tools in association with the Bayesian methods has contributed 
knowledge of potential interest to researchers, traffic control system developers and practicing professional engineers.

- The practical application of inherent resilience includes serviceability enhancing measures that can be built-in critical areas in the road networks to ease traffic surges in case of an unforeseen event.

- Dynamic resilience can be initiated when there is a major incident. The original framework uses advanced tools of DSA, UE, and Bayesian method so that traffic planners can cope with major incidents that may otherwise create a major issue in the urban system

\subsection{FUTURE RESEARCH RECOMMENDATION}

- In the inherent resilience part of this thesis research, the importance of developing and application of detailed road category-specific volume-delay or volume-speed functions was demonstrated. The current functions that are built in traffic assignment software are too coarse and these cannot differentiate designs with or without inherent resilience treatments. Research is needed in the development and application of these volume-delay or volume-speed functions that can produce results of use in benefit-cost studies. Without the availability of research products in this subject, software developers may not be able to update functions.

- In the dynamic resilience part of this thesis research, the application of dynamic stochastic and user equilibrium assignment models in association with Bayesian method enabled the development and testing of measures for coping with major disruptive events. Research is needed to develop traffic 
management algorithms that can implement dynamic resilience measures in real time. In addition, as an extension of this research, communication between road users or vehicles and traffic personnel needs further research. 


\section{REFERENCES}

AASHTO, 2004. A Policy on Geometric Design of Highways and Streets, 5th Edition, 5th ed. American Association of State Highway and Transportation Officials, Washington DC, USA.

Armoogum, J., Madre, J.-L., Bussière, Y., 2009. Measuring Uncertainty In Long-Term Travel Demand Forecasting From Demographic Modelling: Case Study of the Paris and Montreal Metropolitan Areas. IATSS Research 33, 9-20. https://doi.org/10.1016/S0386-1112(14)60241-7

Bell, M.G.H., 1999. Measuring network reliability: A game theoretic approach. Journal of Advanced Transportation 33, 135-146. https://doi.org/10.1002/atr.5670330204

Ben-Akiva, M., Bierlaire, M., 1999. Discrete Choice Methods and their Applications to Short Term Travel Decisions, in: Hall, R.W. (Ed.), Handbook of Transportation Science, International Series in Operations Research \& Management Science. Springer US, Boston, MA, pp. 5-33. https://doi.org/10.1007/978-1-4615-5203$1 \_2$

Burke, A., 2017. Tunnel work likely loosened sandy soil, causing Rideau Street sinkhole: Report | CBC News. CBC.

Cascetta, E., Nuzzolo, A., Russo, F., Vitetta, A., 1996. A Modified Logit Route Choice Model Overcoming Path Overlapping Problems. Specification and Some Calibration Results for Interurban Networks. Presented at the Transportation and Traffic Theory. Proceedings of the 13th International Symposium On Transportation And Traffic Theory, Lyon, France, 24-26 July 1996.

Cavaliere, D., Loia, V., Saggese, A., Senatore, S., Vento, M., 2018. Semantically Enhanced UAVs to Increase the Aerial Scene Understanding. IEEE Transactions on Systems, Man, and Cybernetics: Systems 1-13. https://doi.org/10.1109/TSMC.2017.2757462

City of Ottawa, 2013. Transportation Master Plan.

City of Ottawa, 2011. Downtown Ottawa Transit Tunnel: Tunney's Pasture to Blair Station via a Downtown LRT Tunnel: Environmental Project Report. Ottawa, ON.

City of Ottawa, n.d. City of Ottawa [WWW Document]. URL https://ottawa.ca/en/home (accessed 1.22.20). 
Doherty, P., Granlund, G., Kuchcinski, K., Sandewall, E., Nordberg, K., Skarman, E., Wiklund, J., 2000. The WITAS unmanned aerial vehicle project, in: European Conference on Artificial Intelligence. pp. 747-755.

Dowling, R., Ryus, P., Schroeder, B., Kyte, M., Creasey, T., Rouphail, N., Hajbabaie, A., Rhoades, D., National Cooperative Highway Research Program, Transportation Research Board, National Academies of Sciences, Engineering, and Medicine, 2016. Planning and Preliminary Engineering Applications Guide to the Highway Capacity Manual. Transportation Research Board, Washington, D.C. https://doi.org/10.17226/23632

Faturechi, R., Miller-Hooks, E., 2014. Travel time resilience of roadway networks under disaster. Transportation Research Part B: Methodological 70, 47-64. https://doi.org/10.1016/j.trb.2014.08.007

Flyvbjerg, B., Holm, M., Buhl, S., 2007. Inaccuracy in Traffic Forecasts (SSRN Scholarly Paper No. ID 2278241). Social Science Research Network, Rochester, NY.

Friedrich, M., Hofsäß, I., Nökel, K., Vortisch, P., 2000. A Dynamic Traffic Assignment Method For Planning And Telematic Applications. Presented At The Proceedings Of Seminar K Of The European Transport Conference 2000, Held Homerton College, Cambridge, Uk, 11-13 September 2000 - Transport Modelling. Volume P445.

Godschalk, D.R., 2003. URBAN HAZARD MITIGATION: CREATING RESILIENT CITIES. Natural Hazards Review 4.

Google Maps [WWW Document], n.d. . Google Maps. URL https://www.google.com/maps/@45.3064192,-75.614031,15z_ (accessed 1.22.20).

Holling, C.S., 1973. Resilience and Stability of Ecological Systems. Annual Review of Ecology and Systematics 4, 1-23. https://doi.org/10.1146/annurev.es.04.110173.000245

Hollnagel, E., Woods, D.D., Leveson, N., 2007. Resilience Engineering: Concepts and Precepts. Ashgate Publishing, Ltd.

IBI Group, 2016. National Capital Region Travel Trends (No. Final Report). TRANS Committee, Ottawa, ON.

Iida, Y., 1999. BASIC CONCEPTS AND FUTURE DIRECTIONS OF ROAD NETWORK RELIABILITY ANALYSIS. Journal of Advanced Transportation 33.

Jagannathan, R., Khan, A.M., 2001. METHODOLOGY FOR THE ASSESSMENT OF TRAFFIC ADAPTIVE CONTROL SYSTEMS. ITE Journal 71. 
Khan, A.M., Whelen, M., Snobar, N., Elsafdi, O., Jones, B., Arnold, P., 2016. Enhancing Resilience Of Traffic Networks With Connected Vehicles. Canadian Society for Civil Engineering 11.

Khan, M.A., Ectors, W., Bellemans, T., Janssens, D., Wets, G., 2017. Unmanned Aerial Vehicle-Based Traffic Analysis. Transportation Research Record: Journal of the Transportation Research Board 2626, 25-33. https://doi.org/10.3141/2626-04

Kopardekar, P.H., 2014. Unmanned Aerial System (UAS) Traffic Management (UTM): Enabling Low-Altitude Airspace and UAS Operations.

Kurth, D., van den Hout, A., Ives, B., 1996. Implementation of Highway Capacity Manual-Based Volume-Delay Functions in Regional Traffic Assignment Process. Transportation Research Record: Journal of the Transportation Research Board 1556, 27-37. https://doi.org/10.3141/1556-05

Lopez, E., 2017. I-85 overpass collapse to cause months of congestion in GA. Supply Chain Dive.

MIOVISION, 2019. Traffic Data Online [WWW Document]. URL https://www.trafficdataonline.com/home.aspx (accessed 1.22.20).

Mitsakis, E., Salanova, J.M., Giannopoulos, G., 2011. Combined dynamic traffic assignment and urban traffic control models. Procedia - Social and Behavioral Sciences 20, 427-436. https://doi.org/10.1016/j.sbspro.2011.08.049

Mtoi, E.T., Moses, R., 2014. Calibration and Evaluation of Link Congestion Functions: Applying Intrinsic Sensitivity of Link Speed as a Practical Consideration to Heterogeneous Facility Types within Urban Network. Journal of Transportation Technologies 2014. https://doi.org/10.4236/jtts.2014.42014

Mucsi, K., Khan, A.M., Ahmadi, M., 2011. An Adaptive Neuro-Fuzzy Inference System for estimating the number of vehicles for queue management at signalized intersections. Transportation Research Part C: Emerging Technologies 19, 10331047. https://doi.org/10.1016/j.trc.2011.05.016

Murray-Tuite, P., Mahmassani, H., 2004. Methodology for Determining Vulnerable Links in a Transportation Network. Transportation Research Record: Journal of the Transportation Research Board 1882, 88-96. https://doi.org/10.3141/1882-11

Murray-tuite, P.M., 2006. A Comparison of Transportation Network Resilience under Simulated System Optimum and User Equilibrium Conditions, in: Proceedings of the 2006 Winter Simulation Conference. Presented at the Proceedings of the 2006 Winter Simulation Conference, pp. 1398-1405. https://doi.org/10.1109/WSC.2006.323240

National Academies of Sciences, E., 2015. Signal Timing Manual - Second Edition. https://doi.org/10.17226/22097 
Oak Ridge National Laboratory [WWW Document], n.d. . National Transportation Research Center. URL https://www.ornl.gov/facility/ntrc (accessed 1.21.20).

Public Works and Government Services Canada, 2016. Turning Movement Count - Peak Hour Diagram. Ottawa

Ouyang, M., Dueñas-Osorio, L., Min, X., 2012. A three-stage resilience analysis framework for urban infrastructure systems. Structural Safety 36-37, 23-31. https://doi.org/10.1016/j.strusafe.2011.12.004

Pline, J.L., Institute of Transportation Engineers, 1999. Traffic engineering handbook. Institute of Transportation Engineers, Washington, D.C.

PTV AG, 2019. PTV VISUM 18 Manual. Karlsruhe, Germany

PTV AG, 2018. PTV VISSIM 11 User Manual. Karlsruhe, Germany

Puri, A., 2005. A survey of unmanned aerial vehicles (UAV) for traffic surveillance. Department of computer science and engineering, University of South Florida 129.

Rose, A., 2004. Defining and measuring economic resilience to disasters. Disaster Prev and Management 13, 307-314. https://doi.org/10.1108/09653560410556528

Schnurr, J., 2017. Ottawa 4th most congested city in Canada according to study. CTV.

Skabardonis, A., Dowling, R., 1997. Improved Speed-Flow Relationships for Planning Applications. Transportation Research Record: Journal of the Transportation Research Board 1572, 18-23. https://doi.org/10.3141/1572-03

Srinivasan, S., Latchman, H., Shea, J., Wong, T., McNair, J., 2004. Airborne Traffic Surveillance Systems: Video Surveillance of Highway Traffic, in: Proceedings of the ACM 2Nd International Workshop on Video Surveillance \& Sensor Networks, VSSN '04. ACM, New York, NY, USA, pp. 131-135. https://doi.org/10.1145/1026799.1026821

Ta, C., Goodchild, A.V., Pitera, K., 2009. Structuring a Definition of Resilience for the Freight Transportation System. Transportation Research Record 2097, 19-25. https://doi.org/10.3141/2097-03

Technical Activities Division, Transportation Research Board, National Academies of Sciences, Engineering, and Medicine, 2011. Dynamic Traffic Assignment: A Primer. Transportation Research Board, Washington, D.C. https://doi.org/10.17226/22872

THE CANADIAN PRESS, 2017. Flood fighting continues in Central, Eastern and Western Canada. The Chronicle Herald. 
Tian, Z., Lin, D., Yin, K., 2014. Development of a Dynamic Traffic Assignment Model for Northern Nevada (No. FINAL REPORT). Center for Advanced Transportation Education and Research (CATER), University of Nevada, Reno.

Traffic Engineering VISSIM Modeling Guidance, n.d. . Louisiana Department of Transportation \& Development.

Transportation Research Board, ECONorthwest, 2002. Estimating The Benefits And Costs Of Public Transit Projects: A Guidebook For Practitioners. TCRP Report.

TRB, 1999. NCHRP 3-55(2)A PLANNING APPLICATIONS FOR THE YEAR 2000 HIGHWAY CAPACITY MANUAL - APPENDIX A: LITERATURE REVIEW.

University of Florida Transportation Institute, n.d. TRANSYT-7F $\mathrm{F}^{\mathrm{TM}}$ [WWW Document]. McTrans. URL https://mctrans.ce.ufl.edu/mct/index.php/hcs/transyt7f/ (accessed 1.21.20).

U.S DOT, 2004. Chapter 12 - Signalized Intersections: Informational Guide, August 2004 - FHWA-HRT-04-091 [WWW Document]. Federal Highway Administration Research and Technology. URL https://www.fhwa.dot.gov/publications/research/safety/04091/12.cfm (accessed 1.21.20).

Victoria Transport Policy Institute, 2017. Evaluating Transportation resilience: Evaluating The Transportation System's Ability To Accommodate Diverse, Variable and Unexpected Demands With Minimal Risk [WWW Document]. URL http://www.vtpi.org/tdm/tdm88.htm (accessed 8.21.18).

VISSIM Calibration Settings, 2018.

Wang, J.W., Wang, H.F., Zhang, W.J., Ip, W.H., Furuta, K., 2013. Evacuation Planning Based on the Contraflow Technique With Consideration of Evacuation Priorities and Traffic Setup Time. IEEE Trans. Intell. Transport. Syst. 14, 480-485. https://doi.org/10.1109/TITS.2012.2204402

Wiedemann, R., 1974. Simulation des Straßenverkehrsflusses. Univ., Inst. für Verkehrswesen, Karlsruhe.

Wise, J.A., Hopkin, V.D., Gibson, R.S., Stager, P., Stubler, W.F., 1993. Verification and Validation of Complex Systems: Human Factors Issues. Proceedings of the Human Factors and Ergonomics Society Annual Meeting 37, 1165-1169. https://doi.org/10.1177/154193129303701709

Yekhshatyan, L., Schnell, T., 2008. Turn Lane Lengths for Various Speed Roads and Evaluation of Determining Criteria (Final Report No. MN/RC 2008-14). Minnesota Department of Transportation. 
Zhu, S., Levinson, D., 2015. Do People Use the Shortest Path? An Empirical Test of Wardrop's First Principle. PLOS ONE 10, e0134322. https://doi.org/10.1371/journal.pone.0134322

Zi-lei, W., Chang-qiao, S., Jian, R., 2010. Analysis of Vehicle Running Speed and Its Influencing Factors on Urban Major Streets. ICCTP 2010, Proceedings. https://doi.org/10.1061/41127(382)197 


\section{APPENDIX-A}

\section{IMPORTANT PARAMETERS IN PTV-VISSIM}

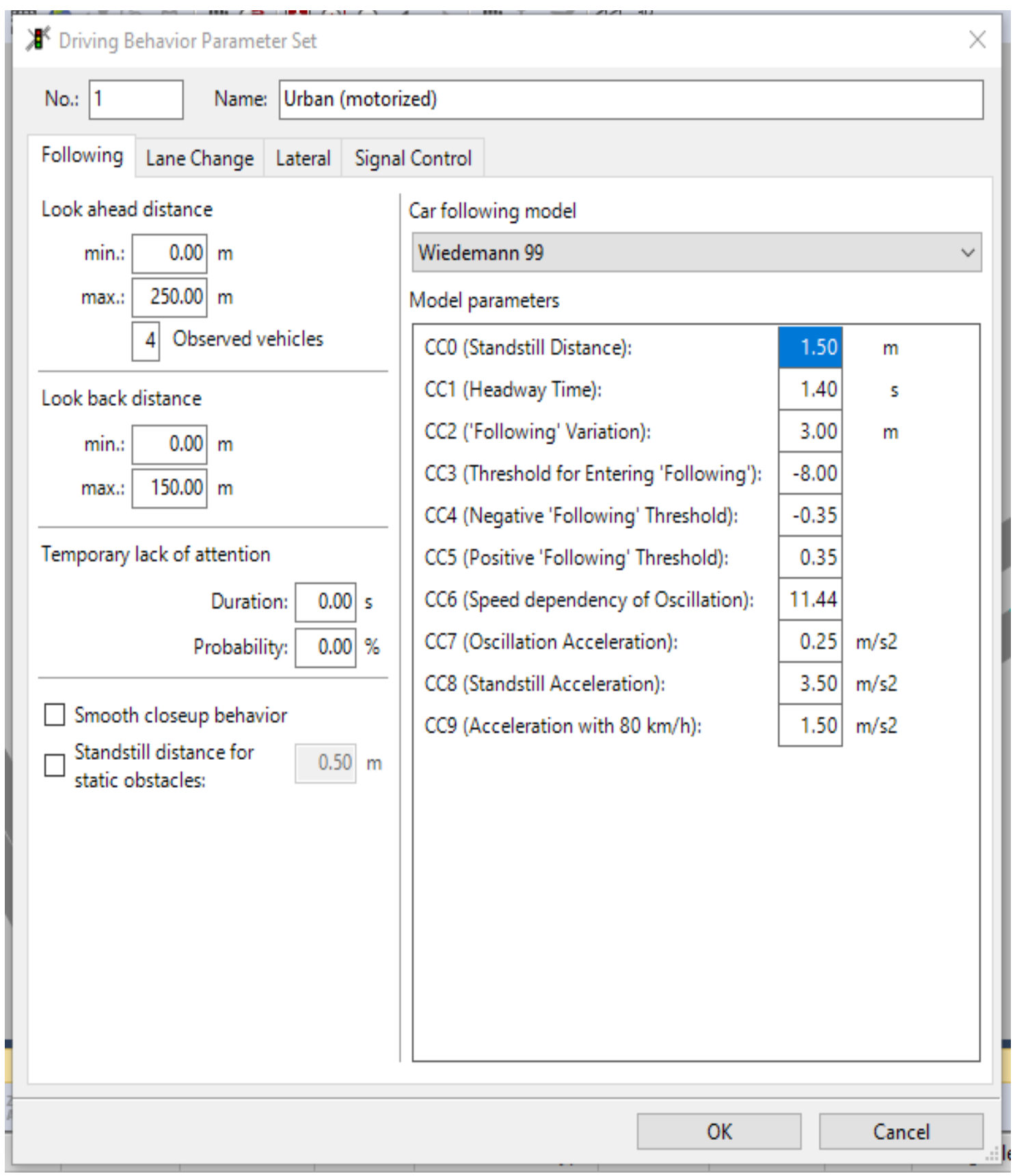

Figure 1: Driving Behaviour Parameter Set in Vissim (Wiedemann, 1974) 


\begin{tabular}{|c|c|}
\hline Parameters & Description \\
\hline $\begin{array}{l}\text { CC0 } \\
\text { (Standstill } \\
\text { Distance) }\end{array}$ & $\begin{array}{l}\text { the average desired standstill distance between two vehicles. It has no } \\
\text { variation. }\end{array}$ \\
\hline $\begin{array}{l}\text { CC1 } \\
\text { (Headway } \\
\text { Time) }\end{array}$ & $\begin{array}{l}\text { It is the distance in seconds which a driver wants to maintain at a certain } \\
\text { speed. The higher the value, the more cautious the driver is. Thus, at a given } \\
\text { speed } v[\mathrm{~m} / \mathrm{s}] \text {, the average safety distance is computed as: } \\
d x_{s a f e}=\mathrm{CCO}+\mathrm{CCl} \cdot v \\
\text { The safety distance is defined in the car following model as the minimum } \\
\text { distance a driver will maintain while following another vehicle. In case of high } \\
\text { volumes this distance becomes the value which has a determining influence } \\
\text { on capacity. }\end{array}$ \\
\hline $\mathrm{CC} 2$ & $\begin{array}{l}\text { It restricts the distance difference (longitudinal oscillation) or how much more } \\
\text { distance than the desired safety distance a driver allows before he intentionally } \\
\text { moves closer to the car in front. If this value is set to e.g. } 10 \mathrm{~m} \text {, the following } \\
\text { behavior results in distances between } d x_{\text {safe }} \text { and } d x_{\text {safe }}+10 \mathrm{~m} \text {. The default value } \\
\text { is } 4.0 \mathrm{~m} \text { which results in a quite stable following behavior. }\end{array}$ \\
\hline $\mathrm{CC} 3$ & $\begin{array}{l}\text { It controls the start of the deceleration process, i.e. the number of seconds } \\
\text { before reaching the safety distance. At this stage the driver recognizes a } \\
\text { preceding slower vehicle. }\end{array}$ \\
\hline CC4 & $\begin{array}{l}\text { defines negative speed difference during the following process. } \\
\text { Low values result in a more sensitive driver reaction to the acceleration or } \\
\text { deceleration of the preceding vehicle. }\end{array}$ \\
\hline $\mathrm{CC} 5$ & $\begin{array}{l}\text { defines positive speed difference during the following process. Enter a positive } \\
\text { value for } \mathrm{CC} 5 \text { which corresponds to the negative value of } \mathrm{CC} 4 \text {. Low values } \\
\text { result in a more sensitive driver reaction to the acceleration or deceleration of } \\
\text { the preceding vehicle. }\end{array}$ \\
\hline CC6 & $\begin{array}{l}\text { Influence of distance on speed oscillation while in following process. } \\
\text { Value } 0 \text { : If set to } 0 \text { the speed oscillation is independent of the distance } \\
\text { Larger values: Larger values lead to a greater speed oscillation with } \\
\text { increasing distance. }\end{array}$ \\
\hline $\mathrm{CC} 7$ & Oscillation during acceleration \\
\hline $\mathrm{CC} 8$ & $\begin{array}{l}\text { Desired acceleration when starting from standstill (limited by maximum } \\
\text { acceleration defined within the acceleration curves). }\end{array}$ \\
\hline CC9 & $\begin{array}{l}\text { Desired acceleration at } 80 \mathrm{~km} / \mathrm{h} \text { (limited by maximum acceleration defined } \\
\text { within the acceleration curves). }\end{array}$ \\
\hline
\end{tabular}

Figure 2: Driving Behaviour Parameter Set in Vissim Description (Vissim, 2018) 
The Following figures lists traffic signals programs for different intersections used for Case 1 and Case 2 of inherent resilience analysis, Chapter 6 for different intersections
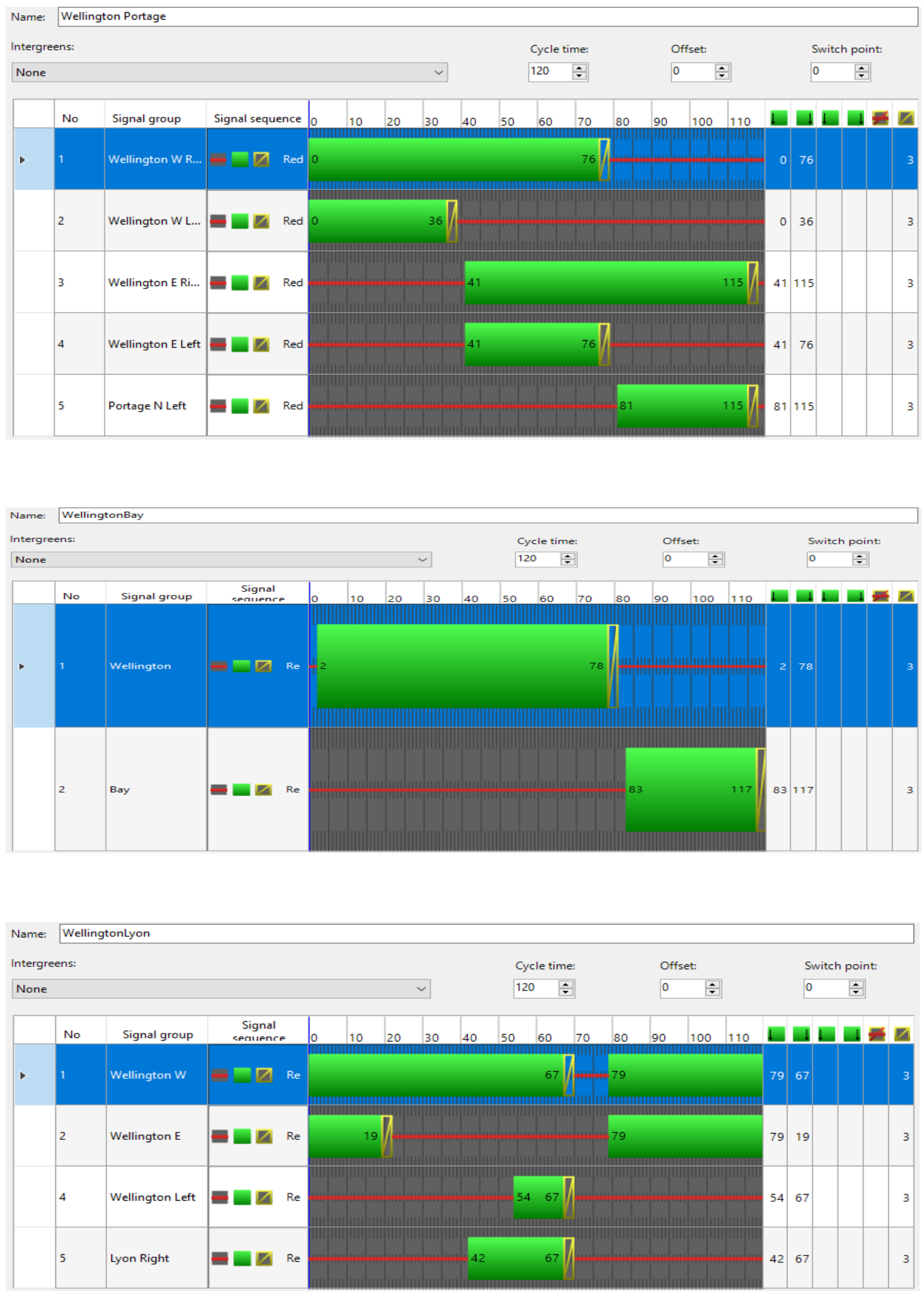

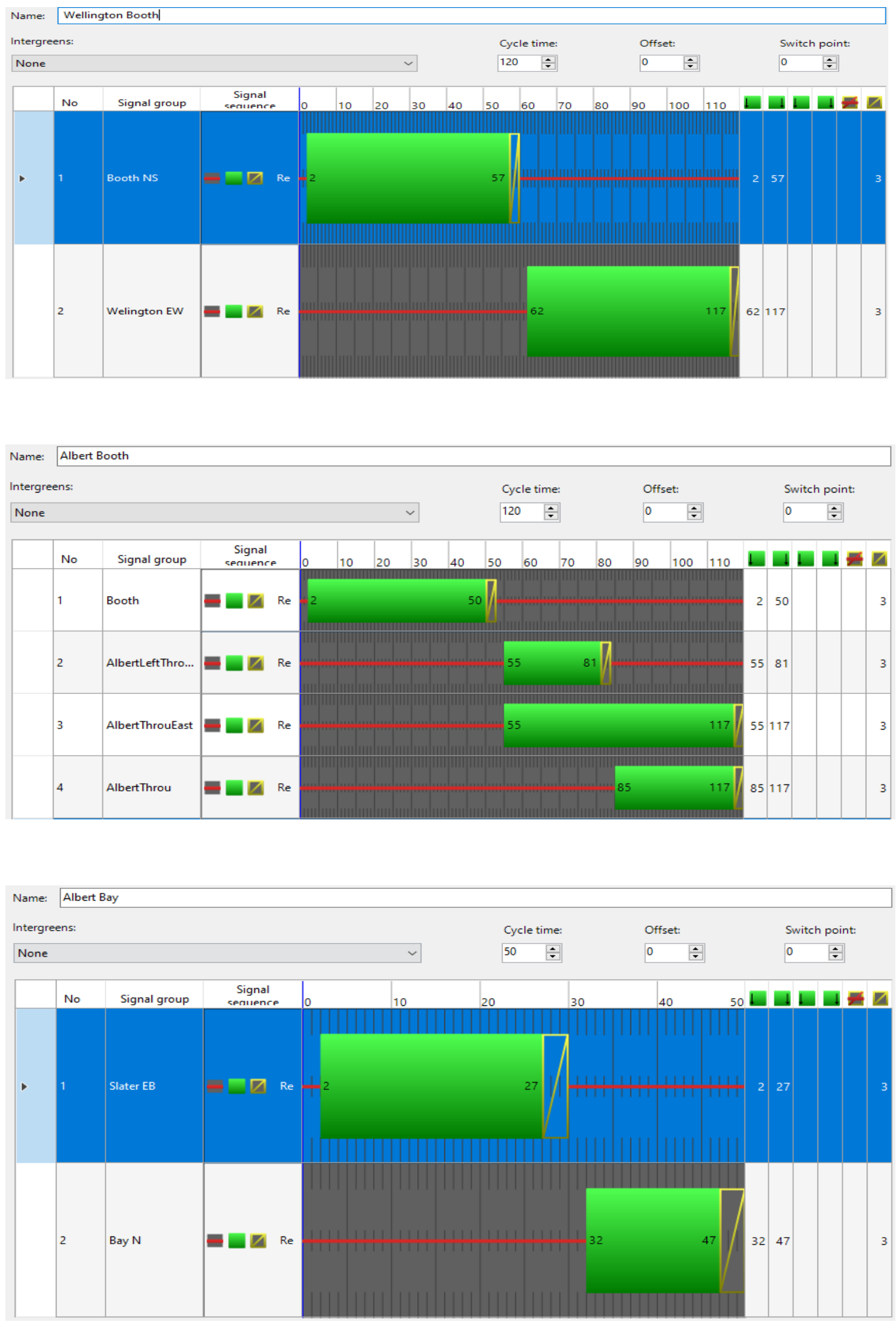

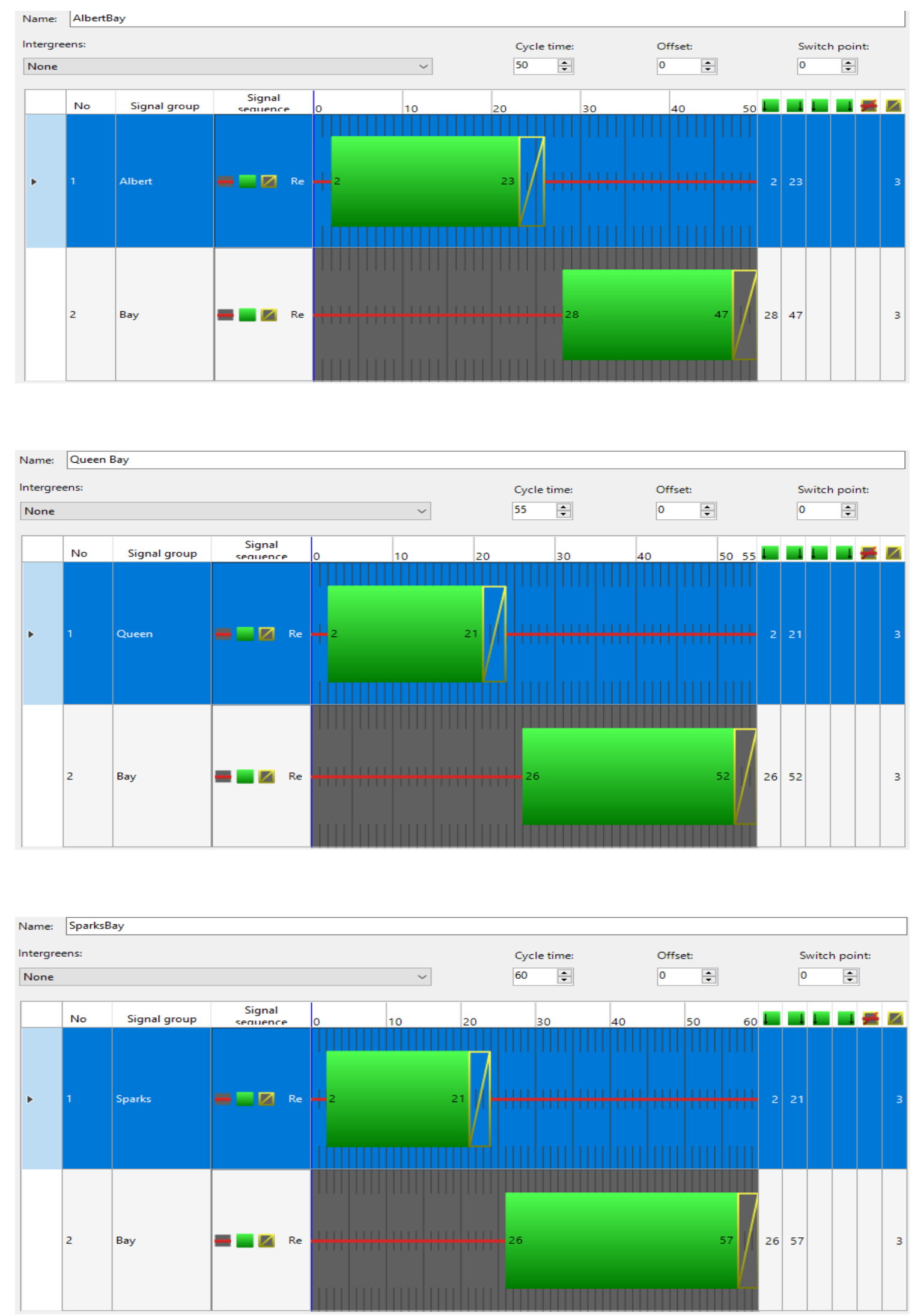

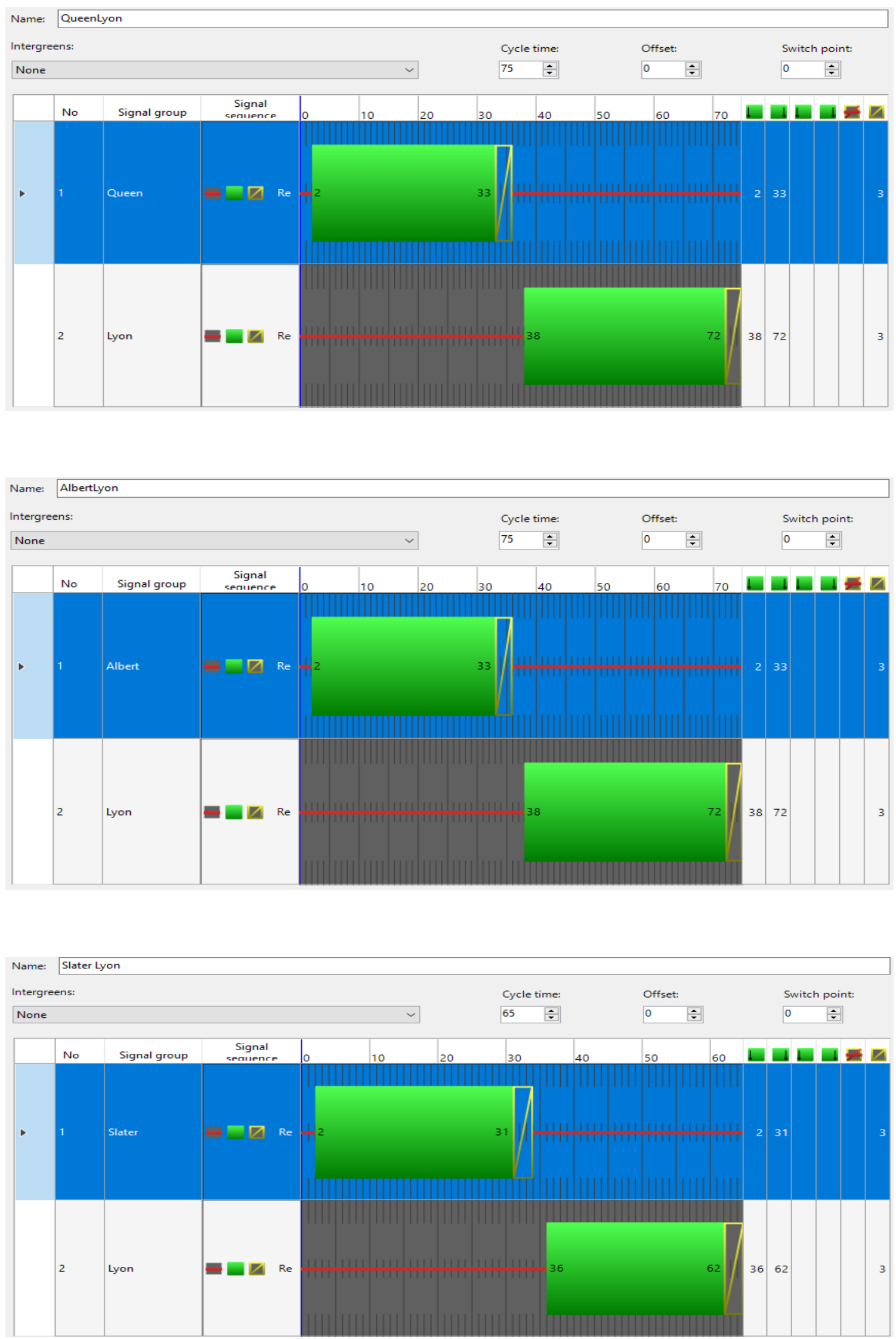

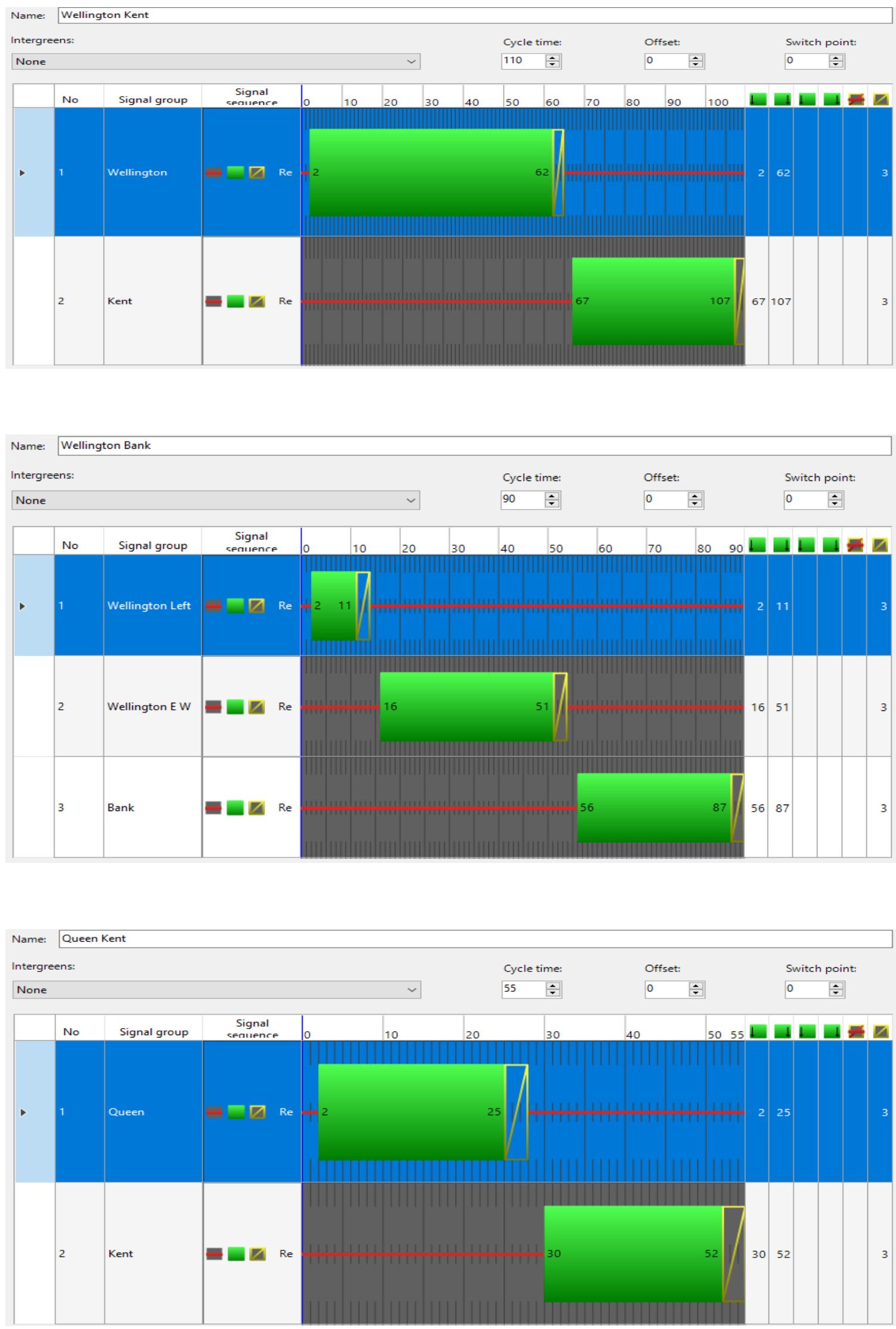

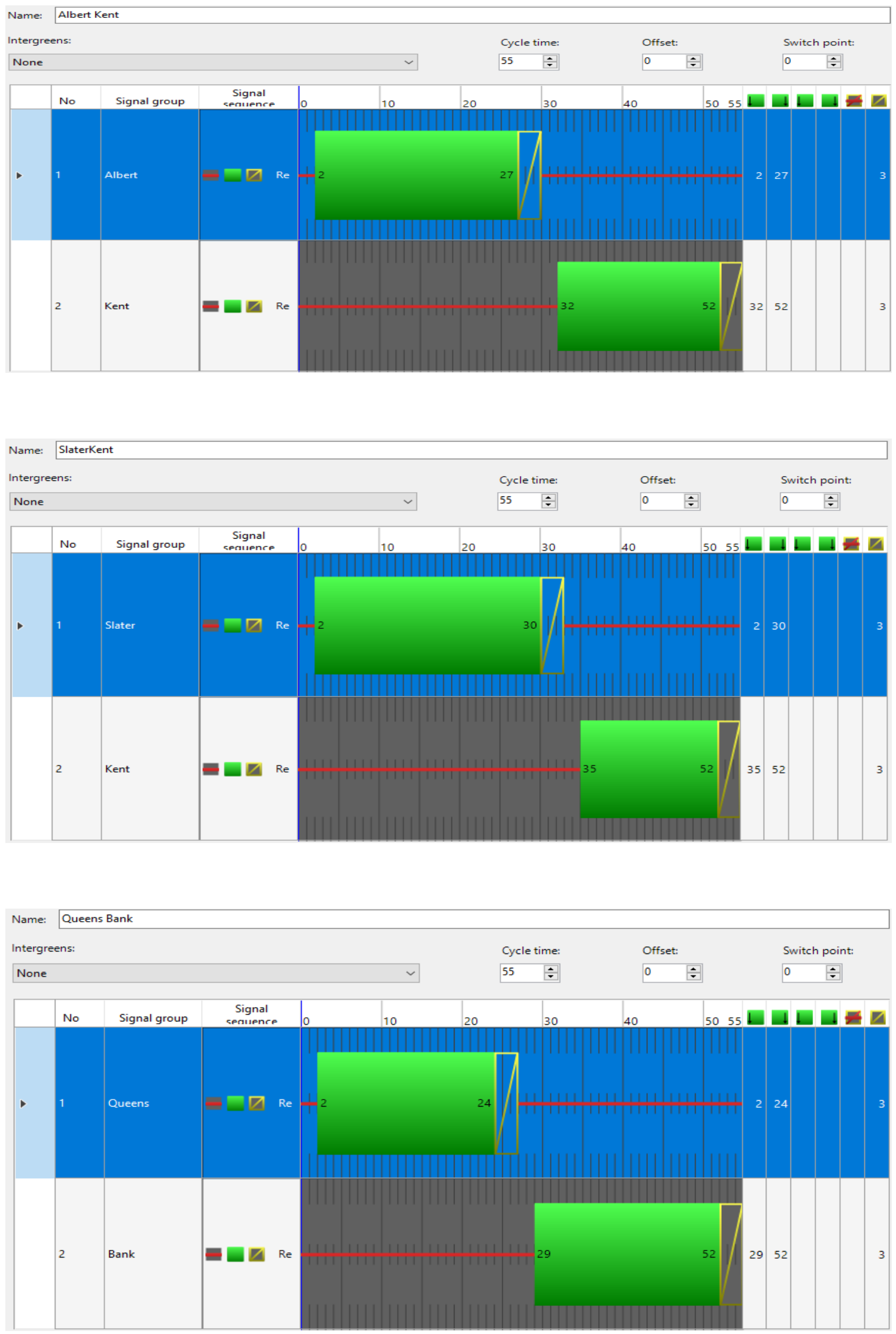

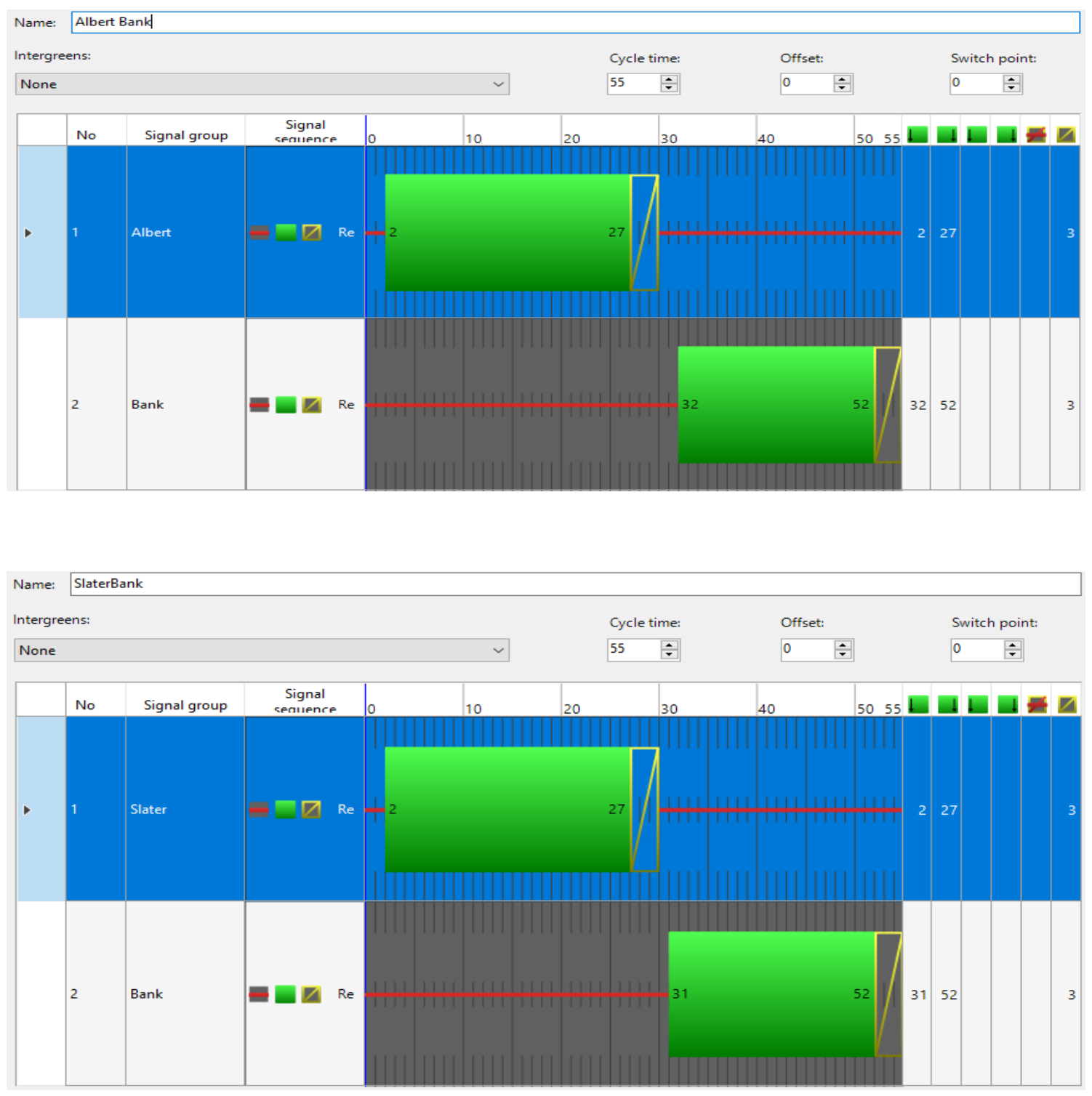

Name: Slater Bronson Intersection

\begin{tabular}{|c|c|c|c|c|c|c|c|}
\hline \multicolumn{2}{|l|}{ Intergreens: } & \multicolumn{2}{|c|}{ Cycle time: } & \multicolumn{2}{|c|}{ Offset: } & \multicolumn{2}{|c|}{ Switch point: } \\
\hline None & $\sim$ & 60 & $\div$ & 0 & $\div$ & 0 & $\div$ \\
\hline
\end{tabular}

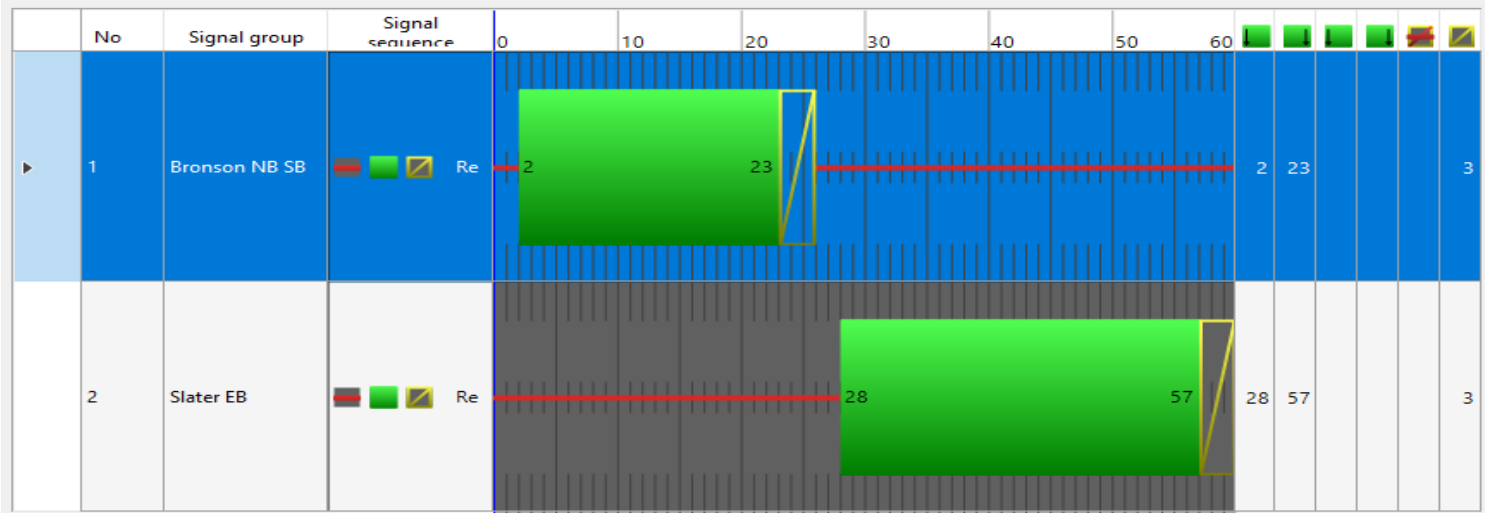




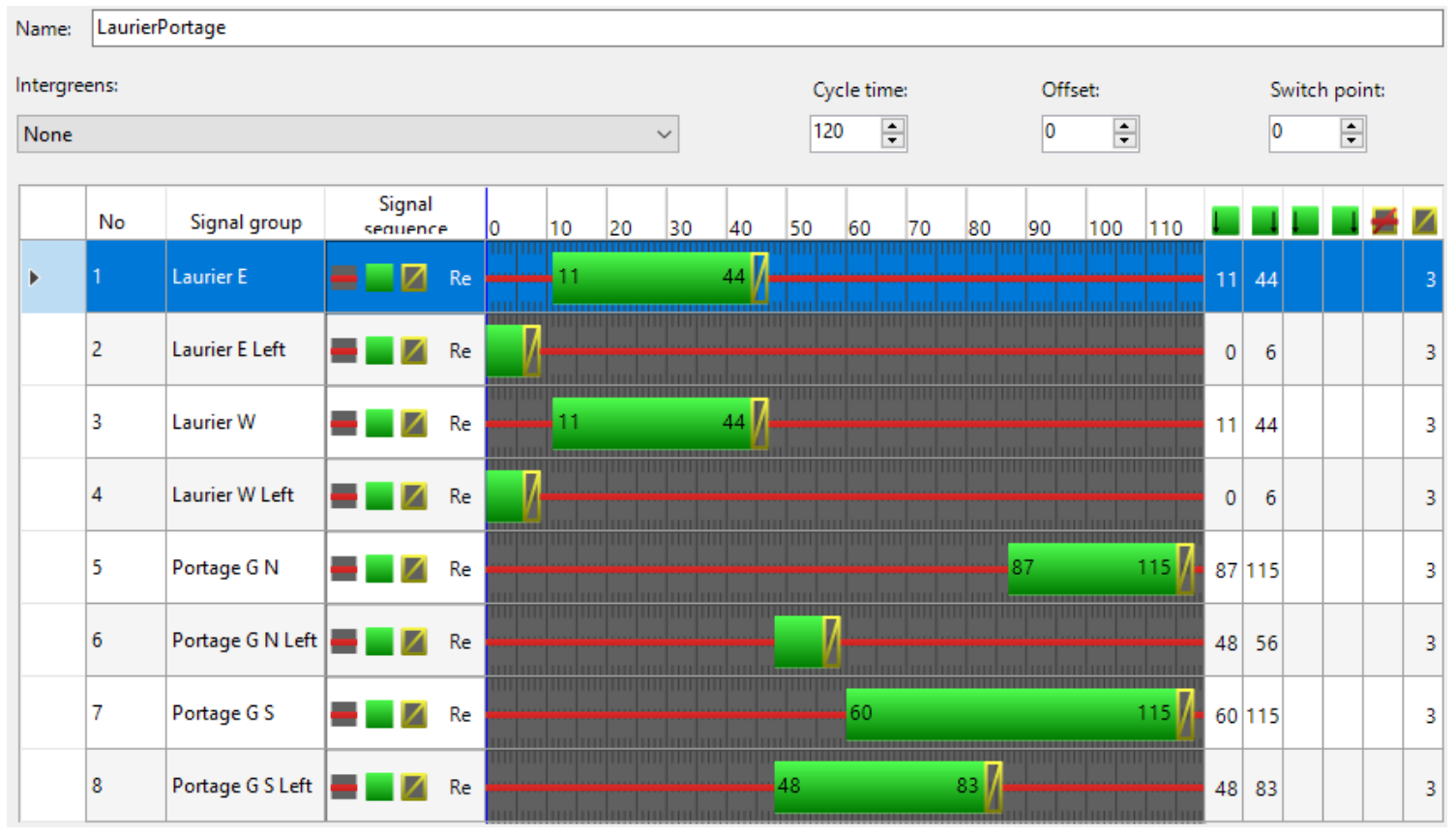




\section{APPENDIX B}

\section{TURNING MOVEMENT COUNTS FOR INTERSECTIONS USED IN CALCULATION OF RIGHT/ LEFT TURNING MOVEMENT IN OTTAWA}




\begin{tabular}{c} 
Public Works - Traffic Services \\
Turning Movement Count - Peak Hour Diagram \\
\hline BRONSON AVE @ COMMISSIONER ST/SLATER ST
\end{tabular}

Survey Date: Friday, May 27, 2011

Start Time: 07:00
WO No: $\quad 29749$

Device:

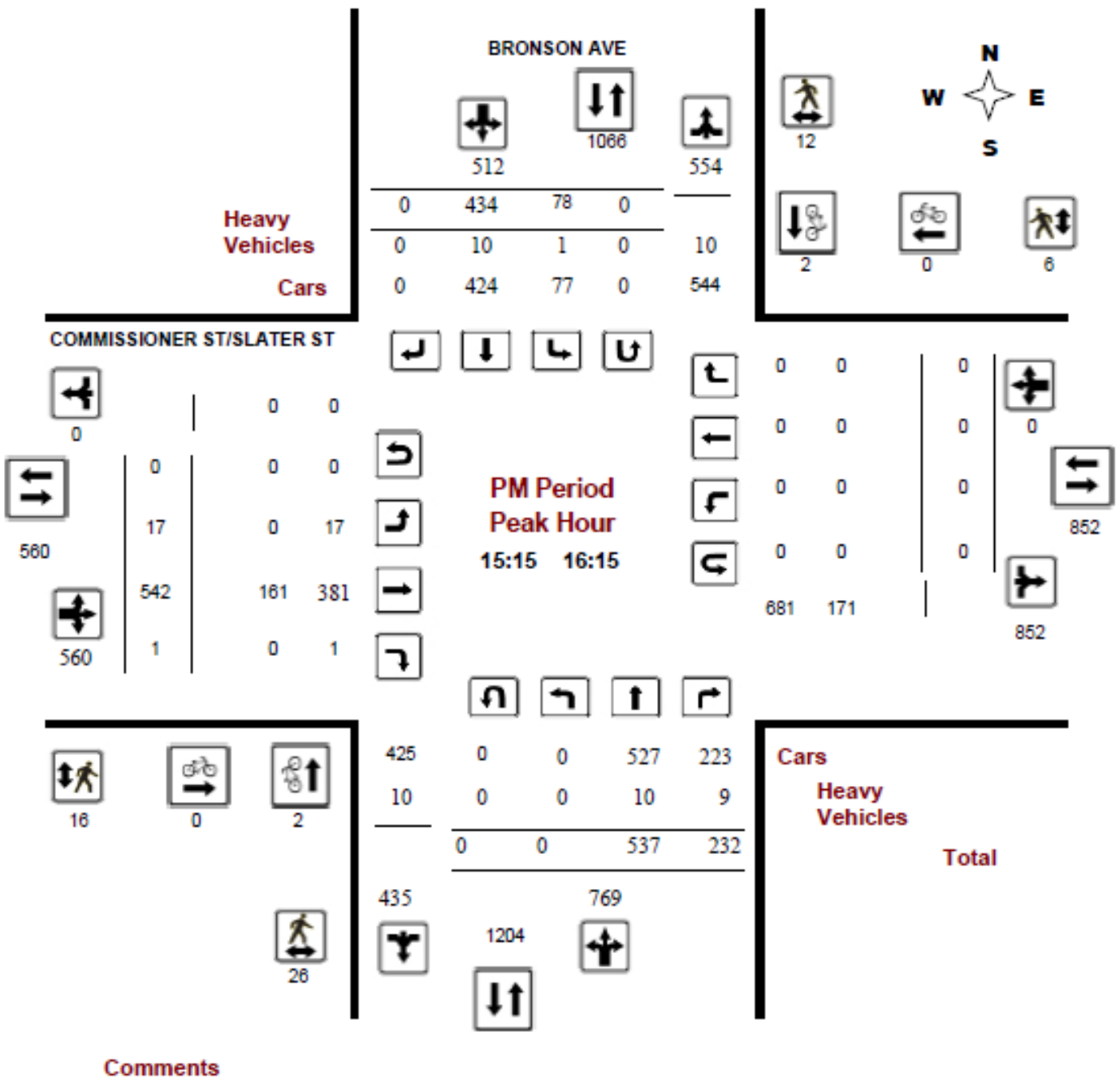




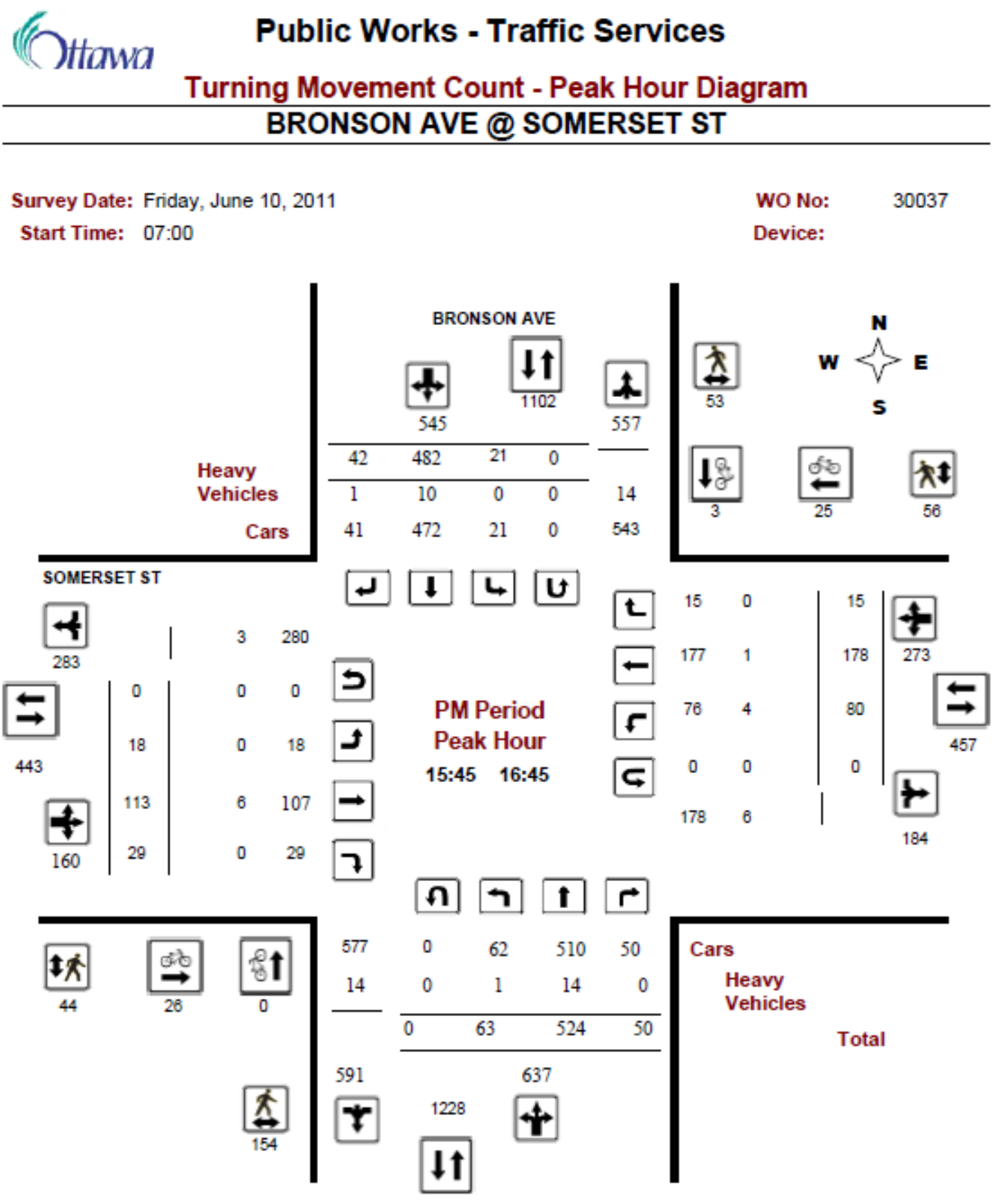

Comments 


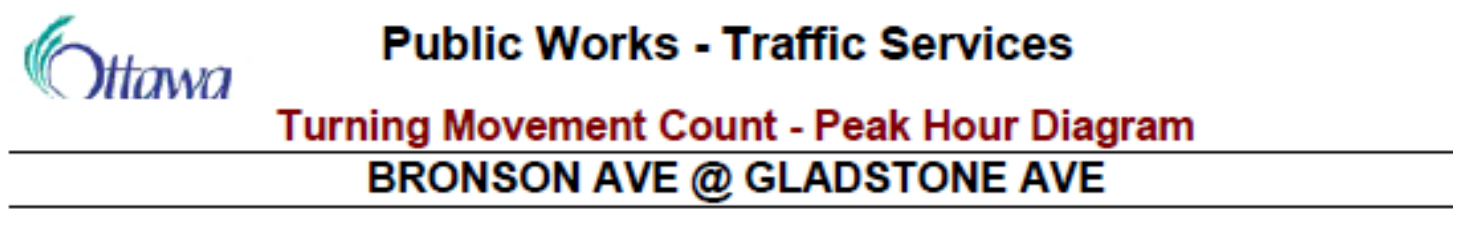

Survey Date: Monday, June 29, 2015

WO No: $\quad 34789$

Start Time: $07: 00$

Device: $\begin{gathered}\text { Jamar } \\ \text { Technologies, } \\ \text { Inc }\end{gathered}$

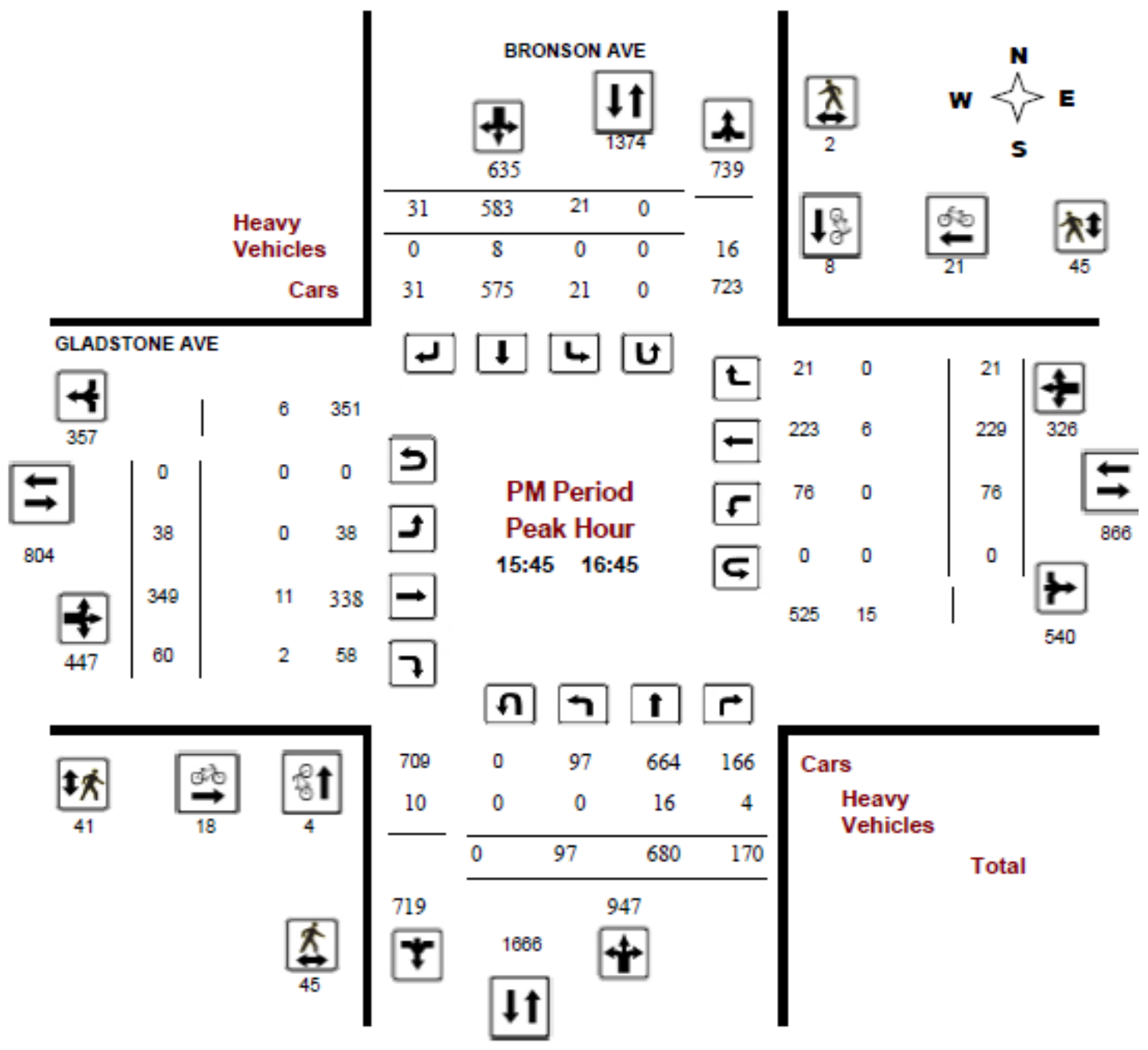

Comments 


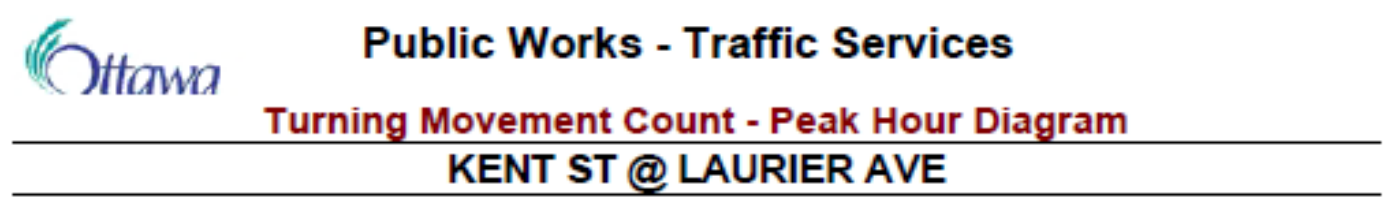

Survey Date: Thursday. June 14, 2012

WO No: $\quad 30709$

Start Time: $\quad$ 07:00

Device:

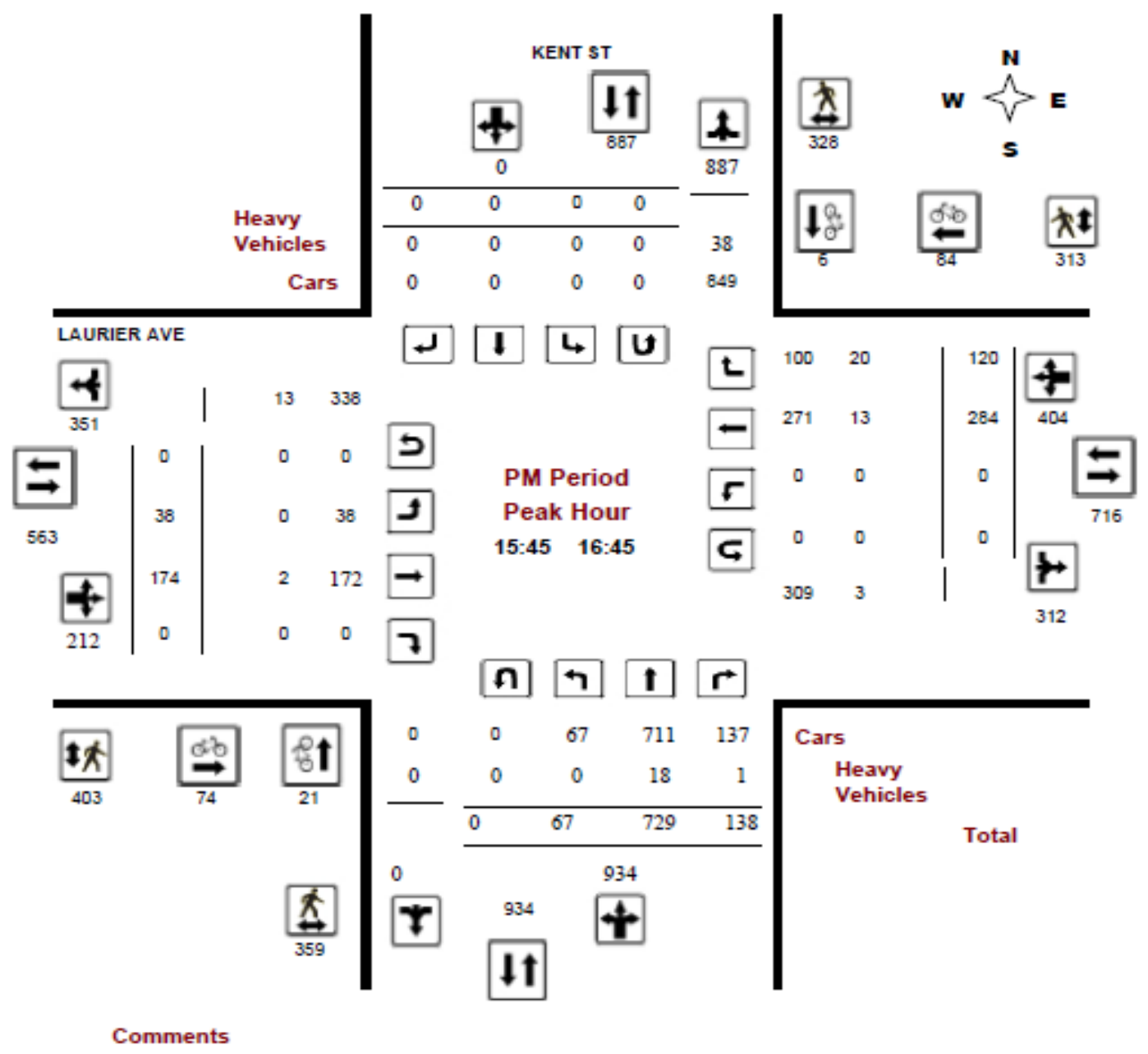




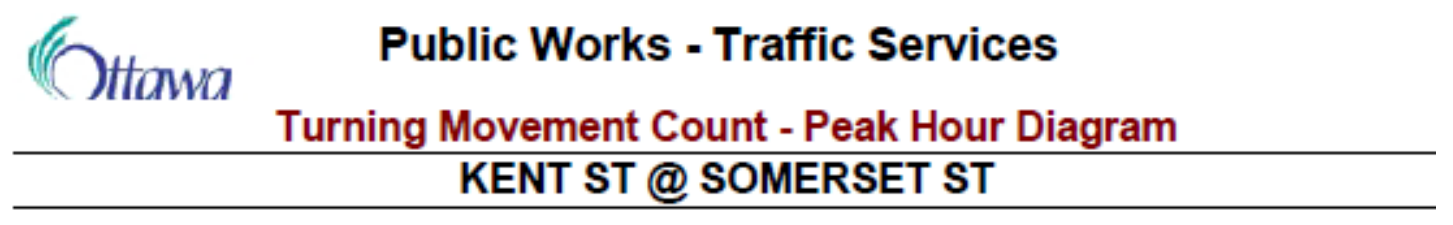

Survey Date: Monday, June 18, 2012

WO No: $\quad 30726$

Start Time: $\quad$ 07:00

Device:

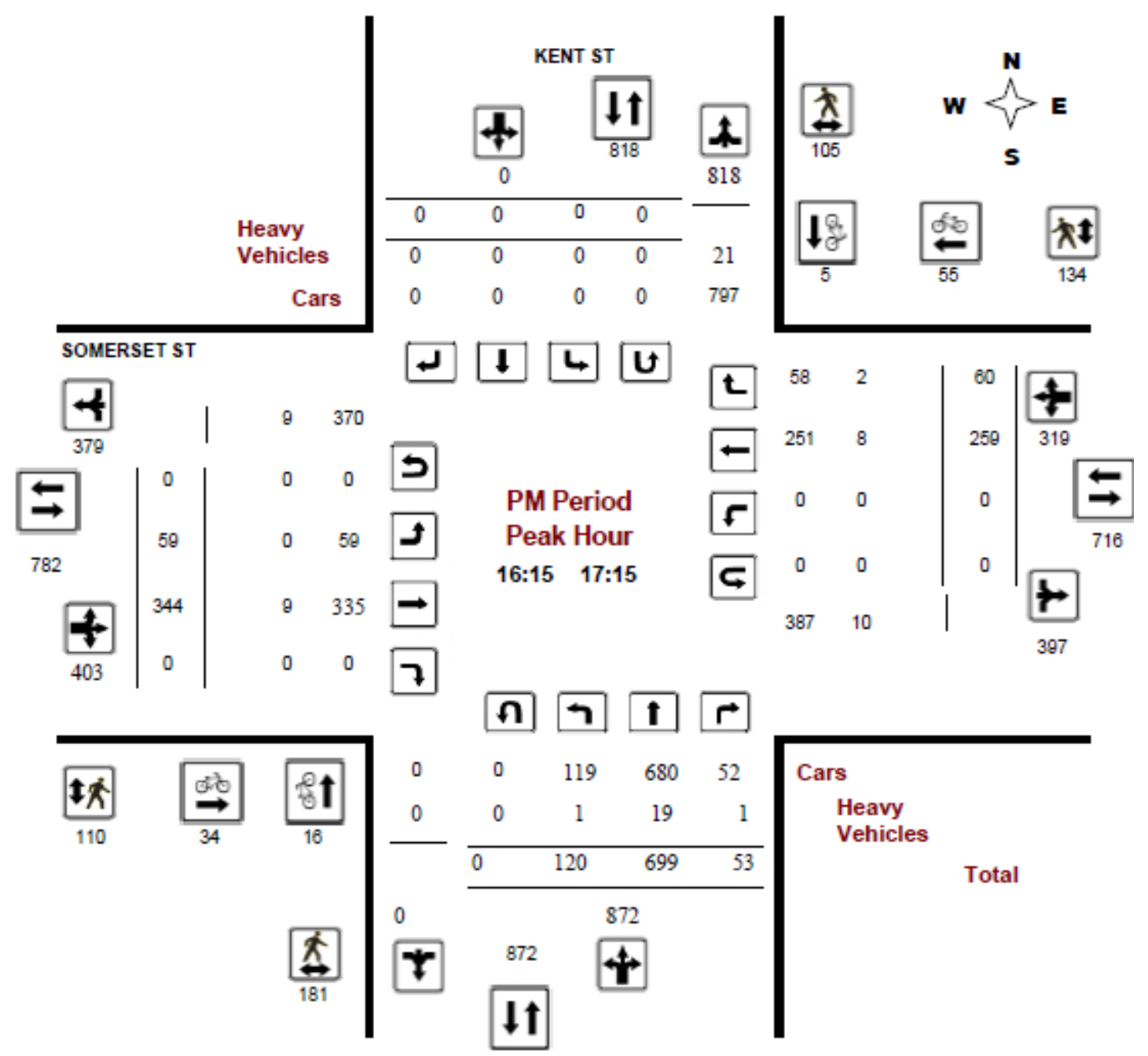

Comments 


\section{Public Works - Traffic Services \\ Turning Movement Count - Peak Hour Diagram \\ BANK ST @ WELLINGTON ST}

Survey Date: Wednesday, August 10, 2011

Start Time: 07:00
WO No: $\quad 30481$

Device:

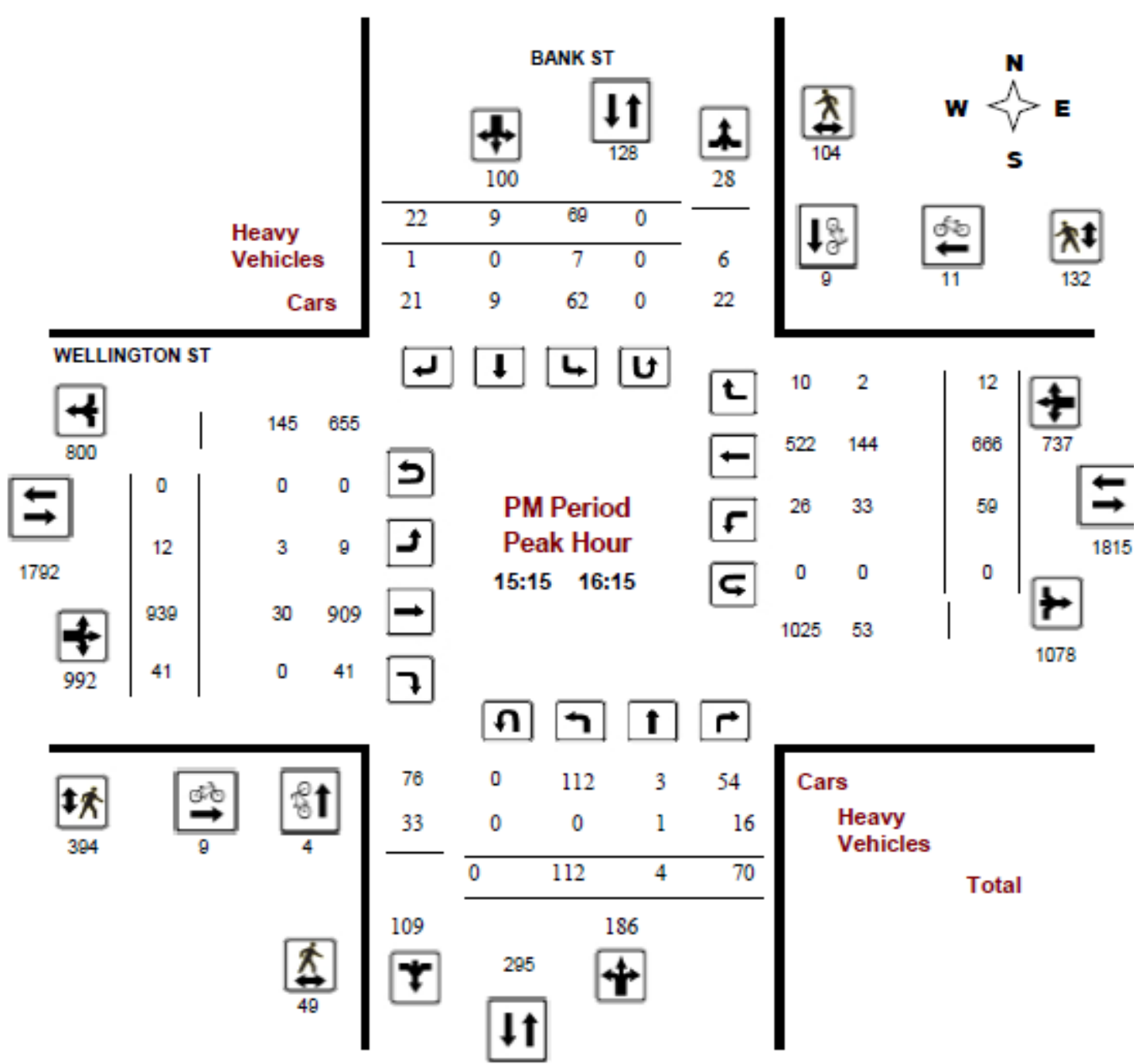

Comments 


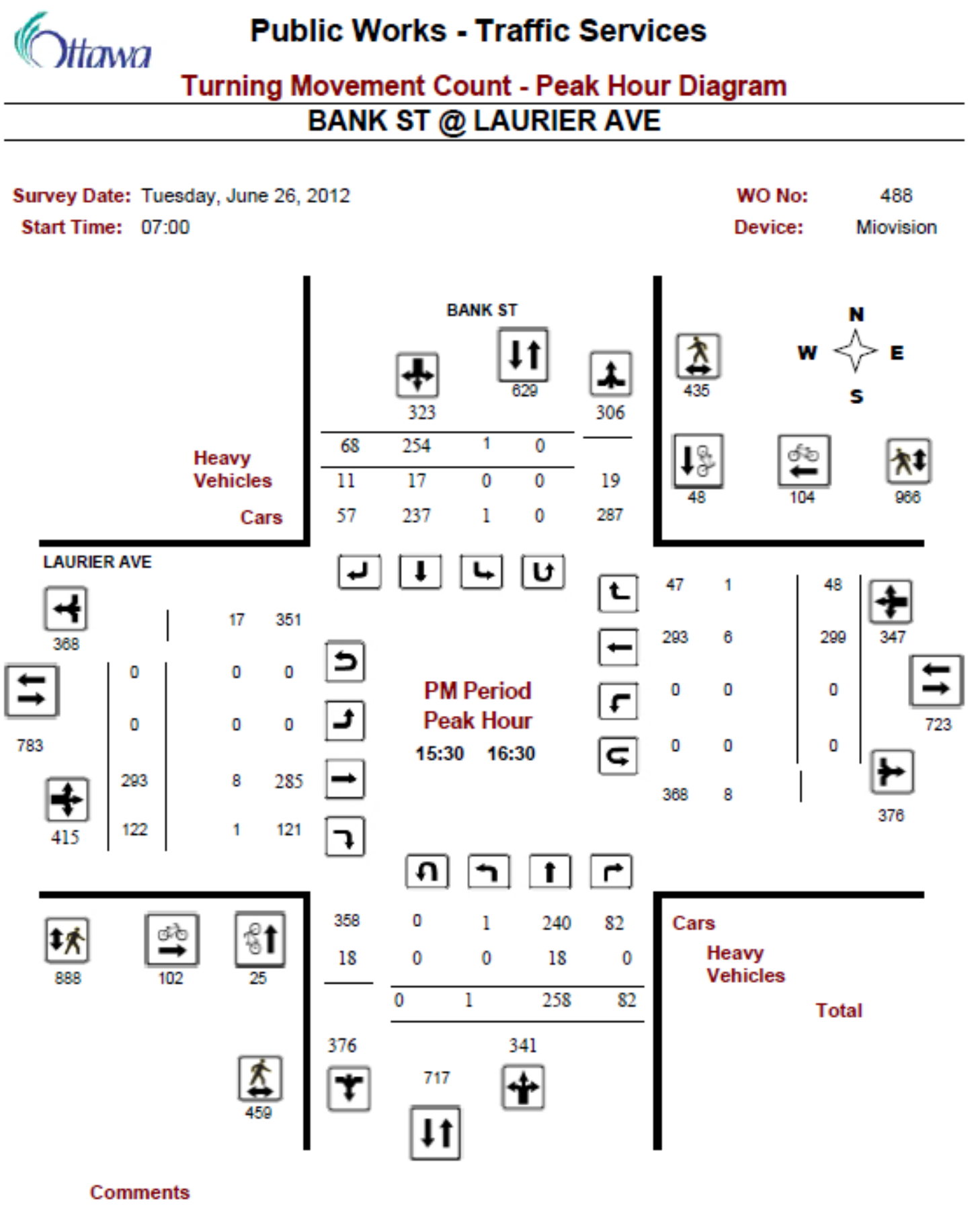




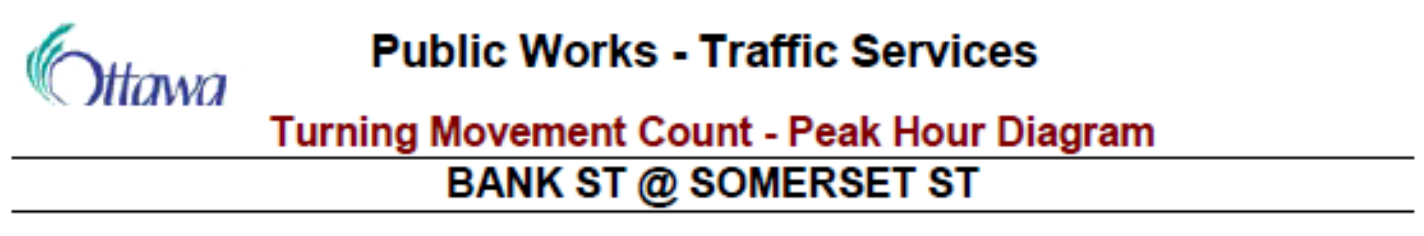

Survey Date: Thursday, August 02, 2012
Start Time: $07: 00$

WO No: $\quad 31033$

Device:

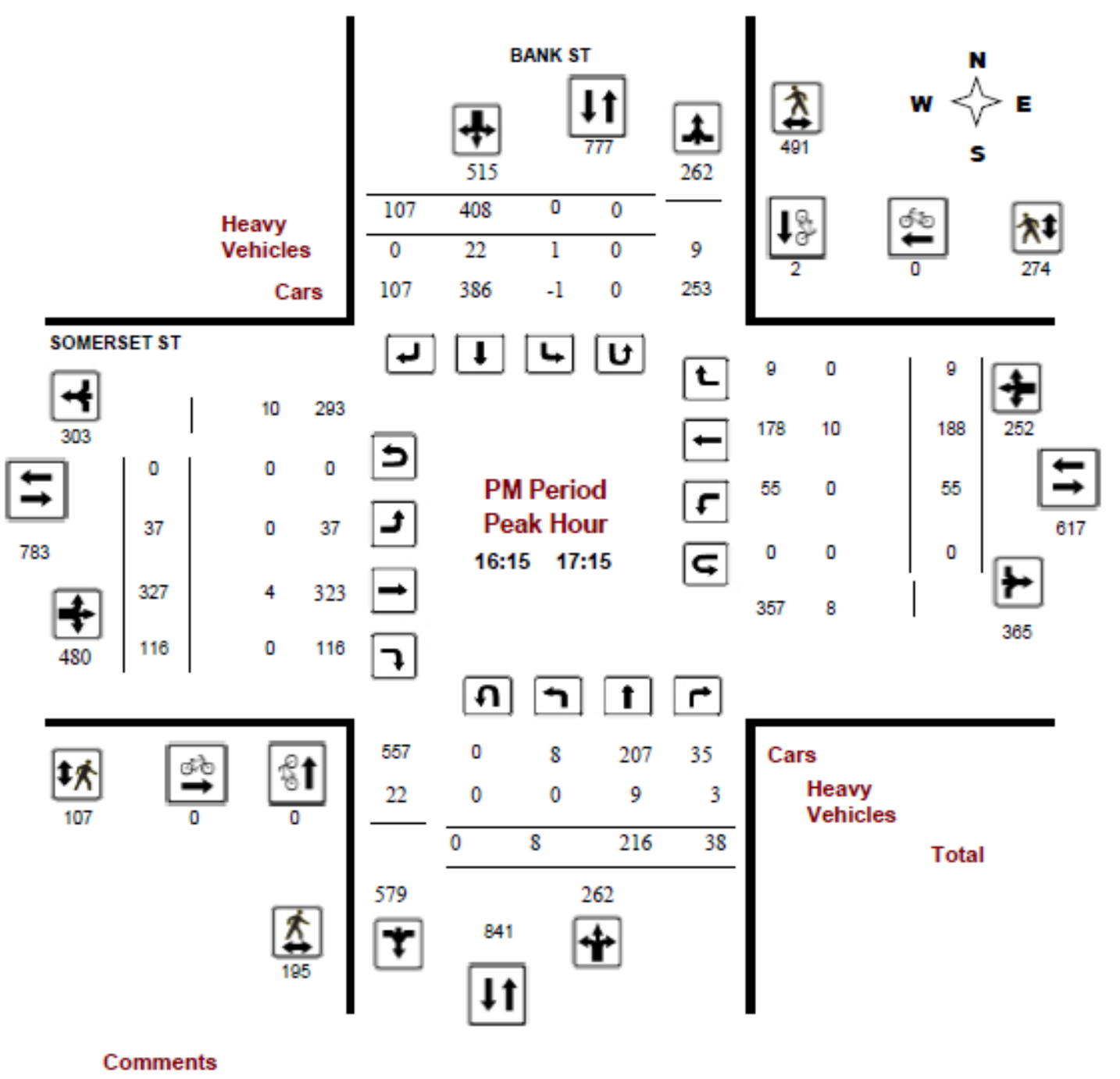




\section{( ) thawa \\ Public Works - Traffic Services \\ Turning Movement Count - Peak Hour Diagram \\ BANK ST @ GLADSTONE AVE}

Survey Date: Thursday, July 26, 2012

Start Time: 07:00
WO No: $\quad 30978$

Device:

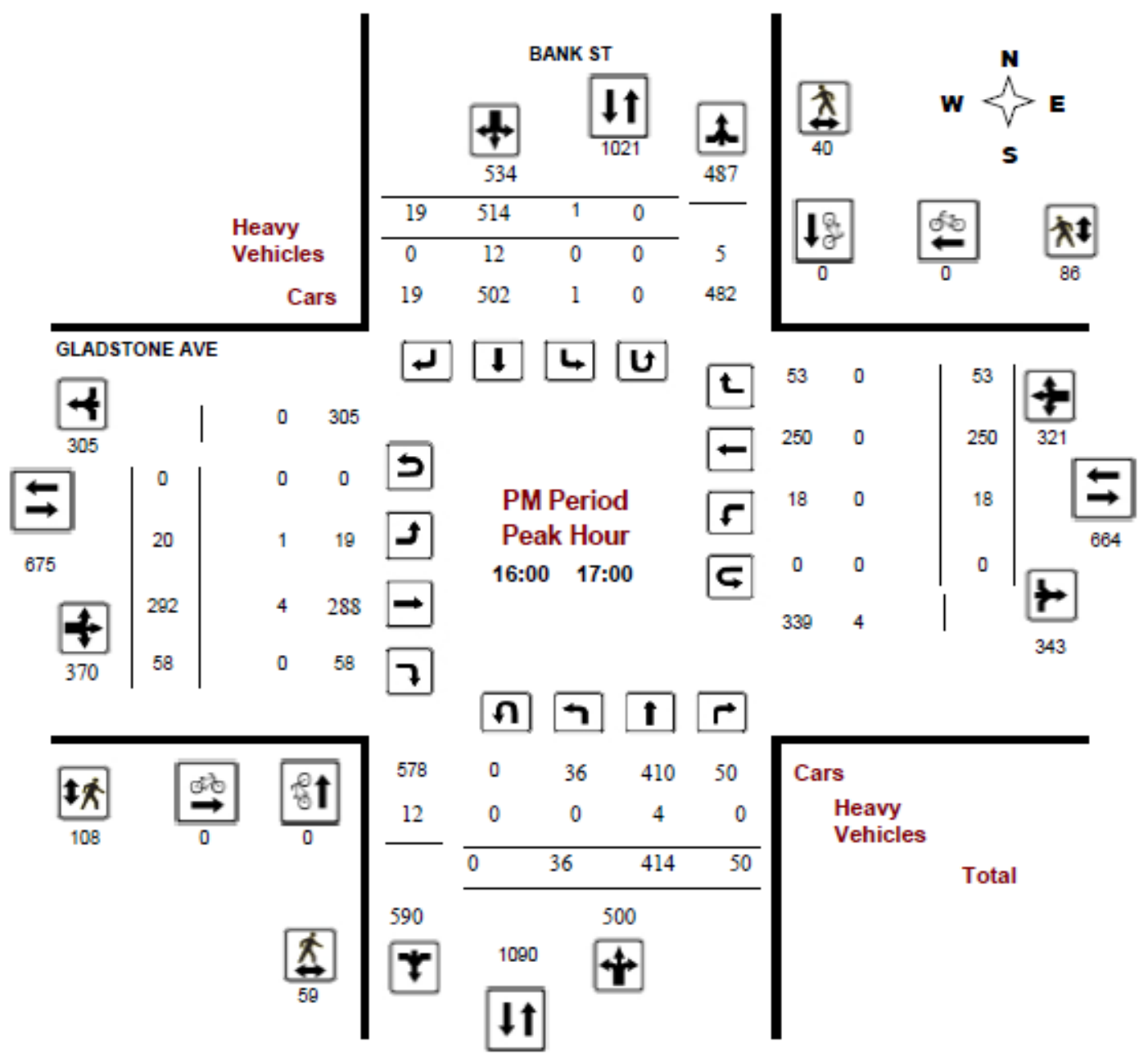

Comments 


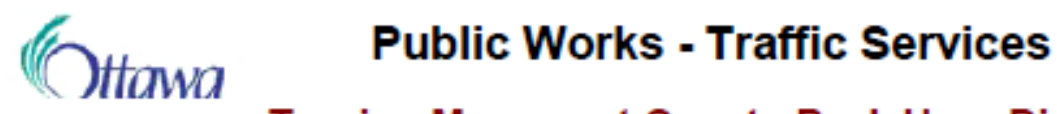

Turning Movement Count - Peak Hour Diagram

LAURIER AVE @ O'CONNOR ST

Survey Date: Wednesday, June 13, 2012

Start Time: 07:00

WO No: 504

Device: Miovision

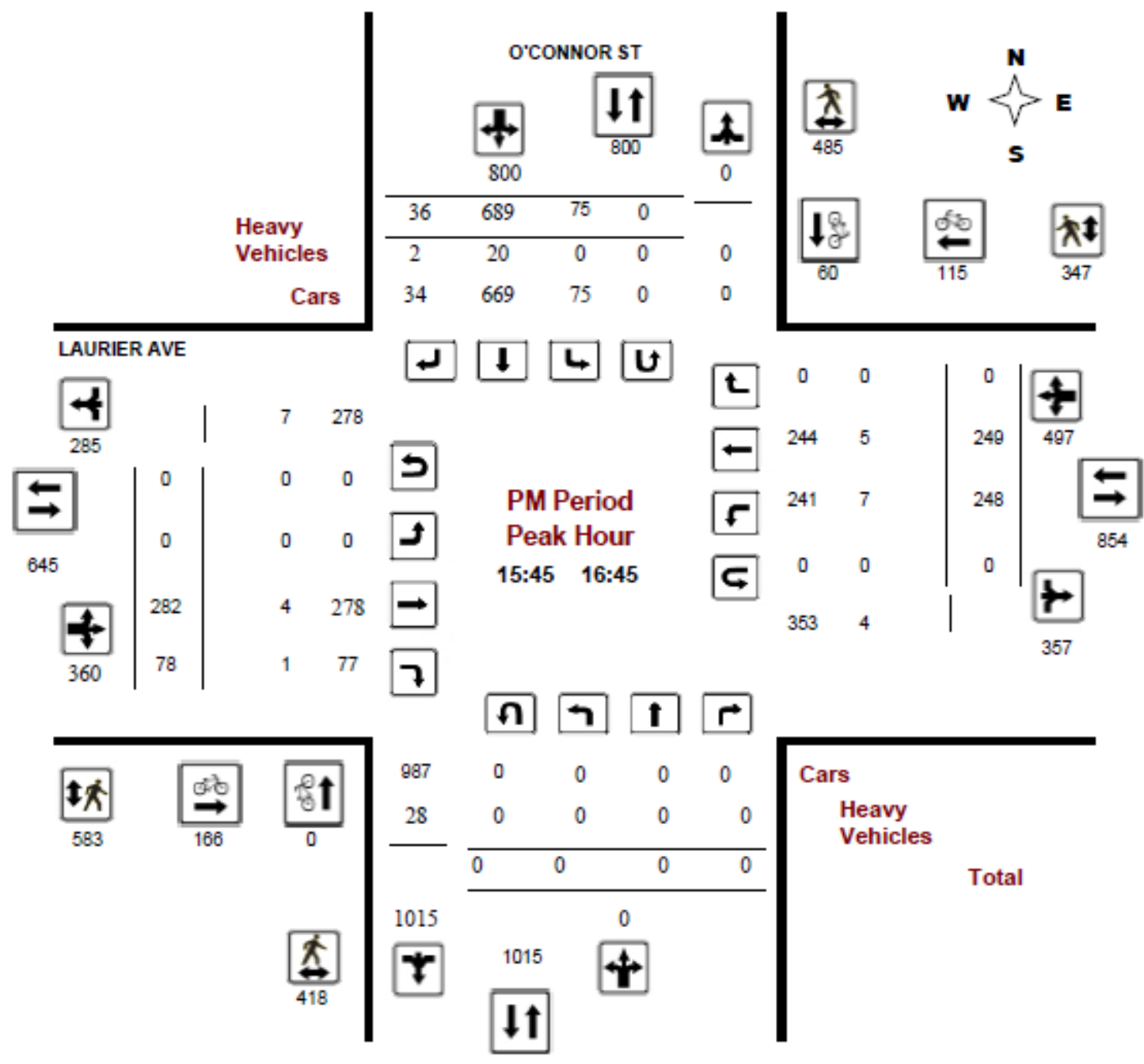

Comments 


\section{Public Works - Traffic Services \\ Turning Movement Count - Peak Hour Diagram O'CONNOR ST @ SOMERSET ST}

Survey Date: Wednesday, June 13, 2012

Start Time: 07:00
WO No: $\quad 503$

Device: Miovision

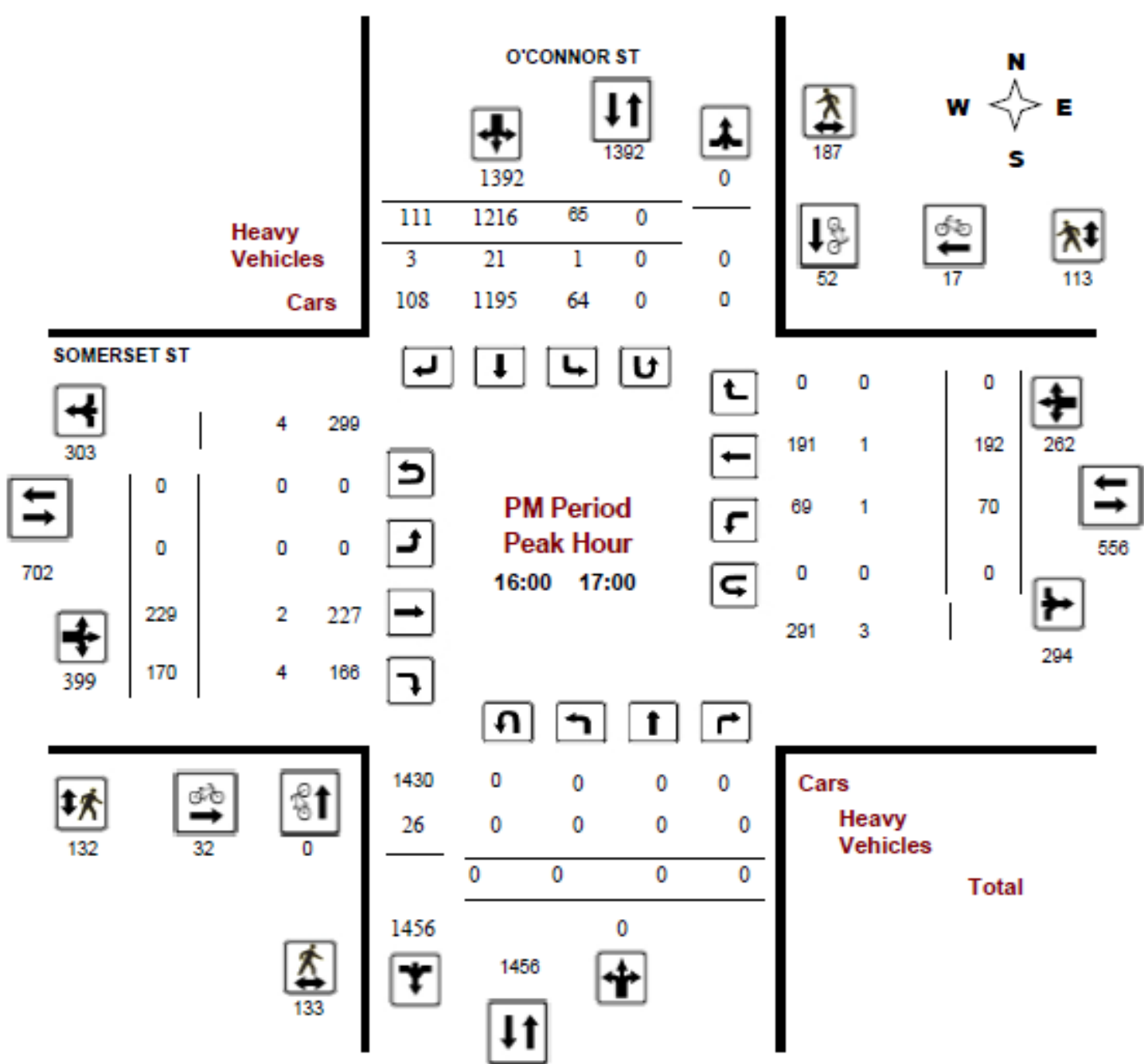

Comments 


Public Works - Traffic Services
Turning Movement Count - Peak Hour Diagram

Survey Date: Wednesday, May 23, 2012

Start Time: $07: 00$

WO No: $\quad 512$

Device: Miovision

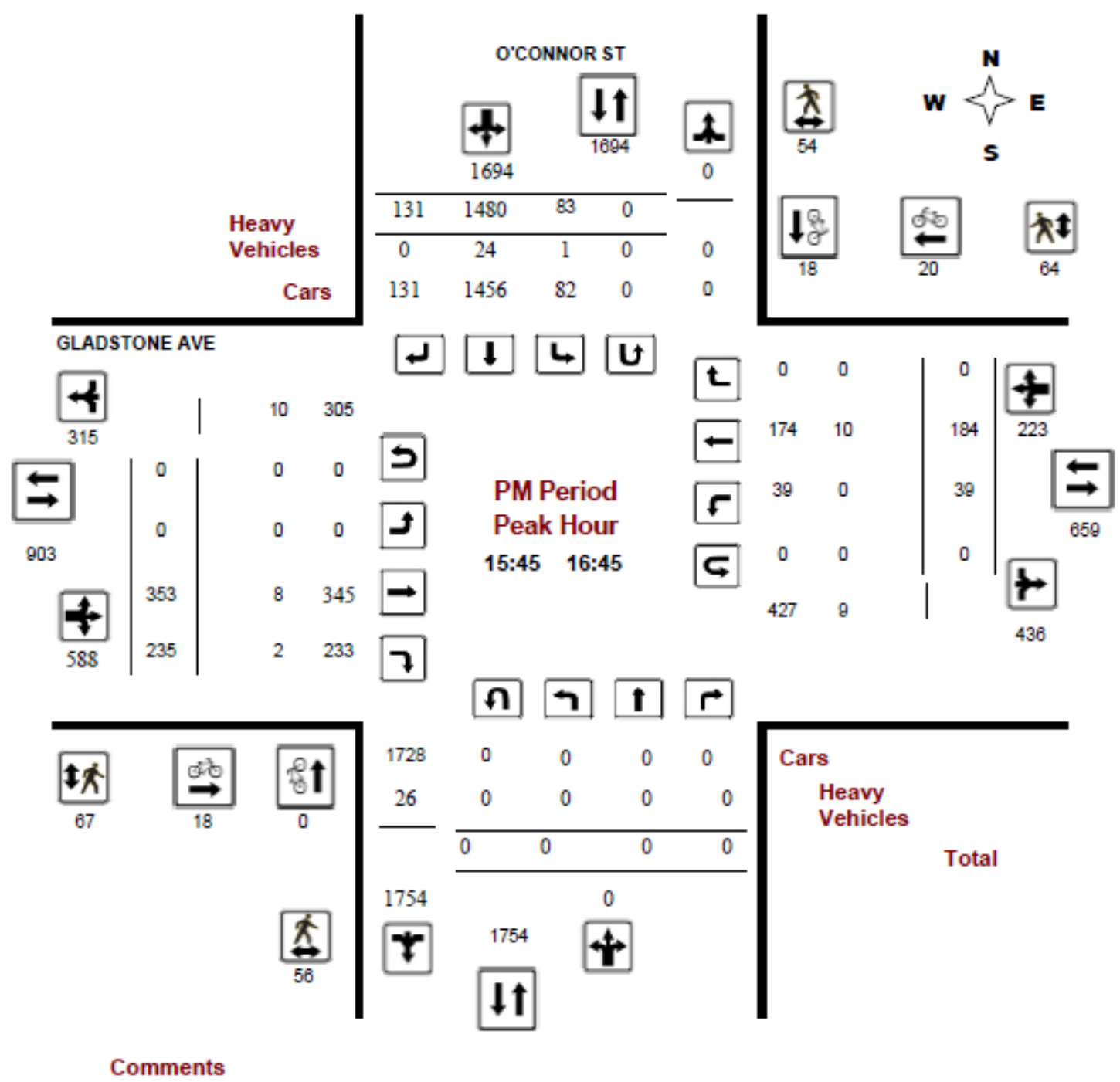




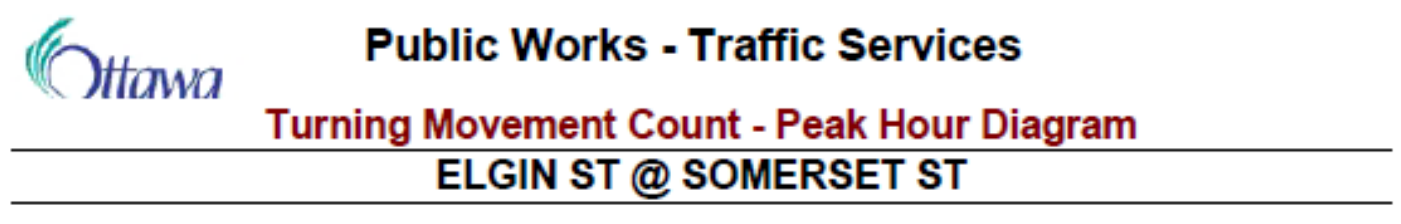

Survey Date: Friday, May 11, 2012

WO No: $\quad 30636$

Start Time: 07:00

Device:

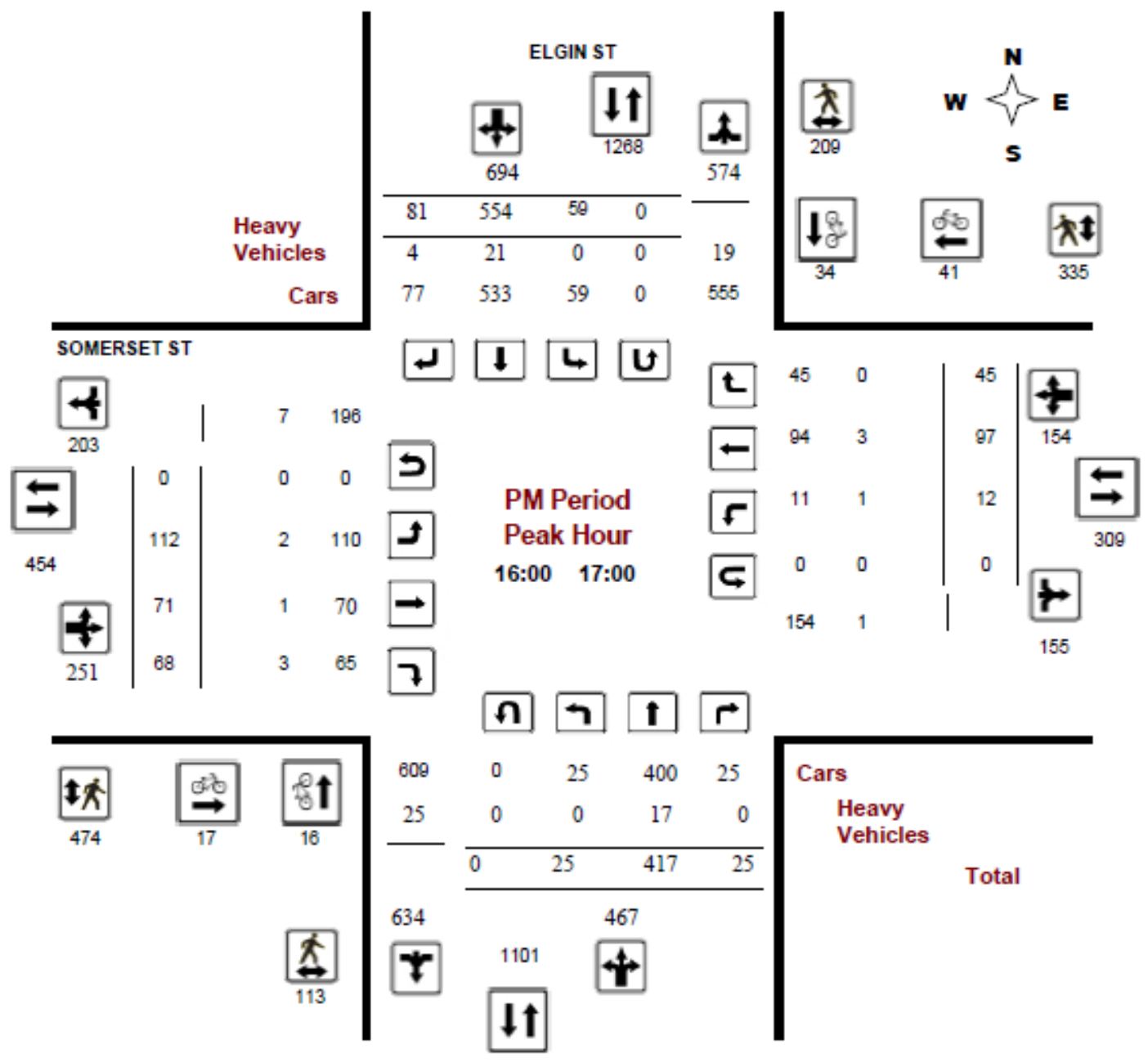

Comments 


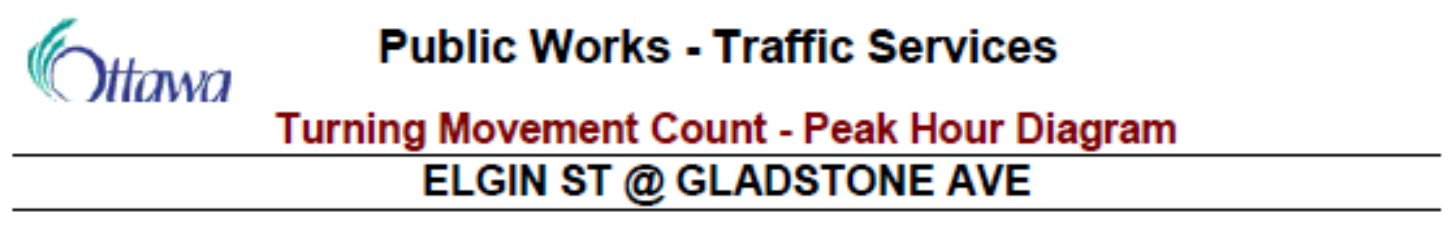

Survey Date: Thursday, May 10, 2012

Start Time: $07: 00$
WO No: $\quad 30628$

Device:

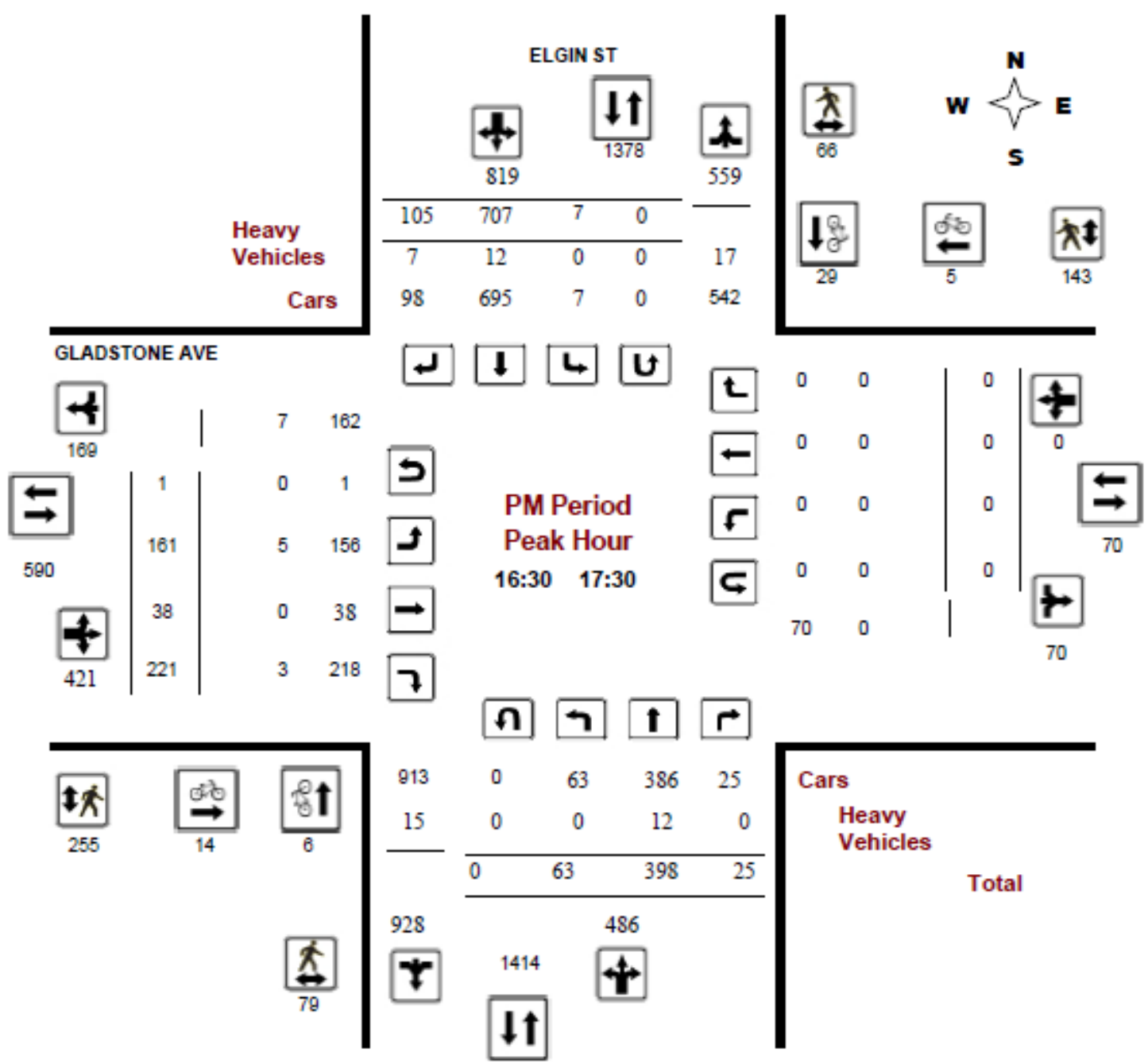

Comments 


\section{(Cublic Works - Traffic Services}

Turning Movement Count - Peak Hour Diagram KING EDWARD AVE @ RIDEAU ST

Survey Date: Friday, August 01, 2014

Start Time: $07: 00$ $\begin{array}{cc}\text { WO No: } & 29262 \\ \text { Device: } & \begin{array}{c}\text { Jamar } \\ \text { Technologies, } \\ \text { Inc }\end{array}\end{array}$

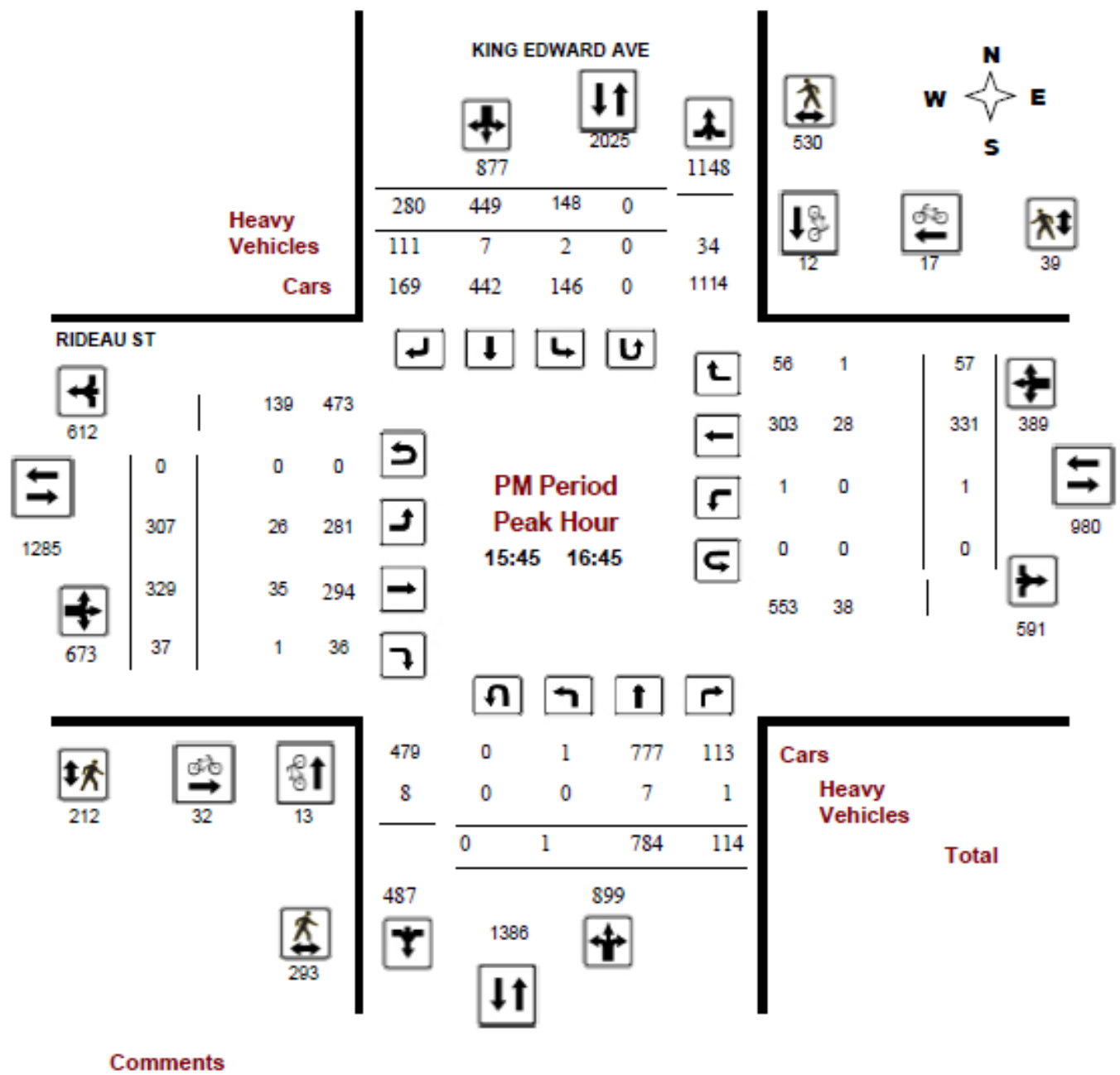




\section{(Chowa Public Works - Traffic Services \\ Turning Movement Count - Full Study Peak Hour Diagram DALHOUSIE ST @ YORK ST}

Survey Date: Wednesday, August 15, 2012

Start Time: 07:00
WO No: $\quad 31101$

Device:

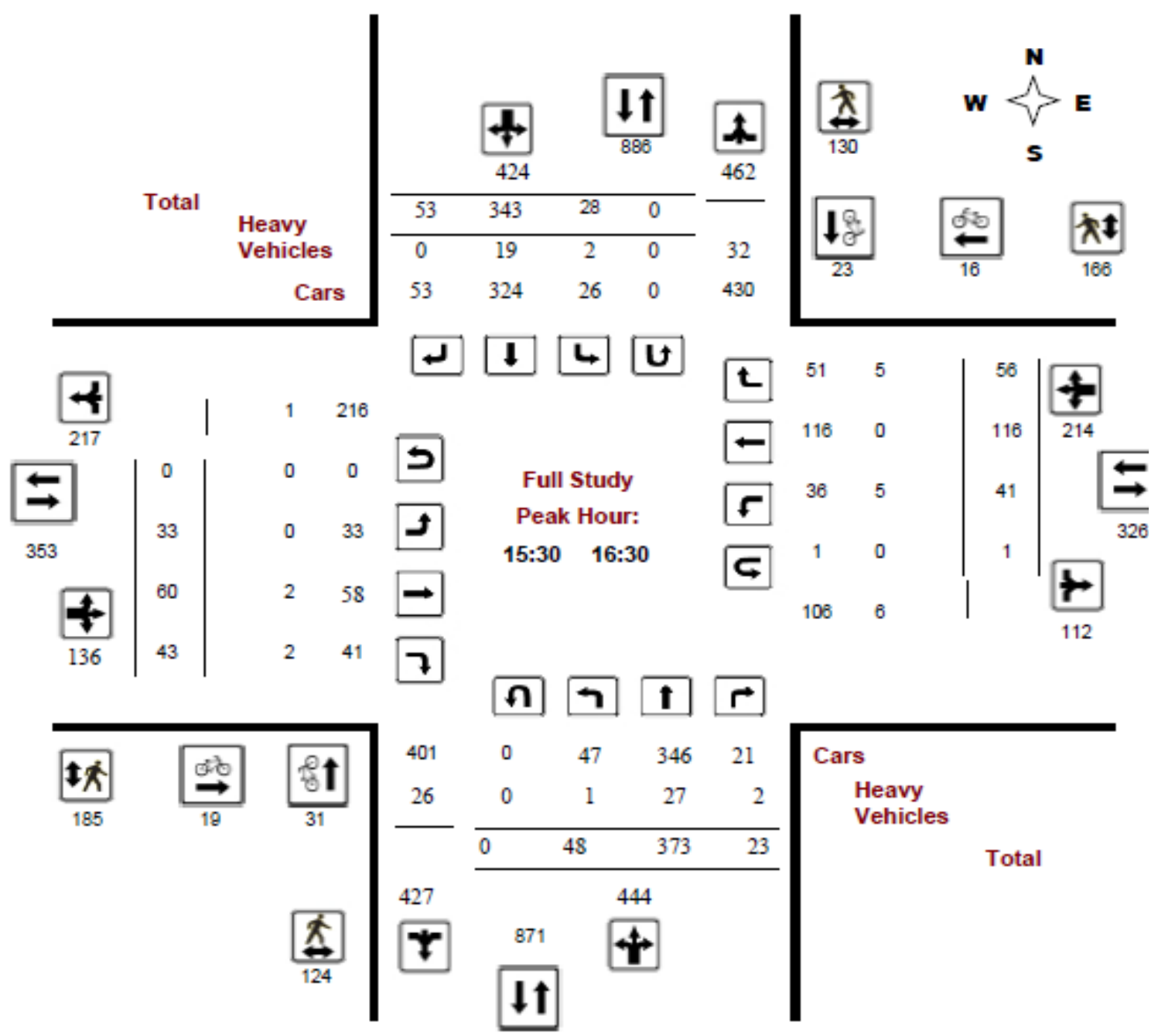

Comments 


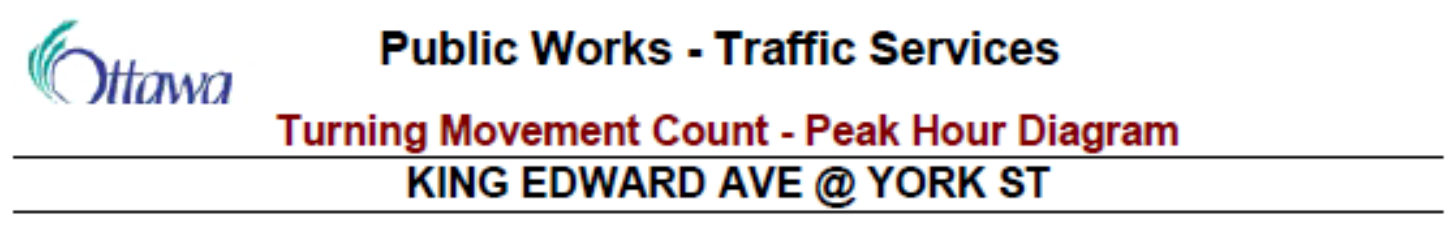

Survey Date: Thursday, July 17, 2014

Start Time: 07:00

$\begin{array}{cc}\text { WO No: } & 29259 \\ \text { Device: } & \begin{array}{c}\text { Jamar } \\ \text { Technologies, } \\ \text { Inc }\end{array}\end{array}$

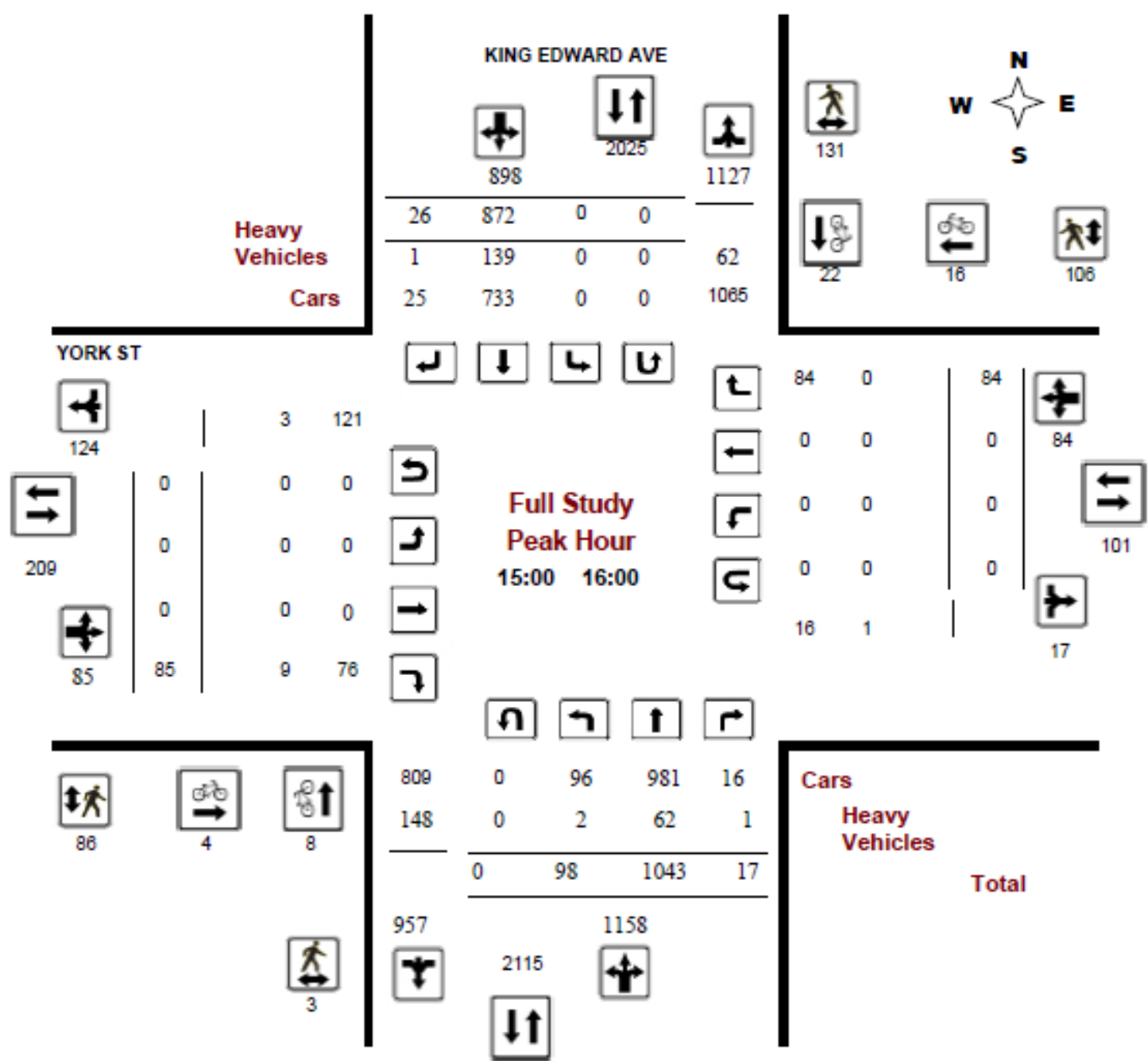

Comments 


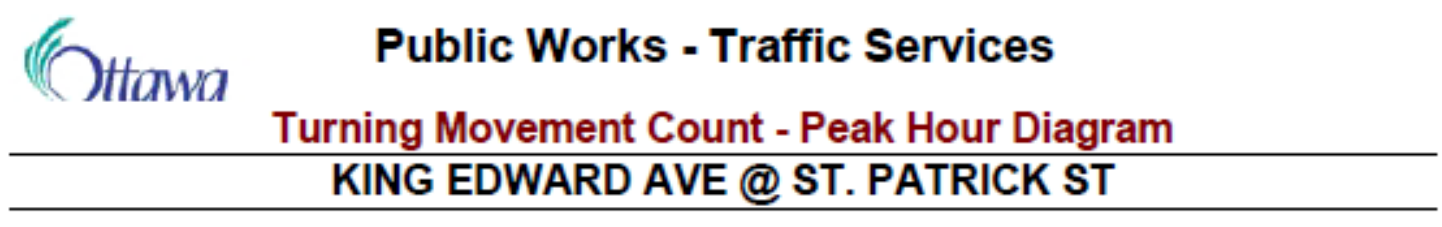

Survey Date: Wednesday, May 27, 2015

Start Time: 07:00

$\begin{array}{cc}\text { WO No: } & 34510 \\ \text { Device: } & \begin{array}{c}\text { Jamar } \\ \text { Technologies, } \\ \text { Inc }\end{array}\end{array}$

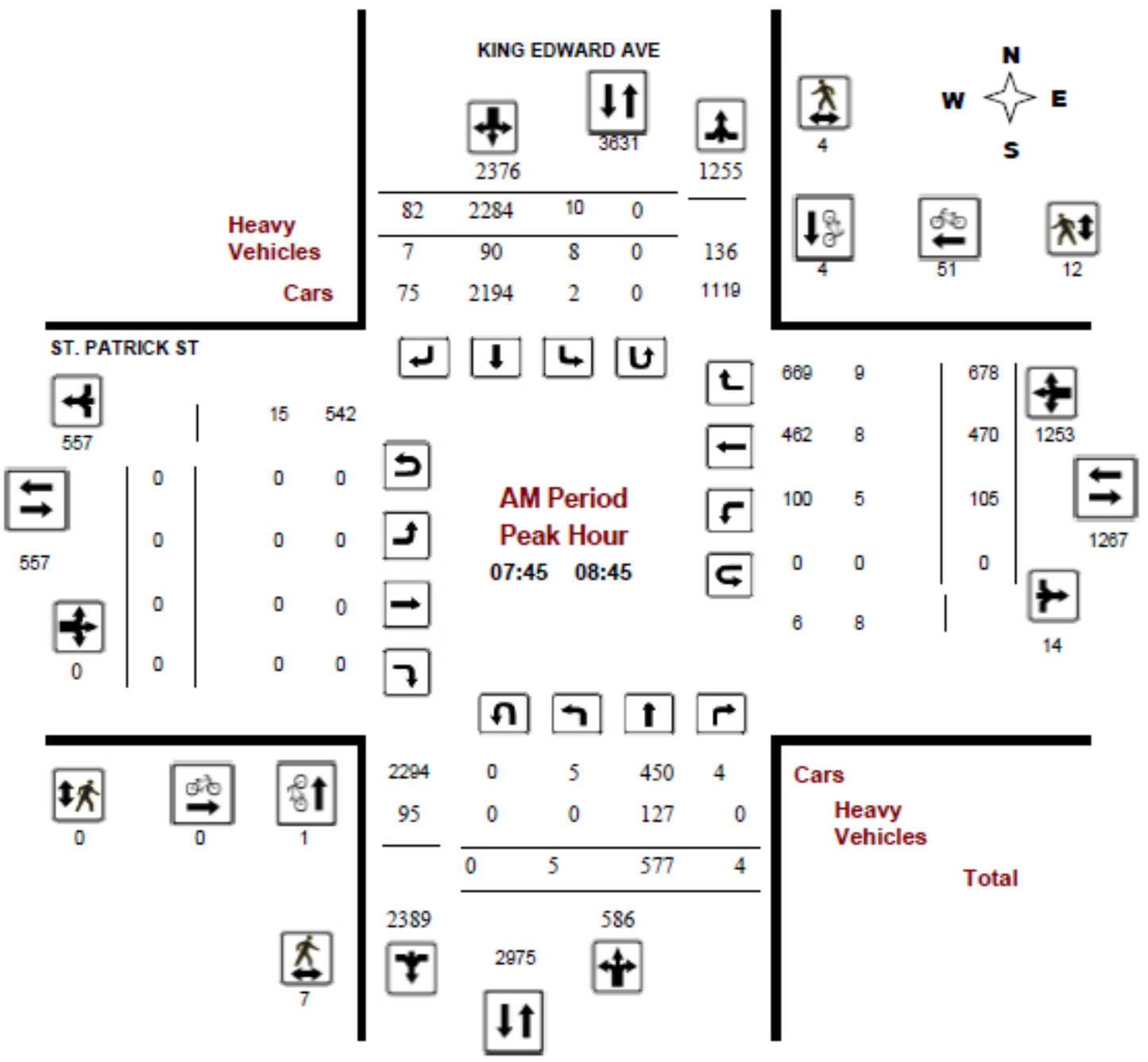

Comments 


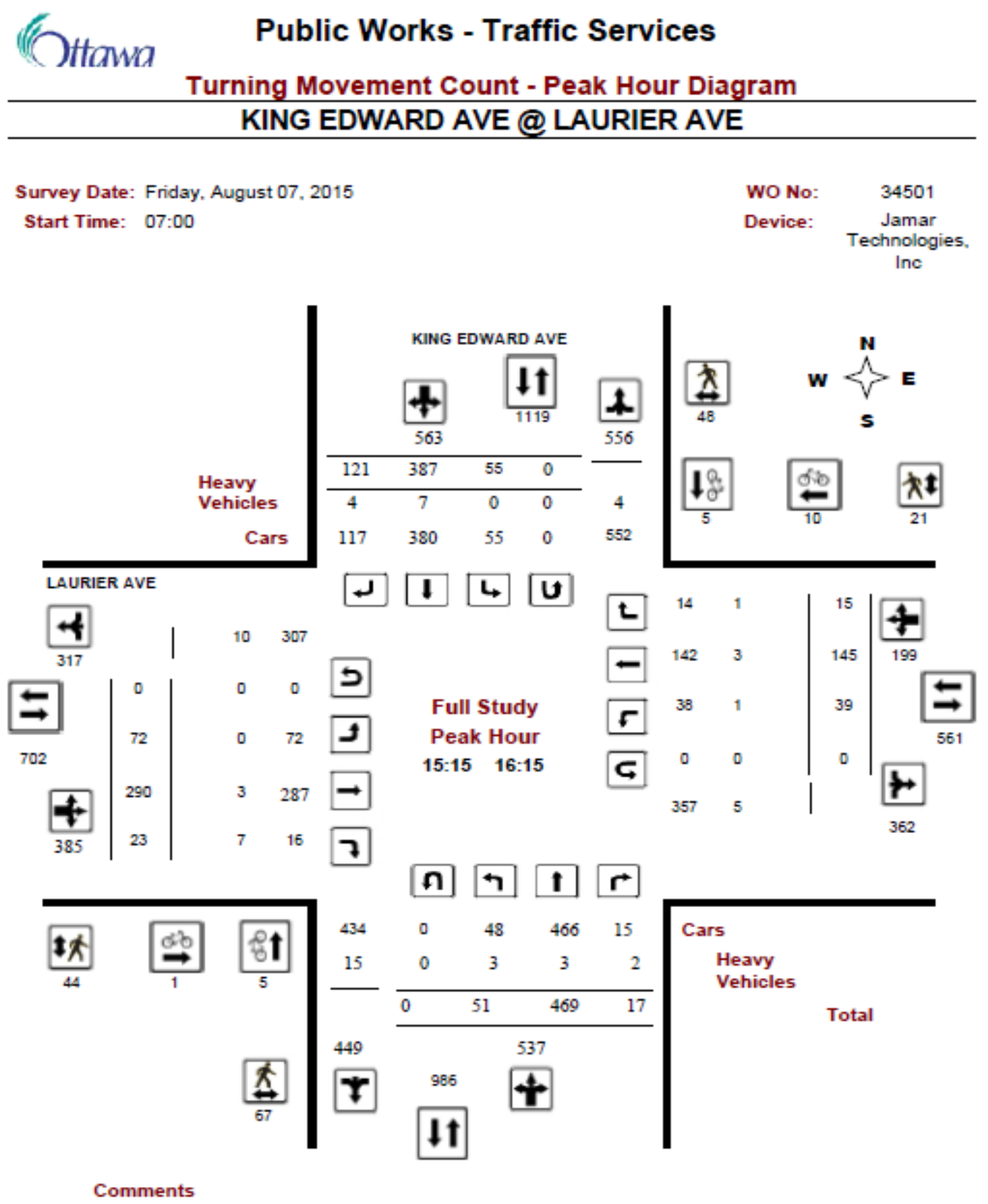




\section{Public Works - Traffic Services}

Turning Movement Count - Peak Hour Diagram

BANK ST @ LAURIER AVE

Survey Date: Tuesday, June 26, 2012

Start Time: $07: 00$
WO No: $\quad 488$

Device: Miovision

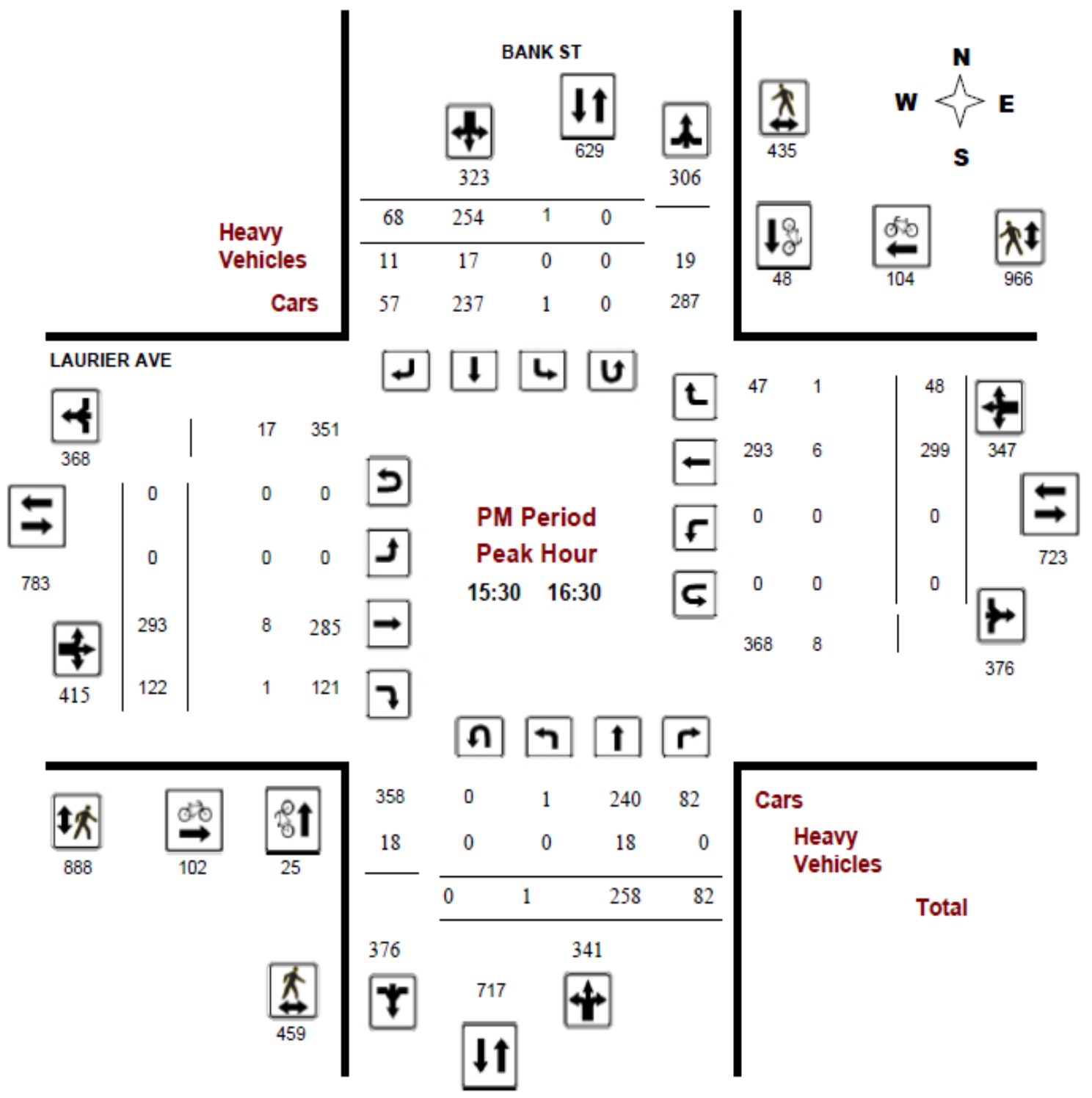




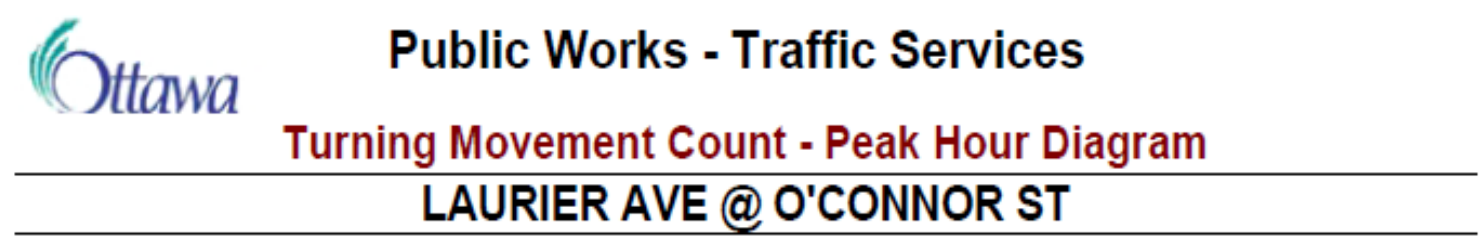

Survey Date: Wednesday, June 13, 2012

WO No: $\quad 504$

Start Time: 07:00

Device: Miovision

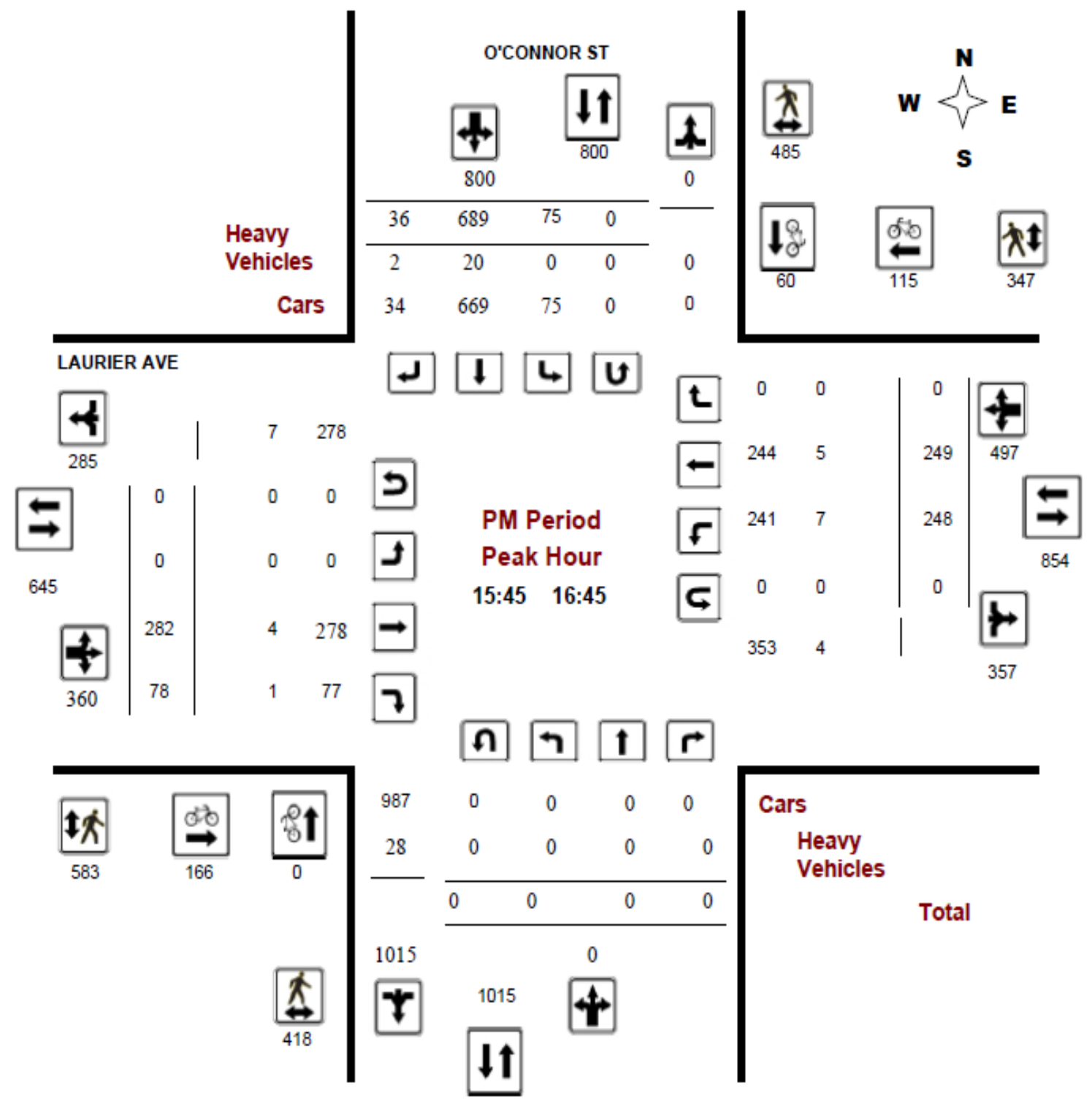




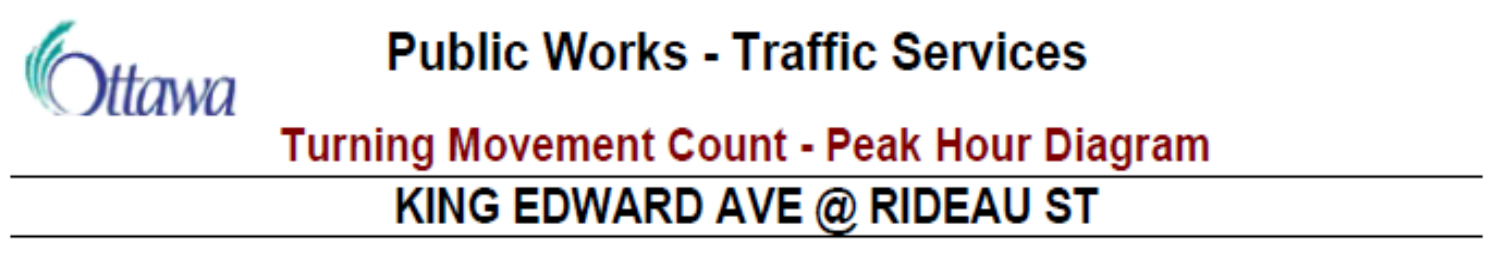

Survey Date: Friday, August 01, 2014

WO No: 29262

Start Time: $07: 00$

Device: Jamar

Technologies,

Inc

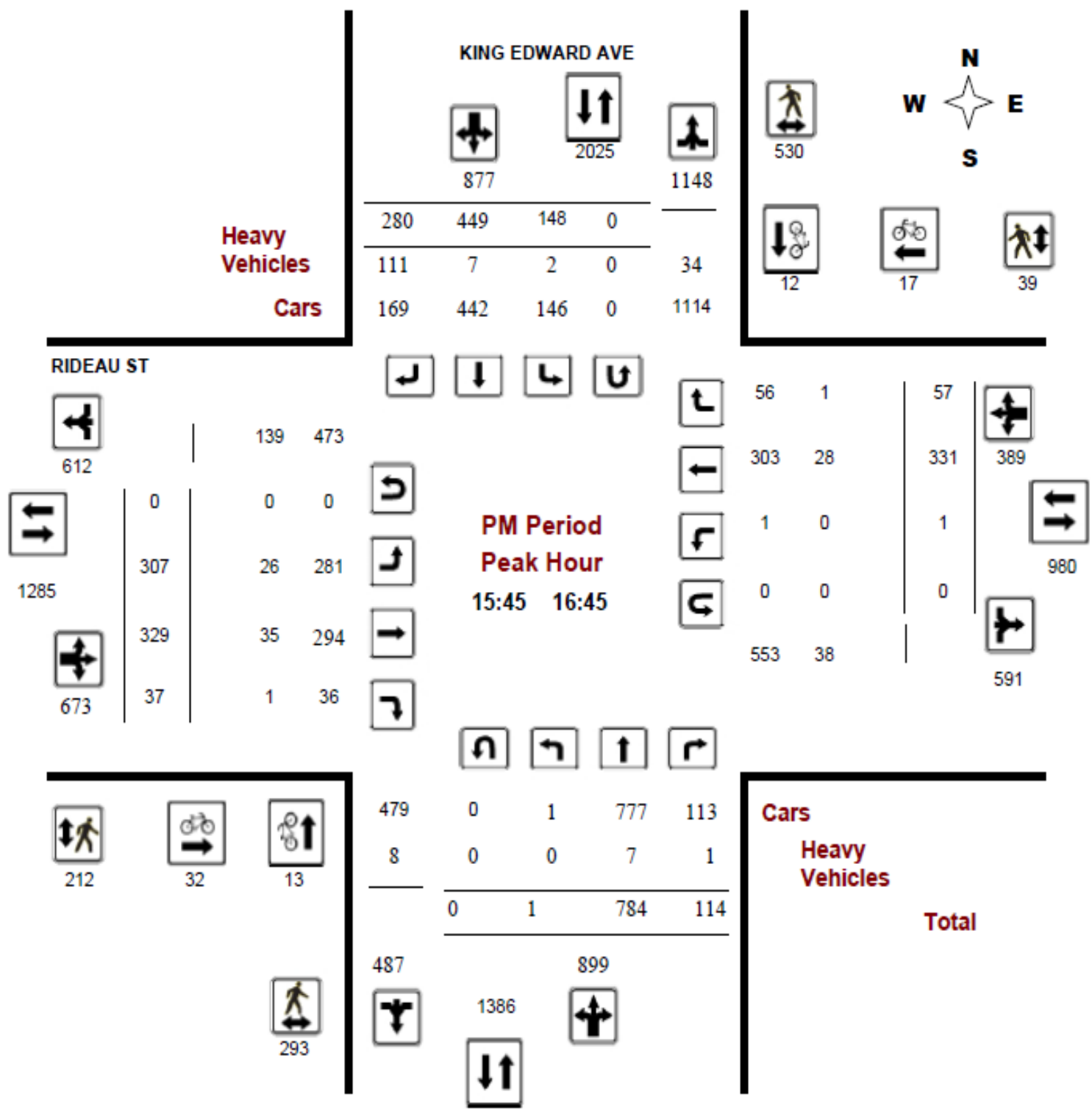




\section{APPENDIX C}

\section{STUDY AREA MAP AND GOODNESS OF TRAFFIC \\ PROJECTION IN PTV-VISUM}




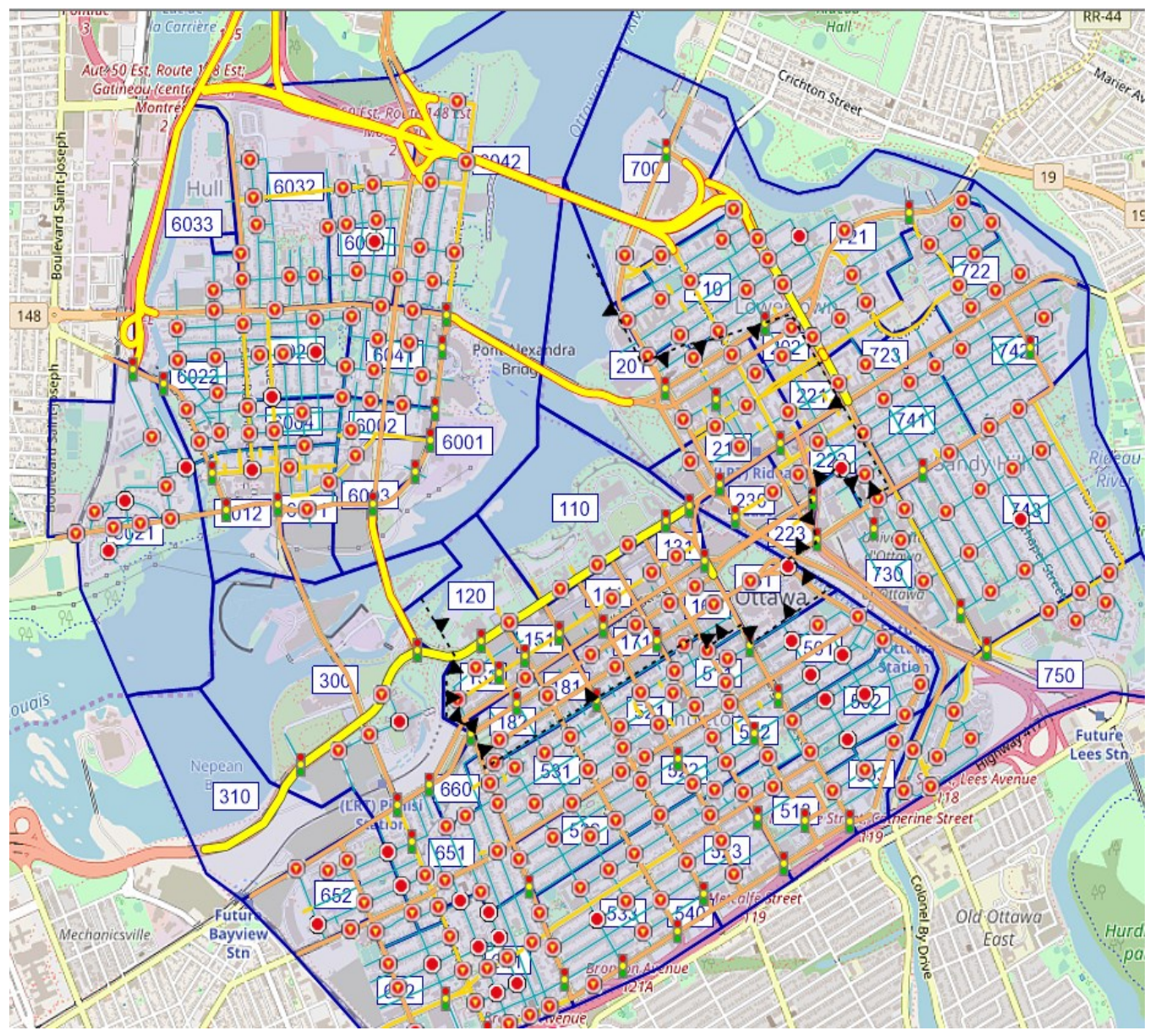

Figure 1: Ottawa-Hull Are Map used in Analysis of Dynamic Resilience (Chapter 7)

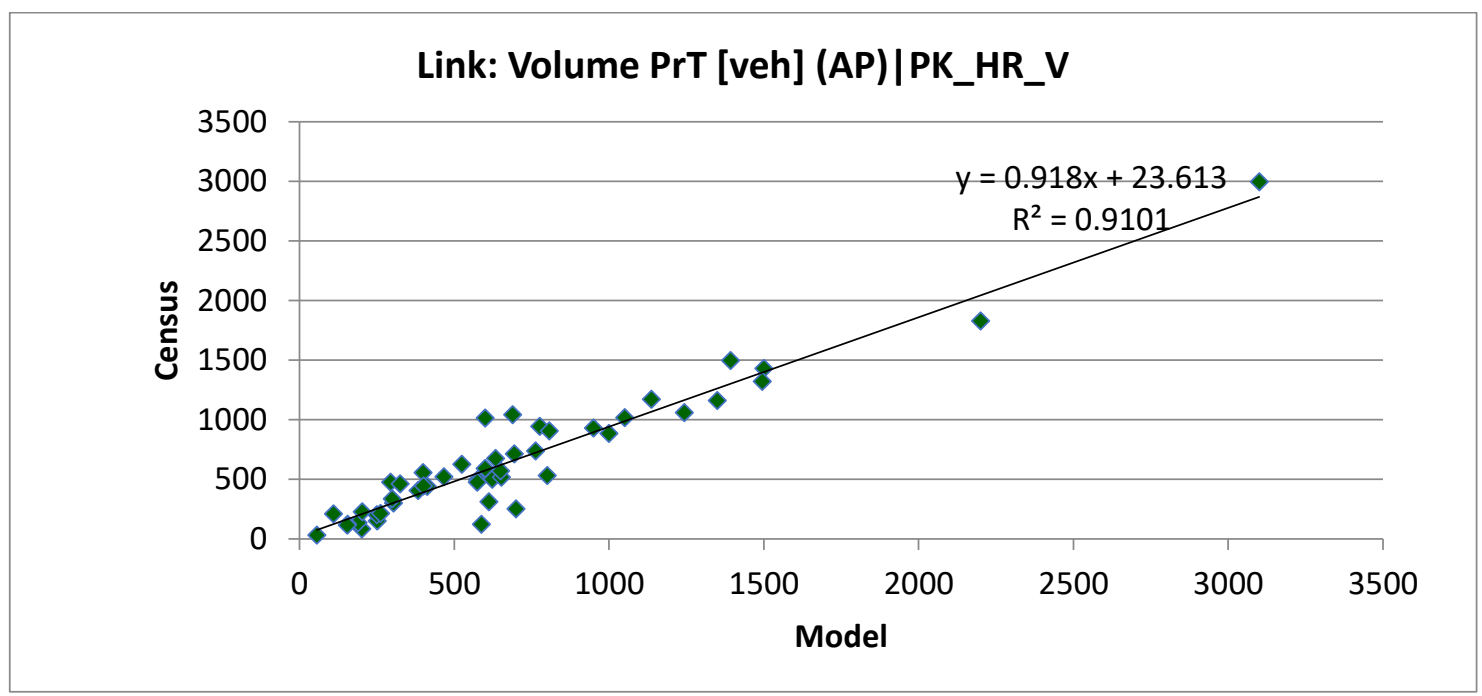

Figure 1: Goodness of Traffic Projection Based on Traffic Actual Counts for 2011 for PM Peak Hour. 


\section{APPENDIX D}

\section{ROADS CLASSIFICATIONS AND CHARACTERISTICS USED IN PTV-VISUM ANALYSIS}


Major Roadways Data (City of Ottawa, 2010)

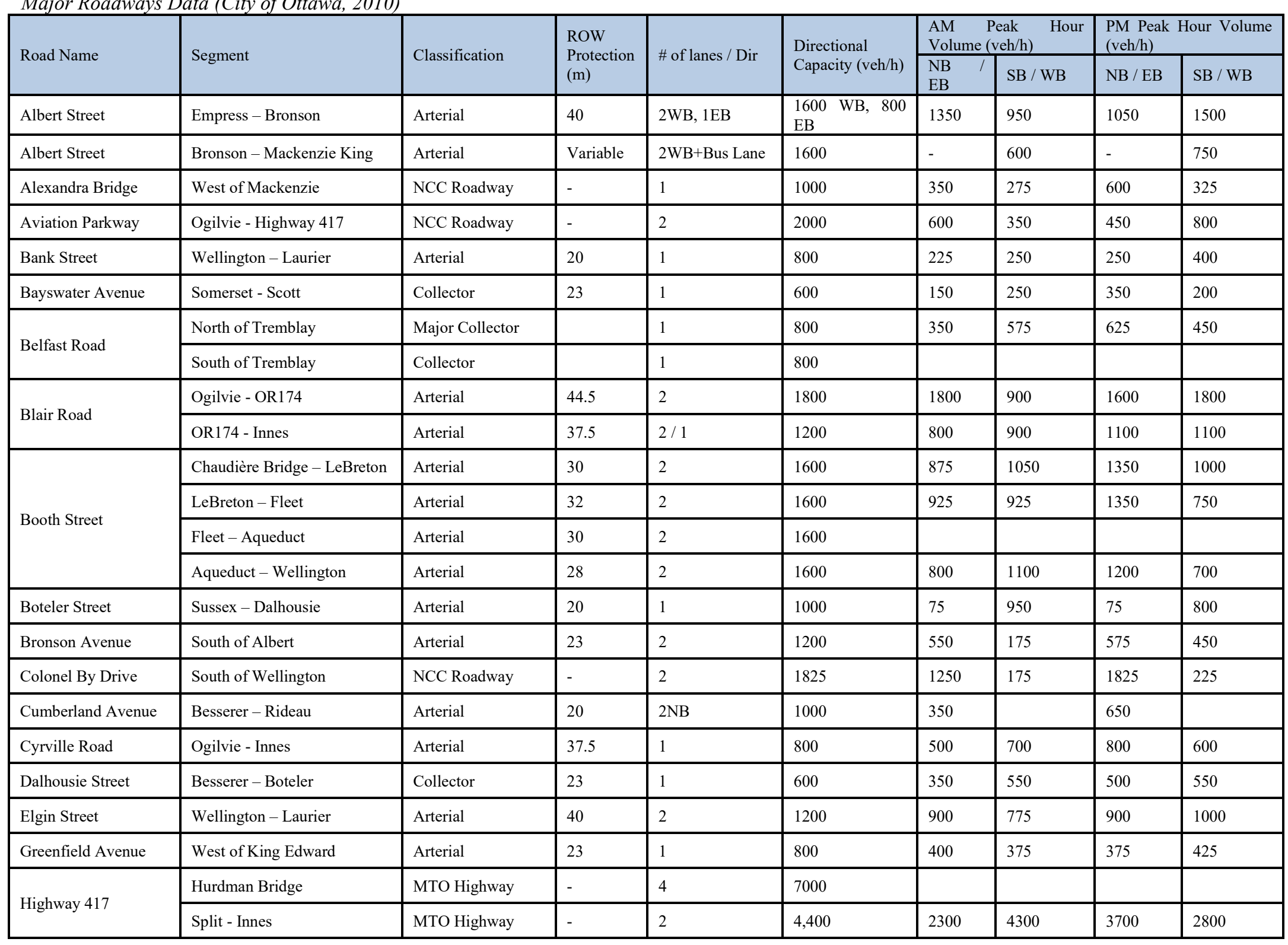




\begin{tabular}{|c|c|c|c|c|c|c|c|c|c|}
\hline \multirow{2}{*}{ Road Name } & \multirow{2}{*}{ Segment } & \multirow{2}{*}{ Classification } & \multirow{2}{*}{$\begin{array}{l}\text { ROW } \\
\text { Protection } \\
\text { (m) }\end{array}$} & \multirow{2}{*}{ \# of lanes / Dir } & \multirow{2}{*}{$\begin{array}{l}\text { Directional } \\
\text { Capacity (veh/h) }\end{array}$} & \multicolumn{2}{|c|}{$\begin{array}{lll}\text { AM } & \text { Peak } & \text { Hour } \\
\text { Volume } & (\mathrm{veh} / \mathrm{h}) & \\
\end{array}$} & \multicolumn{2}{|c|}{$\begin{array}{l}\text { PM Peak Hour Volume } \\
\text { (veh/h) }\end{array}$} \\
\hline & & & & & & $\begin{array}{ll}\mathrm{NB} & / \\
\mathrm{EB} & \end{array}$ & $\mathrm{SB} / \mathrm{WB}$ & $\mathrm{NB} / \mathrm{EB}$ & $\mathrm{SB} / \mathrm{WB}$ \\
\hline Holland Avenue & $\begin{array}{lll}\text { Tunney's } & \text { Pasture } & - \\
\text { Wellington } & & \\
\end{array}$ & Major Collector & 26 & 1 & 800 & 500 & 300 & 500 & 400 \\
\hline Kent Street & Wellington - Laurier & Arterial & 20 & $3 \mathrm{NB}$ & 1600 & 1000 & - & 1300 & - \\
\hline \multirow{3}{*}{ King Edward Avenue } & $\begin{array}{l}\text { Macdonald-Cartier Bridge - } \\
\text { Rideau }\end{array}$ & Arterial & 40 & 3 & 3400 & 1300 & 3350 & 3100 & 1625 \\
\hline & Laurier - Mann & Arterial & 20 & 1 & 1000 & 600 & 1000 & 700 & 1000 \\
\hline & Mann - Highway 417 & Arterial & 26 & 1 & 800 & & & & \\
\hline \multirow{3}{*}{ Laurier Avenue } & Bronson - Elgin & Arterial & 20 & 1 & 1000 & 550 & 550 & 600 & 700 \\
\hline & Elgin - Nicholas & Arterial & 26 & 2 & 1600 & 550 & 1150 & 1175 & 800 \\
\hline & Nicholas - King Edward & Arterial & 23 & 1 & 750 & 525 & 575 & 725 & 350 \\
\hline Lyon Street & Wellington - Laurier & Arterial & 20 & $3 \mathrm{SB}$ & 1600 & - & 1000 & - & 1000 \\
\hline $\begin{array}{ll}\text { Macdonald } & \text { Cartier } \\
\text { Bridge } & \\
\end{array}$ & North of Sussex & NCC Roadway & - & 3 & 4800 & 1300 & 3000 & 3100 & 1500 \\
\hline Mackenzie avenue & Wellington - St. Patrick & Arterial & 20 & $2 \mathrm{SB}$ & 1600 & - & 1250 & - & 950 \\
\hline $\begin{array}{l}\text { Mackenzie-King } \\
\text { Bridge }\end{array}$ & Elgin - Waller & Arterial & 20 & 1+Bus Lane & 800 & 500 & 400 & 525 & 300 \\
\hline Metcalfe Street & Wellington - Laurier & Arterial & 20 & $3 \mathrm{NB}$ & 1600 & 775 & - & 650 & - \\
\hline Murray Avenue & $\begin{array}{l}\text { Alexandra Bridge }- \text { King } \\
\text { Edward }\end{array}$ & Arterial & 20 & $2 \mathrm{~EB}$ & 1000 & 450 & - & 750 & - \\
\hline \multirow{2}{*}{ Nicholas Street } & Rideau - Laurier & Arterial & 20 & $2 \mathrm{SB}$ & 1600 & 1150 & 100 & 1475 & 175 \\
\hline & Laurier - Highway 417 & Arterial & 26 & 2 & 2000 & 1000 & 950 & 1075 & 1525 \\
\hline O'Connor Street & Wellington - Laurier & Arterial & 20 & $3 \mathrm{SB}$ & 1600 & - & 775 & - & 1200 \\
\hline Ogilvie Road & St. Laurent - Blair & Arterial & 44.5 & 2 & 2000 & 700 & 1800 & 1800 & 1000 \\
\hline $\begin{array}{ll}\text { Ottawa } & \text { River } \\
\text { Parkway } & \\
\end{array}$ & West of Portage Bridge & NCC Parkway & - & 2 & 2000 & 1800 & 750 & 1100 & 1300 \\
\hline Parkdale Avenue & $\begin{array}{lll}\text { Ottawa River } & \text { Parkway } & \text { - } \\
\text { Wellington } & & \\
\end{array}$ & Major Collector & 26 & 1 & 800 & 350 & 525 & 675 & 500 \\
\hline Portage Avenue & North of Wellington & NCC Roadway & - & $2+\mathrm{HOV}$ & 2400 & 1425 & 1725 & 2200 & 1050 \\
\hline
\end{tabular}




\begin{tabular}{|c|c|c|c|c|c|c|c|c|c|}
\hline \multirow{2}{*}{ Road Name } & \multirow{2}{*}{ Segment } & \multirow{2}{*}{ Classification } & \multirow{2}{*}{$\begin{array}{l}\text { ROW } \\
\text { Protection (m) }\end{array}$} & \multirow{2}{*}{ \# of lanes / Dir } & \multirow{2}{*}{$\begin{array}{l}\text { Directional } \\
\text { Capacity } \\
(\mathrm{veh} / \mathrm{h})\end{array}$} & \multicolumn{2}{|c|}{$\begin{array}{l}\text { AM Peak Hour } \\
\text { Volume }(\text { veh/h) }\end{array}$} & \multicolumn{2}{|c|}{$\begin{array}{l}\text { PM Peak Hour Volume } \\
(\text { veh/h) }\end{array}$} \\
\hline & & & & & & $\begin{array}{ll}\mathrm{NB} & / \\
\mathrm{EB}\end{array}$ & $\mathrm{SB} / \mathrm{WB}$ & $\mathrm{NB} / \mathrm{EB}$ & $\mathrm{SB} / \mathrm{WB}$ \\
\hline Queen Street & Bronson - Elgin & Local & - & 1 & 600 & 400 & 425 & 525 & 250 \\
\hline Rideau Street & Sussex - King Edward & Arterial & 30 & 1+Bus Lane & 800 & 500 & 800 & 550 & 500 \\
\hline Riverside Drive & Highway 417 - Industrial & Arterial & 44.5 & 3 & 2700 & 2350 & 1875 & 2700 & 1800 \\
\hline \multirow[t]{2}{*}{ Scott Street } & Island Park - Holland & Arterial & 26 & 2 & 1200 & 900 & 425 & 500 & 700 \\
\hline & Holland - Bayview & Arterial & 26 & 2 & 1200 & 800 & 500 & 900 & 800 \\
\hline \multirow{2}{*}{ Slater Street } & Empress - Bronson & Arterial & 40 & $\begin{array}{ll}\text { 2EB } & + \text { Bus } \\
\text { Lane } & \end{array}$ & 1200 & 450 & - & 550 & - \\
\hline & Bronson-Mackenzie King & Arterial & Variable & $\begin{array}{ll}\text { 2EB } & + \text { Bus } \\
\text { Lane } & \\
\end{array}$ & 1200 & 850 & - & 800 & - \\
\hline Sparks Street & Lyon-Elgin & $\begin{array}{l}\text { Local } \\
\text { (Pedestrian Mall) }\end{array}$ & - & $\mathrm{n} / \mathrm{a}$ & $\mathrm{n} / \mathrm{a}$ & & & & \\
\hline St. Laurent Avenue & Coventry - Highway 417 & Arterial & 44.5 & 3 & 2000 & 1350 & 1800 & 1800 & 1900 \\
\hline St. Patrick Street & $\begin{array}{llll}\text { Alexandra } & \text { Bridge } & - & \text { King } \\
\text { Edward } & & & \\
\end{array}$ & Arterial & 20 & $2 \mathrm{WB}$ & 1000 & - & 800 & - & 500 \\
\hline Sussex Drive & Wellington - King Edward & Arterial & 20 & $2 \mathrm{NB}$ & 1700 & 1050 & 950 & 1700 & 600 \\
\hline Terminal Avenue & West of Riverside - Belfast & Collector & Existing & 1 & 600 & & & & \\
\hline \multirow{4}{*}{ Transitway } & Dominion - Bayview & Transitway & Existing & Bus Lane & $\mathrm{n} / \mathrm{a}$ & 75 & 50 & 50 & 50 \\
\hline & Bayview - MacKenzie King & Transitway & Existing & Bus Lane & $\mathrm{n} / \mathrm{a}$ & & & & \\
\hline & MacKenzie King- St. Laurent & Transitway & Existing & Bus Lane & $\mathrm{n} / \mathrm{a}$ & 200 & 175 & 175 & 175 \\
\hline & St. Laurent - Blair & Transitway & Existing & Bus Lane & $\mathrm{n} / \mathrm{a}$ & & & & \\
\hline Tremblay Road & East of Riverside & Major Collector & Existing & 2 & 800 & 400 & 200 & 500 & 350 \\
\hline Waller Street & Rideau - Nicholas & Arterial & 23 & 02-Jan & 1200 & 800 & 300 & 1200 & 200 \\
\hline Wellington Street & East of Portage Bridge & Arterial & 26 & 2 & 2500 & 2500 & 1150 & 1050 & 2450 \\
\hline Wellington/Albert & Preston - Empress & Arterial & 32 & 2 & 1000 & 1000 & 900 & 800 & 900 \\
\hline
\end{tabular}




\section{APPENDIX E}

\section{MAXIMUM FLOW “CAPACITY” ANALYSIS TABLE}




\begin{tabular}{|c|c|c|c|c|c|c|c|c|}
\hline Link & $\begin{array}{l}\text { Segment } \\
\text { length } \\
(\mathrm{m})\end{array}$ & $\begin{array}{l}\text { Left } \\
\text { Lane }\end{array}$ & $\begin{array}{l}\text { Right } \\
\text { Lane }\end{array}$ & $\mathrm{g} / \mathrm{C}$ & $\begin{array}{l}\text { Link } \\
\text { Configuration }\end{array}$ & $\begin{array}{l}\text { Maximum } \\
\text { Flow } \\
\text { (Vehs Per } \\
\text { Hour) }\end{array}$ & $\begin{array}{l}\text { Max. } \\
\text { Flow } \\
\text { Mean }\end{array}$ & $\begin{array}{l}\text { Max. } \\
\text { Flow } \\
\text { Standard } \\
\text { Deviation }\end{array}$ \\
\hline \multirow{7}{*}{1} & 300 & 1 & 1 & 0.3 & Link $1 ; 0.3 \mathrm{~g} / \mathrm{C}$ & 693 & \multirow{7}{*}{687.38} & \multirow{7}{*}{3.16} \\
\hline & 400 & 1 & 1 & 0.3 & Link $1 ; 0.3 \mathrm{~g} / \mathrm{C}$ & 689 & & \\
\hline & 500 & 1 & 1 & 0.3 & Link $1 ; 0.3 \mathrm{~g} / \mathrm{C}$ & 688 & & \\
\hline & 600 & 1 & 1 & 0.3 & Link $1 ; 0.3 \mathrm{~g} / \mathrm{C}$ & 688 & & \\
\hline & 700 & 1 & 1 & 0.3 & Link $1 ; 0.3 \mathrm{~g} / \mathrm{C}$ & 687 & & \\
\hline & 800 & 1 & 1 & 0.3 & Link $1 ; 0.3 \mathrm{~g} / \mathrm{C}$ & 687 & & \\
\hline & 900 & 1 & 1 & 0.3 & Link $1 ; 0.3 \mathrm{~g} / \mathrm{C}$ & 685 & & \\
\hline & 1000 & 1 & 1 & 0.3 & Link $1 ; 0.3 \mathrm{~g} / \mathrm{C}$ & 682 & & \\
\hline \multirow{8}{*}{1} & 300 & 1 & 1 & 0.4 & Link $1 ; 0.4 \mathrm{~g} / \mathrm{C}$ & 866 & \multirow{7}{*}{862.75} & \multirow{7}{*}{1.83} \\
\hline & 400 & 1 & 1 & 0.4 & Link $1 ; 0.4 \mathrm{~g} / \mathrm{C}$ & 864 & & \\
\hline & 500 & 1 & 1 & 0.4 & Link $1 ; 0.4 \mathrm{~g} / \mathrm{C}$ & 863 & & \\
\hline & 600 & 1 & 1 & 0.4 & Link $1 ; 0.4 \mathrm{~g} / \mathrm{C}$ & 861 & & \\
\hline & 700 & 1 & 1 & 0.4 & Link $1 ; 0.4 \mathrm{~g} / \mathrm{C}$ & 864 & & \\
\hline & 800 & 1 & 1 & 0.4 & Link $1 ; 0.4 \mathrm{~g} / \mathrm{C}$ & 862 & & \\
\hline & 900 & 1 & 1 & 0.4 & Link $1 ; 0.4 \mathrm{~g} / \mathrm{C}$ & 861 & & \\
\hline & 1000 & 1 & 1 & 0.4 & Link $1 ; 0.4 \mathrm{~g} / \mathrm{C}$ & 861 & & \\
\hline \multirow{8}{*}{1} & 300 & 1 & 1 & 0.5 & Link $1 ; 0.5 \mathrm{~g} / \mathrm{C}$ & 1038 & \multirow{7}{*}{1034.38} & \multirow{7}{*}{3.34} \\
\hline & 400 & 1 & 1 & 0.5 & Link $1 ; 0.5 \mathrm{~g} / \mathrm{C}$ & 1037 & & \\
\hline & 500 & 1 & 1 & 0.5 & Link $1 ; 0.5 \mathrm{~g} / \mathrm{C}$ & 1036 & & \\
\hline & 600 & 1 & 1 & 0.5 & Link $1 ; 0.5 \mathrm{~g} / \mathrm{C}$ & 1036 & & \\
\hline & 700 & 1 & 1 & 0.5 & Link $1 ; 0.5 \mathrm{~g} / \mathrm{C}$ & 1036 & & \\
\hline & 800 & 1 & 1 & 0.5 & Link $1 ; 0.5 \mathrm{~g} / \mathrm{C}$ & 1030 & & \\
\hline & 900 & 1 & 1 & 0.5 & Link $1 ; 0.5 \mathrm{~g} / \mathrm{C}$ & 1033 & & \\
\hline & 1000 & 1 & 1 & 0.5 & Link $1 ; 0.5 \mathrm{~g} / \mathrm{C}$ & 1029 & & \\
\hline \multirow{8}{*}{2} & 300 & 0 & 1 & 0.3 & Link $2 ; 0.3 \mathrm{~g} / \mathrm{C}$ & 680 & \multirow{7}{*}{674.25} & \multirow{7}{*}{4.56} \\
\hline & 400 & 0 & 1 & 0.3 & Link $2 ; 0.3 \mathrm{~g} / \mathrm{C}$ & 679 & & \\
\hline & 500 & 0 & 1 & 0.3 & Link $2 ; 0.3 \mathrm{~g} / \mathrm{C}$ & 678 & & \\
\hline & 600 & 0 & 1 & 0.3 & Link $2 ; 0.3 \mathrm{~g} / \mathrm{C}$ & 676 & & \\
\hline & 700 & 0 & 1 & 0.3 & Link $2 ; 0.3 \mathrm{~g} / \mathrm{C}$ & 672 & & \\
\hline & 800 & 0 & 1 & 0.3 & Link $2 ; 0.3 \mathrm{~g} / \mathrm{C}$ & 671 & & \\
\hline & 900 & 0 & 1 & 0.3 & Link $2 ; 0.3 \mathrm{~g} / \mathrm{C}$ & 670 & & \\
\hline & 1000 & 0 & 1 & 0.3 & Link $2 ; 0.3 \mathrm{~g} / \mathrm{C}$ & 668 & & \\
\hline \multirow{6}{*}{2} & 300 & 0 & 1 & 0.4 & Link $2 ; 0.4 \mathrm{~g} / \mathrm{C}$ & 857 & \multirow{6}{*}{853.13} & \multirow{6}{*}{2.47} \\
\hline & 400 & 0 & 1 & 0.4 & Link $2 ; 0.4 \mathrm{~g} / \mathrm{C}$ & 855 & & \\
\hline & 500 & 0 & 1 & 0.4 & Link $2 ; 0.4 \mathrm{~g} / \mathrm{C}$ & 854 & & \\
\hline & 600 & 0 & 1 & 0.4 & Link $2 ; 0.4 \mathrm{~g} / \mathrm{C}$ & 853 & & \\
\hline & 700 & 0 & 1 & 0.4 & Link $2 ; 0.4 \mathrm{~g} / \mathrm{C}$ & 854 & & \\
\hline & 800 & 0 & 1 & 0.4 & Link $2 ; 0.4 \mathrm{~g} / \mathrm{C}$ & 852 & & \\
\hline
\end{tabular}




\begin{tabular}{|c|c|c|c|c|c|c|c|c|}
\hline & 900 & 0 & 1 & 0.4 & Link $2 ; 0.4 \mathrm{~g} / \mathrm{C}$ & 851 & & \\
\hline & 1000 & 0 & 1 & 0.4 & Link $2 ; 0.4 \mathrm{~g} / \mathrm{C}$ & 849 & & \\
\hline \multirow{8}{*}{2} & 300 & 0 & 1 & 0.5 & Link $2 ; 0.5 \mathrm{~g} / \mathrm{C}$ & 1037 & \multirow{7}{*}{1028.38} & \multirow{7}{*}{4.69} \\
\hline & 400 & 0 & 1 & 0.5 & Link $2 ; 0.5 \mathrm{~g} / \mathrm{C}$ & 1032 & & \\
\hline & 500 & 0 & 1 & 0.5 & Link $2 ; 0.5 \mathrm{~g} / \mathrm{C}$ & 1031 & & \\
\hline & 600 & 0 & 1 & 0.5 & Link $2 ; 0.5 \mathrm{~g} / \mathrm{C}$ & 1028 & & \\
\hline & 700 & 0 & 1 & 0.5 & Link $2 ; 0.5 \mathrm{~g} / \mathrm{C}$ & 1026 & & \\
\hline & 800 & 0 & 1 & 0.5 & Link $2 ; 0.5 \mathrm{~g} / \mathrm{C}$ & 1024 & & \\
\hline & 900 & 0 & 1 & 0.5 & Link $2 ; 0.5 \mathrm{~g} / \mathrm{C}$ & 1023 & & \\
\hline & 1000 & 0 & 1 & 0.5 & Link $2 ; 0.5 \mathrm{~g} / \mathrm{C}$ & 1026 & & \\
\hline \multirow{8}{*}{3} & 300 & 1 & 0 & 0.3 & Link $3 ; 0.3 \mathrm{~g} / \mathrm{C}$ & 609 & \multirow{7}{*}{606.38} & \multirow{7}{*}{1.85} \\
\hline & 400 & 1 & 0 & 0.3 & Link $3 ; 0.3 \mathrm{~g} / \mathrm{C}$ & 608 & & \\
\hline & 500 & 1 & 0 & 0.3 & Link $3 ; 0.3 \mathrm{~g} / \mathrm{C}$ & 607 & & \\
\hline & 600 & 1 & 0 & 0.3 & Link $3 ; 0.3 \mathrm{~g} / \mathrm{C}$ & 607 & & \\
\hline & 700 & 1 & 0 & 0.3 & Link $3 ; 0.3 \mathrm{~g} / \mathrm{C}$ & 607 & & \\
\hline & 800 & 1 & 0 & 0.3 & Link $3 ; 0.3 \mathrm{~g} / \mathrm{C}$ & 605 & & \\
\hline & 900 & 1 & 0 & 0.3 & Link 3; $0.3 \mathrm{~g} / \mathrm{C}$ & 604 & & \\
\hline & 1000 & 1 & 0 & 0.3 & Link 3; $0.3 \mathrm{~g} / \mathrm{C}$ & 604 & & \\
\hline \multirow{8}{*}{3} & 300 & 1 & 0 & 0.4 & Link $3 ; 0.4 \mathrm{~g} / \mathrm{C}$ & 793 & \multirow{7}{*}{787.13} & \multirow{7}{*}{3.18} \\
\hline & 400 & 1 & 0 & 0.4 & Link $3 ; 0.4 \mathrm{~g} / \mathrm{C}$ & 790 & & \\
\hline & 500 & 1 & 0 & 0.4 & Link $3 ; 0.4 \mathrm{~g} / \mathrm{C}$ & 787 & & \\
\hline & 600 & 1 & 0 & 0.4 & Link $3 ; 0.4 \mathrm{~g} / \mathrm{C}$ & 787 & & \\
\hline & 700 & 1 & 0 & 0.4 & Link $3 ; 0.4 \mathrm{~g} / \mathrm{C}$ & 787 & & \\
\hline & 800 & 1 & 0 & 0.4 & Link $3 ; 0.4 \mathrm{~g} / \mathrm{C}$ & 786 & & \\
\hline & 900 & 1 & 0 & 0.4 & Link $3 ; 0.4 \mathrm{~g} / \mathrm{C}$ & 784 & & \\
\hline & 1000 & 1 & 0 & 0.4 & Link $3 ; 0.4 \mathrm{~g} / \mathrm{C}$ & 783 & & \\
\hline \multirow{8}{*}{3} & 300 & 1 & 0 & 0.5 & Link $3 ; 0.5 \mathrm{~g} / \mathrm{C}$ & 971 & \multirow{7}{*}{964.63} & \multirow{7}{*}{4.00} \\
\hline & 400 & 1 & 0 & 0.5 & Link 3; $0.5 \mathrm{~g} / \mathrm{C}$ & 970 & & \\
\hline & 500 & 1 & 0 & 0.5 & Link $3 ; 0.5 \mathrm{~g} / \mathrm{C}$ & 965 & & \\
\hline & 600 & 1 & 0 & 0.5 & Link $3 ; 0.5 \mathrm{~g} / \mathrm{C}$ & 964 & & \\
\hline & 700 & 1 & 0 & 0.5 & Link $3 ; 0.5 \mathrm{~g} / \mathrm{C}$ & 964 & & \\
\hline & 800 & 1 & 0 & 0.5 & Link 3; $0.5 \mathrm{~g} / \mathrm{C}$ & 962 & & \\
\hline & 900 & 1 & 0 & 0.5 & Link $3 ; 0.5 \mathrm{~g} / \mathrm{C}$ & 961 & & \\
\hline & 1000 & 1 & 0 & 0.5 & Link $3 ; 0.5 \mathrm{~g} / \mathrm{C}$ & 960 & & \\
\hline \multirow{7}{*}{4} & 300 & 0 & 0 & 0.3 & Link $4 ; 0.3 \mathrm{~g} / \mathrm{C}$ & 600 & \multirow{7}{*}{596.13} & \multirow{7}{*}{3.14} \\
\hline & 400 & 0 & 0 & 0.3 & Link $4 ; 0.3 \mathrm{~g} / \mathrm{C}$ & 599 & & \\
\hline & 500 & 0 & 0 & 0.3 & Link $4 ; 0.3 \mathrm{~g} / \mathrm{C}$ & 598 & & \\
\hline & 600 & 0 & 0 & 0.3 & Link $4 ; 0.3 \mathrm{~g} / \mathrm{C}$ & 597 & & \\
\hline & 700 & 0 & 0 & 0.3 & Link $4 ; 0.3 \mathrm{~g} / \mathrm{C}$ & 597 & & \\
\hline & 800 & 0 & 0 & 0.3 & Link $4 ; 0.3 \mathrm{~g} / \mathrm{C}$ & 594 & & \\
\hline & 900 & 0 & 0 & 0.3 & Link $4 ; 0.3 \mathrm{~g} / \mathrm{C}$ & 593 & & \\
\hline
\end{tabular}




\begin{tabular}{|c|c|c|c|c|c|c|c|c|}
\hline & 1000 & 0 & 0 & 0.3 & Link $4 ; 0.3 \mathrm{~g} / \mathrm{C}$ & 591 & & \\
\hline \multirow{8}{*}{4} & 300 & 0 & 0 & 0.4 & Link $4 ; 0.4 \mathrm{~g} / \mathrm{C}$ & 780 & \multirow{7}{*}{775.63} & \multirow{7}{*}{3.62} \\
\hline & 400 & 0 & 0 & 0.4 & Link $4 ; 0.4 \mathrm{~g} / \mathrm{C}$ & 779 & & \\
\hline & 500 & 0 & 0 & 0.4 & Link $4 ; 0.4 \mathrm{~g} / \mathrm{C}$ & 777 & & \\
\hline & 600 & 0 & 0 & 0.4 & Link $4 ; 0.4 \mathrm{~g} / \mathrm{C}$ & 776 & & \\
\hline & 700 & 0 & 0 & 0.4 & Link $4 ; 0.4 \mathrm{~g} / \mathrm{C}$ & 777 & & \\
\hline & 800 & 0 & 0 & 0.4 & Link $4 ; 0.4 \mathrm{~g} / \mathrm{C}$ & 775 & & \\
\hline & 900 & 0 & 0 & 0.4 & Link $4 ; 0.4 \mathrm{~g} / \mathrm{C}$ & 772 & & \\
\hline & 1000 & 0 & 0 & 0.4 & Link $4 ; 0.4 \mathrm{~g} / \mathrm{C}$ & 769 & & \\
\hline \multirow{8}{*}{4} & 300 & 0 & 0 & 0.5 & Link $4 ; 0.5 \mathrm{~g} / \mathrm{C}$ & 962 & \multirow{7}{*}{956.38} & \multirow{7}{*}{4.24} \\
\hline & 400 & 0 & 0 & 0.5 & Link $4 ; 0.5 \mathrm{~g} / \mathrm{C}$ & 960 & & \\
\hline & 500 & 0 & 0 & 0.5 & Link $4 ; 0.5 \mathrm{~g} / \mathrm{C}$ & 959 & & \\
\hline & 600 & 0 & 0 & 0.5 & Link $4 ; 0.5 \mathrm{~g} / \mathrm{C}$ & 958 & & \\
\hline & 700 & 0 & 0 & 0.5 & Link $4 ; 0.5 \mathrm{~g} / \mathrm{C}$ & 956 & & \\
\hline & 800 & 0 & 0 & 0.5 & Link $4 ; 0.5 \mathrm{~g} / \mathrm{C}$ & 955 & & \\
\hline & 900 & 0 & 0 & 0.5 & Link $4 ; 0.5 \mathrm{~g} / \mathrm{C}$ & 951 & & \\
\hline & 1000 & 0 & 0 & 0.5 & Link $4 ; 0.5 \mathrm{~g} / \mathrm{C}$ & 950 & & \\
\hline
\end{tabular}




\section{APPENDIX F}

REPORT OF LINEAR REGRESSION MODEL FOR CAPACITY ESTIMATION 
REGRESSION

/STATISTICS COEFF OUTS CI(95) R ANOVA COLLIN TOL ZPP

$/$ CRITERIA $=$ PIN $(.05)$ POUT(.10)

/NOORIGIN

/DEPENDENT MaxFlow "Capacity"

/METHOD=ENTER LeftLane RightLane GreenOverCycle

/SCATTERPLOT $=(*$ ZRESID,$*$ ZPRED $)$

/RESIDUALS HISTOGRAM(ZRESID) NORMPROB(ZRESID).

\section{Regression}

\begin{tabular}{|c|c|c|}
\hline \multicolumn{3}{|r|}{ Notes } \\
\hline \multicolumn{2}{|c|}{ Output Created } & 26-DEC-2019 02:52:06 \\
\hline \multirow[t]{6}{*}{ Input } & Data & 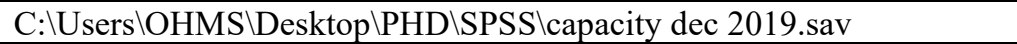 \\
\hline & Active Dataset & DataSet1 \\
\hline & Filter & $<$ none $>$ \\
\hline & Weight & $<$ none $>$ \\
\hline & Split File & $<$ none $>$ \\
\hline & $\begin{array}{l}\mathrm{N} \text { of Rows in } \\
\text { Working Data File }\end{array}$ & 96 \\
\hline \multirow{2}{*}{$\begin{array}{l}\text { Missing } \\
\text { Value } \\
\text { Handling }\end{array}$} & $\begin{array}{l}\text { Definition of } \\
\text { Missing }\end{array}$ & User-defined missing values are treated as missing. \\
\hline & Cases Used & $\begin{array}{l}\text { Statistics are based on cases with no missing values for any variable } \\
\text { used. }\end{array}$ \\
\hline \multicolumn{2}{|l|}{ Syntax } & $\begin{array}{l}\text { REGRESSION } \\
\text { /DESCRIPTIVES MEAN STDDEV CORR SIG N } \\
\text { /MISSING LISTWISE } \\
\text { /STATISTICS COEFF OUTS CI(95) R ANOVA COLLIN TOL ZPP } \\
\text { /CRITERIA=PIN(.05) POUT(.10) } \\
\text { /NOORIGIN } \\
\text { /DEPENDENT MaxFlow } \\
\text { /METHOD=ENTER LeftLane RightLane GreenOverCycle } \\
\text { /SCATTERPLOT=(*ZRESID ,*ZPRED) } \\
\text { /RESIDUALS HISTOGRAM(ZRESID) NORMPROB(ZRESID). }\end{array}$ \\
\hline
\end{tabular}




\begin{tabular}{|l|l|l|l|}
\multicolumn{4}{c|}{ Variables Entered/Removed $^{\mathbf{a}}$} \\
\hline Model & Variables Entered & $\begin{array}{l}\text { Variables } \\
\text { Removed }\end{array}$ & Method \\
\hline 1 & $\begin{array}{l}\text { GreenOverCycle, } \\
\text { RightLane, } \\
\text { LeftLane }\end{array}$ & & Enter \\
\hline
\end{tabular}

a. Dependent Variable: MaxFlow "Capacity"

b. All requested variables entered.

\section{Model Summary ${ }^{\mathrm{b}}$}

\begin{tabular}{|l|r|r|r|r|}
\hline Model & R & R Square & $\begin{array}{c}\text { Adjusted R } \\
\text { Square }\end{array}$ & Std. Error of the Estimate \\
\hline 1 & $1.000^{\mathrm{a}}$ & .999 & .999 & 3.99953 \\
\hline
\end{tabular}

a. Predictors: (Constant), GreenOverCycle, RightLane, LeftLane

b. Dependent Variable: MaxFlow "Capacity"

ANOVAa

\begin{tabular}{|l|l|r|r|r|r|r|}
\hline \multicolumn{2}{|l|}{ Model } & Sum of Squares & df & Mean Square & \multicolumn{1}{|c|}{ F } & \multicolumn{1}{l|}{ Sig. } \\
\hline \multirow{3}{*}{1} & Regression & 2155046.849 & 3 & 718348.950 & 44907.455 & $.000^{\mathrm{b}}$ \\
\cline { 2 - 7 } & Residual & 1471.651 & 92 & 15.996 & & \\
\cline { 2 - 7 } & Total & 2156518.500 & 95 & & & \\
\hline
\end{tabular}

a. Dependent Variable: MaxFlow "Capacity"

b. Predictors: (Constant), GreenOverCycle, RightLane, LeftLane 


\section{Coefficients $^{\mathrm{a}}$}

\begin{tabular}{|c|c|c|c|c|c|c|c|c|c|c|c|c|c|}
\hline \multirow{2}{*}{\multicolumn{2}{|c|}{ Model }} & \multicolumn{2}{|c|}{$\begin{array}{l}\text { Unstandardized } \\
\text { Coefficients }\end{array}$} & \multirow{2}{*}{$\begin{array}{c}\begin{array}{c}\text { Standardized } \\
\text { Coefficients }\end{array} \\
\text { Beta }\end{array}$} & \multirow{2}{*}{$\mathrm{t}$} & \multirow{2}{*}{ Sig. } & \multicolumn{2}{|c|}{$\begin{array}{l}95.0 \% \text { Confidence } \\
\text { Interval for B }\end{array}$} & \multicolumn{3}{|c|}{ Correlations } & \multicolumn{2}{|c|}{$\begin{array}{l}\text { Collinearity } \\
\text { Statistics }\end{array}$} \\
\hline & & B & $\begin{array}{l}\text { Std. } \\
\text { Error }\end{array}$ & & & & $\begin{array}{l}\text { Lower } \\
\text { Bound }\end{array}$ & $\begin{array}{l}\text { Upper } \\
\text { Bound }\end{array}$ & $\begin{array}{l}\text { Zero- } \\
\text { order }\end{array}$ & Partial & Part & Tolerance & VIF \\
\hline \multirow{4}{*}{1} & (Constant) & 66.333 & 2.121 & & 31.274 & 0 & 62.121 & 70.546 & & & & & \\
\hline & LeftLane & 9.792 & 0.816 & 0.033 & 11.994 & 0 & 8.17 & 11.413 & 0.033 & 0.781 & 0.033 & 1 & 1 \\
\hline & RightLane & 75.667 & 0.816 & 0.252 & 92.683 & 0 & 74.045 & 77.288 & 0.252 & 0.995 & 0.252 & 1 & 1 \\
\hline & GreenOverCycle & 1774.531 & 4.999 & 0.967 & 354.948 & 0 & 1764.602 & 1784.461 & 0.967 & 1 & 0.967 & 1 & 1 \\
\hline
\end{tabular}

a. Dependent Variable: MaxFlow “Capacity”

\section{Collinearity Diagnostics ${ }^{\mathrm{a}}$}

\begin{tabular}{|c|c|c|c|c|c|c|c|}
\hline \multirow[t]{2}{*}{ Model } & \multirow[t]{2}{*}{ Dimension } & \multirow[t]{2}{*}{ Eigenvalue } & \multirow[t]{2}{*}{ Condition Index } & \multicolumn{4}{|c|}{ Variance Proportions } \\
\hline & & & & (Constant) & LeftLane & RightLane & $\begin{array}{c}\text { GreenOverCycl } \\
\mathrm{e}\end{array}$ \\
\hline \multirow{4}{*}{1} & 1 & 3.160 & 1.000 & .00 & .03 & .03 & .00 \\
\hline & 2 & .500 & 2.514 & .00 & .50 & .50 & .00 \\
\hline & 3 & .320 & 3.143 & .02 & .46 & .46 & .03 \\
\hline & 4 & .020 & 12.640 & .98 & .01 & .01 & .97 \\
\hline
\end{tabular}

a. Dependent Variable: MaxFlow “Capacity”

\section{Residuals Statistics ${ }^{a}$}

\begin{tabular}{|l|r|r|r|r|r|}
\hline & \multicolumn{1}{|c|}{ Minimum } & \multicolumn{1}{c|}{ Maximum } & \multicolumn{1}{c|}{ Mean } & \multicolumn{1}{c|}{ Std. Deviation } & \multicolumn{1}{c|}{ N } \\
\hline Predicted Value & 598.6927 & 1039.0573 & 818.8750 & 150.61442 & 96 \\
\hline Residual & -10.05729 & 8.84896 & .00000 & 3.93587 & 96 \\
\hline Std. Predicted Value & -1.462 & 1.462 & .000 & 1.000 & 96 \\
\hline Std. Residual & -2.515 & 2.213 & .000 & .984 & 96 \\
\hline
\end{tabular}

a. Dependent Variable: MaxFlow 


\section{Charts}

Histogram

Dependent Variable: MaxFlow

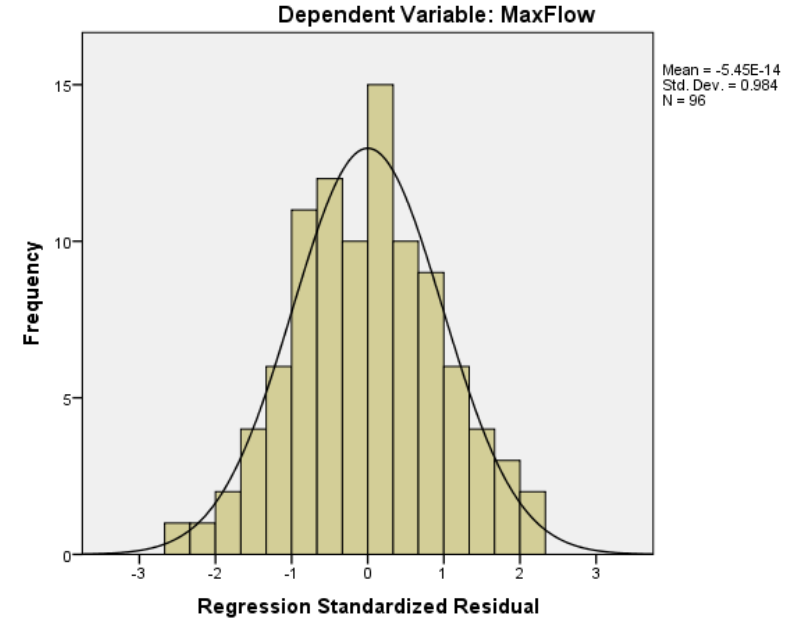

Normal P-P Plot of Regression Standardized Residual

Dependent Variable: MaxFlow

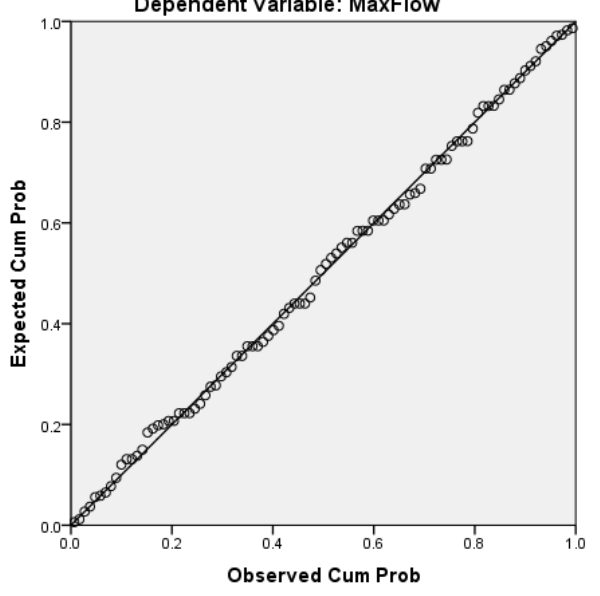

Scatterplot

Dependent Variable: MaxFlow

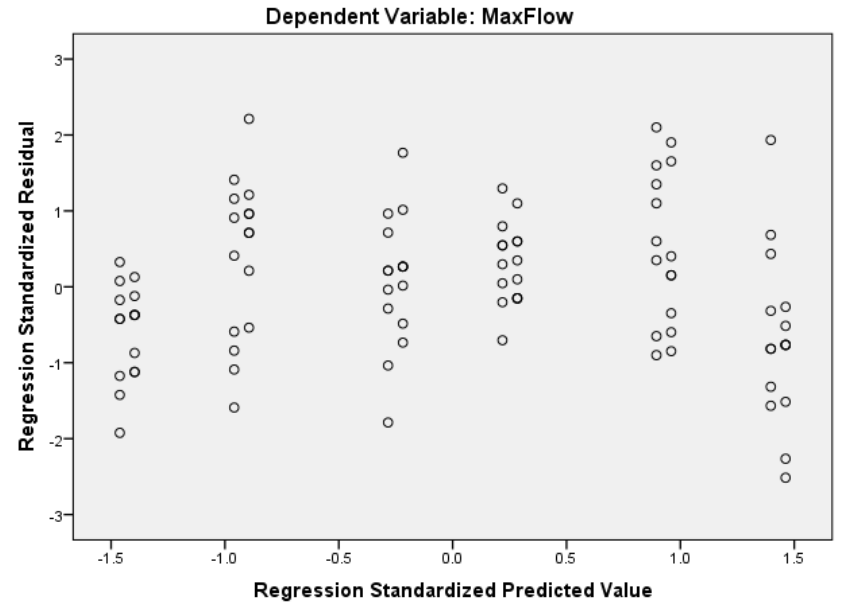




\section{APPENDIX G}

REPORT OF MULTIPLE REGRESSION MODEL FOR SPEED ON ROAD LINK 
MULTIPLE REGRESSION

/STATISTICS COEFF OUTS CI(95) R ANOVA COLLIN TOL ZPP

/CRITERIA=PIN(.05) POUT(.10)

/NOORIGIN

/DEPENDENT TravelSpeed

/METHOD=ENTER segmentLength LeftTurnLane RightTurnLane GreenOverCycle Flow

/SCATTERPLOT $=(*$ ZRESID,$*$ ZPRED $)$

/RESIDUALS HISTOGRAM(ZRESID) NORMPROB(ZRESID).

\section{Regression}

\begin{tabular}{|c|c|c|}
\hline \multicolumn{2}{|l|}{ Output Created } & 26-DFC-2019 21·39.16 \\
\hline \multirow{6}{*}{ Input } & Data & 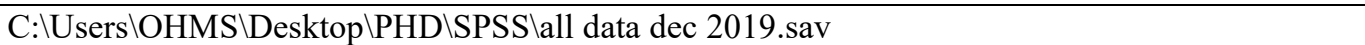 \\
\hline & Active Dataset & DataSet2 \\
\hline & Filter & $<$ none $>$ \\
\hline & Weight & $<$ none $>$ \\
\hline & Split File & $<$ none $>$ \\
\hline & $\begin{array}{l}\mathrm{N} \text { of Rows in } \\
\text { Working Data File }\end{array}$ & 1872 \\
\hline \multirow{2}{*}{ Missing Value Handling } & $\begin{array}{l}\text { Definition of } \\
\text { Missing }\end{array}$ & User-defined missing values are treated as missing. \\
\hline & Cases Used & Statistics are based on cases with no missing values for any variable used. \\
\hline \multicolumn{2}{|l|}{ Syntax } & $\begin{array}{l}\text { REGRESSION } \\
\text { /DESCRIPTIVES MEAN STDDEV CORR SIG N } \\
\text { /MISSING LISTWISE } \\
\text { /STATISTICS COEFF OUTS CI(95) R ANOVA COLLIN TOL ZPP } \\
\text { /CRITERIA=PIN(.05) POUT(.10) } \\
\text { /NOORIGIN } \\
\text { /DEPENDENT Speed } \\
\text { /METHOD=ENTER segmentLength, LeftTurnLane, RightTurnLane, GreenOverCycle, Flow } \\
\text { /SCATTERPLOT=(*ZRESID ,*ZPRED) } \\
\text { /RESIDUALS HISTOGRAM(ZRESID) NORMPROB(ZRESID). }\end{array}$ \\
\hline \multirow{2}{*}{ Resources } & Processor Time & 00:00:00.55 \\
\hline & Elapsed Time & 00:00:00.67 \\
\hline
\end{tabular}


Variables Entered/Removed $^{\mathbf{a}}$

\begin{tabular}{|l|l|l|l|}
\hline Model & Variables Entered & Variables Removed & Method \\
\hline \multirow{4}{*}{1} & $\begin{array}{l}\text { Flow, } \\
\text { LeftTurnLane, } \\
\text { segmentLength, } \\
\text { RightTurnLane, } \\
\text { GreenOverCycle }\end{array}$ & & \\
\hline
\end{tabular}

a. Dependent Variable: TravelSpeed

b. All requested variables entered.

\section{Model Summary ${ }^{b}$}

\begin{tabular}{|l|r|r|r|r|}
\hline Model & R & R Square & $\begin{array}{c}\text { Adjusted R } \\
\text { Square }\end{array}$ & $\begin{array}{c}\text { Std. Error of the } \\
\text { Estimate }\end{array}$ \\
\hline 1 & $.884^{\mathrm{a}}$ & .781 & .781 & 6.11515 \\
\hline
\end{tabular}

a. Predictors: (Constant), Flow, LeftTurnLane, segmentLength, RightTurnLane, GreenOverCycle b. Dependent Variable: TravelSpeedSpeed

ANOVAa

\begin{tabular}{|rl|r|r|r|r|r|}
\hline Model & & Sum of Squares & \multicolumn{1}{|c|}{ df } & Mean Square & \multicolumn{1}{c|}{ F } & \multicolumn{1}{c|}{ Sig. } \\
\hline \multirow{2}{*}{1} & Regression & 249126.439 & 5 & 49825.288 & 1332.404 & $.000^{\mathrm{b}}$ \\
& Residual & 69779.125 & 1866 & 37.395 & & \\
& Total & 318905.564 & 1871 & & & \\
\hline
\end{tabular}

a. Dependent Variable: TravelSpeed

b. Predictors: (Constant), Flow, LeftTurnLane, segmentLength, RightTurnLane, GreenOverCycle 


\begin{tabular}{|c|c|c|c|c|c|c|c|c|c|c|c|c|c|}
\hline \multicolumn{14}{|c|}{ Coefficients $^{\mathbf{a}}$} \\
\hline \multirow{2}{*}{\multicolumn{2}{|c|}{ Model }} & \multicolumn{2}{|c|}{$\begin{array}{l}\text { Unstandardized } \\
\text { Coefficients }\end{array}$} & \multirow{2}{*}{$\begin{array}{c}\text { Standardized } \\
\text { Coefficients }\end{array}$} & \multirow[t]{2}{*}{$\mathrm{t}$} & \multirow[t]{2}{*}{ Sig. } & \multicolumn{2}{|c|}{$\begin{array}{c}95.0 \% \\
\text { Confidence } \\
\text { Interval for B }\end{array}$} & \multicolumn{3}{|c|}{ Correlations } & \multicolumn{2}{|c|}{$\begin{array}{l}\text { Collinearity } \\
\text { Statistics }\end{array}$} \\
\hline & & $\mathrm{B}$ & $\begin{array}{l}\text { Std. } \\
\text { Error }\end{array}$ & & & & $\begin{array}{l}\text { Lower } \\
\text { Bound }\end{array}$ & $\begin{array}{l}\text { Upper } \\
\text { Bound }\end{array}$ & $\begin{array}{l}\text { Zero- } \\
\text { order }\end{array}$ & Partial & Part & Tolerance & VIF \\
\hline \multirow{6}{*}{1} & (Constant) & 16.383 & 0.858 & & 19.09 & 0 & 14.699 & 18.066 & & & & & \\
\hline & segmentLength & 0.013 & 0.001 & 0.223 & 20.608 & 0 & 0.011 & 0.014 & 0.215 & 0.431 & 0.223 & 1 & 1 \\
\hline & LeftTurnLane & 0.728 & 0.283 & 0.028 & 2.576 & 0.01 & 0.174 & 1.283 & 0.032 & 0.06 & 0.028 & 1 & 1 \\
\hline & RightTurnLane & 3.488 & 0.283 & 0.134 & 12.334 & 0 & 2.933 & 4.043 & 0.109 & 0.275 & 0.134 & 0.999 & 1.001 \\
\hline & GreenOverCycle & 71.19 & 1.794 & 0.442 & 39.683 & 0 & 67.672 & 74.709 & 0.246 & 0.677 & 0.43 & 0.944 & 1.059 \\
\hline & Flow & -0.041 & 0.001 & -0.837 & -75.118 & 0 & -0.042 & -0.04 & -0.727 & -0.867 & -0.813 & 0.944 & 1.06 \\
\hline
\end{tabular}

a. Dependent Variable: TravelSpeed

\section{Collinearity Diagnostics ${ }^{\mathrm{a}}$}

\begin{tabular}{|c|c|c|c|c|c|c|c|c|c|}
\hline \multirow{2}{*}{$\begin{array}{l}\text { Mod } \\
\text { el }\end{array}$} & \multirow{2}{*}{ Dimension } & \multirow{2}{*}{ Eigenvalue } & \multirow{2}{*}{$\begin{array}{l}\text { Condition } \\
\text { Index }\end{array}$} & \multicolumn{3}{|c|}{ Variance Proportions } & \multicolumn{3}{|c|}{ Variance Proportions } \\
\hline & & & & (Constant) & segmentLength & LeftTurnLane & RightTurnLane & GreenOverCycle & Flow \\
\hline \multirow{6}{*}{1} & 1 & 4.817 & 1 & 0 & 0 & 0.01 & 0.01 & 0 & 0.01 \\
\hline & 2 & 0.505 & 3.089 & 0 & 0 & 0.52 & 0.47 & 0 & 0 \\
\hline & 3 & 0.407 & 3.44 & 0 & 0.02 & 0.42 & 0.48 & 0 & 0.07 \\
\hline & 4 & 0.181 & 5.163 & 0.01 & 0.16 & 0.02 & 0.01 & 0 & 0.78 \\
\hline & 5 & 0.074 & 8.084 & 0.05 & 0.71 & 0.01 & 0.01 & 0.17 & 0.15 \\
\hline & 6 & 0.017 & 16.847 & 0.94 & 0.11 & 0.01 & 0.01 & 0.82 & 0 \\
\hline
\end{tabular}

a. Dependent Variable: TravelSpeed 
Residuals Statistics ${ }^{\mathrm{a}}$

\begin{tabular}{|l|r|r|r|r|r|}
\hline & \multicolumn{1}{|c|}{ Minimum } & Maximum & \multicolumn{1}{c|}{ Mean } & Std. Deviation & \multicolumn{1}{c|}{ N } \\
\hline Predicted Value & 16.6063 & 66.9003 & 35.8852 & 11.53913 & 1872 \\
\hline Residual & -18.98080 & 9.34265 & .00000 & 6.10697 & 1872 \\
\hline Std. Predicted Value & -1.671 & 2.688 & .000 & 1.000 & 1872 \\
\hline Std. Residual & -3.104 & 1.528 & .000 & .999 & 1872 \\
\hline
\end{tabular}

a. Dependent Variable: TravelSpeed

\section{Charts}

Normal P-P Plot of Regression Standardized Residual

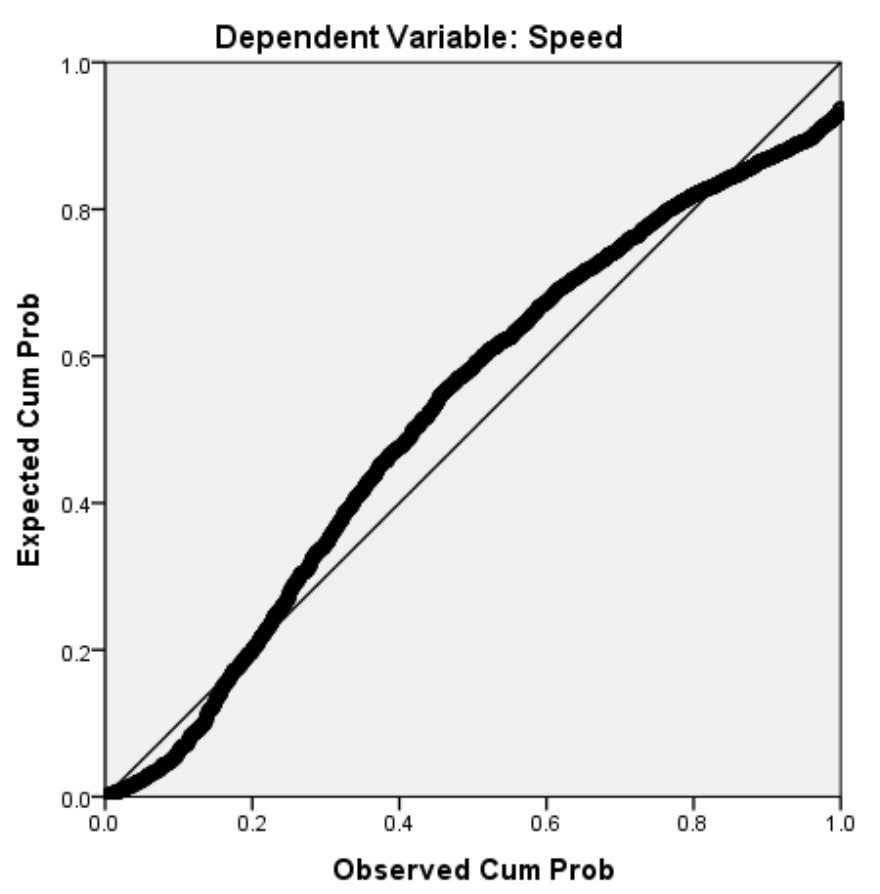

